RODRIGO BERNARDELLO UNZUETA

ESTUDO TEÓRICO E EXPERIMENTAL DE UMA MÁQUINA A VAPOR ALTERNATIVA

São Paulo

2014 
RODRIGO BERNARDELLO UNZUETA

\section{ESTUDO TEÓRICO E EXPERIMENTAL DE UMA MÁQUINA A VAPOR ALTERNATIVA}

Dissertação apresentada à Escola Politécnica da Universidade de São Paulo para obtenção do título de Mestre em Engenharia Mecânica

São Paulo 


\title{
ESTUDO TEÓRICO E EXPERIMENTAL DE UMA MÁQUINA A VAPOR ALTERNATIVA
}

\author{
Dissertação apresentada à Escola Politécnica \\ da Universidade de São Paulo para obtenção \\ do título de Mestre em Engenharia Mecânica \\ Área de Concentração: \\ Engenharia Mecânica de Energia e Fluidos \\ Orientador: \\ Prof. Dr. José Roberto Simões Moreira
}

São Paulo 


\section{DEDICATÓRIA}

A todos que utilizam seu conhecimento e suas habilidades para a melhoria do lugar onde vivem, seja em pequenas ou grandes proporções. 


\section{AGRADECIMENTOS}

Agradeço a todos que influenciaram direta ou indiretamente minha vida, permitindo o aprendizado e crescimento, tanto no âmbito profissional como no âmbito pessoal. Também à orientação (José Roberto Simões Moreira), ao laboratório Sisea e todos seus integrantes, dentre os quais tiveram grande influência para a concretização desse trabalho, pode-se citar o nome Thyago Reynaldo José Miranda. Às pessoas que não são ligadas à instituição e que contribuíram tecnicamente e/ou pessoalmente, como podem ser citadas, Pedro Jesus Unzueta Urien, Marília Martins de Moura, Rafael Vega, Renato Lhamas, Renato Franhani, e todos meus amigos e familiares pela ajuda e pelo suporte nesse período.

À Escola Politécnica da Universidade de São Paulo, pelo conhecimento e sabedoria adquiridos.

À Coordenação de Aperfeiçoamento de Pessoal de Nível Superior pela bolsa de mestrado - pelo apoio financeiro - que me permitiu realizar esta pesquisa. 


\section{RESUMO}

Este trabalho apresenta uma revisão dos ciclos teóricos estudados por outros autores sobre o funcionamento de uma máquina a vapor funcionando como máquina de expansão e propõe um ciclo generalizado para o estudo. Esse ciclo generalizado é equacionado e seus pontos operacionais de otimização são determinados. Ao estudar os ciclos teóricos, verificou-se que a máquina a vapor pode atingir a eficiência isentrópica igual de $100 \%$. Um estudo experimental foi conduzido em uma máquina a vapor, a fim de verificar os fenômenos que ocorrem e que influenciam na sua eficiência, fazendo o funcionamento real se afastar do ciclo teórico. Ao fazer o estudo experimental, verificou-se que a máquina a vapor real utilizada possui baixa eficiência, atingindo um máximo de $10 \%$ de eficiência isentrópica. Essa eficiência não é do ciclo e sim do conjunto todo, e é devido a diversos fatores, como, por exemplo, atritos, problemas de lubrificação, imperfeições físicas que provocam o vazamento do fluido de trabalho. Uma simulação computacional é realizada, visando prever o comportamento real da máquina a vapor e comparar com os dados obtidos experimentalmente. Verificando assim se a simulação consegue prever os fenômenos físicos e auxiliar no projeto de uma máquina a vapor. Após analisar os dados simulados, verificou-se que as válvulas possuem grande influência na eficiência isentrópica do ciclo da máquina a vapor. Válvulas de acionamento rápido preveem uma eficiência que pode chegar a 96\%, enquanto as válvulas reais provocam uma eficiência de aproximadamente $60 \%$ para as mesmas condições de simulação. Uma das principais diferenças entre a simulação e os dados reais é a restrição ao fluxo provocada pelas válvulas, e que exigem coeficientes de descarga específicos para esse tipo de válvula.

Palavras-chave: Máquinas a vapor, motores a vapor, ciclo orgânico de Rankine, ciclos motores, simulação. 


\begin{abstract}
This work reviews the theoretical cycles studied by other authors on the operation of a steam engine as an expansion machine and chooses a generalized cycle for the study. This generalized cycle is modeled and the points of optimization are determined. By studying the theoretical cycles, it was found that the steam engine can reach the isentropic efficiency equal to $100 \%$. An experimental study carried out in a steam engine in order to verify the phenomena occurring that influence their effectiveness, moving the actual operation away from the theoretical cycle. By making the experimental study, it was found that the actual steam engine has a low efficiency, reaching a maximum $10 \%$ isentropic efficiency. This efficiency is not of the cycle, but of the whole set, and is due to several factors, such as friction problems, lubrication problems, physical imperfections causing leakage of the working fluid. A computer simulation was performed in order to predict the actual behavior of the steam engine and compare with the experimental data. After analyzing the simulated data, it was found that the valves have a great influence on the isentropic efficiency of the steam cycle. Valves operating instantly can reach $96 \%$ of isentropic efficiency, while real valves cause an efficiency of approximately $60 \%$ for the same simulation conditions. A major difference between the simulation and the actual data is the flow restriction caused by valves, which requires specific discharge coefficients for this type of valve.
\end{abstract}

Keywords: Steam machine, Steam engine, organic Rankine cycle, workscycles. simulation 


\section{LISTA DE ILUSTRAÇÕES}

Figura 1.1 - Esquema geral de um Ciclo Orgânico de Rankine para geração de eletricidade a partir de painéis solares.(GARI et al., 1988)

Figura 1.2 - Relação da temperatura de funcionamento com a potência gerada para diferentes ciclos de potência (Tarique, 2011).

Figura 1.3 - Representação esquemática de uma máquina a vapor, com os nomes das partes principais.

Figura 1.4 - Etapas de funcionamento de um ciclo da máquina a vapor.

Figura 1.5 - Diagrama PxV de uma máquina a vapor alternativa.

Figura 2.1 - Diagrama PxV para um ciclo com volume morto nulo utilizado por Mariño (1948) e Alanne et al. (2012).

Figura 2.2 - Diagrama PxV pressão-volume com compressão de vapor e volume morto utilizada por Trajkovic (2010).

Figura 2.3 - Diagrama PxV mostrando trabalho útil que pode ser menor que o atrito do mesmo trecho.

Figura 2.4 - Diagrama PxV com compressão e expansão incompletas utilizado na simulação de Prasad (1993).

Figura 2.5 - Diagrama PxV com expansão e compressão incompletas, considerando admissão no curso em direção ao PMI (Badami e Mura, 2009).

Figura 2.6 - Diagrama PxV considerando expansão e compressão incompletas, utilizado por Antonelli e Martorano (2012) e Basbous et al. (2012).

Figura 2.7 - Diagrama PxV de um motor de expansão utilizando uma válvula de admissão auto operada normalmente aberta (Kalekin e Kalekin, 2009).

Figura 2.8 - Diagrama PxV da simulação de Prilutskii (2008), as linhas grossa e fina representam vazões de 1,0 ton/h e 1,5 ton/h respectivamente. C $\varphi$ é uma posição relativa do pistão.

Figura 2.9 - Diagramas PxV da expansão: a) válvula de escape com uma mola que pressiona a válvula para o assento, b) válvula de escape sem mola, c) válvula de escape que desencosta a válvula do assento, e d) sistema de distribuição combinado (Vanyashov et al., 2001). 
Figura 2.10 - Pressão de $\mathrm{CO}_{2}$ dentro do cilindro em função do ângulo da manivela (Baek et al., 2005).

Figura 2.11 - Comportamento da pressão interna do cilindro da máquina de expansão, considerando vazamento de $\mathrm{CO}_{2}$ através dos anéis de vedação (Baek et al., 2005).

Figura 2.12 - Comparação entre os ciclos reais (simulados) e o ciclo teórico (Badami e Mura, 2009).

Figura 2.13 - Comparação do comportamento da pressão indicada simulada com o ciclo ideal para (a) $100 \mathrm{rpm}$, (b) $1000 \mathrm{rpm} \mathrm{e} \mathrm{(c)} 2500 \mathrm{rpm}$. 30

Figura 2.14 - Diagrama PxV da pressão em função do volume para o funcionamento como motor a ar comprimido para pressões do tanque de (a) 16,5 bar e (b) 6,5 bar (Trajkovic, 2010).

Figura 2.15 - Comparação entre o ciclo simulado e o ciclo experimental para pressão de admissão de 5,5 bar e rotação de 1500 rpm. (Antonelli et al., 2014)

Figura 2.16 - Diagrama PxV simulado para a máquina a vapor com processos quaseestáticos.

Figura 2.17 - Diagrama PxV simulado para a máquina a vapor sem considerar processos quase-estáticos. (Ferrara et al., 2013) 36

Figura 3.1 - Volume de controle para o balanço de energia ..................................................45

Figura 3.2 - Ciclo com sobrecompressão e sobre-expansão ...............................................53

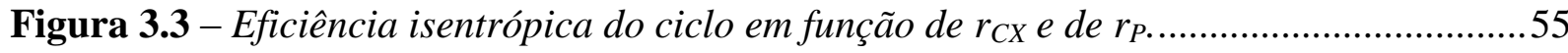

Figura 3.4 - Eficiência isentrópica do ciclo em função de $r_{F X}$ e de $r_{P .}$.....................................56

Figura 3.5 - Eficiência isentrópica do ciclo em função de $r_{V}$ e de $r_{P}$......................................57

Figura 3.6 - Eficiência isentrópica do ciclo em função de $r_{V}$ para diferentes combinações de $r_{C X}$ e $r_{F X}$

Figura 3.7 - Trabalho realizado em um ciclo de operação para diferentes razões de volume em função da pressão de admissão.

Figura 3.8 - Massa consumida em um ciclo de operação para diferentes razões de volume em função da pressão de admissão.

Figura 3.9 - Trabalho específico para diferentes temperaturas de admissão em função da razão de pressões.

Figura 3.10 - Ciclo sem sobre-expansão ou sobrecompressão que possui a menor eficiência isentrópica.

Figura 4.1 - Vista frontal da máquina a vapor 
Figura 4.2 - Vista superior da máquina a vapor 64

Figura 4.3 - Vista em perspectiva da máquina a vapor 65

Figura 4.4 - Fotografia da máquina a vapor testada. .66

Figura 4.5 - Fotografia indicando o detalhe do sistema biela manivela da máquina a vapor testada

Figura 4.6 - Nomenclatura utilizada para as regiões do bloco da máquina a vapor....

Figura 4.7 - Os dois modelos de transdutores de pressão utilizados nos testes. .68

Figura 4.8 - Termopares do tipo K utilizados nos testes.

Figura 4.9 - Foto do freio de Prony com duas balanças e uma tira de couro sobre a roda de inércia .70

Figura 4.10 - Esquema do freio de Prony para a edição do torque da máquina a vapor.......71

Figura 4.11 - Bocal convergente para medição da vazão, conforme a norma NBR ISO 5167-1 (1994). .72

Figura 4.12 - Bocal convergente para medição de vazão acoplado à tubulação 72

Figura 4.13 - Arranjo Experimental 73

Figura 4.14 - Esquema do tubo de admissão com cotas .74

Figura 4.15 - Bloco da máquina a vapor com os transdutores de pressão. .74

Figura 4.16 - Conexões das tubulações de admissão e escape no bloco da máquina a vapor.

Figura 4.17 - Manômetro de pressão absoluta utilizado como referência para a calibração dos transdutores de pressão .76

Figura 4.18 - Arranjo para a calibração .77

Figura 4.19 - Fluxograma elaborado no programa Labview para a calibração dos transdutores de pressão

Figura 4.20 - Arranjo Experimental com câmara de amortecimento

Figura 4.21 - Fluxograma elaborado no programa Labview para aquisição de dados nos testes .85

Figura 4.22 - Diagrama $P_{x}$ tempo para o ciclo médio da medição com pressão de 0,5bar e 623,1 rpm

Figura 4.23 - Diagrama $P_{x}$ tempo para o ciclo médio da medição com pressão de 2 bar e $823,3 \mathrm{rpm}$

Figura 4.24 - Diagrama $P x V$ da pressão em relação à posição relativa do pistão (Vanyashov et al., 2001), acrescentado as indicações do sentido de rotação de cada trecho do diagrama. 
Figura 4.25 - Diagramas PxV da máquina a vapor para pressão nominal de 0,5 bar à 792,6 rpm.

Figura 4.26 - Diagramas PxV da máquina a vapor para pressão nominal de 0,5 bar à 792,6 rpm.

Figura 4.27 - Diagramas PxV da máquina a vapor para pressão nominal de 0,5 bar à $437,5 \mathrm{rpm}$.

Figura 4.28 - Diagramas PxV da máquina a vapor para pressão nominal de 1 bar à $455,8 \mathrm{rpm}$

Figura 4.29 - Diagramas PxV da máquina a vapor para pressão nominal de 2 bar à 1471,7 rpm.

Figura 4.30 - Diagramas indicados da máquina a vapor para pressão nominal de 2,5 bar à 1513,4 rpm.

Figura 4.31 - Diagramas PxV da máquina a vapor para pressão nominal de 3,5 bar à $1386 \mathrm{rpm}$. .98

Figura 4.32 - Diagramas PxV da máquina a vapor para pressão nominal de 3,5 bar à 960,7 rpm.

Figura 4.33 - Corte da máquina a vapor passando pelo centro do cilindro, indicando a região de desgaste do eixo do pistão com a tampa do cilindro.

Figura 4.34 - Ilustração das porta e das válvulas da máquina a vapor. 102

Figura 4.35 - Pressão em função do tempo para um ciclo para pressão nominal de 0,75 bar à 494,7 rpm.

Figura 4.36 - Pressão em função do tempo para um ciclo para pressão nominal de 1,5 bar à 734,9 rpm.

Figura 4.37 -Diagrama $P_{x}$ t para pressão de 0,75 bar a 494,7 rpm, com indicação das oscilações e linhas verticais para verificar o período de cada uma.

Figura 4.38 - Diagrama $P_{x} t$ para pressão nominal de 1,5 bar à 734,9 rpm, com indicação das oscilações e linhas verticais para verificar o período de cada uma.

Figura 5.1 - Esquema com as cotas e peças principais da máquina a vapor estudada na simulação

Figura 5.2 - Os cinco volumes de controle estudados

Figura 5.3 - Cotas utilizadas para o cálculo das posições e geometria da máquina a vapor.

Figura 5.4 - Fluxos de massa calculados na simulação 
Figura 5.5 - Cotas para a determinação da área de abertura das válvulas.....

Figura 5.6 - Cotas para calcular a área, o perímetro molhado e o diâmetro hidráulico de abertura da porta

Figura 5.7 - Esquema de orifício utilizado para o cálculo da vazão em massa através

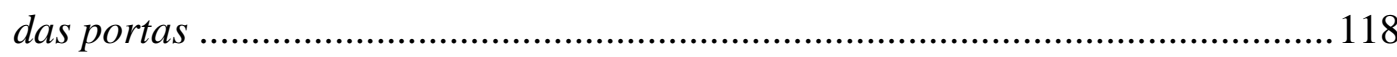

Figura 5.8 - Fator multiplicativo f calculado por meio de diferentes equações. 122

Figura 5.9 - Diagrama PXV para as câmaras esquerda e direita da máquina a vapor para pressão nominal de 0,5 bar à 792,6 rpm.

Figura 5.10 - Área de abertura das portas em função da posição relativa do pistão 126

Figura 5.11 - Diagrama PxV da câmara esquerda da máquina a vapor para pressão nominal de 0,5 bar à 792,6 rpm.

Figura 5.12 - Diagrama PxV da câmara esquerdada máquina a vapor para pressão nominal de 0,5 bar à 354,3 rpm.

Figura 5.13 - Diagrama PxV da câmara esquerdada máquina a vapor para pressão nominal de 1 bar à 591,4 rpm.

Figura 5.14 - Diagrama PxV da câmara esquerdada máquina a vapor para pressão nominal de 2,5 bar à 1513,3 rpm.

Figura 5.15 - Diagrama PxV da câmara esquerdada máquina a vapor para pressão nominal de 3,5 bar à 1386 rpm.

Figura 5.16 - Diagrama PxV da câmara esquerdada máquina a vapor para pressão nominal de 3,5 bar à 960,7 rpm.

Figura 5.17 - Pressão em função do tempo para um ciclo para pressão nominal de 0,5 bar à 354,3 rpm.

Figura 5.18 - Pressão em função do tempo para um ciclo para pressão nominal de 1,5 bar à 676,5 rpm.

Figura 5.19 - Pressão em função do tempo para um ciclo para pressão nominal de 3,5 bar à 960,7 rpm.

Figura 5.20 - Pressão em função do tempo para um ciclo para pressão nominal de 2 bar à $1471,7 \mathrm{rpm}$.

Figura 5.21 - Diagrama PxV para as câmaras da máquina a vapor que utiliza válvulas de comutação instantâneas para pressão nominal de 0,5 bar à 792,6 rpm

Figura 5.22 - Diagrama PxV para as câmaras da máquina a vapor que utiliza válvulas de comutação instantâneas para pressão nominal de 0,5 bar à 354,3 rpm 
Figura 5.23 - Diagrama PxV para as câmaras da máquina a vapor que utiliza válvulas de comutação instantâneas para pressão nominal de 1,5 bar à 1358,6 rpm

Figura 5.24 - Diagrama PxV para as câmaras da máquina a vapor que utiliza válvulas de comutação instantâneas para pressão nominal de 1,5 bar à 676,5 rpm

Figura5.25 - Diagrama PxV para as câmaras da máquina a vapor que utiliza válvulas de comutação instantâneas para pressão nominal de 3,5 bar à 1386 rpm

Figura 5.26 - Diagrama PxV para as câmaras da máquina a vapor que utiliza válvulas de comutação instantâneas para pressão nominal de 3,5 bar à 960,7 rpm

Figura 5.27 - Sobreposição dos diagramas PxV simulados e do ciclo ideal para pressão nominal de 0,5 bar à 792,6 rpm.

Figura 5.28 - Sobreposição dos diagramas PxV simulados e do ciclo ideal para pressão nominal de 1,5 bar à 1358,6 rpm.

Figura 6.1 - Diagrama PxV simulado da câmara esquerdada máquina a vapor para pressão nominal de 2,5 bar à 1513,3 rpm, com indicação da principal característica que se repete em todas simulações.

Figura 6.2 - Diagrama $P_{x}$ t simulado para a câmara esquerda da máquina a vapor para pressão nominal de 2,5 bar à 1513,3 rpm, com indicação da principal característica que se repete em todas simulações.

Figura 6.3 - Diagrama $P_{x}$ t para o acoplamento do ciclo simulado e o ciclo experimental para a pressão de 2,5 bar e 1531,3 rpm utilizando as pressões da câmara esquerda.

Figura 6.4 - Diagrama $P_{x}$ t para o acoplamento do ciclo simulado e o ciclo experimental para a pressão de 2,5 bar e 1531,3 rpm utilizando as pressões da câmara direita.

Figura 6.5 - Diagramas PxV simulado e medido da câmara direita do cilindro para uma pressão de 0,5bar e 792,6 rpm.

Figura 6.6 - Diagramas PxV simulado e medido da câmara esquerda do cilindro para uma pressão de 0,5bar e 792,6 rpm.

Figura 6.7 - Diagramas PxV simulado e medido da câmara direita do cilindro para uma pressão de 0,75bar e 494,7 rpm.

Figura 6.8 - Diagramas PxV simulado e medido da câmara esquerda do cilindro para uma pressão de 0,75bar e 494,7 rpm.

Figura 6.9 - Diagramas PxV simulado e medido da câmara direita do cilindro para uma pressão de lbar e 897 rpm. 
Figura 6.10 - Diagramas PxV simulado e medido da câmara esquerda do cilindro para uma pressão de lbar e 897 rpm.

Figura 6.11 - Diagramas PxV simulado e medido da câmara direita do cilindro para uma pressão de 2 bar e 1471,7 rpm.

Figura 6.12 - Diagramas PxV simulado e medido da câmara esquerda do cilindro para uma pressão de 2 bar e 1471,7 rpm.

Figura 6.13 - Diagramas PxV simulado e medido da câmara direita do cilindro para uma pressão de 3.5 bar e 1386 rpm.

Figura 6.14 - Diagramas PxV simulado e medido da câmara esquerda do cilindro para uma pressão de 3.5 bar e 1386 rpm.

Figura 6.15 - Diagramas PxV simulado e medido da câmara direita do cilindro para uma pressão de 3.5 bar e 1146 rpm.

Figura 6.16 - Diagramas PxV simulado e medido da câmara esquerda do cilindro para uma pressão de 3.5 bar e 1146 rpm.

Figura 6.17 - Diagramas $P_{x} t$ indicados simulado e medido da câmara direita do cilindro para uma pressão de 0.5 bar e 792,6 rpm.

Figura 6.18 - Sobreposição dos diagramas PxV simulado, experimental e teórico (utilizando o ciclo generalizado) para pressão de 3,5 bar e rotação de 960,7 rpm. 


\section{LISTA DE TABELAS}

Tabela 4.1 - Valores médios obtidos para a calibração dos transdutores de pressão para a primeira sequência de testes

Tabela 4.2 - Valores médios obtidos para a calibração dos transdutores de pressão para a segunda sequência de testes .80

Tabela 4.3 - Curvas de calibração para a primeira sequência de testes .81

Tabela 4.4 - Curvas de calibração para a segunda sequência de testes..... 82

Tabela 4.5 - Dados obtidos nas medições .89

Tabela 4.6 - Medidas de desempenho da máquina a vapor .91

Tabela 4.7 - Medidas de desempenho realizado pelo fluido 108

Tabela 5.1 - Condições das simulações e valores iniciais. 119

Tabela 5.2-Medidas simuladas de desempenho do ciclo da máquina a vapor. 137

Tabela 5.3 - Medidas de desempenho do ciclo da máquina a vapor com válvulas instantâneas 146 


\section{LISTA DE SÍMBOLOS}

\section{Símbolos Latinos}

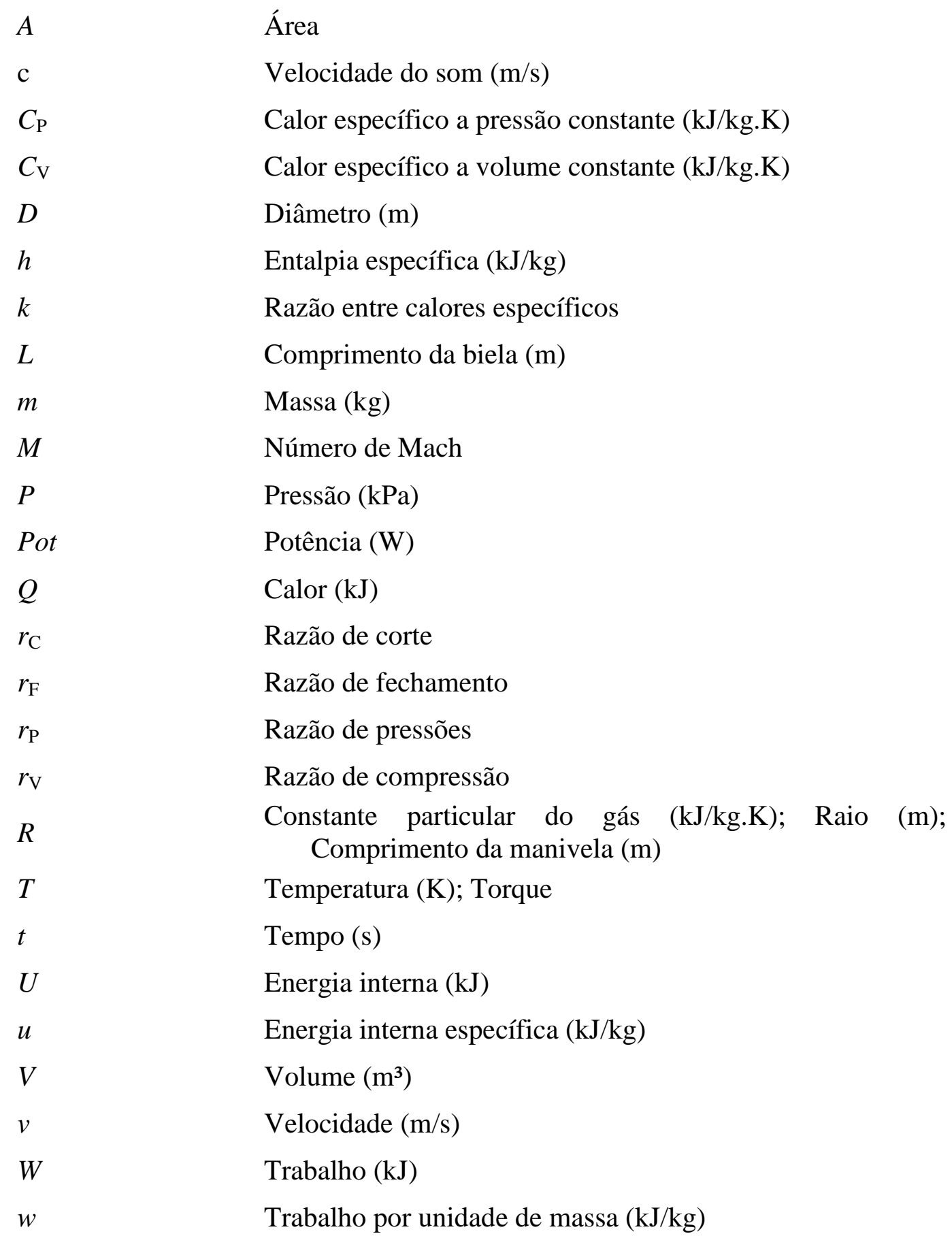




\section{Símbolos Gregos}

$\begin{array}{ll}\beta & \text { Razão de diâmetros } \\ \eta & \text { Eficiência isentrópica } \\ \rho & \text { Densidade }\left(\mathrm{kg} / \mathrm{m}^{3}\right) \\ \sigma & \text { Desvio padrão/ Perímetro molhado }(\mathrm{m}) \\ \theta & \text { Ângulo da manivela (rad) }\end{array}$

\section{Subscritos}

$\begin{array}{ll}\text { 1-8 } & \text { Pontos do diagrama PxV } \\ \text { adm } & \text { Admissão } \\ \text { atm } & \text { Atmosférico } \\ \text { ciclo } & \text { Referente a um ciclo de funcionamento } \\ \text { cond } & \text { Condensador } \\ \text { e } & \text { Entrada } \\ \text { esc } & \text { Escape } \\ \text { iso } & \text { Isentrópico } \\ \text { max } & \text { Máximo } \\ \text { min } & \text { Mínimo } \\ \text { s } & \text { Saída } \\ \text { VC } & \text { Volume de contole } \\ \mathrm{x} & \text { Relativo }\end{array}$




\section{SUMÁRIO}

DEDICATÓRIA

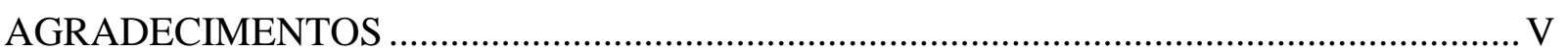

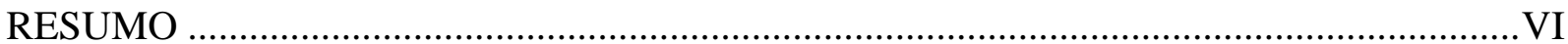

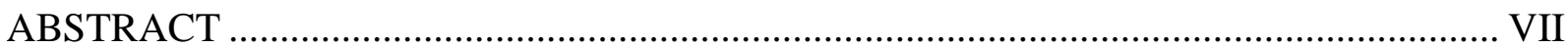

LISTA DE ILUSTRAÇÕES ...........................................................................................

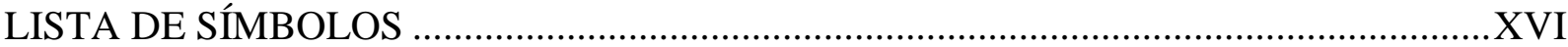

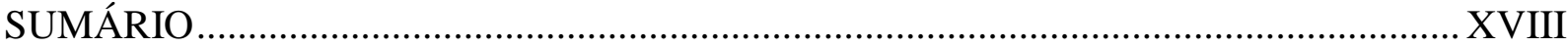

1 INTRODUÇÃO

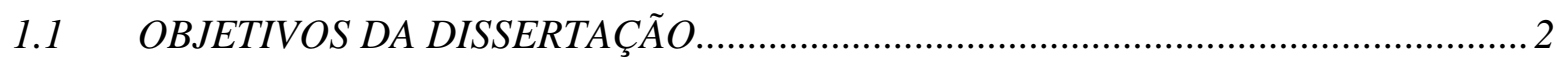

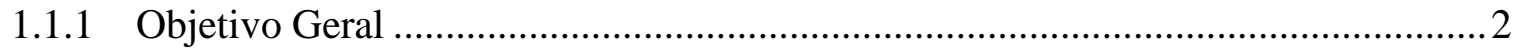

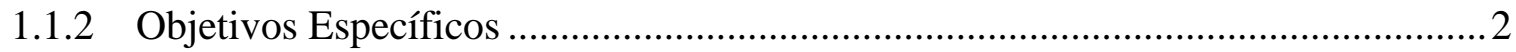

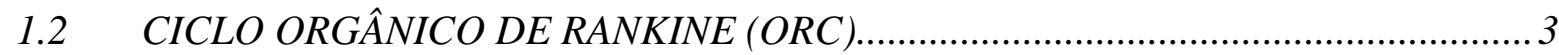

1.3 ESCOLHA DA MÁQUINA DE EXPANSÃ O ..........................................................

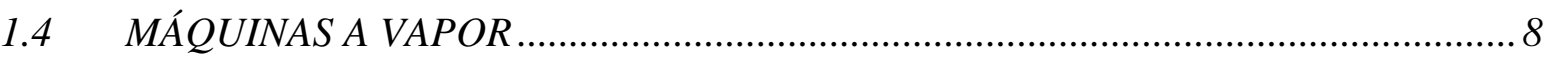

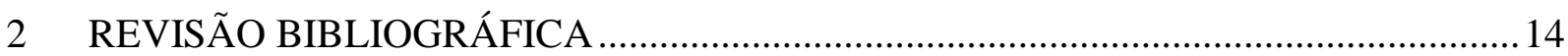

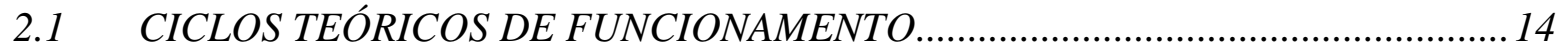

2.2 CICLOS OBTIDOS POR EXPERIMENTOS E SIMULAÇÕES …...........................22

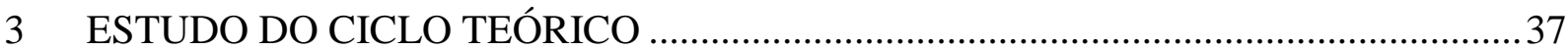

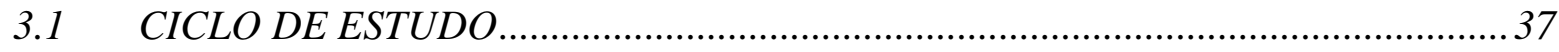

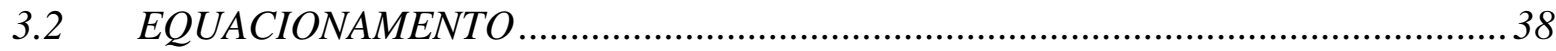

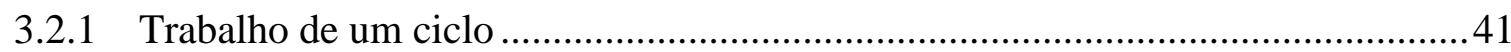

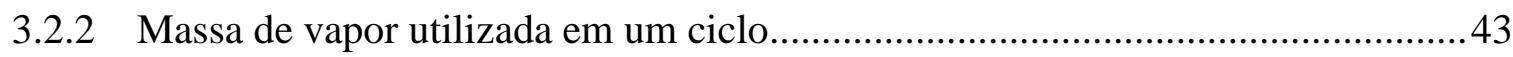

3.2.3 Temperatura em cada ponto do ciclo.................................................................. 49 


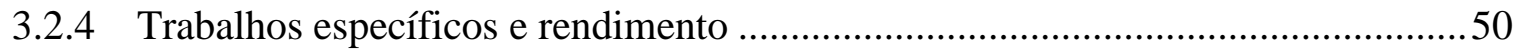

3.3 INFLUENCIA DOS PARÂMETROS NA EFICIÊNCIA DO CICLO.........................52

3.3.1 Influência dos parâmetros sobre a eficiência isentrópica ......................................54

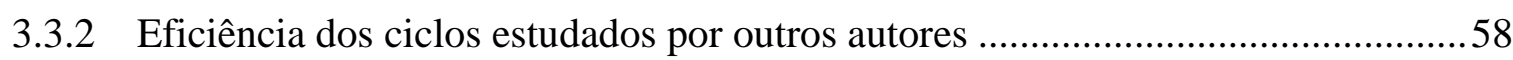

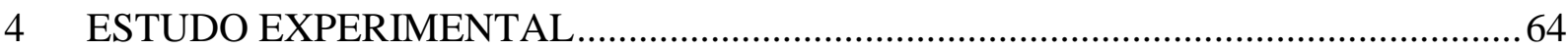

4.1 MÁQUINA DE TESTES E DADOS A SEREM COLETADOS ................................... 64

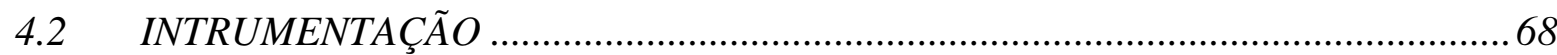

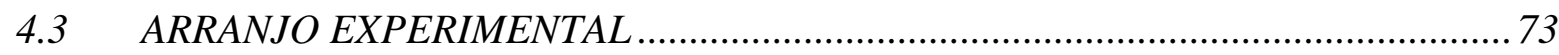

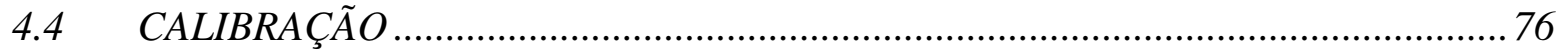

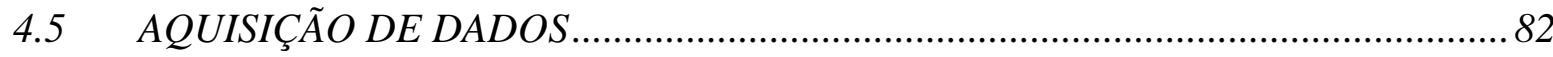

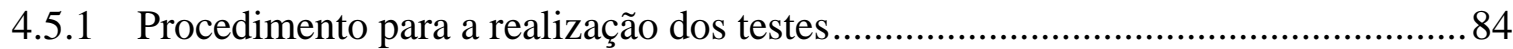

4.5.2 Fluxograma do programa de aquisição feito no LabView ....................................8 84

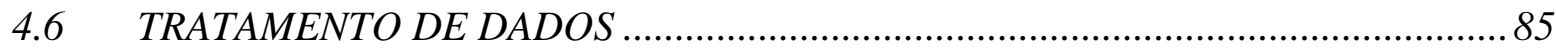

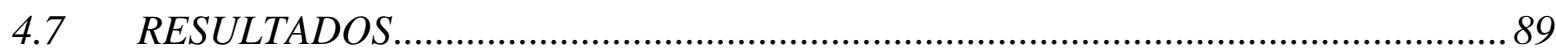

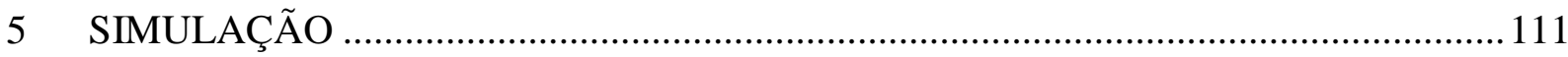

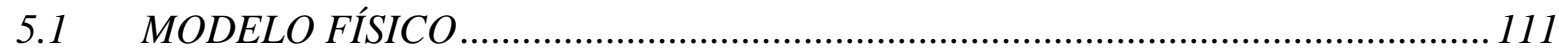

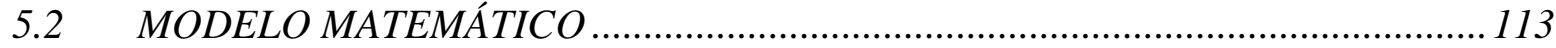

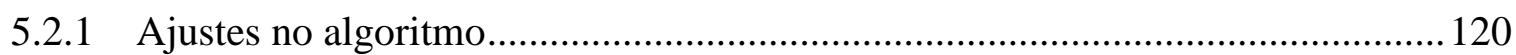

5.3 CONFIGURAÇÕES DAS SIMULAÇÕES ......................................................... 123

5.3.1 Configuração rotativa com válvulas carretel .................................................. 123

5.3.2 Configuração rotativa com válvulas de acionamento instantâneo......................... 123

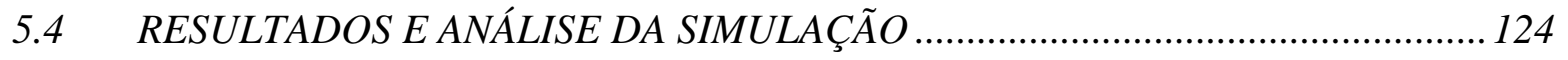

5.4.1 Resultados para a simulação com válvulas carretel............................................. 124

5.4.2 Resultados para a simulação com válvulas que abrem e fecham instantaneamente.

6 COMPARAÇÃO SIMULAÇÕES/EXPERIMENTOS ................................................ 149

6.1 ACOPLAMENTO DOS DADOS SIMULADOS E OBTIDOS

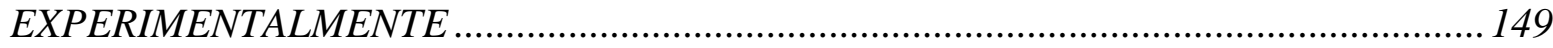

6.2 DIAGRAMAS $P_{X} V$ COMPARATIVOS ENTRE DADOS SIMULADOS E DADOS EXPERIMENTAIS 
6.3 COMPARAÇÃO ENTRE O CICLO TEÓRICO, O SIMULADO E O EXPERIMENTAL

7 CONCLUSÕES 165

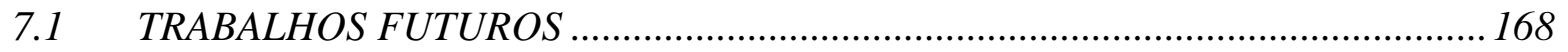

REFERÊNCIAS BIBLIOGRÁFICAS 169

APÊNDICE A - EQUAÇÕES PARA O CICLO GENERALIZADO EM FUNÇÃO DAS RAZÕES DE CORTE E DE FECHAMENTO NA FORMA DE PORCENTAGEM....

APÊNDICE B -DEMONSTRAÇÃO DA EFICIÊNCIA DE 100\% NO CICLO IDEAL ....... 174 APÊNDICE C - ALGORITMO DA SIMULAÇÃO TERMODINÂMICA DA MÁQUINA A VAPOR

APÊNDICE D - ALGORITMO PARA A GERAÇÃO DO CICLO CARACTERÍSTICO DE CADA MEDIÇÃO

APÊNDICE E - ARTIGO ACEITO PARA O ENCIT 2012 


\section{INTRODUÇÃO}

As máquinas a vapor alternativas tiveram um papel importante na Revolução Industrial e foram amplamente utilizadas em diversos setores da indústria nos séculos anteriores. No início do século XX, essa tecnologia foi substituída pelos motores que operam de acordo com os ciclos Otto e Diesel e também pelas turbinas a vapor, concebidas no início do século Assim, as máquinas a vapor ficaram relegadas a um segundo plano devido à sua baixa capacidade de geração de potência elétromecânica por volume de instalação. Ao longo do século XX a tecnologia das máquinas a vapor permaneceu praticamente estagnada e de uso prático restrito na indústria.

Recentemente a tecnologia das máquinas a vapor se tornou interessante novamente. Isso se deve ao fato do crescente interesse nos Ciclos Orgânicos de Rankine (ORC), usados para transformar energia térmica em energia elétrica em instalações de baixa potência, geralmente utilizando energia solar como fonte de calor ou recuperação de energia térmica em sistemas de cogeração ou combustão de biomassa. Os ORCs são mais utilizados em locais afastados dos grandes centros, onde o acesso à rede principal de energia é limitado. Outro interesse nos ORCs é o aproveitamento da energia dissipada na forma de calor em indústrias, cuja energia térmica geralmente é de baixa temperatura. Com esse reaproveitamento, é possível gerar energia elétrica a partir da energia térmica que seria perdida para o ambiente.

Este estudo é baseado em uma máquina a vapor para ser utilizada como o equipamento de expansão em um ORC. Este ORC deve ser utilizado para gerar energia elétrica em locais afastados dos grandes centros, utilizando como fonte de energia, a radiação solar.

Também existe a possibilidade de se utilizar as máquinas a vapor para a expansão de gás a alta pressão, transformando parte dessa energia em energia elétrica ou mecânica. 


\subsection{OBJETIVOS DA DISSERTAÇÃO}

Os objetivos estão divididos em gerais e específicos.

\subsubsection{Objetivo Geral}

Estudar o funcionamento das máquinas a vapor, considerando seus aspectos teóricos e experimentais.

\subsubsection{Objetivos Específicos}

- Estudar e equacionar os ciclos teóricos de funcionamento das máquinas a vapor e analisar as possibilidades de otimização dos mesmos. Determinar qual dos ciclos mecânicos teóricos de expansão utilizados até hoje é melhor para ser determinado como um ciclo padrão para a máquina a vapor, assim como existe um ciclo padrão de estudo para outros equipamentos.

- Simular o funcionamento de um motor a vapor e comparar os resultados com o funcionamento real de um exemplar que foi testado com ar comprimido.

- Por meio da simulação e dos dados coletados, compreender os fenômenos termodinâmicos que ocorrem dentro da máquina a vapor, a fim de entender quais e como os fatores que influenciam na eficiência da mesma, para que no futuro seja possível projetar e construir uma máquina a vapor de qualquer tamanho e potência, e que trabalhe com qualquer fluido, facilitando trabalhos futuros para a construção do ORC. 


\subsection{CICLO ORGÂNICO DE RANKINE (ORC)}

O ORC funciona da mesma maneira que o ciclo de Rankine convencional. Um esquema de um ORC está ilustrado na Figura 1.1, em que a fonte de energia térmica é o sol com complementação por combustível - sistema híbrido. No ORC da figura, existem 2 circuitos fechados, o ciclo de Rankine propriamente dito é o circuito da direita, representado pelos pontos $1,2,3,4,5$ e 6 . Neste ciclo, primeiramente o fluido de trabalho é aquecido de líquido sub-resfriado até vapor superaquecido nos processos 2-3 e 3-4. Após a saída do evaporador, caso o fluido não esteja superaquecido, ou nas condições desejadas, este passa por um superaquecedor por combustão (processo 4-5). Esse fluido superaquecido passa por uma máquina de expansão, geralmente uma turbina, indicado como processo 5-6 da Figura 1.1. A máquina de expansão transforma parte da entalpia do vapor em trabalho mecânico, à custa da diminuição da temperatura e pressão do fluido. Após passar pela máquina de expansão, o vapor passa pelo condensador, onde o calor é retirado até que esse se torne líquido saturado (processo 6-1). O fluido na forma de líquido saturado em baixa pressão passa por uma bomba, que eleva sua pressão até a pressão do evaporador (processo 1-2). O fluido de trabalho na forma líquida entra no preaquecedor e no evaporador, onde recebe calor até que se transforme em vapor, reiniciando o ciclo.

O circuito do lado esquerdo existe para que o aquecimento do fluido de trabalho (circuito do lado direito) seja de forma indireta em relação à fonte de energia, o sol. Assim, uma oscilação brusca no fornecimento de energia no coletor solar não provoca uma variação rápida no ciclo da direita, e consequentemente, na geração de eletricidade. Em alguns casos, pode-se utilizar um armazenador de energia térmica no circuito da esquerda, fazendo com que o ciclo da direita continue funcionando normalmente, mesmo sem o fornecimento adequado de energia solar por um período maior.

No ORC, ao invés de se utilizar água como fluido de trabalho, a substância usada é um fluido orgânico, devido às suas propriedades. "A vantagem de se utilizar um fluido orgânico, ao invés de água, é que esses fluidos possuem baixas temperaturas de evaporação, que é o principal critério para ser utilizado em uma fonte de calor de baixas temperaturas" (Tarique, 2011). 


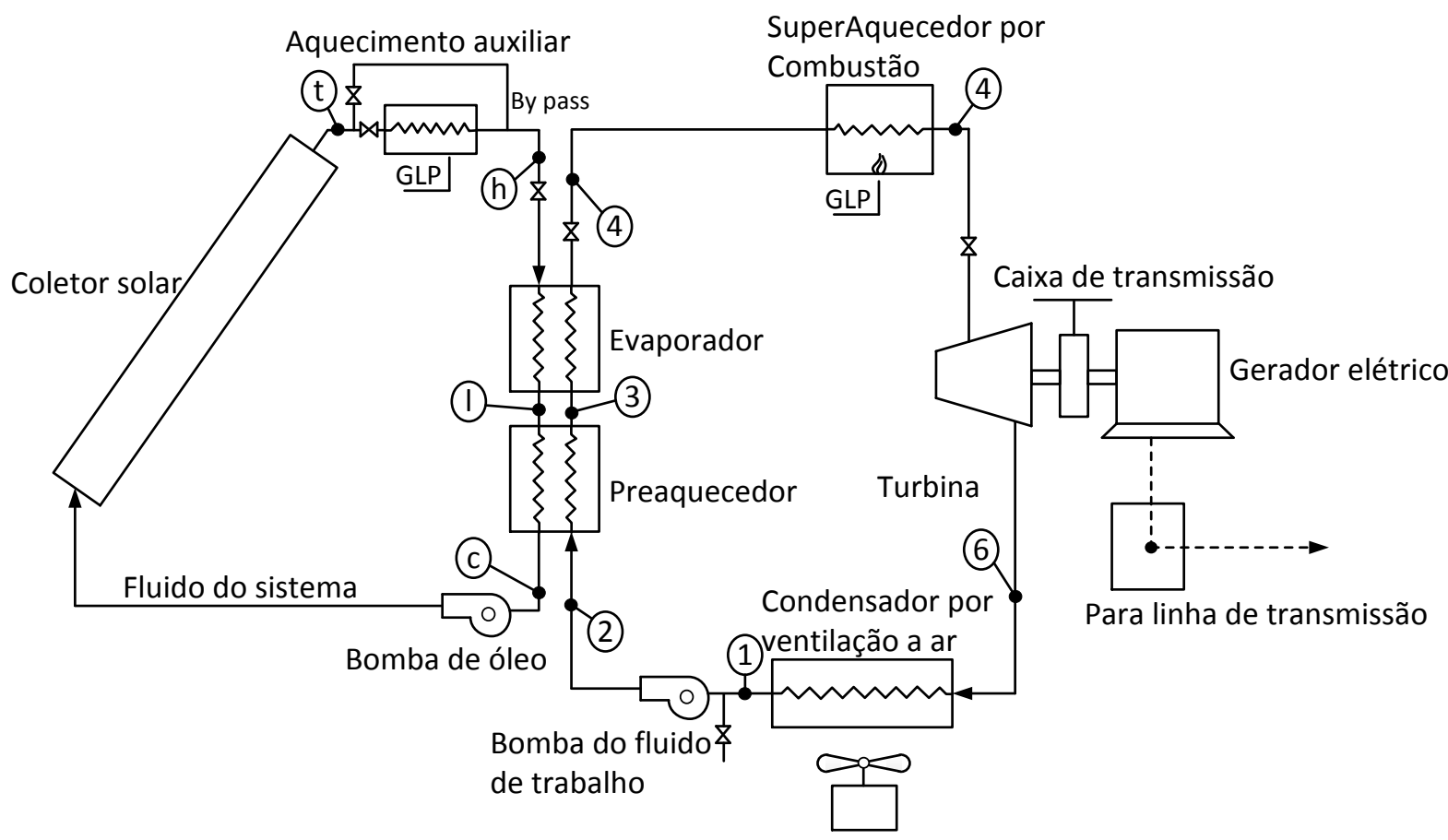

Figura 1.1 - Esquema geral de um Ciclo Orgânico de Rankine para geração de eletricidade a partir de painéis solares.(GARI et al., 1988)

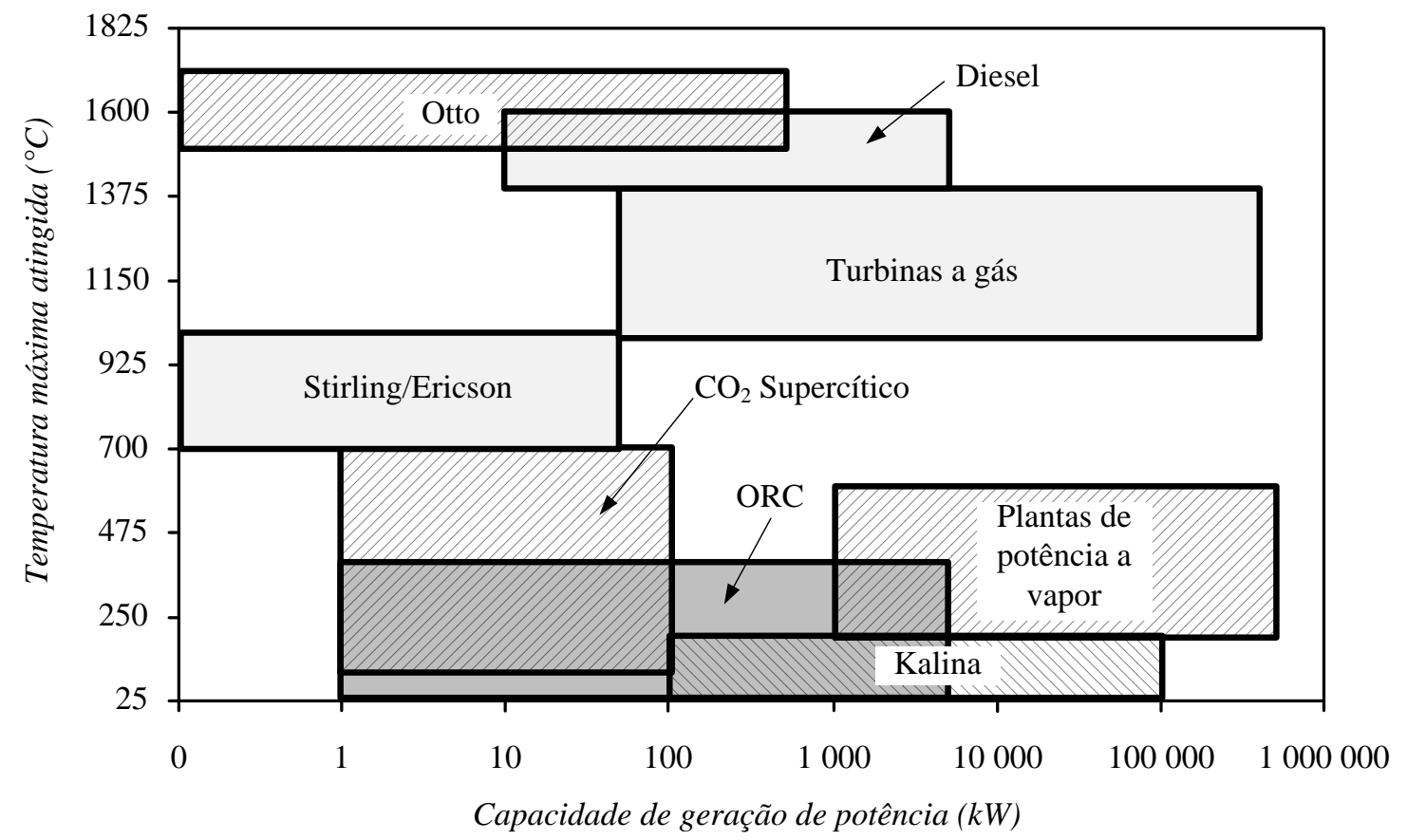

Figura 1.2 - Relação da temperatura de funcionamento com a potência gerada para diferentes ciclos de potência (Tarique, 2011).

A possibilidade de se trabalhar com temperaturas baixas torna o ORC ideal para ser utilizado com energia solar ou no aproveitamento de calor residual de processos. Os fluxos de calor perdidos nas indústrias, nos automóveis e em outras aplicações geralmente são de baixa 
temperatura e existem diversas pesquisas com ORCs para o aproveitamento dessa energia térmica, e consequentemente, o aumento na eficiência energética. O diagrama da Figura 1.2 mostra as faixas de temperaturas de operação de um ORC e de outros ciclos de potência. $\mathrm{O}$ autor discorda dos valores de temperatura utilizados nos ciclos Otto e Diesel indicados no diagrama, porém os valores para o ORC estão de acordo com valores reais, podendo assim, ser utilizado para verificar a faixa de operação do ORC. Nesta figura é possível notar que, para baixas temperaturas, o ORC é o ciclo mais abrangente, cobrindo uma grande faixa de potências.

\subsection{ESCOLHA DA MÁQUINA DE EXPANSÃO}

Para a escolha da máquina de expansão, é necessário conhecer a potência que se deseja obter com o ciclo. Segundo Badr et al. (1991) é interessante que o equipamento de expansão trabalhe entre 3000 e $5000 \mathrm{rpm}$, pois é a rotação mais comum de bombas, geradores, compressores e outros equipamentos que podem ser movidos pelo sistema. É desejável uma eficiência isentrópica entre $65 \%$ e $75 \%$ para que seja possível alcançar uma eficiência de $20 \%$ para o ciclo todo. Além disso, afirmam que a máquina de expansão do ORC tem de possuir alta confiabilidade e durabilidade, poucas partes móveis, baixo ruído de operação, capacidade de trabalhar na mudança de fase sem prejudicar o desempenho ou a vida útil do equipamento, e uma curva de desempenho relativamente plana, com um bom desempenho em uma grande faixa de operação.

Bao e Zhao (2013) afirmam que para a escolha da máquina de expansão, deve-se levar em conta diversos aspectos, como eficiência isentrópica, razão de pressões, potência desejada, lubrificação do equipamento, rotação de operação, balanceamento dinâmico, confiabilidade e custo, assim como temperaturas e pressões de trabalho, vazamentos, barulho e segurança.

Badr et al. (1991) separam as máquinas de expansão em dois tipos, as turbinas e os motores de deslocamento positivo, e citam características positivas e negativas de ambas. No grupo dos motores de deslocamento positivo são citados o motor Wankel, o motor de palhetas, o expansor de parafuso helicoidal, e o motor alternativo. Curran (1981) (apud Badr et al., 1991) 
diz que os motores de deslocamento positivo são lentos $(<5000 \mathrm{rpm})$ e são utilizados para produzir potências de até $10 \mathrm{~kW}$, enquanto as turbinas são máquinas de alta rotação (> 5000 rpm) e são utilizadas para potências superiores a $10 \mathrm{~kW}$. Para motores de deslocamento positivo, a potência de saída aumenta conforme aumento da rotação, e para turbinas, as maiores potências são para rotações próximas ao ponto de projeto.

As características de cada equipamento citadas por Badr et al. (1991) e por Bao e Zhao (2013) são as seguintes:

Turbinas - Necessitam de uma razão de pressões maior quando comparadas com os equipamentos de deslocamento positivo, possuem boa eficiência em altas rotações, porém essa eficiência diminui quando operam fora do ponto de funcionamento de projeto. Também existem problemas de grande estresse mecânico e vedação quando operam em rotações muito elevadas. Não toleram a fase líquida. Pode-se manter uma turbina funcionando sempre no ponto de projeto se for utilizado um sistema complexo de controle automático de velocidade.

Motores alternativos - Maior quantidade de partes móveis, gerando um problema de balanceamento inerente ao equipamento, menor respiro do motor (menor fluxo de vapor entrando ou saindo do motor) devido às grandes perdas por fricção do fluido no sistema de válvulas, dificuldade de lubrificação quando o fluido de trabalho é vapor, possuem baixa eficiência e são volumosos, quando comparados com motores Wankel e motores de palhetas. Esse tipo de motor não é estudado como equipamento de expansão devido às perdas por vazamentos internos e pela faixa de potência e rotação desejadas no tipo de interesse do estudo do autor, que é cogeração com uma potência de $5 \mathrm{~kW}$ a $20 \mathrm{~kW}$. Possuem boa tolerância à fase líquida e são adaptáveis para diferentes condições de trabalho.

Motores Wankel - Têm sido objeto de estudo na indústria automotiva, porém poucos trabalhos estudam esse tipo de motor para expansão de vapor. Em um programa de testes, o principal problema encontrado foi a ruptura do assento da válvula de admissão, provocando uma perda excessiva de vapor. Possui problemas de lubrificação e desgaste, mas mesmo com essas características, Badr et al. (1991) dizem que esse é o equipamento de expansão mais adequado para um ORC de $10 \mathrm{~kW}$, embora o projeto desses motores ainda precise ser melhorado. 
Motores de palhetas - São utilizados na indústria para baixas temperaturas e pequenas expansões. Nessas condições possuem baixa eficiência, que é compensada pelo baixo custo, boa confiabilidade e tamanho compacto. Possuem simplicidade na construção, baixa velocidade de operação, baixo ruído, baixa vibração, não necessita de um motor de arranque, alta tolerância à presença da fase líquida e problemas de lubrificação. São utilizados para potências menores que $10 \mathrm{~kW}$.

Motores de parafuso helicoidal - Possuem boa eficiência e também problemas de lubrificação e vedação. Trabalham em rotações menores que $6000 \mathrm{rpm}$, possuem boa eficiência quando operam em condições fora do ponto de projeto. Os autores descrevem casos em que foi utilizado um motor de parafuso helicoidal e casos em que foi comparado e testado com turbinas e motores alternativos, mostrando o bom desempenho desse tipo de motor.

Bao e Zhao (2013) estudam também os motores do tipo Scroll, que possuem alta eficiência, problemas de lubrificação e trabalham com rotações menores que $6000 \mathrm{rpm}$. Toleram bem a fase líquida e trabalham com potências menores que $10 \mathrm{~kW}$.

Segundo Alanne et al. (2012), as vantagens dos motores rotativos são o tamanho compacto, uma boa relação peso-potência e uma conexão simples com um gerador, sem necessitar de reduções. Os motores rotativos também não precisam de superaquecimento na admissão, pois segundo sua forma construtiva, eles são mais ou menos insensíveis à presença da fase líquida formada durante a expansão, no caso do fluido de trabalho ser água.

Embora o trabalho de Badr et al. (1991) aponte o motor alternativo como uma possibilidade pouco viável para ser utilizado como equipamento de expansão de um Ciclo Orgânico de Rankine, para este trabalho foi escolhido um motor alternativo, devido as justificativas a seguir: a proposta é que ORC trabalhe longe dos grandes centros e portanto, deve ser de fácil manutenção, não necessitando de mão de obra especializada. Mesmo Badr et al. (1991) afirmam que os motores alternativos são mais custosos que outros modelos para fabricar, e possuem muito atrito, também quando comparados com outros tipos de motor. o autor possui um ponto de vista discordante. Os motores alternativos amplamente utilizados e estudados são rotativos (máquinas a vapor, e motores de combustão interna), portanto trabalham com um eixo de manivelas e possuem muitas partes móveis, porém é possível construir um motor 
alternativo com poucas partes móveis, com um sistema linear ao invés da biela-manivela. Essa possibilidade é incomum, porém reduz o atrito e a quantidade de partes móveis.

Os motores de movimento alternativo possuem um custo de fabricação igual ou menor quando comparado com turbinas, motores wankel e parafuso helicoidal, pois os formatos das peças são simples de serem fabricadas e poucas superfícies necessitam de uma precisão maior, viabilizando a utilização em locais de baixa renda. Dentre as possibilidades de máquinas de expansão listadas por Badr et al. (1991), os motores de movimento alternativo se destacam por não necessitarem de mão de obra especializada para manutenção, possuírem peças de geometria simples de serem fabricadas e substituídas, e um tamanho compacto quando comparados com turbinas. Segundo esses autores, os motores de movimento alternativo possuem baixa eficiência, porém esse fator se torna secundário perante a facilidade de mão de obra necessária para o projeto do ORC para trabalhar em locais afastados dos grandes centros.

\subsection{MÁQUINAS A VAPOR}

Como descrito por Farey (1827), ao longo da história, existiram diversos equipamentos "movidos com fogo", utilizados para facilitar o trabalho do homem. Uma máquina notável foi a máquina de Newcomen, ou como é conhecida, máquina a vapor de Newcomen. Essa máquina a vapor foi inventada em 1710 e era comumente utilizada para drenar água das minas de carvão. A partir de 1759, a máquina a vapor de Newcomen começou a ser estudada por James Watt. A partir dessa data, J. Watt começou a fazer inúmeros experimentos de como melhorar o desempenho da máquina de Newcomen, diminuindo o consumo de água e queimando menos carvão para realizar o mesmo trabalho. James Watt obteve sua primeira patente em 1769. A primeira máquina a vapor de Watt, como ficou conhecida, foi concebida entre 1775 e 1778. Essa invenção de Watt permitiu que a máquina a vapor fosse utilizada amplamente nas indústrias, dando impulsionando a Revolução Industrial.

A Figura 1.3 mostra esquematicamente as peças principais de uma máquina a vapor alternativa. Essa máquina a vapor é de dupla ação, ou seja, ambos os lados do pistão recebem 
vapor em alta pressão e empurram o pistão. Existem máquinas a vapor em que apenas um lado do pistão recebe vapor a alta pressão e temperatura, enquanto o outro lado fica sempre na mesma pressão, esse tipo de configuração é dita de ação simples. As válvulas mostradas na Figura 1.3 são em forma de paralelepípedo, mas existem outros tipos de válvulas e mecanismos para sincronizar o movimento do pistão e das válvulas.

Na Figura 1.3, o pistão se encontra em uma extremidade do seu curso, na extremidade mais próxima da roda. Esse ponto é chamado de ponto morto inferior (PMI). A outra extremidade do curso do pistão, quando ele está mais afastado da roda, é chamada de ponto morto superior (PMS). Na máquina a vapor dessa figura, quando o pistão se encontra no PMI, a câmara do lado esquerdo do cilindro possui o menor volume possível, esse volume é chamado de volume morto. Quando o pistão se deslocar para a direita, atingindo o PMS, a câmara do lado direito terá o menor volume que ela pode assumir, o volume morto.

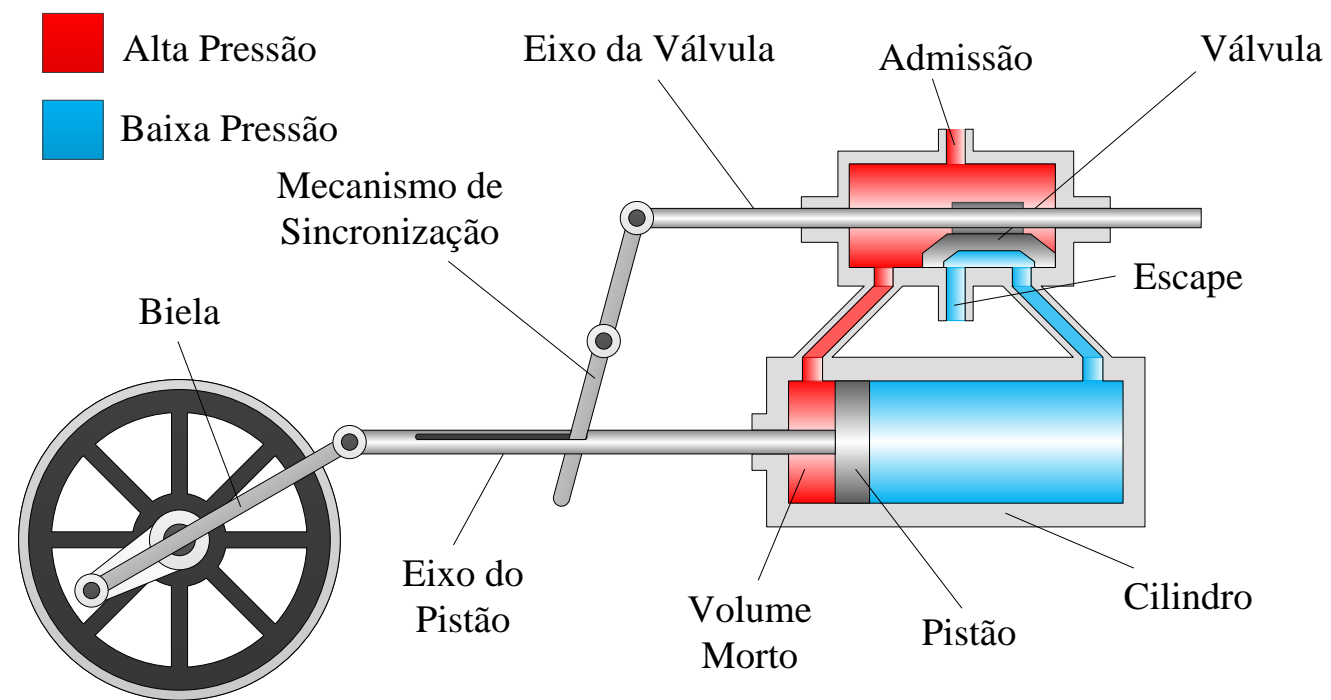

Figura 1.3 - Representação esquemática de uma máquina a vapor, com os nomes das partes principais.

O funcionamento da máquina a vapor é descrito utilizando a Figura 1.4. Na câmara onde ficam as válvulas, existe uma região que armazena vapor vindo da caldeira (em vermelho no desenho), e existe outra região que está sempre aberta para a câmara de escape (em azul no desenho). A posição da válvula permite que uma das câmaras do cilindro receba vapor a alta temperatura e pressão (em vermelho), enquanto a outra câmara está aberta para p escape (em azul), permitindo que o vapor saia em baixa pressão. As duas câmaras sempre estão em processos opostos do ciclo de funcionamento do motor a vapor. 


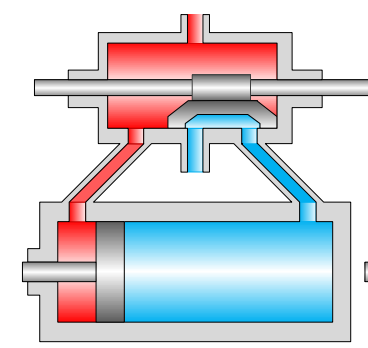

(a)

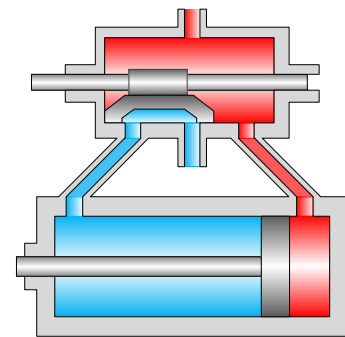

(d)

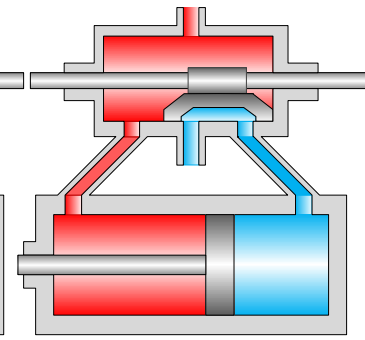

(b)

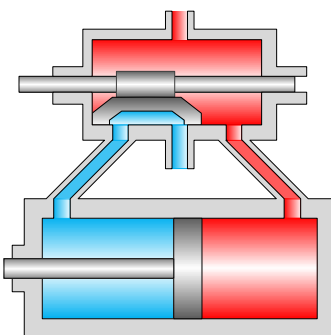

(e)

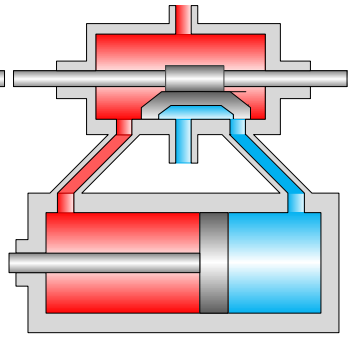

(c)

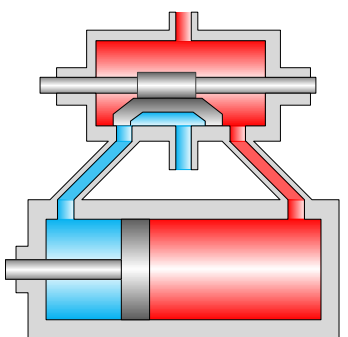

(f)

Figura 1.4 - Etapas de funcionamento de um ciclo da máquina a vapor.

Tendo como ponto inicial a Figura 1.4(a), a câmara do lado esquerdo recebe vapor a alta pressão e temperatura, enquanto a câmara do lado direito está aberta para o escape. Devido à diferença entre as pressões dos dois lados do pistão, este se movimenta de forma a expulsar o vapor em baixa pressão que está do lado direito do cilindro, Figura 1.4(b). Acionado pelo movimento do pistão, um sistema conectado ao pistão através de seu eixo movimenta a válvula, fazendo com que a câmara que estava conectada com a admissão de vapor, se conecte com o escape, e vice-versa, Figura 1.4(c). Portanto, a câmara do cilindro que estava em alta pressão, passa a ter baixa pressão, e a câmara que estava com baixa pressão, recebe vapor a alta pressão, Figura 1.4(d). Isso inverte a resultante das forças sobre o pistão, devido às pressões das câmaras nos dois lados do pistão. Essa nova configuração faz com que o pistão se movimente no sentido contrário, retornando à sua posição inicial, Figura 1.4(e). Durante o retorno, o mecanismo acoplado ao pistão movimenta novamente as válvulas, Figura 1.4(f), invertendo as pressões das câmaras, e reiniciando o ciclo.

Em uma rotação da máquina a vapor, ela parte de uma condição inicial e retorna para essa mesma condição, podendo dizer que seu movimento é cíclico. Porém na Termodinâmica existem ciclos mecânicos e ciclos termodinâmicos. Os ciclos mecânicos se referem à repetição de movimento, e os ciclos termodinâmicos transformam energia térmica em energia mecânica. As máquinas a vapor não realizam ciclos termodinâmicos, elas realizam ciclos mecânicos. Neste trabalho, por uma questão de escrita, será utilizada apenas a palavra ciclo 
para designar o ciclo mecânico de uma máquina a vapor, visto que as máquinas a vapor não realizam um ciclo termodinâmico. Assim, é feito um estudo termodinâmico sobre o ciclo mecânico de funcionamento das máquinas a vapor.

Uma medida importante para o estudo das máquinas a vapor é a variação da pressão no interior do cilindro ao longo do trajeto do pistão. Normalmente é construído um gráfico da pressão em função do volume da câmara do cilindro ou da posição do pistão, como ilustra a Figura 1.5. Esse é o diagrama PxV, e é o principal ponto de estudo de uma máquina a vapor. Utilizando este gráfico, pode-se determinar o trabalho produzido pela máquina a vapor em um ciclo, o consumo de massa e também sua eficiência. Nos próximos capítulos serão mostrados apenas os diagramas PxV nos estudos de desempenho dos motores a vapor. Na Figura 1.5 pode-se observar 2 diagramas $\mathrm{PxV}$, um representado por uma linha azul e outro por uma linha vermelha, ambos os diagramas são válidos para o estudo de uma das câmaras da máquina, e a outra câmara possui comportamento simétrico similar. O diagrama PxV azul é de um ciclo que alguns autores consideram como ideal, e era mais comum de ser utilizado nos primeiros estudos sobre o diagrama PxV de máquinas a vapor. Este diagrama PxV possui os mesmo processos do diagrama $\mathrm{PxV}$ vermelho, com exceção do processo de compressão. O diagrama PxV vermelho seria um ciclo considerado como real, ou mais próximo do real.

Analisando a Figura 1.5 é possível reconhecer e estudar todos os processos que ocorrem com o vapor devido aos processos mecânicos que são indicados na Figura 1.4. Esses processos são admissão, expansão, escape, e compressão do vapor. A admissão é representada pela linha vertical ascendente e a linha quase horizontal que vai para a direita no digrama vermelho, e no diagrama azul é uma linha vertical de volume zero e uma linha horizontal em alta pressão. A expansão é indicada pela curva isentrópica onde o volume da câmara aumenta e a pressão do fluido diminui, isso ocorre em ambos os diagramas. Quando o pistão se aproxima do ponto morto de maior volume, a válvula de escape abre e a pressão interna do cilindro cai para a pressão de escape, e em parte do retorno do pistão para a esquerda, a pressão permanece constante no diagrama vermelho. No diagrama azul, a pressão interna permanece constante até o pistão chegar ao ponto morto de menor volume, representado por um volume morto nulo. No diagrama vermelho, no meio do processo de escape, a válvula de escape é fechada e o fluido passa a sofrer uma compressão isentrópica até chegar ao ponto morto de menor volume, instante esse no qual a válvula de admissão é aberta e o ciclo se reinicia. É notável também que o diagrama PxV ideal (azul) possui um volume morto nulo, representando que o 
vapor seria totalmente expulso do cilindro antes de admitir novamente vapor em alta pressão. Fazer uma máquina com volume morto nulo é impraticável, pois indica que haveria um impacto do pistão com o fundo do cilindro, provocando altas tensões nas peças e isso reduzindo drasticamente a vida útil do equipamento.

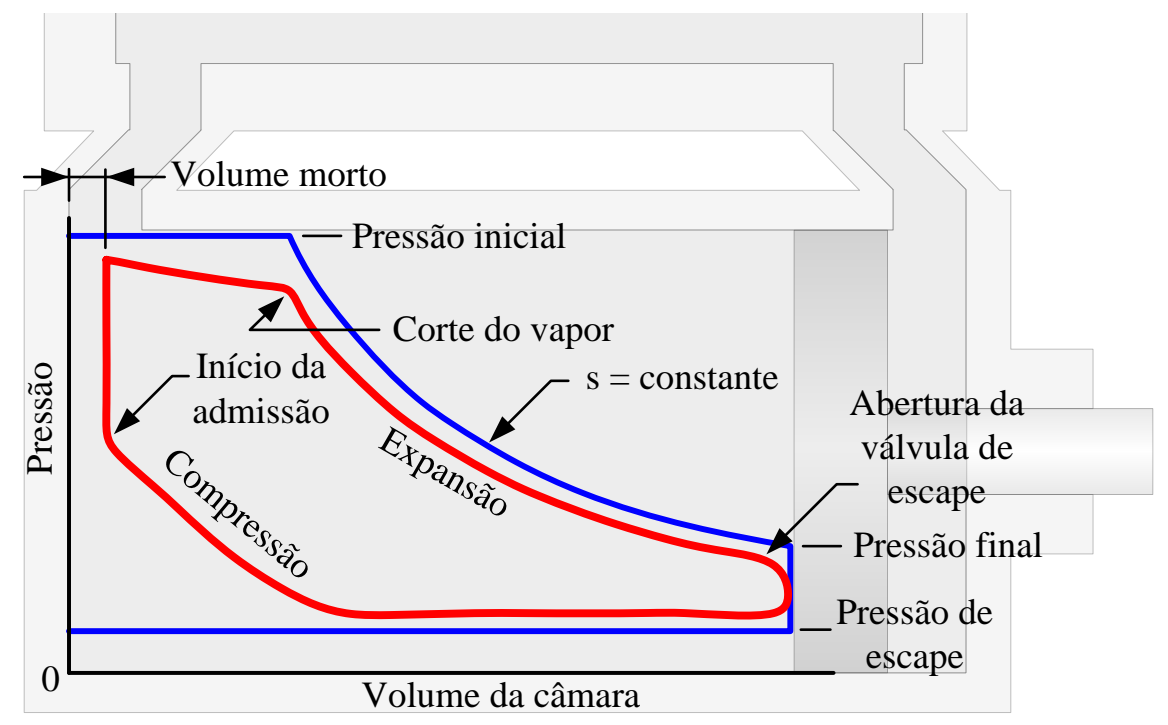

Figura 1.5 - Diagrama PxV de uma máquina a vapor alternativa.

Outros equipamentos possuem exatamente o mesmo comportamento da pressão em relação ao volume, como todos os motores pneumáticos ou máquinas de expansão que trabalham com outros fluidos (com exceção das turbinas e motores de parafuso helicoidal). Portanto, todo o estudo desenvolvido nesse trabalho pode ser utilizado para qualquer máquina de expansão, com exceção das turbinas.

Embora existam diagramas $\mathrm{PxV}$ de máquinas a vapor, e alguns estudos sobre eficiência, esses dados são por vezes divergentes e superficiais. Isso se deve ao fato de que o aprofundamento dos estudos da Termodinâmica ocorreu ao longo do século XIX e início do século XX, período que os motores de combustão interna e as turbinas apareceram e tomaram o lugar das máquinas a vapor. Assim, os conceitos mais elaborados da Termodinâmica foram utilizados para estudar as turbinas e os motores de combustão interna, pois as máquinas a vapor já estavam em desuso no período que os conceitos e equações do comportamento dos fluidos foram desenvolvidos. Assim, existem ciclos padrões para um motor térmico que funciona de acordo com o ciclo Otto, com o ciclo Diesel ou até outro ciclo utilizado, mas não existe um ciclo padrão para a máquina a vapor, cada autor utiliza um ciclo diferente, e até abordagens diferentes, que divergem entre si. 
Sendo assim, torna-se necessário um estudo mais aprofundado sobre o funcionamento e o comportamento de uma máquina a vapor, a fim de compreender os fenômenos que interferem no modo de operação da máquina a vapor, na potência, e consumo de fluido necessário.

Embora o equipamento estudado seja uma máquina a vapor, se trata de uma máquina de expansão com pistão, sendo um motor de expansão que pode trabalhar com qualquer fluido na fase gasosa. Neste trabalho, o termo 'máquina a vapor' é recorrente e representa não só as máquinas a vapor, mas também todos equipamentos de expansão de gases ou vapor, que podem trabalhar com vapor de água, vapor de qualquer fluido ou gases. 


\section{REVISÃO BIBLIOGRÁFICA}

Nesse capítulo são abordadas as principais características encontradas na literatura para o estudo de um motor a vapor. Uma das principais características são os ciclos utilizados e os resultados obtidos por diferentes autores através de simulações ou experimentos.

\subsection{CICLOS TEÓRICOS DE FUNCIONAMENTO}

Para o motor a vapor de movimento alternativo não existe um ciclo mecânico padrão bem definido de funcionamento, assim como existe para o ciclo térmico Otto e o ciclo Diesel. Na literatura diversos ciclos são utilizados como padrão, porém possuem diferenças significativas entre si. Dessa forma, existe o interesse de estudar os ciclos mecânicos de expansão de máquinas a vapor encontrados na literatura, a fim de verificar se existe um ciclo mais generalizado que possa substituir os outros, e caso não exista, determinar um ciclo padrão para o funcionamento das máquinas a vapor que possa ser utilizado em todos os casos, sem negligenciar os ciclos já utilizados por outros autores. O funcionamento de uma máquina a vapor é similar ao funcionamento de motores movidos a ar comprimido ou qualquer outro gás pressurizado, tornando esse estudo útil em diversas aplicações.

Para estabelecer um ciclo generalizado, é necessário conhecer e estudar os ciclos que já foram utilizados por outros autores, a partir de seus respectivos diagramas PxV. Em todos os diagramas $\mathrm{PxV}$, os processos representados por linhas vermelhas indicam a admissão de vapor a alta pressão e alta temperatura, as linhas azuis indicam o escape do vapor do cilindro e as linhas em preto representam uma compressão ou expansão isentrópicas. A sequência de funcionamento dos ciclos é no sentido horário, seguindo a sequência numérica dos pontos principais.

Os autores que utilizam os ciclos da Figura 2.1 definem esse ciclo como um ciclo de Rankine. Este ciclo é o mesmo ilustrado em azul na Figura 1.5 e foi considerado como ideal por muitos. Esses autores relacionam o ciclo de funcionamento da máquina a vapor com o ciclo 
de Rankine devido ao fato de o ciclo da Figura 2.1 que segue a sequência 1-2-3-6 é composto por dois processos isobáricos e dois processos isentrópicos. Um desses autores, Prasad (1993) afirma que no ciclo ideal, todos os processos do ciclo de Rankine deveriam ocorrer dentro do cilindro, e nesse ciclo ideal os processos seriam caracterizados da seguinte forma: no processo 1-2 entra calor no cilindro, alterando o estado da água de líquido para vapor. No processo 2-3 ocorre a expansão isentrópica do vapor, no retorno do pistão (processo 3-6), o vapor é condensado através da retirada de calor. A pressão do vapor sofre um aumento até a pressão do evaporador por uma "bomba" no processo 6-1, reiniciando o ciclo.

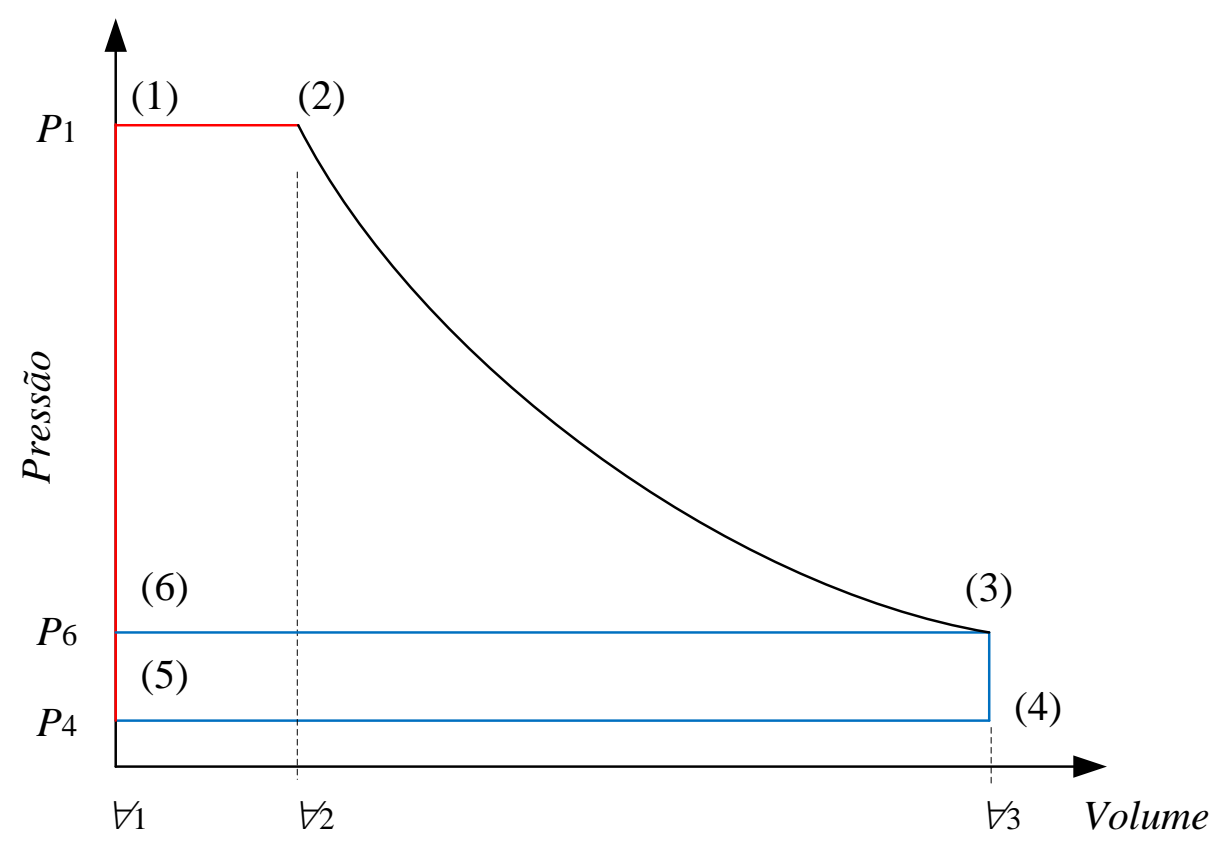

Figura 2.1 - Diagrama PxV para um ciclo com volume morto nulo utilizado por Mariño (1948) e Alanne et al. (2012).

Alanne et al. (2012) e Ferrara et al. (2013) estudam o mesmo diagrama PxV, porém apenas como um ciclo mecânico de expansão de vapor ou gás, fazendo com que a interpretação de cada processo seja um pouco diferente da interpretação de Prasad (1993). O ciclo 1-2-3-6 se inicia no ponto morto superior (PMS), ponto 1, com vapor a alta pressão e alta temperatura entrando no cilindro e empurrando o pistão em direção ao ponto morto inferior (PMI). A válvula de admissão fecha no ponto 2 , em uma posição ao longo do percurso do pistão em direção ao PMI, finalizando o processo de admissão e iniciando o processo de expansão. $\mathrm{O}$ vapor é expandido até atingir a pressão do condensador no PMI (ponto 3). Nesse momento a válvula de escape abre instantaneamente e o vapor é expulso do interior do cilindro no curso de retorno do pistão, até chegar novamente no PMS (ponto 6). Chegando ao PMS a válvula de escape fecha e a válvula de admissão abre, ambas instantaneamente, admitindo vapor e 
aumentando a pressão interna do cilindro para a pressão de admissão, reiniciando o ciclo. A diferença do ciclo 1-2-3-6 e do ciclo 1-2-3-4-5, é que no segundo ciclo, quando a válvula de escape abre, a pressão interna do cilindro é maior do que a pressão de escape, fazendo com que a pressão do cilindro diminua instantaneamente para a pressão de escape antes de o pistão iniciar seu retorno em direção ao PMS.

O ciclo utilizado nos primeiros estudos sobre máquinas a vapor utilizam como padrão o ciclo 1-2-3-6 da Figura 2.1, esse ciclo é utilizado por Mariño (1948). Ainda hoje esse ciclo é utilizado por Alanne et al. (2012), embora esses autores também considerem a possibilidade do ciclo 1-2-3-4-5 da Figura 2.1. Mariño (1948) e Prasad (1993) consideram a máquina a vapor como uma máquina térmica, e portanto, para estudar seu desempenho definem uma eficiência térmica para esse ciclo. Alanne et al. (2012) e Ferrara et al. (2013) consideram a máquina a vapor como um equipamento de expansão dentro do ciclo de Rankine, e para estudar seu desempenho, definem uma eficiência isentrópica para o ciclo mecânico de expansão.

O volume morto nulo nesse diagrama é uma representação de que o vapor dentro do cilindro deve ser totalmente expulso e ao longo do processo de admissão, exista apenas vapor vindo do evaporador dentro do cilindro. Em termos práticos, é inviável construir uma máquina a vapor ou motor de expansão com um volume morto nulo, pois isso provocaria impactos entre a cabeça do cilindro e o pistão. Esse impacto provoca grandes tensões nas peças e consequentemente uma redução significativa na vida útil do equipamento. Por essa razão, é necessário que exista um volume morto não nulo no cilindro, mas para termos de eficiência, esse volume morto deve ser o menor possível.

Pensando nisso, Prasad (1993) e Baek et al. (2005) utilizam como ideal o ciclo 1-2-3-6 da Figura 2.1, Ferrara et al. (2013) utilizam o ciclo 1-2-3-4-5 da Figura 2.1, todos com volume morto não-nulo. Devido à existência do volume morto, a pressão interna do cilindro quando a válvula de escape fecha e a válvula de admissão abre (ponto 6) é menor do que a pressão de admissão. Isso faz com que uma parcela do vapor que entra no cilindro aumente a pressão interna até que esta atinja a pressão do evaporador. Essa parcela de vapor não realiza trabalho útil, reduzindo a eficiência do ciclo. 
Para resolver essa questão e fazer com que nenhuma parcela de vapor que entre no cilindro seja utilizada para aumentar a pressão do vapor sem produzir trabalho útil, a pressão interna do cilindro quando a válvula de admissão abre deve ser igual à pressão do evaporador. A fim de tornar isso possível, a válvula de escape deve fechar antes de chegar ao PMS, e consequentemente em um trecho do curso do pistão ambas as válvulas estão fechadas e o vapor é comprimido isentropicamente até a pressão do evaporador. Algo similar é feito antes da abertura da válvula de escape, o vapor sofre uma expansão isentrópica até que sua pressão atinja a pressão de escape. Isso é feito porque se a válvula de escape abrir e a pressão interna do vapor for maior que a pressão de escape, o vapor se expande para a câmara de escape sem realizar trabalho útil, reduzindo a eficiência do ciclo. Esse ciclo é utilizado por Trajkovic (2010) e por Keenan (1966), e corresponde ao diagrama PxV da Figura 2.2. Sendo que a expansão e a compressão são isentrópicas, esse ciclo é formado por dois processos isobáricos e dois processos isentrópicos. Segundo Keenan (1966), todos os processos desse ciclo são isentrópicos, e esse é um diagrama de um motor adiabático e reversível.

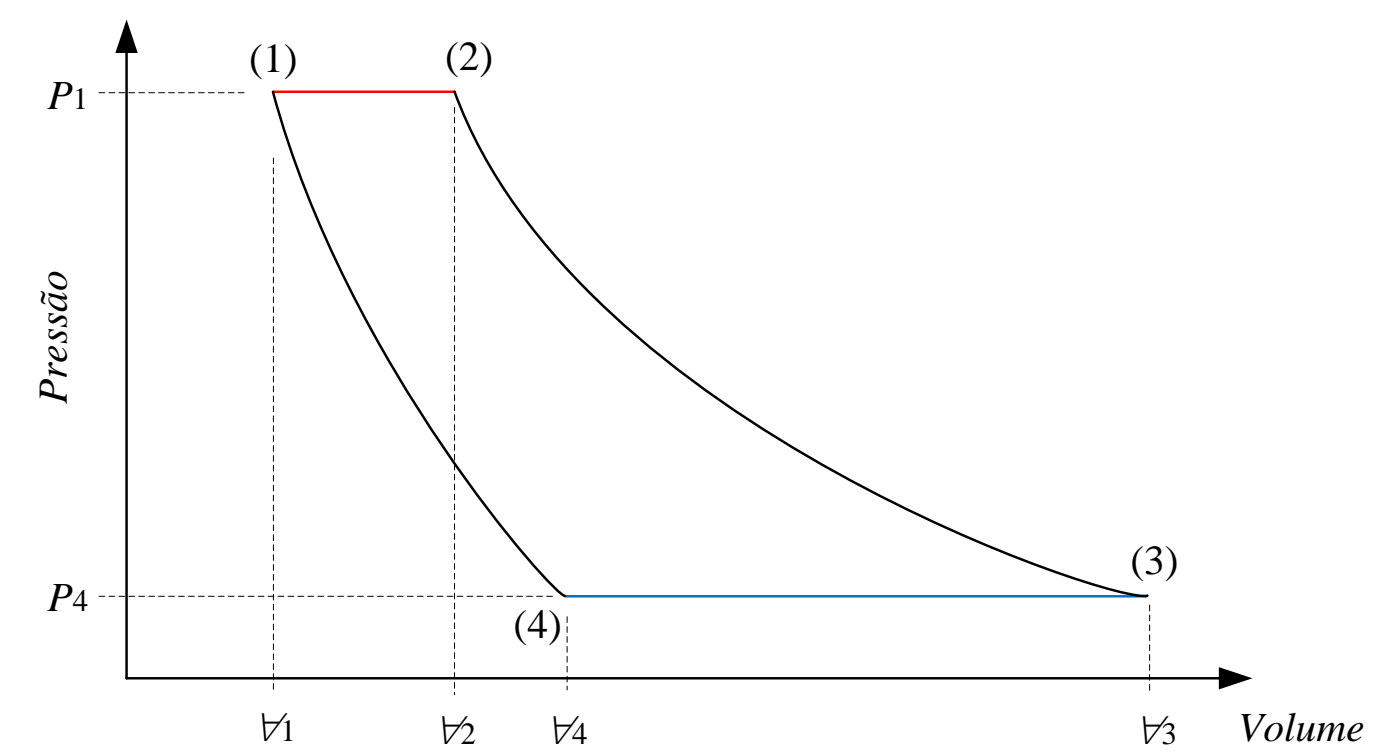

Figura 2.2 - Diagrama PxV pressão-volume com compressão de vapor e volume morto utilizada por Trajkovic (2010).

Para o ciclo da Figura 2.2, geralmente não é possível alcançar a expansão completa (processo 2-3) do vapor ou a compressão completa (processo 4-1) devido a algumas limitações técnicas. Segundo Mariño (1948), uma possível limitação, é a de que se a partir de um determinado ponto durante a expansão (processo 2-3), o trabalho ganho for menor do que o trabalho perdido por atrito. Esse trecho está indicado pela área hachurada da Figura 2.3, onde a válvula de escape deve abrir no ponto 3 a caso o trabalho fornecido pelos processos $3 \mathrm{a}-3-3 \mathrm{~b}$ for menor 
que o trabalho de atrito nesse mesmo trecho. Dessa forma, a sequência se torna 1-2-3a-3b-4 ao invés de 1-2-3-4. Outras limitações podem ser devido a uma pressão de admissão variável, uma pressão de admissão muito alta, ou a máquina a vapor não conseguir realizar a expansão ou a compressão completa do vapor devido à sua variação de volume ser limitada. Trajkovic (2010) estuda esse ciclo para o funcionamento de um motor movido a ar comprimido, e disse que se o motor necessitar de maior potência, o ponto de fechamento da válvula de admissão é alterado para um ponto mais próximo do PMI, fazendo com que a expansão seja incompleta e reduzindo a eficiência do ciclo. Essas limitações levam a uma expansão ou compressão do vapor incompleta.

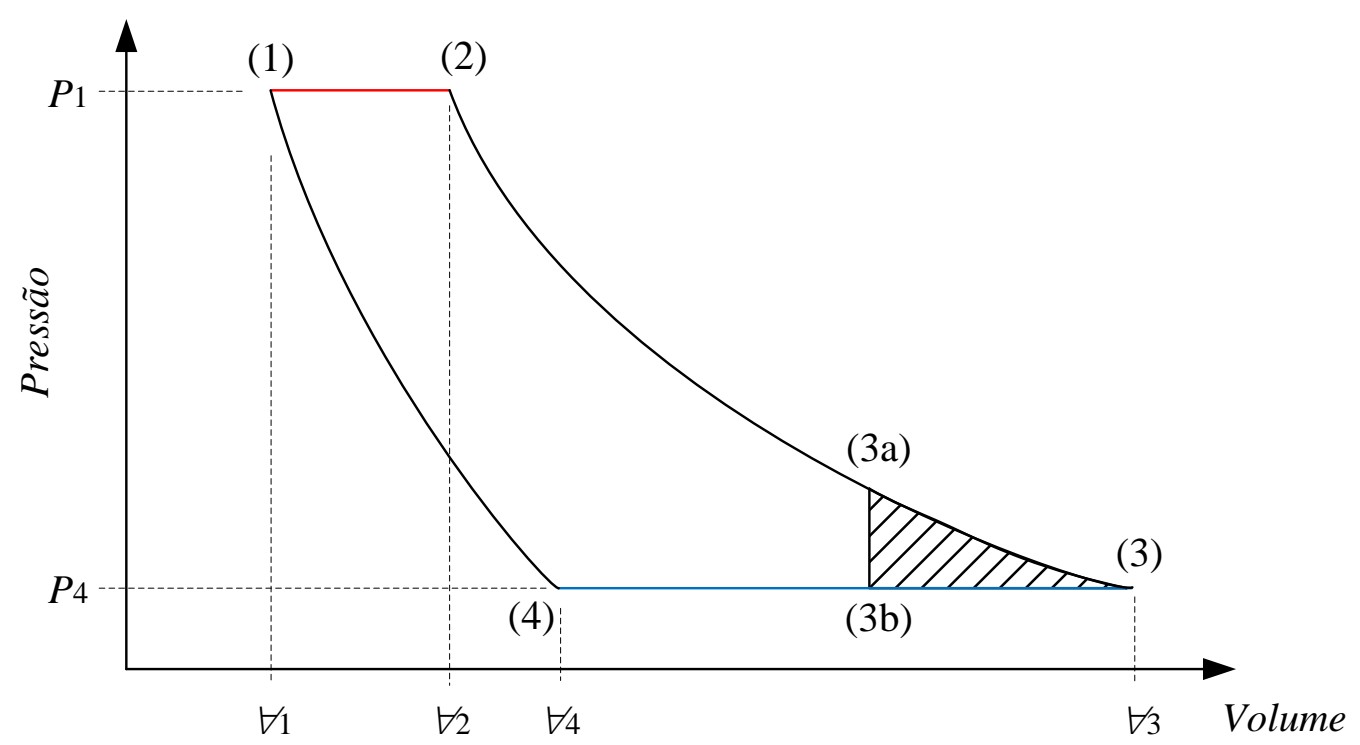

Figura 2.3 - Diagrama PxV mostrando trabalho útil que pode ser menor que o atrito do mesmo trecho.

Devido a isso, mesmo considerando o ciclo da Figura 2.1 como ideal, Prasad (1993) usou em suas simulações o ciclo mostrado na Figura 2.4, onde é considerada uma expansão e uma compressão incompleta do vapor dentro do cilindro. 


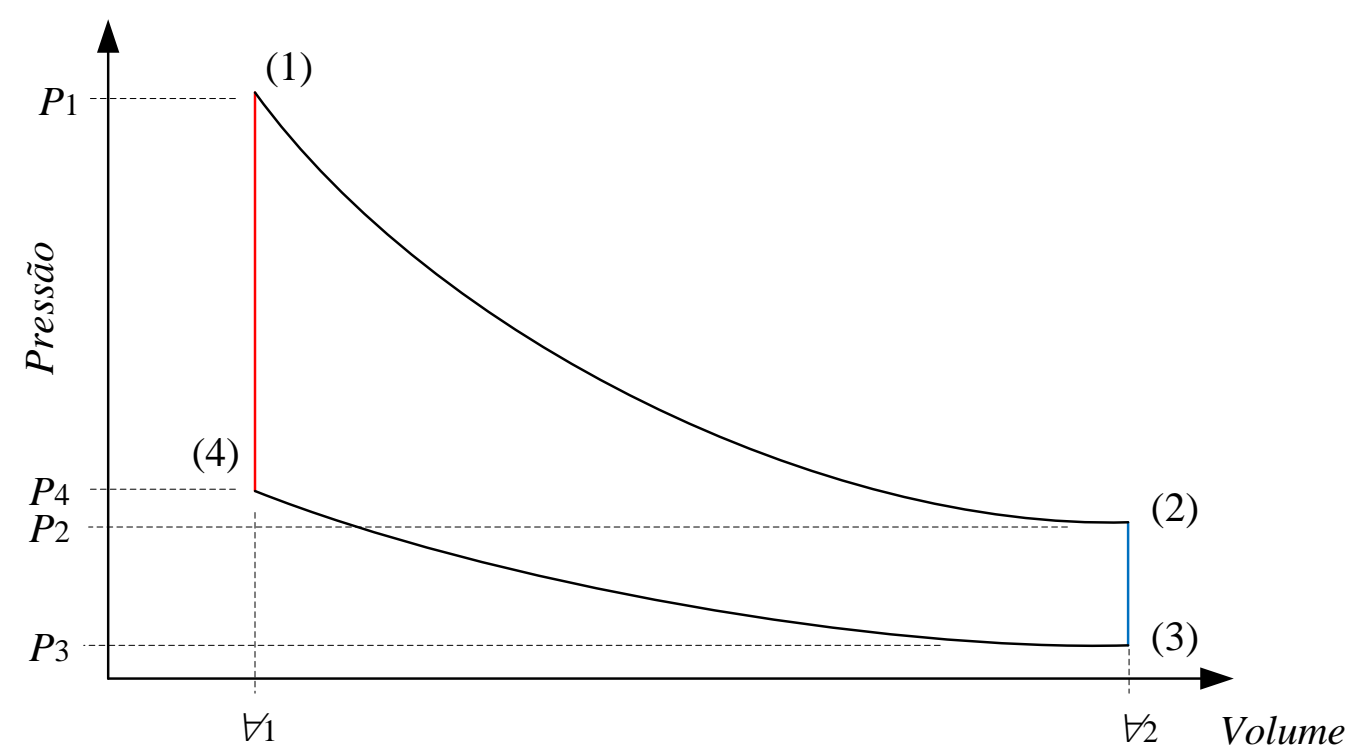

Figura 2.4 - Diagrama PxV com compressão e expansão incompletas utilizado na simulação de Prasad (1993).

Badami e Mura (2009) utilizam um ciclo com expansão e compressão incompletas, porém consideram que em uma parcela do curso do pistão em direção ao PMI existe admissão de vapor, como pode ser observado na Figura 2.5. Esse ciclo tem uma eficiência isentrópica maior do que o ciclo da Figura 2.4 e é mais próxima do comportamento real das máquinas a vapor.

Nos ciclos da Figura 2.4 e Figura 2.5 existem dois pontos de dissipação de energia, o primeiro deles vem da expansão incompleta, pois o vapor que sai do ponto 3 em direção ao condensador está a uma pressão maior que a do mesmo, fazendo com que essa energia seja dissipada. O segundo ponto é na primeira parte da admissão (processo 5-1), onde o vapor que entra no cilindro se expande comprimindo o vapor que ocupa o volume morto, sem geração de trabalho útil. 


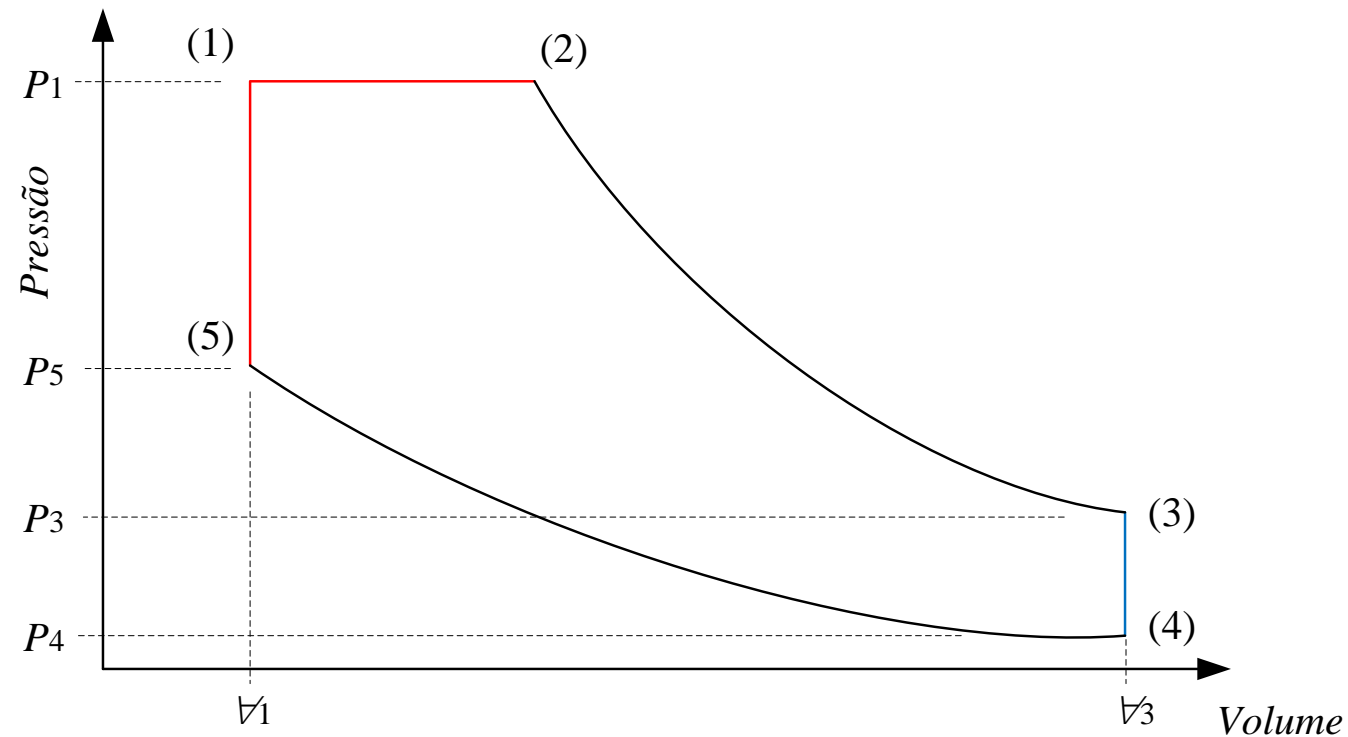

Figura 2.5 - Diagrama PxV com expansão e compressão incompletas, considerando admissão no curso em direção ao PMI (Badami e Mura, 2009).

Antonelli e Martorano (2012) e Basbous et al. (2012) adotam o diagrama da 2.6, que é um ciclo mais próximo do funcionamento real de uma máquina a vapor. Esse ciclo considera que a válvula de admissão permanece aberta ao longo de um trecho do curso do pistão em direção ao PMI, assim como a válvula de escape permanece aberta em um trecho ao longo do curso de retorno do pistão. Quando a válvula de escape fecha, o vapor sofre uma compressão isentrópica.

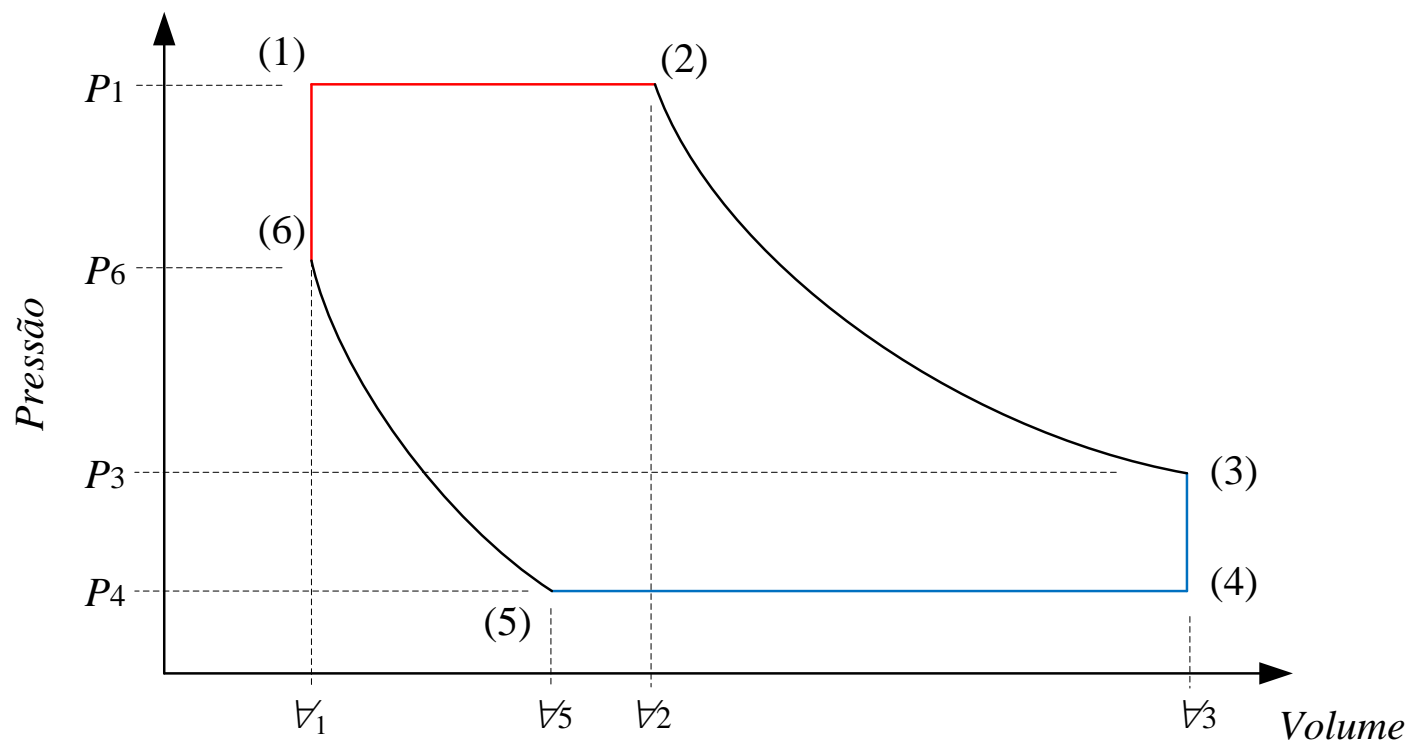

Figura 2.6 - Diagrama PxV considerando expansão e compressão incompletas, utilizado por Antonelli e Martorano (2012) e Basbous et al. (2012). 
Kalekin e Kalekin (2009) e Vanyashov e Kovalenko (2004) estudam ciclos ideais para motores de expansão que possuem diferentes combinações de válvulas de admissão e escape, podendo ser essas válvulas sempre abertas ou válvulas auto operadas normalmente abertas. Os diagramas PxV estudados por essas duplas são muito similares, e o ciclo de estudo de Kalekin e Kalekin (2009) é mostrado na Figura 2.7. Devido à utilização de tipos de válvulas específicas, esse ciclo ideal é exclusivo para motores as válvulas utilizadas por esses autores em diferentes combinações, não podendo ser estudado para as máquinas a vapor e motores de expansão de forma generalizada.

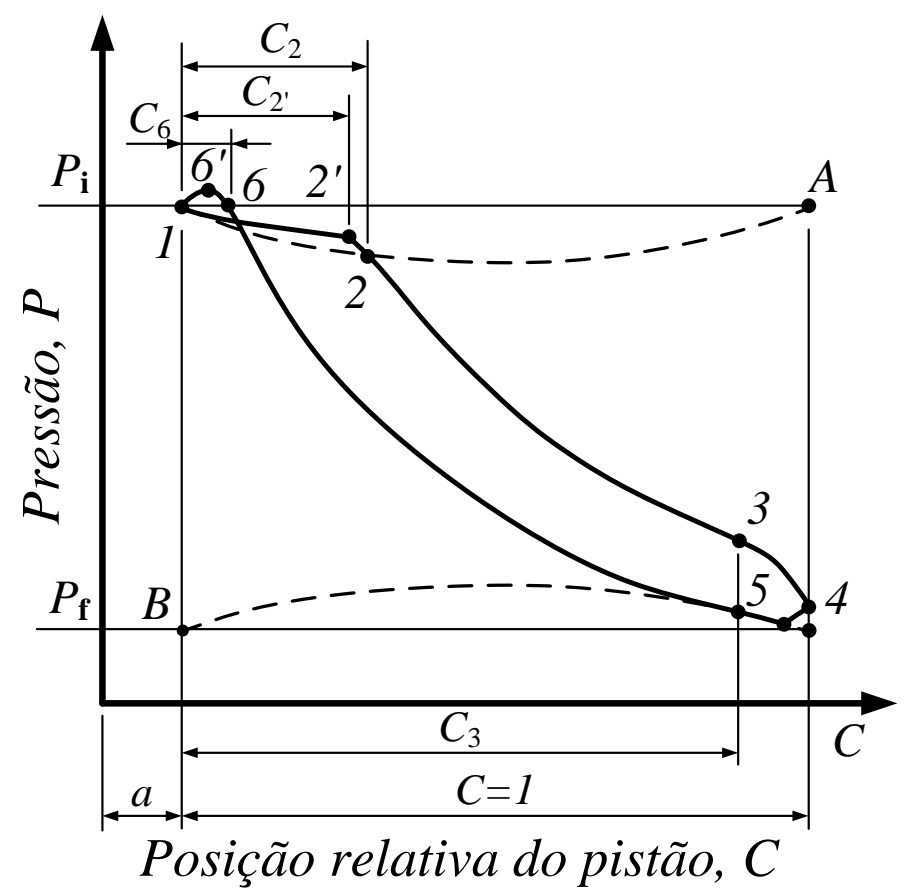

Figura 2.7 - Diagrama PxV de um motor de expansão utilizando uma válvula de admissão auto operada normalmente aberta (Kalekin e Kalekin, 2009).

O eixo horizontal do diagrama PxV da Figura 2.7 é a posição adimensional do pistão $C$, dada pela razão entre a posição do pistão $S_{i}$ e o curso do pistão $S, C=S_{i} / S$. De forma análoga, eles adotam posições adimensionais do pistão para os pontos mais importantes do ciclo, $\mathrm{C}_{2}=\mathrm{S}_{2} / \mathrm{S}$ é o posição adimensional do pistão no momento onde termina o processo de admissão (chamado de cut-off), $\mathrm{C}_{3}=\mathrm{S}_{3} / \mathrm{S}$ é a posição adimensional do pistão no momento onde se inicia a saída dos gases de dentro do cilindro, $\mathrm{C}_{5}=\mathrm{S}_{5} / \mathrm{S}$ é a posição adimensional do pistão no momento de término do escape e início da compressão e $\mathrm{C}_{6}=\mathrm{S}_{6} / \mathrm{S}$ é a posição adimensional do pistão no momento de termino da compressão. A posição $\mathrm{C}_{4}$ está representada como $\mathrm{C}=1$, e indica o fim de curso do pistão em seu volume máximo. Devido à forma construtiva do escape citada anteriormente, a razões C3 e C5 serão sempre iguais. 
É interessante notar que a válvula de admissão abre antes do pistão atingir o PMS, fazendo com que no final do retorno do pistão a pressão do cilindro ultrapasse a pressão de admissão. Isso gera um trabalho negativo, reduzindo a eficiência do ciclo e é uma característica inerente ao tipo de válvula utilizada.

Um resultado relevante obtido por esses autores foi que "a eficiência do motor pneumático com uma distribuição automática de gás pode permanecer praticamente inalterada quando a pressão do ar comprimido na admissão do motor desviar do valor nominal." (Kalekin e Kalekin (2009).

\subsection{CICLOS OBTIDOS POR EXPERIMENTOS E SIMULAÇÕES}

Alguns autores comparam valores obtidos experimentalmente, com valores obtidos através de simulações e valores calculados pelos ciclos teóricos de funcionamento.

Para auxiliar no projeto de um motor a vapor, Prasad (1993) realiza simulações computacionais para verificar qual a influência de diversos parâmetros no funcionamento e no desempenho de um motor a vapor, em sua simulação foi utilizado o ciclo da Figura 2.4. Para análise, esse autor calcula uma eficiência térmica, pois considera que o motor a vapor trabalha de acordo com um ciclo de Rankine.

Um dos parâmetros estudado foi o grau de superaquecimento (temperatura acima da temperatura de saturação) e ele verificou que a potência de saída para todos os valores de superaquecimento testados é basicamente uma função linear da pressão do vapor. Para uma pressão constante, a potência de saída, o fluxo de massa e o calor fornecido (energia térmica que entra no motor a vapor) possuem seus valores máximos utilizando vapor saturado na entrada do motor e diminuem com o superaquecimento. Já a eficiência possui um comportamento contrário, aumentando com o superaquecimento.

Ao estudar a influência da pressão nesses parâmetros, Prasad (1993) obteve que a potência de saída, a vazão de vapor, a potência fornecida e a eficiência do motor aumentam quando se 
trabalha com pressões maiores. Em relação à pressão do condensador, a potência de saída e a eficiência diminuem com o aumento da pressão do condensador. Esse fato é de se esperar analisando o ciclo utilizado. Outra conclusão obtida é de que para aumentar a eficiência do motor, deve-se trabalhar com alta rotação, alta taxa de expansão, bom isolamento térmico e um pequeno volume morto, assim como manter o vapor superaquecido ao longo da admissão. E afirma que a potência de saída não está diretamente ligada com a eficiência, pois uma grande potência de saída não significa uma grande eficiência e vice-versa.

Prilutskii (2008) afirma que para o transporte de gás natural, a pressão utilizada é de 7,5 MPa e a pressão desse gás no uso final é mais baixa. Uma das formas de se reduzir essa pressão é utilizar uma válvula de expansão, porém essa energia armazenada não é aproveitada. Outra forma de se realizar a expansão desse gás é através de motores a pistão, produzindo trabalho útil ao realizar a expansão.

O mesmo autor estuda quatro possíveis usos da expansão de gás natural e verifica quais os melhores pontos de abertura e fechamento das válvulas. Não é utilizado nenhum ciclo padrão e os detalhes da simulação não são descritos, apenas é mostrado o diagrama PxV otimizado (Figura 2.8) obtido através das suas simulações. Nesse diagrama PxV, a linha mais espessa indica um ciclo trabalhando com um fluxo mássico de 1,0 ton/h e a linha fina indica o ciclo trabalhando com um fluxo mássico de 1,5 ton/h.

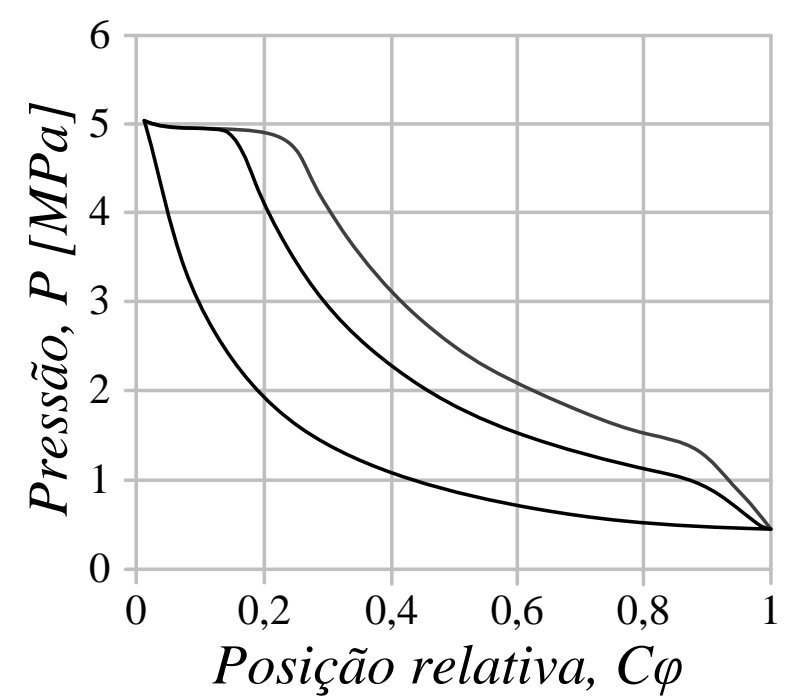

Figura 2.8 - Diagrama PxV da simulação de Prilutskii (2008), as linhas grossa e fina representam vazões de 1,0 ton/h e 1,5 ton/h respectivamente. C $\varphi$ é uma posição relativa do pistão. 
O autor desse estudo verifica através do diagrama da Figura 2.8 que para fluxos de massa diferentes, o processo de preenchimento do cilindro deve ter durações diferentes, alterando também o comportamento no processo de escape.

Vanyashov et al.(2001) estudaram experimentalmente a influência de diferentes arranjos de válvulas no funcionamento de uma máquina de expansão de gás. Os arranjos utilizam válvulas auto operadas normalmente abertas, normalmente fechadas e portas de escape. É também utilizado o esquema combinado, onde o escape se dá por portas de escape e válvulas de escape auto operadas. Eles afirmam que em virtude da baixa inércia das válvulas utilizadas, o motor opera em rotações mais elevadas quando comparado com motores que usam diferentes tipos de válvulas.

Testando quatro combinações diferentes de válvulas, Vanyashov et al.(2001) obtiveram os diagramas indicas que estão mostrados na Figura 2.9.

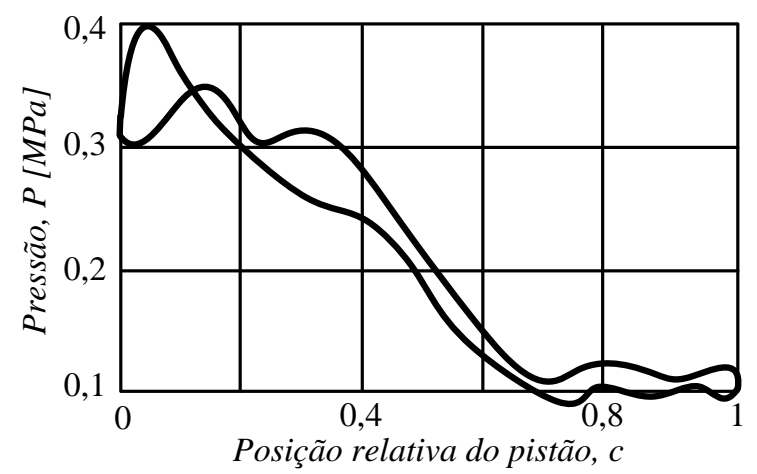

(a)

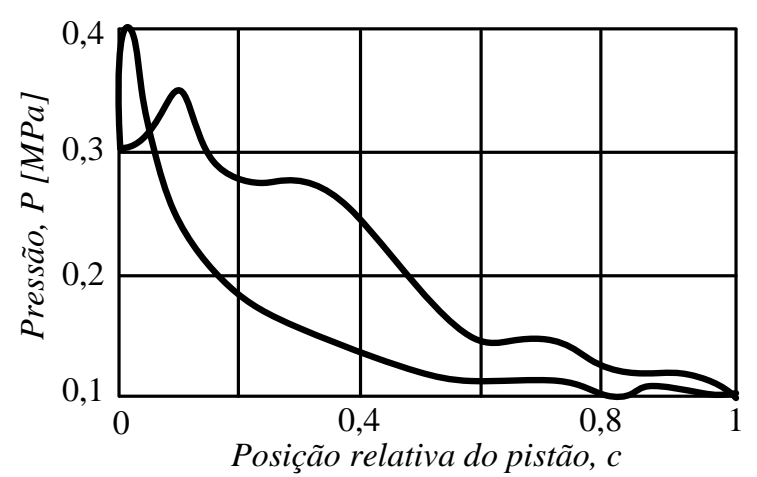

(c)

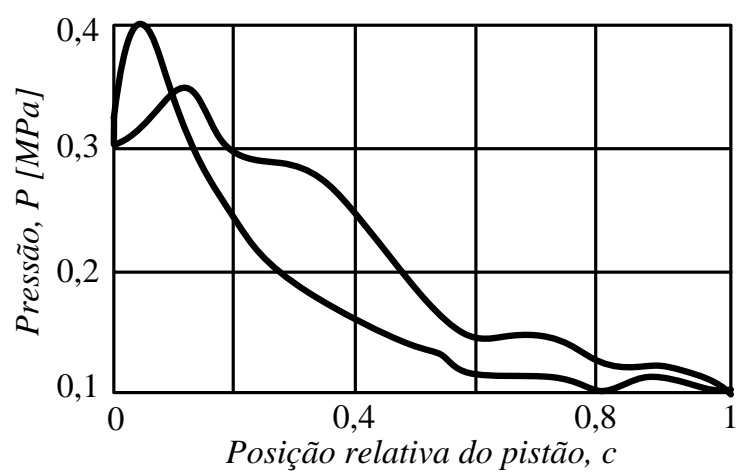

(b)

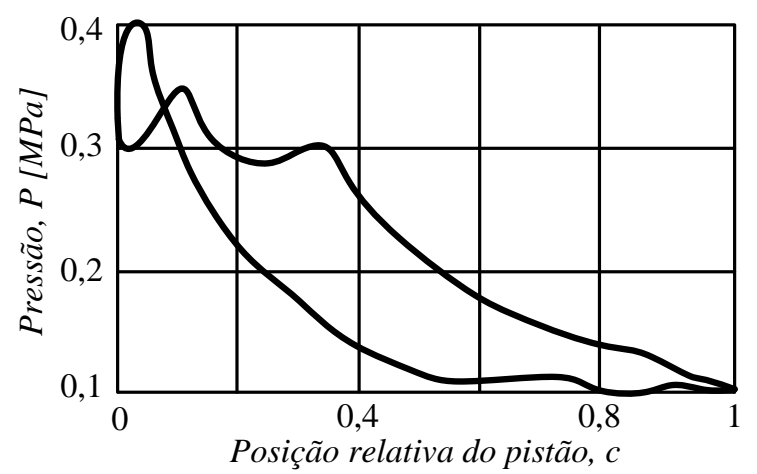

(d)

Figura 2.9 - Diagramas PxV da expansão: a) válvula de escape com uma mola que pressiona a válvula para o assento, $b$ ) válvula de escape sem mola, c) válvula de escape que desencosta a válvula do assento, e d) sistema de distribuição combinado (Vanyashov et al., 2001). 
O eixo horizontal $c$, é uma posição relativa do pistão, onde 0 indica que o pistão se encontra no PMS e 1 representa que o pistão está no PMI. Sobre o ciclo da Figura 2.9(a), os autores dizem que é um ciclo ineficiente, pois esse tipo de válvula necessita que o gás se expanda para pressões abaixo da pressão atmosférica para que a válvula de escape abra, causando um menor grau de preenchimento do cilindro. $\mathrm{O}$ uso da configuração de válvula de escape normalmente aberta sem molas, Figura 2.9(b), faz com que a eficiência do ciclo aumente, porém o tempo do preenchimento do cilindro e o tempo de escape não se alteram. A válvula de escape com mola que gera força a favor da abertura da mesma Figura 2.9(c) possui um melhor desempenho que as configurações anteriores. Eles afirmam que o aumento da pressão interna do cilindro durante o processo de compressão faz com que a válvula de escape fique mais tempo aberta, permitindo que mais gás saia, melhorando a eficiência do ciclo. A configuração combinada de válvulas de escape Figura 2.9(d) é a que provoca um maior grau de preenchimento do cilindro e um maior tempo de escape. Ao analisar essas 4 configurações de distribuição de gás, os autores afirmam que a distribuição combinada foi a que obteve melhor eficiência, chegando a um aumento entre $20 \%$ e $40 \%$ quando comparada com as outras possibilidades.

Baek et al. (2005) criaram um modelo computacional para um motor de expansão a pistão, para trabalhar com a expansão de $\mathrm{CO}_{2}$ em um ciclo de refrigeração, utilizando como base o ciclo 1-2-3-6 da Figura 2.1. Esse modelo computacional é utilizado pra projetar e construir a máquina, levando em consideração as perdas na admissão, as perdas no escape, a perda por atrito entre o anel de vedação do pistão e a parede do cilindro.

Cada processo foi equacionado separadamente e feitas algumas considerações. Nos processos de admissão e de escape as energias cinéticas e potenciais foram desprezadas e as propriedades do fluido dentro da câmara foram consideradas uniformes. Não foi considerado nenhum fluxo de calor, porém as perdas por atrito foram colocadas nas equações como perdas de calor. Segundo Baek et al. (2005), devido ao método numérico utilizado, o cálculo da admissão e do escape foi feito em duas etapas. Primeiramente a massa que entra ou que sai do cilindro é calculada de acordo com as condições anteriores do passo anterior, e para esse processo o cilindro não se move, fazendo com que o volume interno da câmara seja constante. Na segunda etapa o pistão se move, porém a massa no interior do cilindro não se altera. No processo de admissão, se a pressão calculada for igual ou maior do que a pressão do gás de admissão, então é considerado que a pressão interna da câmara é igual à pressão de admissão. 
Em todos os processos a pressão interna da câmara é considerada constante ao longo do passo.

A máquina de expansão foi simulada em quatro rotações escolhidas para comparação, 120, 240, 360 e 600 rpm. A Figura 2.10 mostra o comportamento da pressão em função do ângulo da manivela para essas quatro rotações. Como é possível verificar na Figura 2.10, apenas nas rotações de 120 e 240 rpm a pressão dentro do cilindro no fim da admissão é igual a pressão do $\mathrm{CO}_{2}$ vindo do evaporador. De acordo com Baek et al. (2005), isso se deve ao fato de que em rotações elevadas, o tempo em que o $\mathrm{CO}_{2}$ tem para entrar na câmara é muito pequeno e o $\mathrm{CO}_{2}$ não consegue preencher totalmente o interior do cilindro. Na rotação de $240 \mathrm{rpm}$ há um aumento na pressão interna do cilindro no retorno do pistão devido ao diâmetro do orifício de escape ser pequeno e o tempo do escape também ser curto. Essa característica não existe para rotações mais altas por que entra pouco gás dentro do cilindro na admissão, e esse gás não é o suficiente para provocar esse aumento de pressão no escape.

Portanto, Baek et al. (2005) escolhem como rotação nominal da máquina de expansão a rotação de $120 \mathrm{rpm}$, pois o ciclo funciona de maneira mais próxima ao ciclo ideal. Trabalhando a $120 \mathrm{rpm}$, com uma pressão de admissão de 10,2 MPa e uma pressão de escape de 3,4 Mpa, é previsto que o ciclo gere um trabalho de 40,6 Joules, fornecendo uma potência de $81 \mathrm{~W}$.

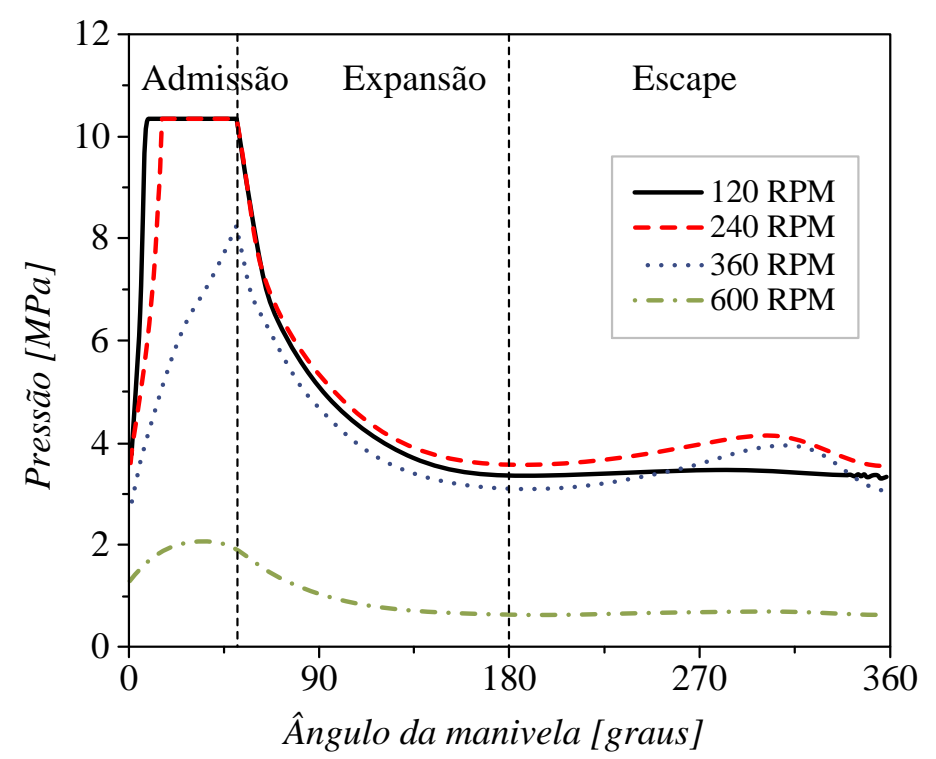

Figura 2.10 - Pressão de $\mathrm{CO}_{2}$ dentro do cilindro em função do ângulo da manivela (Baek et al., 2005). 
Após construir a máquina de expansão, Baek et al. (2005) fizeram uma simulação computacional nas condições de operação da máquina para validar e melhorar seu modelo teórico. Ao comparar os resultados experimentais com a simulação feita, verificou-se que as pressões no fim do processo de expansão e no processo de escape, obtidas através da simulação, eram maiores do que as mesmas pressões medidas experimentalmente. Os autores afirmaram que essa diferença se dá pelo vazamento de $\mathrm{CO}_{2}$ através do vão entre o anel de vedação e o cilindro. Esse fato foi confirmado ao medir vazões de $\mathrm{CO}_{2}$ acima das previstas na simulação. Então, foi acrescentado um fator multiplicativo constante para essa massa perdida e esse fator foi ajustado de forma que os resultados da simulação ficassem os mais próximos possíveis dos resultados experimentais.

A Figura 2.11 mostra o comportamento da pressão em relação ao ângulo da manivela para a simulação considerando o vazamento de $\mathrm{CO}_{2}$ através do vão do anel de vedação. A simulação foi realizada para três condições de contorno diferentes, onde a pressão de admissão e a pressão de escape foram alteradas, os autores chamaram essas três condições de contorno de caso 1 , caso 2 e caso 3 . Na curva da pressão em função do ângulo da manivela, deram os nomes das curvas de vazamento no caso 1 , no caso 2 e no caso 3, como indicado na legenda do gráfico. Segundo os autores do estudo, os resultados foram satisfatórios e podem ser utilizados para projetos futuros de máquinas de expansão de $\mathrm{CO}_{2}$. Embora os próprios autores afirmem que a porcentagem de massa perdida foi considerada nos cálculos como constante (uma característica que deve ser melhorada na simulação), também afirmam que a tendência é que essa perda se torne cada vez menor com os avanços tecnológicos.

Em números, Baek et al. (2005) calculam uma eficiência isentrópica experimental entre $10,5 \%$ e $11 \%$, enquanto a simulação aponta entre $29 \%$ e $34 \%$. Segundo os autores, isso é devido à deficiência do modelo do vazamento de $\mathrm{CO}_{2}$ através do anel de vedação, perda esta que tende a ser cada vez menor com os avanços da tecnologia. Os autores não comentam sobre a oscilação da pressão dentro do cilindro nos últimos $90^{\circ}$ do ciclo, que ocorre quando simulam o funcionamento do motor em condições de operação.

Badami e Mura (2009) também utilizam um modelo teórico e uma simulação computacional para projetar um motor a vapor, que deve ser utilizado em um ciclo de Rankine em pequena escala, tendo resíduos de madeira como combustível. O ciclo teórico é equacionado, porém apenas as equações finais são mostradas. 


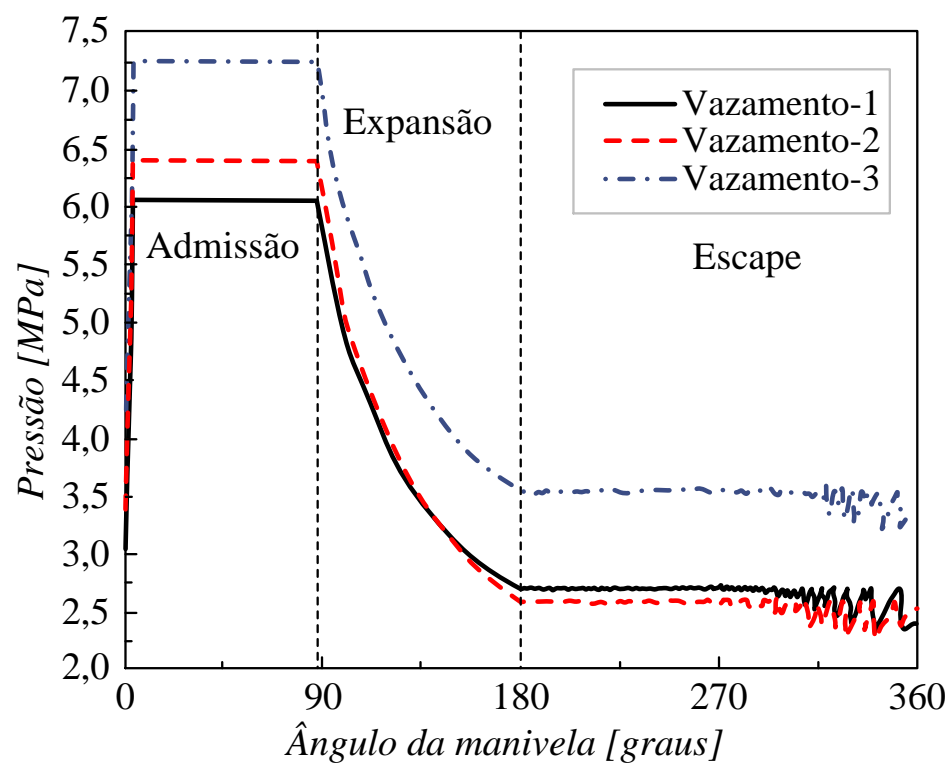

Figura 2.11 - Comportamento da pressão interna do cilindro da máquina de expansão, considerando vazamento de $\mathrm{CO}_{2}$ através dos anéis de vedação (Baek et al., 2005).

Para o projeto do motor a vapor, Badami e Mura (2009) simulam o ciclo real de funcionamento do mesmo (Figura 2.12), levando em consideração efeitos dissipativos da natureza da dinâmica do fluido na admissão e no escape do cilindro, a troca de calor com as paredes do cilindro ao longo da movimentação do pistão e vazamentos de vapor, diminuindo o trabalho realizado. Segundo os autores foi utilizado um modelo detalhado das válvulas, que inclui coeficientes típicos do escoamento, levantados experimentalmente.

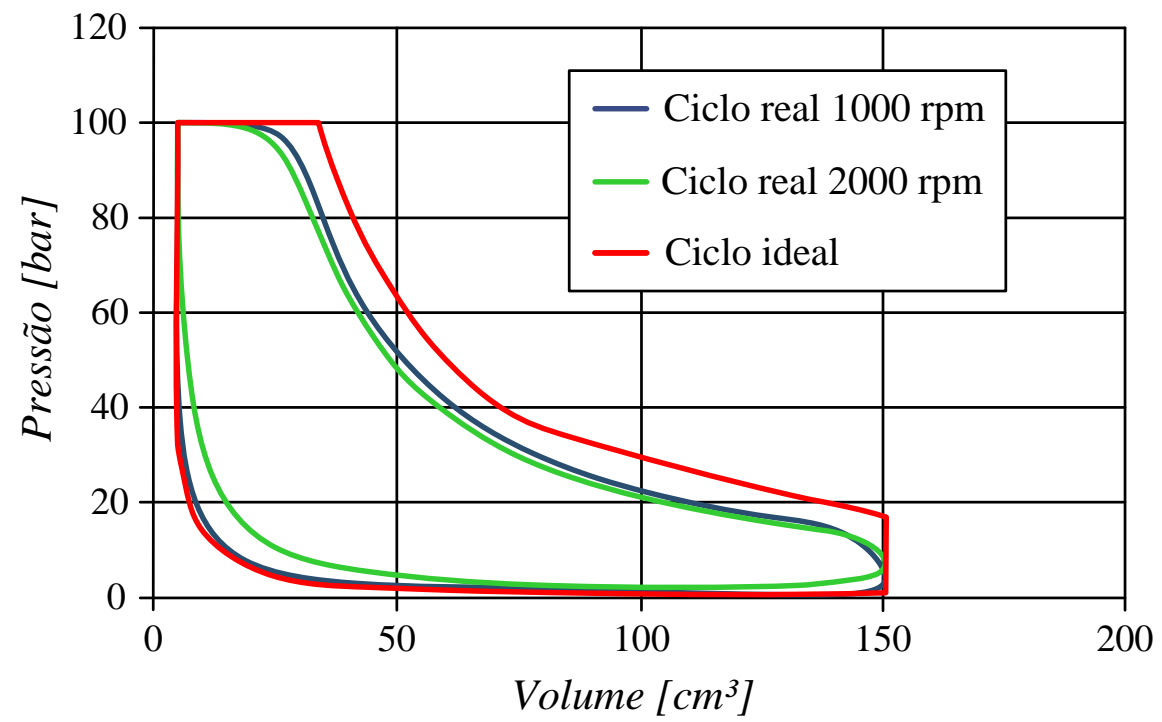

Figura 2.12 - Comparação entre os ciclos reais (simulados) e o ciclo teórico (Badami e Mura, 2009). 
Para o fluxo de calor foi considerado um coeficiente convectivo em função da velocidade do pistão, resultando em uma perda de $5 \%$ do trabalho do ciclo e a perda de massa por vazamentos foi considerada $2 \%$. Após esse estudo, o motor a vapor foi projetado e construído, e a razão de corte escolhida não foi a razão que proporciona uma melhor eficiência. Um dos requisitos do projeto é de que o motor deveria ser o menor possível, e deslocando um pouco a razão de corte do ponto de máxima eficiência, conseguiram uma redução no volume do motor, de $450 \mathrm{~cm}^{3}$ para $295 \mathrm{~cm}^{3}$.

Antonelli e Martorano (2012) estudaram o funcionamento e a otimização de um motor Wankel adaptado para funcionar como máquina de expansão de um ciclo orgânico de Rankine, e os resultados foram comparados com ciclo ideal da Figura 2.6. A simulação foi realizada no ambiente de simulação AMESim, enquanto o levantamento dos dados experimentais ocorreu com um motor de teste utilizando ar comprimido provido de um compressor, que fornece entre 5 e 9 bar de pressão absoluta, e o escape ocorre em pressão atmosférica.

O modelo numérico é composto de três câmaras de volumes variáveis com a correta defasagem entre si e prevê perdas através das válvulas de admissão e escape. Nesse trabalho, Antonelli e Martorano (2012) consideram uma eficiência mecânica constante e igual a 0,9, e dizem que essa consideração simples é feita uma vez que o foco de seu trabalho é o fenômeno da dinâmica do fluido. O submodelo das câmaras considera a transferência de calor através das paredes utilizando um expoente apropriado para um processo politrópico.

Foram levantadas curvas de torque e vazão em massa em função da rotação do motor, e segundo os autores, houve uma boa concordância dos resultados obtidos através da simulação e dos resultados experimentais. Ao analisar esses resultados, Antonelli e Martorano (2012) fizeram um estudo sobre o comportamento da pressão indicada em função da posição da manivela para diferentes rotações do motor, a fim de compreender a não linearidade do fluxo de massa que entra no motor em relação à rotação. Para isso, foram escolhidas três rotações para análise, $100 \mathrm{rpm}, 1000 \mathrm{rpm}$ e $2500 \mathrm{rpm}$. O comportamento da pressão indicada obtida em ambiente de simulação comparado com o comportamento ideal para essas três rotações é mostrado na Figura 2.13. 
Nota-se que para a rotação de 100 rpm o diagrama experimental é muito próximo ao diagrama ideal, e para as rotações de $1000 \mathrm{rpm}$ e $2500 \mathrm{rpm}$ é possível perceber que existe um aumento na pressão de escape. Segundo Antonelli e Martorano (2012), isso ocorre devido às perdas na válvula de escape que faz com que saia menos ar do motor. Já na fase de admissão, a pressão interna aumenta muito para as rotações de $1000 \mathrm{rpm}$ e $2500 \mathrm{rpm}$, podendo ultrapassar a pressão de admissão, o que faz com que durante uma parcela da fase de admissão, ao invés de entrar ar na câmara, o ar saia dela através da válvula de admissão, reduzindo a eficiência volumétrica do motor.

Para melhorar esse ponto, Antonelli e Martorano (2012) aumentaram o diâmetro das válvulas e obtiveram um aumento no fluxo de massa e no torque do motor, pois isso permitiu ao motor trabalhar em rotações mais elevadas, mantendo as condições de trabalho mais próximas às condições ideais.

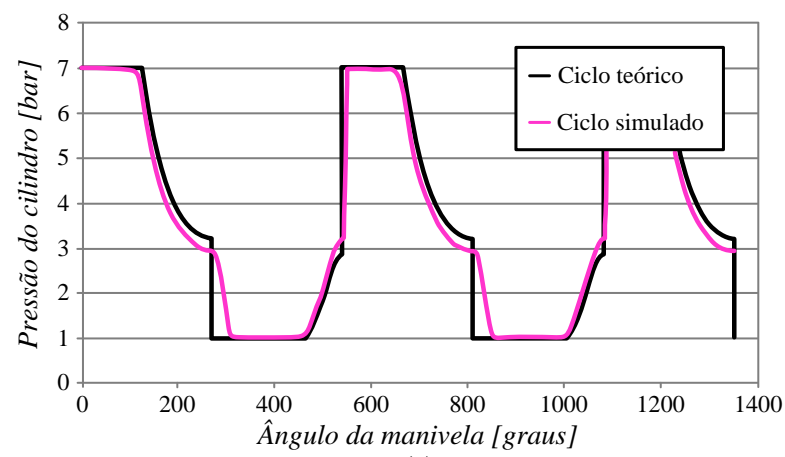

(a)

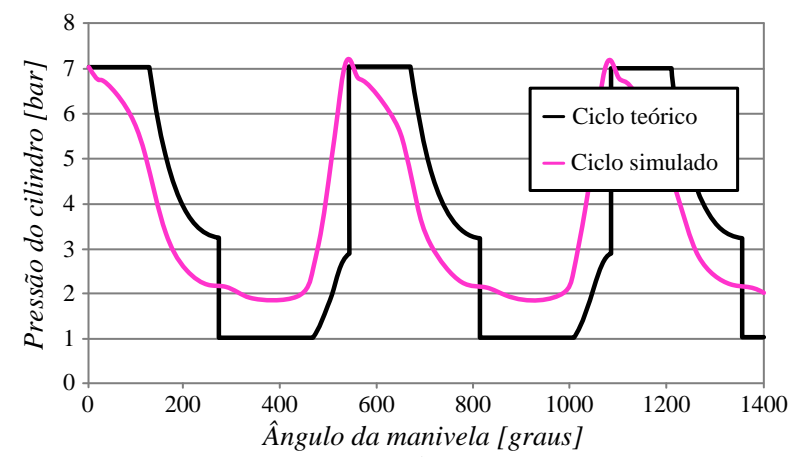

(b)

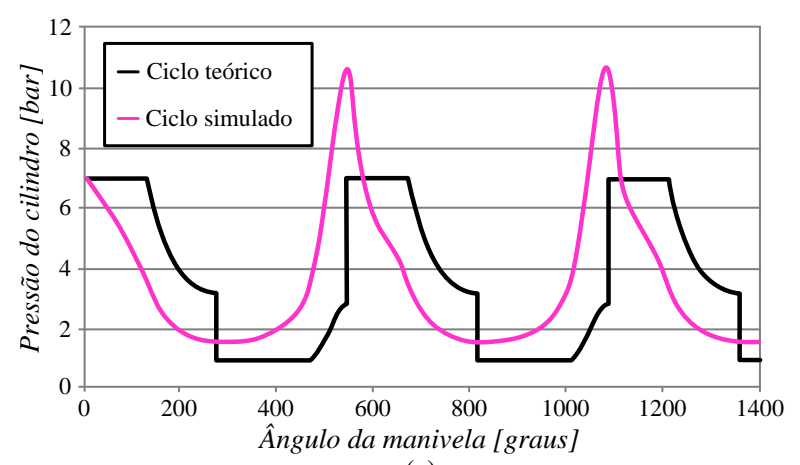

(c)

Figura 2.13 - Comparação do comportamento da pressão indicada simulada com o ciclo ideal para (a) $100 \mathrm{rpm}$, (b) $1000 \mathrm{rpm} \mathrm{e} \mathrm{(c)} 2500 \mathrm{rpm}$.

Trajkovic (2010) faz um estudo sobre um automóvel que é movido por motor híbrido pneumático. Esse motor pode trabalhar de diversas maneiras, como um motor a combustão sobrealimentado com ar comprimido, como compressor, ou como motor a ar comprimido. 
Aqui será apresentado apenas o funcionamento do motor no modo pneumático. O ciclo de funcionamento considerado como ideal pelo autor é o ciclo da Figura 2.2.

O autor ressalta que se a válvula de escape for fechada tardiamente, a pressão do ar no interior do cilindro quando o pistão atingir o PMS será menor do que a pressão do tanque, e quando o ar comprimido vindo do tanque entrar no cilindro, esse irá se expandir e aumentar a pressão do ar contido no interior do cilindro, o que provoca uma diminuição da eficiência do motor.

Segundo Trajkovic (2010), a demanda de uma carga maior durante a operação do motor no veículo faz com que o período de carga seja estendido, criando uma situação em que a pressão do ar no cilindro ao fim da expansão seja maior do que a pressão atmosférica, resultando em uma expansão desse ar para a atmosfera quando a válvula de escape se abrir. Isso é um desperdício de energia útil e deve ser evitado durante a operação do motor.

Um motor de combustão interna funcionando como um motor pneumático foi testado por Trajkovic (2010). O teste foi realizado utilizando duas pressões diferentes no tanque de ar comprimido (16,5 e 6,5 bar), e ambas foram testadas em uma condição não otimizada e uma condição otimizada de abertura e fechamento de válvulas. Os diagramas PxV desses testes estão mostrados na Figura 2.14.

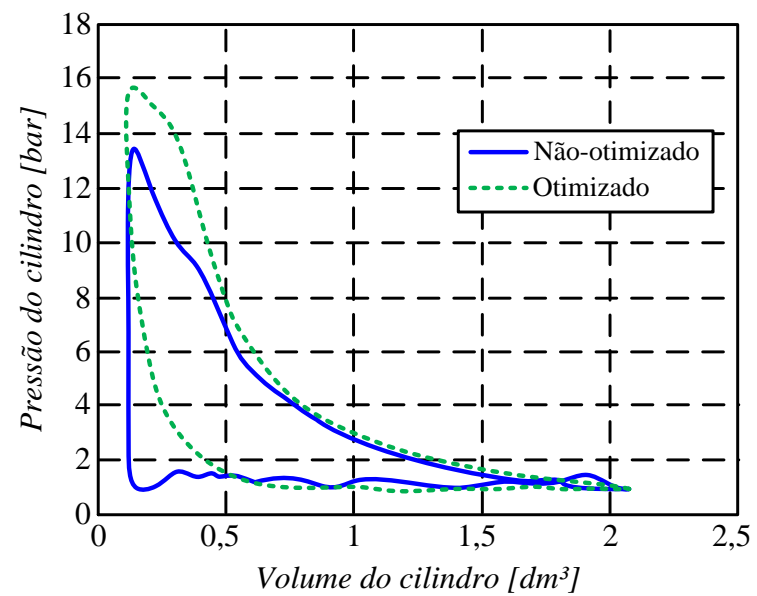

(a)

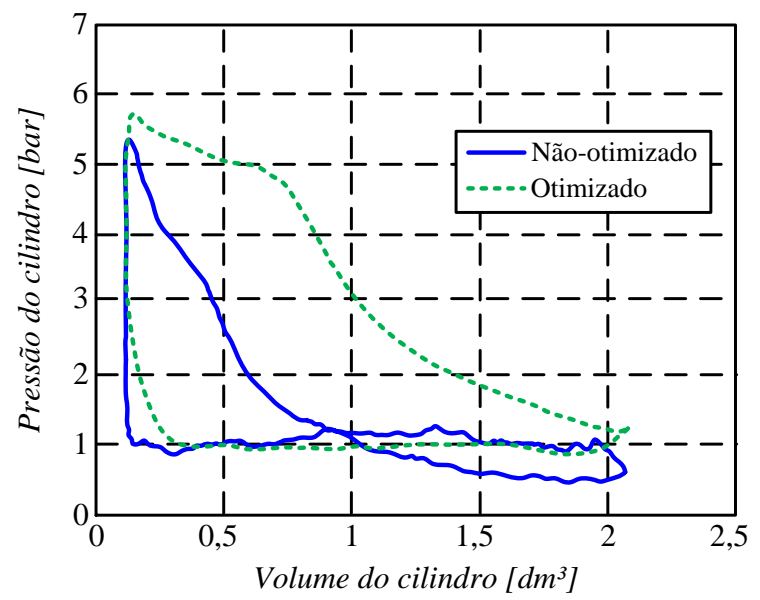

(b)

Figura 2.14 - Diagrama PxV da pressão em função do volume para o funcionamento como motor a ar comprimido para pressões do tanque de (a) 16,5 bar e (b) 6,5 bar (Trajkovic, 2010).

Na condição não otimizada, a válvula de admissão do ar que vem do tanque pressurizado abre $5^{\circ}$ após o PMS (ela abre um pouco depois do PMS para não haver o risco do ar começar a 
entrar no cilindro enquanto a válvula de escape ainda estiver aberta, e ocorrer a saída do ar pressurizado direto para a atmosfera) e fecha aos $40^{\circ}$ após o PMS. A válvula de escape abre no PMI e fecha no PMS (ela não fecha antes pois valores mais altos da pressão dentro do cilindro ao atingir o PMS pode dificultar a abertura da válvula de admissão).

A configuração otimizada de abertura e fechamento das válvulas poderia ser calculada através da relação politrópica, porém os cálculos com essa relação não consideram o tempo que leva para o ar comprimido preencher a câmara devido à restrição imposta pela válvula. Como Trajkovic (2010) havia feito a otimização anterior do motor operando no modo de compressor, foram utilizados os mesmo pontos de abertura e fechamento das válvulas do motor funcionando como compressor para o motor no modo pneumático, apenas invertendo o ciclo de funcionamento. Para essa configuração otimizada, o diâmetro das válvulas foi alterado de $16 \mathrm{~mm}$ para $28 \mathrm{~mm}$ para diminuir a restrição imposta pelas válvulas.

Uma queda acentuada na pressão interna do cilindro pode ser notada em ambos os diagramas para a condição não otimizada, isso se deve à restrição do fluxo provocada pela válvula de admissão. Essa restrição faz com que o cilindro não seja preenchido com ar comprimido suficiente no processo de carga.

Comparando com o ciclo ideal da Figura 2.2, é possível verificar que no caso não otimizado não existe o processo de compressão do ar após o fechamento da válvula de escape (processo 4-1), isso se deve a uma escolha inapropriada do ponto de fechamento da válvula de escape. Por não existir a fase de compressão, quando a válvula de admissão abrir, a pressão do cilindro é próxima à pressão atmosférica, provocando uma queda na pressão do ar que vem do tanque, sem a realização de trabalho.

Pode-se também verificar para o caso não otimizado da Figura 2.14 (b), que a região esquerda do ciclo gera um trabalho positivo, porém a região fechada do lado direito gera um trabalho negativo no ciclo do pistão. Isso significa que não existe ar comprimido o suficiente dentro do cilindro no início do período de expansão para que a pressão seja igual a pressão atmosférica no fim da expansão, sendo uma característica também de uma escolha inadequada para o ponto de abertura e fechamento das válvulas. Segundo Trajkovic (2010) há duas formas de se evitar ou minimizar essa região que gera um trabalho negativo, uma delas é somente abrir a válvula de escape durante o retorno do pistão, quando a pressão interna se igualar novamente 
com a pressão atmosférica e a outra forma é fechar a válvula de admissão em um ponto mais avançado, fazendo com que entre mais ar no cilindro no processo de carga.

Nas curvas da configuração otimizada é possível perceber que a pressão do cilindro no PMS é mais próxima da pressão do tanque, devido à menor restrição provocada pela válvula. O efeito do aumento do diâmetro da válvula pode também ser notado na menor inclinação da curva durante o processo de carga, ou seja, mais ar entra no cilindro, aumentando a pressão durante o processo de carga.

Também é possível perceber que a região de trabalho negativo que existia no ciclo não otimizado deixou de existir devido à melhora na posição de abertura e fechamento das válvulas. A otimização das posições de abertura e fechamento das válvulas também fez com que existisse um período de compressão do ar no interior do cilindro quando o pistão se movimenta em direção ao PMS, provocando uma menor perda de pressão do ar ao passar pela válvula de admissão, diminuindo a massa de ar necessária e melhorando a eficiência do ciclo.

Trajkovic (2010) efetuou um estudo para definir qual o principal motivo da melhora no desempenho do motor, se vem do aumento no diâmetro das válvulas ou da melhor posição de abertura e fechamento das válvulas. Ele apenas concluiu que em baixas rotações (600 rpm), o diâmetro das válvulas teve pouco efeito, porém em maiores rotações (1200 rpm) ele verificou que maiores diâmetros das válvulas é a chave para uma boa eficiência.

Alguns autores trabalham com motores Wankel e outros com motores de movimento alternativo, porém os ciclos teóricos são similares e servem para os dois tipos de motores, com exceção do ciclo utilizado por Kalekin e Kalekin (2009). Esse autores utilizaram um ciclo específico para um motor de expansão com válvulas normalmente abertas, e que por ser específico, foram feitas considerações que faz com que se o ciclo assemelhe mais com o comportamento real. Algumas características que demonstram essas considerações são as duas linhas tracejadas da Figura 2.7, essas linhas representam o comportamento da pressão ao longo do curso do pistão para um motor de movimento alternativo caso as válvulas de admissão e de escape permanecessem abertas ao longo da admissão e do escape, respectivamente. A curva 6'-6-1 representa uma sobrecompressão do fluido de trabalho, característica onde a pressão se eleva acima da pressão de admissão devido à abertura 
antecipada da válvula de admissão. Isso mostra que já fizeram considerações para que o ciclo, ainda que teórico, se assemelhe mais ao ciclo real.

Alguns ciclos simulados, como os da 2.8, da Figura 2.11 e Figura 2.12 estão muito próximos dos ciclos teóricos, já os ciclos da Figura 2.10 e da Figura 2.13 se assemelham com os respectivos ciclos teóricos em baixas rotações, divergindo em altas. É notável que os ciclos obtidos experimentalmente possuam uma maior divergência em relação aos ciclos teóricos, como ocorre com o ciclo da Figura 2.9 e da Figura 2.14. Embora os ciclos das máquinas de expansão sejam ciclos mecânicos, essa divergência entre o teórico e o real ocorre com os ciclos térmicos Otto e Diesel, utilizados em motores de movimento alternativo e Wankel.

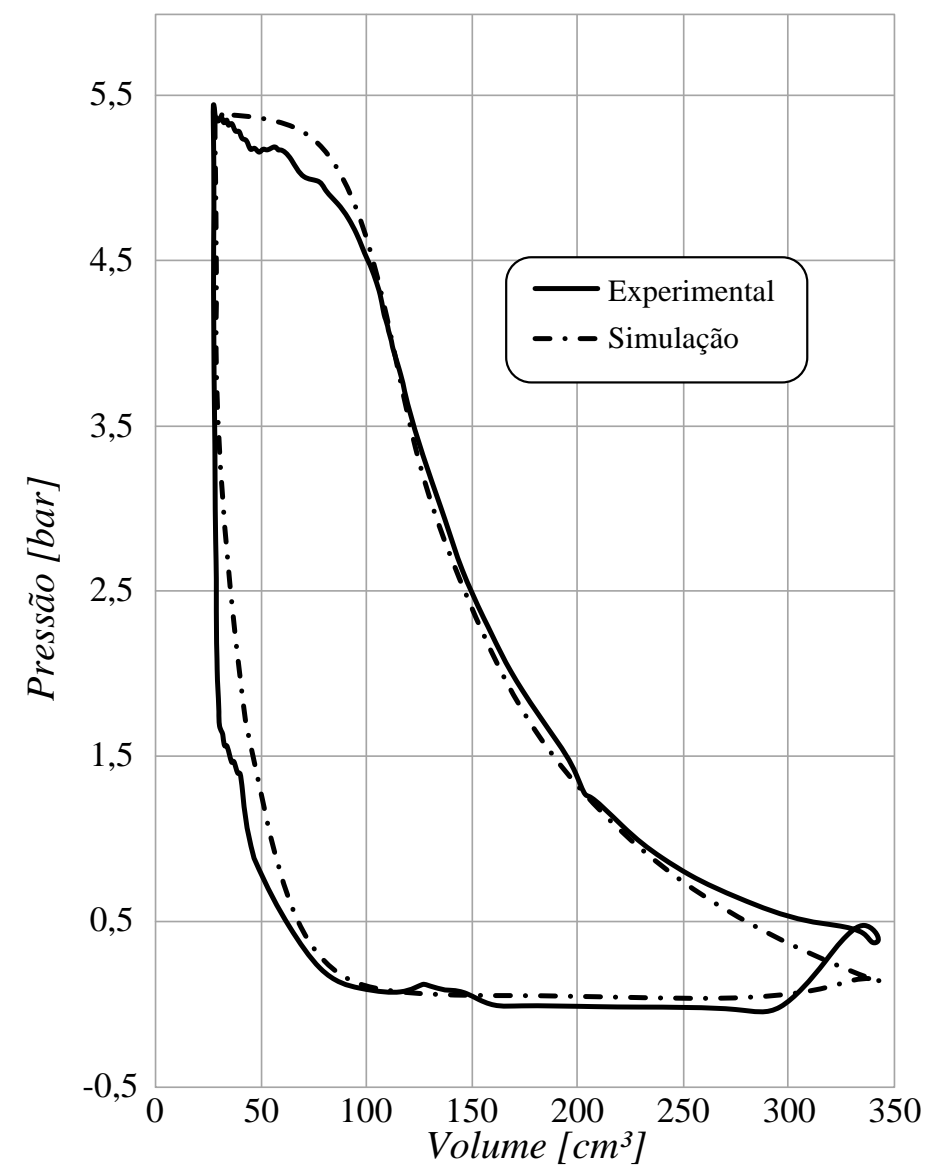

Figura 2.15 - Comparação entre o ciclo simulado e o ciclo experimental para pressão de admissão de 5,5 bar e rotação de 1500 rpm. (Antonelli et al., 2014)

Antonelli et al. (2014) estudam um motor Wankel como máquina de expansão de um ORC. Para isso, simulam o funcionamento do equipamento de expansão com diferentes fluidos orgânicos, e testam um equipamento em bancada com ar comprimido para validar as simulações. Para a comparação, foram realizados um experimento e uma simulação para a 
rotação de 1500 rpm e uma pressão de admissão 5,5 bar. O diagrama PxV dessa comparação é o diagrama da Figura 2.15. Segundo os autores, as pequenas diferenças são devido às trocas térmicas e pequenos detalhes geométricos que não foram consideradas no modelo numérico.

Nos diagramas da Figura 2.15, nota-se que o processo de admissão enquanto o pistão se afasta do ponto morto superior é curto e a pressão diminui durante esse trecho da admissão. $\mathrm{O}$ processo de compressão é quase nulo, e parte da admissão ocorre quase à pressão constate. É notável que não existe sobrecompressão do fluido, e no processo de admissão onde o pistão se afasta do ponto morto superior, ocorre uma oscilação na pressão interna da câmara. Os autores não comentam à que se devem essas oscilações. Pode-se verificar também que a expansão do fluido é incompleta e o processo de escape ocorre praticamente à pressão constante.

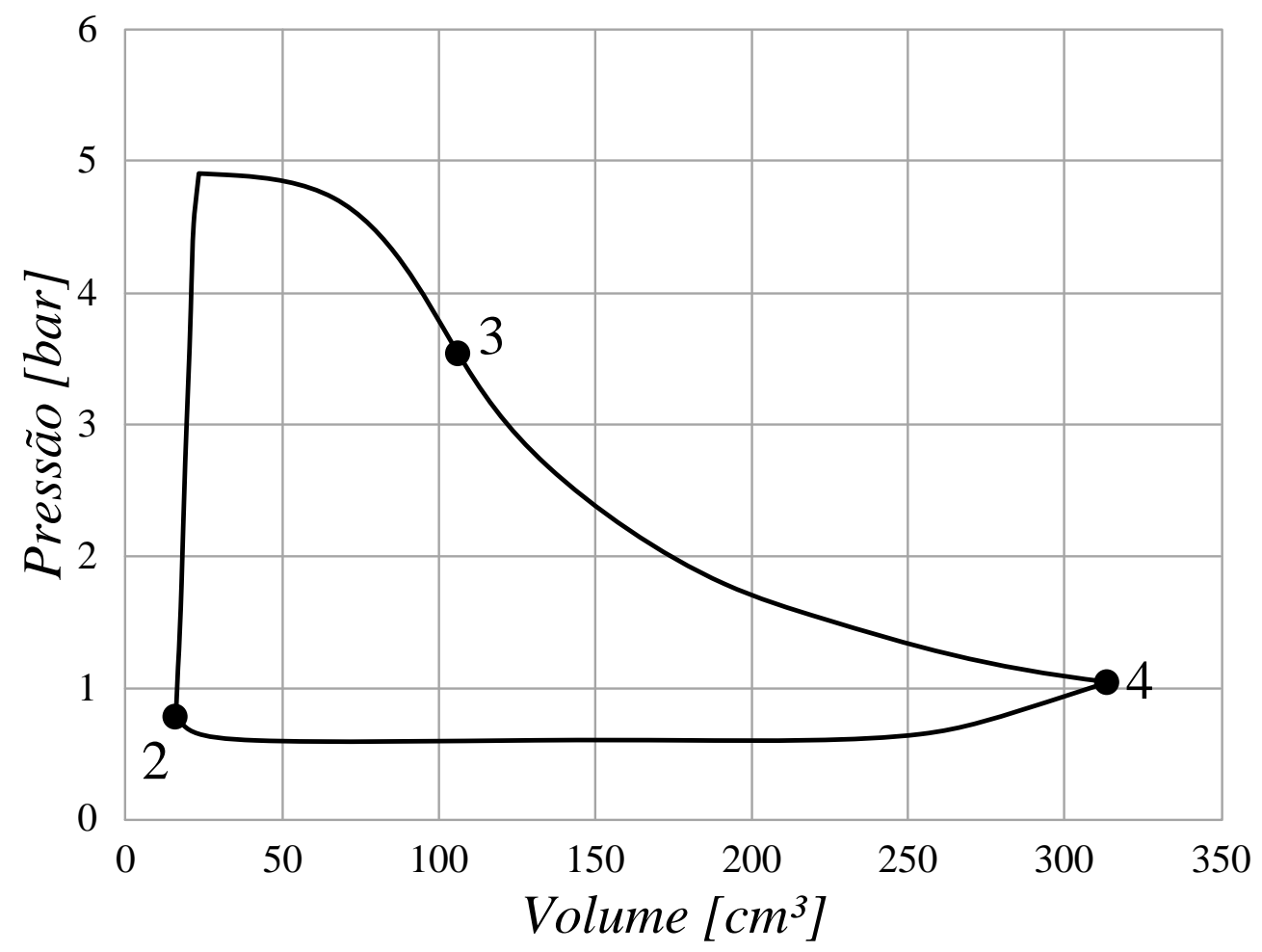

Figura 2.16 - Diagrama PxV simulado para a máquina a vapor com processos quase-estáticos. (Ferrara et al., 2013)

Ferrara et al. (2013) estudam uma máquina a vapor com pistão como equipamento de expansão de um ciclo de cogeração. Para estudar o comportamento da máquina a vapor, fazem um estudo do ciclo teórico, uma simulação considerando processos quase-estáticos 
utilizando o programa EES, e uma outra simulação onde os processos não são quase-estáticos utilizando o programa WAVE.

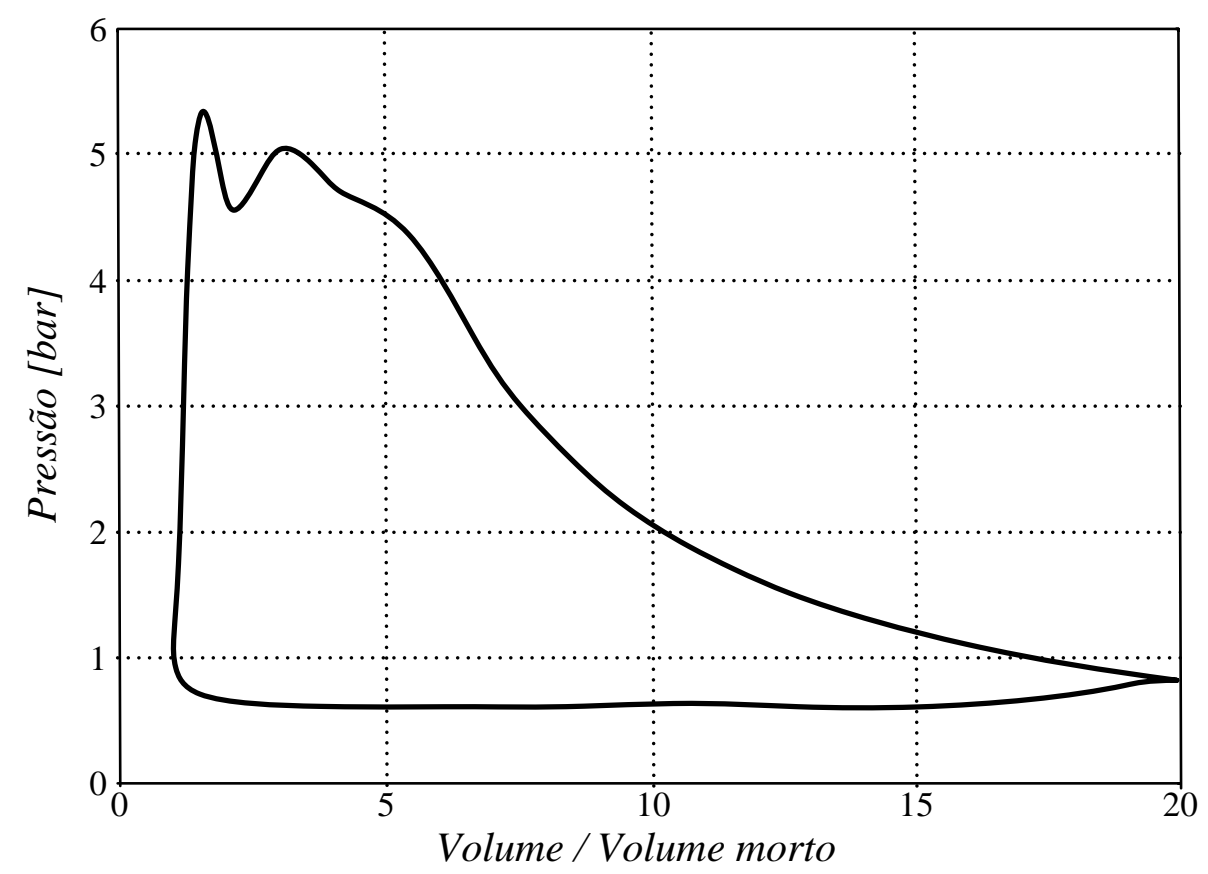

Figura 2.17 - Diagrama PxV simulado para a máquina a vapor sem considerar processos quase-estáticos. (Ferrara et al., 2013)

Na Figura 2.16 está o diagrama PxV simulado da máquina a vapor utilizando processos quase-estáticos. O ponto 2 indica o início da admissão, o ponto 3 marca o fim da admissão, e o ponto 4 marca a abertura da válvula de admissão. É possível perceber que parte do processo de admissão ocorre quase a volume constante e conforme o pistão começa a se movimentar, a pressão interna do cilindro diminui. Entre os pontos 3 e 4 ocorre uma expansão isentrópica, e o escape, que ocorre entre os pontos 4 e 2, ocorre praticamente à pressão constante.

No diagrama PxV da simulação onde não se consideram os processos como sendo quaseestáticos, Figura 2.17, os processos são os mesmos que os da Figura 2.16. Os dois diagramas são muito similares, e uma diferença entre eles é a de que no trecho da admissão em que o pistão se desloca do menor para o maior volume ocorre uma oscilação de pressão dentro do cilindro na simulação que não considera processos quase-estáticos. Os autores afirmam que a diferença entre as duas simulações, é que a simulação sem processos quase-estáticos considera ondas de pressão percorrendo as tubulações de admissão e escape, assim como ondas de pressão dentro do cilindro. Portanto, essas oscilações de pressão no processo de admissão são devidas às ondas de pressão percorrendo o sistema. 


\section{ESTUDO DO CICLO TEÓRICO}

O ciclo proposto para ser considerado como ciclo padrão é o ciclo da Figura 2.6. Todos os outros ciclos teóricos disponíveis na literatura podem ser considerados como casos particulares desse mais generalizado. Esse ciclo representa de forma mais realista o funcionamento de um motor a vapor, todos os cálculos e estudos serão feitos para esse ciclo e serão indicadas as simplificações desse ciclo que conduzem aos demais ciclos obtidos na literatura.

\subsection{CICLO DE ESTUDO}

Na literatura foram encontrados cinco ciclos diferentes utilizados por outros autores, que estão representados entre a Figura 2.1 e Figura 2.6. Os autores que utilizam esses ciclos fazem estudos teóricos, mas que ficam restritos a um ciclo específico. Torna-se interessante verificar a existência de um ciclo generalizado, no qual o estudo teórico posa ser aplicado a qualquer outro ciclo.

O ciclo generalizado deve conter todas as características dos outros ciclos. Ao observar todos os ciclos teóricos entre a Figura 2.1 e Figura 2.6, é possível notar que todos os ciclos são compostos de 6 processos diferentes. Admissão à volume constante, admissão a pressão constante, expansão isentrópica, escape a volume constante, escape a pressão constante e compressão isentrópica. São então dois processos isobáricos, dois isentrópicos e dois isocóricos. Dentre os ciclos disponíveis na literatura, já existe um ciclo que possui todos esses processos, que é o ciclo da Figura 2.6.

O ciclo se inicia no ponto (1), com o pistão no ponto morto de menor volume, com a pressão igual a pressão de admissão e a válvula de admissão aberta. O pistão se movimenta de forma a aumentar o volume interno do cilindro, e a válvula de admissão permanece aberta até o ponto (2). No ponto (2) a válvula de admissão se fecha, e ocorre uma expansão isentrópica do vapor até o pistão atingir o ponto morto de maior volume, ponto (3). Nesse ponto, a válvula de escape abre e a pressão do cilindro cai para a pressão de escape, até atingir o ponto (4). No 
ponto (4) o pistão inicia seu retorno e a válvula de escape se mantém aberta até o ponto (5), instante em que se fecha. A partir do ponto (5), existe uma compressão isentrópica até o ponto (6), onde o volume do cilindro é o volume morto. No ponto (6) a válvula de admissão se abre, admitindo vapor para dentro do cilindro e elevando a pressão da câmara até a pressão de admissão, ponto (1). Ao chegar no ponto (1), o ciclo se reinicia.

Ao manipular as grandezas envolvidas nesse ciclo generalizado, ele pode tomar a forma de todos os outros ciclos estudados por outros autores. Apenas alterando a posição, ou o volume onde ocorrem, os pontos (1), (2), e (5), é possível estudar qualquer outro ciclo. Essas relações exatas serão estudadas na seção 3.3.1.

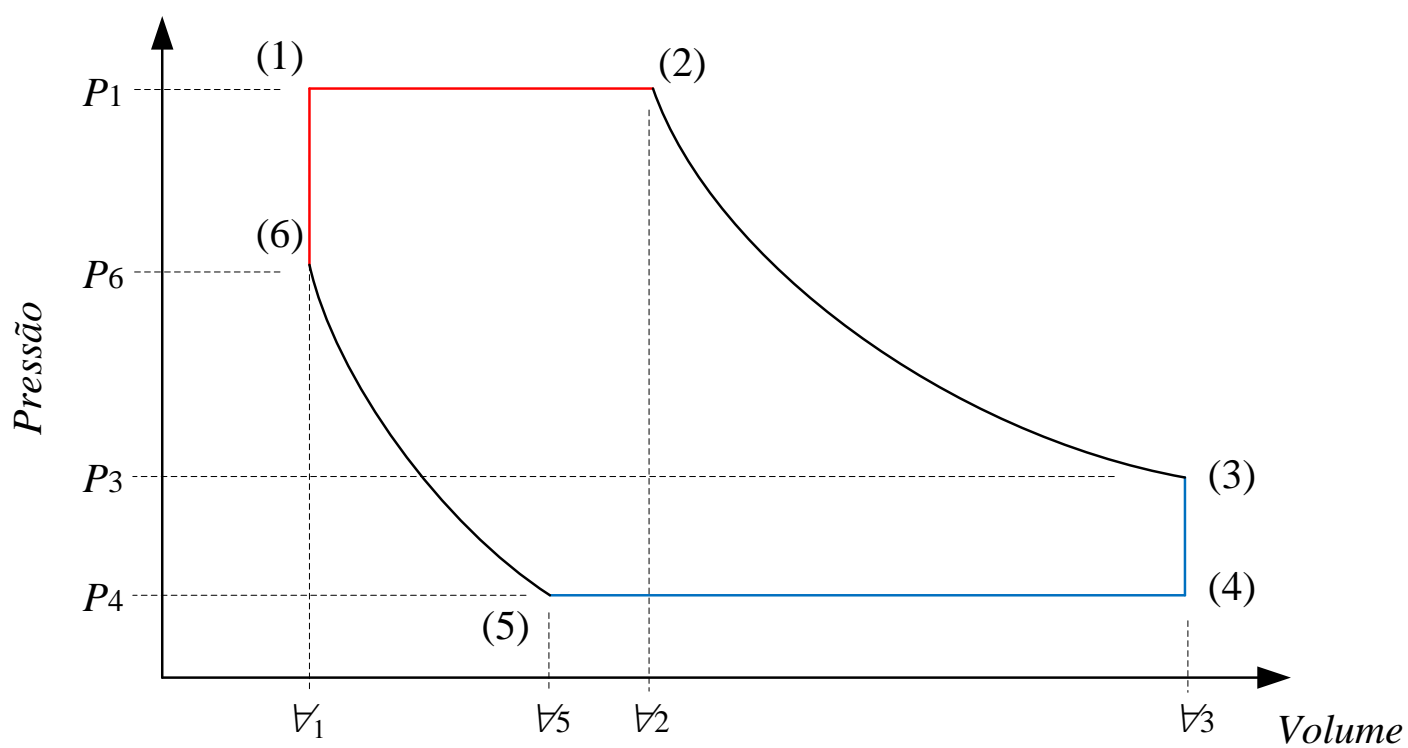

Figura 2.6-Diagrama PxV generalizado de um ciclo, considerando expansão e compressão incompletas, utilizado por Antonelli e Martorano (2012) e Basbous et al. (2012).

\subsection{EQUACIONAMENTO}

As máquinas a vapor e os motores de expansão são equipamentos fisicamente similares, trabalham da mesma forma e apenas diferem em relação ao fluido utilizado e suas consequentes peculiaridades. Dessa forma, os estudos realizados serão feitos de forma generalizada sem, portanto, se preocupar com a finalidade da máquina. Para o equacionamento e estudo dos parâmetros que influenciam o desempenho de um motor a vapor ou de uma máquina de expansão serão consideradas as seguintes hipóteses simplificadoras: 
a) O fluido de trabalho se comporta como um gás perfeito com propriedades constantes. Essa consideração é feita devido à facilidade dos cálculos e pelo fato que os ciclos estudados servem para máquinas de expansão de vapor e de gás, sendo que alguns fluidos possuem comportamento similar ao comportamento de gás perfeito.

b) O volume de controle não troca de calor com nenhum meio externo.

c) Propriedades uniformes dentro do volume de controle

d) Não há perda de carga nas válvulas de admissão e escape.

As propriedades constantes do gás que serão utilizadas são: o calor específico a pressão constante $\left(C_{P}\right)$, o calor específico a volume constante $\left(C_{V}\right)$, a razão entre calores específicos ( $k$ ) dada pela eq. (3.1) e a constante particular do gás $(R)$ dada pela eq.(3.2).

$$
\begin{gathered}
k=\frac{C_{P}}{C_{V}} \\
R=C_{P}-C_{V}
\end{gathered}
$$

Assim como é feito por Prilutskii (2008) e Vanyashov et al.(2001), autores que realizam estudos paramétricos sobre o funcionamento do motor a vapor, é interessante determinar relações entre os parâmetros importantes do ciclo. O equacionamento é feito por meio do diagrama PxV, que representa a variação da pressão em uma câmara do motor a vapor em função do volume da mesma. Se o motor for de dupla ação, a segunda câmara terá um ciclo igual, se considerado o volume da mesma, ou um ciclo simétrico se considerado o volume da primeira câmara. A nomenclatura utilizada nas equações é a mesma nomenclatura do diagrama da Figura 2.6, que será utilizado como referência para o equacionamento.

A primeira definição importante é a razão de compressão, $r_{V}$, sendo a razão entre o volume máximo, $\forall_{3}$, e o volume mínimo ou, volume morto, $\forall_{1}$, da câmara de expansão, como expresso na eq.(3.3).

$$
r_{V}=\frac{\forall_{3}}{\forall_{1}}
$$


A segunda definição importante é a razão de pressões, $r_{P}$, que é a relação entre a pressão de admissão, $\mathrm{P}_{\mathrm{adm}}$, e a pressão de escape, $\mathrm{P}_{\mathrm{esc}}$, eq.(3.4).

$$
r_{P}=\frac{P_{a d m}}{P_{e s c}}
$$

É definida como razão de corte, $r_{C}$, a razão entre o volume do cilindro, no instante em que a válvula de admissão se fecha, $\forall_{2}$, e o volume mínimo do cilindro (volume morto, $\forall_{1}$ ). Essa razão é dada pela eq.(3.5).

$$
r_{C}=\frac{\forall_{2}}{\forall_{1}}
$$

Da mesma forma, é definida uma razão de fechamento, $r_{F}$, que é a razão entre o volume do cilindro no instante em que a válvula de escape se fecha, $\forall_{5}$, e o volume morto $\forall_{1}$, essa razão é dada pela eq.(3.6).

$$
r_{F}=\frac{\forall_{5}}{\forall_{1}}
$$

As razões de corte e de fechamento podem ser expressas de forma relativa da posição do pistão em relação ao seu curso, sendo que 0 representa a posição do volume mínimo $\left(\forall_{1}\right)$ e 1 representa a posição de volume máximo dentro do cilindro. Dessa forma, a razão de corte relativa, $\mathrm{r}_{\mathrm{CX}}$, e a razão de fechamento relativa, $\mathrm{r}_{\mathrm{FX}}$, podem ser expressas por meio da eq.(3.7) e da eq.(3.8), respectivamente.

$$
\begin{aligned}
& r_{C X}=\frac{\forall_{2}-\forall_{1}}{\forall_{3}-\forall_{1}}=\frac{r_{C}-1}{r_{V}-1} \\
& r_{F X}=\frac{\forall_{5}-\forall_{1}}{\forall_{3}-\forall_{1}}=\frac{r_{F}-1}{r_{V}-1}
\end{aligned}
$$

A utilização das razões de corte e de fechamento na forma relativa facilita a visualização das posições dentro do ciclo. Porém as equações se tornam maiores e mais complexas ao utilizar 
essas razões na forma relativa. Aqui serão mostradas as equações na forma da razão de compressão e no APÊNDICE a - equações para o ciclo GENERALIZADO em função das razões de corte e de fechamento na forma de porcentagem serão mostradas as equações na forma relativa.

\subsubsection{Trabalho de um ciclo}

O trabalho reversível realizado pela máquina a vapor em um ciclo de funcionamento sobre a cabeça do pistão pode ser calculado por meio da eq.(3.9), que é numericamente igual à área interna do ciclo da Figura 2.6. Badami et al. (2008) utilizam a mesma expressão para calcular o trabalho total do ciclo da Figura 2.5. No ciclo da figura abaixo, o processo 1-2 representa admissão de fluido em pressão constante, e a válvula de admissão fecha no ponto (2). O processo 2-3 indica uma expansão isentrópica sem troca de massa. No ponto (3) a válvula de escape se abre, iniciando o processo 3-4, que é um processo de escape a volume constante. O processo 4-5 é um escape a pressão constante, e o chegar em (5), a válvula de escape se fecha. O processo 5-6 indica uma compressão isentrópica sem troca de fluido, até q no ponto (6) a válvula de admissão se abre. O processo 6-1 representa admissão à volume constante.

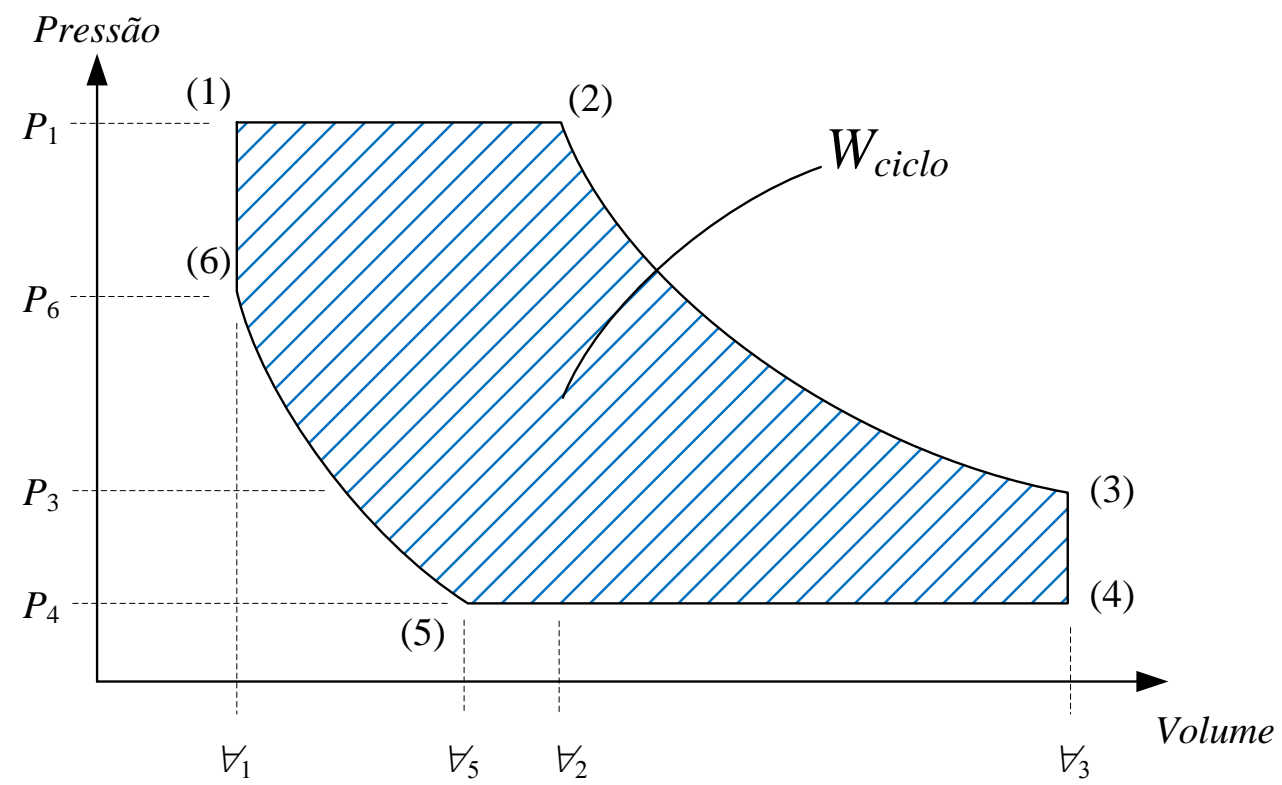

Figura 2.6- Diagrama PxV generalizado de um ciclo, considerando expansão e compressão incompletas, utilizado por Antonelli e Martorano (2012) e Basbous et al. (2012). 


$$
W_{\text {ciclo }}=\oint P d V=W_{1-2}+W_{2-3}+W_{3-4}+W_{4-5}+W_{5-6}+W_{6-1}
$$

Portanto é necessário calcular o trabalho realizado em cada etapa do ciclo. O processo 1-2 é realizado a pressão constante, assim o trabalho realizado sobre o pistão nesse processo pode ser calculado através da equação:

$$
W_{1-2}=\int_{1}^{2} P d \forall=P_{a d m}\left(\forall_{2}-\forall_{1}\right)
$$

Reescrevendo a equação acima em função da razão de corte, tem-se:

$$
W_{1-2}=P_{a d m} \cdot \forall_{1}\left(r_{C}-1\right)
$$

O processo 2-3 é uma expansão isentrópica, portanto é um processo politrópico cujo expoente é $k$, e o trabalho realizado é dado por:

$$
W_{2-3}=\int_{2}^{3} P d \forall=\frac{\left(P_{2} \forall_{2}-P_{3} \forall_{3}\right)}{k-1}
$$

Reescrevendo em função da razão de corte:

$$
W_{2-3}=\frac{P_{a d m} \cdot \forall_{1} \cdot r_{C}}{k-1}\left[1-\left(\frac{r_{C}}{r_{V}}\right)^{k-1}\right]
$$

Os processos 3-4 e 6-1 ocorrem a volume constante, não havendo a realização de trabalho sobre o pistão. O processo 4-5 acontece à pressão constante, e o trabalho realizado pode ser escrito como:

$$
W_{4-5}=\int_{4}^{5} P d \forall=P_{e s c}\left(\forall_{5}-\forall_{4}\right)
$$

Em função da razão de fechamento: 


$$
W_{4-5}=\frac{P_{a d m} \cdot \forall_{1}\left(r_{F}-r_{V}\right)}{r_{P}}
$$

O processo 5-6 é uma compressão isentrópica, considerado como um processo politrópico com expoente $k$, dessa forma o trabalho do processo 5-6 pode ser escrito como:

$$
W_{5-6}=\int_{5}^{6} P d \forall=\frac{\left(P_{5} \forall_{5}-P_{6} \forall_{6}\right)}{k-1}
$$

Reescrevendo em função da razão de fechamento, tem-se:

$$
W_{5-6}=\frac{P_{a d m} \cdot \forall_{1} \cdot r_{F}\left(1-r_{F}^{k-1}\right)}{r_{P}(k-1)}
$$

Substituindo as eqs. (, (3.13), (3.15) e (3.17) na eq.(3.9), chega-se em uma expressão para o trabalho total realizado sobre o pistão em um ciclo, que é dado pela eq.(3.18).

$$
W_{\text {ciclo }}=\frac{\forall_{1} P_{a d m}}{k-1}\left\{k\left(r_{C}-1\right)+1-\frac{r_{C}{ }^{k}}{r_{V}{ }^{k-1}}+\frac{1}{r_{P}}\left[(k-1)\left(r_{F}-r_{V}\right)-r_{F}\left(r_{F}^{k-1}-1\right)\right]\right\}
$$

\subsubsection{Massa de vapor utilizada em um ciclo}

Ao longo de um ciclo de funcionamento, a massa no interior do cilindro varia. Quando o pistão está no PMS, no instante anterior à abertura da válvula de admissão, existe uma quantidade residual de massa dentro do cilindro. Essa massa residual não se altera após um ciclo completo, e também não gera trabalho útil. Essa massa é expandida no curso do pistão até o PMI, fornecendo energia ao pistão, porém no retorno do pistão, essa massa é comprimida, retirando energia do pistão. Por se tratar de um gás perfeito, a energia de compressão do pistão em metade do ciclo é igual à energia de expansão daquela massa sobre o pistão no seu retorno. 
Após o fechamento da válvula de admissão, dentro do cilindro existe a maior quantidade de massa do ciclo, e essa massa inclui a parcela da massa residual e a parcela da massa que efetivamente é responsável pelo trabalho útil sobre o pistão. Essa parcela que realiza o trabalho útil representa o fluxo mássico que passa pela máquina a vapor e, consequentemente, o fluxo da instalação. Dessa forma, a massa consumida em um ciclo é dada pela diferença entre a máxima massa $\left(m_{2}\right)$ e a mínima massa $\left(m_{6}\right)$ no interior do cilindro ao longo do ciclo. Badami et al. (2008) utilizam a mesma expressão para calcular a massa consumida em um ciclo.

$$
m_{\text {ciclo }}=m_{2}-m_{6}
$$

A equação da conservação da energia utilizada é independente do tempo, pois o fluido sofre dois processos isobáricos, dois processos isentrópicos e dois processos isocóricos, todos com limites determinados no Diagrama PxV do ciclo (Figura 2.6). Essa imposição de quais processos ocorrem já determina como as grandezas físicas variam uma em relação as outras, tornando o processo independente do tempo. Para se obter a massa consumida em um ciclo e a massa contida no cilindro em cada ponto do ciclo, é utilizada a $1^{\mathrm{a}}$ Lei da Termodinâmica para regime transiente na forma diferencial independente do tempo. Desprezando as energias cinéticas e potenciais gravitacionais, obtém-se a eq. (3.20):

$$
\delta Q+d m_{e} h_{e}-d m_{s} h_{s}-\delta W=d U
$$

Dessa forma, na eq.(3.20), os termos de entrada e saída de massa podem ser substituídos por um único termo em que a massa que entra ou a massa que sai do volume de controle é a própria variação de massa do volume de controle. A entalpia se torna a respectiva entalpia da massa que entra ou que sai do volume de controle dependendo do processo. Com isso, os termos envoltos por linha tracejada podem ser substituídos pelo termo escrito abaixo do destaque na eq. (3.20).

O volume de controle estudado para a utilização da eq.(3.20) é o volume interno do cilindro, compreendido entre o cilindro e o pistão, destacado na Figura 3.1. Sendo que uma das hipóteses é a de que o volume de controle não troca calor, $\delta Q$ é igual a zero. Em qualquer 
processo do ciclo, não existe um ponto onde existe massa entrando e massa saindo do volume de controle simultaneamente.

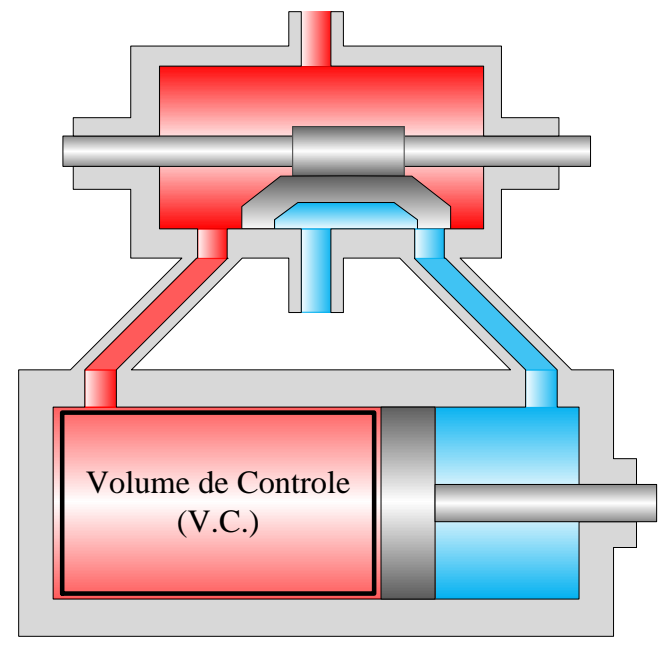

Figura 3.1 - Volume de controle para o balanço de energia.

Dessa forma, por meio de um balanço de massa, eq.(3.21), tem-se que a variação da massa no volume de controle é dada pela diferença entre a massa que entra e a massa que sai do volume de controle, como expresso na eq.(3.21).

$$
d m_{V C}=d m_{e}-d m_{s}
$$

Como para o ciclo se conhece o comportamento da pressão e da temperatura em todos os pontos, é interessante escrever o trabalho e a variação da energia interna em função apenas da pressão e do volume do cilindro. O trabalho infinitesimal realizado sobre o pistão é dado por:

$$
\delta W=P d \forall
$$

A energia interna pode ser expressa como $U=m . u$, e para um gás perfeito com propriedades constantes, $u=C_{V} \cdot T$, portanto:

$$
d U=C_{V} \cdot d(m \cdot T)
$$

Retrabalhando as das eqs. (3.1) e (3.2), tem-se que:

$$
C_{V}=\frac{R}{k-1}
$$


Substituindo a equação acima e a equação de estado para gases perfeitos (eq.(3.25)) na eq.(3.23), chega-se na expressão para a variação da energia interna em função da pressão e do volume, expressa na eq.(3.26).

$$
\begin{aligned}
& P \cdot \forall=m \cdot R \cdot T \\
& d U=\frac{d(P \cdot \forall)}{k-1}
\end{aligned}
$$

Lembrando que a entalpia para um gás perfeito com propriedades constantes pode ser escrita por $h=C_{P} . T$, e através das eqs.(3.1) e (3.2), tem-se que:

$$
C_{P}=\frac{k}{k-1} \cdot R
$$

Substituindo a equação acima e as eqs. (3.22) e (3.26) na eq.(3.20), chega-se na expressão do balanço de energia em qualquer ponto do ciclo na forma diferencial e, consequentemente, na expressão para a massa que entra ou sai do cilindro:

$$
d m_{V C}=\left(\frac{d(P \cdot \forall)}{k-1}+P \cdot d \forall\right)\left(\frac{k-1}{k \cdot R \cdot T_{e / s}}\right)
$$

O processo 1-2 ocorre à pressão constante, e nesse processo a massa entra com a temperatura de admissão, portanto a eq.(3.28) pode ser escrita como:

$$
d m_{1-2}=\frac{P \cdot d \forall}{R \cdot T_{a d m}}
$$

Integrando entre os pontos 1 e 2 , e isolando $m_{2}$, obtém-se:

$$
m_{2}=\frac{P_{a d m}\left(\forall_{2}-\forall_{1}\right)}{R \cdot T_{a d m}}+m_{1}
$$


No processo 2-3, todas as válvulas permanecem fechadas, portanto $m_{2}=m_{3}$. O processo 3-4 ocorre a volume constante e sai massa do volume de controle com uma temperatura $T$, igual à temperatura interna do volume de controle. Dessa forma, a eq. (3.28) pode ser escrita como:

$$
d m_{3-4}=\frac{\forall_{3} \cdot d P}{k \cdot R \cdot T}
$$

Isolando $T$ na eq.(3.25) e substituindo na equação acima, chega-se em:

$$
\frac{d m_{3-4}}{m}=\frac{d P}{k \cdot P}
$$

Integrando entre os pontos 3 e 4 e isolando $m_{4}$, obtém-se a expressão para a massa no ponto 4 .

$$
m_{4}=m_{3}\left(\frac{P_{4}}{P_{3}}\right)^{1 / k}
$$

O processo 4-5 ocorre à pressão constante e a temperatura do fluido que sai do volume de controle é $T$, igual à temperatura do volume de controle. Isolando $T$ na eq.(3.25) e substituindo na eq.(3.28), chega-se a:

$$
\frac{d m_{4-5}}{m}=\frac{d \forall}{\forall}
$$

Integrando entre os pontos 4 e 5 , e isolando $m_{5}$ :

$$
m_{5}=m_{4} \frac{\forall_{5}}{\forall_{4}}
$$

Por meio da eq.(3.35) é possível notar que o volume específico dentro do volume de controle é constante no processo 4-5. Ao longo do processo 5-6 as válvulas de admissão e escape estão fechadas e portanto, a massa interna do cilindro não se altera. O processo 6-1 ocorre a volume constante e a massa que entra possui a temperatura igual à temperatura de admissão $T_{a d m}$, substituindo essas informações na eq.(3.28), obtém-se: 


$$
d m_{6-1}=\frac{\forall \cdot d P}{k \cdot R \cdot T_{a d m}}
$$

Integrando entre os pontos 6 e 1 :

$$
m_{1}=\frac{\forall_{1}\left(P_{1}-P_{6}\right)}{k \cdot R \cdot T_{a d m}}+m_{6}
$$

Sendo $m_{2}$ e $m_{6}$ a maior e a menor massa dentro do cilindro ao longo de um ciclo, respectivamente, e a massa consumida em um ciclo é a diferença entre essas duas quantidades de massa, pode-se combinar as eqs. (3.30) e (3.37) para chegar na expressão da massa do ciclo. Escrevendo a massa do ciclo em função da razão de corte e de fechamento, obtém-se:

$$
m_{\text {ciclo }}=m_{2}-m_{6}=\frac{P_{a d m} \cdot \forall_{1}}{k \cdot R \cdot T_{a d m}}\left(k\left(r_{C}-1\right)+1-\frac{r_{F}^{k}}{r_{P}}\right)
$$

Se a massa $m_{2}$ é igual à massa $m_{3}$, e $m_{5}$ é igual à $m_{6}$, então a massa do ciclo pode ser calculada como a diferença entre as massas do ponto 5 e do ponto 3.

$$
m_{\text {ciclo }}=m_{3}-m_{5}
$$

Substituindo as eqs. (3.33), (3.35) e (3.38) na equação acima, pode-se determinar uma expressão explícita para a massa do ponto 4. Escrevendo em função das razões de corte e de fechamento:

$$
m_{4}=\frac{P_{a d m} \cdot \forall_{1} \cdot r_{V}}{k \cdot R \cdot T_{a d m} \cdot\left(r_{C} \cdot r_{P}^{\frac{1}{k}}-r_{F}\right)}\left(k\left(r_{C}-1\right)+1-\frac{r_{F}^{k}}{r_{P}}\right)
$$

Substituindo a eq.(3.40) nas eqs. (3.30), (3.33), (3.35) e (3.37), chega-se em expressões explícitas para a massa de qualquer ponto do ciclo. Aqui serão escritas apenas as massas em função de $m_{4}$, pois se tornam relações mais simples.

$$
m_{2}=m_{3}=\frac{m_{4} \cdot r_{P}^{1 / k} \cdot r_{C}}{r_{V}}
$$




$$
\begin{gathered}
m_{1}=\frac{m_{4} \cdot r_{C} \cdot r_{P}{ }^{1 / k}}{r_{V}}-\frac{P_{a d m} \cdot \forall_{1}\left(r_{C}-1\right)}{R \cdot T_{a d m}} \\
m_{5}=m_{6}=\frac{m_{4} \cdot r_{F}}{r_{V}}
\end{gathered}
$$

\subsubsection{Temperatura em cada ponto do ciclo}

Substituindo a equação da massa para cada ponto do ciclo na equação de estado (eq.(3.25)), e escrevendo a pressão e o volume de cada ponto em função da pressão de admissão $\left(P_{\text {adm }}\right)$ e do volume morto $\left(\forall_{1}\right)$, através das razões das eqs. (3.3) até (3.6), chega-se a uma expressão explícita da temperatura em qualquer ponto do ciclo.

$$
\begin{gathered}
T_{1}=\frac{T_{a d m}}{\frac{r_{C}\left(r_{P} \cdot k\left(r_{C}-1\right)+r_{P}-r_{F}^{k}\right)}{k \cdot r_{P}^{\frac{k-1}{k}}\left(r_{C} \cdot r_{P}^{\frac{1}{k}}-r_{F}\right)}-r_{C}+1} \\
T_{2}=\frac{k \cdot T_{a d m} \cdot r_{P}^{\frac{k-1}{k}} \cdot\left(r_{C} \cdot r_{P}^{\frac{1}{k}}-r_{F}\right)}{k \cdot r_{P}\left(r_{C}-1\right)+r_{P}-r_{F}^{k}}
\end{gathered}
$$

As outras temperaturas serão escritas em função de $T_{2}$, sendo o processo 2-3 isentrópico, $T_{3}$ é definido pela (3.46):

$$
T_{3}=T_{2}\left(\frac{r_{C}}{r_{V}}\right)^{k-1}
$$

Conforme descrito anteriormente, através da eq.(3.35) pode-se notar que o volume específico entre os pontos 4 e 5 permanece constante, e por se tratar de um processo a pressão constante, conclui-se que o estado termodinâmico entre 4 e 5 é o mesmo e, consequentemente, $T_{4}$ é igual a $T_{5}$ : 


$$
T_{4}=T_{5}=\frac{T_{2}}{r_{P}^{\frac{k-1}{k}}}
$$

E finalmente, a temperatura $T_{6}$ pode ser escrita como:

$$
T_{6}=T_{5} \cdot r_{F}^{k-1}=\frac{T_{2} \cdot r_{F}^{k-1}}{r_{P} \frac{k-1}{k}}
$$

\subsubsection{Trabalhos específicos e rendimento}

O trabalho específico realizado pelo ciclo é a razão entre o trabalho total realizado e massa de fluido consumida no ciclo.

$$
w_{\text {ciclo }}=\frac{W_{\text {ciclo }}}{m_{\text {ciclo }}}
$$

Substituindo as eqs. (3.18) e (3.38) na eq. (3.49), tem-se:

$$
w_{\text {ciclo }}=\frac{\frac{\forall_{1} P_{a d m}}{k-1}\left\{k\left(r_{C}-1\right)+1-\frac{r_{C}{ }^{k}}{r_{V}{ }^{k-1}}+\frac{1}{r_{P}}\left[(k-1)\left(r_{F}-r_{V}\right)-r_{F}\left(r_{F}^{k-1}-1\right)\right]\right\}}{\frac{P_{a d m} \cdot \forall_{1}}{k \cdot R \cdot T_{a d m}}\left(k\left(r_{C}-1\right)+1-\frac{r_{F}^{k}}{r_{P}}\right)}
$$

Simplificando, chega-se à eq.(3.51):

$$
w_{\text {ciclo }}=\frac{\frac{k \cdot R \cdot T_{a d m}}{k-1}\left\{k\left(r_{C}-1\right)+1-\frac{r_{C}{ }^{k}}{r_{V}{ }^{k-1}}+\frac{1}{r_{P}}\left[(k-1)\left(r_{F}-r_{V}\right)-r_{F}\left(r_{F}^{k-1}-1\right)\right]\right\}}{\left(k\left(r_{C}-1\right)+1-\frac{r_{F}^{k}}{r_{P}}\right)}
$$

Ao analisar a eq.(3.51), pode-se verificar que o trabalho específico de um ciclo é independente do volume morto $\forall_{1}$ e da pressão de admissão $P_{a d m}$, sendo dependente da temperatura de admissão $T_{a d m}$, das propriedades do gás e das razões de pressão, volume, corte e fechamento. 
O trabalho específico máximo possível que pode ser realizado pelo ciclo ocorreria se a massa de vapor pudesse realizar trabalho sofrendo apenas uma expansão isentrópica da pressão de admissão até a pressão de escape. Utilizando relações para processos isentrópicos, conclui-se que:

$$
w_{\text {iso }}=\frac{k \cdot R \cdot T_{a d m}}{k-1}\left(1-\frac{1}{r_{P} \frac{k-1}{k}}\right)
$$

Alguns autores que trabalham com máquinas a vapor calculam um rendimento térmico para a máquina a vapor, por considerarem que seu ciclo é como um ciclo de Rankine, e portanto um ciclo termodinâmico, porém diversos autores utilizam o rendimento isentrópico para avaliar o desempenho do ciclo ou da máquina isoladamente, pois estudam um ciclo mecânico de expansão. Os autores que consideram que os motores a vapor funcionam como um ciclo de Rankine utilizam o Diagrama PxV da Figura 2.2 ou da Figura 2.1 para seu estudo. Esse ciclo é composto de 2 processos isobáricos e 2 processos isentrópicos, podendo ser comparado ao ciclo Rankine. O motor estudado trabalha com um ciclo mecânico e não um ciclo térmico, e é um equipamento que está na mesma classe das turbinas e compressores, que por sua vez são estudados e comparados através de uma eficiência isentrópica. Portanto, neste trabalho foi escolhida a eficiência isentrópica para avaliar o motor a vapor e poder compará-lo com uma turbina como equipamento de expansão de um Ciclo Orgânico de Rankine. Sendo assim, o rendimento isentrópico de uma máquina de expansão pode ser definido como:

$$
\eta_{\text {iso }}=\frac{w_{\text {ciclo }}}{w_{\text {iso }}}
$$

Substituindo as eqs. (3.18), (3.38) e (3.52) na eq. (3.53), chega-se à expressão:

$$
\eta_{\text {iso }}=\frac{k\left(r_{C}-1\right)+1-\frac{r_{C}{ }^{k}}{r_{V}{ }^{k-1}}+\frac{1}{r_{P}}\left[(k-1)\left(r_{F}-r_{V}\right)-r_{F}\left(r_{F}^{k-1}-1\right)\right]}{\left(k\left(r_{C}-1\right)+1-\frac{r_{F}{ }^{k}}{r_{P}}\right) \cdot\left(1-\frac{1}{r_{P} \frac{k-1}{k}}\right)}
$$


É importante notar que a eficiência do ciclo da máquina a vapor é independente da temperatura de admissão $T_{a d m}$, pois esse parâmetro está presente da mesma forma no trabalho específico do ciclo e no trabalho específico isentrópico. Assim, a eficiência é função apenas das propriedades do gás e das razões de pressão, de volume, de corte e de fechamento. Se considerar $\mathrm{r}_{\mathrm{F}}=\mathrm{r}_{\mathrm{V}}$, chega-se à expressão para a eficiência encontrada por Badami e Mura (2009).

\subsection{INFLUÊNCIA DOS PARÂMETROS NA EFICIÊNCIA DO CICLO}

Primeiramente, deve-se tomar cuidado com a escolha das razões de corte e de fechamento, pois se essas razões forem escolhidas de forma inapropriada, pode ocorrer uma sobrecompressão (quando o vapor é comprimido para pressão acima da pressão de admissão) e uma sobre-expansão (quando o vapor é expandido para pressões menores que a pressão de escape) do vapor, podendo até mesmo fazer com que a máquina a vapor trabalhe como um compressor. A Figura 3.2 mostra um ciclo onde ocorre sobrecompressão e sobre-expansão. Se o vapor é comprimido para pressões acima da pressão de admissão e/ou expandido para pressões abaixo da pressão de escape, a eficiência do ciclo sofre uma redução devido à diminuição da área que representa o trabalho útil do ciclo (7-2-8-5). A eficiência também sofre redução devido ao aparecimento de áreas com trabalho negativo (1-6-7) e (8-3-4).

Para evitar que isso ocorra, a válvula de admissão deve fechar após uma determinada posição (mais próximo ao PMI) e a válvula de escape deve fechar antes de um determinado ponto (mais próximo ao PMS). Esses pontos são chamados de $r_{C m i n}$ e $r_{F m a x}$, respectivamente, e podem ser calculados da seguinte forma:

$$
\begin{aligned}
& r_{C \min }=\frac{r_{V}}{r_{P}{ }^{1 / k}} \\
& r_{\text {Fmax }}=r_{P}{ }^{1 / k}
\end{aligned}
$$

Também podem ser expressas na forma relativa como: 


$$
\begin{gathered}
r_{C X \min }=\frac{r_{V}-r_{P}{ }^{1 / k}}{r_{P}^{1 / k \cdot\left(r_{V}-1\right)}} \\
r_{F X \max }=\frac{r_{P}{ }^{1 / k}-1}{r_{V}-1}
\end{gathered}
$$

Esses valores utilizados como $r_{C}$ e $r_{F}$ fazem com que no processo de expansão, o vapor atinja a pressão de escape exatamente quando o pistão estiver no PMI e o vapor atinja a pressão de admissão quando o pistão estiver no PMS. Portanto, com esses valores para as razões de corte e fechamento, o ciclo de funcionamento se torna o ciclo da Figura 2.2, que como será mostrado mais adiante, é o mais eficiente.

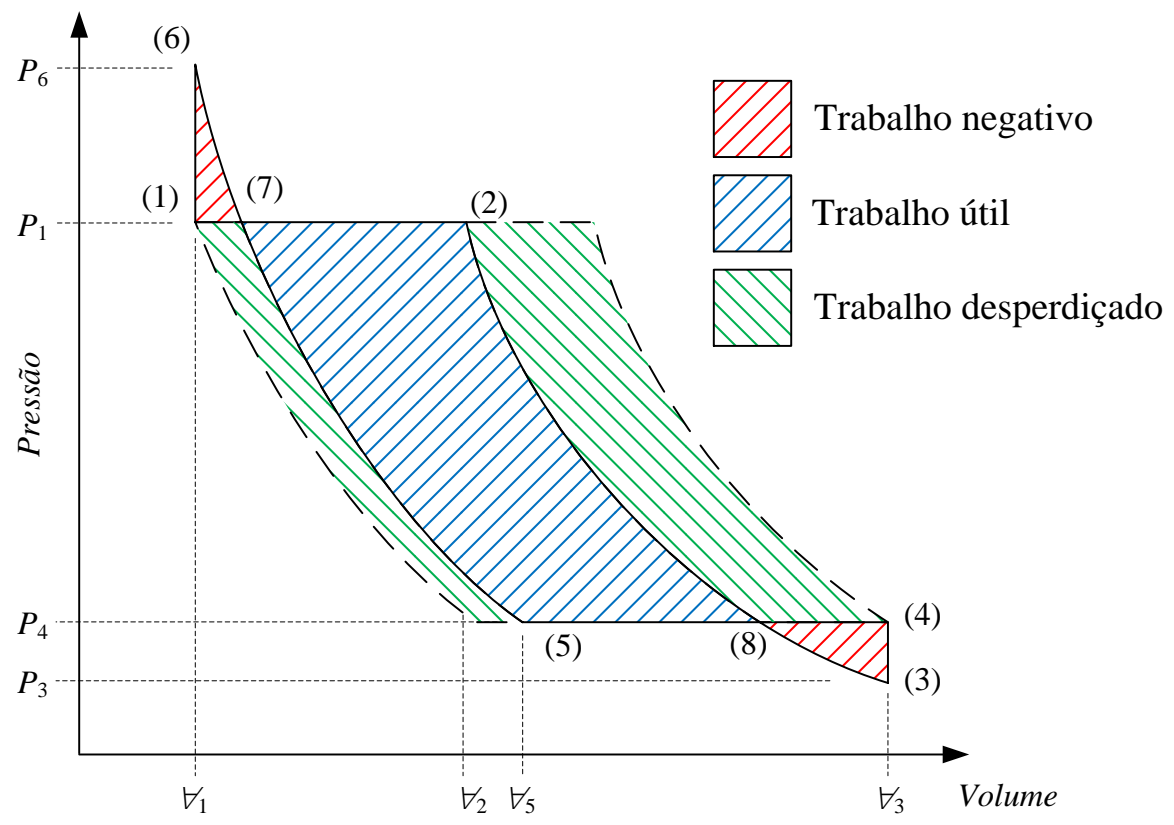

Figura 3.2 - Ciclo com sobrecompressão e sobre-expansão.

Se a razão de corte for maior do que o resultado da eq.(3.55), ocorre uma expansão incompleta do vapor, ou sub-expansão. E se a razão de fechamento for menor que o resultado da eq. (3.56), ocorre uma compressão incompleta do vapor, ou sub-compressão. Se a expansão e a compressão forem incompletas, tem-se o ciclo generalizado, como mostrado na Figura 2.6. A expansão e a compressão incompletas fazem com que no ciclo ocorram dois processos a volume constante, e esses processos representam dissipação de energia útil, e devem ser evitados (Trajkovic, 2010). 


\subsubsection{Influência dos parâmetros sobre a eficiência isentrópica}

Para estudar a influência dos parâmetros no desempenho do motor, foi realizada uma análise paramétrica das grandezas que influenciam o ciclo. Ao analisar a eq. (3.54), verifica-se que a eficiência é dependente apenas da constante adiabática do fluido e das razões de corte, fechamento, pressão e volume, e a visualização do comportamento da eficiência em relação a cada variável não é explícita. Para esse estudo paramétrico, fixou-se a pressão de escape $P_{\text {esc }}$ em 100 kPa e a pressão de admissão foi alterada para se estudar o efeito da razão de pressões.

Observando a Figura 3.3, nota-se que a razão de corte tem grande influência na eficiência da máquina a vapor em todas as pressões estudadas. Para a maioria das razões de pressão, os pontos de máxima eficiência ocorrem para razões de corte pequenas, quando a válvula de admissão fecha antes da metade do curso do pistão. Para as razões de volume e fechamento adotadas, a máxima eficiência para a razão de pressões de 20 é de aproximadamente 0,994, e as razões de pressão de 50 e 100 possuem seus pontos de máximo em $\mathrm{r}_{\mathrm{CX}}=0,015$ e $r_{C X}=0,00625$ respectivamente. Existe uma combinação entre as razões de corte e fechamento que faz essas eficiências aumentarem. Para uma razão de compressão fixa, quanto maior for a pressão de admissão, mais próximo do PMS a válvula deve fechar. Ainda não foi determinada uma expressão analítica para quais valores de $\mathrm{r}_{\mathrm{CX}}$ a eficiência é máxima. A eficiência possui uma assíntota vertical na razão de corte relativa dada pela eq.(3.59):

$$
r_{C X_{-} a s s i n t}=\frac{\left[r_{F X} \cdot\left(r_{V}-1\right)+1\right]^{k}-r_{P}}{k \cdot r_{P} \cdot\left(r_{V}-1\right)}
$$

O mesmo estudo foi realizado para a razão de fechamento. Observando a Figura 3.4, é notável que a eficiência sofre grande influência da razão de fechamento para baixas razões de pressão, quando se mantém a razão de compressão fixa. Porém para altas razões de pressão, a razão de fechamento praticamente não altera a eficiência da máquina de expansão. 


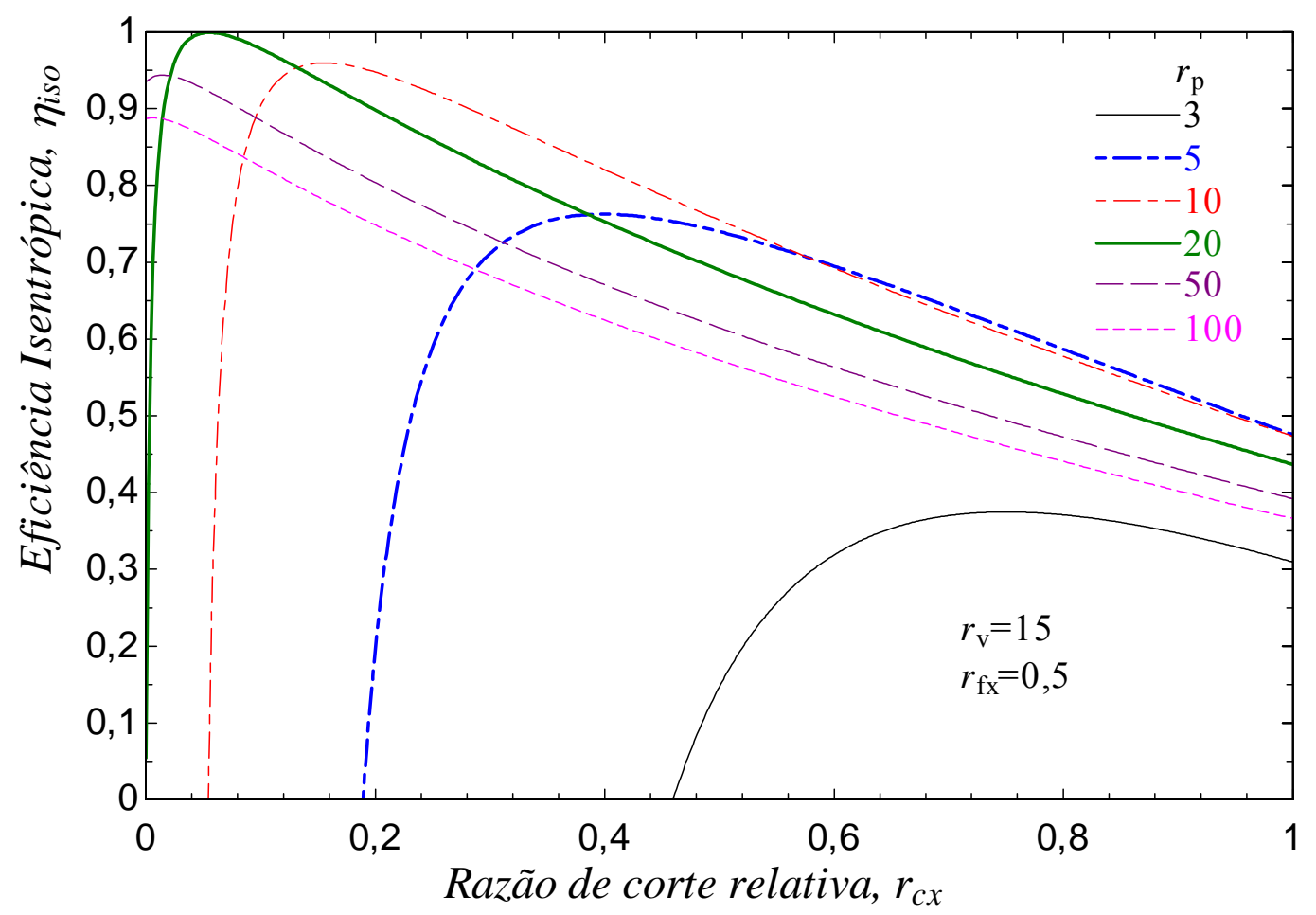

Figura 3.3 - Eficiência isentrópica do ciclo em função de $r_{C X}$ e de $r_{P}$.

A queda acentuada da eficiência para altos valores de razão de fechamento em baixas razões de pressão é devido ao fato de esse fechamento antecipado das válvulas de escape provocar uma sobrecompressão no fluido, reduzindo muito a eficiência do ciclo. Em valores muito altos da razão de fechamento, é possível que se tenha a condição onde ainda exista um consumo de massa, porém as regiões de trabalho negativo superam as regiões de trabalho positivo do ciclo, fazendo com que mesmo consumindo massa e seja necessário fornecer trabalho à máquina. Em outras palavras, é possível se atingir eficiências negativas caso a razão de fechamento for muito alta.

Ainda não foi determinada uma expressão analítica explícita para calcular em quais razões de fechamento relativas se tem os pontos de máximo. Mas é possível prever uma assíntota vertical para a razão de fechamento dada pela eq.(3.60): 


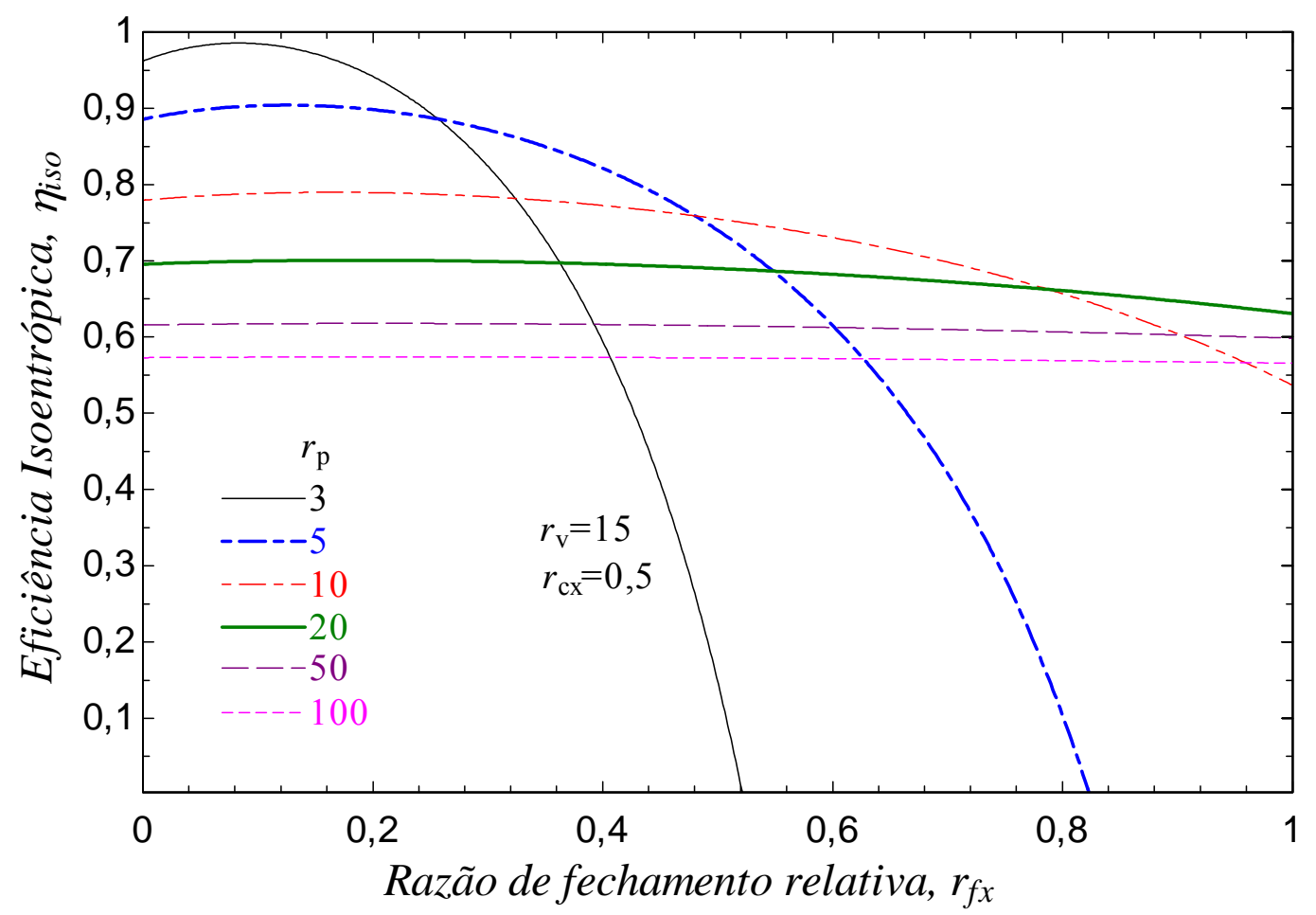

Figura 3.4 - Eficiência isentrópica do ciclo em função de $r_{F X}$ e de $r_{P}$.

$$
r_{F X_{-} a s s i n t}=\frac{\left[\left(k \cdot r_{C X} \cdot\left(r_{V}-1\right)+1\right) \cdot r_{P}\right]^{\frac{1}{k}}-1}{\left(r_{V}-1\right)}
$$

O diagrama da Figura 3.5 mostra que fixando as razões de corte e de fechamento, há uma razão de compressão que traz uma eficiência máxima para cada pressão. É possível notar que quanto maior a razão de pressão, maior a razão de compressão para se atingir a máxima eficiência. De acordo com o gráfico, a eficiência máxima diminui conforme a razão de pressão aumenta, porém isso é um efeito combinado dos valores das razões de corte e de fechamento. Como não é possível determinar uma expressão analítica explícita para se determinar em qual razão de compressão que o ponto de máximo ocorre, não é possível afirmar se há um ponto de máximo para as razões de pressão maiores. Uma possibilidade é calcular e desenhar o gráfico até razões de volume maiores para verificar, porém não há motivo para estudar razões de volume tão elevadas, uma vez que esse gráfico já traz valores impraticáveis para essa grandeza.

Esses valores adotados para serem mantidos como fixos na Figura 3.5 trazem melhores resultados para baixas pressões de admissão, e em altas pressões tornam o ciclo ineficiente. Para altas pressões, ao se escolher razões de fechamento e de corte adequadas, pode-se atingir 
eficiências semelhantes às máximas para baixas razões de pressão. Para demonstrar isso, foi escolhida a razão de pressão $\mathrm{r}_{\mathrm{P}}=100$, e desenhadas as curvas da eficiência isentrópica em função da razão de compressão para diferentes combinações de $r_{\mathrm{CX}}$ e $\mathrm{r}_{\mathrm{FX}}$. Essas curvas estão na Figura 3.6.

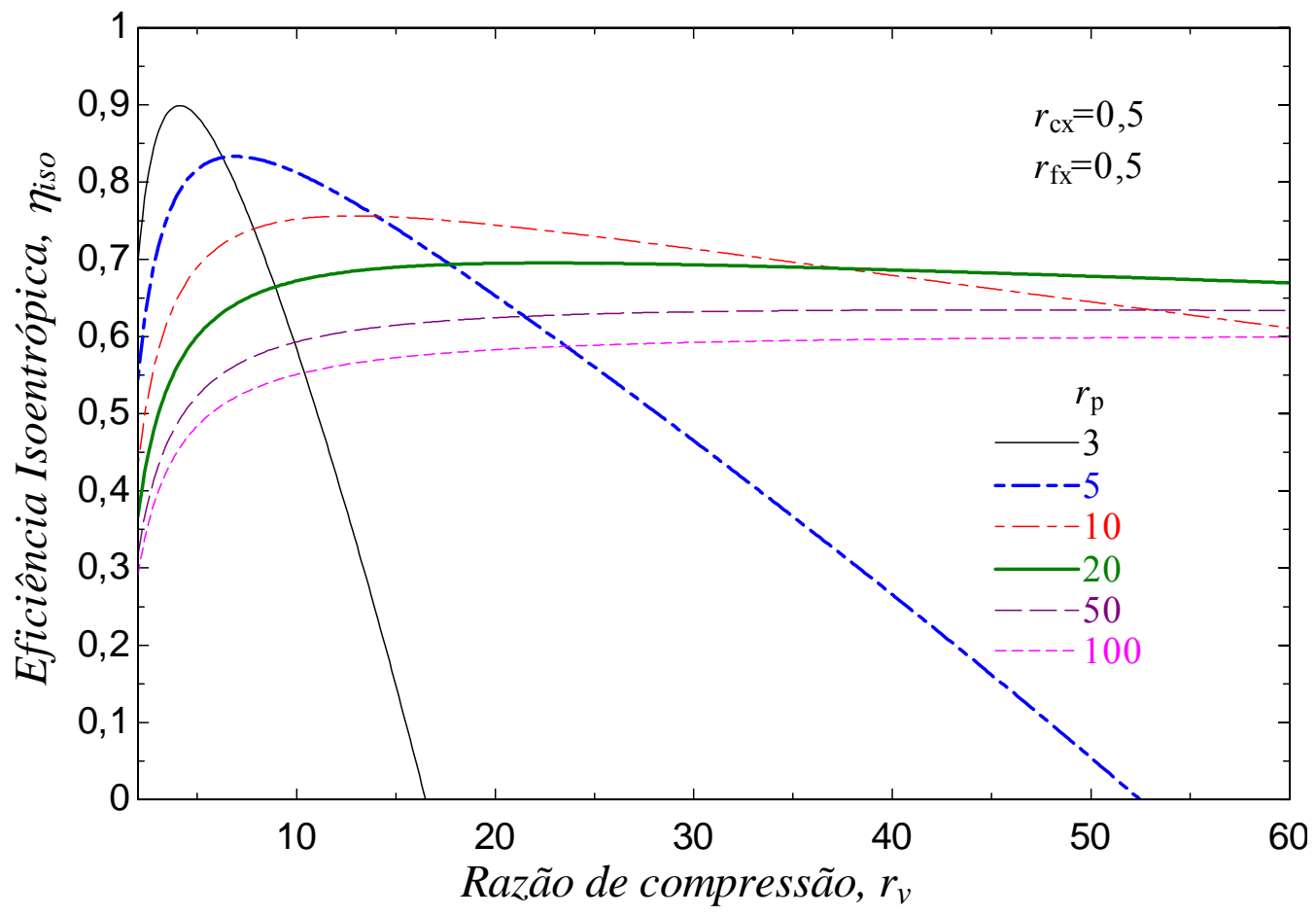

Figura 3.5 - Eficiência isentrópica do ciclo em função de $r_{V}$ e de $r_{P}$.

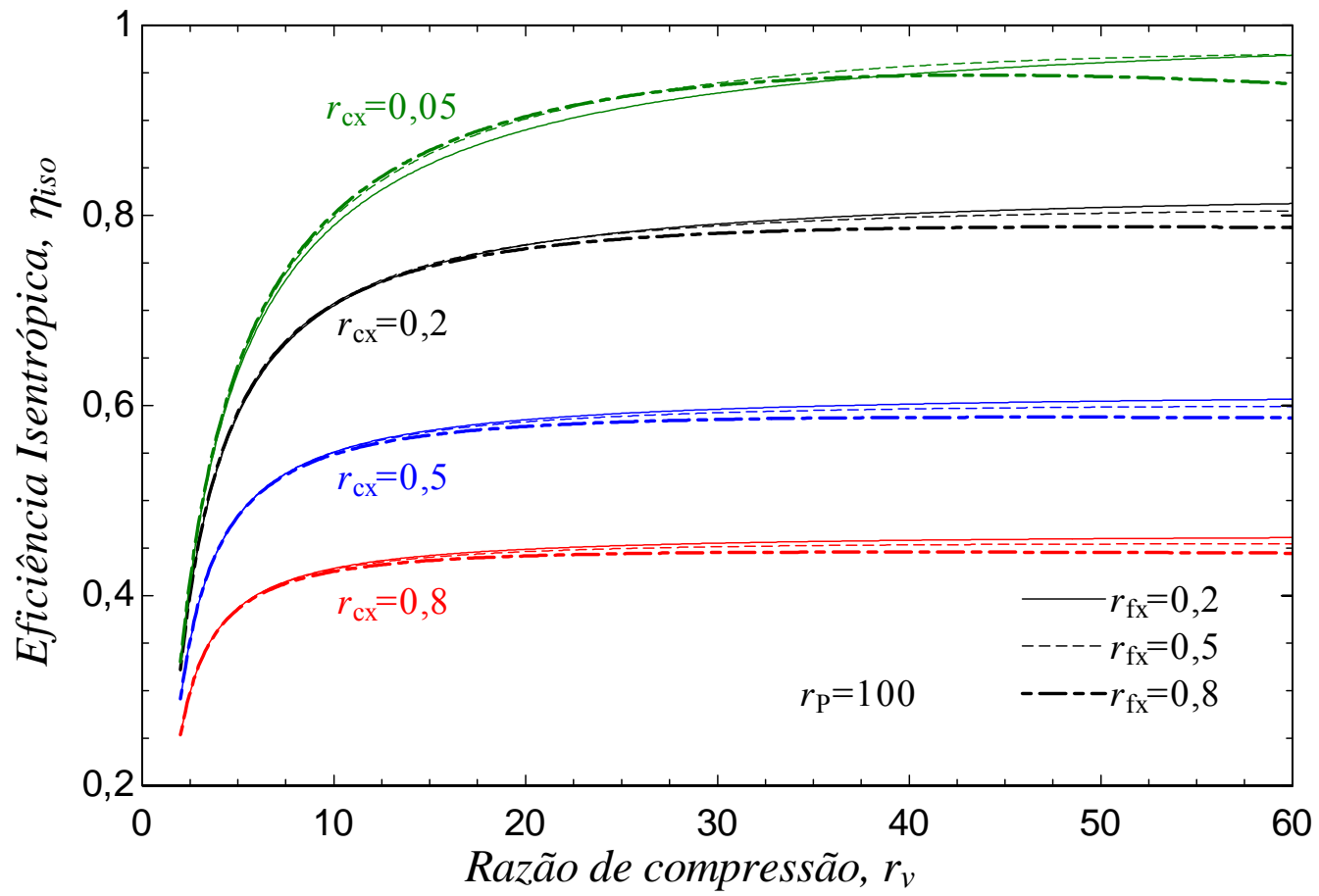

Figura 3.6 - Eficiência isentrópica do ciclo em função de $r_{V}$ para diferentes combinações de $r_{C X} e r_{F X}$. 
Analisando a Figura 3.6, percebe-se que a razão de corte possui uma maior influência na eficiência isentrópica do que a razão de fechamento. Isso ocorre porque as curvas foram obtidas para uma alta razão de pressão, e como verificado na Figura 3.4, a razão de fechamento tem pouca influência na eficiência isentrópica para altas razões de pressão. E para essa alta razão de pressão, o ciclo chegou a aproximadamente 97\% de eficiência isentrópica. Talvez exista uma combinação entre as razões de corte e de fechamento que otimize ainda mais a eficiência isentrópica. Embora esse estudo tenha sido feito com uma razão de pressão de $\mathrm{r}_{\mathrm{P}}=100$, para as outras razões de pressão também é possível otimizar a eficiência se forem alteradas as razões de fechamento e de corte.

\subsubsection{Eficiência dos ciclos estudados por outros autores}

Para fazer com que o ciclo generalizado da Figura 2.6 se comporte como os ciclos estudados por outros autores, devem-se alterar apenas as razões de corte e de fechamento. Para estudar o ciclo da Figura 2.1, não é possível utilizar as razões de corte e de fechamento, pois o volume morto $\forall_{1}$ é igual a 0 , e faz com que essas razões não existam. Mesmo assim ainda é possível trabalhar com as razões de corte e fechamento relativas, por meio de suas definições nas eqs. (3.7) e (3.8). Dessa forma, para que o ciclo mais generalizado se comporte como o ciclo da Figura 2.1, o volume morto $\left(\forall_{1}\right)$ deve ser igual a zero, bem como a razão de fechamento relativa $\left(\mathrm{r}_{\mathrm{FX}}\right)$ seja igual a zero e a razão de corte relativa deve ser maior que a razão de corte relativa mínima expressa pela eq. (3.57). Para esse caso a eficiência depende apenas de $r_{C}$, sendo que quando $r_{C}=r_{C \min }$ a eficiência isentrópica do ciclo vale um 1.

Para se obter o ciclo da Figura 2.2, como citado anteriormente, é necessário que $r_{C}=r_{C \min } \mathrm{e}$ $r_{F}=r_{\text {Fmax }}$. Calculando a eficiência para esse ciclo, verifica-se que ela é sempre igual a 1. A demonstração dessa eficiência isentrópica está no APÊNDICE B -demonstração da eficiência de $100 \%$ no ciclo ideal. Isso faz deste o ciclo ideal para um projeto de uma máquina a vapor, portanto deve-se tentar alcançá-lo. O trabalho realizado por esse ciclo não é nulo e aumenta também com a razão de pressões e com a razão de compressão.

O ciclo da Figura 2.4 é obtido para as razões de corte e de fechamento como $r_{C}=1$ e $r_{F}=r_{V}$. Esse ciclo sempre possui eficiência isentrópica menor do que um, e tende à unidade quando a 
razão de pressões diminui e o trabalho realizado tende a zero. Portanto esse ciclo dificilmente terá um bom desempenho operando em condições reais. Para estudar o ciclo da Figura 2.5, deve-se utilizar $r_{F}=r_{V}$ e $r_{C} \geq r_{C m i n}$. Esse ciclo também possui uma eficiência isentrópica menor do que 1, porém tende a ser um pouco mais eficiente do que o ciclo da Figura 2.4, devido ao processo a pressão constante. O ciclo da Figura 2.6, deve ter $r_{C} \geq r_{C \min }$ e $r_{F} \leq r_{F \max }$. $\mathrm{O}$ ponto de eficiência máxima para esse ciclo é quando $r_{C}=r_{C \min }$ e $r_{F}=r_{F m a x}$. Porém, nesse caso, ele se torna o ciclo da Figura 2.2, chegando a uma eficiência isentrópica de $100 \%$.

Sendo o ciclo da Figura 2.2, o ciclo de maior eficiência possível, é feito um estudo para analisar se ainda assim é possível otimizá-lo para encontrar pontos ótimos de projeto. Foram levantadas as curvas do trabalho total realizado em um ciclo, da massa consumida em um ciclo, e do trabalho específico realizado pelo fluido, todos em função da razão de pressões e da razão de compressão. Os resultados são mostrados nas Figura 3.7, Figura 3.8 e Figura 3.9. Analisando as Figura 3.7 e Figura 3.8, nota-se que quanto maior a razão de compressão, maior o trabalho realizado e a massa consumida, porém para cada razão de compressão, existe uma razão de pressões que faz com que ocorra o maior trabalho possível e outra que provoca o maior consumo de massa possível em um ciclo. É interessante observar que a razão de pressões que gera o maior trabalho útil não é a mesma que gera o maior consumo de massa, embora sejam valores próximos. Isso pode ser utilizado para otimizar a pressão de trabalho para cada razão de compressão.

Essa variação do trabalho total de um ciclo ocorre porque para baixas pressões, a razão de pressões é pequena, aproximando os dois processos isobáricos (processos 1-2 e 4-5) da Figura 2.2, e fazendo com que a área interna ao gráfico seja pequena. Para altas pressões, as linhas dos dois processos isentrópicos (processos 2-3 e 5-6) se aproximam, reduzindo a área interna do gráfico, e diminuindo o trabalho realizado. Ao continuar aumentando a razão de pressões, chega-se a uma proporção entre a razão de compressão e a razão de pressões que faz com que o trabalho seja nulo. Nessa proporção, a expansão do fluido em alta pressão para baixa pressão se dá exatamente entre os dois extremos do ciclo. Isso faz com que a expansão e a compressão do vapor percorram os mesmos pontos de pressão e volume. Em outras palavras, a energia obtida pela expansão do vapor é a mesma fornecida ao fluido na fase de compressão. Nessas condições, a máquina não realiza trabalho útil e também não consome vapor, uma vez que só comprime expande o fluido que está dentro da câmara do cilindro. 
Essa proporção que faz com que o trabalho realizado e a massa consumida sejam nulos é dada pela eq (3.61).

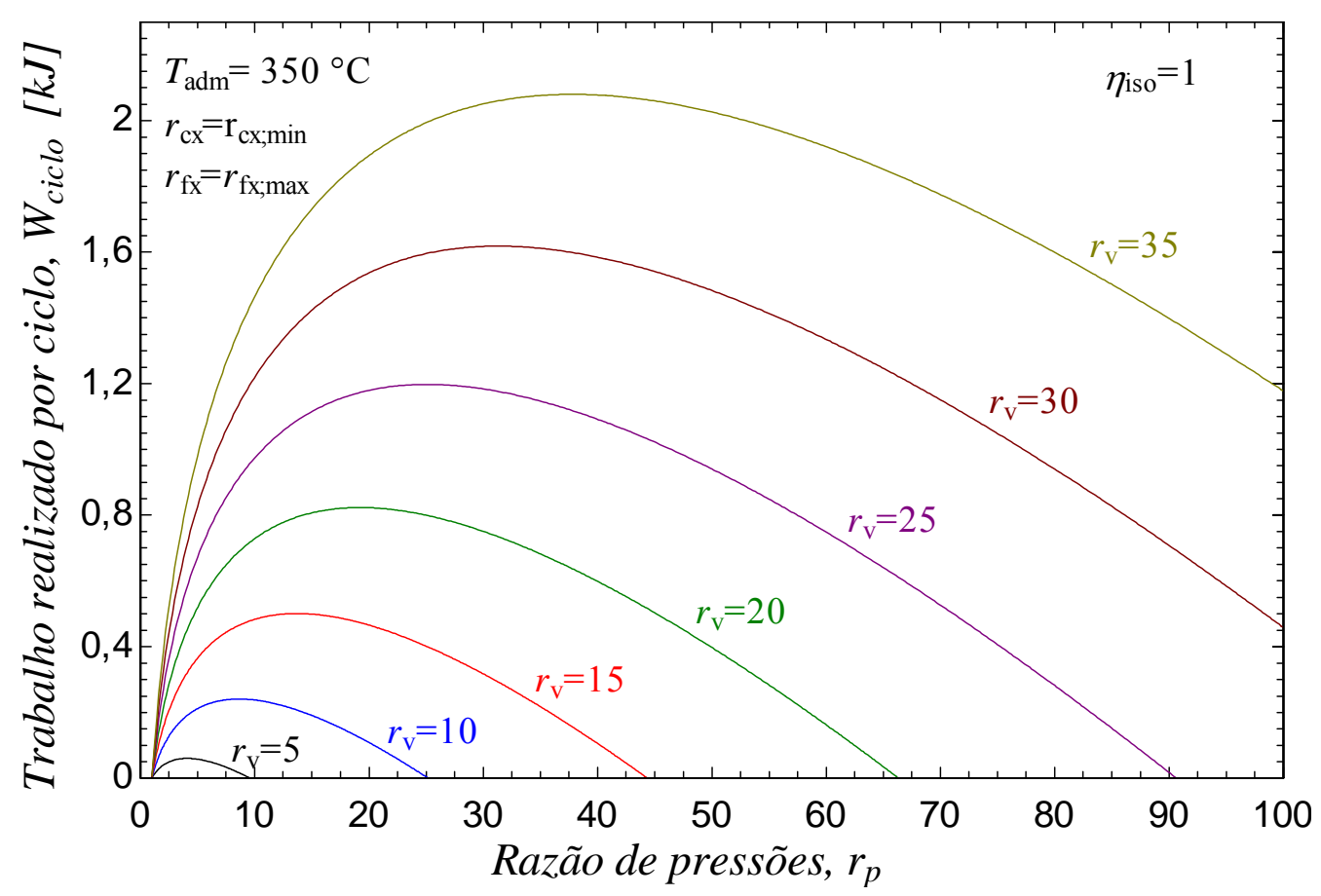

Figura 3.7 - Trabalho realizado em um ciclo de operação para diferentes razões de volume em função da pressão de admissão.

$$
r_{P}=r_{V}^{k}
$$

Para se determinar qual a razão de pressão que maximiza o trabalho realizado em um ciclo, substitui-se as eqs. (3.55) e (3.56) na eq. (3.18), deriva-se a expressão resultante na variável $\mathrm{r}_{P}$ e se iguala essa derivada a zero. Essa equação não possui solução analítica, é possível fatorá-la, mas ainda assim, não é possível resolvê-la. Após simplificações, chega-se a eq. (3.62). Assim, a razão de pressões que faz com que o ciclo realiza o máximo trabalho é dada pela resolução da eq, (3.62) na variável $\mathrm{r}_{\mathrm{P}}$.

$$
r_{P}^{\frac{2}{k}}-k \cdot r_{P} \cdot r_{P}^{\frac{1}{k}}+r_{P} \cdot r_{V}(k-1)=0
$$




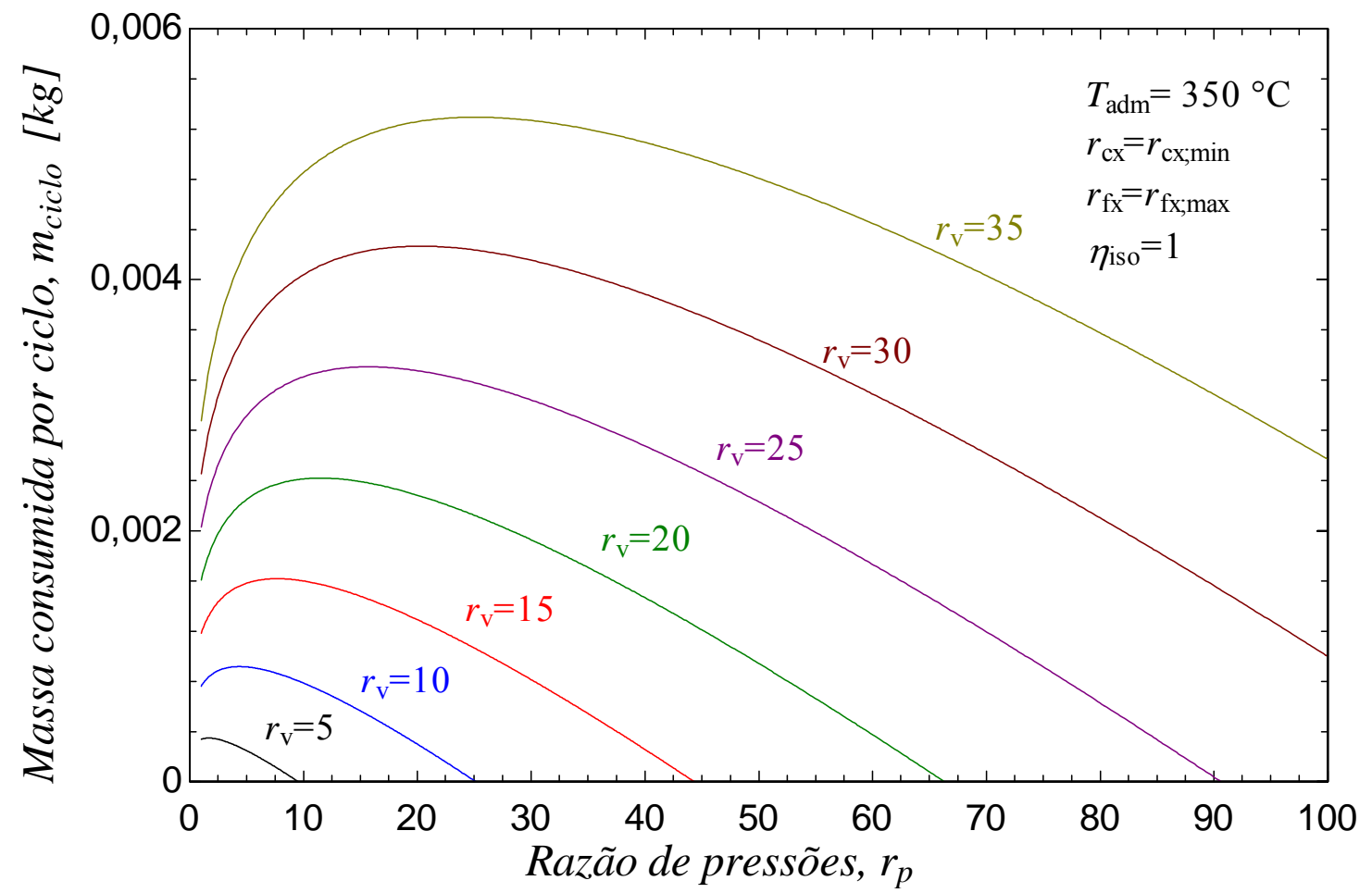

Figura 3.8 - Massa consumida em um ciclo de operação para diferentes razões de volume em função da pressão de admissão.

Como dito, a razão de pressões que faz com que o trabalho e a massa consumida no ciclo sejam nulos é dada pela eq. (3.61). E a razão de pressões que faz com que a massa consumida seja máxima está indicada pela eq. (3.63).

$$
r_{P}=\left(\frac{r_{V}(k-1)}{k}\right)^{k}
$$

Dessa forma, a massa máxima consumida em um ciclo de eficiência isentrópica igual a um para uma determinada razão de compressão é:

$$
m_{\max }=\frac{\forall_{1} \cdot P_{e s c}}{R \cdot T_{a d m}}\left(\frac{r_{V}}{k}\right)^{k} \cdot(k-1)^{(k-1)}
$$




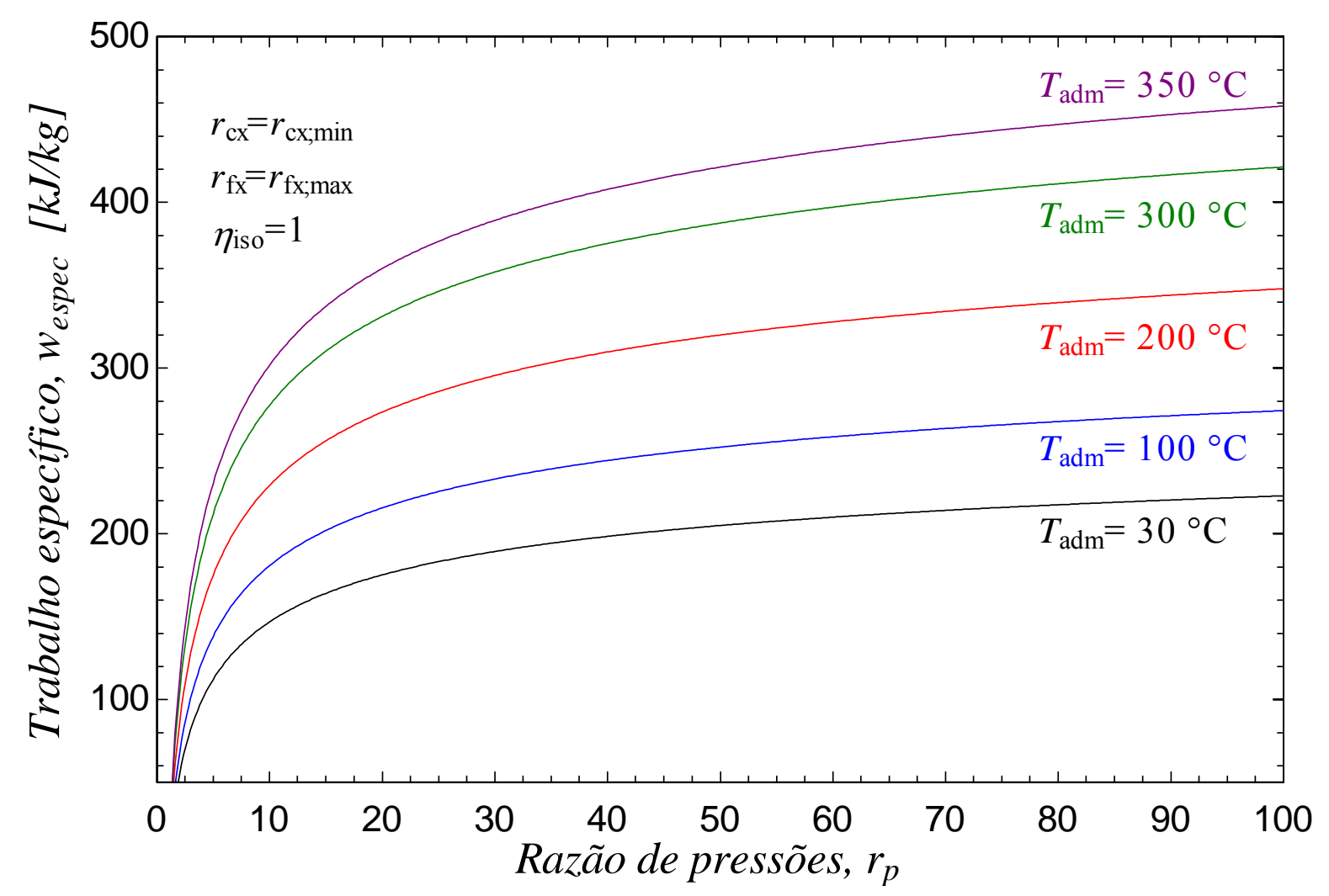

Figura 3.9 - Trabalho específico para diferentes temperaturas de admissão em função da razão de pressões.

A Figura 3.9 representa o trabalho específico realizado pelo ciclo. O trabalho específico é uma função linear da temperatura de admissão, conforme mostrado na eq. (3.51), e aumenta de forma não linear com a pressão. Para baixas razões de pressão, o ganho no trabalho específico é grande para pequenos aumentos de pressão, no entanto, para altas razões de pressão o ganho se torna pequeno com a variação de pressão. Isso mostra que a partir de um determinado ponto, provavelmente o ganho no trabalho específico não justifica o aumento de pressão. Uma maneira de escolher esse ponto, pode ser através do trabalho total ou do consumo de massas mostrados na Figura 3.7 e na Figura 3.8, mas pode variar de acordo com os interesses de cada projeto.

Da mesma forma que o ciclo da Figura 2.2 é o melhor ciclo possível, existe um ciclo que trabalha com a menor eficiência isentrópica possível, desde que não exista sobrecompressão ou sobre-expansão. Na pior condição, o processo de admissão dura até o pistão atingir o PMI, nesse ponto, a válvula de admissão fecha e a válvula de escape abre instantaneamente. A válvula de escape permanece aberta até que o pistão atinja o PMS, nesse instante a válvula de escape fecha e a válvula de admissão abre instantaneamente, reiniciando o ciclo. 
Esse ciclo é mostrado na Figura 3.10, e embora tenha a pior eficiência dentre os ciclos estudados, ele possui o maior trabalho realizado. Trajkovic (2010) estuda o ciclo da Figura 2.2 para um motor de expansão de ar comprimido para ser utilizado em um automóvel, e quando há necessidade de maior potência, o processo de admissão dura mais tempo, reduzindo a eficiência do ciclo. No caso da necessidade de maior potência requerida, o ciclo pode se tornar o ciclo mostrado na Figura 3.10. Se comparando com o ciclo ideal, o trabalho realizado aumenta e a eficiência diminui, isso significa que o consumo de massa aumenta em uma proporção maior do que o aumento de trabalho. O valor dessa eficiência mínima é função de $r_{V}$ e $r_{P}$, como mostrado através da eq.(3.65).

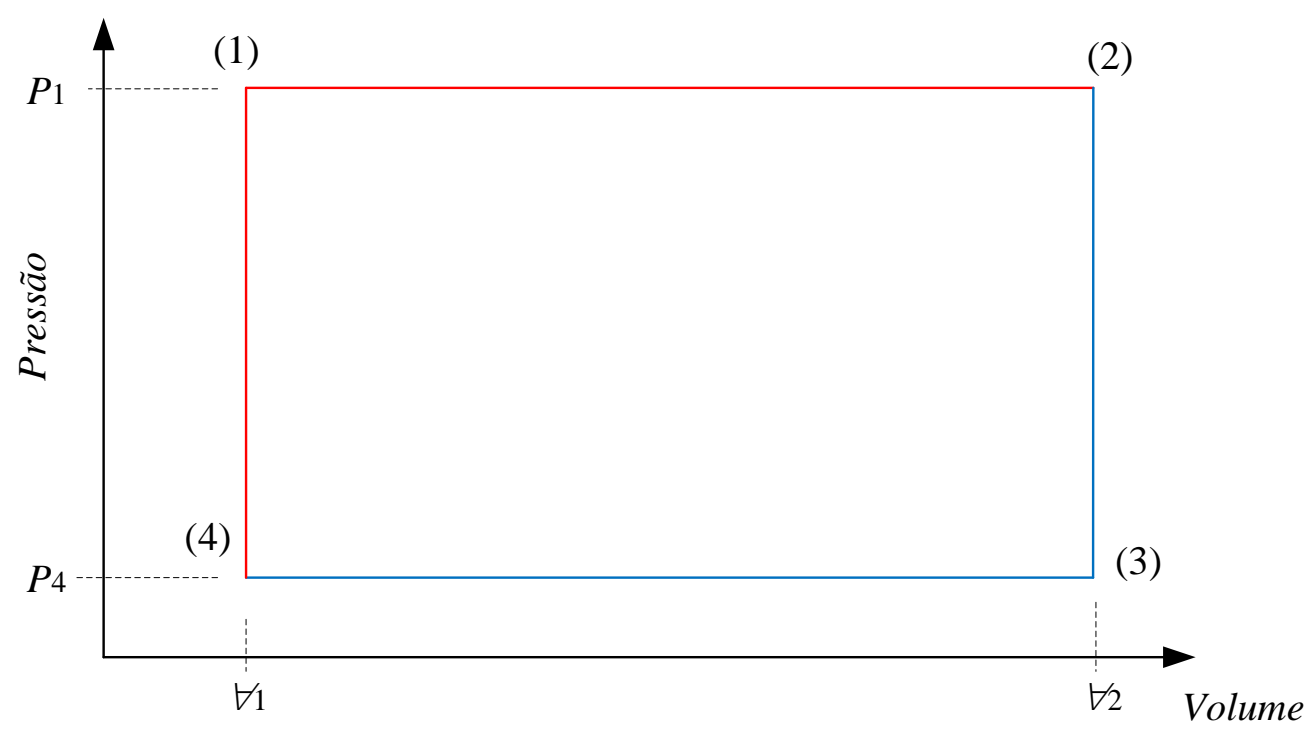

Figura 3.10 - Ciclo sem sobre-expansão ou sobrecompressão que possui a menor eficiência isentrópica.

$$
\eta_{\text {min }}=\frac{(k-1)\left(r_{V}-1\right)\left(1-\frac{1}{r_{P}}\right)}{\left(k\left(r_{V}-1\right)+1-\frac{1}{r_{P}}\right)\left(1-\frac{1}{r_{P} \frac{k-1}{k}}\right)}
$$




\section{ESTUDO EXPERIMENTAL}

Uma máquina a vapor já existente foi testada em laboratório a fim de verificar seu modo de funcionamento e os fatores que influenciam na sua eficiência e comportamento.

\subsection{MÁQUINA DE TESTES E DADOS A SEREM COLETADOS}

A máquina a ser testada foi resultado do trabalho de Bassi e Machado (2011). Alguns desenhos referentes à máquina podem ser vistos na Figura 4.1, na Figura 4.2 e na Figura 4.3.

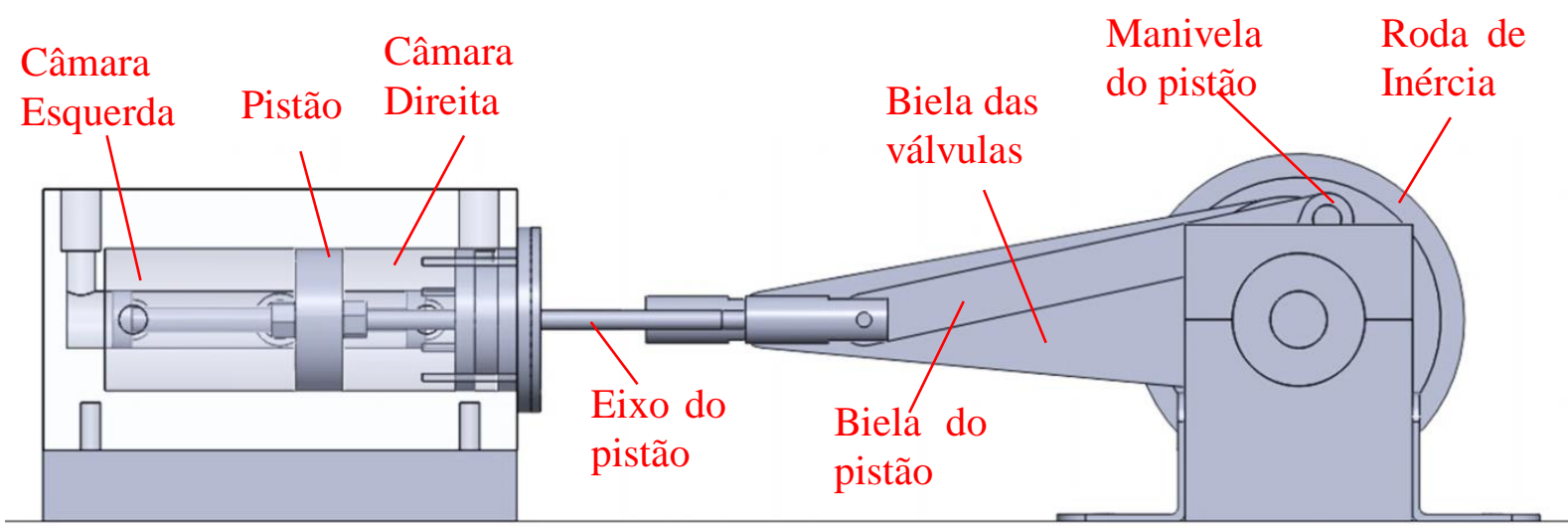

Figura 4.1 - Vista frontal da máquina a vapor

Roda de

Inércia

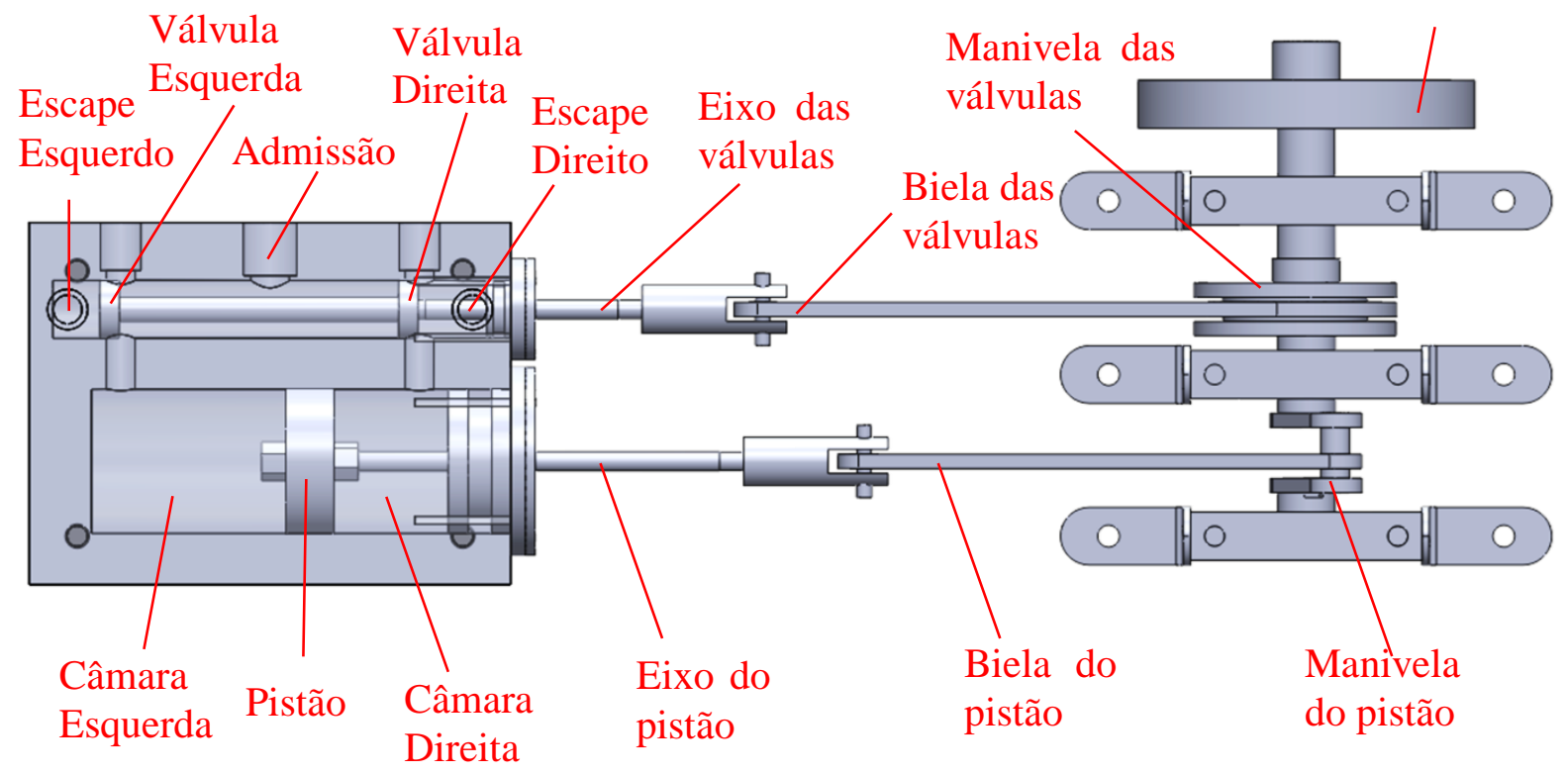

Figura 4.2 - Vista superior da máquina a vapor 


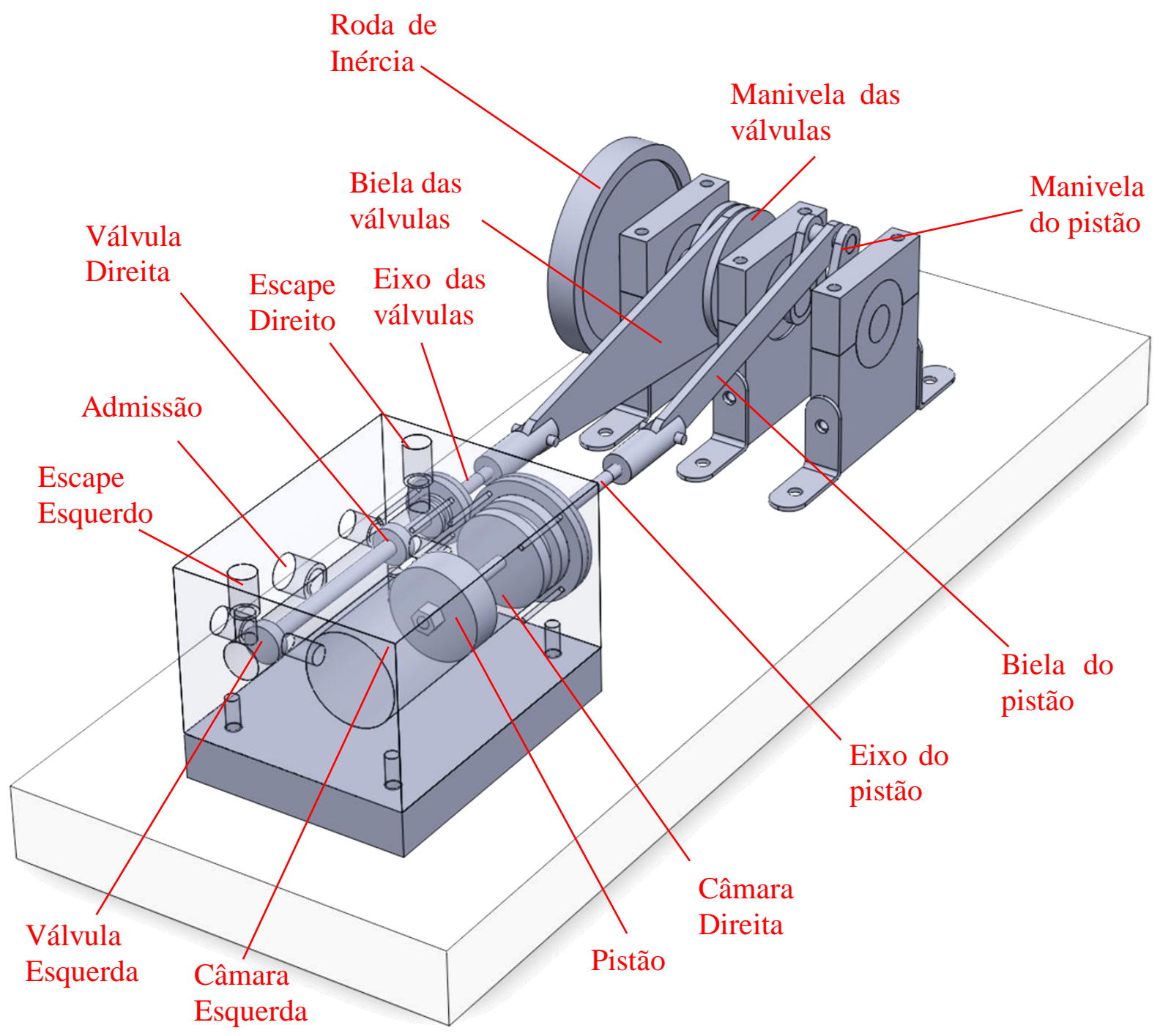

Figura 4.3 - Vista em perspectiva da máquina a vapor

Duas fotos ilustrativas da máquina a vapor estão na Figura 4.4 e na Figura 4.5. A primeira mostra uma visão geral da máquina, e a segunda mostra mais o sistema biela-manivela. As fotos foram feitas sem o terceiro mancal, por questão de visualização.

A nomenclatura utilizada para cada região do bloco da máquina a vapor está indicada na Figura 4.6. As informações que se deseja obter são:

- Diagrama PxV,

- pressão de admissão,

- pressão de escape,

- torque,

- rotação,

- potência,

- eficiência isentrópica. 
Para isso, serão medidas as seguinte informações:

- temperaturas do fluido nas tubulações de admissão e de escape,

- pressões do fluido nas tubulações de admissão e de escape,

- pressão em cada câmara do cilindro,

- torque na roda de inércia

- vazão em massa.

O fluido de trabalho utilizado nos testes é ar comprimido, principalmente pela facilidade de obtenção. Esse ar comprimido é fornecido por um compressor existente no laboratório. Embora o fluido de trabalho nos testes é diferente do fluido de trabalho em uma expansão de gás ou um ORC, para este trabalho não haverá muita influência, visto que o objetivo é compreender o funcionamento da máquina a vapor e quais fenômenos influenciam na sua eficiência isentrópica.

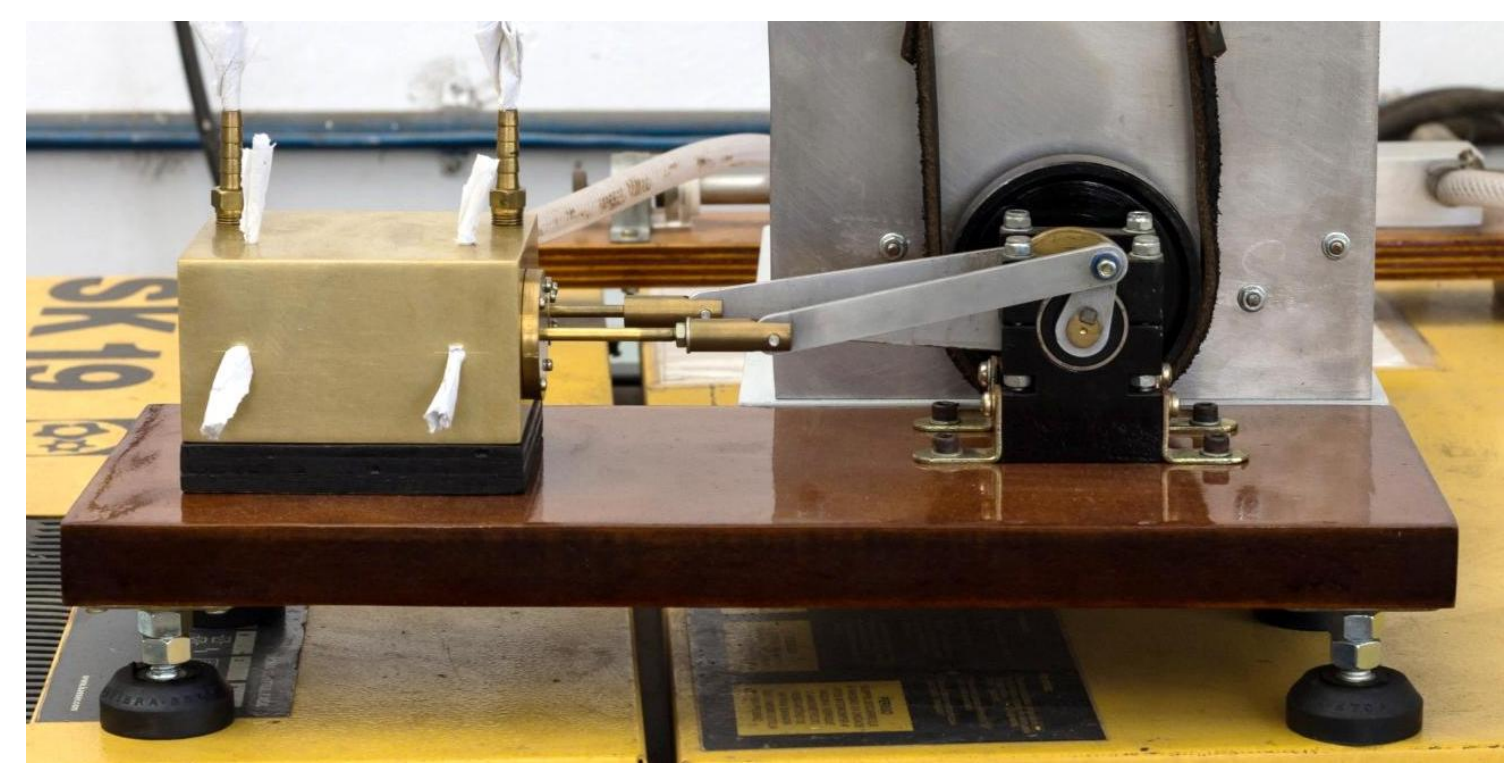

Figura 4.4 - Fotografia da máquina a vapor testada. 


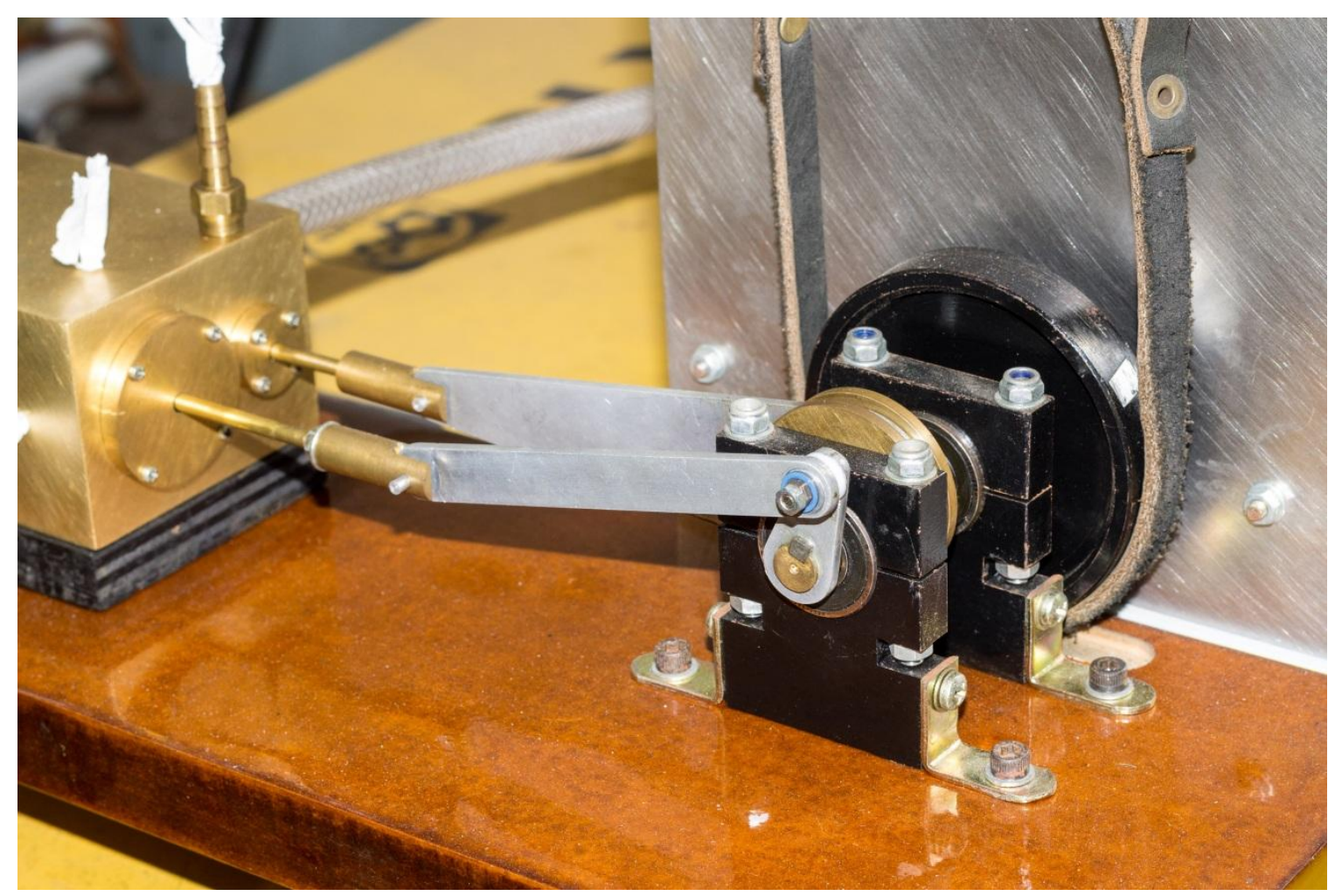

Figura 4.5 - Fotografia indicando o detalhe do sistema biela manivela da máquina a vapor testada

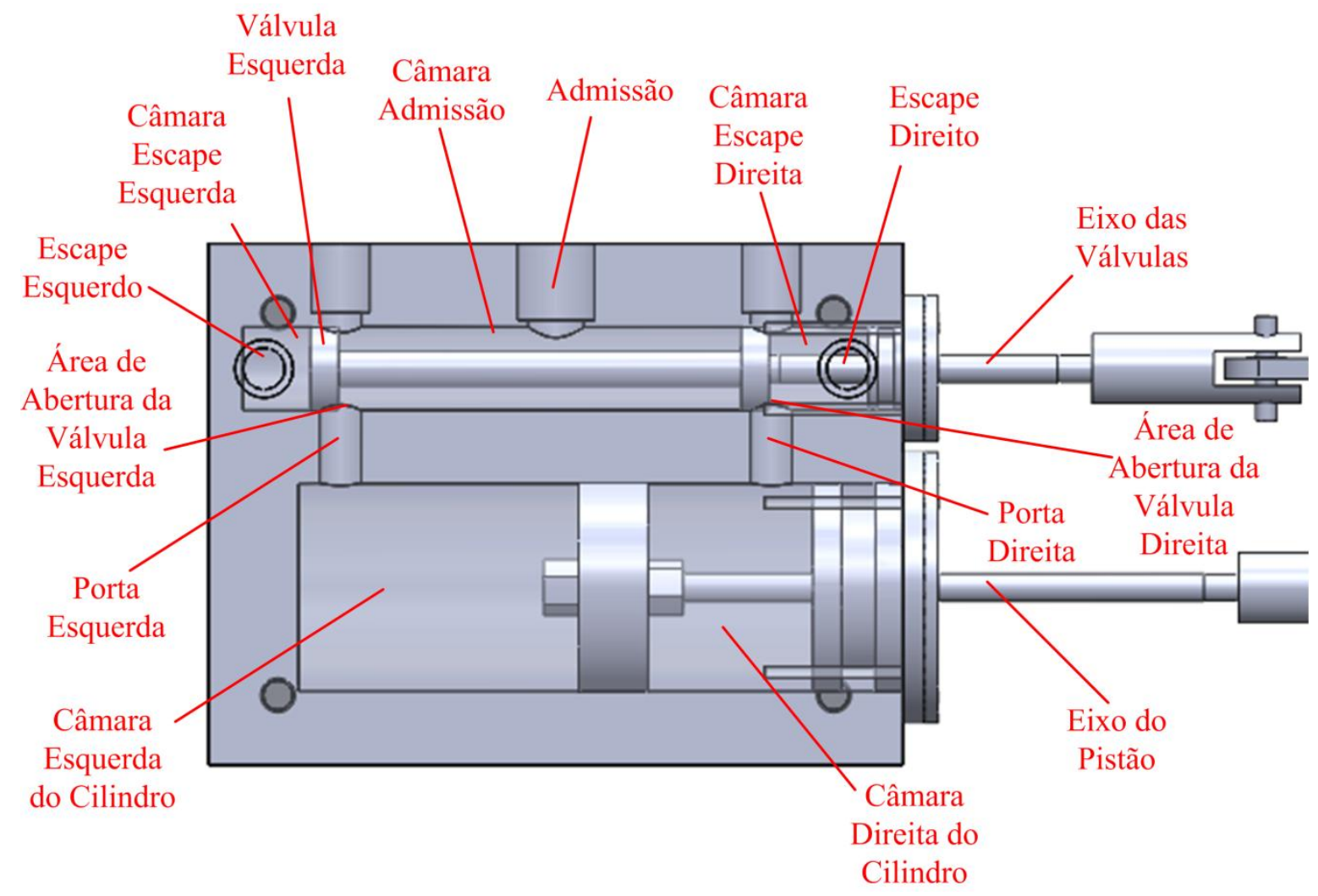

Figura 4.6 - Nomenclatura utilizada para as regiões do bloco da máquina a vapor 


\subsection{INTRUMENTAÇÃO}

Foram utilizados 4 transdutores de pressão relativa, modelos SB38 e SB48, vendidos pela empresa FullGauge. A Figura 4.7 contém os dois modelos utilizados nos experimentos.

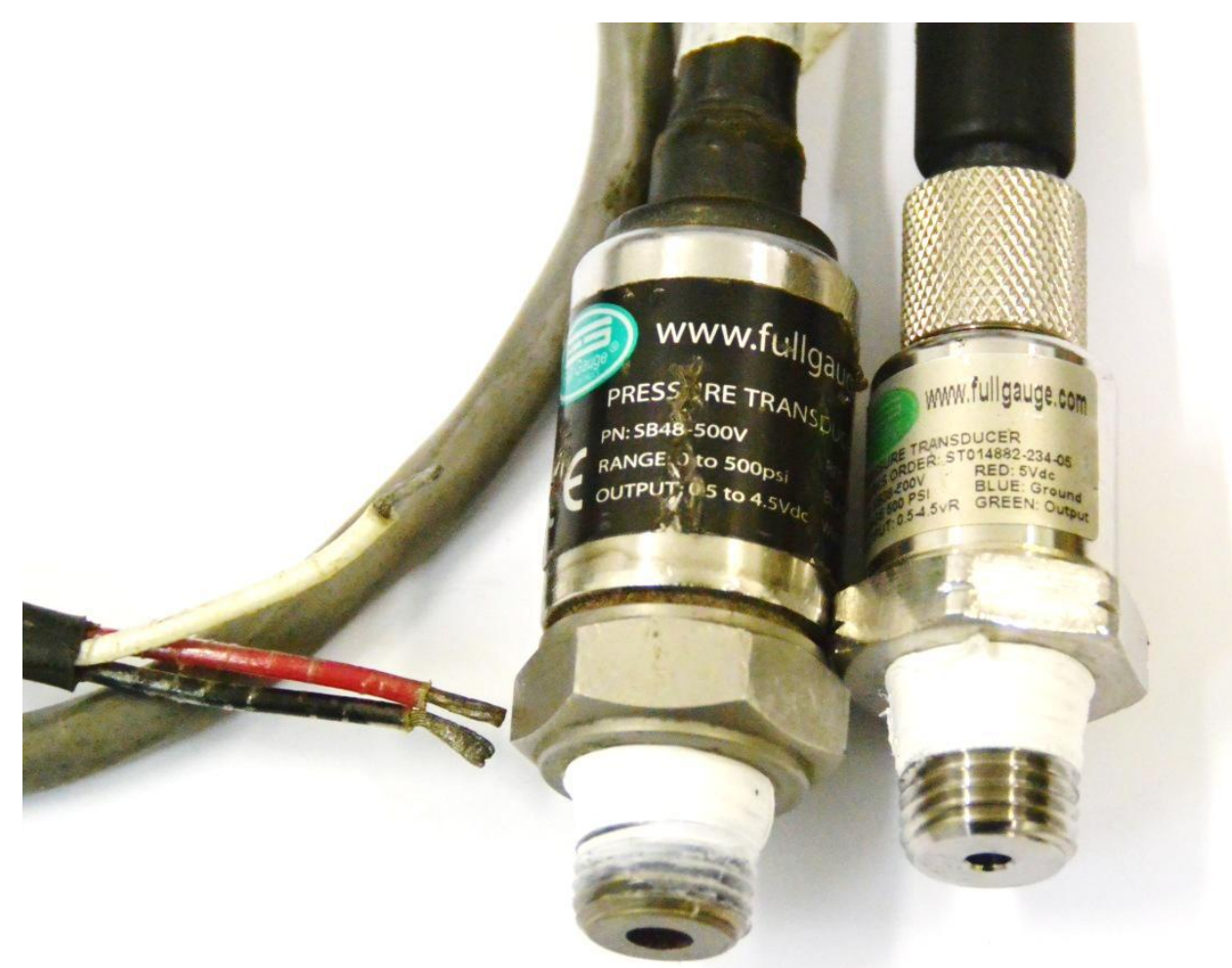

Figura 4.7 - Os dois modelos de transdutores de pressão utilizados nos testes.

As informações técnicas dos dois modelos são similares, divergindo apenas em relação à escala de leitura, onde três modelos possuem leitura entre 0 e 100 psi e um modelo possui leitura entre 0 e 500 psi. As informações técnicas de todos modelo estão a seguir:

- Alimentação: 4,75 5,25 Vdc

- Sinal de saída: 0,5 4,5 Vdc @5Vdc (ratiométrico)

- Temperatura de operação: $-40 \sim+125^{\circ} \mathrm{C}$

Para as medições de temperatura nas tubulações de admissão e de escape foram utilizados três termopares do tipo K, com bainha de $1 \mathrm{~mm}$ de diâmetro externo e junta exposta. Os três termopares podem ser vistos na Figura 4.8. 
A leitura dos transdutores de pressão é realizada por dois módulos da National Instruments, modelo NI 9201. A leitura dos termopares é feita a partir de um módulo modelo NI 9211, também da National Instruments. Os módulos são acoplados a um rack modelo NI cDAQ9172, do mesmo fabricante dos módulos.

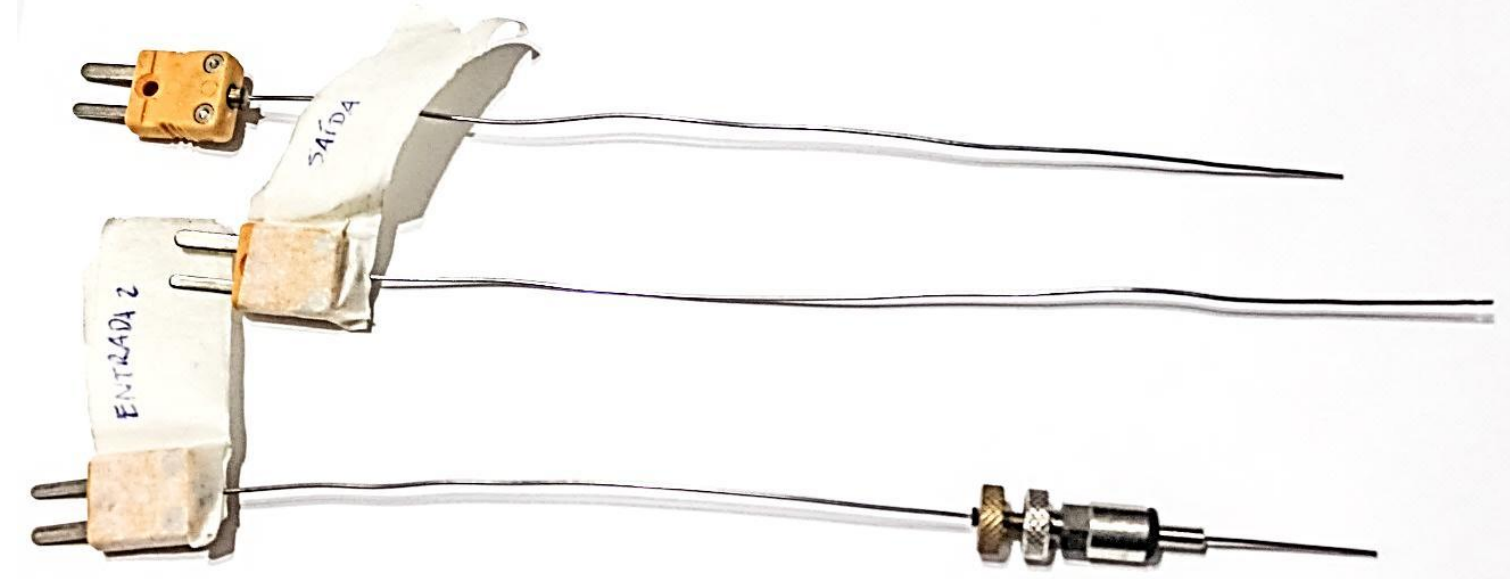

Figura 4.8 - Termopares do tipo K utilizados nos testes.

As informações técnicas do módulo de leitura de termopar, modelo NI 9211 são as seguintes:

- Termopares aceitos: (J, K, R, S, T, N, E e B)

- Precisão do sensor de compensação de junta fria: $0,6^{\circ} \mathrm{C}$ (média); $1,3^{\circ} \mathrm{C}$ (máx)

- Taxa de aquisição máxima: $12 \mathrm{~Hz}$

- Erro de amplificação: $0,05 \%(\max )$ a $25^{\circ} \mathrm{C} ; 0,06 \%$ (méd) a temperaturas maiores; $0,1 \%$ (máx) a temperaturas maiores

- $\quad$ Erro de offset: $15 \mu \mathrm{V}$ (méd); $20 \mu \mathrm{V}$ (máx)

As informações técnicas referentes ao módulo de leitura de tensão utilizado para a leitura dos transdutores de pressão, modelo NI 9201 são:

- Tensões de entrada: $\pm 10 \mathrm{~V}$

- Taxa de aquisição máxima em modo de leitura serial: $500 \mathrm{kS} / \mathrm{s}$

- Erro médio de leitura sem calibração a $25^{\circ} \mathrm{C}\left( \pm 5^{\circ} \mathrm{C}\right): \pm 0,26 \%$

- Erro máximo de leitura sem calibração $\left(-40^{\circ} \mathrm{C}\right.$ a $\left.70{ }^{\circ} \mathrm{C}\right): \pm 0,67 \%$

O rack modelo NI cDAQ-9172 possui uma taxa de aquisição máxima de 3,2 MS/s e de transferência máxima de 1,6 MS/s, ambos com resolução de tempo de 50 ns. 
A medição do torque é feita por meio de um freio de Prony, que consiste em 2 dinamômetros e uma tira de couro para atritar com a roda de inércia e frear a máquina a vapor. A montagem do freio de Prony é mostrada na Figura 4.9, na qual se observa a fixação das peças e a possibilidade de deslocamento vertical dos dinamômetros.

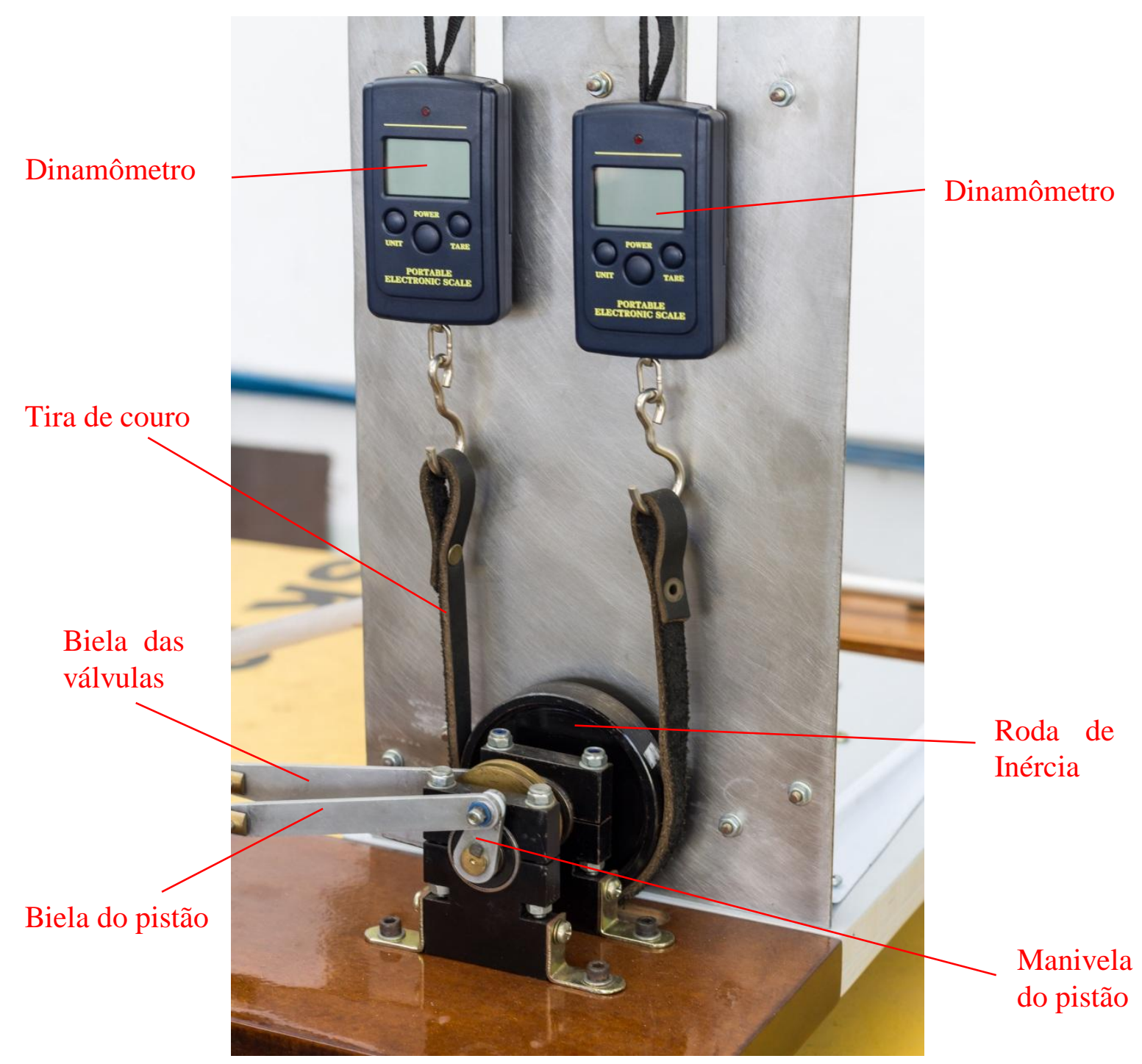

Figura 4.9 - Foto do freio de Prony com duas balanças e uma tira de couro sobre a roda de inércia

A tira de couro é posicionada de forma a ficar em contato com a roda de inércia do eixo de manivelas do motor e suas extremidades são fixadas nos dinamômetros. Ao movimentar uma balança para cima, o atrito entre a roda de inércia e o couro gera um torque contrário à máquina e faz com que cada extremidade da tira de couro aplique uma força diferente em sua respectiva balança. Um esquema do freio é mostrado na Figura 4.10, também são indicadas as forças que agem sobre a tira de couro e a nomenclatura utilizada para o cálculo do torque. 


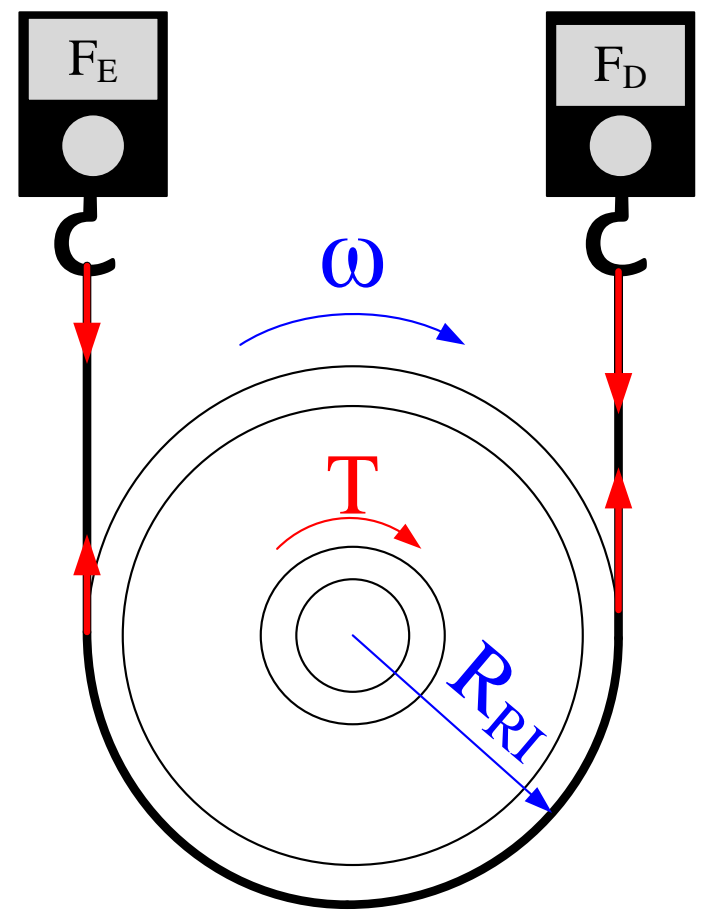

Figura 4.10 - Esquema do freio de Prony para a edição do torque da máquina a vapor.

Dessa forma, o torque pode ser calculado utilizando-se a eq. (4.1).

$$
\text { Torque }=\left(F_{\text {direita }}-F_{\text {esquerda }}\right) \cdot R_{R I}
$$

A vazão em massa é medida com um bocal convergente conectado a um manômetro em $U$, que utiliza água como fluido manométrico e possui resolução de $1 \mathrm{~mm}$. O bocal foi projetado conforme a norma NBR ISO 5167-1 (1994). O desenho técnico do bocal é mostrado na Figura 4.11. A curvatura do bocal representada pela linha M-N é uma elipse, que se tomar o ponto C como origem do sistema de coordenadas, é descrita pela equação (4.2).

$$
y=13-8 \cdot \sqrt{1-\frac{(35-x)^{2}}{12^{2}}} \quad \text { unidade }:[\mathrm{mm}]
$$




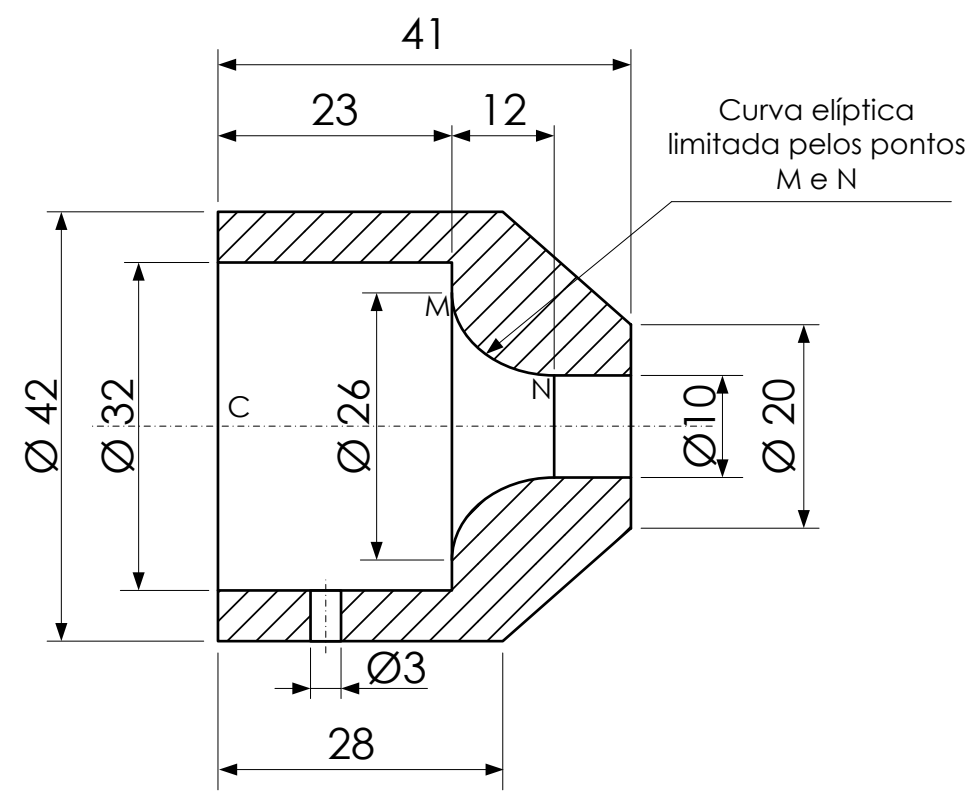

Figura 4.11 - Bocal convergente para medição da vazão, conforme a norma NBR ISO 5167-1 (1994).

A equação da velocidade do escoamento na seção (1) para o bocal, considerando escoamento compressível está escrita na eq. (4.3).

(1)

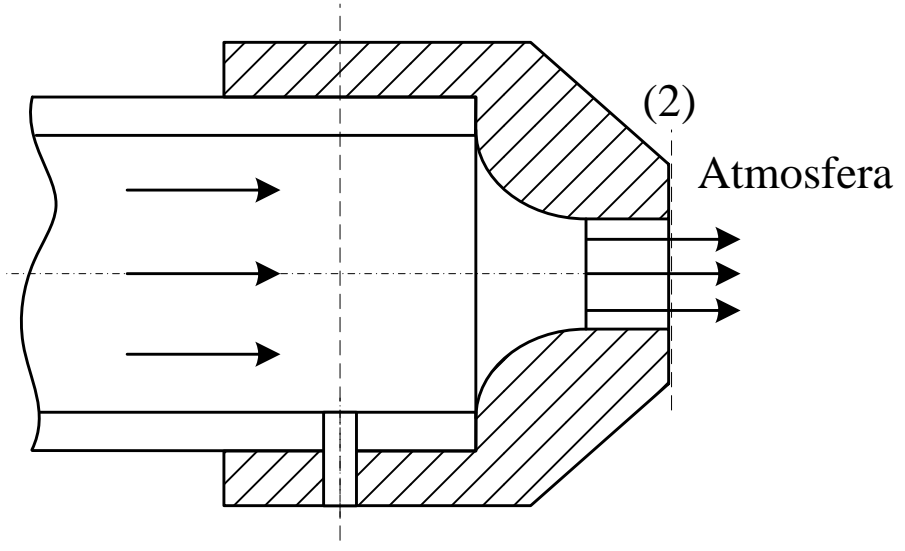

Figura 4.12 - Bocal convergente para medição de vazão acoplado à tubulação

$$
v_{1}=\sqrt{\frac{2 \cdot c_{P} \cdot T_{1} \cdot\left(1-\left(\frac{P_{a t m}}{P_{1}}\right)^{\left(\frac{k-1}{k}\right)}\right)}{\left(\frac{A_{1}}{A_{2}}\right)^{2} \cdot\left(\frac{P_{1}}{P_{a t m}}\right)^{\frac{2}{k}}-1}}
$$


Onde a pressão $\mathrm{P}_{1}$ é dada pela eq (4.4):

$$
P_{1}=P_{\text {atm }}+\rho_{\text {fluido_manom }} \cdot g \cdot \Delta z_{\text {manom }}
$$

Assim, a vazão em massa é dada por:

$$
\dot{m}=A_{1} \cdot \frac{P_{1}}{R \cdot T_{1}} \cdot v_{1}
$$

\subsection{ARRANJO EXPERIMENTAL}

Para os experimentos foi utilizado ar comprimido proveniente de um compressor existente no local dos testes. Um desenho esquemático do arranjo experimental é mostrado na Figura 4.13. O sistema de alimentação de ar comprimido consiste em um compressor de ar, um reservatório de ar comprimido em alta pressão, e uma válvula reguladora de pressão. Após passar pela válvula reguladora de pressão, o ar comprimido é direcionado para a máquina a vapor através de uma tubulação rígida de PVC, um desenho esquemático dessa tubulação está na Figura 4.14. Nessa tubulação rígida de admissão estão conectados dois termopares de um transdutor de pressão.

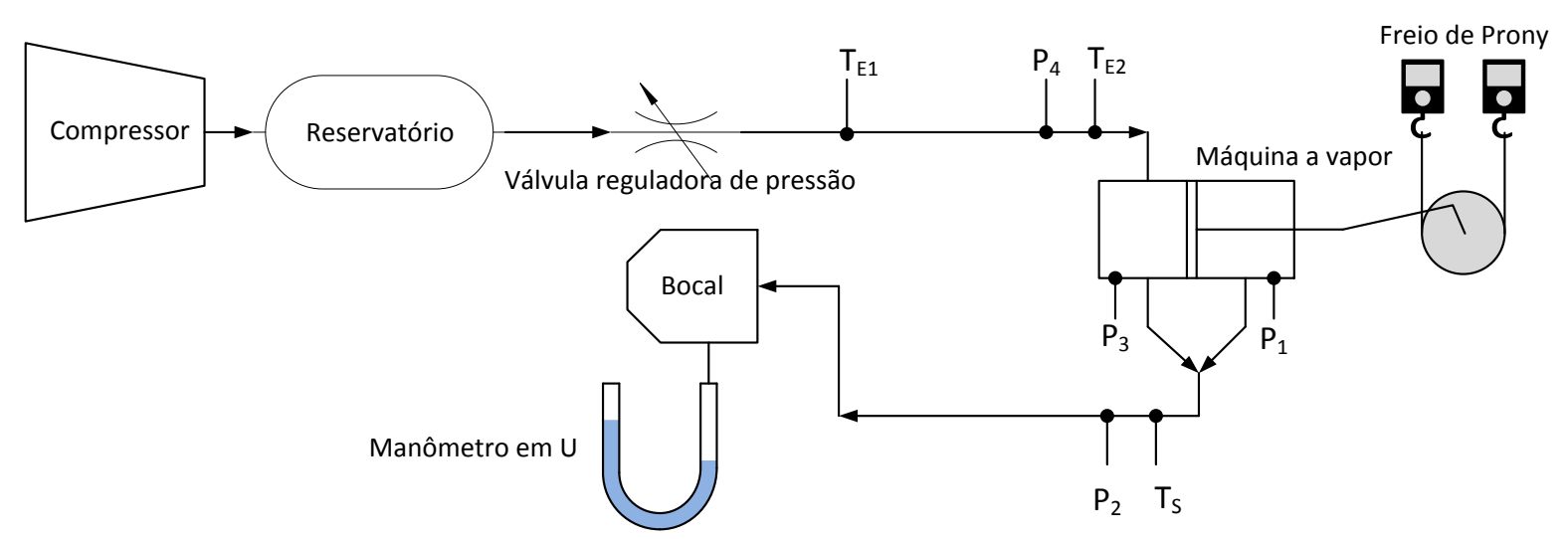

Figura 4.13 - Arranjo Experimental 


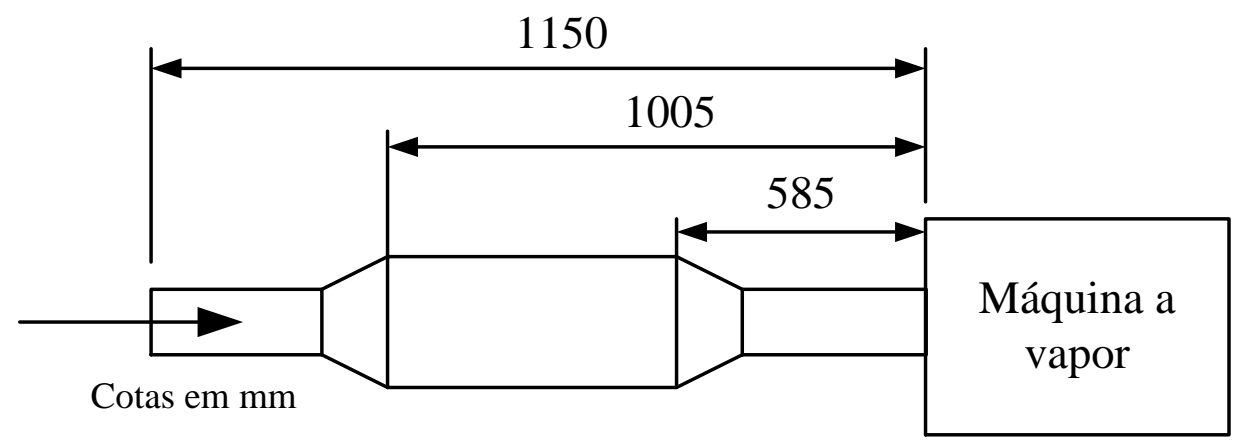

Figura 4.14 - Esquema do tubo de admissão com cotas

No bloco da máquina a vapor existem dois transdutores de pressão, um em cada câmara, para a aquisição das pressões internas das duas câmaras durante o funcionamento da mesma. A montagem desses transdutores é mostrada na Figura 4.15

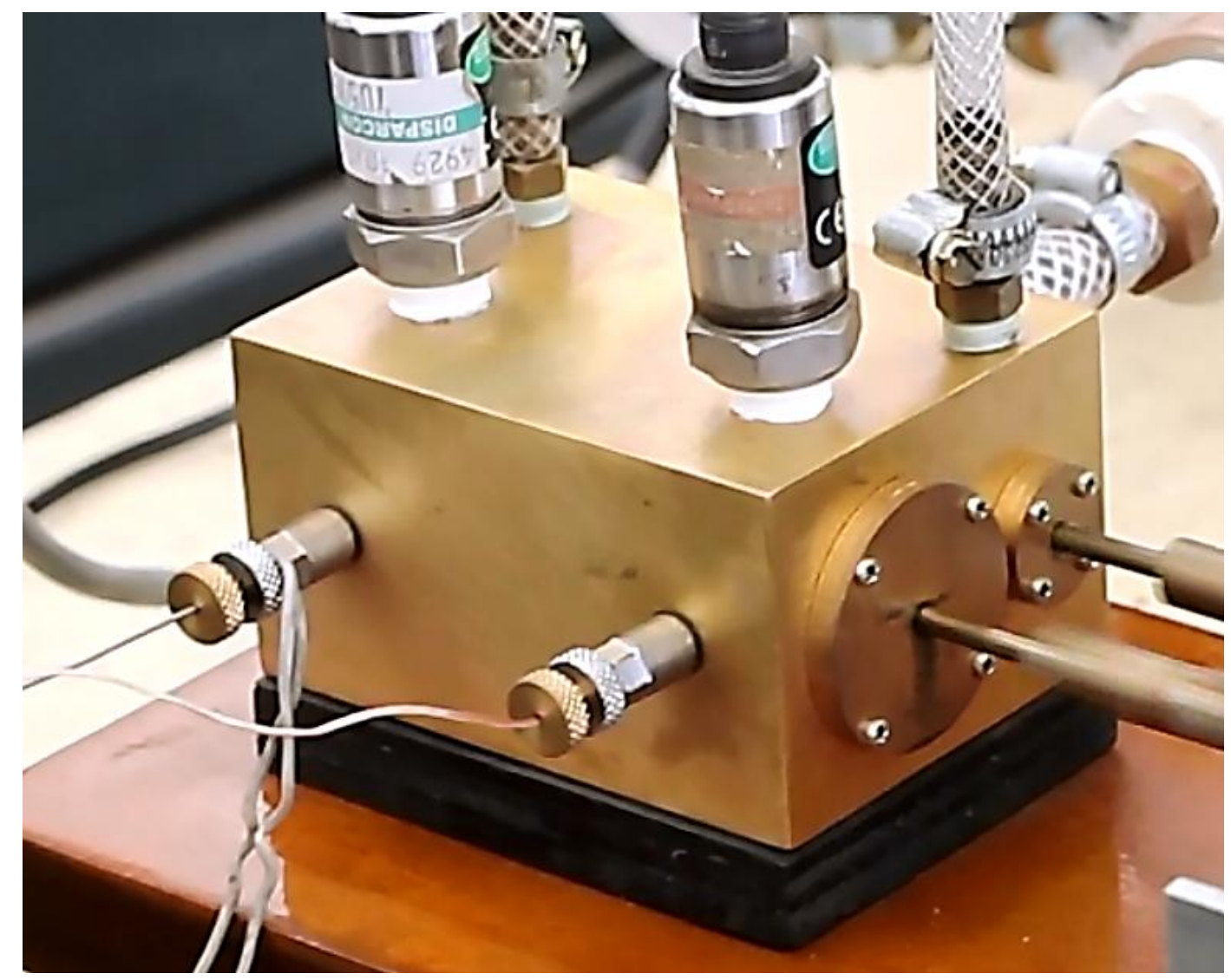

Figura 4.15 - Bloco da máquina a vapor com os transdutores de pressão. 


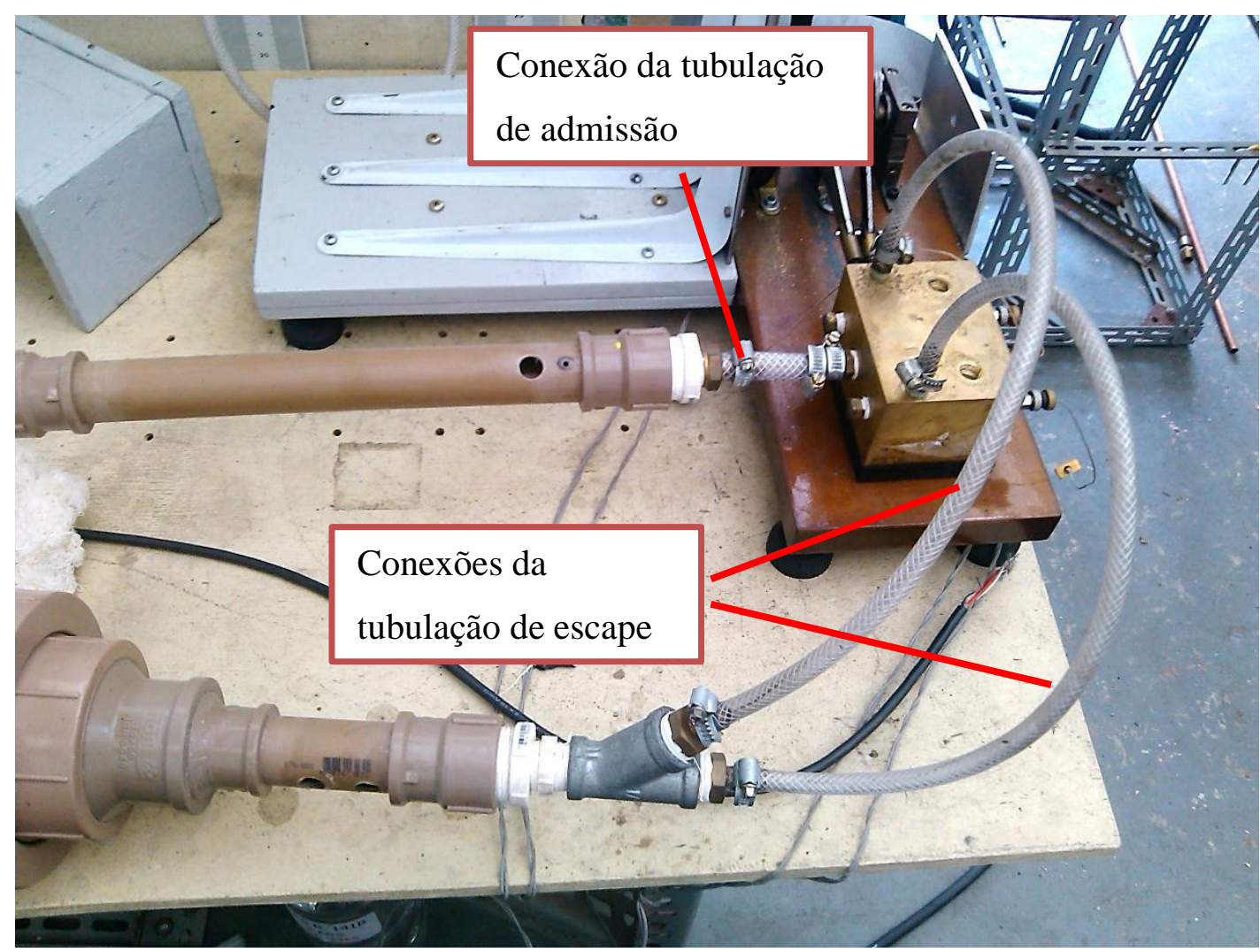

Figura 4.16 - Conexões das tubulações de admissão e escape no bloco da máquina a vapor.

O ar comprimido sai da máquina a vapor por magueiras flexíveis, que conectam a máquina a vapor com uma tubulação rígida de PVC, cada mangueira conectada a uma câmara da máquina a vapor, como mostra a Figura 4.16. Os dois fluxos de escape da máquina a vapor são unidos em uma junta Y, e seguem por uma tulução rígida de PVC similar à tubulação de admissão, onde existem um termopar e um transdutor de pressão para a medição das propriedades de saída.

Após passar pela tubulação rígida, existe mais uma mangueira flexível que encaminha o fluido para um segundo trecho de tubulação rígida no escape, onde existe o bocal convergente conectado ao manômetro difrencial em U. Após a pasagem pela bocal convergente, o fluxo é descarregado para a atmosfera. 


\subsection{CALIBRAÇÃO}

Os transdutores de pressão foram calibrados utilizando como referência o manômetro da Figura 4.17, que possui resolução de $1 \mathrm{kPa}$ e mede pressão absoluta.

Para a calibração foi utilizado ar comprimido, proveniente do mesmo compressor que fornece ar comprido para o arranjo experimental. O esquema do arranjo para a calibração é mostrado na Figura 4.18. A mangueira, as peças e encaixes do manômetro e dos transdutores são usados como reservatório de ar em alta pressão. O compressor é ligado até que atinja a pressão efetiva de 5 bar, ao atingir essa pressão no reservatório do compressor uma válvula reguladora de pressão é aberta e o ar à alta pressão preenche a mangueira e conexões do arranjo para a calibração. Logo após a pressão estabilizar, a válvula reguladora de pressão é fechada. Uma válvula agulha na extremidade da mangueira e das conexões é utilizada para regular a pressão interna da mangueira e das conexões. Com o auxílio da válvula agulha, são ajustadas 10 pressões diferentes no manômetro referencial, sempre variando da maior para a menor pressão.

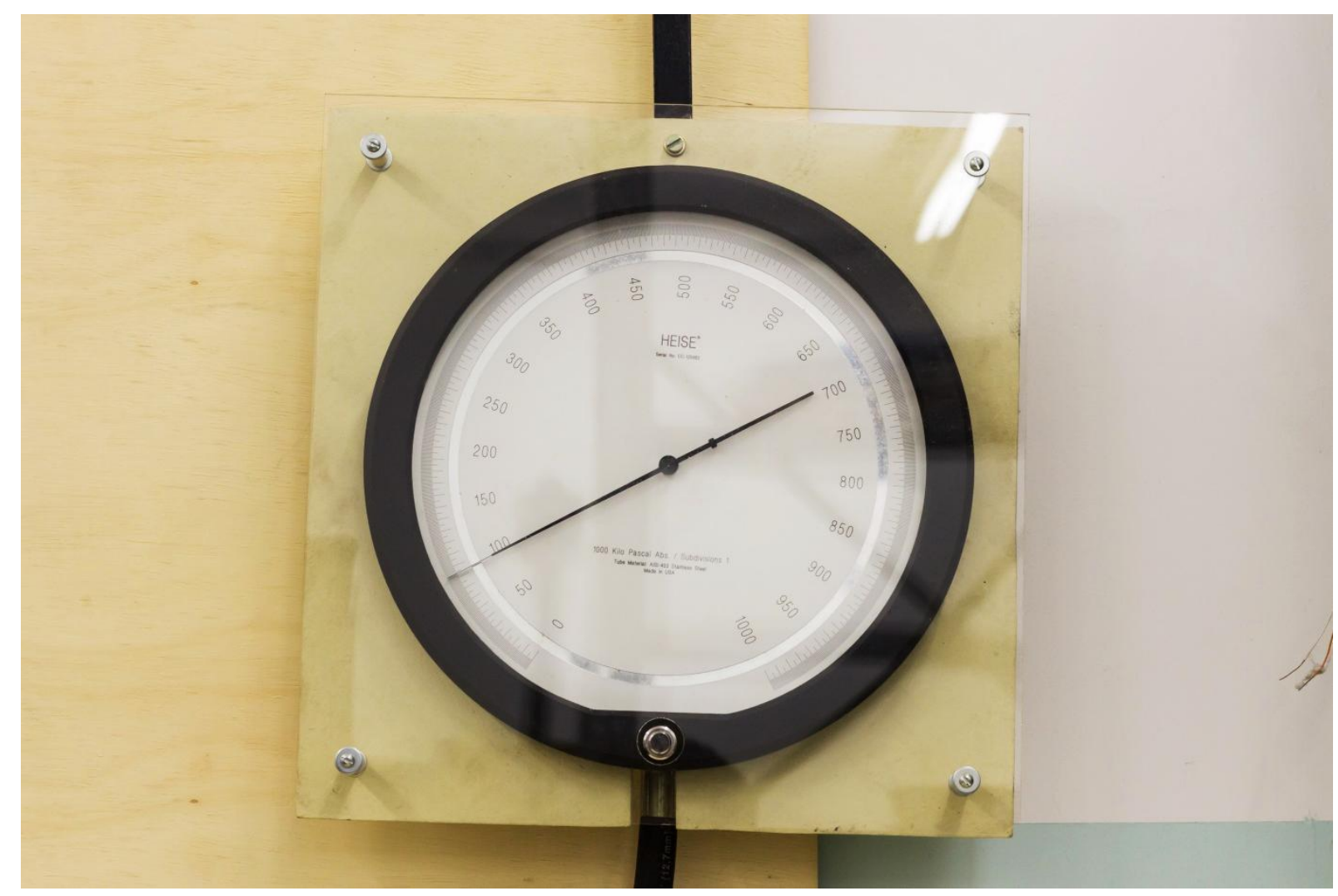

Figura 4.17 - Manômetro de pressão absoluta utilizado como referência para a calibração dos transdutores de pressão 


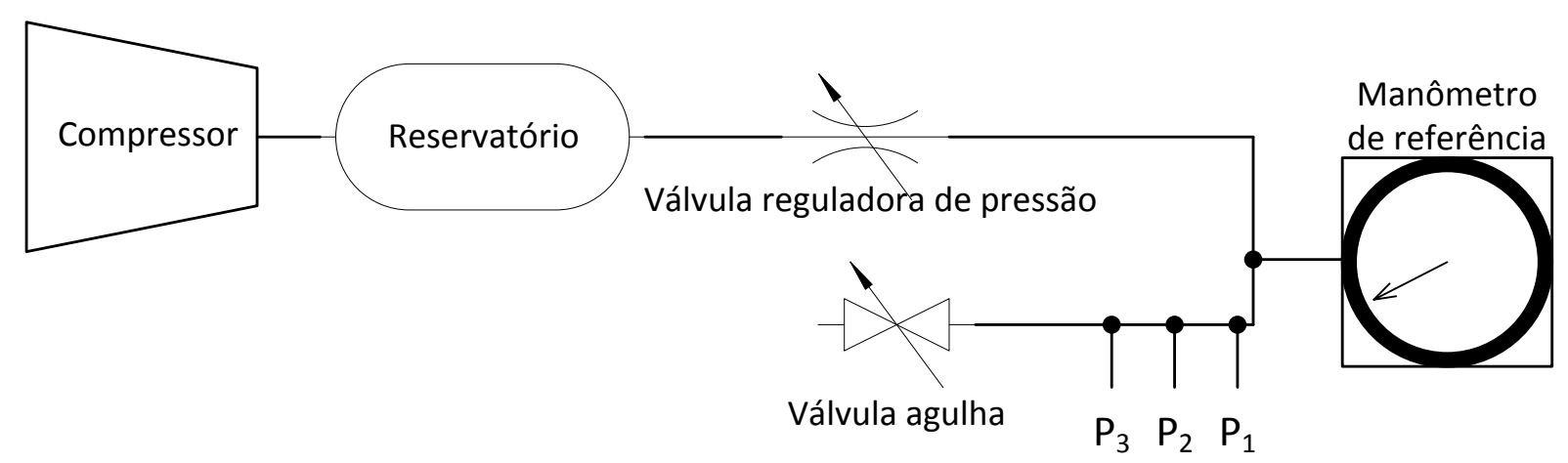

Figura 4.18 - Arranjo para a calibração

Para cada pressão ajustada é feita uma aquisição de dados durante $10 \mathrm{~s}$ à taxa de $2 \mathrm{kHz}$. Após chegar à pressão atmosférica, a válvula agulha é fechada e o compressor ligado novamente, quando a pressão do compressor atinge 5 bar, a válvula reguladores de pressão é aberta e o 10 novas medições são feitas. O ciclo é repetido três vezes.

O fluxograma do programa de aquisição para a calibração é mostrado na Figura 4.19. Para cada pressão medida, são feitas as leituras das tensões de alimentação positiva, de alimentação negativa, e as saídas dos transdutores. Primeiramente o programa faz a diferença entre a leitura de alimentação positiva e a de alimentação negativa para obter a tensão de alimentação. Após obter a tensão de alimentação, são determinadas também a diferença entre a tensão de alimentação e a tensão de saída do transdutor e a razão da tensão de saída do transdutor pela tensão de alimentação. Para fechar a medição dessa pressão, o programa obtém um valor médio para cada valor adquirido. Dessa forma o programa fornece 4 valores numéricos: A tensão de alimentação, a tensão de saída do transdutor, a diferença entre as duas tensões e a razão entre a tensão de saída do transdutor e a tensão de alimentação. Esse processo é feito para as 10 pressões. Ao término das 10 medidas, o sistema recebe novamente a alta pressão e o processo de reinicia. Ao todo o processo é realizado 3 vezes, ou seja, cada pressão é medida 3 vezes, totalizando 30 medidas. 


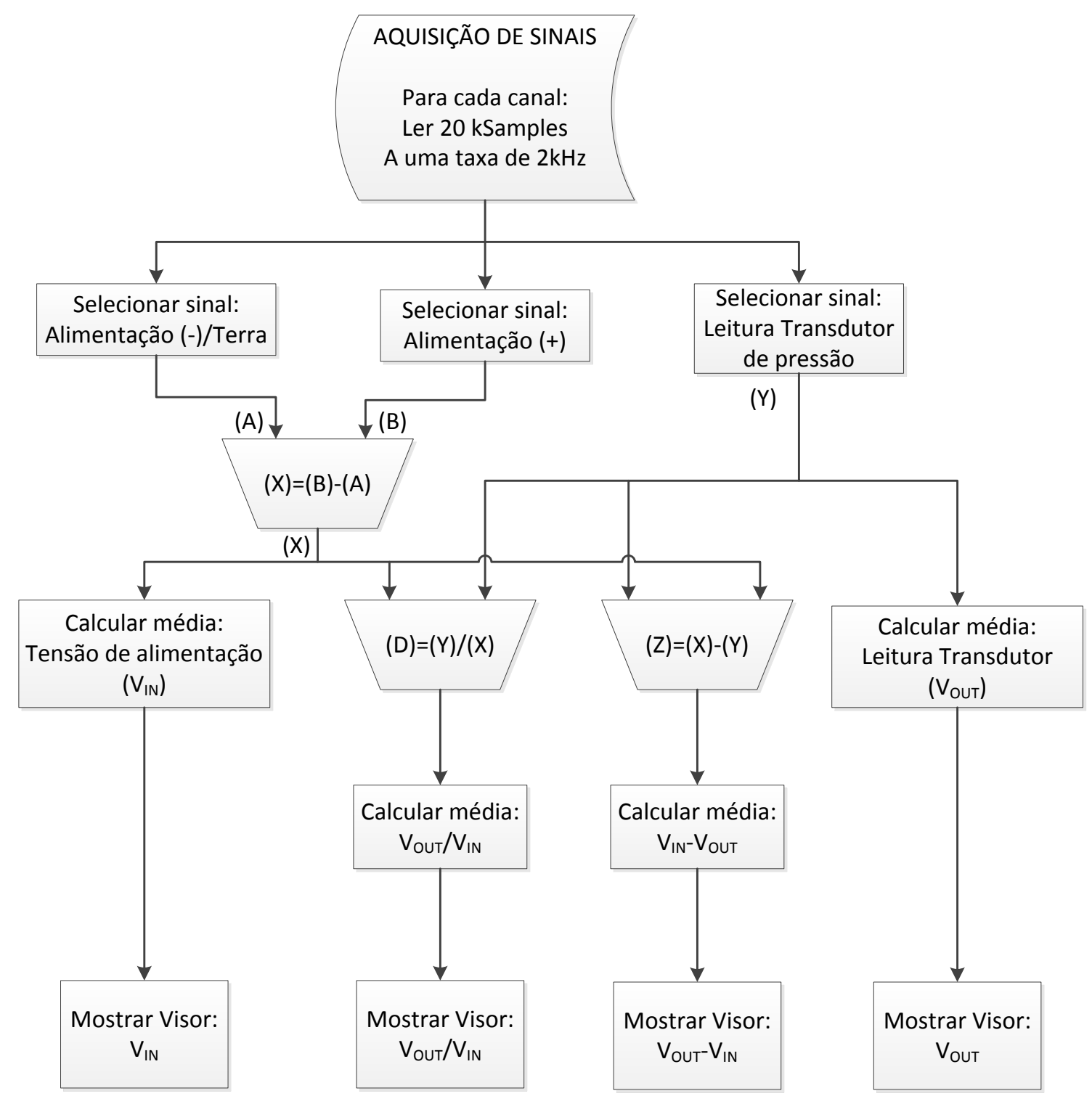

Figura 4.19 - Fluxograma elaborado no programa Labview para a calibração dos transdutores de pressão

Depois de obter 3 medidas de cada pressão, é tirada uma média das medidas de cada pressão, e assim, se tem 10 pressões diferentes e 10 leituras. Essas médias são mostradas na Tabela 4.1 e na Tabela 4.2. A calibração foi realizada duas vezes, pois os testes foram realizados duas vezes, e a fonte de alimentação utilizada não foi a mesma nos dois testes. Houve uma diferença significativa entre as duas calibrações. 
Tabela 4.1 - Valores médios obtidos para a calibração dos transdutores de pressão para a primeira sequência de testes

\begin{tabular}{|c|c|c|c|c|c|c|}
\hline \multicolumn{7}{|c|}{ Médias } \\
\hline Transdutor & $\begin{array}{c}\text { Pressão } \\
{[\mathrm{kPa}]}\end{array}$ & $\begin{array}{c}\text { Pressão } \\
{\left[\mathrm{kPa} \_a b s\right]}\end{array}$ & $\begin{array}{l}\mathrm{V} \text { in } \\
{[\mathrm{V}]}\end{array}$ & $\begin{array}{c}\text { V_out } \\
{[\mathrm{V}]}\end{array}$ & $\begin{array}{c}\text { DeltaV } \\
{[\mathrm{V}]}\end{array}$ & V_out/V_in \\
\hline \multirow{10}{*}{1} & 531,14100 & 624,33333 & 5,00134 & 3,55679 & 1,44454 & 0,71117 \\
\hline & 432,47433 & 525,66667 & 5,00144 & 2,98627 & 2,01512 & 0,59709 \\
\hline & 357,47433 & 450,66667 & 5,00127 & 2,55174 & 2,44956 & 0,51021 \\
\hline & 307,14100 & 400,33333 & 5,00133 & 2,26120 & 2,74014 & 0,45212 \\
\hline & 257,14100 & 350,33333 & 5,00132 & 1,97166 & 3,02966 & 0,39423 \\
\hline & 207,30766 & 300,50000 & 5,00124 & 1,68484 & 3,31647 & 0,33687 \\
\hline & 156,80766 & 250,00000 & 5,00126 & 1,39339 & 3,60792 & 0,27859 \\
\hline & 106,80766 & 200,00000 & 5,00131 & 1,10738 & 3,89394 & 0,22141 \\
\hline & 56,80766 & 150,00000 & 5,00143 & 0,82001 & 4,18137 & 0,16396 \\
\hline & 0,00000 & 93,19234 & 5,00127 & 0,49459 & 4,50670 & 0,09889 \\
\hline \multirow{10}{*}{2} & 531,14100 & 624,33333 & 5,00199 & 1,16950 & 3,83249 & 0,23099 \\
\hline & 431,97433 & 525,16667 & 5,00199 & 1,05644 & 3,94555 & 0,21120 \\
\hline & 357,80766 & 451,00000 & 5,00204 & 0,96794 & 4,03410 & 0,19351 \\
\hline & 307,47433 & 400,66667 & 5,00204 & 0,90881 & 4,09324 & 0,18169 \\
\hline & 257,47433 & 350,66667 & 5,00191 & 0,84989 & 4,15202 & 0,16991 \\
\hline & 207,30766 & 300,50000 & 5,00195 & 0,79319 & 4,20877 & 0,15858 \\
\hline & 157,14100 & 250,33333 & 5,00201 & 0,73499 & 4,26701 & 0,14694 \\
\hline & 106,80766 & 200,00000 & 5,00205 & 0,67575 & 4,32630 & 0,13510 \\
\hline & 57,30766 & 150,50000 & 5,00196 & 0,62000 & 4,38196 & 0,12395 \\
\hline & 0,00000 & 93,19234 & 5,00205 & 0,55168 & 4,45037 & 0,11029 \\
\hline \multirow{10}{*}{3} & 531,14100 & 624,33333 & 5,00134 & 1,11583 & 3,88550 & 0,22311 \\
\hline & 432,47433 & 525,66667 & 5,00144 & 0,99996 & 4,00148 & 0,19993 \\
\hline & 357,47433 & 450,66667 & 5,00127 & 0,91236 & 4,08891 & 0,18243 \\
\hline & 307,14100 & 400,33333 & 5,00133 & 0,85317 & 4,14816 & 0,17059 \\
\hline & 257,14100 & 350,33333 & 5,00132 & 0,79605 & 4,20527 & 0,15917 \\
\hline & 207,30766 & 300,50000 & 5,00124 & 0,73761 & 4,26362 & 0,14749 \\
\hline & 156,80766 & 250,00000 & 5,00126 & 0,67850 & 4,32276 & 0,13567 \\
\hline & 106,80766 & 200,00000 & 5,00131 & 0,62253 & 4,37878 & 0,12447 \\
\hline & 56,80766 & 150,00000 & 5,00143 & 0,56430 & 4,43713 & 0,11283 \\
\hline & 0,00000 & 93,19234 & 5,00127 & 0,49788 & 4,50339 & 0,09955 \\
\hline \multirow{8}{*}{4} & 531,14100 & 624,33333 & 5,00199 & 1,10925 & 3,89269 & 0,22177 \\
\hline & 432,47433 & 525,66667 & 5,00198 & 0,99415 & 4,00784 & 0,19875 \\
\hline & 357,80766 & 451,00000 & 5,00204 & 0,90746 & 4,09457 & 0,18142 \\
\hline & 307,47433 & 400,66667 & 5,00204 & 0,84852 & 4,15349 & 0,16964 \\
\hline & 257,47433 & 350,66667 & 5,00191 & 0,79156 & 4,21036 & 0,15825 \\
\hline & 207,30766 & 300,50000 & 5,00195 & 0,73376 & 4,26823 & 0,14669 \\
\hline & 157,14100 & 250,33333 & 5,00201 & 0,67547 & 4,32654 & 0,13504 \\
\hline & 106,80766 & 200,00000 & 5,00205 & 0,61903 & 4,38304 & 0,12375 \\
\hline
\end{tabular}


Tabela 4.1 - Continuação

\begin{tabular}{c|c|c|c|c|c|c}
\hline Transdutor & $\begin{array}{c}\text { Pressão } \\
{[\mathrm{kPa}]}\end{array}$ & $\begin{array}{c}\text { Pressão } \\
{\left[\mathrm{kPa} \_a b s\right]}\end{array}$ & $\begin{array}{c}\text { V_in } \\
{[\mathrm{V}]}\end{array}$ & $\begin{array}{c}\text { V_out } \\
{[\mathrm{V}]}\end{array}$ & $\begin{array}{c}\text { DeltaV } \\
{[\mathrm{V}]}\end{array}$ & V_out/V_in \\
\hline \multirow{2}{*}{4} & 57,30766 & 150,50000 & 5,00196 & 0,56112 & 4,44085 & 0,11218 \\
\cline { 2 - 7 } & 0,00000 & 93,19234 & 5,00205 & 0,49376 & 4,50828 & 0,09871 \\
\hline
\end{tabular}

Tabela 4.2 - Valores médios obtidos para a calibração dos transdutores de pressão para a segunda sequência de testes

\begin{tabular}{|c|c|c|c|c|c|c|}
\hline \multicolumn{7}{|c|}{ Médias } \\
\hline Transdutor & $\begin{array}{c}\text { Pressão } \\
{[\mathrm{kPa}]}\end{array}$ & $\begin{array}{c}\text { Pressão } \\
{\left[\mathrm{kPa} \_ \text {abs }\right]}\end{array}$ & $\begin{array}{l}\text { V_in } \\
{[\mathrm{V}]}\end{array}$ & $\begin{array}{l}\text { V_out } \\
{[\mathrm{V}]}\end{array}$ & $\begin{array}{c}\text { DeltaV } \\
{[\mathrm{V}]}\end{array}$ & V_out/V_in \\
\hline \multirow{10}{*}{1} & 514,97433 & 608,16667 & 5,01142 & 3,46172 & 1,54974 & 0,69076 \\
\hline & 431,80766 & 525,00000 & 5,01139 & 2,97935 & 2,03202 & 0,59452 \\
\hline & 357,14100 & 450,33333 & 5,01143 & 2,54973 & 2,46171 & 0,50878 \\
\hline & 306,97433 & 400,16667 & 5,01143 & 2,25956 & 2,75186 & 0,45088 \\
\hline & 256,80766 & 350,00000 & 5,01140 & 1,96826 & 3,04312 & 0,39276 \\
\hline & 206,80766 & 300,00000 & 5,01142 & 1,68161 & 3,32983 & 0,33555 \\
\hline & 156,80766 & 250,00000 & 5,01138 & 1,39052 & 3,62088 & 0,27747 \\
\hline & 106,80766 & 200,00000 & 5,01142 & 1,10480 & 3,90660 & 0,22046 \\
\hline & 56,64100 & 149,83333 & 5,01139 & 0,81557 & 4,19581 & 0,16274 \\
\hline & 0,00000 & 93,19234 & 5,01143 & 0,49337 & 4,51804 & 0,09845 \\
\hline \multirow{10}{*}{2} & 484,34101 & 577,66667 & 5,01037 & 1,16499 & 3,84537 & 0,23252 \\
\hline & 431,84101 & 525,16667 & 5,01047 & 1,10493 & 3,90549 & 0,22054 \\
\hline & 357,17434 & 450,50000 & 5,01045 & 1,01667 & 3,99374 & 0,20292 \\
\hline & 307,00767 & 400,33333 & 5,01042 & 0,95794 & 4,05244 & 0,19120 \\
\hline & 256,67434 & 350,00000 & 5,01041 & 0,89882 & 4,11164 & 0,17938 \\
\hline & 206,67434 & 300,00000 & 5,01041 & 0,84019 & 4,17023 & 0,16769 \\
\hline & 156,50767 & 249,83333 & 5,01043 & 0,78318 & 4,22728 & 0,15631 \\
\hline & 106,67434 & 200,00000 & 5,01037 & 0,72484 & 4,28554 & 0,14467 \\
\hline & 56,67434 & 150,00000 & 5,01037 & 0,66585 & 4,34451 & 0,13290 \\
\hline & 0,00000 & 93,32566 & 5,01041 & 0,60102 & 4,40941 & 0,11995 \\
\hline \multirow{10}{*}{3} & 514,97433 & 608,16667 & 5,01142 & 1,09153 & 3,91988 & 0,21781 \\
\hline & 431,80766 & 525,00000 & 5,01139 & 0,99330 & 4,01809 & 0,19821 \\
\hline & 357,14100 & 450,33333 & 5,01143 & 0,90651 & 4,10493 & 0,18089 \\
\hline & 306,97433 & 400,16667 & 5,01143 & 0,84740 & 4,16403 & 0,16909 \\
\hline & 256,80766 & 350,00000 & 5,01140 & 0,79006 & 4,22133 & 0,15765 \\
\hline & 206,80766 & 300,00000 & 5,01142 & 0,73178 & 4,27963 & 0,14602 \\
\hline & 156,80766 & 250,00000 & 5,01138 & 0,67268 & 4,33870 & 0,13423 \\
\hline & 106,80766 & 200,00000 & 5,01142 & 0,61684 & 4,39458 & 0,12309 \\
\hline & 56,64100 & 149,83333 & 5,01139 & 0,55819 & 4,45319 & 0,11139 \\
\hline & 0,00000 & 93,19234 & 5,01143 & 0,49270 & 4,51872 & 0,09832 \\
\hline \multirow{3}{*}{4} & 514,97433 & 608,16667 & 5,01142 & 1,08474 & 3,92668 & 0,21645 \\
\hline & 431,80766 & 525,00000 & 5,01139 & 0,98711 & 4,02428 & 0,19697 \\
\hline & 357,14100 & 450,33333 & 5,01143 & 0,90068 & 4,11075 & 0,17973 \\
\hline
\end{tabular}


Tabela 4.2 - Continuação

\begin{tabular}{c|c|c|c|c|c|c}
\hline Transdutor & $\begin{array}{c}\text { Pressão } \\
{[\mathrm{kPa}]}\end{array}$ & $\begin{array}{c}\text { Pressão } \\
{[\mathrm{kPa} \text { abs }]}\end{array}$ & $\begin{array}{c}\text { V_in } \\
{[\mathrm{V}]}\end{array}$ & $\begin{array}{c}\text { V_out } \\
{[\mathrm{V}]}\end{array}$ & $\begin{array}{c}\text { DeltaV } \\
{[\mathrm{V}]}\end{array}$ & V_out/V_in \\
\hline \multirow{5}{*}{4} & 306,97433 & 400,16667 & 5,01143 & 0,84207 & 4,16936 & 0,16803 \\
\cline { 2 - 7 } & 256,80766 & 350,00000 & 5,01140 & 0,78541 & 4,22599 & 0,15672 \\
\cline { 2 - 8 } & 206,80766 & 300,00000 & 5,01142 & 0,72747 & 4,28394 & 0,14516 \\
\cline { 2 - 8 } & 156,80766 & 250,00000 & 5,01138 & 0,66858 & 4,34280 & 0,13341 \\
\cline { 2 - 7 } & 106,80766 & 200,00000 & 5,01142 & 0,61281 & 4,39860 & 0,12228 \\
\cline { 2 - 7 } & 56,64100 & 149,83333 & 5,01139 & 0,55415 & 4,45724 & 0,11058 \\
\cline { 2 - 7 } & 0,00000 & 93,19234 & 5,01143 & 0,49011 & 4,52131 & 0,09780 \\
\hline
\end{tabular}

A variação da razão entre a tensão de saída do transdutor e a tensão de alimentação é linear, assim como a diferença entre essas duas tensões também forma um diagrama linear. A empresa fornecedora dos transdutores não soube informar se os mesmos medem a pressão por extensômetros elétricos, por um sistema piezelétrico ou outro método. Sendo que um tipo muito comum de transdutores de pressão é o de membrana com extensômetros elétricos, formando uma Ponte de Wheatstone. Sendo assim, foi escolhido trabalhar com a razão entre a tensão de saída do transdutor e a tensão de alimentação, pois essa grandeza é linear em transdutores de Ponte de Wheatstone. Sendo assim, é ajustada uma curva linear de calibração através do método dos mínimos quadrados para cada transdutor, onde a pressão medida é função linear da razão entre a tensão de saída do transdutor e a tensão de alimentação. Os valores da função linear ajustada pelo método dos mínimos quadrados estão mostrados na Tabela 4.3 e na Tabela 4.4.

Tabela 4.3 - Curvas de calibração para a primeira sequência de testes

\begin{tabular}{c|c|c|c}
\hline \multicolumn{4}{c}{$\mathrm{V}_{\text {OUT }} / \mathrm{V}_{\text {IN }}=\mathrm{a} \cdot \mathrm{P}_{\text {EFETIVA }}+\mathrm{b}$} \\
\hline Transdutor & $\mathrm{a}$ & $\mathrm{b}$ & $\mathrm{R}^{2}$ \\
\hline 1 & 0,0011529801 & 0,0982283317 & 0,9999956 \\
\hline 2 & 0,0002294128 & 0,1108256880 & 0,9996081 \\
\hline 3 & 0,0002322905 & 0,0994686473 & 0,9999807 \\
\hline 4 & 0,0002311389 & 0,0988008984 & 0,9999849 \\
\hline
\end{tabular}


Tabela 4.4 - Curvas de calibração para a segunda sequência de testes

\begin{tabular}{c|c|c|c}
\hline \multicolumn{4}{|c}{$\mathrm{V}_{\text {OUT }} / \mathrm{V}_{\text {IN }}=\mathrm{a} \cdot \mathrm{P}_{\text {EFETIVA }}+\mathrm{b}$} \\
\hline Transdutor & $\mathrm{a}$ & $\mathrm{b}$ & $\mathrm{R}^{2}$ \\
\hline 1 & 0,0011508816 & 0,0976286429 & 0,9999954 \\
\hline 2 & 0,0002327868 & 0,1197847580 & 0,9999868 \\
\hline 3 & 0,0002317753 & 0,0981648362 & 0,9999791 \\
\hline 4 & 0,0002303152 & 0,0975593424 & 0,9999781 \\
\hline
\end{tabular}

\subsection{AQUISIÇÃO DE DADOS}

Inicialmente, a máquina a vapor na qual foram realizados os testes foi concebida para estar acoplada a um sistema linear de geração de eletricidade, onde os ímãs permanentes do sistema linear de geração de eletricidade influenciariam no funcionamento da mesma. Por esse motivo optou-se por construir a máquina em latão, por sua característica de não ser ferromagnético. Quando o projeto já estava em fase avançada, o sistema linear de ímãs foi trocado por um sistema biela-manivela que poderia então ser acoplado a um gerador de eletricidade rotativo comercial, porém o material das peças não foi alterado. $\mathrm{O}$ fato de a máquina ter sido construída em latão fez com que ela não tivesse muita resistência mecânica em algumas peças que sofrem mais esforços, tornando-a relativamente frágil.

Primeiramente o arranjo experimental incluía uma câmara de amortecimento no sistema, logo antes do bocal convergente que libera o fluxo para a atmosfera, como pode ser observado na Figura 4.20. Os testes foram realizados com pressões crescentes, e em uma dada pressão a câmara de amortecimento se rompeu, librando parte do fluxo de ar e invalidando as medidas de vazão. Mesmo assim as medições continuaram para a aquisição dos diagramas PxV. Na pressão de 3,5 bar, a câmara de amortecimento foi retirada e a tubulação foi ligada diretamente no bocal convergente, como indicado na Figura 4.13. Assim as medições para a pressão de 3,5bar da primeira sequência de medições foram válidas. Como não foi notado o exato instante em que a câmara de amortecimento se rompeu, os demais valores foram invalidados. Na sétima medição com 3,5 bar de pressão o eixo do pistão sofreu uma flexão e emperrou a máquina. 


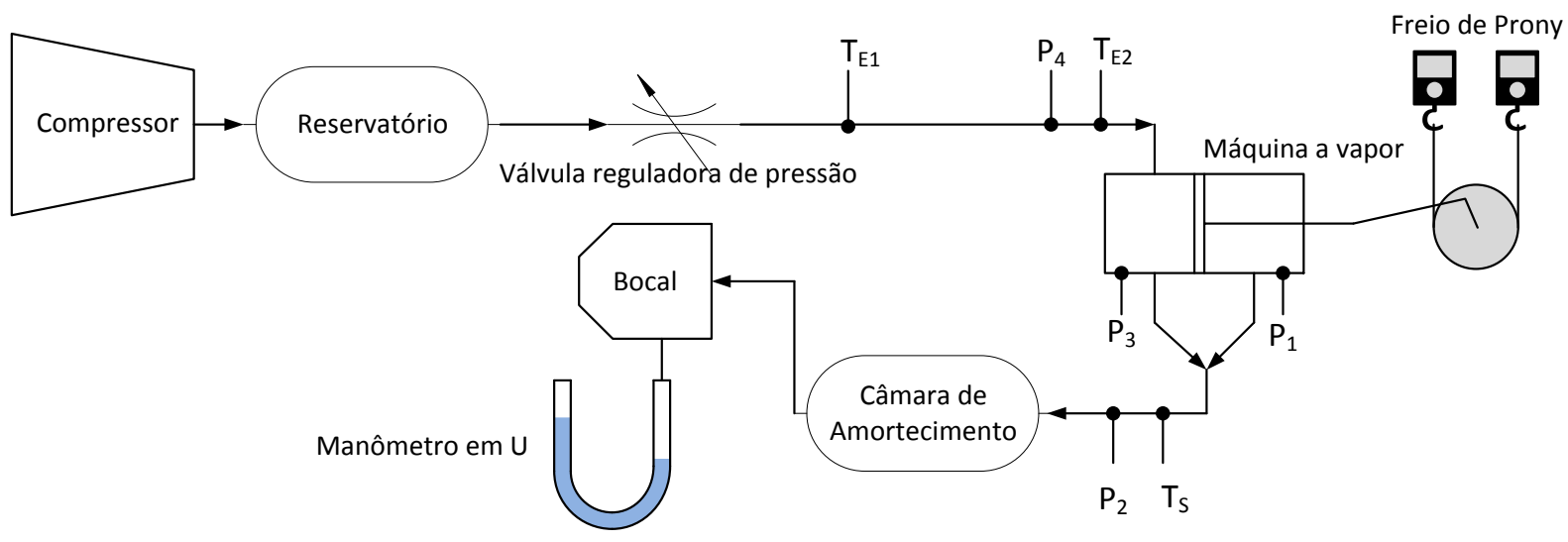

Figura 4.20 - Arranjo Experimental com câmara de amortecimento

Alguns dias depois a máquina foi consertada, o eixo foi trocado e foram realizados os testes novamente, até a pressão de 3 bar. Após fazer a aquisição, e analisar os diagramas PxV, verificou-se que o funcionamento da máquina a vapor estava incoerente, as duas câmaras estavam trabalhando em um modo assimétrico. Então a máquina a vapor foi desmontada, algumas peças foram substituídas, e percebeu-se que as válvulas sofreram um deslocamento de $0,7 \mathrm{~mm}$ da posição correta. Após realizar o reparo, foi feita uma terceira sequência de testes.

Nessa terceira sequência de testes, algumas peças (como o eixo do sistema biela-manivela, por exemplo), já possuíam algumas avarias que influenciam os resultados. A roda de inércia onde a tira de couro atrita para frear a máquina estava com uma pequena folga na chaveta, devido ao desgaste no eixo. Dessa forma, por vezes a máquina parava de girar se a roda de inércia se mexia e aumentava o atrito com a tira de couro. Em algumas medições, principalmente aquelas com cargas mais severas, a rotação da máquina a vapor oscilava consideravelmente durante os 10 s de aquisição de dados, fazendo com que algumas medições não retratem com precisão o que estava ocorrendo dentro da máquina a vapor para uma dada rotação, ou fazendo com que a vazão em massa oscilasse. Após coletar alguns dados para a pressão de 3 bar, o eixo do pistão da máquina a vapor se rompeu, finalizando os testes. A sequência realizada nos testes está descrita abaixo. 
4.5.1 Procedimento para a realização dos testes

Os testes foram realizados da seguinte forma:

a) Verificação se todas as peças estão montadas corretamente, e fixação das conexões elétricas dos transdutores e termopares nos módulos de leitura. As balanças são posicionadas de forma a não provocar atrito entre a tira de couro e a roda de inércia da máquina.

b) Ligar o computador e abrir o programa da aquisição de dados.

c) Posicionar o ângulo da manivela do pistão da máquina a vapor em aprox. $20^{\circ}$ contados no sentido de giro da máquina a vapor em relação à horizontal, com o pistão próximo ao PMS. Garantir que a tira de couro não está encostando na roda de inércia.

d) A pressão de admissão é ajustada na válvula de saída do compressor e a mesma é aberta, fazendo com que a máquina a vapor começa a funcionar. A estabilização da rotação da máquina a vapor é muito rápida, menos de $1 \mathrm{~s}$.

e) Iniciar a aquisição de dados pelo programa LabView, e enquanto a aquisição é feita, anotar a indicação das balanças e a altura das colunas de água no manômetro em U. A aquisição via computador é feita ao longo de 10 s à taxa de $10 \mathrm{kHz}$ cada canal.

f) Terminada a aquisição, as balanças são movidas para cima de forma a frear a roda de inércia da máquina, e então o passo anterior é repetido.

g) Fazer aquisições freando a roda de inércia cada vez mais, até atingir uma rotação mínima na qual a máquina continue funcionando com a carga aplicada.

h) Após fazer a aquisição da máquina funcionando na rotação mínima para aquela pressão, fechar a válvula do compressor, fazendo com que a máquina pare.

i) Ajustar uma nova pressão na válvula do compressor e reiniciar o processo. As pressões reguladas na válvula na saída do compressor foram 0,5 bar, 0,75 bar, 1 bar, 1,5 bar, 2 bar, 2,5 bar, 3 bar e 3,5 bar.

4.5.2 Fluxograma do programa de aquisição feito no LabView

O fluxograma do programa feito no LabView é mostrado na Figura 4.21. 


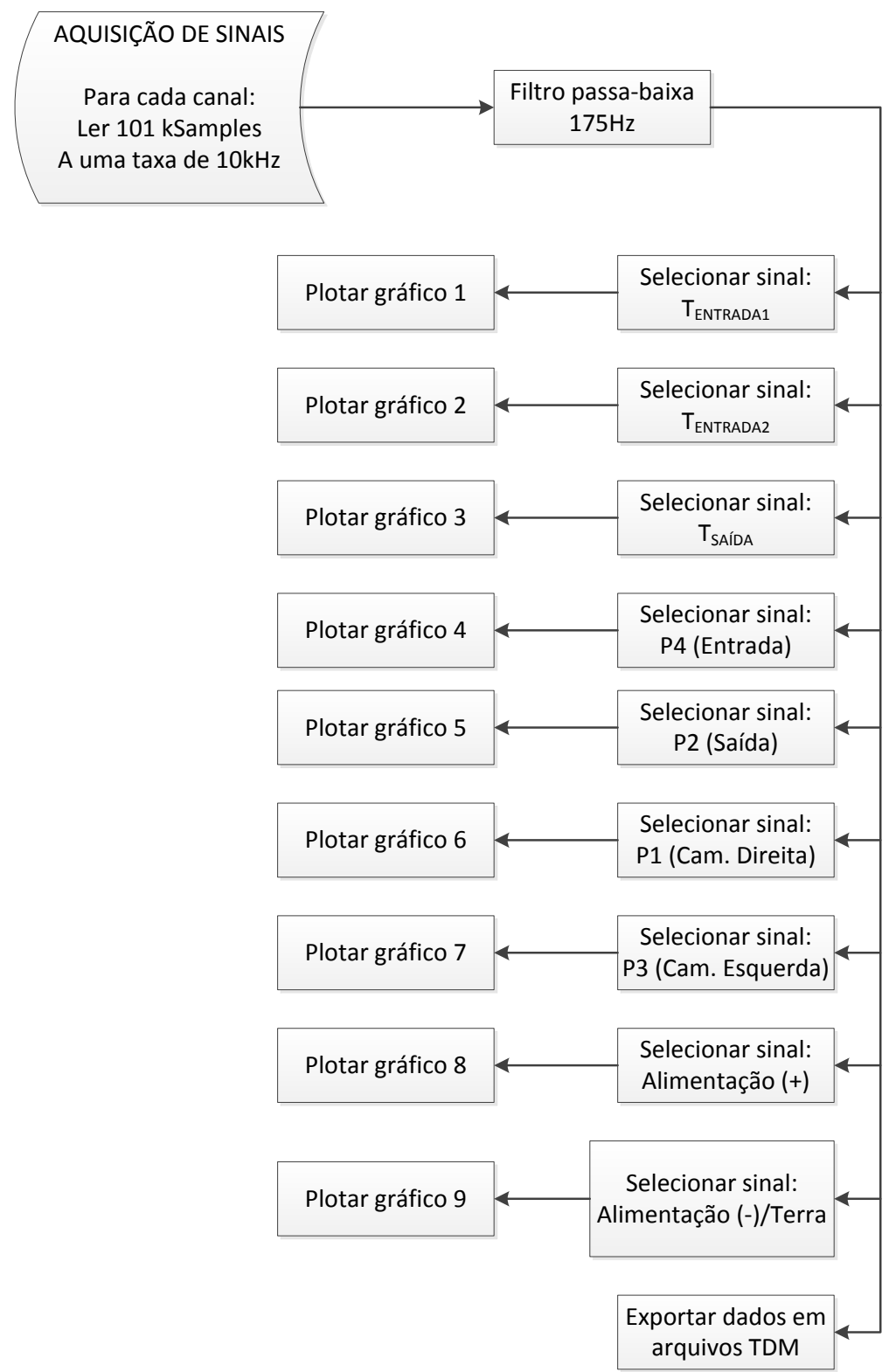

Figura 4.21 - Fluxograma elaborado no programa Labview para aquisição de dados nos testes

\subsection{TRATAMENTO DE DADOS}

Após serem coletados, os dados passam por um tratamento, para a análise e a comparação dos resultados.

Primeiramente é calculada uma média dos valores adquiridos para a pressão de admissão, pressão de escape, temperaturas de admissão e temperatura de escape. A vazão em massa é calculada com as eqs. (4.3), (4.5), (4.4), adotando o valor de $\mathrm{R}=287 \mathrm{~J} /(\mathrm{kg} . \mathrm{K}), \mathrm{k}=1,4$ e 
$\mathrm{cp}=1004,5 \mathrm{~J} /(\mathrm{kg} \cdot \mathrm{K})$, as áreas $\mathrm{A}_{1}$ e $\mathrm{A}_{2}$ são as áreas das seções (1) e (2), mostradas na Figura 4.12 e cotadas na Figura 4.11 . O torque é calculado utilizando a eq (4.1), e o raio da roda de inércia vale $\mathrm{R}_{\mathrm{RI}}=0,04 \mathrm{~m}$.

Para estudar as pressões internas às câmaras do cilindro, foi utilizado um algoritmo no programa no EES. Esse programa verifica os dados obtidos em uma aquisição de dados, calcula a rotação média da máquina a vapor, e determina qual o ciclo médio padrão de funcionamento para cada câmara que representa aquela rotação. O algoritmo completo está no APÊNDICE D - algoritmo para a geração do ciclo característico de cada medição, e a ordem lógica para a obtenção do ciclo padrão de cada rotação segue a sequência:

a) Os dados coletados são copiados dentro do EES, em uma "Lookup Table" do mesmo.

b) As leituras em tensão são convertidas em pressão, usando para isso as equações de calibração de cada transdutor.

c) São calculadas as pressões médias de admissão e de escape.

d) O programa verifica todas as vezes que a pressão na câmara direita passa por valor escolhida de forma crescente. O programa guarda a quantidade de vezes e todos os instantes ' $t$ ' em que isso ocorre, usando uma interpolação linear para determinar o instante ' $\mathrm{t}$ '.

e) Com essa informação, têm-se o número total de ciclos e o tempo de cada um. Calculase a rotação média da máquina em cada ciclo.

f) Verifica-se qual foi o ciclo mais rápido de toda a aquisição e quantos pontos foram adquiridos nesse ciclo, esse valor é guardado em uma variável chamada pontos_ciclo.

g) Cada ciclo é dividido em "pontos_ciclo-1" partes iguais. Assim, é gravada a mesma quantidade de pontos em cada ciclo. E a lógica é que se todos os ciclos forem iguais, a pressão em cada ponto deve igual em todos os ciclos.

h) É determinada a pressão em cada ponto de todos os ciclos e é calculada a pressão média, a pressão máxima, a pressão mínima, o desvio padrão e o coeficiente de variação para cada ponto.

i) Dessa forma se obtém um ciclo médio padrão, e esse ciclo médio padrão tem duração equivalente à duração média de todos os ciclos.

Os dados como vazão em massa, potência e torque foram calculados para todas as medidas, e mostram um comportamento inconsistente da máquina a vapor. O principal motivo para esse comportamento inconsistente é o de que ao longo dos testes a máquina sofria diversas 
pequenas avarias e foi consertada algumas vezes durante as aquisições de dados. Após ser consertada ela se mostrava com maior torque e características diferentes que as medidas anteriormente, tendo uma tendência descontinua ao longo das medições.

Foi criado então um critério para quantificar o quanto as medições de pressão dentro de cada câmara estavam boas. Ao realizar o item $h$ do procedimento para definir o ciclo padrão, são determinadas as pressões máxima, mínima e média dentre todos os ciclos, assim como o coeficiente de variação de cada ponto do ciclo. O coeficiente de variação é definido como a razão do desvio padrão pela média das medidas, e indica a porcentagem que o desvio padrão representa do valor médio. O coeficiente de variação é dado pela expressão:

$$
C V=\frac{\sigma}{\bar{P}}
$$

Onde, por sua vez, o desvio padrão das pressões de cada ponto do ciclo é definido por:

$$
\sigma=\sqrt{\frac{\sum_{i=1}^{n}\left(P_{i}-\bar{P}\right)^{2}}{n-1}}
$$

Porém para o estudo dos diagramas $\mathrm{PxV}$, foram selecionados apenas os ciclos nos quais o coeficiente de variação foi menor ou igual a $4 \%$, significando que existiu uma boa repetitividade do ciclo ao longo do período medido. Alguns exemplos de aquisições que mostram os mínimos, máximos, média e coeficiente de variação em um ciclo são mostrados na Figura 4.22 e na Figura 4.23. O gráfico da Figura 4.22 se refere aos ciclos da medição de 0,5 bar e 623,1 rpm para a câmara direita do cilindro, e pode-se verificar que os pontos de máximos e de mínimos estão bem próximos da curva média e possuem um coeficiente de variação de aprox. 0,46\%. O mesmo não ocorre na Figura 4.23, que mostra o mesmo diagrama para a medição com pressão de 2 bar e rotação média de 823,3 rpm. Na segunda figura, nota-se que as curvas de pressão máxima e pressão mínima estão afastadas da pressão média, e essa distribuição de pressões possui um coeficiente de variação máximo de aprox. 7,5\%. Fazendo com que esse diagrama PxV não seja estudado. 


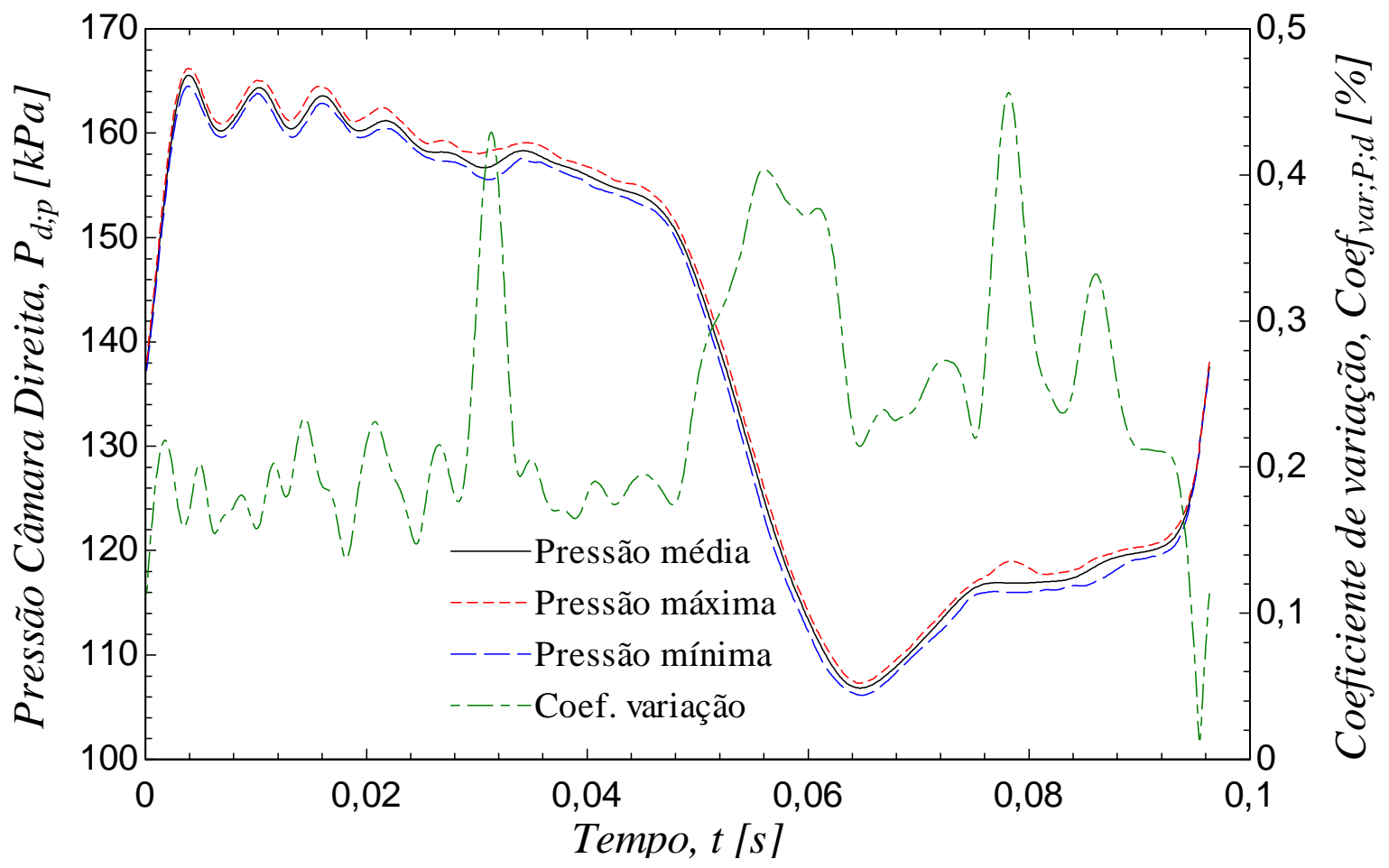

Figura 4.22 - Diagrama $P_{x}$ tempo para o ciclo médio da medição com pressão de 0,5bar e 623,1 rpm

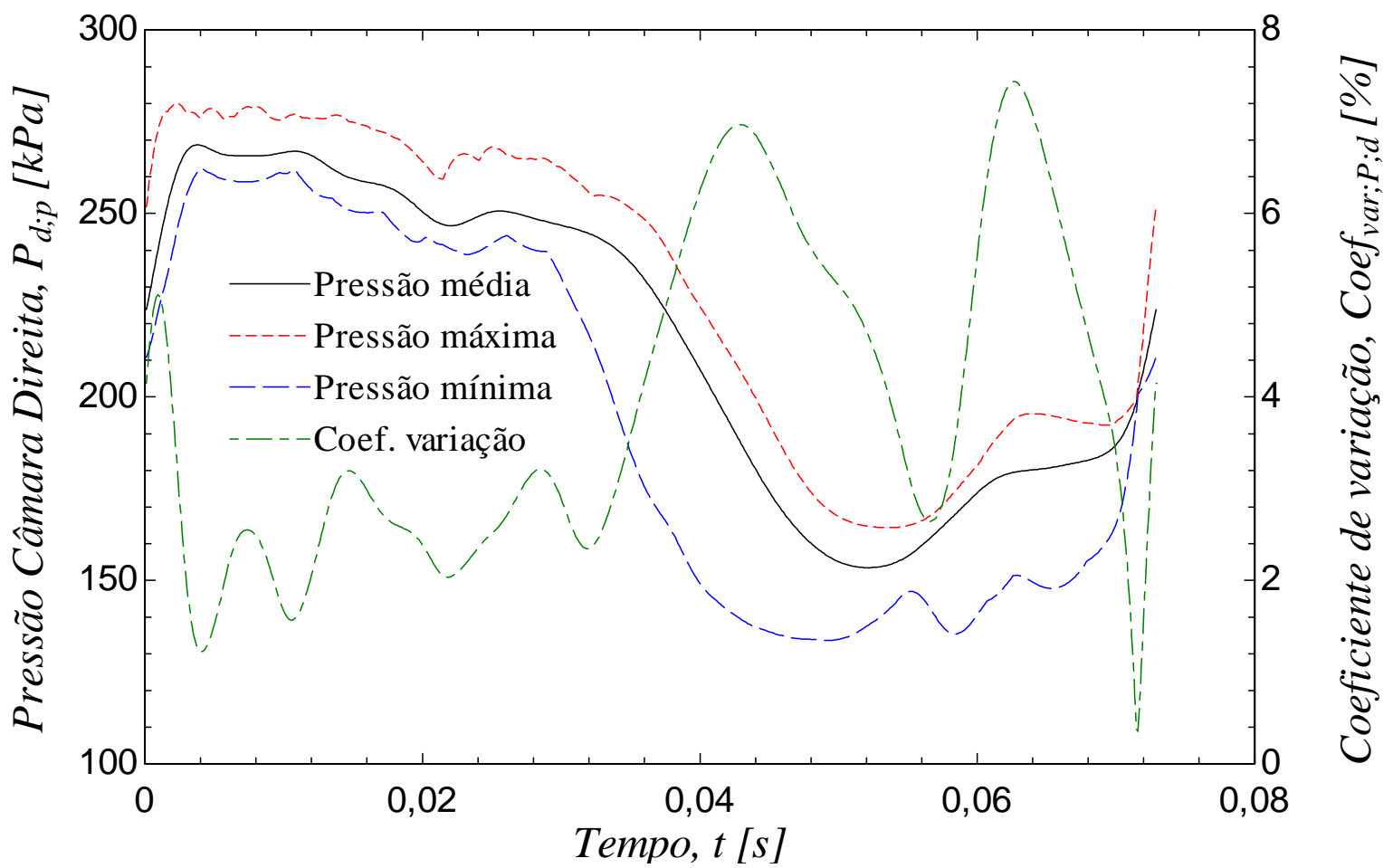

Figura 4.23 - Diagrama $P_{x}$ tempo para o ciclo médio da medição com pressão de 2 bar e 823,3 rpm 


\subsection{RESULTADOS}

Durante os 10s de aquisição de dados, eram anotados as marcações da balança e o desnível da coluna de água do manômetro em U. No processamento dos dados coletados utilizando os módulos de aquisição de dados, foram determinadas as pressões médias de entrada e de saída, assim como as temperaturas médias de entrada e de saída. Na tubulação de entrada foram utilizados dois termopares, e a temperatura de entrada considerada é a média da leitura desses dois termopares. As medidas com o símbolo * tiveram em seus ciclos algum ponto com coeficiente de variação superior a 4\%. Esses resultados estão expressos na Tabela 4.5.

Tabela 4.5 - Dados obtidos nas medições

\begin{tabular}{|c|c|c|c|c|c|c|c|}
\hline $\begin{array}{c}\text { Pressão } \\
\text { [bar] }\end{array}$ & Medição & $\begin{array}{c}\Delta \text { Balança } \\
{[\mathrm{kg}]}\end{array}$ & $\begin{array}{c}\text { Coluna } \mathrm{H}_{2} \mathrm{O} \\
{[\mathrm{mm}]}\end{array}$ & $\begin{array}{c}\text { T_entrada } \\
{\left[{ }^{\circ} \mathrm{C}\right]}\end{array}$ & $\begin{array}{l}\text { T_média } \\
\text { saída }\left[{ }^{\circ} \mathrm{C}\right]\end{array}$ & $\begin{array}{c}\text { P_entrada } \\
{[\mathrm{kPa}]}\end{array}$ & $\begin{array}{c}\text { P_saída } \\
{[\mathrm{kPa}]}\end{array}$ \\
\hline \multirow{7}{*}{0,5} & 1 & --- & 38,0 & 29,05 & 28,7 & 164,277 & 93,663 \\
\hline & 2 & 0,13 & 35,0 & 29,11 & 28,2 & 165,125 & 93,192 \\
\hline & 3 & 0,21 & 32,0 & 29,12 & 27,9 & 165,726 & 92,737 \\
\hline & 4 & 0,25 & 28,0 & 29,08 & 27,6 & 164,913 & 92,119 \\
\hline & 5 & 0,30 & 25,0 & 29,12 & 27,6 & 165,101 & 91,655 \\
\hline & 6 & 0,36 & 24,0 & 29,09 & 27,3 & 167,874 & 91,566 \\
\hline & $7 *$ & 0,33 & 22,5 & 29,09 & 27,2 & 166,462 & 91,233 \\
\hline \multirow{5}{*}{0,75} & 1 & --- & 40,0 & 30,51 & 28,5 & 168,831 & 94,309 \\
\hline & 2 & 0,13 & 38,0 & 30,36 & 27,7 & 169,989 & 94,128 \\
\hline & 3 & 0,20 & 36,0 & 30,3 & 27,6 & 170,934 & 93,925 \\
\hline & 4 & 0,26 & 35,0 & 30,31 & 27,5 & 170,405 & 93,492 \\
\hline & 5 & 0,30 & 32,0 & 30,3 & 27,5 & 171,473 & 93,373 \\
\hline \multirow{6}{*}{1} & 1 & --- & 66,5 & 32,91 & 32,1 & 189,63 & 99,126 \\
\hline & 2 & 0,15 & 61,0 & 32,86 & 31,5 & 187,911 & 98,294 \\
\hline & 3 & 0,34 & 54,0 & 32,76 & 31,0 & 189,648 & 97,574 \\
\hline & 4 & 0,42 & 50,0 & 32,5 & 29,8 & 191,047 & 97,111 \\
\hline & 5 & 0,49 & 43,0 & 32,72 & 30,4 & 190,016 & 96,142 \\
\hline & 6 & 0,57 & 55,0 & 43,48 & 41,3 & 201,729 & 105,542 \\
\hline \multirow{6}{*}{1,5} & 1 & --- & 138,5 & 43,96 & 42,3 & 230,927 & 116,562 \\
\hline & 2 & 0,19 & 127,0 & 44,33 & 41,8 & 229,642 & 113,909 \\
\hline & 3 & 0,41 & 118,0 & 44,34 & 41,2 & 230,523 & 112,573 \\
\hline & 4 & 0,49 & 115,0 & 44,42 & 40,5 & 232,002 & 112,14 \\
\hline & 5 & 0,62 & 102,0 & 43,93 & 40,4 & 232,578 & 111,324 \\
\hline & 6* & 0,74 & 97,5 & 43,48 & 39,8 & 233,024 & 110,569 \\
\hline \multirow{2}{*}{2} & 1 & --- & 209,0 & 44,63 & 42,9 & 266,272 & 125,618 \\
\hline & 2 & 0,16 & 198,0 & 44,73 & 42,0 & 267,347 & 124,429 \\
\hline
\end{tabular}


Tabela 4.5 - Continuação

\begin{tabular}{|c|c|c|c|c|c|c|c|}
\hline $\begin{array}{c}\text { Pressão } \\
\text { [bar] }\end{array}$ & Medição & $\begin{array}{c}\Delta \text { Balança } \\
{[\mathrm{kg}]}\end{array}$ & $\begin{array}{c}\text { Coluna } \mathrm{H}_{2} \mathrm{O} \\
{[\mathrm{mm}]}\end{array}$ & $\begin{array}{c}\text { T_entrada } \\
{\left[{ }^{\circ} \mathrm{C}\right]}\end{array}$ & $\begin{array}{l}\text { T_média } \\
\text { saída }\left[{ }^{\circ} \mathrm{C}\right]\end{array}$ & $\begin{array}{c}\text { P_entrada } \\
{[\mathrm{kPa}]}\end{array}$ & $\begin{array}{c}\text { P_saída } \\
{[\mathrm{kPa}]}\end{array}$ \\
\hline \multirow{6}{*}{2} & 3 & 0,22 & 198,0 & 44,77 & 41,4 & 265,669 & 124,222 \\
\hline & 4 & 0,28 & 193,0 & 44,91 & 41,1 & 266,638 & 123,594 \\
\hline & $5 *$ & 0,44 & 176,0 & 44,94 & 40,7 & 269,723 & 121,334 \\
\hline & 6* & 0,54 & 173,0 & 45,03 & 40,5 & 269,947 & 120,983 \\
\hline & $7 *$ & 0,61 & 169,0 & 45,43 & 41,0 & 265,628 & 120,632 \\
\hline & $8 *$ & 0,71 & 160,0 & 45,4 & 41,4 & 269,173 & 120,054 \\
\hline \multirow{9}{*}{2,5} & 1 & --- & 310,5 & 42,59 & 40,3 & 315,097 & 137,022 \\
\hline & 2 & 0,00 & 310,5 & 42,44 & 39,5 & 312,922 & 136,399 \\
\hline & 3 & 0,15 & 299,0 & 42,32 & 39,0 & 313,85 & 135,732 \\
\hline & 4 & 0,26 & 288,0 & 42,2 & 38,5 & 316,007 & 134,746 \\
\hline & $5 *$ & 0,32 & 260,0 & 42,16 & 38,1 & 317,41 & 133,531 \\
\hline & 6 & 0,53 & 290,0 & 42,07 & 37,7 & 315,963 & 134,347 \\
\hline & 7 & 0,66 & 277,0 & 41,87 & 37,0 & 317,9 & 133,309 \\
\hline & 8* & 0,84 & 259,0 & 41,74 & 36,5 & 319,915 & 131,805 \\
\hline & $9 *$ & 0,98 & 207,0 & 41,61 & 36,0 & 325,552 & 128,013 \\
\hline \multirow{4}{*}{3} & 1 & --- & 402,0 & 36,36 & 34,4 & 354,545 & 147,576 \\
\hline & 2 & 0,17 & 390,0 & 35,95 & 33,0 & 353,947 & 146,429 \\
\hline & $3 *$ & 0,30 & 382,0 & 35,82 & 32,3 & 359,975 & 142,376 \\
\hline & 4* & 0,47 & 352,0 & 35,66 & 31,5 & 359,961 & 141,592 \\
\hline \multirow{6}{*}{3,5} & 1 & --- & 510,0 & 28,24 & 23,7 & 399,195 & 179,612 \\
\hline & 2 & 0,27 & 485,0 & 28,48 & 22,8 & 395,878 & 175,602 \\
\hline & 3 & 0,50 & 472,0 & 28,51 & 22,5 & 396,728 & 174,241 \\
\hline & 4 & 0,92 & 446,0 & 28,55 & 21,8 & 400,642 & 171,574 \\
\hline & 5 & 0,67 & 461,0 & 28,53 & 21,5 & 398,315 & 172,957 \\
\hline & 6 & 1,25 & 436,0 & 28,5 & 20,8 & 401,723 & 170,275 \\
\hline
\end{tabular}

Com os dados da Tabela 4.5 e a rotação determinada no processamento dos dados, o torque, a velocidade na seção (1) que está indicada na Figura 4.12, e a vazão em massa são calculados pelas eqs. (4.1), (4.3) e (4.5) respectivamente. A potência da máquina a vapor pode ser calculada pela expressão:

$$
P o t=\dot{\theta} \cdot T \cdot \frac{\pi}{30}
$$

Onde T é o toque e $\dot{\theta}$ é a rotação em $\mathrm{rad} / \mathrm{s}$. A eficiência isentrópica da máquina a vapor pode ser determinada como: 


$$
\eta_{\text {iso }}=\frac{P o t / \dot{m}}{w_{\text {iso }}}
$$

E o trabalho específico isentrópico é obtido pela eq. (3.52). Essa eficiência isentrópica da máquina engloba a eficiência do ciclo e as perdas por atrito na máquina a vapor, portanto é uma eficiência da máquina como um todo. Os valores calculados para os dados obtidos experimentalmente estão mostrados na Tabela 4.6.

Tabela 4.6 - Medidas de desempenho da máquina a vapor

\begin{tabular}{|c|c|c|c|c|c|c|c|}
\hline $\begin{array}{c}\text { Pressão } \\
\text { [bar] }\end{array}$ & Medição & $\begin{array}{c}\text { Rotação } \\
{[\mathrm{rpm}]}\end{array}$ & $\begin{array}{l}\text { Torque } \\
\text { [N.m] }\end{array}$ & $\begin{array}{c}\text { Potência } \\
\text { [W] }\end{array}$ & $\mathrm{v}_{1}[\mathrm{~m} / \mathrm{s}]$ & $\dot{\mathrm{m}}[\mathrm{g} / \mathrm{s}]$ & $\eta_{\text {Iso }}[\%]$ \\
\hline \multirow{7}{*}{0,5} & 1 & 792,56 & -- & -- & 3,92 & 2,25 & --- \\
\hline & 2 & 692,24 & 0,051 & 3,70 & 3,76 & 2,16 & 3,96 \\
\hline & 3 & 623,14 & 0,082 & 5,38 & 3,60 & 2,07 & 5,93 \\
\hline & 4 & 508,33 & 0,098 & 5,22 & 3,36 & 1,93 & 6,14 \\
\hline & 5 & 437,48 & 0,118 & 5,39 & 3,18 & 1,83 & 6,64 \\
\hline & 6 & 386,42 & 0,141 & 5,72 & 3,11 & 1,79 & 6,97 \\
\hline & 7 & 354,34 & 0,129 & 4,81 & 3,02 & 1,73 & 5,78 \\
\hline \multirow{5}{*}{0,75} & 1 & 729,85 & --- & --- & 4,02 & 2,31 & --- \\
\hline & 2 & 658,06 & 0,051 & 3,52 & 3,91 & 2,25 & 3,48 \\
\hline & 3 & 604,20 & 0,078 & 4,97 & 3,81 & 2,19 & 4,98 \\
\hline & 4 & 552,52 & 0,102 & 5,90 & 3,76 & 2,16 & 5,99 \\
\hline & 5 & 494,74 & 0,118 & 6,10 & 3,59 & 2,07 & 6,39 \\
\hline \multirow{6}{*}{1} & 1 & 897,04 & --- & --- & 5,20 & 2,96 & -- \\
\hline & 2 & 807,73 & 0,059 & 4,98 & 4,98 & 2,84 & 3,53 \\
\hline & 3 & 658,89 & 0,133 & 9,21 & 4,68 & 2,67 & 6,77 \\
\hline & 4 & 576,13 & 0,165 & 9,94 & 4,50 & 2,57 & 7,46 \\
\hline & 5 & 455,85 & 0,192 & 9,18 & 4,18 & 2,39 & 7,38 \\
\hline & 6 & 591,43 & 0,224 & 13,85 & 4,81 & 2,65 & 10,14 \\
\hline \multirow{6}{*}{1,5} & 1 & 1358,57 & --- & --- & 7,57 & 4,20 & --- \\
\hline & 2 & 1157,05 & 0,075 & 9,03 & 7,25 & 4,02 & 4,01 \\
\hline & 3 & 943,28 & 0,161 & 15,89 & 6,99 & 3,88 & 7,17 \\
\hline & 4 & 852,23 & 0,192 & 17,16 & 6,89 & 3,84 & 7,72 \\
\hline & 5 & 734,94 & 0,243 & 18,72 & 6,50 & 3,61 & 8,85 \\
\hline & 6 & 676,53 & 0,290 & 20,57 & 6,35 & 3,54 & 9,84 \\
\hline \multirow{6}{*}{2} & 1 & 1471,66 & --- & --- & 9,24 & 5,15 & --- \\
\hline & 2 & 1335,29 & 0,063 & 8,78 & 8,99 & 5,02 & 2,87 \\
\hline & 3 & 1283,52 & 0,086 & 11,60 & 8,98 & 5,02 & 3,81 \\
\hline & 4 & 1229,21 & 0,110 & 14,14 & 8,87 & 4,96 & 4,65 \\
\hline & 5 & 1002,80 & 0,173 & 18,13 & 8,48 & 4,74 & 6,02 \\
\hline & 6 & 961,46 & 0,212 & 21,33 & 8,40 & 4,70 & 7,10 \\
\hline
\end{tabular}


Tabela 4.6 - Continuação

\begin{tabular}{|c|c|c|c|c|c|c|c|}
\hline $\begin{array}{c}\text { Pressão } \\
\text { [bar] }\end{array}$ & Medição & $\begin{array}{c}\text { Rotação } \\
\text { [rpm] }\end{array}$ & $\begin{array}{l}\text { Torque } \\
{[\text { N.m] }}\end{array}$ & $\begin{array}{c}\text { Potência } \\
\text { [W] }\end{array}$ & $\mathrm{v}_{1}[\mathrm{~m} / \mathrm{s}]$ & $\dot{\mathrm{m}}[\mathrm{g} / \mathrm{s}]$ & $\eta_{\text {Iso }}[\%]$ \\
\hline \multirow{2}{*}{2} & 7 & 963,90 & 0,239 & 24,16 & 8,32 & 4,65 & 8,26 \\
\hline & 8 & 823,31 & 0,279 & 24,02 & 8,11 & 4,52 & 8,27 \\
\hline \multirow{9}{*}{2,5} & 1 & 1513,36 & --- & --- & 11,09 & 6,30 & --- \\
\hline & 2 & 1524,24 & 0,000 & 0,00 & 11,08 & 6,31 & --- \\
\hline & 3 & 1419,01 & 0,059 & 8,75 & 10,87 & 6,19 & 2,14 \\
\hline & 4 & 1262,77 & 0,102 & 13,49 & 10,67 & 6,08 & 3,31 \\
\hline & 5 & 1202,60 & 0,126 & 15,81 & 10,17 & 5,79 & 4,02 \\
\hline & 6 & 1167,29 & 0,208 & 25,42 & 10,70 & 6,11 & 6,19 \\
\hline & 7 & 1093,29 & 0,259 & 29,65 & 10,46 & 5,98 & 7,27 \\
\hline & 8 & 962,07 & 0,330 & 33,21 & 10,12 & 5,79 & 8,26 \\
\hline & 9 & 704,43 & 0,385 & 28,37 & 9,09 & 5,18 & 7,53 \\
\hline \multirow{4}{*}{3} & 1 & 1363,06 & $\overline{---}$ & --- & 12,38 & 7,23 & --- \\
\hline & 2 & 1322,61 & 0,067 & 9,24 & 12,18 & 7,14 & 1,90 \\
\hline & 3 & 1115,91 & 0,118 & 13,76 & 12,05 & 7,07 & 2,74 \\
\hline & 4 & 1145,98 & 0,184 & 22,13 & 11,59 & 6,80 & 4,56 \\
\hline \multirow{6}{*}{3,5} & 1 & 1386,07 & --- & --- & 13,54 & 8,29 & --- \\
\hline & 2 & 1202,74 & 0,106 & 13,34 & 13,22 & 8,09 & 2,63 \\
\hline & 3 & 1143,65 & 0,196 & 23,50 & 13,05 & 7,99 & 4,63 \\
\hline & 4 & 1006,65 & 0,361 & 38,06 & 12,71 & 7,78 & 7,50 \\
\hline & 5 & 1092,70 & 0,263 & 30,08 & 12,89 & 7,91 & 5,92 \\
\hline & 6 & 960,73 & 0,491 & 49,35 & 12,56 & 7,70 & 9,72 \\
\hline
\end{tabular}

Analisando a Tabela 4.6, pode-se verificar que as maiores eficiências ocorrem para pressões a partir de 1 bar em suas rotações mais baixas, exceto para a pressão de 3 bar. As eficiências para 3 bar são menores que as eficiências das pressões anteriores, por dois motivos. $\mathrm{O}$ primeiro é que as maiores eficiências ocorrem para menores rotações, e os testes para essa pressão foram feitos apenas para rotações maiores. Em segundo lugar, a sequência de 3 bar de pressão foi a última dos testes realizados na máquina, que já havia passado por 3 sequências de testes que exigiram grandes esforços da máquina, e as folgas e vazamentos de fluido eram maiores.

Essas folgas fazem com que exista um fluxo mássico entre as duas câmaras do cilindro através da folga entre o pistão e o cilindro, também existe um fluxo entre as câmaras de admissão e escape através da folga entre as válvulas e o cilindro onde ficam. Outra folga que reduz a eficiência da máquina a vapor é entre o eixo do pistão e a tampa guia mostrada na Figura 4.33, que permite um fluxo saindo da câmara direita do cilindro para fora da máquina a vapor. As duas primeiras folgas citadas fazem com que o consumo de fluido seja maior e 
parte desse fluido não seja utilizado para o movimento do pistão. A terceira folga citada faz com que a pressão interna da câmara direita seja menor devido à perda de massa para o ambiente, diminuindo o trabalho realizado pelo fluido.

A eficiência isentrópica dessa máquina a vapor é muito baixa para todas as pressões medidas, e existem alguns fatores principais que influenciam nesses valores. Um fator é a característica de a máquina a vapor não realizar expansão ou compressão isentrópicas, como será mostrado posteriormente na Figura 4.34, isso aumenta o consumo de massa da máquina a vapor. Além de sempre estar aberta para a admissão ou para o escape, existem pontos que ambas as válvulas estão abertas, provocando um fluxo de fluido da câmara de admissão direto para a câmara de escape, sem entrar no cilindro e sem realizar trabalho.

Outro fator, como citado acima são as folgas entras o pistão, as válvulas e seus respectivos cilindros, também aumentando o consumo de massa. Um terceiro fator que pode ser citado é a alta restrição ao fluxo de massa imposta pelas válvulas, dificultando principalmente o escape do fluido de dentro das câmaras do cilindro, fazendo com que o pistão comprima o fluido ao invés de expulsá-lo, quando está retornando ao menor volume. Isso pode ser verificado nos diagramas das Figura 4.29, Figura 4.30 e Figura 4.31, principalmente observando as curvas para a câmara esquerda do cilindro.

Por último, um fator que contribui para a baixa eficiência da máquina a vapor é o alto atrito e problemas de lubrificação. Devido às pequenas dimensões e espessuras do eixo do pistão e de outras peças, todo o conjunto teve que ser bem apertado para que a máquina operasse da melhor forma possível e resistisse mais aos testes, sem sofrer muitos danos, além do atrito dos rolamentos utilizados. Uma parcela do trabalho realizado pelo fluido é para vencer os atritos da máquina, chegando pouca energia na roda de inércia, onde foi medido o torque e a potência do conjunto. Isso é notável ao observar a Tabela 4.6, onde o maior torque do conjunto foi de 0,491 N.m e a maior potência 49,35 W. Os problemas de lubrificação ocorrem principalmente no eixo do pistão e no eixo das válvulas, mas são notáveis em todas as peças móveis externas ao bloco. Devido à baixa folga entre o eixo do pistão e a bucha que existe quando este entre no bloco do motor, qualquer lubrificante colocado no eixo é retirado pelo atrito em poucas medições, fazendo com que o eixo fique totalmente seco ao fim das medidas de cada pressão. 
Para o estudo dos diagramas $\mathrm{PxV}$, é necessário reconhecer sempre o sentido da curva de pressão. Nos ciclos teóricos estudados no Capítulo 3, sempre havia uma numeração indicando a sequência de funcionamento do diagrama PxV nos dados experimentais essas indicações não existem. De modo geral os ciclos sempre possuem uma grande área do lado direito que funciona no sentido horário e é a região que realiza trabalho, e por vezes aparece uma pequena área à esquerda no sentido anti-horário, que acaba gerando um trabalho negativo. Essas duas partes estão indicadas na Figura 4.24.

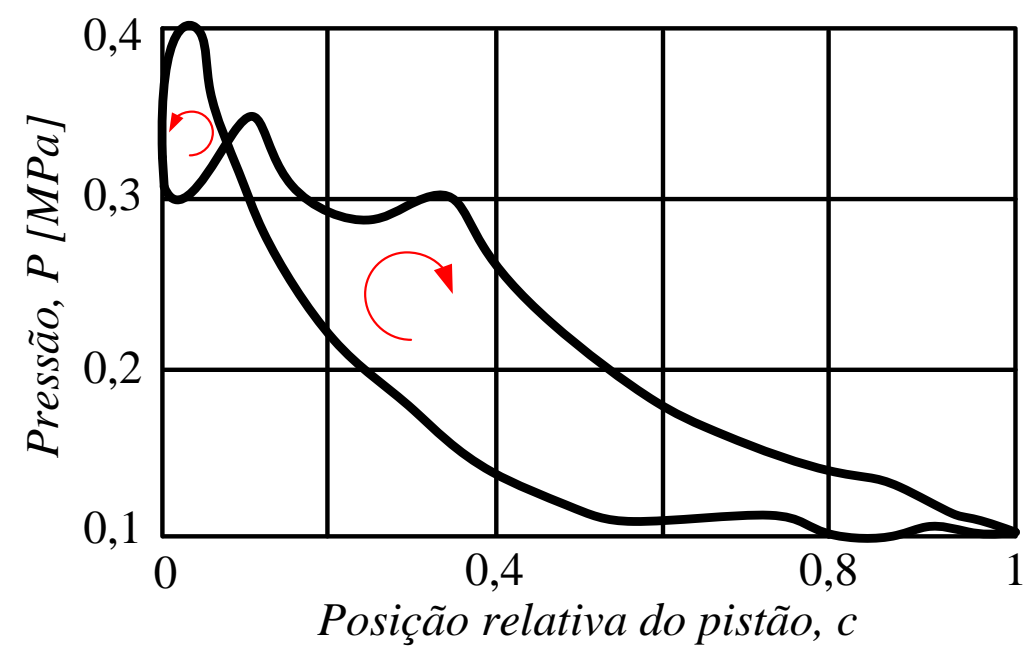

Figura 4.24 - Diagrama PxV da pressão em relação à posição relativa do pistão (Vanyashov et al., 2001), acrescentado as indicações do sentido de rotação de cada trecho do diagrama.

A máquina a vapor possui duas câmaras dentro do cilindro, operando de forma simétrica entre si. Assim, ao plotar o diagrama $\mathrm{PxV}$ médio tem-se dois diagramas opostos e relativamente simétricos entre si, como mostrado na Figura 4.25. Nessa figura, a posição relativa do pistão igual a 0 significa que o pistão está no PMS, o ponto morto mais afastado do eixo de manivelas, e a posição relativa igual a 1 indica a posição do pistão no PMI, mais próximo do eixo de manivelas.

Para facilitar a comparação entre as duas câmaras, o diagrama PxV da câmara direita é plotado em função da posição relativa do pistão do ponto de vista da câmara direita, ficando invertido quando comparado com o diagrama mostrado na Figura 4.25. Dessa forma, a posição relativa do pistão igual a 0 indica que o pistão está no ponto morto de menor volume para ambas as câmaras, e quando este vale 1, o pistão está no ponto morto de maior volume para ambas as câmaras. 


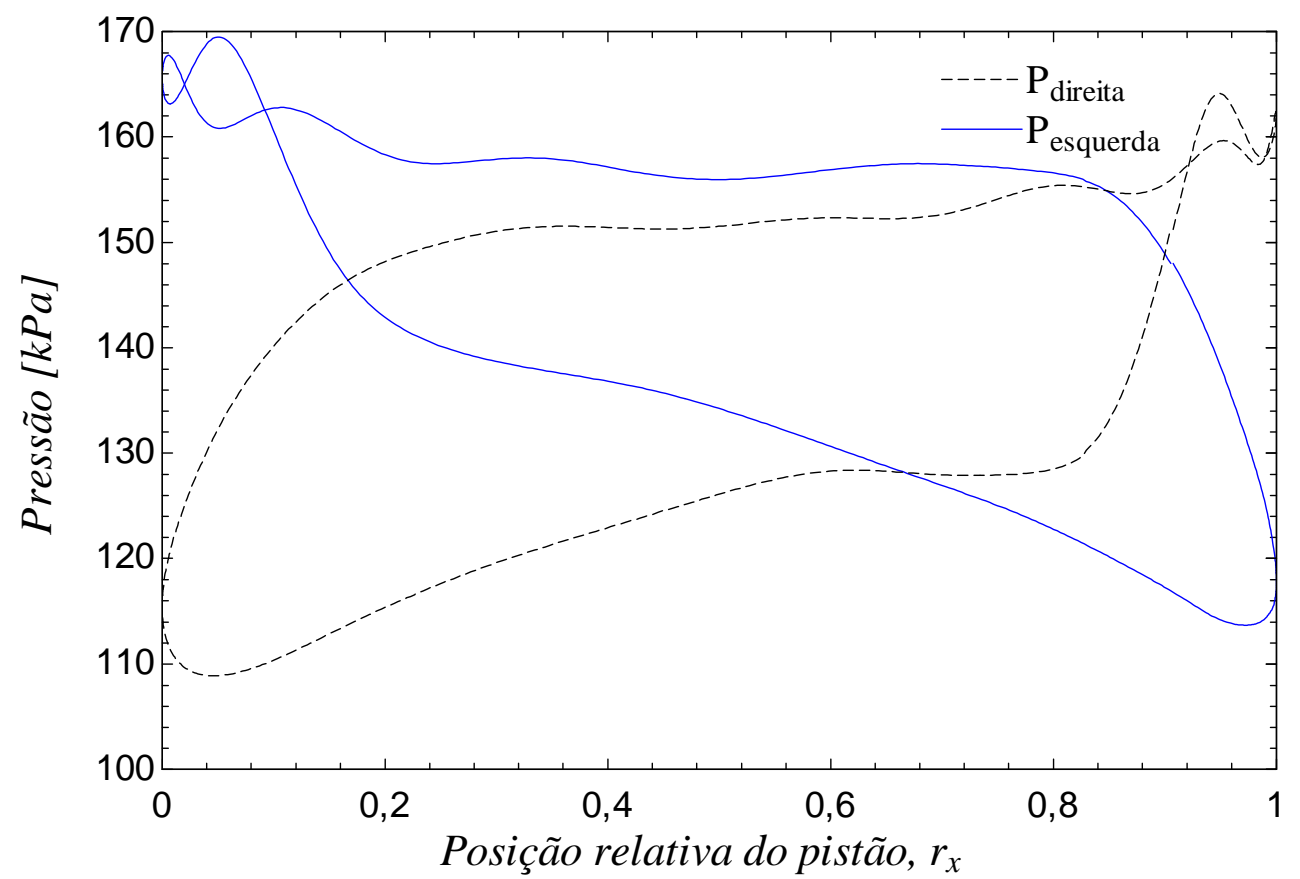

Figura 4.25 - Diagramas PxV da máquina a vapor para pressão nominal de 0,5 bar à 792,6 rpm.

Após os dados coletados passarem pelo tratamento de dados descrito nesse capítulo, foram consideradas como válidas apenas as medições nas quais nenhum ponto do ciclo padrão teve o coeficiente de variação maior que $4 \%$. Os dados obtidos relacionam a pressão interna de cada câmara do cilindro com o tempo, e nenhum dado de posição do pistão foi adquirido. Dessa forma não seria possível verificar os diagramas PxV. Porém, após fazer as simulações e notar alguns pontos chaves, que serão descritos no Capítulo 6, foi feito um acoplamento do ciclo padrão medido com o simulado para cada rotação. Esse acoplamento será melhor explanado no Capítulo 6. Assim, foi possível estimar a posição correta do pistão e analisar os diagramas PxV das medições também. Alguns exemplos desses diagramas PxV e dos dados coletados da pressão em função do tempo estão na Figura 4.26 até a Figura 4.32.

A sequência dessas figuras é uma imagem com o diagrama PxV para as duas câmaras para uma determinada combinação de pressão e rotação, e em seguida as pressões das duas câmaras em função do tempo para a mesma combinação de pressão e rotação. As grandezas que variam entre as medições são a pressão de admissão, a rotação e a pressão de escape. 


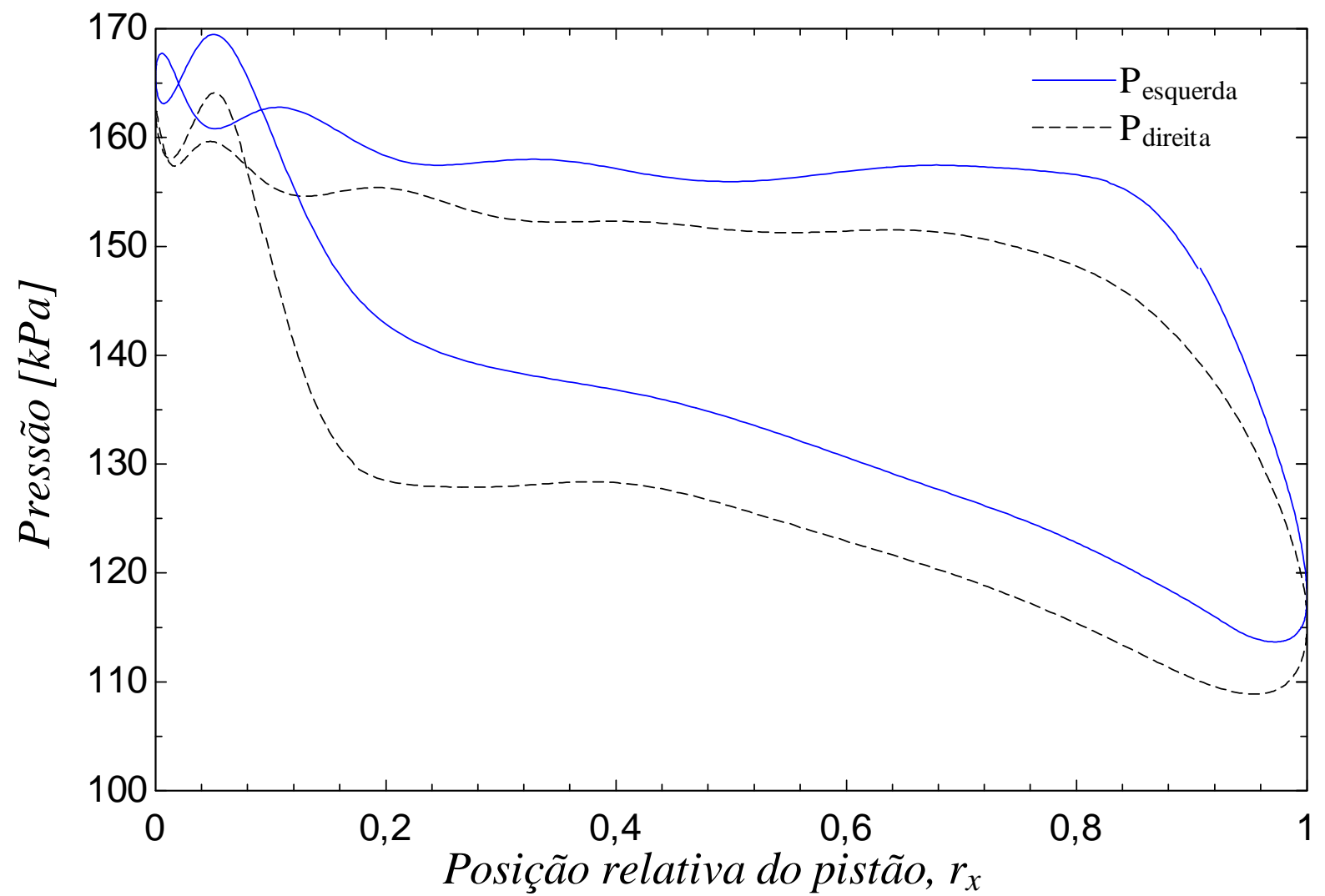

Figura 4.26 - Diagramas PxV da máquina a vapor para pressão nominal de 0,5 bar à 792,6 rpm.

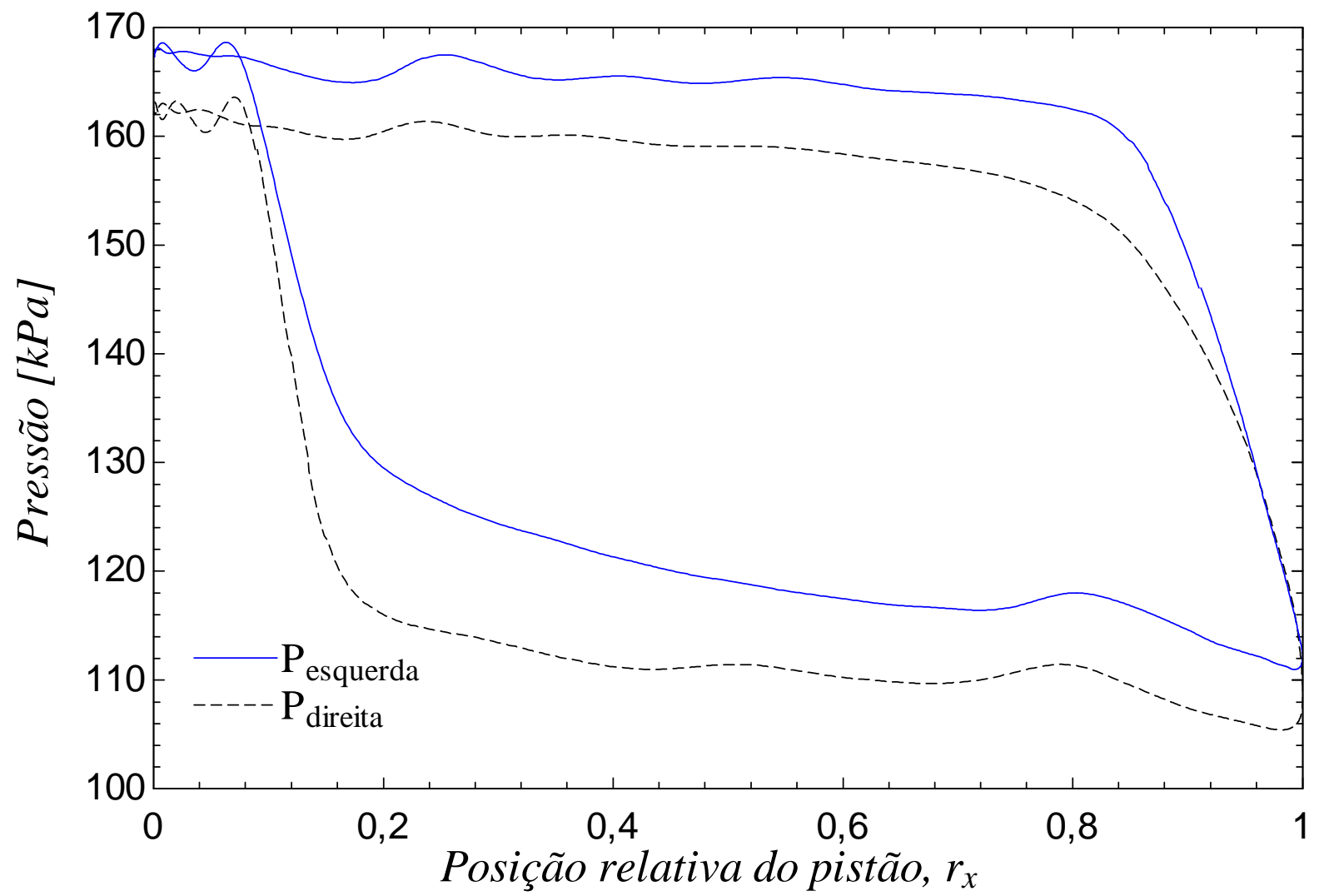

Figura 4.27 - Diagramas PxV da máquina a vapor para pressão nominal de 0,5 bar à 437,5 rpm. 


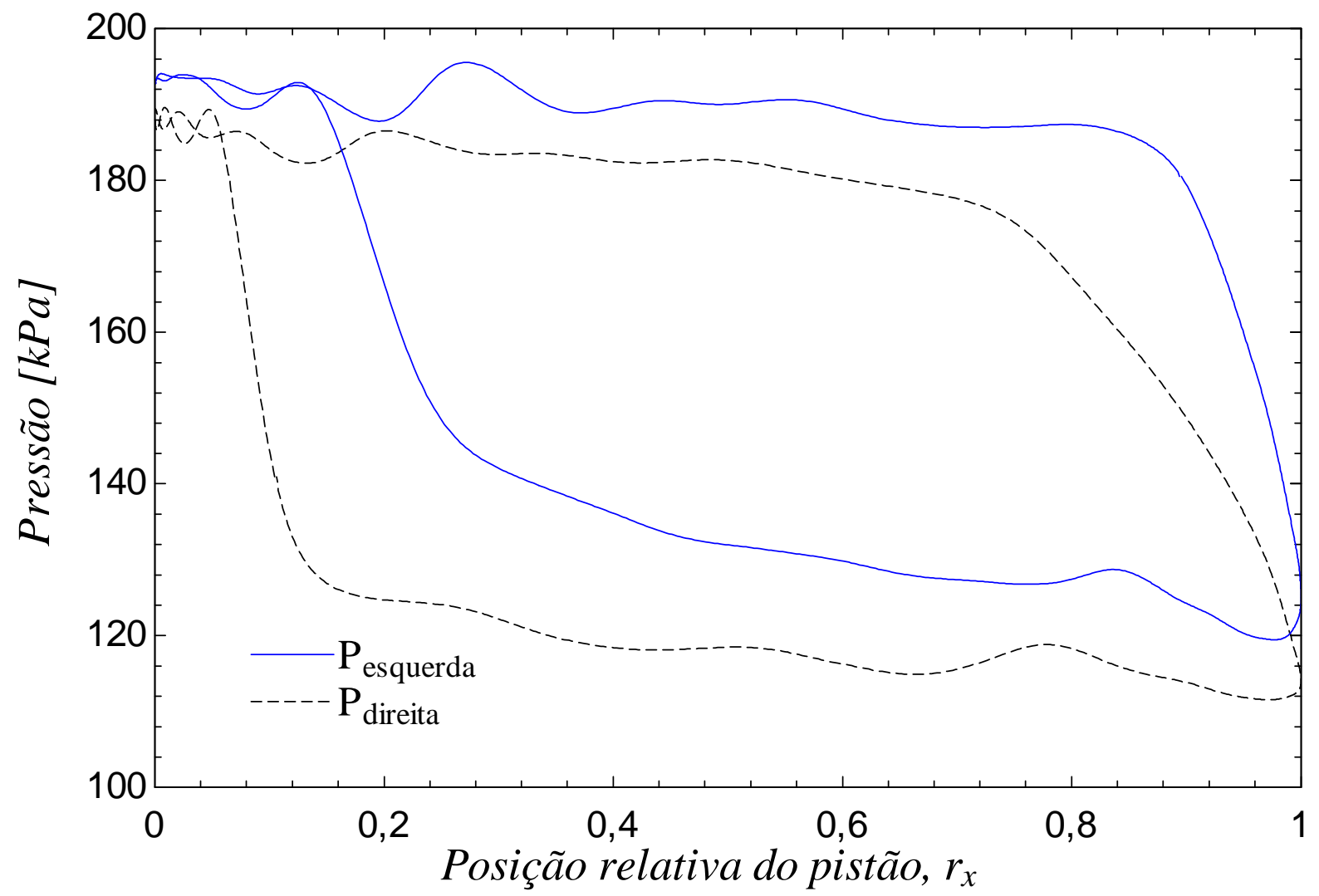

Figura 4.28 - Diagramas PxV da máquina a vapor para pressão nominal de 1 bar à 455,8 rpm.

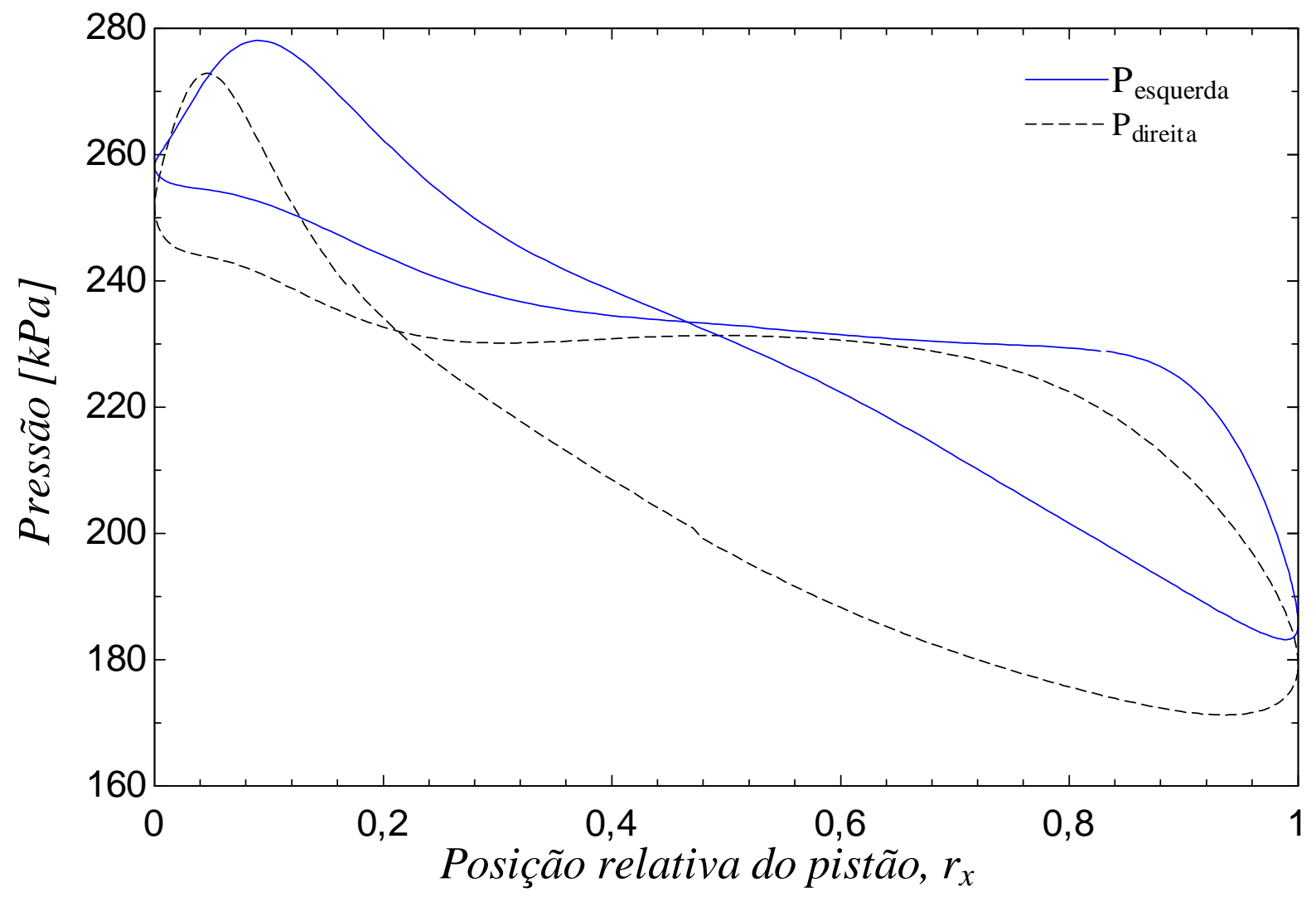

Figura 4.29 - Diagramas PxV da máquina a vapor para pressão nominal de 2 bar à 1471,7 rpm. 


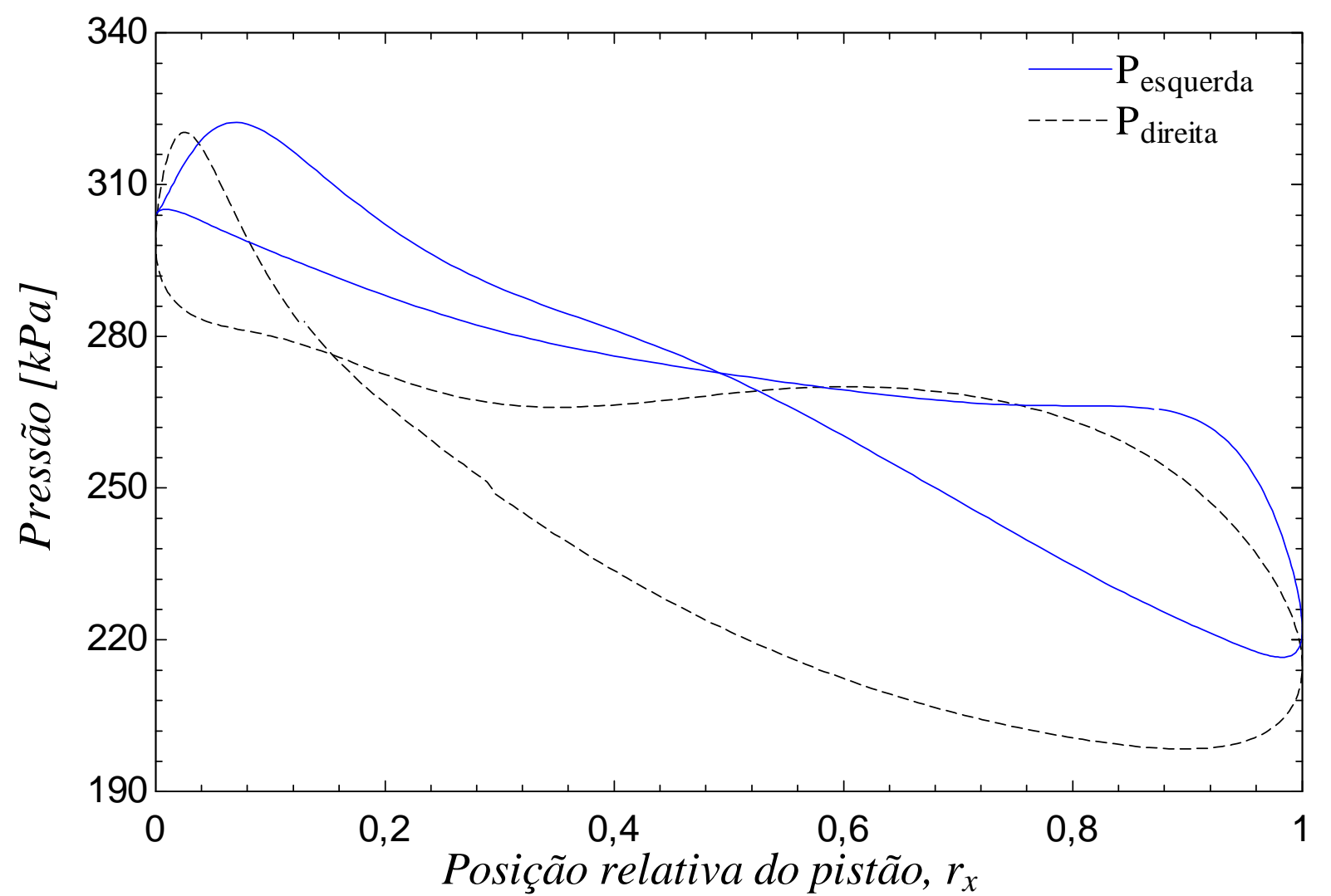

Figura 4.30 - Diagramas indicados da máquina a vapor para pressão nominal de 2,5 bar à 1513,4 rpm.

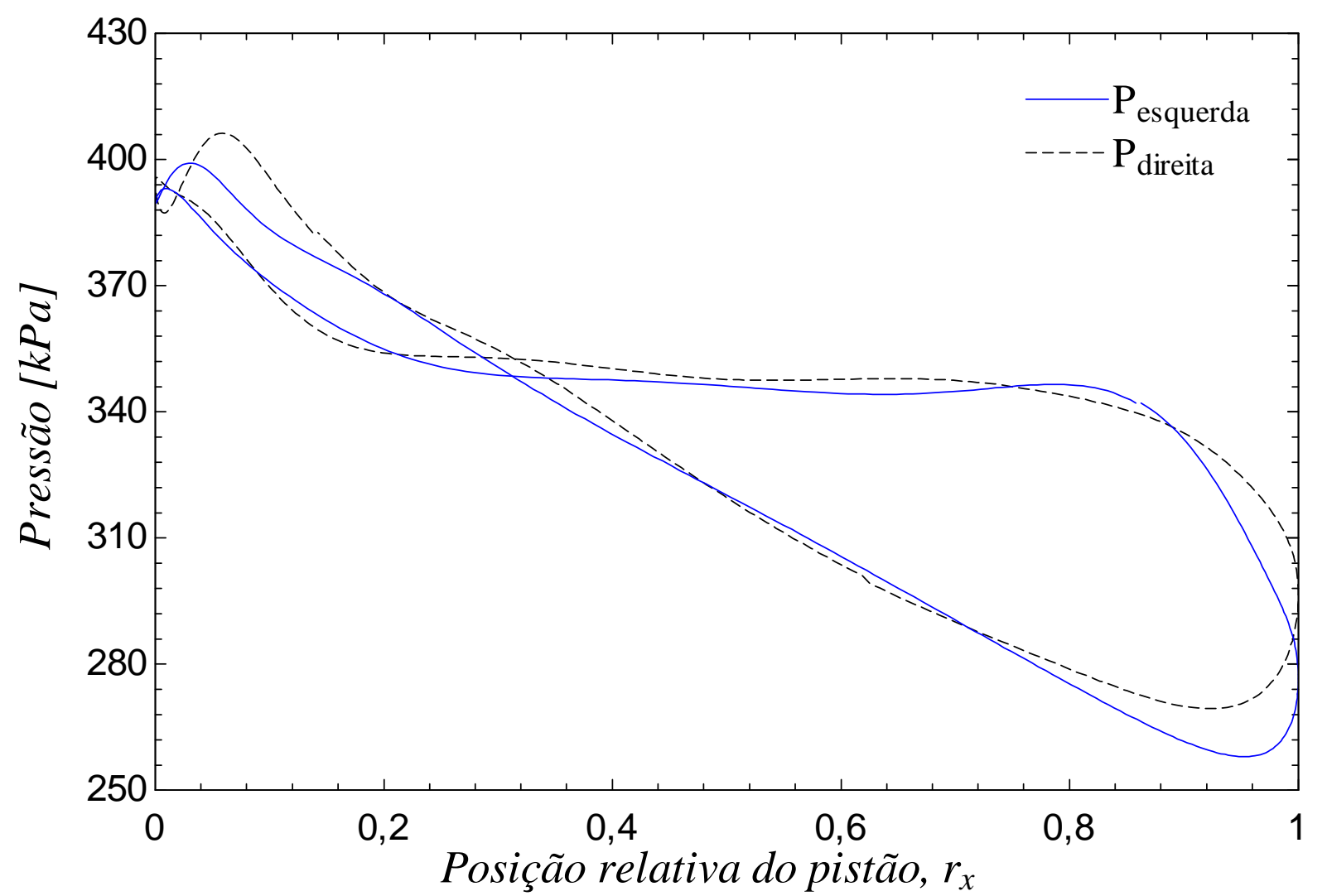

Figura 4.31 - Diagramas PxV da máquina a vapor para pressão nominal de 3,5 bar à 1386 rpm. 


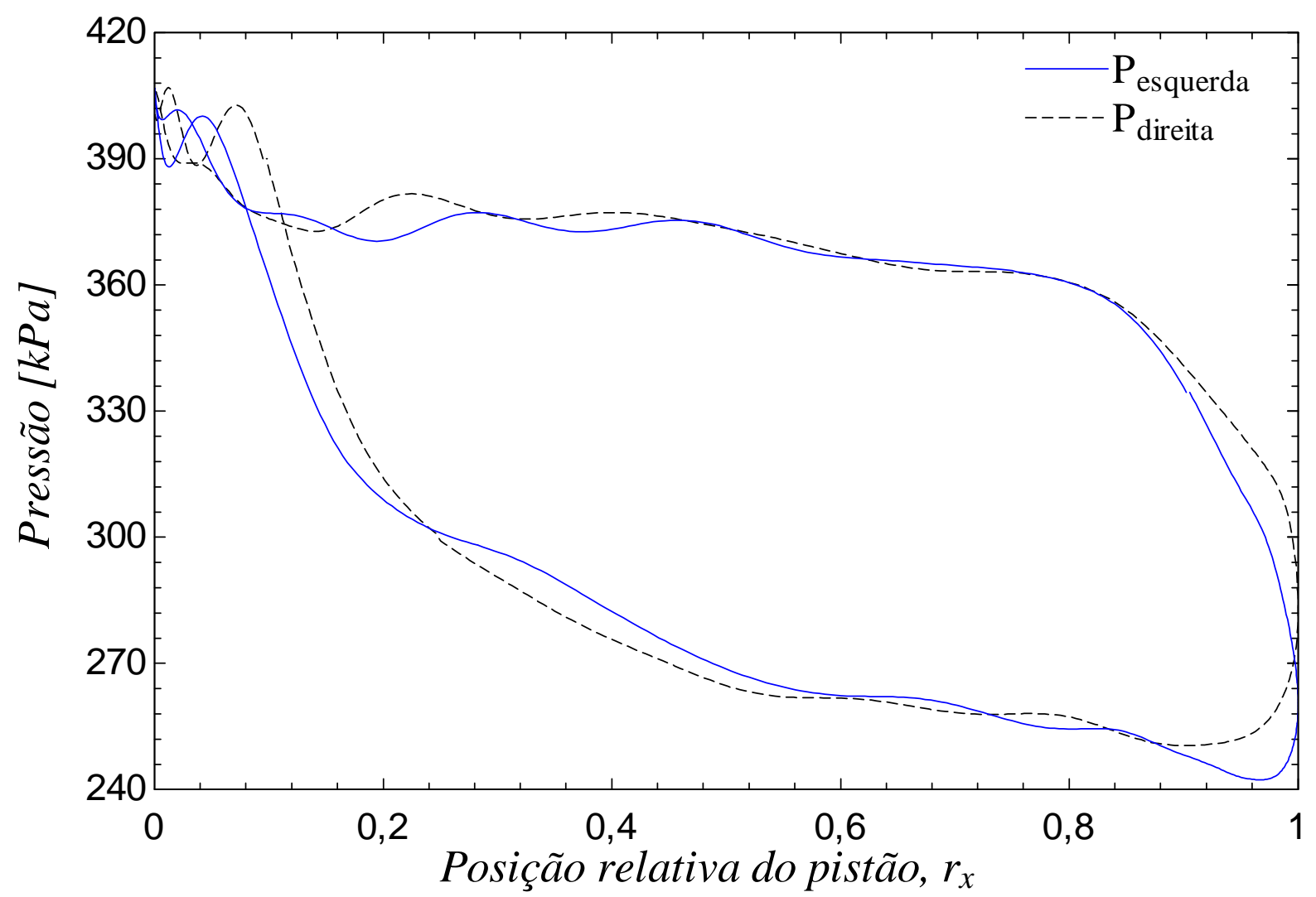

Figura 4.32 - Diagramas PxV da máquina a vapor para pressão nominal de 3,5 bar à 960,7 rpm.

Uma característica comum em todas as medições é a de que a câmara direita possui sempre uma pressão menor do que a câmara esquerda, exceto para as medições realizadas para a pressão de admissão de 3,5 bar (Figura 4.31 e Figura 4.32). Isso ocorre devido ao desgaste na tampa do cilindro que também serve como guia do eixo do pistão, essa região está indicada em vermelho na Figura 4.33. Esse desgaste ocorre devido às forças verticais geradas pelo sistema biela-manivela e transmitidas através do ponto A.

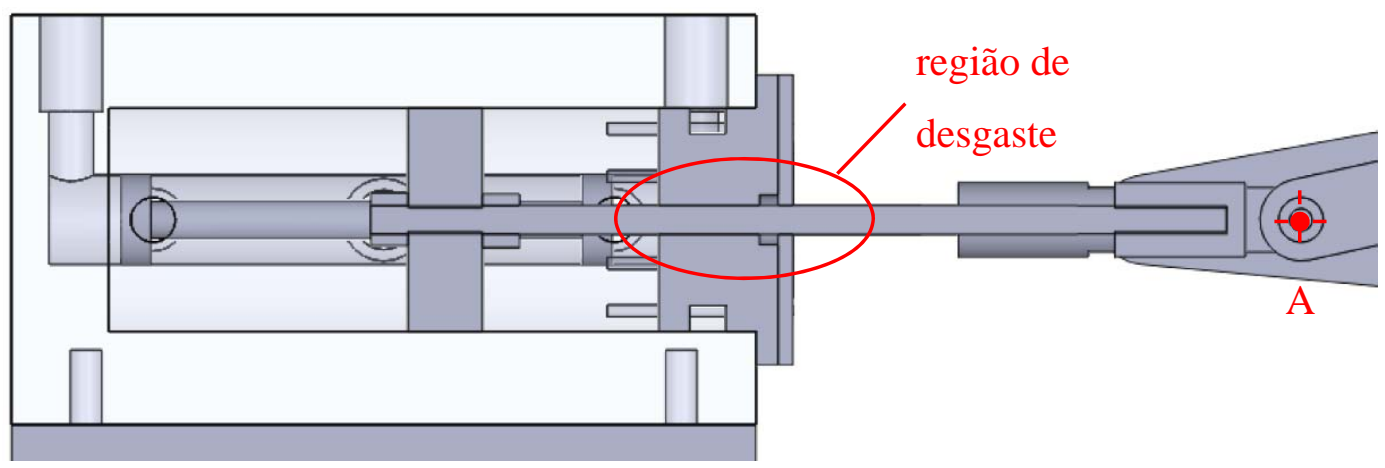

Figura 4.33 - Corte da máquina a vapor passando pelo centro do cilindro, indicando a região de desgaste do eixo do pistão com a tampa do cilindro 
Esse desnivelamento entre as pressões da câmara esquerda e da câmara direita não ocorre na pressão de 3,5 bar porque as medições para essa pressão foram realizadas na primeira sequência de testes, e as demais foram realizadas na terceira sequência de testes. No fim da primeira sequência de testes o eixo do pistão fletiu, travando a máquina. O desgaste dessa tampa e guia do eixo faz com que constantemente saia ar comprimido pelo vão criado, reduzindo a pressão da câmara direita.

Se os fluxos de admissão e de escape fossem ideais, na maior parte do processo de admissão a pressão estaria igual ou bem próxima da pressão de admissão, e o mesmo ocorreria para o processo de escape em relação à pressão de escape. Para que isso ocorra, a restrição ao fluxo entrando ou saindo da câmara deve ser muito baixa ou inexistente. No extremo oposto, se não houver fluxo entrando ou saindo do cilindro, a curva tende a ser próxima a uma curva de expansão/compressão isentrópica. Para casos reais, dificilmente se chega a um dos extremos, porém em alguns casos é possível notar que a curva está muito próxima de ter pressão constante ou muito próxima de uma curva isentrópica. Essa capacidade do fluxo entrar ou sair do cilindro é popularmente chamada de “respiro do motor”. Motores com menor restrição ao fluxo de ar são aqueles que possuem um "bom respiro do motor”, e os de maior restrição são ditos de um "baixo respiro do motor". Em baixas rotações, devido ao tempo maior de admissão e escape, os fluxos são praticamente ideais, já em altas rotações o fluido encontra maiores resistências para entrar ou sair do cilindro. A pressão também influencia nessa capacidade de troca de massa com a admissão e com o escape, quanto maior a diferença de pressão, maior o fluxo mássico e melhor o "respiro do motor". A capacidade de admissão/escape é resultado principalmente da rotação, das pressões de admissão e escape e da razão entre a área de abertura das válvulas e o volume interna da câmara, pois quanto maior a área de abertura, melhor o fluxo mássico.

Em alguns diagramas PxV, principalmente aqueles que expressam ciclos acima de $1000 \mathrm{rpm}$, é possível notar uma grande discordância entre as duas câmaras. Dois exemplos onde isso ocorre são: Figura 4.29 e Figura 4.30. Ao analisar o retorno do pistão de $r_{x}=1$ para $r_{x}=0$ para a câmara esquerda, pode-se verificar que ocorre uma compressão do fluido dentro da câmara e a pressão varia sempre de forma crescente e quase linear com a posição do pistão. Já o mesmo processo para a câmara direita é mais suave, e o fluido é menos comprimido do que o fluido da câmara esquerda, fazendo com que as pressões da câmara direita se mantenham sempre bem menores que as da câmara esquerda. De início, isso pode indicar um melhor fluxo de ar 
da câmara direita para o escape do que da câmara esquerda. Mas ao se observar a Figura 4.31, verifica-se que ambas as câmaras não possuem um bom fluxo para o escape, e a compressão do fluido no retorno do pistão ocorre de forma similar nas duas câmaras, mesmo a máquina trabalhando em condições parecidas com as condições das outras imagens citadas.

Essa diferença se dá pelo desgaste da tampa e guia do eixo do pistão, já citado anteriormente e indicado na Figura 4.33. Como já mencionado, esse desgaste faz com que exista sempre um fluxo de massa da câmara direita para o exterior da máquina através da folga criada pelo atrito. Com isso, o escape da câmara direita acaba ocorrendo por dois locais, que são a válvula de escape e a folga na tampa, diferentemente da câmara esquerda que tem apenas a abertura da válvula de escape para realizar a expulsão do fluido.

Em algumas condições, pode-se verificar que a máquina a vapor trabalha praticamente com um fluxo ideal, isso ocorre na Figura 4.27 e na Figura 4.28, em que os processos de admissão e de escape permanecem praticamente à pressão constante, principalmente a admissão. Essas três imagens mostram a máquina a vapor trabalhando em rotações menores que 500 rpm.

Nessa condição, o diagrama PxV se aproxima cada vez mais do diagrama da Figura 3.10, que é o ciclo de pior eficiência isentrópica caso não exista sobre-expansão ou sobrecompressão. Isso se dá pelo fato de que não existe nenhum instante em que tanto a válvula de admissão e a de escape estejam fechadas, fazendo com que o fluido sofra uma expansão/compressão isentrópica. A válvula deveria tampar totalmente as portas por alguns instantes, mas isso não ocorre, porque a espessura da válvula é menor que o diâmetro das portas. Essa característica está indicada na Figura 4.34. A câmara de admissão está representada em vermelho e a as câmaras de escape estão representadas em azul, e é possível perceber que as válvulas permitem a troca de massa simultânea do cilindro com a admissão e o escape. Sendo assim, cada câmara do cilindro pode estar trocando massa com a admissão, com o escape ou com ambos, mas nunca está totalmente fechada, permitindo uma expansão/compressão isentrópica do fluido. 


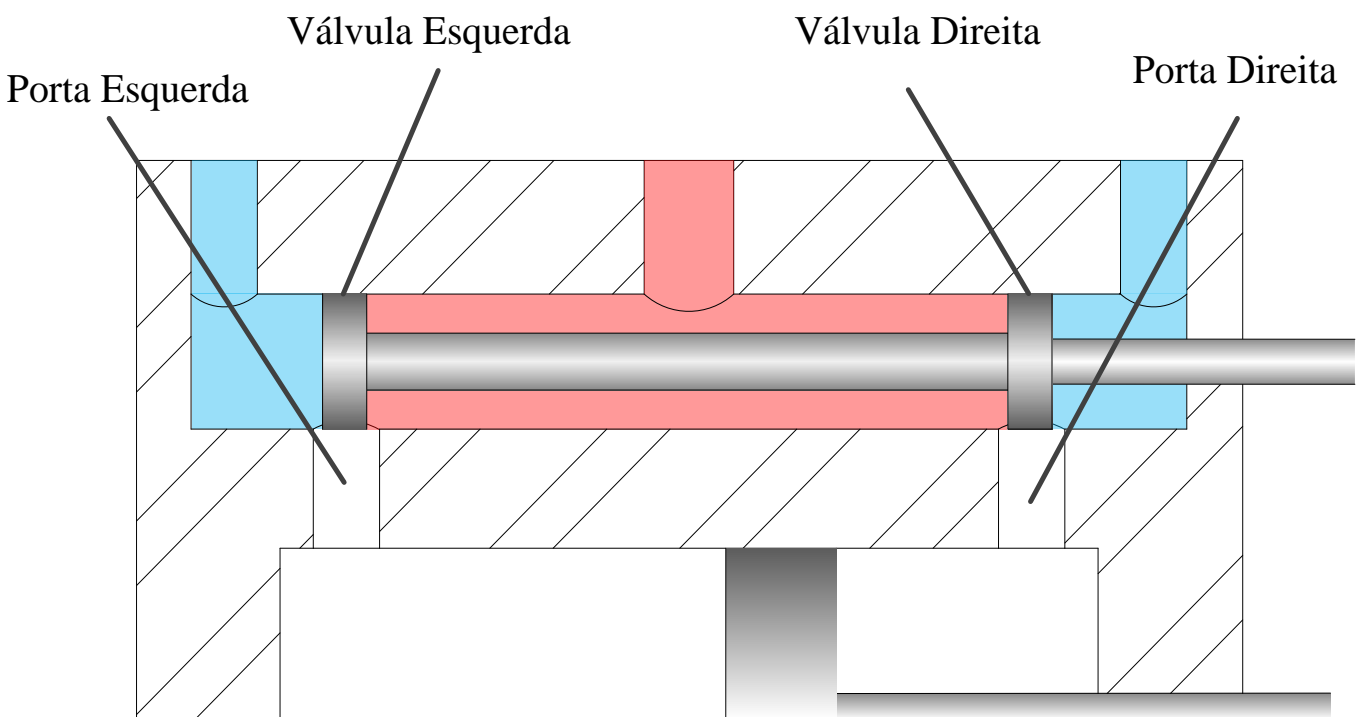

Figura 4.34 - Ilustração das porta e das válvulas da máquina a vapor.

Para rotações acima de 500 rpm, pode-se verificar que o escape já não está próximo à uma curva de pressão constante, porém a admissão ainda se mantém mais próxima de uma horizontal. Isso pode ser observado na Figura 4.26 e na Figura 4.32. Todas tem em comum o fato de estarem em uma rotação abaixo de $1000 \mathrm{rpm}$.

Para rotações acima de $1000 \mathrm{rpm}$, pode-se notar que o fluxo de escape é bem comprometido, fazendo com a curva do escape se aproxime bem mais de uma compressão isentrópica do que um processo isobárico. Isso faz com que a pressão interna do cilindro aumente no processo de escape, e quando o pistão atinge seu ponto morto, a pressão está acima da pressão de admissão, ou seja, fazendo com que exista um sobrecompressão do fluido, comprometendo também o processo de admissão. Essa característica pode ser verificada na Figura 4.29 e na Figura 4.31.

Embora nessas condições fique mais evidente que pode haver uma sobrecompressão do fluido, pois nessas condições o processo de escape passa a ser quase um processo de compressão, essa característica não é exclusiva para rotações acima de $1000 \mathrm{rpm}$. O próprio funcionamento da máquina a vapor tende a fazer com que existam sobrecompressão quando o pistão se aproxima do ponto morto de menor volume. Devido às válvulas serem do tipo carretel e serem acionadas por um sistema biela-manivela, elas devem começar a abrir para a admissão antes de o pistão atingir o ponto morto de menor volume. Isso deve ocorrer, pois se 
as válvulas de admissão começassem a abrir quando o pistão está nesse ponto morto, o processo de admissão será ineficiente, pois as válvulas estariam abrindo ao longo do processo no qual deveriam já estar abertas para ter a maior área possível, e para que o fluxo de admissão tenha menos restrições.

Dessa forma, as válvulas de admissão devem começar a abrir antes da chegada do pistão ao ponto morto, fazendo com que o cilindro comece a ser preenchido com fluido em alta pressão e o pistão se aproximando do ponto morto de menor volume comprima o fluido em alta pressão que entra no cilindro, causando uma sobrecompressão do fluido. Essa característica é perceptível em quase todos os gráficos, pois possuem um ou alguns picos de pressão, e o primeiro pico de pressão é devido a essa sobrecompressão do vapor. Esta característica apenas não é evidente quando a máquina trabalha em baixas rotações e consegue manter a pressão quase constante durante a admissão e o escape. Em baixas rotações, a estabilização da pressão interna com a câmara de admissão é mais rápida que o movimento do cilindro.

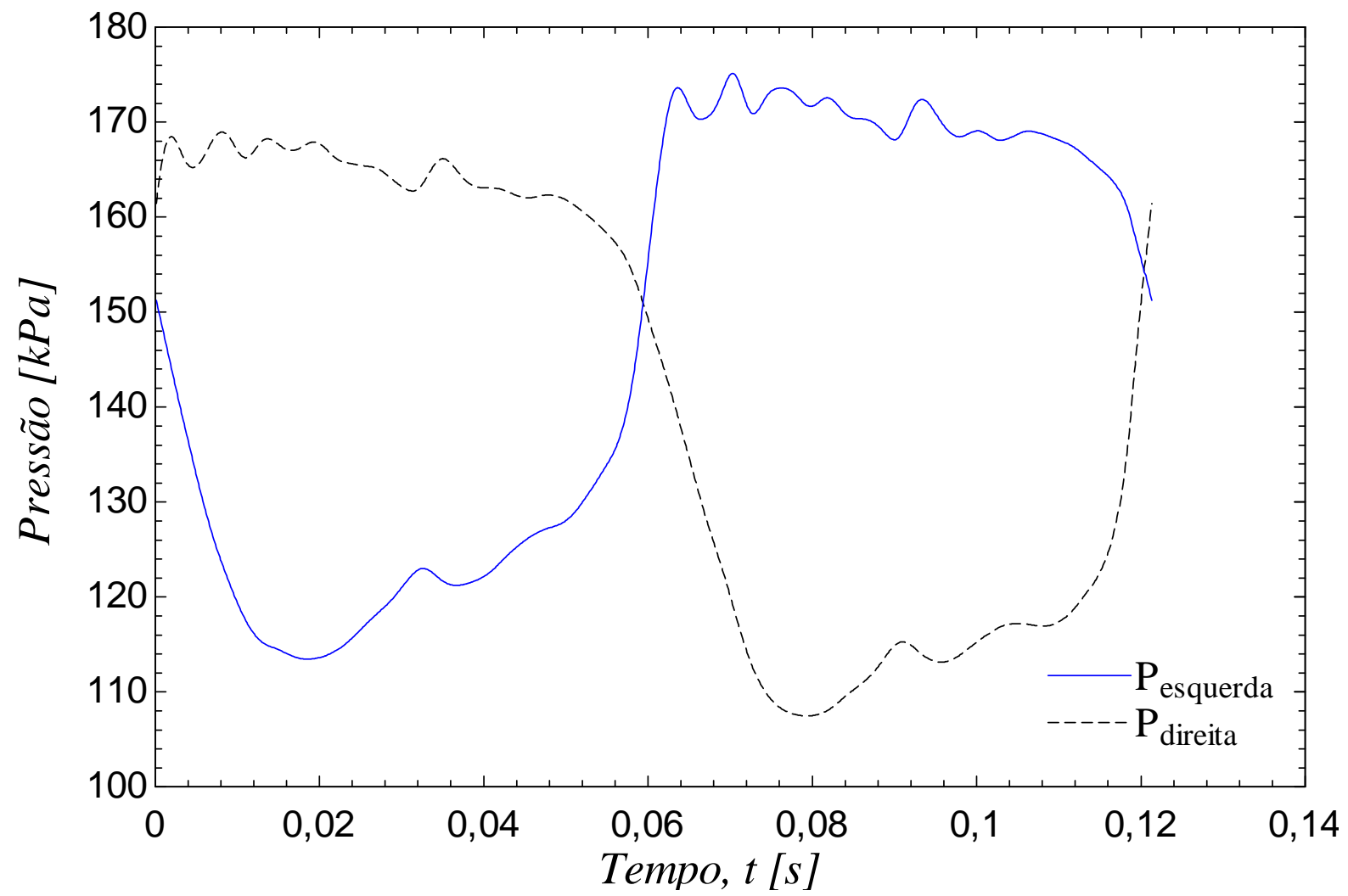

Figura 4.35 - Pressão em função do tempo para um ciclo para pressão nominal de 0,75 bar à 494,7 rpm. 


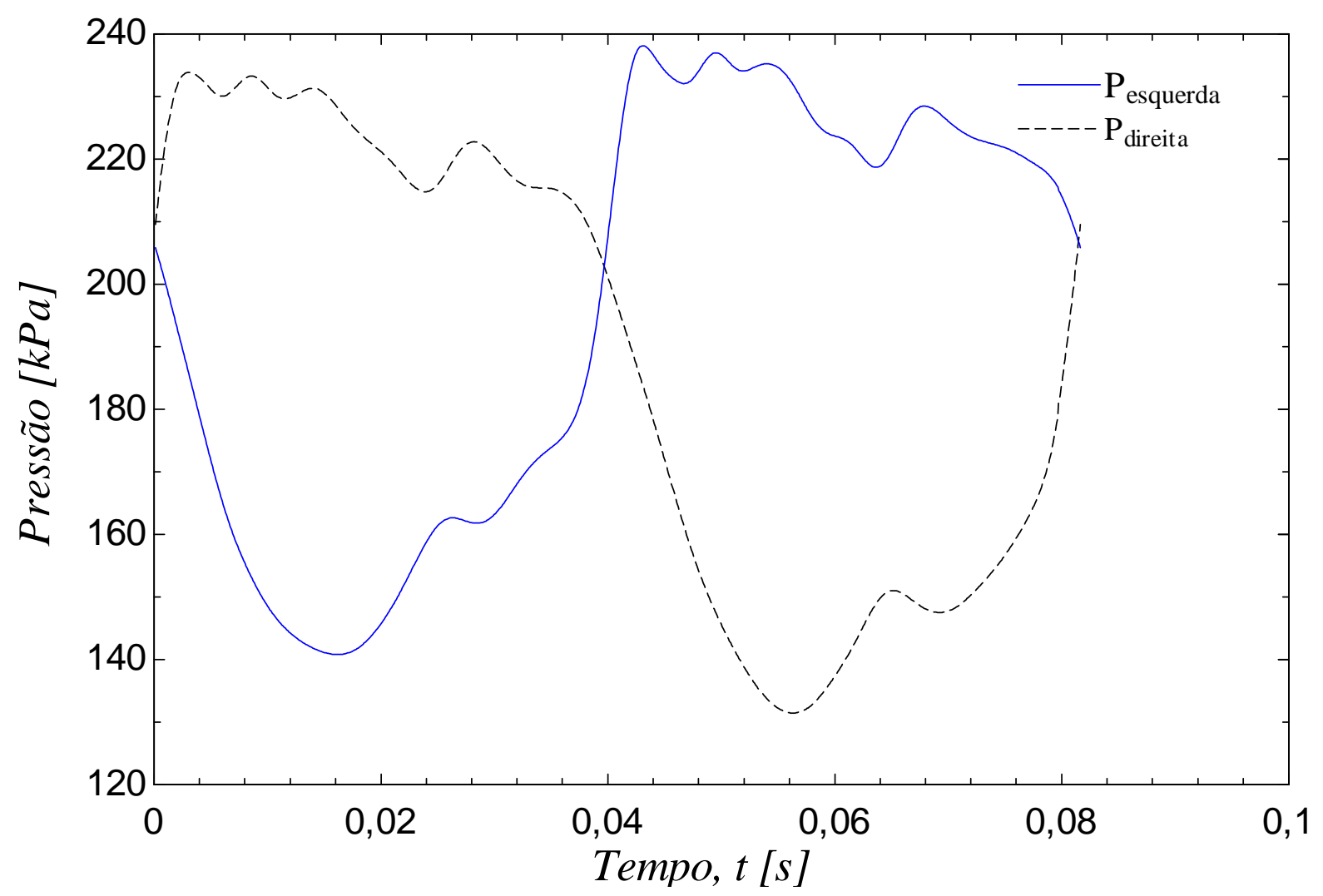

Figura 4.36 - Pressão em função do tempo para um ciclo para pressão nominal de 1,5 bar à 734,9 rpm.

Existem dois outros fenômenos notáveis que são melhor observáveis no diagrama Pxt e ocorrem em algumas medidas abaixo de 1000 rpm, como por exemplo os diagramas Pxt na Figura 4.35 e Figura 4.36. Esses fenômenos sãso oscilações de pressão que são indicados na Figura 4.37 e na Figura 4.38. O primeiro deles são oscilações de pressão no processo de admissão e estão representados por linhas verticais vermelhas utilizadas para medir seus períodos. O segundo deles é um comportamento simétrico das duas câmaras em um pequeno intervalo de tempo, representados por elipses vermelhas nessas figuras.

As oscilações de pressão no processo de admissão que não aparecem nos processos de escape. Essas oscilações não condizem com a teoria ou com a geometria da máquina a vapor. Utilizando as linhas verticais vermelhas, pode-se verificar que os períodos das oscilações variam entre 5 e 7 ms, sendo que a três oscilações ocorram em períodos menores que 6 ms. Nessas três figuras, e em todas as outras, os períodos são os mesmos, exceto para a pressão de 3,5 bar, onde as oscilações possuem períodos que são metade dos períodos citados, variando entre 3 e 4 ms. 


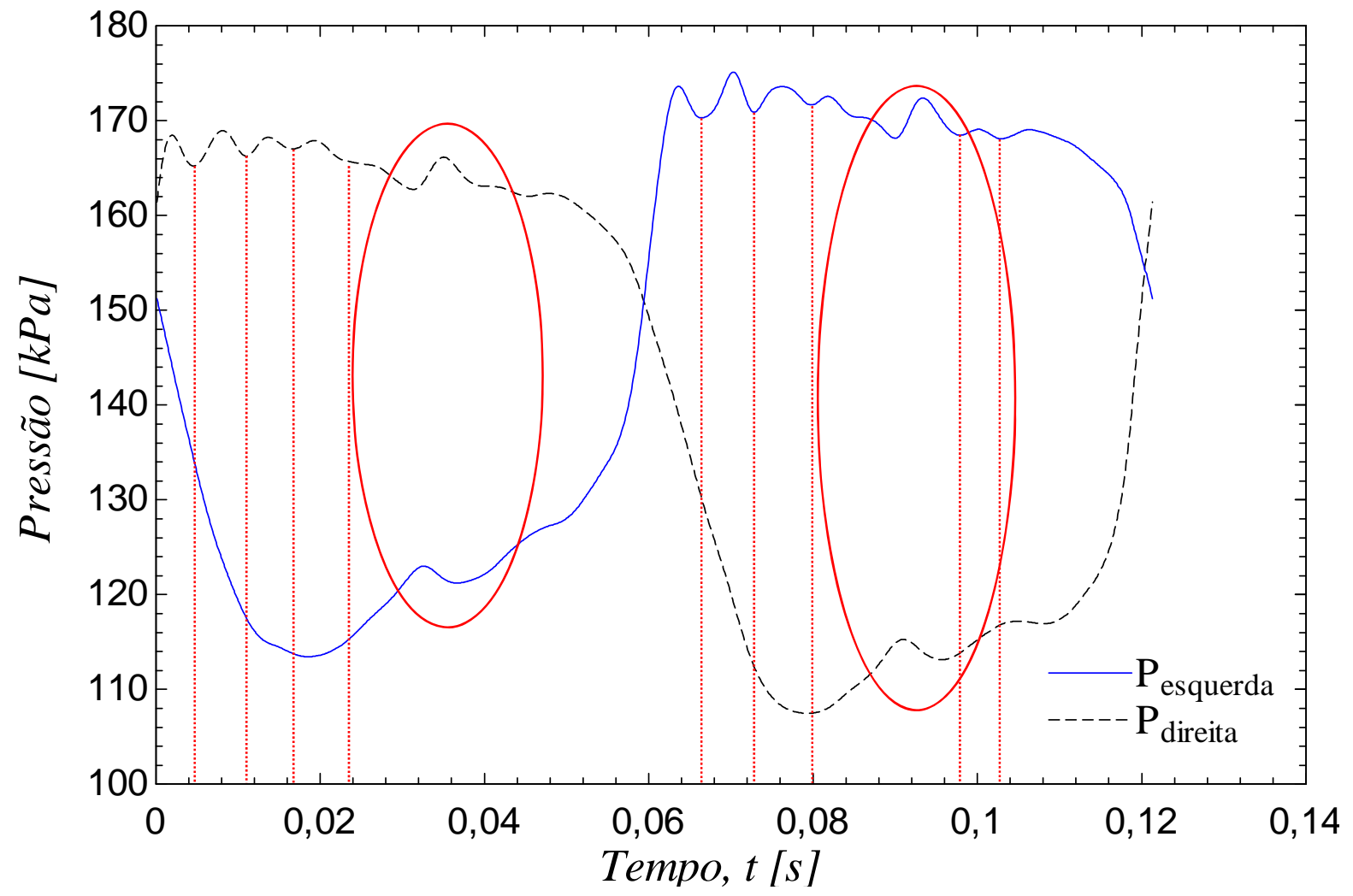

Figura 4.37 -Diagrama $P_{x}$ t para pressão de 0,75 bar a 494,7 rpm, com indicação das oscilações e linhas verticais para verificar o período de cada uma.

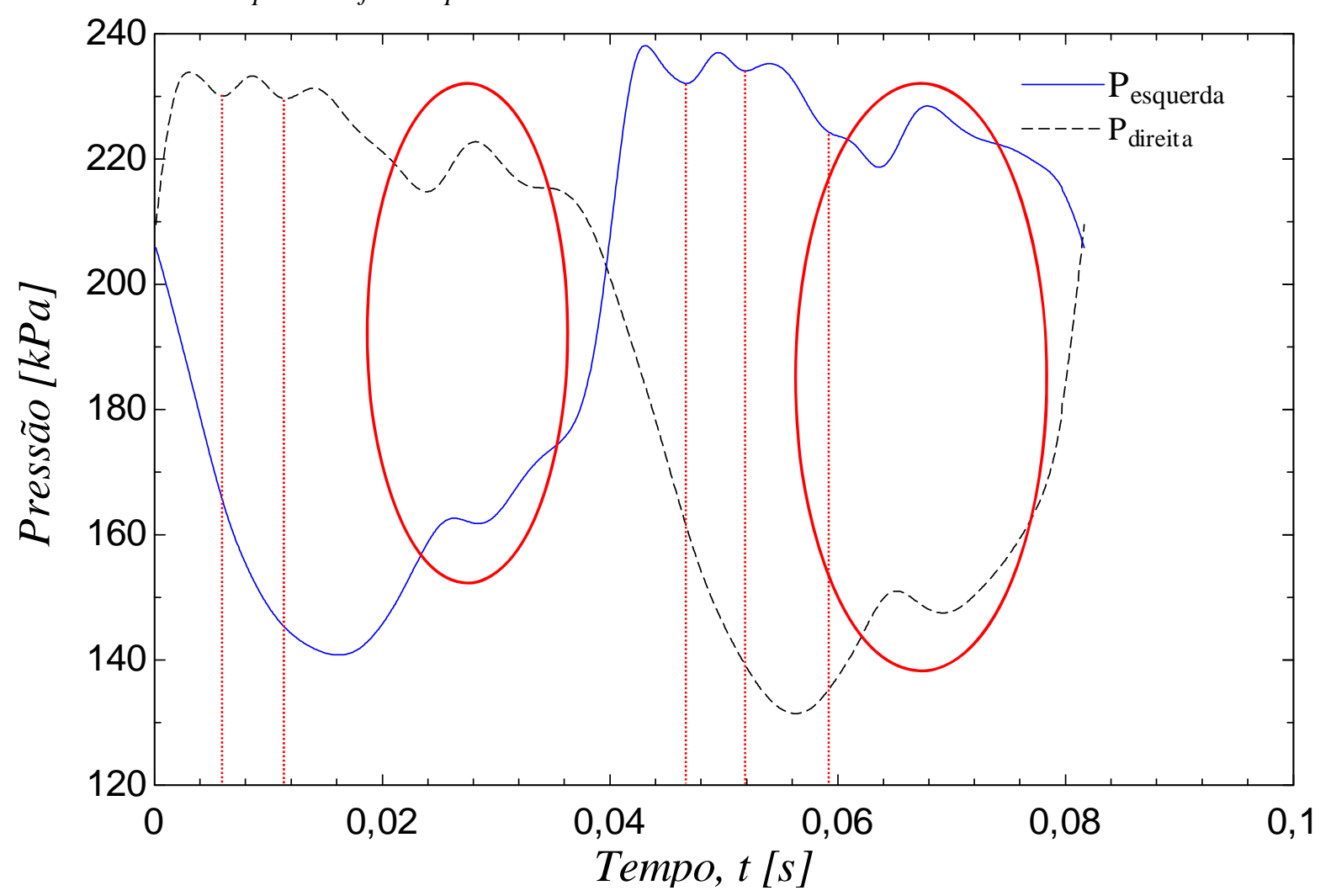

Figura 4.38 - Diagrama $P_{x}$ t para pressão nominal de 1,5 bar à 734,9 rpm, com indicação das oscilações $e$ linhas verticais para verificar o período de cada uma. 
Por serem ligadas apenas com a admissão, uma explicação possível é a reverberação de ondas de pressão na tubulação de admissão. A Figura 4.14 mostra um desenho esquemático do tubo de admissão e algumas cotas do mesmo.

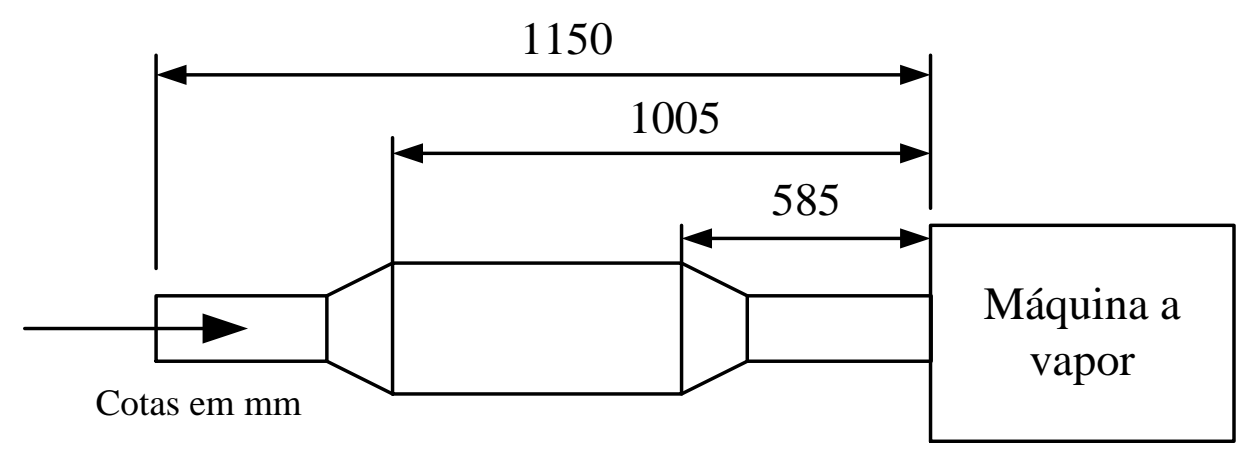

Figura 4.14 - Esquema do tubo de admissão com cotas

Sendo que as ondas de pressão se propagam na velocidade do som e considerando o ar como um fluido ideal, a velocidade de propagação das ondas de pressão é dada por:

$$
c=\sqrt{k \cdot R \cdot T}
$$

Sendo considerada uma temperatura de admissão média de $35^{\circ} \mathrm{C}$, e as propriedades do ar como $\mathrm{k}=1,4$ e $\mathrm{R}=287 \mathrm{~J} /(\mathrm{kg} \cdot \mathrm{K})$, tem-se que a velocidade das ondas de pressão é igual a 351,87 $\mathrm{m} / \mathrm{s}$. Para calcular o tempo que uma onda de pressão demora pra percorrer cada uma das três distâncias cotadas acima, deve-se levar em consideração que a onda de pressão deve percorrer duas vezes essa distâncias. Então o tempo necessário para percorrer cada distância é:

$$
\begin{aligned}
& t_{1}=\frac{2 \cdot 0,585}{351,85}=3,3 \mathrm{~ms} \\
& t_{1}=\frac{2 \cdot 1,005}{351,85}=5,7 \mathrm{~ms} \\
& t_{1}=\frac{2 \cdot 1,15}{351,85}=6,5 \mathrm{~ms}
\end{aligned}
$$

Todos esses tempos estão dentro dos períodos das oscilações, embora as oscilações com períodos próximos a 3,3 ms apenas aparecem na pressão de 3,5 bar. Portanto essa pode ser uma explicação para esse fenômeno. Se esse for o fenômeno correto, também deveriam 
aparecer oscilações na tubulação de escape, e elas apareceriam nas pressões mais baixas dos ciclos da máquina a vapor. Provavelmente existam oscilações na tubulação de escape, porém a conexão da saída da máquina a vapor com a tubulação de escape é feita através de um tubo flexível curvo, o que pode amortecer as oscilações na tubulação de escape, tornando-as imperceptíveis para a máquina a vapor. A tubulação de entrada por sua vez, é conectada com um tubo mais rígido e reto com a máquina a vapor, não oferecendo nenhum obstáculo à onda de pressão. Ambas as conexões são mostradas na Figura 4.16.

O fenômeno representado pelas elipses vermelhas onde as pressões das duas câmaras se comportam de forma simétrica pode ser explicado de duas formas. A primeira delas é a possibilidade de que devido ao movimento do pistão e suas respectivas folgas em relação à lateral do cilindro, pode passar um fluxo mássico de uma câmara para outra dentro do cilindro, aumentando a pressão de uma e diminuindo a pressão da outra. A outra possibilidade é a de que a velocidade do pistão pode sofrer uma oscilação brusca em algum ponto do seu curso, devido a problemas de folga, atrito ou até mesmo pequenos impactos entre peças do sistema biela manivela ou do próprio conjunto do pistão e cilindro.

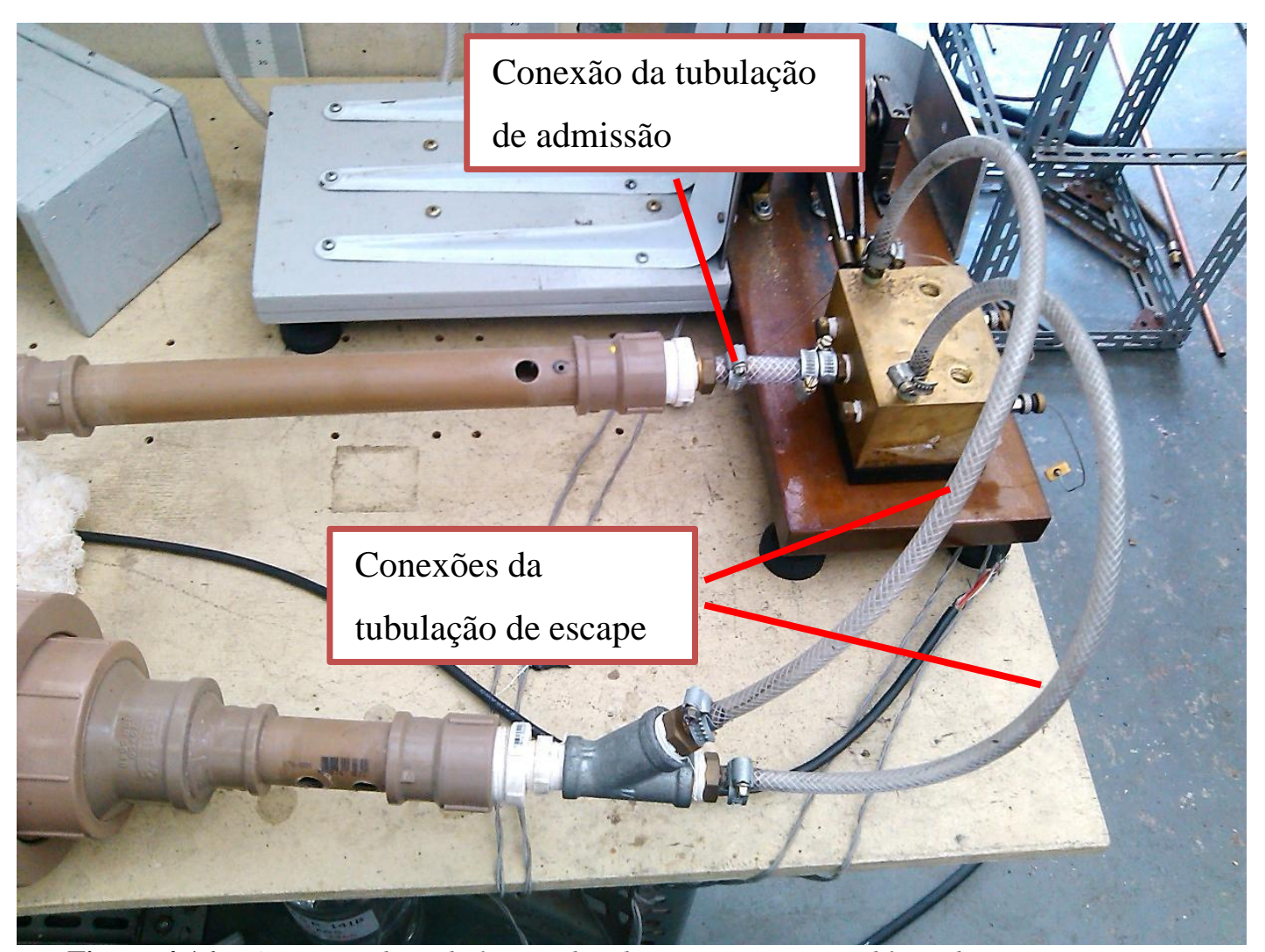

Figura 4.16 - Conexões das tubulações de admissão e escape no bloco da máquina a vapor. 
Dentre essas duas possibilidades, a que é mais plausível é a de que a velocidade do pistão sofre uma oscilação brusca em algum ponto do seu movimento. Primeiramente porque são interferências significativas na pressão de ambos os lados em períodos muito curtos, o que indica que deveria haver um fluxo de massa relativamente grande entre as duas câmaras do cilindro. Também devido a imperfeições na montagem do conjunto, com a máquina desligada era possível perceber que existiam dois ângulos extados da manivela onde a resistência ao movimento do sistema era maior, e a maioria das vezes que a máquina parava de funcionar devido à frenagem imposta, ela parava em um desses ângulos.

Na Tabela 4.7 estão os valores para o estudo do desempenho da máquina a vapor calculados a partir dos diagramas PxV experimentais. A vazão em massa utilizada para os cálculos é a mesma vazão indicada na Tabela 4.6. Os valores na tabela abaixo que diferem dos valores para o conjunto completo da máquina a vapor são o trabalho por ciclo (W/ciclo), o trabalho específico $(w)$, a potência média $\left(\operatorname{Pot}_{\text {media }}\right)$ e a eficiência isentrópica $(\eta)$.

Tabela 4.7 - Medidas de desempenho realizado pelo fluido

\begin{tabular}{|c|c|c|c|c|c|c|c|c|}
\hline $\begin{array}{c}\text { Pressão } \\
\text { [bar] }\end{array}$ & Medida & $\begin{array}{c}\text { Rotação } \\
\text { [rpm] }\end{array}$ & $\begin{array}{c}\mathrm{W}_{\text {iso }} \\
{[\mathrm{kJ} / \mathrm{kg}]}\end{array}$ & $\begin{array}{c}\mathrm{W} \\
{[\mathrm{kJ} / \mathrm{kg}]}\end{array}$ & $\begin{array}{c}\text { W/ciclo } \\
{[\mathrm{J}]}\end{array}$ & $\begin{array}{c}\text { Pot }_{\text {media }} \\
{[\mathrm{W}]}\end{array}$ & $\begin{array}{c}\dot{\mathrm{m}} \\
{[\mathrm{g} / \mathrm{s}]}\end{array}$ & $\eta_{\text {iso }}[\%]$ \\
\hline \multirow{7}{*}{0,5} & 1 & 792,56 & 45,02 & 7,77 & 1,323 & 17,48 & 2,25 & 17,27 \\
\hline & 2 & 692,24 & 45,78 & 8,83 & 1,652 & 19,06 & 2,16 & 19,28 \\
\hline & 3 & 623,14 & 46,41 & 9,66 & 1,923 & 19,97 & 2,07 & 20,82 \\
\hline & 4 & 508,33 & 46,53 & 9,50 & 2,169 & 18,38 & 1,93 & 20,43 \\
\hline & 5 & 437,48 & 46,99 & 9,78 & 2,45 & 17,87 & 1,83 & 20,81 \\
\hline & 6 & 386,42 & 48,28 & 9,45 & 2,63 & 16,93 & 1,79 & 19,58 \\
\hline & 7 & 354,34 & 47,93 & 8,01 & 2,351 & 13,89 & 1,73 & 16,71 \\
\hline \multirow{5}{*}{0,75} & 1 & 729,85 & 46,75 & 8,20 & 1,556 & 18,93 & 2,31 & 17,55 \\
\hline & 2 & 658,06 & 47,37 & 8,73 & 1,793 & 19,66 & 2,25 & 18,43 \\
\hline & 3 & 604,20 & 47,93 & 9,31 & 2,028 & 20,42 & 2,19 & 19,43 \\
\hline & 4 & 552,52 & 48,04 & 8,79 & 2,063 & 19 & 2,16 & 18,29 \\
\hline & 5 & 494,74 & 48,59 & 9,25 & 2,32 & 19,13 & 2,07 & 19,04 \\
\hline \multirow{5}{*}{1} & 1 & 897,04 & 52,01 & 8,14 & 1,61 & 24,07 & 2,96 & 15,65 \\
\hline & 2 & 807,73 & 51,95 & 9,89 & 2,083 & 28,04 & 2,84 & 19,03 \\
\hline & 3 & 658,89 & 53,14 & 10,10 & 2,455 & 26,96 & 2,67 & 19,00 \\
\hline & 4 & 576,13 & 53,97 & 10,33 & 2,77 & 26,6 & 2,57 & 19,14 \\
\hline & 5 & 455,85 & 54,35 & 9,13 & 2,866 & 21,78 & 2,39 & 16,80 \\
\hline
\end{tabular}


Tabela 4.7 - Continuação

\begin{tabular}{|c|c|c|c|c|c|c|c|c|}
\hline $\begin{array}{c}\text { Pressão } \\
\text { [bar] }\end{array}$ & Medida & $\begin{array}{c}\text { Rotação } \\
\text { [rpm] }\end{array}$ & $\begin{array}{c}W_{\text {iso }} \\
{[\mathrm{kJ} / \mathrm{kg}]}\end{array}$ & $\begin{array}{c}\mathrm{W} \\
{[\mathrm{kJ} / \mathrm{kg}]}\end{array}$ & $\begin{array}{c}\text { W/ciclo } \\
{[\mathrm{J}]}\end{array}$ & $\begin{array}{c}\text { Pot }_{\text {media }} \\
{[\mathrm{W}]} \\
\end{array}$ & $\begin{array}{c}\dot{\mathrm{m}} \\
{[\mathrm{g} / \mathrm{s}]}\end{array}$ & $\eta_{\text {iso }}[\%]$ \\
\hline 1 & 6 & 591,43 & 53,74 & 11,56 & 3,106 & 30,63 & 2,65 & 21,51 \\
\hline \multirow{6}{*}{1,5} & 1 & 1358,57 & 56,52 & 5,64 & 1,045 & 23,67 & 4,20 & 9,98 \\
\hline & 2 & 1157,05 & 57,89 & 7,45 & 1,569 & 29,95 & 4,02 & 12,86 \\
\hline & 3 & 943,28 & 59,06 & 9,10 & 2,246 & 35,31 & 3,88 & 15,41 \\
\hline & 4 & 852,23 & 59,83 & 9,93 & 2,681 & 38,09 & 3,84 & 16,60 \\
\hline & 5 & 734,94 & 60,46 & 10,54 & 3,108 & 38,07 & 3,61 & 17,43 \\
\hline & 6 & 676,53 & 61,02 & 11,06 & 3,467 & 39,1 & 3,54 & 18,12 \\
\hline \multirow{6}{*}{2} & 1 & 1471,66 & 61,66 & 6,03 & 1,266 & 31,06 & 5,15 & 9,78 \\
\hline & 2 & 1335,29 & 62,68 & 6,82 & 1,539 & 34,25 & 5,02 & 10,89 \\
\hline & 3 & 1283,52 & 62,35 & 6,50 & 1,527 & 32,66 & 5,02 & 10,43 \\
\hline & 4 & 1229,21 & 63,01 & 7,19 & 1,741 & 35,67 & 4,96 & 11,41 \\
\hline & 5 & 1002,80 & 65,20 & 9,26 & 2,628 & 43,93 & 4,74 & 14,21 \\
\hline & 6 & 961,46 & 65,49 & 9,37 & 2,752 & 44,09 & 4,70 & 14,31 \\
\hline \multirow{8}{*}{2,5} & 1 & 1513,36 & 67,16 & 6,25 & 1,561 & 39,37 & 6,30 & 9,31 \\
\hline & 2 & 1524,24 & 66,95 & 5,74 & 1,424 & 36,17 & 6,31 & 8,57 \\
\hline & 3 & 1419,01 & 67,49 & 6,50 & 1,702 & 40,26 & 6,19 & 9,63 \\
\hline & 4 & 1262,77 & 68,47 & 8,29 & 2,396 & 50,43 & 6,08 & 12,11 \\
\hline & 6 & 1167,29 & 68,64 & 7,75 & 2,434 & 47,36 & 6,11 & 11,29 \\
\hline & 7 & 1093,29 & 69,58 & 5,95 & 1,954 & 35,6 & 5,98 & 8,55 \\
\hline & 8 & 962,07 & 70,79 & 9,04 & 3,264 & 52,34 & 5,79 & 12,77 \\
\hline & 9 & 704,43 & 74,01 & 10,73 & 4,738 & 55,62 & 5,18 & 14,50 \\
\hline \multirow{2}{*}{3} & 1 & 1363,06 & 68,87 & 3,61 & 1,149 & 26,1 & 7,23 & 5,24 \\
\hline & 2 & 1322,61 & 69,21 & 5,31 & 1,718 & 37,88 & 7,14 & 7,67 \\
\hline \multirow{6}{*}{3,5} & 1 & 1386,07 & 61,77 & 4,37 & 1,567 & 36,2 & 8,29 & 7,07 \\
\hline & 2 & 1202,74 & 62,80 & 7,05 & 2,846 & 57,04 & 8,09 & 11,22 \\
\hline & 3 & 1143,65 & 63,48 & 8,44 & 3,537 & 67,43 & 7,99 & 13,30 \\
\hline & 4 & 1006,65 & 65,21 & 9,73 & 4,509 & 75,65 & 7,78 & 14,92 \\
\hline & 5 & 1092,70 & 64,26 & 9,60 & 4,169 & 75,92 & 7,91 & 14,94 \\
\hline & 6 & 960,73 & 65,90 & 11,28 & 5,427 & 86,9 & 7,70 & 17,12 \\
\hline
\end{tabular}

As eficiências isentrópicas calculadas para o ciclo são em média $10 \%$ maiores que as referentes ao conjunto todo da máquina, escritas na Tabela 4.6, podendo chegar até $15 \%$ de 
diferença. A potência realizada pelo fluido varia entre 1,2 e 5,56 vezes a potência útil do conjunto da máquina a vapor. Essa diferença é devido aos atritos em todas as peças da máquina a vapor. 


\section{SIMULAÇÃO}

O objetivo da simulação realizada é estudar o comportamento real de um ciclo de uma máquina a vapor e comparar com o modelo teórico e com dados experimentais, avaliando quais as diferenças e estudando os motivos que afastam o funcionamento real do teórico. A máquina a vapor estudada para a simulação é uma máquina de dupla-ação (ambos os lados do pistão são pressurizados) e de expansão simples (apenas um estágio de expansão). A simulação foi elaborada e realizada no programa EES, e para a simulação são feitas algumas hipóteses simplificadoras:

a) Cada volume de controle possui propriedades uniformes em um instante t.

b) Não há vazamento de vapor entre as câmaras internas do motor durante o seu funcionamento.

c) As câmaras de admissão e de escape possuem propriedades constantes, iguais às características do vapor na admissão e no escape.

\subsection{MODELO FÍSICO}

A configuração estudada é de um modelo de máquina a vapor muito utilizada na revolução industrial. Um desenho esquemático da máquina a vapor estudada está na Figura 5.1. A máquina possui um cilindro principal onde está o pistão que realiza o trabalho. O pistão está preso em um eixo que se conecta a um sistema biela manivela. Na lateral do cilindro existem duas portas que conectam cada câmara do cilindro com as pressões de admissão e de escape. Existem duas válvulas do tipo carretel que deslizam dentro de um cilindro menor, fazendo com que existam três câmaras separadas nesse cilindro secundário. A câmara central está conectada com a pressão de admissão e as duas câmaras laterais estão conectadas com a pressão de escape. Ao se movimentar, a válvula carretel faz com que as portas fiquem abertas para a alta e para a baixa pressão, preenchendo as câmaras do cilindro principal. Sempre uma câmara está ligada à pressão de admissão e a outra à pressão de escape. A diferença de pressões dos dois lados do pistão gera uma força resultante, que movimenta o pistão e faz a manivela do pistão girar. O movimento das válvulas é comandado por um sistema biela- 
manivela que está preso no mesmo eixo que o sistema biela-manivela do pistão, e é acionada por esse mesmo eixo. No desenho, o bloco da máquina a vapor está em escala, e isso indica que as válvulas são menores que as portas, e não tampam as portas completamente. Assim, as câmaras principais sempre estão em contato com a alta pressão, com a baixa pressão ou com ambas. Não há nenhum instante que alguma câmara principal esteja totalmente fechada.

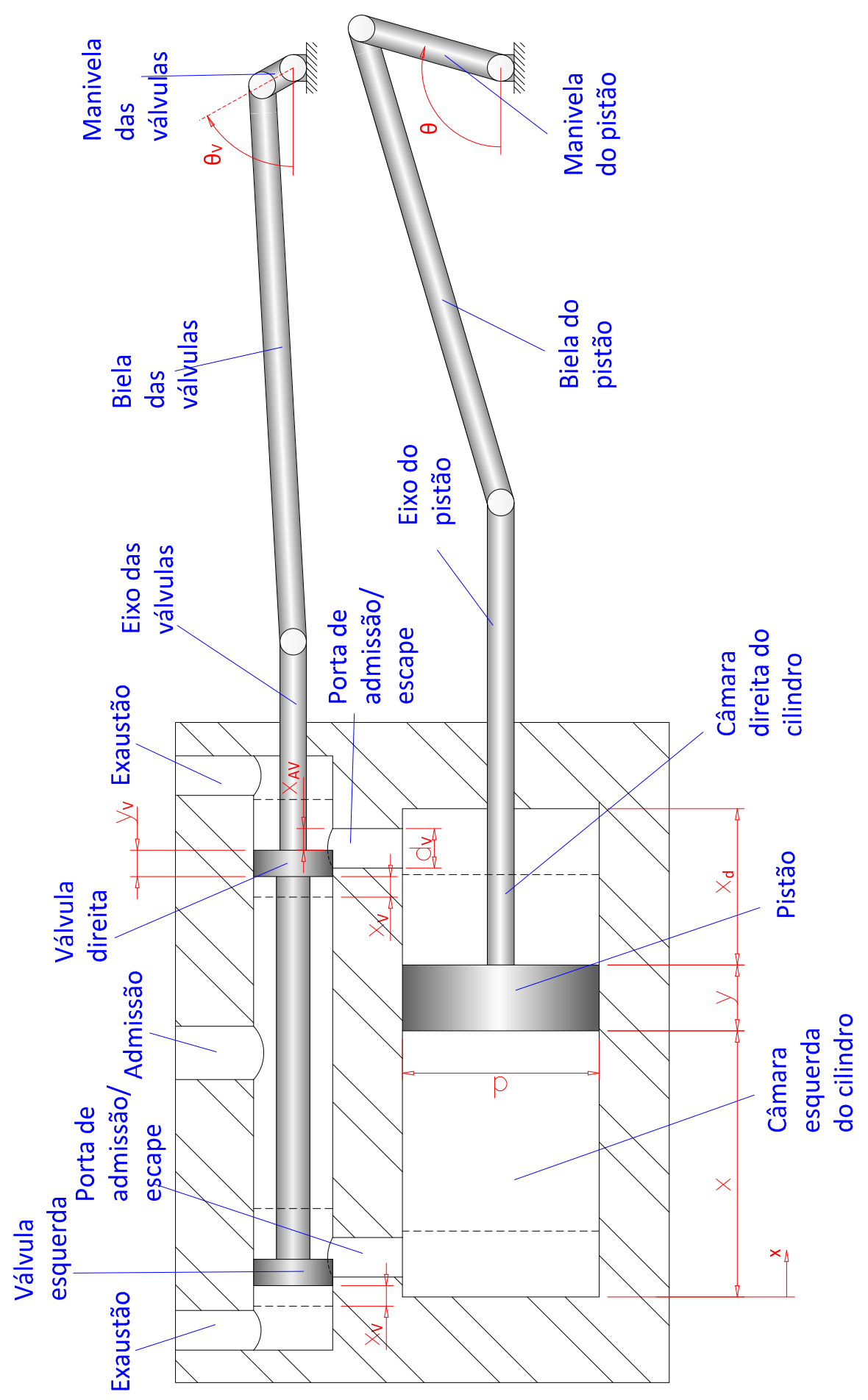

Figura 5.1 - Esquema com as cotas e peças principais da máquina a vapor estudada na simulação 


\subsection{MODELO MATEMÁTICO}

A simulação consiste na resolução das leis de conservação de energia e de massa em sua forma diferencial aplicada às diferentes câmaras da máquina a vapor para um intervalo de tempo t que corresponde a dez ciclos de funcionamento da máquina a vapor para uma rotação desejada. São 5 câmaras estudadas, duas câmaras no cilindro principal e três no cilindro das válvulas. As cinco câmaras são mostradas na Figura 5.2.

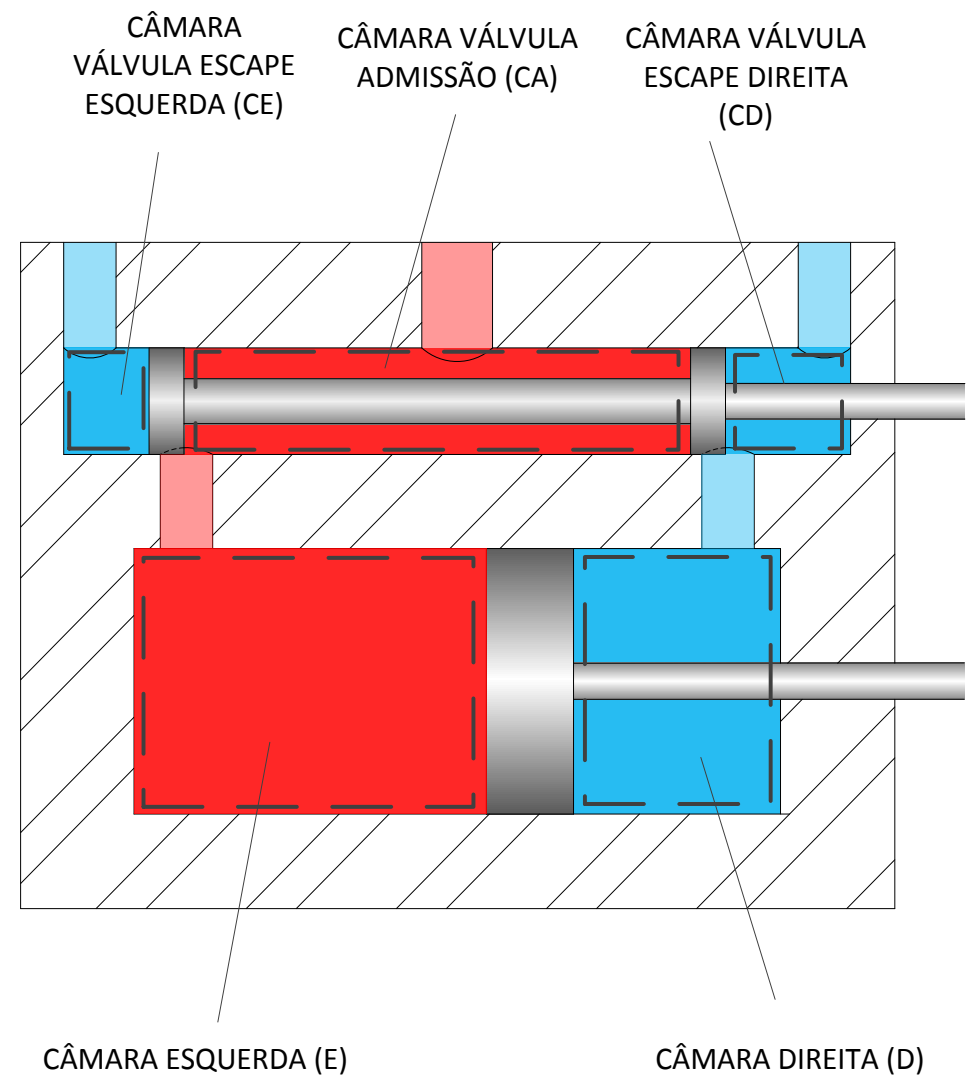

Figura 5.2 - Os cinco volumes de controle estudados

As equações a serem resolvidas para cada volume de controle da mostrado na Figura 5.2 estão escritas a seguir.

$$
\begin{gathered}
\dot{m}_{a d m} \cdot h_{a d m}+\dot{m}_{\text {escape }} \cdot h_{\text {escape }}-\frac{P \cdot d \forall}{d t}=m_{V C} \cdot \frac{d u}{d t}+u \cdot \frac{d m}{d t} \\
\frac{d m}{d t}=\dot{m}_{a d m}+\dot{m}_{\text {escape }}
\end{gathered}
$$




$$
\begin{gathered}
m=m_{i}+\int_{0}^{t} \frac{d m}{d t} \cdot d t \\
\frac{d \forall}{d t}= \pm A_{e / d} \cdot \dot{x}
\end{gathered}
$$

As cotas utilizadas para os cálculos das posições e relações geométricas são mostradas na Figura 5.3.

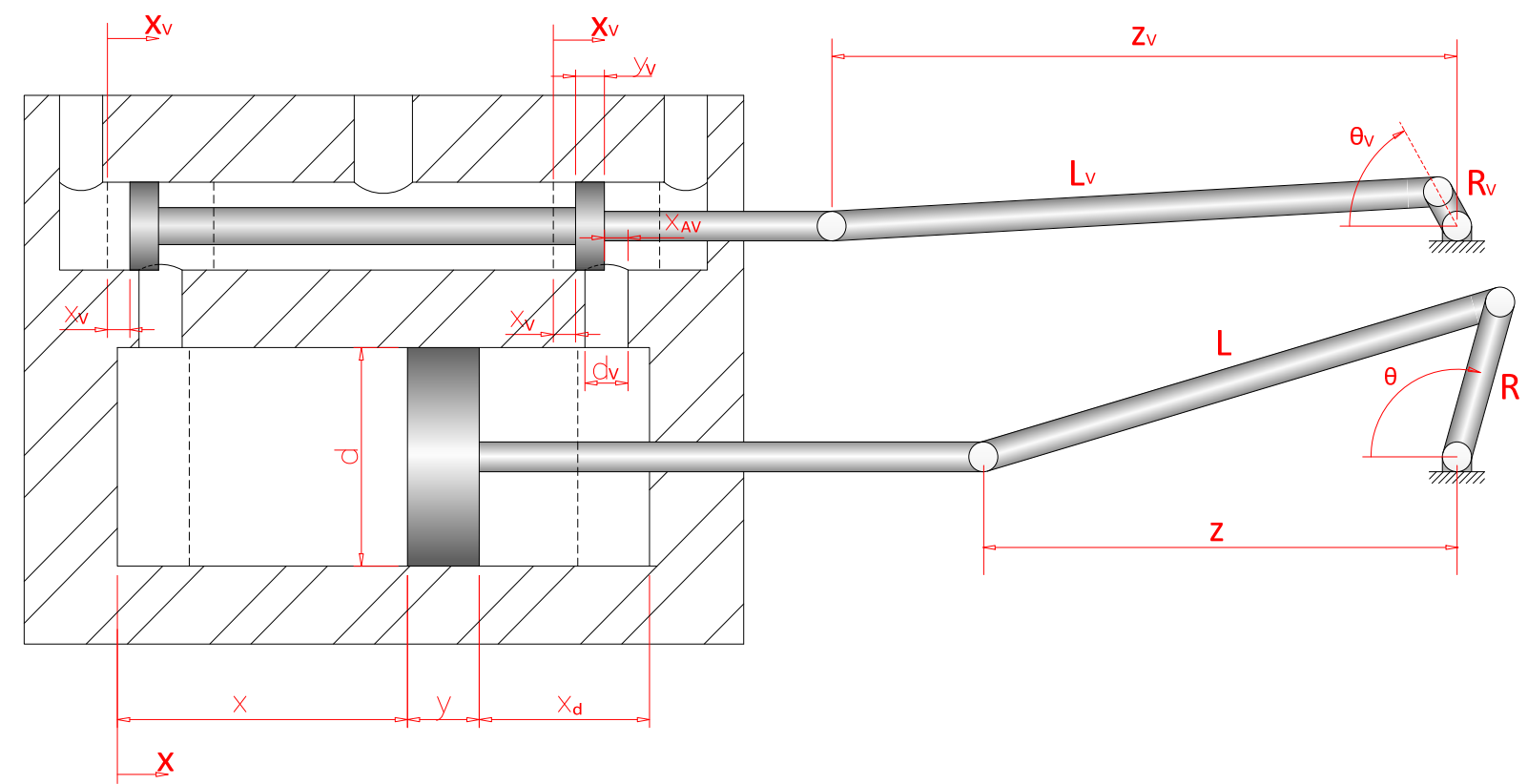

Figura 5.3 - Cotas utilizadas para o cálculo das posições e geometria da máquina a vapor.

As eqs. (5.5) até (5.11) são para o sistema biela-manivela, e interferem nas posições do pistão e das válvulas, na área de abertura das portas, no volume e na variação do volume de cada câmara.

$$
\begin{gathered}
z=R \cdot \cos (\theta)+\sqrt{L^{2}-R^{2} \cdot \sin ^{2}(\theta)} \\
x=x_{0}+L+R-z \\
z_{V}=R_{V} \cdot \cos \left(\theta_{V}\right)+\sqrt{{L_{V}}^{2}-R_{V}{ }^{2} \cdot \sin ^{2}\left(\theta_{V}\right)}
\end{gathered}
$$




$$
\begin{aligned}
& x_{V}=L_{V}+R_{V}-z_{V} \\
& \dot{x}=R \cdot\left(\sin (\theta)+\frac{R \cdot \sin (\theta) \cdot \cos (\theta)}{\sqrt{L^{2}-R^{2} \cdot \sin ^{2}(\theta)}}\right) \cdot \dot{\theta} \\
& \dot{x}_{V}=R_{V} \cdot\left(\sin \left(\theta_{V}\right)+\frac{R_{V} \cdot \sin \left(\theta_{V}\right) \cdot \cos \left(\theta_{V}\right)}{\sqrt{L_{V}^{2}-R_{V}^{2} \cdot \sin ^{2}\left(\theta_{V}\right)}}\right) \cdot \dot{\theta} \\
& \theta=\theta_{i}+\int_{0}^{t} \dot{\theta} \cdot d t
\end{aligned}
$$

Os fluxos mássicos que ocorrem no interior da máquina a vapor são mostrados na Figura 5.4.

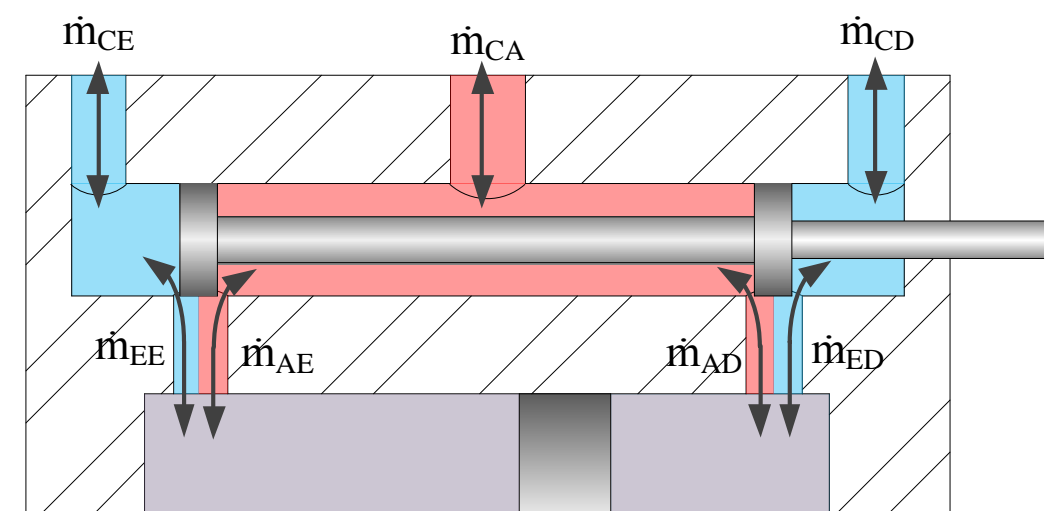

Figura 5.4 - Fluxos de massa calculados na simulação

Para a determinação do fluxo de massa que escoa entre as câmaras, primeiramente deve-se determinar a área de abertura de cada porta. As cotas importantes para os cálculos estão na Figura 5.5. 


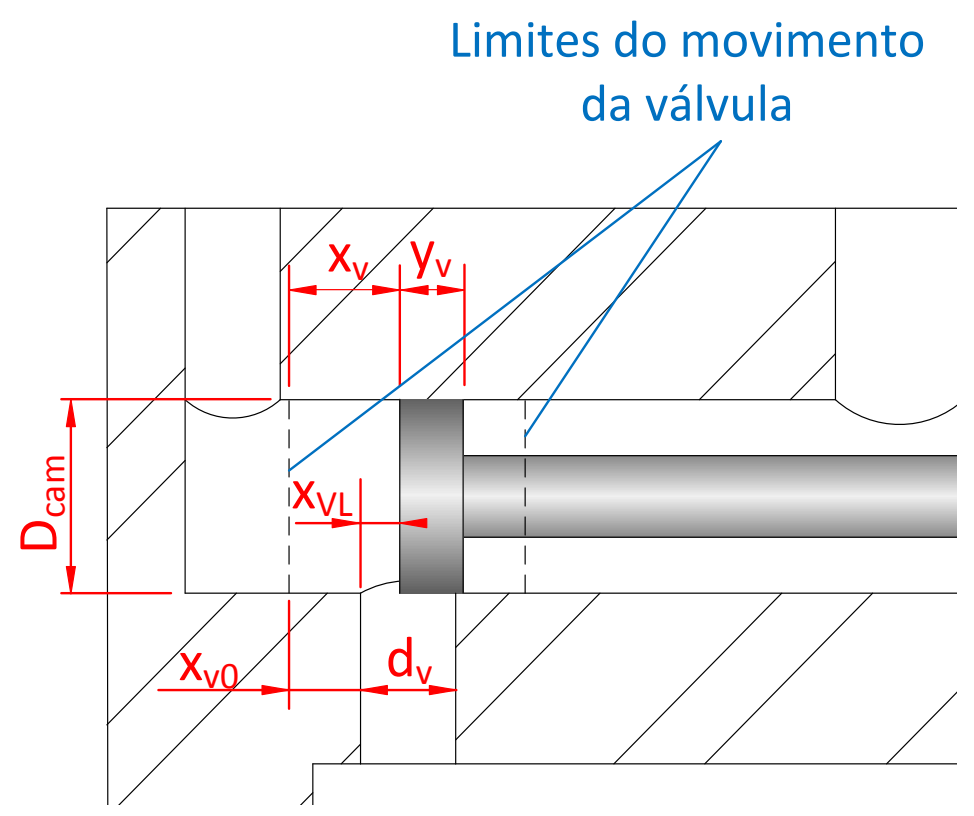

Figura 5.5 - Cotas para a determinação da área de abertura das válvulas

A posição $\mathrm{X}_{\mathrm{V}}$ das válvulas é determinada pela eq.(5.8). Com a posição da válvula calcula-se a abertura da porta $\mathrm{x}_{\mathrm{VL}}$, onde $\mathrm{o}$ índice $L$ pode assumir os valores ae (admissão câmara esquerda), ee (escape câmara esquerda), $a d$ (admissão câmara direita) e $e d$ (escape câmara direita). As equações das aberturas das portas estão descritas a seguir:

$$
\begin{gathered}
x_{V a e}=\left\{\begin{array}{c|c}
0 & x_{V 0}+d_{V}-y_{V} \leq x_{V} \\
x_{V 0}+d_{V}-x_{V}-y_{V} & \begin{array}{c}
x_{V 0}-y_{V} \leq x_{V} \leq x_{V 0}+d_{V}-y_{V} \\
x_{V} \leq x_{V 0}-y_{V}
\end{array}
\end{array}\right. \\
x_{V e e}=\left\{\begin{array}{c}
0 \\
x_{V}-x_{V 0} \\
d_{V}
\end{array}\right. \\
\begin{array}{c}
x_{V 0} \leq x_{V} \leq x_{V 0}+d_{V} \\
x_{V 0}+d_{V} \leq x_{V}
\end{array} \\
x_{V a d}=x_{V e e} \\
x_{V e d}=x_{V a e}
\end{gathered}
$$

Com esses valores, pode-se determinar a área de abertura e o diâmetro hidráulico de cada porta. Para cada abertura, a área e o perímetro molhado estão mostrados na Figura 5.6. Esses valores são calculados com as eqs. (5.17) e (5.18), respectivamente, e o diâmetro hidráulico é calculado utilizando a eq. (5.19). 


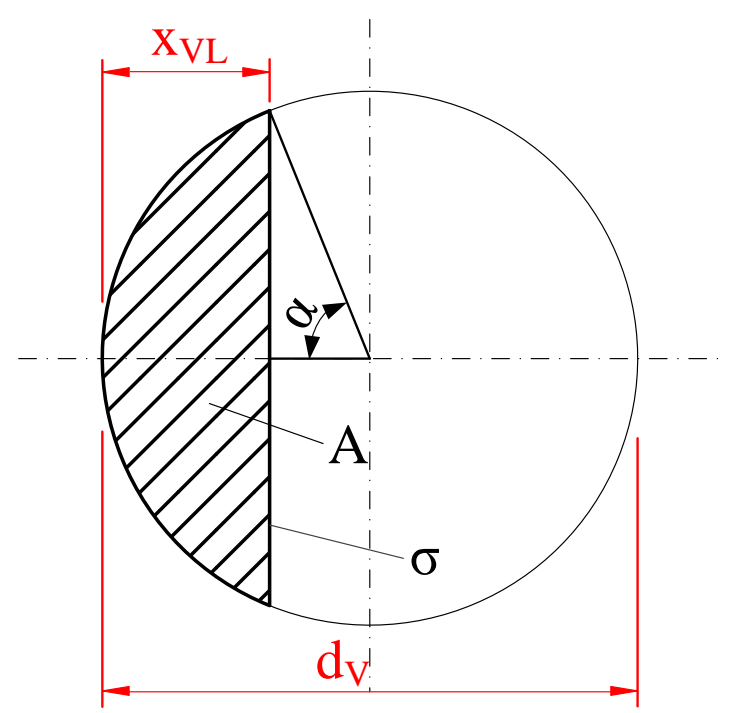

Figura 5.6 - Cotas para calcular a área, o perímetro molhado e o diâmetro hidráulico de abertura da porta

$$
\begin{gathered}
\alpha=\operatorname{acos}\left(1-2 \cdot \frac{x_{V L}}{d_{V}}\right) \\
A=\frac{d_{V}^{2}}{4} \cdot[\alpha-\cos (\alpha) \cdot \sin (\alpha)] \\
\sigma=d_{V} \cdot[\alpha+\sin (\alpha)] \\
D_{H}=\frac{4 \cdot A}{\sigma}
\end{gathered}
$$

Para o cálculo da vazão em massa, foi utilizada a teoria de escoamento compressível em escoamento isentrópico através de um orifício. Ao se estudar o fluxo entre duas câmaras, a câmara com pressão maior é considerada a montante e a com pressão menor é a jusante. As grandezas utilizadas estão na Figura 5.7. 


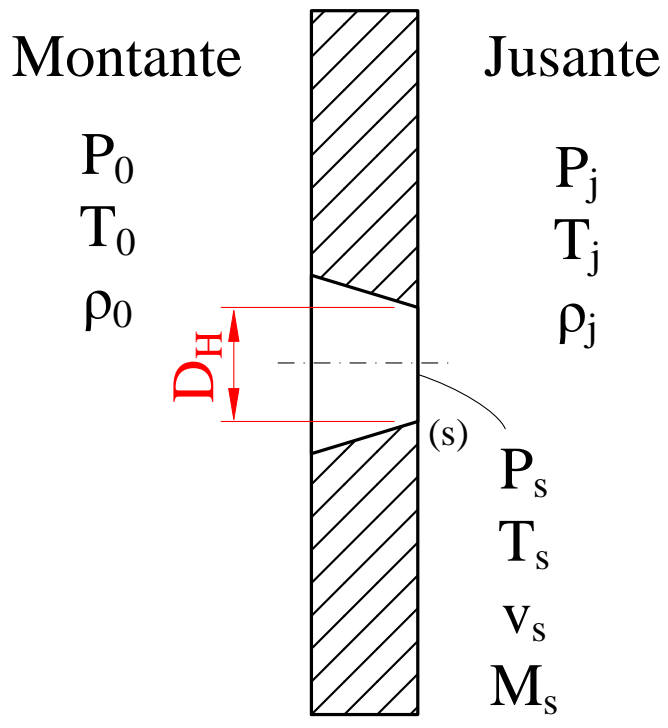

Figura 5.7 - Esquema de orifício utilizado para o cálculo da vazão em massa através das portas

As equações para determinar a vazão em massa entre duas câmaras estão descritas abaixo.

$$
M_{s}=\sqrt{\left(\left(\frac{P_{0}}{P_{j}}\right)^{\left(\frac{k-1}{k}\right)}-1\right) \cdot \frac{2}{k-1}} \quad \mid 0 \leq M_{s} \leq 1
$$

Onde $\mathrm{M}_{\mathrm{S}}$ é o número de Mach na seção de menor diâmetro, definido pela eq.(5.19).

$$
\begin{gathered}
T_{s}=\frac{T_{0}}{1+\left(\frac{k-1}{2}\right) \cdot M_{s}{ }^{2}} \\
v_{s}=M_{s} \cdot \sqrt{k \cdot R \cdot T_{s}} \\
\rho_{s}=\frac{\rho_{0}}{\left(1+\left(\frac{k-1}{2}\right) \cdot M_{s}{ }^{2}\right)^{\left(\frac{1}{k-1}\right)}} \\
R e_{D}=\frac{\rho_{s} \cdot v_{s} \cdot D_{H}}{\mu}
\end{gathered}
$$


A razão entre o menor e o maior diâmetro do escoamento é definido como $\beta$, sendo que o diâmetro hidráulico se refere à abertura da válvula e o diâmetro $\mathrm{D}_{\text {cam }}$ está indicado na Figura 5.5.

$$
\beta=\frac{D_{H}}{D_{\text {cam }}}
$$

O coeficiente de descarga é dado por:

$$
\begin{gathered}
\mathrm{C}_{D}=0,5959+0,0132 \cdot \beta^{2,1}-0,184 \cdot \beta^{8}+0,0029 \cdot \beta^{2,5} \cdot\left(\frac{10^{6}}{R e_{D}}\right)^{\frac{3}{4}} \\
\dot{\mathrm{m}}=\rho_{S} \cdot v_{S} \cdot A \cdot C_{D}
\end{gathered}
$$

As equações de (5.20) até (5.23) são para escoamento de fluido compressível (Brunetti, 2005) e a equação (5.26) do $C_{D}$ é para um orifício e está escrita na NBR ISO 5167-1 (1994). Entre as condições de uso da eq. (5.26) está que o menor diâmetro deve ser maior que 12,5 mm, o que não ocorre neste caso, mas só foram encontradas correlações para furos com diâmetro até $2 \mathrm{~mm}$ ou maior que $12,5 \mathrm{~mm}$, e nenhum dos dois se aplica totalmente neste caso.

As grandezas geométricas da máquina a vapor e as constantes das simulações utilizadas estão na tabela abaixo.

Tabela 5.1 - Condições das simulações e valores iniciais.

\begin{tabular}{c|c}
\hline $\mathrm{d}=0,03 \mathrm{~m}$ & $\mathrm{~d}_{\mathrm{V}}=0,006 \mathrm{~m}$ \\
\hline $\mathrm{y}=0,01 \mathrm{~m}$ & $\mathrm{y}_{\mathrm{V}}=0,004 \mathrm{~m}$ \\
\hline $\mathrm{L}=0,1 \mathrm{~m}$ & $\mathrm{LV}=0,1106 \mathrm{~m}$ \\
\hline $\mathrm{R}=0,022 \mathrm{~m}$ & $\mathrm{RV}=0,0054 \mathrm{~m}$ \\
\hline $\mathrm{P}_{\text {Ei }}=\mathrm{P}_{\text {máx }}$ & $\mathrm{P}_{\mathrm{Di}}=\mathrm{P}_{\text {min }}$ \\
\hline $\mathrm{T}_{\mathrm{Ei}}=\mathrm{T}_{\text {máx }}$ & $\mathrm{T}_{\mathrm{Di}}=\mathrm{T}_{\text {min }}$ \\
\hline$\theta_{\mathrm{i}}=0$ rad & ciclos simulados $=10$ ciclos \\
\hline Pontos/ciclo $=1000$ pontos & $\mathrm{x}_{0}=0,1 \mathrm{~m}$ \\
\hline $\mathrm{d}_{\text {cam }}=0,012 \mathrm{~m}$ & $\mathrm{~d}_{\text {admissão }}=0,008 \mathrm{~m}$ \\
\hline $\mathrm{d}_{\text {escape }}=0,006 \mathrm{~m}$ & \\
\hline
\end{tabular}


O algoritmo completo da simulação está escrito e comentado no APÊNDICE C - algoritmo da simulação termodinâmica da máquina a vapor.

Para a resolução das equações diferenciais foi utilizado o comando Integral do programa. Segundo o manual do EES, essa função utiliza uma variante da regra do trapézio juntamente com um algoritmo "preditor-corretor" de segunda ordem. Esse algoritmo é desenvolvido para a resolução combinada de equações algébricas e diferenciais que resultam quando o integrando é uma função complexa de outras variáveis. O algoritmo é especialmente feito para equações stiff, EES (1998).

As configurações e critérios de convergência utilizados para a resolução das equações foram:

a) Residual Relativo $<10^{-6}$

b) Variação Máxima da Variável $<10^{-9}$

c) Usar a extrapolação de Richardson

d) Foram utilizados passos constantes ao longo da integração, e o passo é um milésimo do tempo de um ciclo.

O Residual Relativo é um teste de convergência e é calculado como sendo a diferença do lado esquerdo da equação e do lado direito da equação dividida pela magnitude do lado esquerdo da equação. Se o cálculo for menor que o valor estipulado, o programa considera que a equação convergiu. O critério Variação Máxima da Variável faz com que o programa pare o cálculo se nenhuma variável tiver uma mudança em seu valor maior que o estipulado entre uma iteração para outra (http://www.fchart.com/ees/eeshelp/64ei_ji.htm).

\subsubsection{Ajustes no algoritmo}

Em algumas simulações o sistema de cálculos do EES falhava na convergência das equações. Após vários testes, foi notado que eram sempre em alguns pontos ou condições específicas. As falhas ocorriam em duas condições específicas.

A primeira delas é quando o pistão se encontra em algum dos pontos mortos, pois como será verificado posteriormente, nesses pontos uma das duas câmaras está no processo de admissão, 
e tem uma pressão igual ou muito próxima da pressão de admissão. Isso faz com que nesse ponto algumas grandezas das equações tendem a zero, e as pequenas oscilações numéricas representam uma variação grande em porcentagem, fazendo com que o programa não reconhecesse que as equações convergiram.

A segunda condição que dificultava a convergência das equações acontece em processos onde o pistão se move ao longo do cilindro, e devido à baixa rotação simulada, a pressão dentro da câmara é igual ou muito próxima da pressão de admissão e permanece inalterada por longos períodos. O que ocorre nessa condição é que a simulação é feita de forma que a massa sempre flui da maior para a menor pressão, e a entalpia do fluxo é a entalpia da montante. Então se a pressão dentro da câmara estiver ligeiramente abaixo da pressão de admissão, a massa de fluido vai da admissão para a câmara do cilindro. Esse pequeno fluxo mássico faz com que a pressão dentro da câmara fique acima da pressão de admissão, fazendo com que na próxima iteração a massa flua da câmara do cilindro para a câmara de admissão. Com a saída de uma ínfima massa de dentro do cilindro, a pressão interna se torna menor que a pressão de admissão, reiniciando o ciclo. Esse processo faz a pressão interna do cilindro oscilar em torno da pressão de admissão, mas em cada oscilação, a câmara considerada como montante se altera, e consequentemente a entalpia considerada muda. Por vezes as condições de dentro da câmara de da admissão são consideravelmente diferentes, fazendo com que a entalpia do fluxo se alterne entre dois valores diferentes.

Devido à oscilação da pressão interna do cilindro e da entalpia que é considerada nos cálculos, as equações não convergiam, pois os valores mudavam consideravelmente entre uma iteração e outra.

Para resolver o problema de ruído numérico acima mencionado, foi criado um fator multiplicativo que não possui qualquer significado físico, mas que acerta a vazão em massa quando a diferença de pressão entre as duas câmaras envolvidas no fluxo de massa estiver abaixo de um valor estipulado como referência. Esse fator varia entre 0 e 1, provocando um "amortecimento" e diminuindo o fluxo de massa e a oscilação da pressão e demais variáveis. Para esse fator foram testadas algumas equações que possuem valor 0 para quando a variável é igual a uma referência mínima e valor 1 para a variável ser igual a uma referência máxima. 
Foram feitos testes de ajustes para amortecer o ruído numérico, e a equação que trouxe melhores resultados é a eq. (5.28). O comportamento de todas as funções testadas é mostrado na Figura 5.8.

$$
\mathrm{f}_{x^{3}}=\left(\frac{x-x_{\min }}{x_{\max }-x_{\min }}\right)^{2} \cdot\left(\frac{3 \cdot x_{\max }-2 \cdot x-x_{\min }}{x_{\max }-x_{\min }}\right)
$$

Essa equação só é utilizada se a diferença de pressão entre as duas câmaras em que existe o fluxo de massa for menor que $0,5 \mathrm{kPa}$, e como referência mínima foi utilizado uma diferença de pressão de $0 \mathrm{~Pa}$.

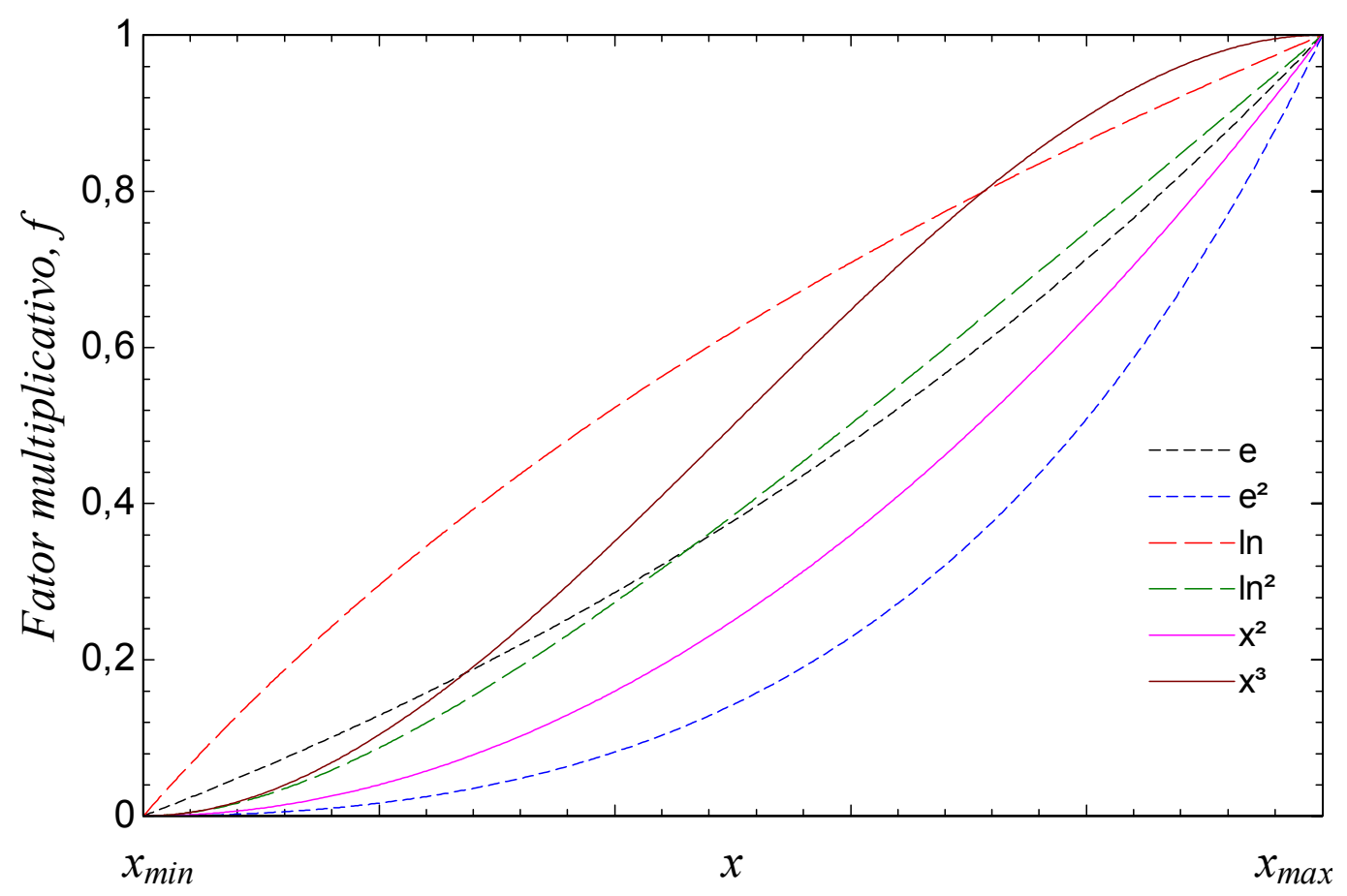

Figura 5.8 - Fator multiplicativo f calculado por meio de diferentes equações.

Após a implantação desse fator, outro aspecto que dificultava a convergência apareceu. Quando o pistão chega ao ponto morto de menor volume, em muitos casos a pressão interna do cilindro é maior que a pressão de admissão, e quando o pistão se afasta do ponto morto, a pressão interna do cilindro é menor que a pressão de admissão. No instante que a pressão interna fica menor que a pressão de admissão, a entalpia e a temperatura do fluxo mudam repentinamente, pela mudança entre montante e jusante, e isso dificultava a convergência da solução. Em alguns casos, o mesmo ocorria para o ponto porto onde se inicia o escape. 
Para resolver esse problema, foi utilizada também a eq (5.28), porém com a finalidade de fazer uma transição suave entre as duas entalpias e temperaturas quando a pressão passar pelo ponto da pressão de admissão nos extremos do curso do pistão. Essa equação é utilizada a partir de uma porcentagem de referência do curso do pistão que indica que ele está chegando ao ponto morto. Essa porcentagem é definida como $r_{\text {xref }}$ e foi utilizado um valor de 0,001 $(0,1 \%)$. Isso significa que essa transição ocorre apenas quando faltar menos de $0,1 \%$ do seu curso para o pistão atingir o respectivo ponto morto.

\subsection{CONFIGURAÇÕES DAS SIMULAÇÕES}

\subsubsection{Configuração rotativa com válvulas carretel}

Foram realizadas simulações considerando a configuração rotativa mostrada na Figura 5.1. Todas as dimensões do motor a vapor utilizadas nessa configuração são da máquina testada experimentalmente, e as rotações, pressões de admissão e escape utilizados para as simulações são as mesmas obtidas experimentalmente nessa máquina. Essa configuração foi testada com ar para que seja possível comparar os resultados com os dados experimentais.

As condições simuladas são as mesmas condições obtidas experimentalmente, para que se possa fazer uma comparação posteriormente. Os dados de entrada são as pressões de entrada e saída, temperaturas de entrada e saída e a rotação da máquina a vapor que estão na Tabela 4.5 e na Tabela 4.6.

\subsubsection{Configuração rotativa com válvulas de acionamento instantâneo}

Simulações da mesma máquina rotativa foram feitas considerando que as válvulas possuem um acionamento instantâneo. Assim, a abertura das válvulas de admissão e de escape podem assumir apenas os valores 'Aberta' e 'Fechada'. Os instantes de abertura e fechamento das 
válvulas são escolhidos de forma a se obter a maior eficiência isentrópica da máquina a vapor, ou seja, os pontos de abertura e fechamento da Figura 2.2. Para isso, a válvula de admissão abre no PMS e fecha no ponto dado pela eq. (3.55), enquanto a válvula de escape abre no PMI e fecha na razão de compressão dada pela eq.(3.56). Essas simulações foram realizadas para estudar qual a influência do período de abertura e fechamento das válvulas na eficiência isentrópica do motor e ver se é possível atingir altas eficiências se o projeto e as tecnologias empregadas forem otimizadas.

\subsection{RESULTADOS E ANÁLISE DA SIMULAÇÃO}

As simulações foram realizadas considerando propriedades de fluidos reais. Foram programadas e calculadas no programa EES. Apenas uma geometria da máquina a vapor foi simulada. Essa geometria vem da máquina que foi construída no laboratório, e na qual foram realizados os testes. As grandezas geométricas, as condições iniciais e as condições de simulação estão escritas na Tabela 5.1.

\subsubsection{Resultados para a simulação com válvulas carretel.}

Assim como ocorre com os dados adquiridos experimentalmente, as duas câmaras trabalham de forma similar e antagônica, e ao plotar o diagrama de pressões em função da posição relativa do pistão, o digrama indicado fica como o da Figura 4.25. Ao plotar o diagrama PxV da câmara direita em função da posição relativa do pistão em relação à câmara direita, os dois diagramas ficam no mesmo sentido, como acontece na Figura 5.9. Nesse diagrama $\mathrm{PxV}$, quando a posição relativa do pistão é igual a zero, significa que o pistão está no ponto morto de menor volume, e quando a posição relativa vale 1 , o pistão está no ponto morto de maior volume.

Nessa imagem, pode-se notar que as pressões do diagrama para a câmara direita são menores que as pressões da câmara esquerda. O principal motivo para que isso ocorra é que os trechos 
do curso do pistão onde a válvula de admissão das duas câmaras permanece aberta são diferentes, e o mesmo ocorre para as válvulas de escape. Analisando a Figura 5.10 é possível observar que a área da admissão do lado esquerdo $\left(\mathrm{A}_{\mathrm{AE}}\right)$ e a área de escape do lado direito $\left(\mathrm{A}_{\mathrm{ED}}\right)$ permanecem em seus máximos durante um curso maior do pistão do que a área de admissão do lado direito $\left(\mathrm{A}_{\mathrm{AD}}\right)$ e a área de escape do lado esquerda $\left(\mathrm{A}_{\mathrm{EE}}\right)$. A Admissão esquerda permanece totalmente aberta por aprox.. 30\% do curso do pistão enquanto a admissão do lado direito permanece aberta por aprox.. 20\% do curso do pistão. No caso das aberturas do escape de cada câmara essas porcentagens se invertem, ou seja, o escape da câmara esquerda permanece aberto por aprox.. 20\% do curso do pistão e o escape direito permanece aberto por aprox.. $30 \%$ do curso do pistão.

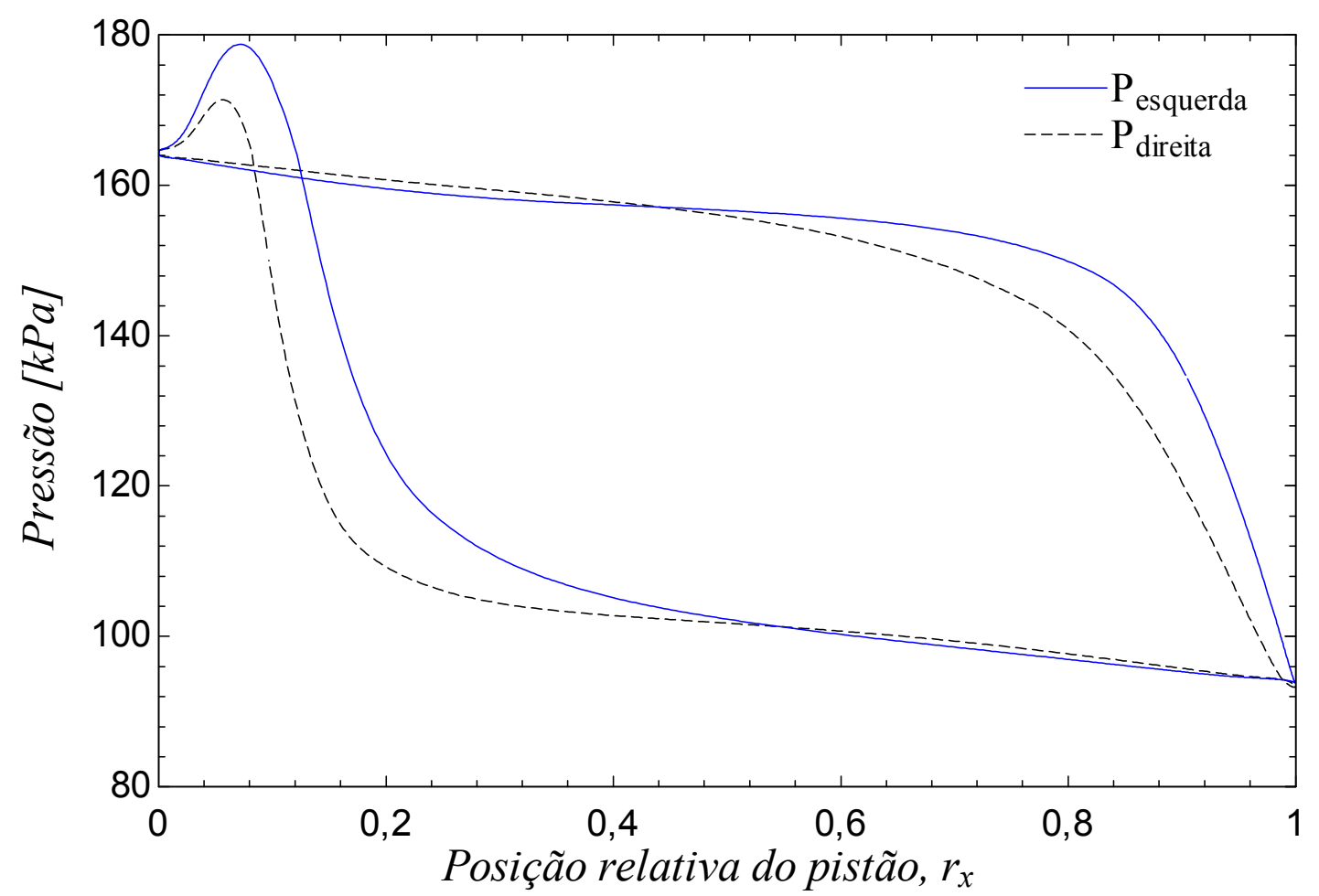

Figura 5.9 - Diagrama PxV para as câmaras esquerda e direita da máquina a vapor para pressão nominal de 0,5 bar à 792,6 rpm. 


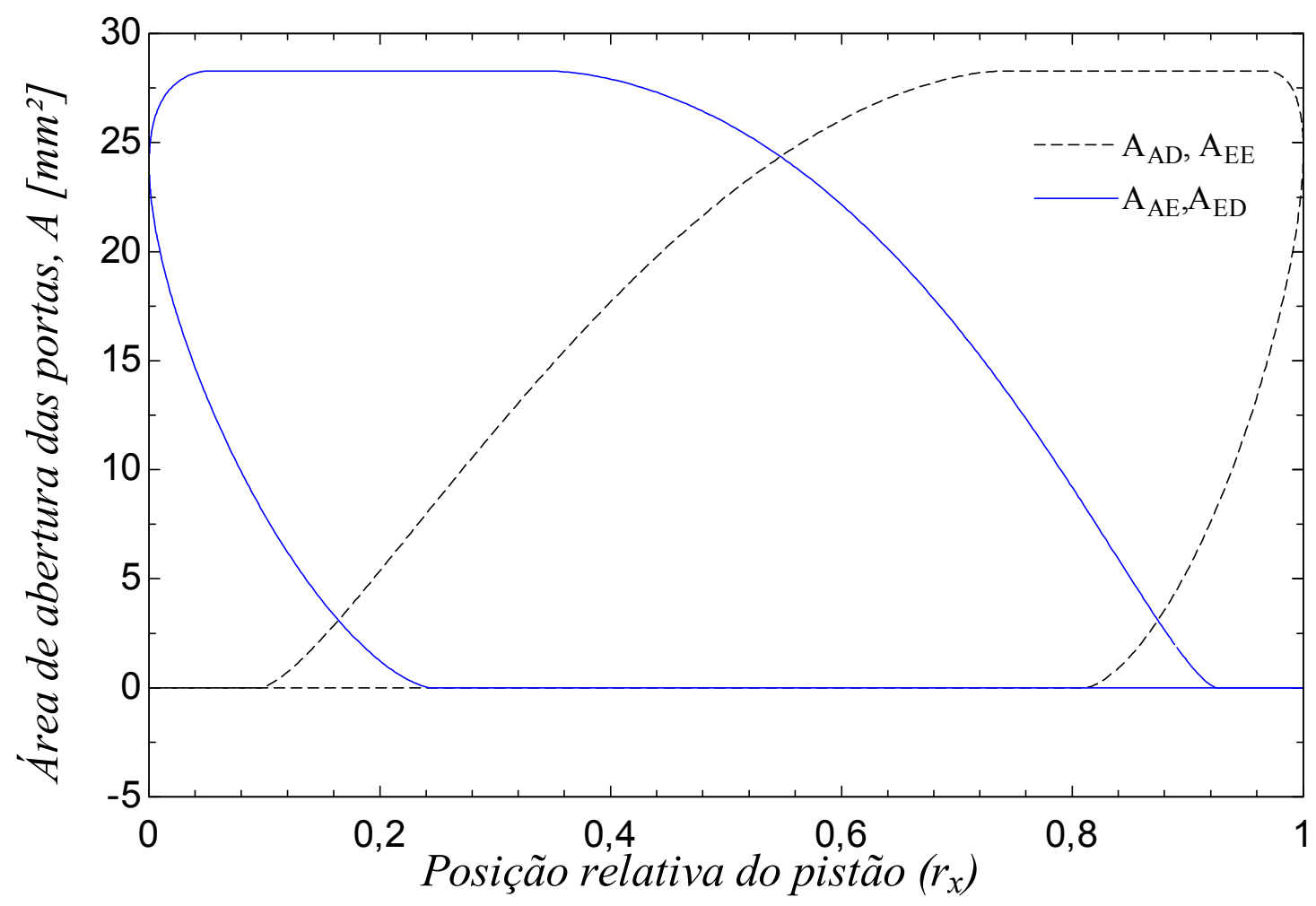

Figura 5.10 - Área de abertura das portas em função da posição relativa do pistão

Por questões visuais, os diagramas $\mathrm{PxV}$ em função da posição relativa do pistão que serão mostrados adiante são apenas da câmara esquerda do cilindro, assim a visualização fica melhor. Embora as pressões da câmara direita são ligeiramente menores que as da câmara esquerda, qualitativamente os diagramas PxV são similares.

Os diagramas PxV para a maior e a menor rotação de cada pressão simulada estão mostrados abaixo. Também são mostrados entre a Figura 5.11 e a Figura 5.19 os diagramas pressão em função do tempo para os mesmo pontos.

A sequência de funcionamento das câmaras da máquina a vapor está indicada pelos números que variam entre (1) e (8) nos diagramas PxV. Os pontos foram marcados sobre a curva referente à pressão na câmara esquerda, os mesmos pontos existem para a câmara direita, e devido à assimetria das válvulas, esses pontos ficam um pouco deslocados em relação à câmara esquerda. Para um efeito de análise e clareza, foram marcados apenas sobre a curva da câmara esquerda.

O ponto (1) marca o instante que a válvula de admissão fica completamente aberta, permanecendo assim até o ponto (2). Nesse processo, a válvula de escape está completamente 
fechada. No ponto (2) se inicia o fechamento da válvula de admissão, esse processo de fechamento dura até o ponto (4). Entre os pontos (2) e (3) a válvula de escape permanece completamente fechada, iniciando sua abertura no ponto (3). Entre os pontos (3) e (4), as duas estão abertas simultaneamente e isso faz com que parte do fluido admitido nesse processo, entre e saia da câmara muito rapidamente, sem realizar trabalho.

O ponto (4) é quando a válvula de admissão se fecha completamente, e a válvula de escape está no processo de abertura. Após o pistão atingir o PMI e iniciar seu retorno, a válvula de escape completa seu processo de abertura no ponto (5), permanecendo totalmente aberta até o ponto (6). No ponto (6) se inicia o fechamento da válvula de escape enquanto a válvula de admissão continua fechada até o ponto (7). Nesse ponto a válvula de admissão começa seu processo de abertura, fazendo com que entre os pontos (7) e (8) as duas válvulas estejam abertas concomitantemente, causado o mesmo problema do trecho (3)-(4). No ponto (8) a válvula de escape é fechada completamente, ao mesmo tempo em que a válvula de admissão continua no seu processo de abertura. Depois de chegar ao PMS, o pistão muda o sentido do seu movimento e chegando ao ponto (1) a abertura da válvula de admissão está completa e o ciclo se reinicia.

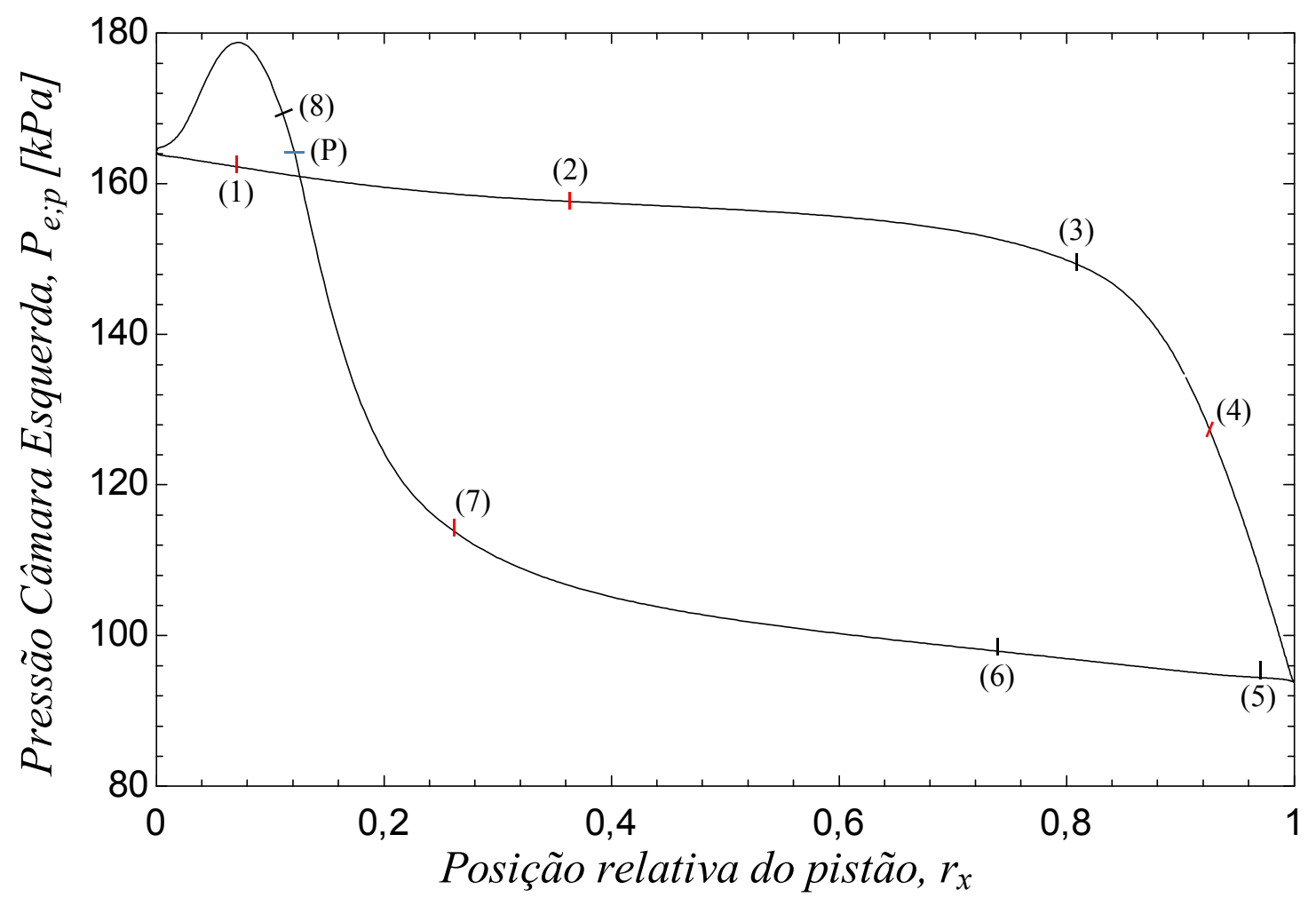

Figura 5.11 - Diagrama PxV da câmara esquerda da máquina a vapor para pressão nominal de 0,5 bar à 792,6 rpm. 


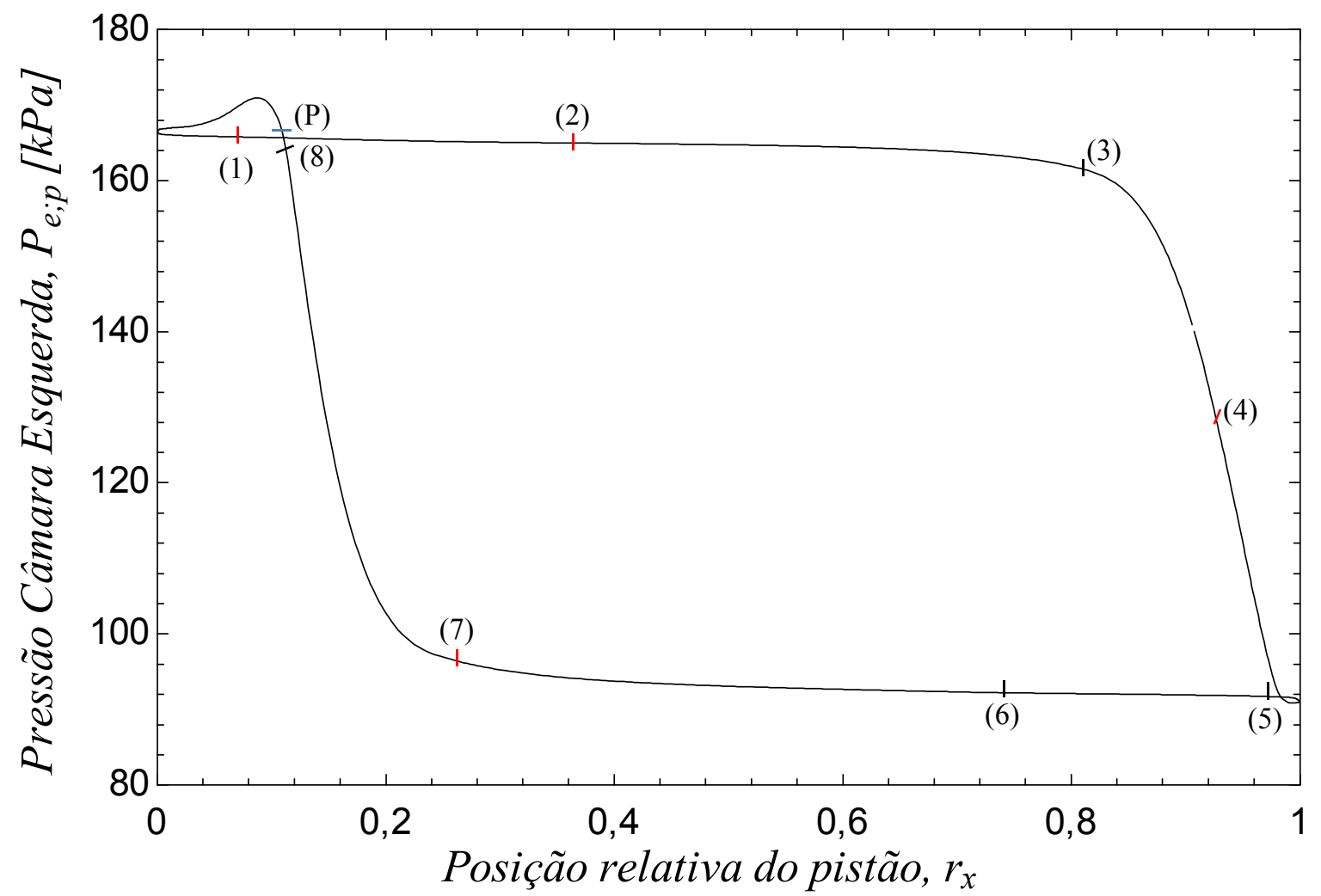

Figura 5.12 - Diagrama PxV da câmara esquerdada máquina a vapor para pressão nominal de 0,5 bar à 354,3 rpm.

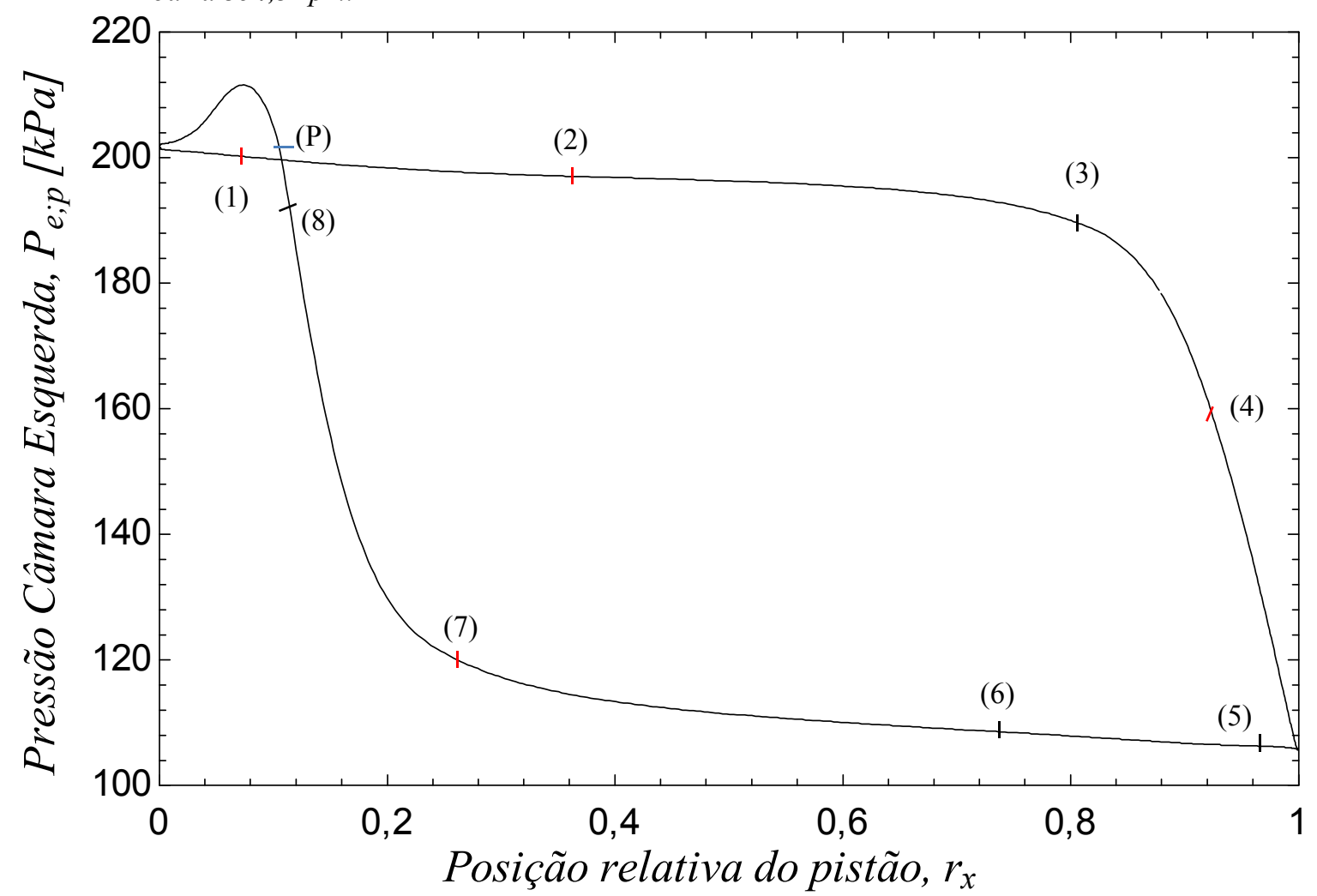

Figura 5.13 - Diagrama PxV da câmara esquerdada máquina a vapor para pressão nominal de 1 bar à 591,4 rpm. 


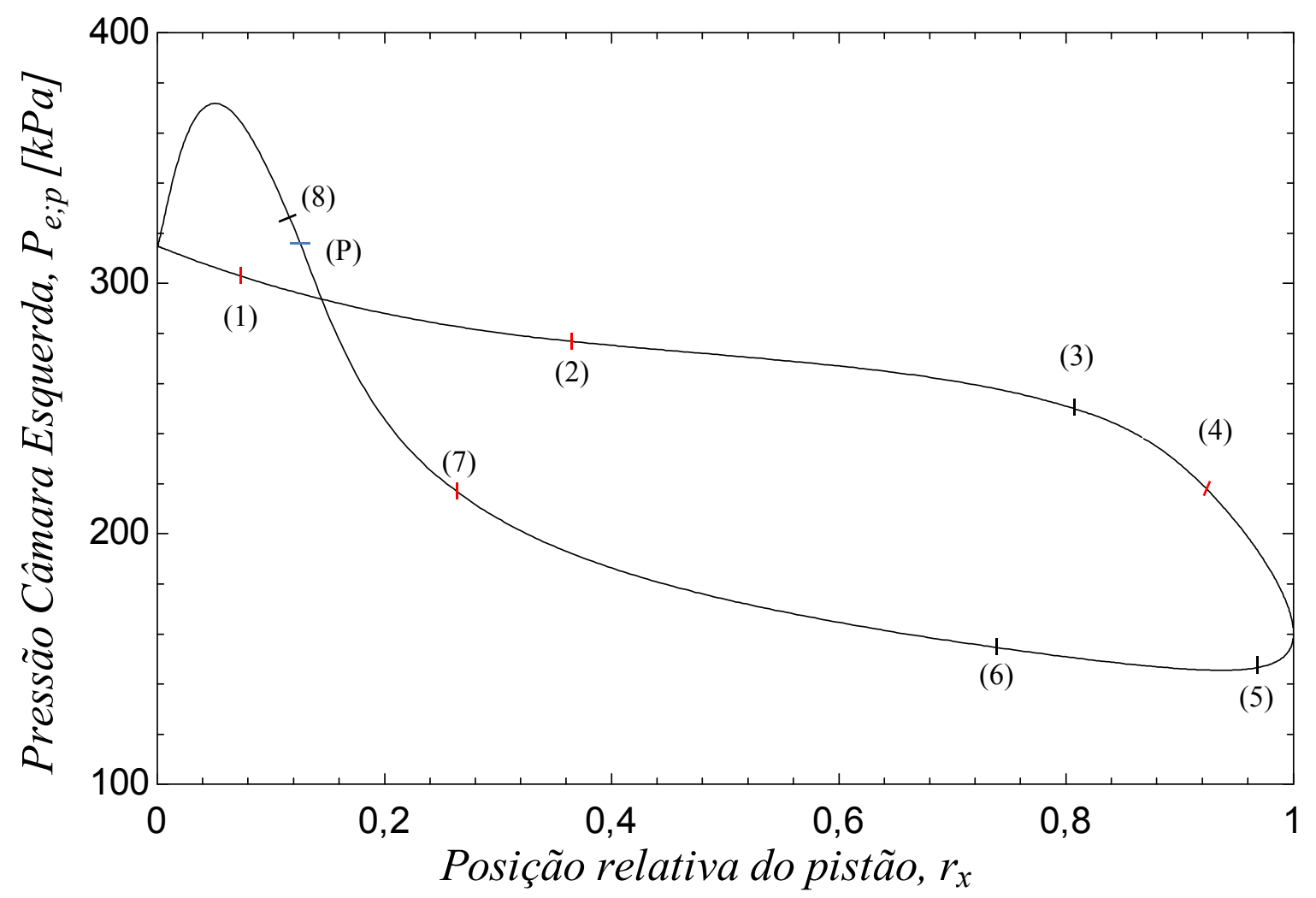

Figura 5.14 - Diagrama PxV da câmara esquerdada máquina a vapor para pressão nominal de 2,5 bar à 1513,3 rpm.

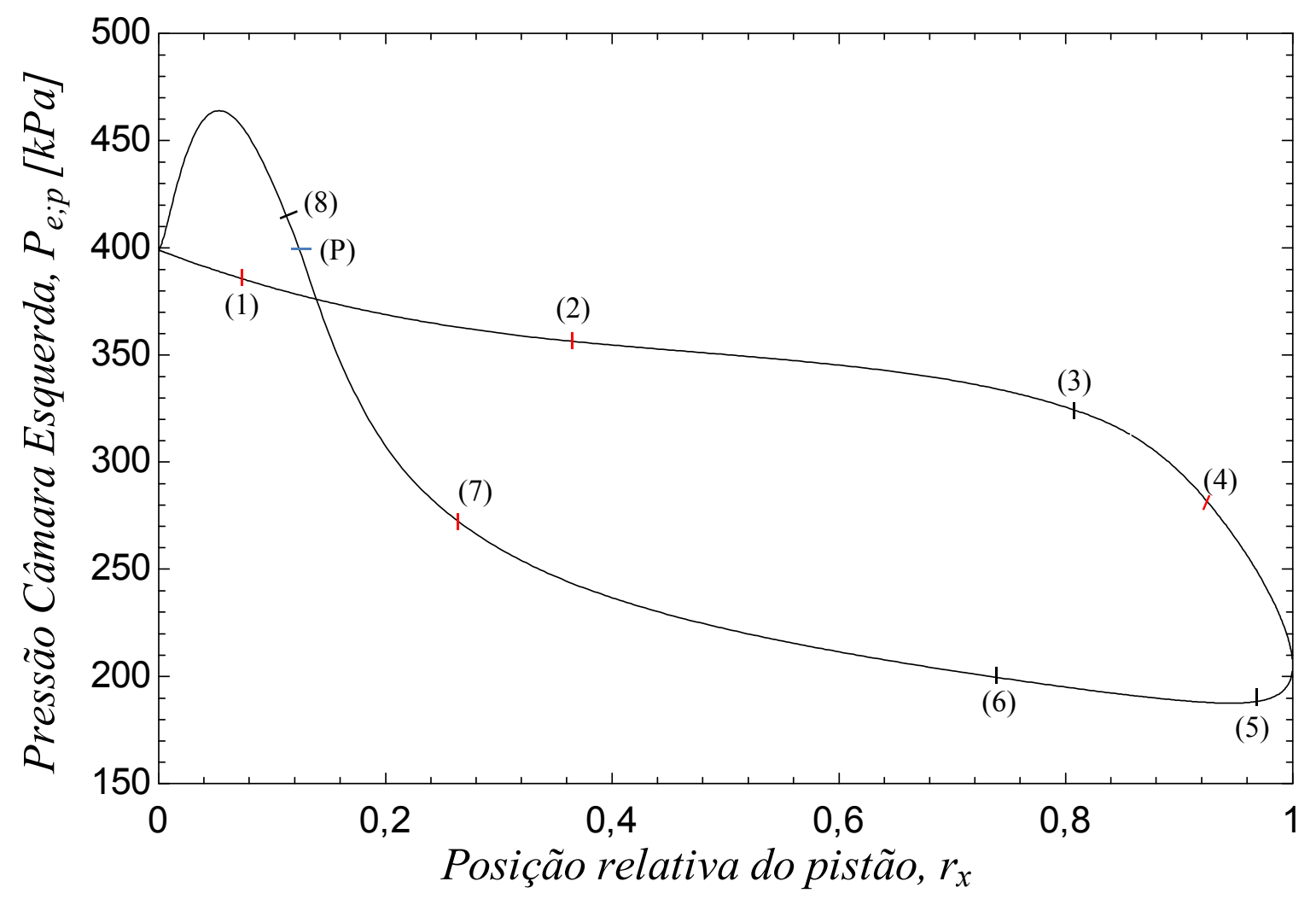

Figura 5.15 - Diagrama PxV da câmara esquerdada máquina a vapor para pressão nominal de 3,5 bar à 1386 rpm. 


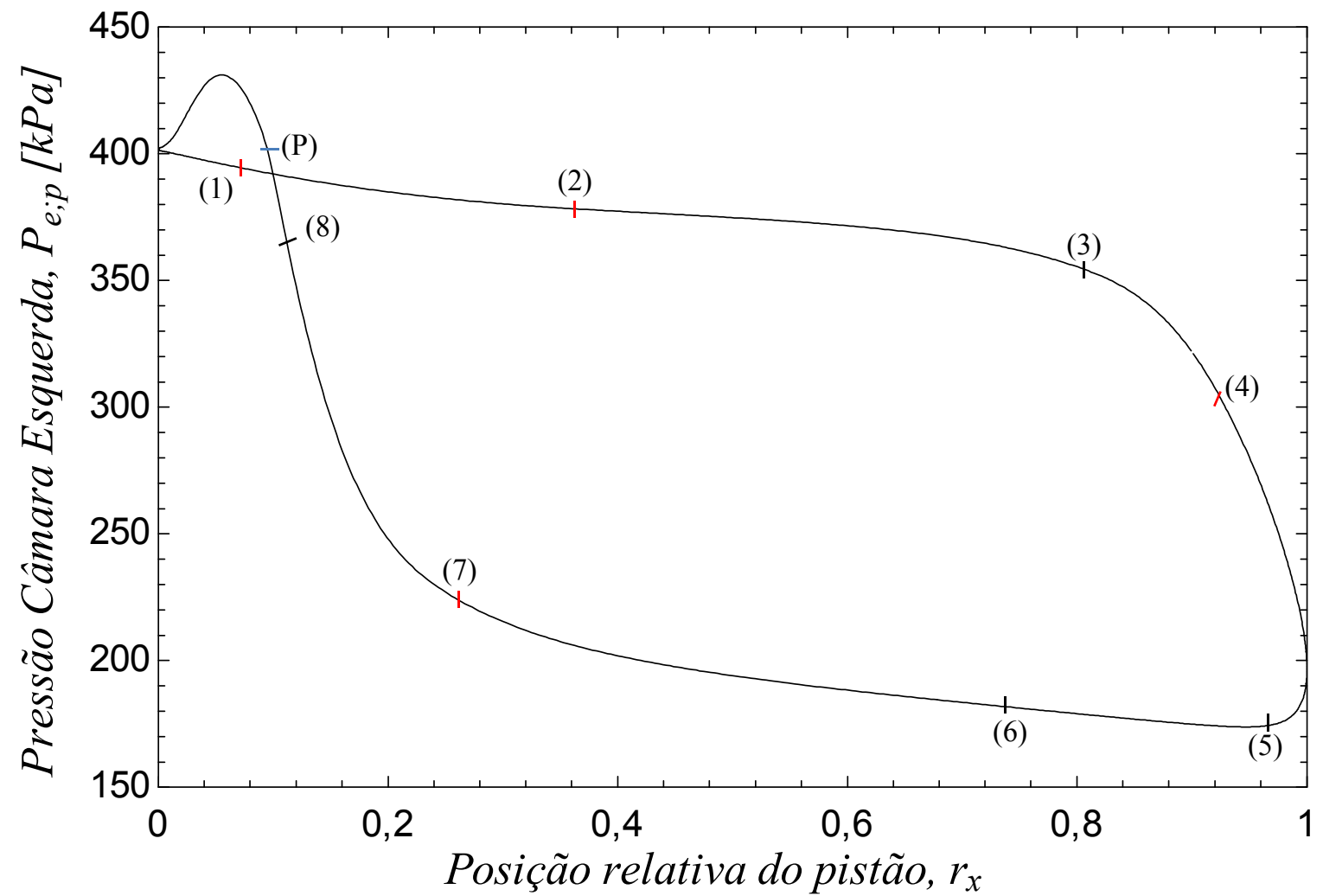

Figura 5.16 - Diagrama PxV da câmara esquerdada máquina a vapor para pressão nominal de 3,5 bar à 960, 7 rpm.

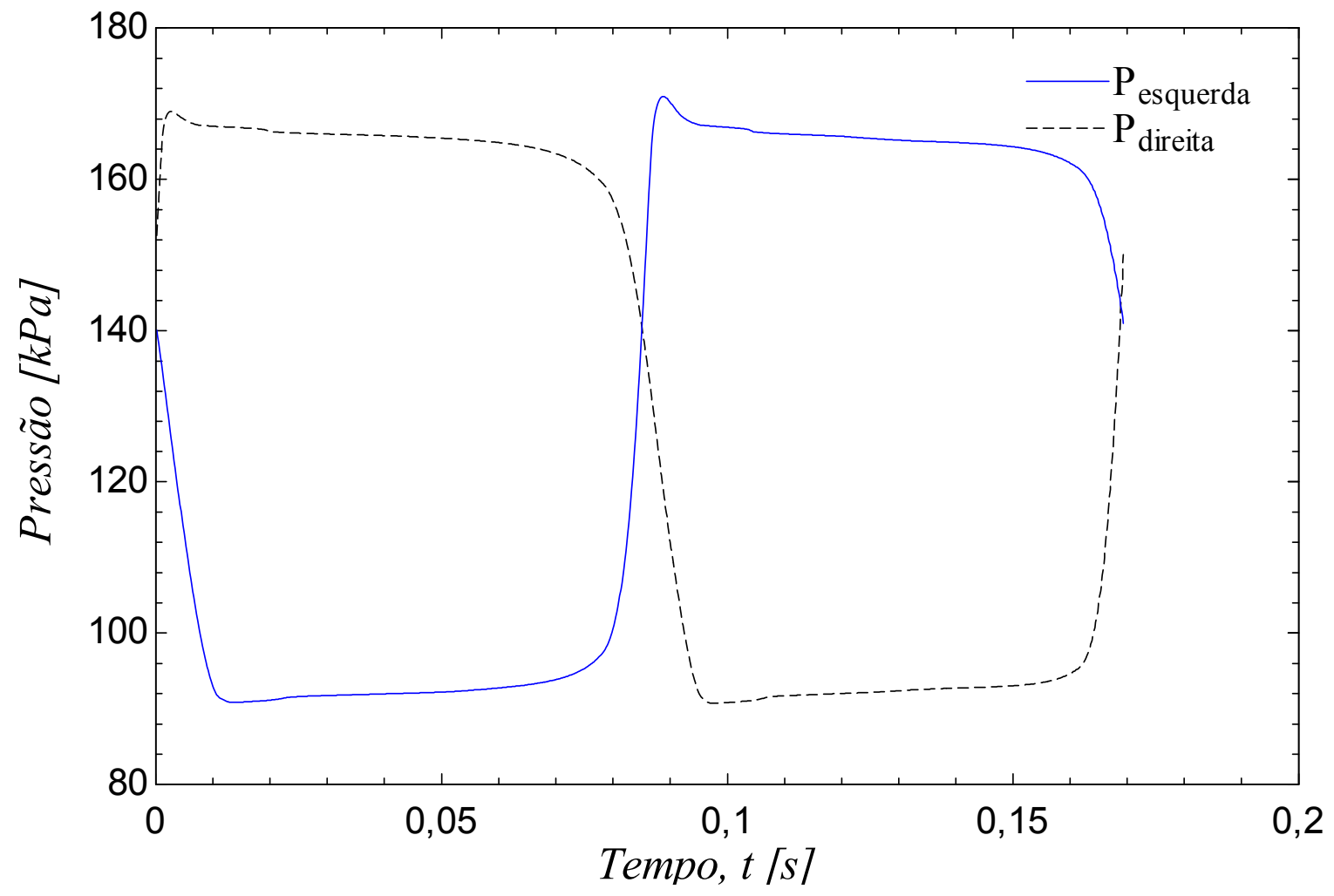

Figura 5.17 - Pressão em função do tempo para um ciclo para pressão nominal de 0,5 bar à 354,3 rpm. 


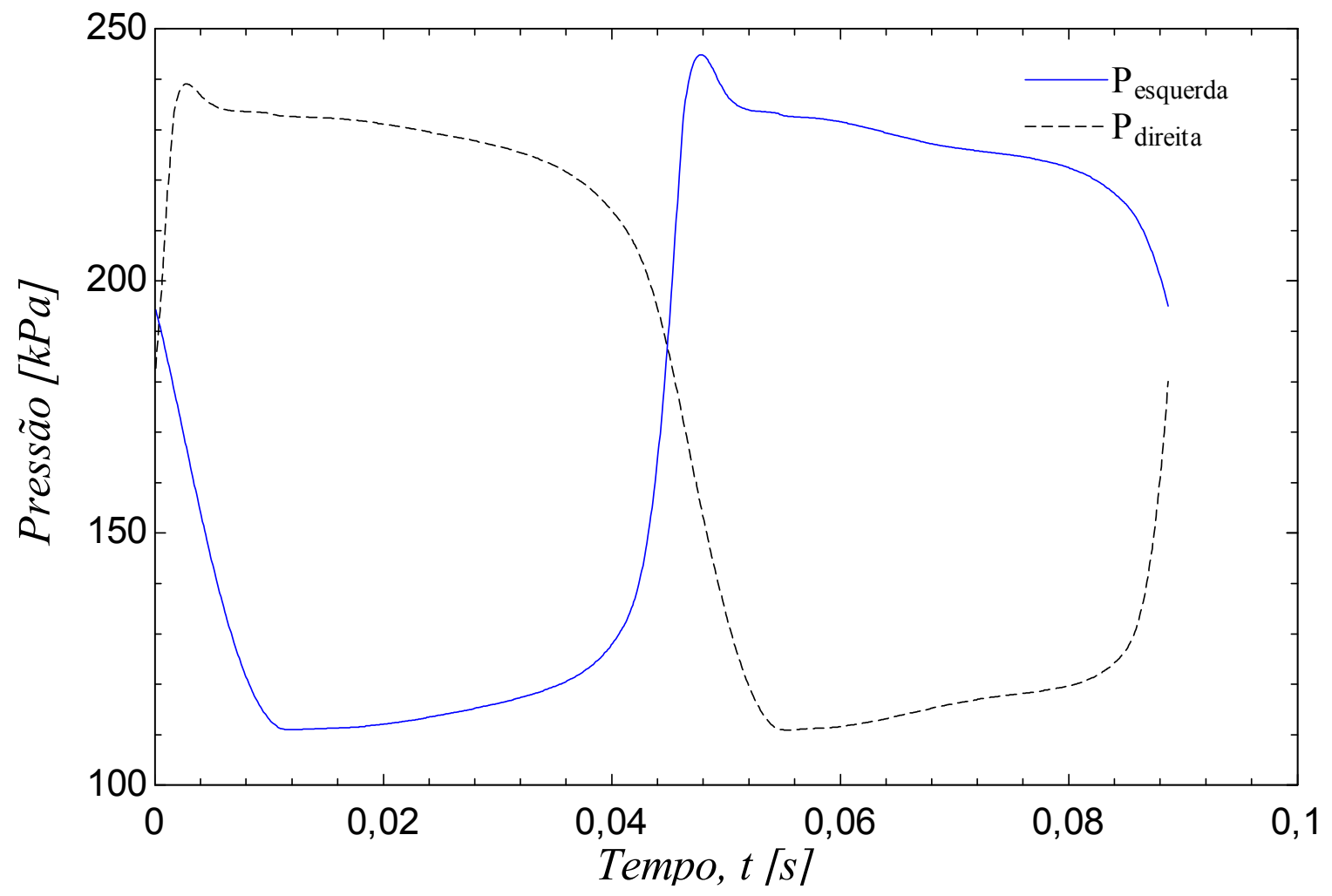

Figura 5.18 - Pressão em função do tempo para um ciclo para pressão nominal de 1,5 bar à 676,5 rpm.

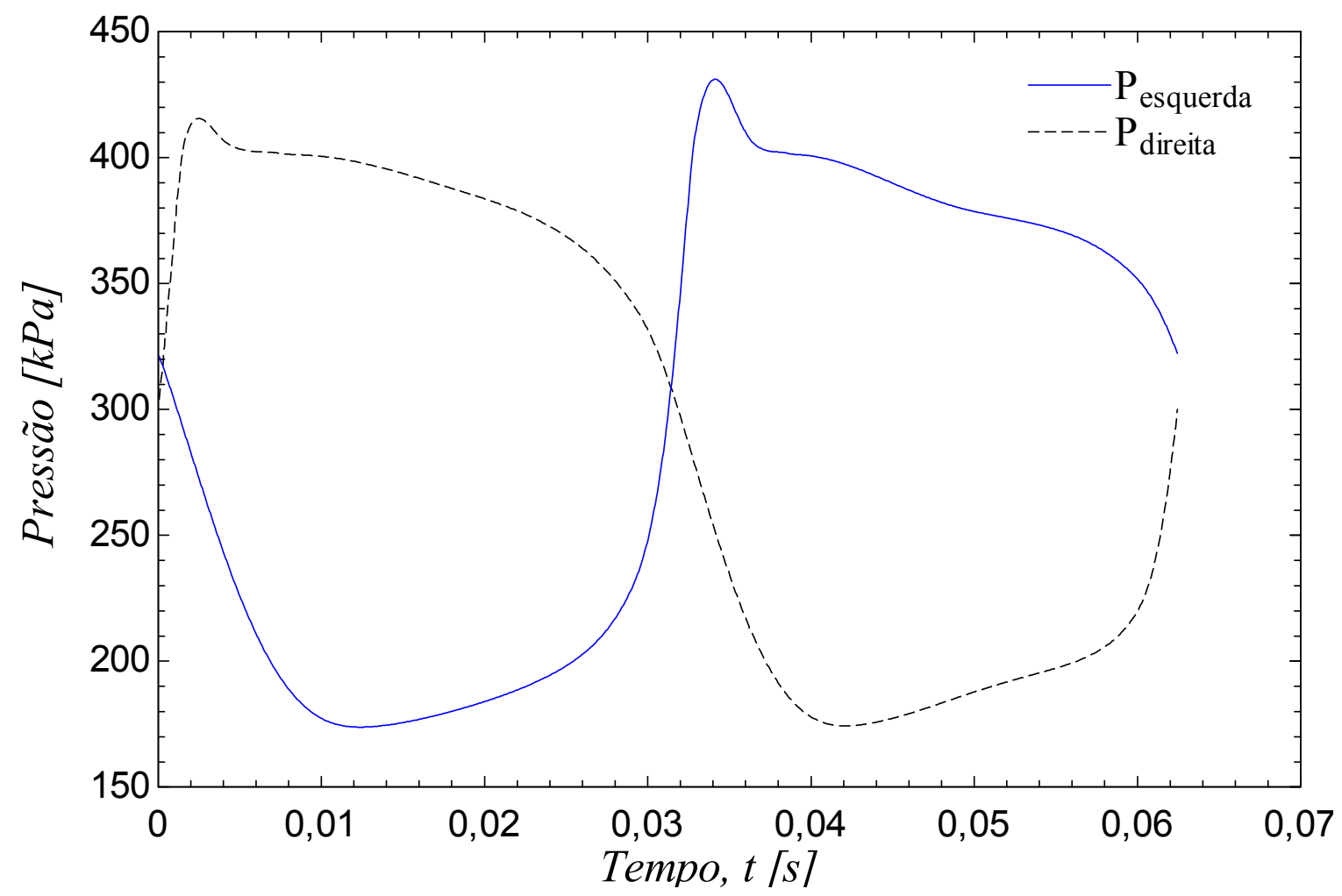

Figura 5.19 - Pressão em função do tempo para um ciclo para pressão nominal de 3,5 bar à 960,7 rpm. 


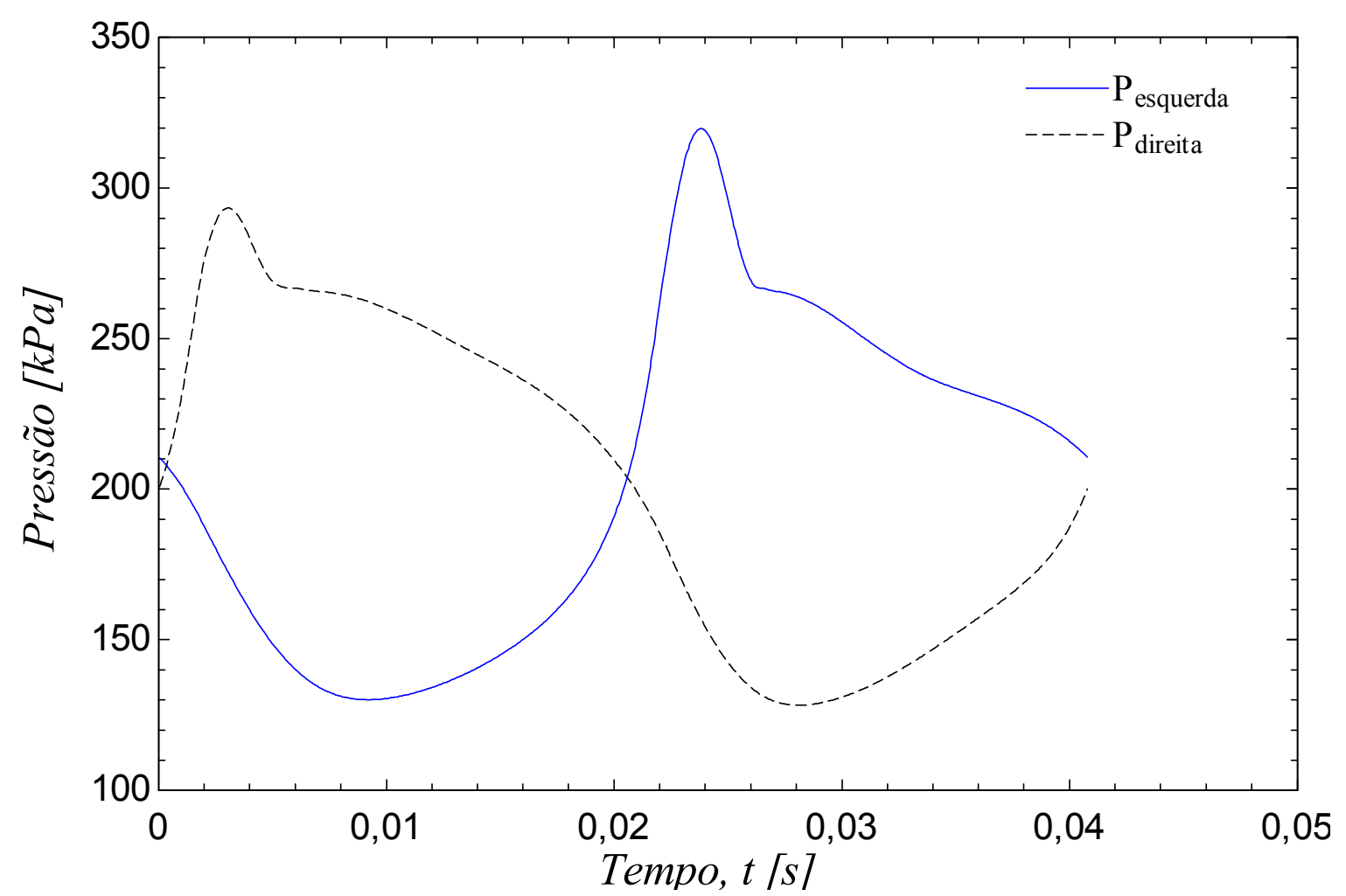

Figura 5.20 - Pressão em função do tempo para um ciclo para pressão nominal de 2 bar à 1471,7 rpm.

Observando os diagramas PxV, nota-se que para rotações até 400 rpm, a admissão e o escape ocorrem quase isobaricamente, como é possível observar na Figura 5.12. Nessa rotação, existe uma pequena sobre compressão quando o pistão está próximo ao PMS. Em rotações intermediárias, entre $500 \mathrm{rpm}$ e $800 \mathrm{rpm}$, o processo de admissão ocorre com uma pequena diminuição da pressão, porém se mantém quase a pressão constante. Nessas rotações o trecho que representa o processo de escape se inclina, demonstrando que as perdas no processo de escape são maiores que as perdas de admissão. Quando o pistão se aproxima do PMS, existe uma sobre compressão mais acentuada, formando uma área maior de trabalho negativo. Essas características podem ser observadas na Figura 5.11 e na Figura 5.13.

Para rotações entre $800 \mathrm{rpm}$ e $1100 \mathrm{rpm}$, o fluxo de admissão deixa de ser quase a pressão constante e a linha que representa esse processo se torna mais inclinada do quando comparada com a mesma linha em rotações menores. A linha de escape também se inclina mais, mostrando dessa forma que a dificuldade do cilindro expulsar o fluido do cilindro aumenta conforme a rotação. Também é possível observar que para rotações menores, quando o pistão se encontra no PMI, a pressão fica constante por um pequeno trecho, formando diagramas mais "pontudos". Porém, para rotações a partir de $800 \mathrm{rpm}$, os diagramas se tornam mais “arredondados". Isso se deve ao fato de que quando o pistão está próximo ao PMI, a pressão 
dentro do cilindro está longe da pressão de admissão e escape, evidenciando que devido à maior rotação a dificuldade de admissão e expulsão do fluido aumenta. Isso ocorre no diagrama da Figura 5.16. Conforme uma tendência já indicada nas rotações já citadas, a sobre compressão quando o pistão se aproxima do PMS aumenta conforme a rotação.

Para rotações acima de 1100 rpm, tanto a admissão quando o escape se inclinam, fazendo com que as linhas de admissão e escape se aproximem, reduzindo a eficiência do ciclo. Devido à maior restrição do fluxo, a tendência de aumentar a área de trabalho negativo gerada pela sobre compressão do fluido quando o pistão se aproxima do PMS se mantém. Isso pode ser observado na Figura 5.14 e na Figura 5.15.

Dessa forma, as simulações mostram uma tendência de pior fluxo de fluido nas válvulas conforme a rotação aumenta. A pressão possui uma influência no fluxo de fluido, porém as simulações mostram como um fenômeno secundário, sendo que o principal responsável é a variação de rotação da máquina a vapor. Isso pode ser observado nos diagramas Pxt.

No diagrama da Figura 5.17 a admissão e o escape ocorrem a pressão constante, e a rotação está abaixo de $400 \mathrm{rpm}$. No diagrama da Figura 5.18, a linha do processo de admissão se inclina um pouco e a curva do escape se tona mais "arredondada". Com rotações maiores, a admissão se torna um processo onde a pressão diminui e o processo de escape atinge a menor pressão apenas por um pequeno trecho. Essa característica fica mais evidente na Figura 5.19 e na Figura 5.20.

É possível notar que existam características comuns em todos os diagramas $\mathrm{PxV}$, relativas ao modo de funcionamento da máquina a vapor. No trecho (1)-(2) percebe-se uma queda da pressão que faz uma curva com concavidade para cima. Este fenômeno ocorre em qualquer sistema cilindro-pistão em processo de admissão ou escape e válvula com abertura constante, nesse caso, abertura total da válvula de admissão. Esse fenômeno está ilustrado na Figura 2.7 pelas linhas tracejadas. 


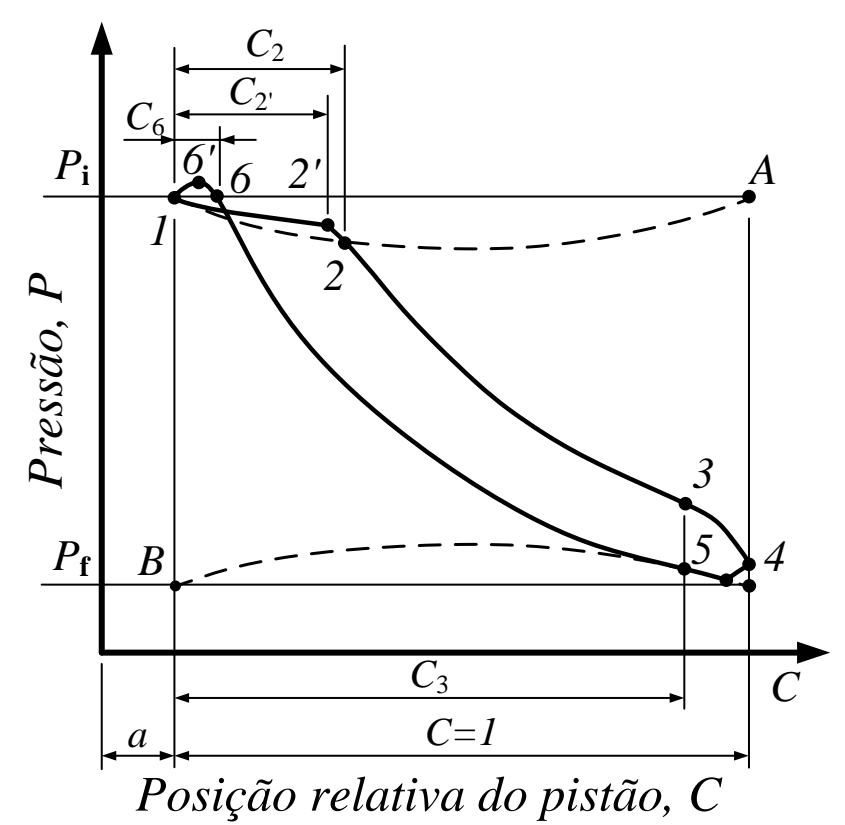

Figura 2.7 - Diagrama PxV de um motor de expansão utilizando uma válvula de admissão auto operada normalmente aberta (Kalekin e Kalekin, 2009).

Na imagem, as linhas foram feitas para um pistão acoplado a um sistema biela-manivela. No processo de admissão (representado pela linha tracejada superior), a queda de pressão em relação à pressão de admissão se dá pela relação área de abertura e volume do cilindro, juntamente com a velocidade do cilindro. Para uma área constate de abertura, a diferença entre a pressão interna do cilindro e a pressão de admissão fica apenas em função da velocidade. Quanto maior a velocidade do pistão, maior a diferença entre as duas pressões. No caso de um sistema biela-manivela, as maiores velocidades do pistão ocorrem próximas ao centro do percurso do pistão. No caso da admissão, a pressão interna do cilindro tende a ser menor que a pressão de admissão, e para o processo de escape ocorre o mesmo fenômeno, porém a pressão da câmara tende a ser maior que a pressão externa.

No início trecho (2)-(3) dos diagramas da máquina a vapor, a pressão continua a seguir a curva tracejada prevista por Kalekin e Kalekin (2009). Nesse trecho a válvula de admissão está fechando e no caminho do pistão entre (2) e (3) a pressão começa a diminuir mais e a curva muda sua concavidade. Isso se dá devido à diminuição da área de abertura da válvula de admissão, fazendo com que o fluxo mássico diminua e o pistão expanda o fluido dentro do cilindro. O trecho com concavidade para baixo é uma transição entre a curva tracejada de admissão indicada na Figura 2.7 (válvula totalmente aberta) e uma curva de expansão isentrópica (válvula totalmente fechada), representada pela curva (2)-(3) da imagem de Kalekin e Kalekin (2009). Essa transição entre a linha tracejada e a curva isentrópica 
(processo 2-3) da máquina a vapor é delimitada pelos ponto (2’) e (2) da Figura 2.7. A curva de expansão isentrópica teria seu início no ponto (4), quando a válvula de admissão fecha completamente, mas na máquina a vapor isso não ocorre devido à abertura antecipada da válvula de escape no ponto (3).

O trecho (3)-(4) do diagrama $\mathrm{PxV}$ da máquina a vapor tende a ser a continuação da transição entre a admissão com velocidade do pistão variável predita por Kalekin e Kalekin (2009) e uma curva de expansão isentrópica. Quanto mais próximo do ponto (4), maior a abertura da válvula de escape, e a queda da pressão se torna cada vez mais acentuada. Isso faz com que a pressão não atinja a curva de expansão isentrópica prevista.

A partir do ponto (4), apenas a válvula de escape está aberta, e com área crescente até o ponto (5). Isso faz com que a pressão interna do cilindro se aproxime mais da pressão de expulsão do fluido. Do ponto (4) até o PMI soma-se o efeito de que o pistão continua realizando a expansão do fluido, e após passar pelo PMI e começar retornar em direção ao PMS, o pistão tende a comprimir o fluido dentro do cilindro. Em alguns casos, antes do pistão atingir o PMI, a pressão interna do cilindro diminui acentuadamente, fazendo com que a pressão interna dentro do cilindro fique menor que a pressão de escape, provocando uma sobre-expansão do fluido e gerando um trabalho negativo para o ciclo. Este fenômeno ocorre no diagrama PxV da Figura 5.12. É um fenômeno que ocorre em baixas pressões e rotações médias.

A partir do ponto (5) até o ponto (6) dos diagramas da máquina a vapor, a válvula de escape está totalmente aberta, se inicia o trecho do processo de expulsão que segue também a curva tracejada da Figura 2.7. Caso a pressão interna do cilindro for superior à pressão de escape ocorrem dois efeitos. Primeiramente a pressão tende a sofrer uma pequena elevação devido à diminuição do volume do cilindro, mas por outro lado, a pressão tende a diminuir por causa do fluxo de massa saindo do cilindro. Assim, a pressão nesse trecho pode aumentar, se manter constante ou diminuir, dependendo da relação entre esses dois efeitos.

No trecho (6)-(7) apenas a válvula de escape está aberta e a esta começa a fechar no ponto (6). Assim, esse trecho é a transição entre a curva (5)-(6) e uma curva de expansão isentrópica que se inicia no instante que a válvula de escape fecha totalmente, ponto (8). É um trecho onde a variação da pressão se torna maior conforme o pistão se aproxima do ponto (7), pois o movimento do pistão tende a comprimir o fluido e a área da válvula cada vez menor impede a 
saída do mesmo. O fluido não chega a passar por uma compressão isentrópica devido ao início da abertura da válvula de admissão no ponto (7).

No trecho (7)-(8) a pressão aumenta rapidamente, devido à área de abertura da válvula de escape diminuindo, à área de abertura da válvula de admissão aumentando e ao movimento de compressão realizado pelo pistão. O fechamento da válvula de escape dificulta a expulsão do fluido, a abertura da válvula de admissão permite a entrada de vapor em alta pressão e o movimento do cilindro tende a comprimir o fluido. Os três efeitos provocam o aumento da pressão, fazendo com que ela varie muito em um percurso pequeno do pistão.

A partir do ponto (8), apenas a válvula de admissão está aberta e a vazão em massa para dentro do cilindro e o movimento do pistão fazem com que o fluido dentro do cilindro seja comprimido. $\mathrm{O}$ ponto $(\mathrm{P})$ marca o instante no qual a pressão interna passa a ser maior que a pressão externa de admissão, em alguns casos o ponto (P) ocorre antes do ponto (8). Mesmo a pressão interna sendo maior que a pressão externa de admissão, a pressão continua a subir até atingir um ponto de máximo e depois diminui até a chegada do pistão ao PMS. Após o ponto (P), a variação da pressão se dá por dois efeitos. O primeiro efeito é a compressão do pistão que faz com que a pressão aumente e o segundo efeito é o retorno da massa de dentro do cilindro para a câmara de admissão, que faz com que a pressão diminua. Enquanto a pressão não atingiu o ponto de máximo, o efeito de compressão causado pelo movimento do pistão é maior que o efeito da diminuição da massa interna do cilindro. Quando o pistão se aproxima do PMS, sua velocidade diminui rapidamente, diminuindo seu efeito e tornando o efeito do fluxo mássico mais significativo. Isso faz com que a pressão interna do cilindro diminua até a chegada ao PMS. O trecho do ponto (P) até o PMS gera um trabalho negativo sobre o pistão, diminuindo o trabalho realizado pelo ciclo e a eficiência do mesmo.

No PMS a pressão do fluido dentro do cilindro é muito próxima à pressão de admissão, e conforme o pistão acelera, a pressão interna do cilindro diminui no processo de admissão, até chegar novamente no ponto (1).

Além de obter os diagramas PxV para estudar os fenômenos que ocorrem no interior das câmaras, também foram obtidos os valores de consumo de massa, potência, trabalho, trabalho específico e eficiência isentrópica do ciclo. Esses dados são apresentados na Tabela 5.2. 
Tabela 5.2 -Medidas simuladas de desempenho do ciclo da máquina a vapor

\begin{tabular}{|c|c|c|c|c|c|c|c|c|}
\hline $\begin{array}{c}\text { Pressão } \\
\text { [bar] }\end{array}$ & Medida & $\begin{array}{c}\text { Rotação } \\
\text { [rpm] }\end{array}$ & $\begin{array}{c}\mathrm{W}_{\text {iso }} \\
{[\mathrm{kJ} / \mathrm{kg}]}\end{array}$ & $\begin{array}{c}\mathrm{w} \\
{[\mathrm{kJ} / \mathrm{kg}]}\end{array}$ & $\begin{array}{c}\text { W/ciclo } \\
{[\mathrm{J}]}\end{array}$ & $\begin{array}{c}\text { Pot }_{\text {media }} \\
{[\mathrm{W}]} \\
\end{array}$ & $\begin{array}{c}\dot{\mathrm{m}} \\
{[\mathrm{g} / \mathrm{s}]}\end{array}$ & $\eta[\%]$ \\
\hline \multirow{7}{*}{0,5} & 1 & 792,56 & 45,40 & 31,10 & 2,416 & 31,91 & 1,03 & 68,49 \\
\hline & 2 & 692,24 & 46,17 & 32,96 & 2,686 & 30,99 & 0,94 & 71,38 \\
\hline & 3 & 623,14 & 46,81 & 34,07 & 2,869 & 29,80 & 0,87 & 72,77 \\
\hline & 4 & 508,33 & 46,93 & 34,76 & 3,048 & 25,82 & 0,74 & 74,06 \\
\hline & 5 & 437,48 & 47,39 & 35,13 & 3,176 & 23,16 & 0,66 & 74,11 \\
\hline & 6 & 386,42 & 48,70 & 35,79 & 3,375 & 21,74 & 0,61 & 73,50 \\
\hline & 7 & 354,34 & 48,33 & 35,38 & 3,353 & 19,80 & 0,56 & 73,20 \\
\hline \multirow{5}{*}{0,75} & 1 & 729,85 & 47,16 & 33,31 & 2,732 & 33,23 & 1,00 & 70,64 \\
\hline & 2 & 658,06 & 47,78 & 34,50 & 2,938 & 32,23 & 0,93 & 72,20 \\
\hline & 3 & 604,20 & 48,36 & 35,31 & 3,094 & 31,15 & 0,88 & 73,03 \\
\hline & 4 & 552,52 & 48,70 & 35,85 & 3,18 & 29,29 & 0,82 & 73,60 \\
\hline & 5 & 494,74 & 49,02 & 36,19 & 3,325 & 27,42 & 0,76 & 73,83 \\
\hline \multirow{6}{*}{1} & 1 & 897,04 & 52,50 & 35,35 & 3,084 & 46,11 & 1,30 & 67,33 \\
\hline & 2 & 807,73 & 52,44 & 36,46 & 3,265 & 43,95 & 1,21 & 69,53 \\
\hline & 3 & 658,89 & 53,64 & 38,66 & 3,714 & 40,78 & 1,06 & 72,06 \\
\hline & 4 & 576,13 & 54,49 & 39,59 & 3,964 & 38,07 & 0,96 & 72,66 \\
\hline & 5 & 455,85 & 54,86 & 39,86 & 4,154 & 31,56 & 0,79 & 72,66 \\
\hline & 6 & 591,43 & 54,24 & 39,57 & 4,005 & 39,48 & 1,00 & 72,95 \\
\hline \multirow{6}{*}{1,5} & 1 & 1358,57 & 57,12 & 30,15 & 2,586 & 58,56 & 1,94 & 52,79 \\
\hline & 2 & 1157,05 & 58,50 & 35,93 & 3,366 & 64,91 & 1,81 & 61,42 \\
\hline & 3 & 943,28 & 59,67 & 40,29 & 4,15 & 65,24 & 1,62 & 67,52 \\
\hline & 4 & 852,23 & 60,46 & 41,91 & 4,508 & 64,02 & 1,53 & 69,32 \\
\hline & 5 & 734,94 & 61,10 & 43,31 & 4,891 & 59,91 & 1,38 & 70,89 \\
\hline & 6 & 676,53 & 61,66 & 43,98 & 5,097 & 57,47 & 1,31 & 71,33 \\
\hline \multirow{8}{*}{2} & 1 & 1471,66 & 62,40 & 32,62 & 3,141 & 77,04 & 2,36 & 52,28 \\
\hline & 2 & 1335,29 & 63,43 & 36,67 & 3,783 & 84,19 & 2,30 & 57,82 \\
\hline & 3 & 1283,52 & 63,09 & 37,42 & 3,915 & 83,74 & 2,24 & 59,31 \\
\hline & 4 & 1229,21 & 63,76 & 39,01 & 4,202 & 86,09 & 2,21 & 61,19 \\
\hline & 5 & 1002,80 & 65,99 & 44,11 & 5,302 & 88,62 & 2,01 & 66,84 \\
\hline & 6 & 961,46 & 66,28 & 44,78 & 5,476 & 87,74 & 1,96 & 67,57 \\
\hline & 7 & 963,90 & 65,38 & 44,14 & 5,283 & 84,87 & 1,92 & 67,52 \\
\hline & 8 & 823,31 & 66,71 & 46,32 & 5,938 & 81,48 & 1,76 & 69,44 \\
\hline
\end{tabular}


Tabela 5.2 - Continuação

\begin{tabular}{|c|c|c|c|c|c|c|c|c|}
\hline $\begin{array}{c}\text { Pressão } \\
\text { [bar] }\end{array}$ & Medida & $\begin{array}{c}\text { Rotação } \\
\text { [rpm] }\end{array}$ & $\begin{array}{c}\mathrm{W}_{\text {iso }} \\
{[\mathrm{kJ} / \mathrm{kg}]}\end{array}$ & $\begin{array}{c}\mathrm{W} \\
{[\mathrm{kJ} / \mathrm{kg}]}\end{array}$ & $\begin{array}{c}\text { W/ciclo } \\
{[\mathrm{J}]}\end{array}$ & $\begin{array}{c}\text { Pot }_{\text {media }} \\
{[\mathrm{W}]}\end{array}$ & $\begin{array}{c}\dot{\mathrm{m}} \\
{[\mathrm{g} / \mathrm{s}]}\end{array}$ & $\eta[\%]$ \\
\hline \multirow{9}{*}{2,5} & 1 & 1513,36 & 68,10 & 36,94 & 4,275 & 107,83 & 2,92 & 54,24 \\
\hline & 2 & 1524,24 & 67,90 & 36,53 & 4,175 & 106,07 & 2,90 & 53,80 \\
\hline & 3 & 1419,01 & 68,45 & 39,21 & 4,719 & 111,61 & 2,85 & 57,28 \\
\hline & 4 & 1262,77 & 69,44 & 42,80 & 5,562 & 117,07 & 2,74 & 61,64 \\
\hline & 5 & 1202,60 & 70,40 & 44,44 & 5,965 & 119,56 & 2,69 & 63,12 \\
\hline & 6 & 1167,29 & 69,62 & 44,38 & 5,997 & 116,67 & 2,63 & 63,75 \\
\hline & 7 & 1093,29 & 70,57 & 46,02 & 6,464 & 117,79 & 2,56 & 65,21 \\
\hline & 8 & 962,07 & 71,81 & 48,22 & 7,188 & 115,25 & 2,39 & 67,15 \\
\hline & 9 & 704,43 & 75,09 & 51,49 & 8,614 & 101,13 & 1,96 & 68,58 \\
\hline \multirow{4}{*}{3} & 1 & 1363,06 & 70,01 & 41,35 & 5,904 & 134,14 & 3,24 & 59,06 \\
\hline & 2 & 1322,61 & 70,35 & 42,30 & 6,149 & 135,55 & 3,21 & 60,13 \\
\hline & 3 & 1115,91 & 73,46 & 47,37 & 7,697 & 143,14 & 3,02 & 64,48 \\
\hline & 4 & 1145,98 & 73,80 & 47,22 & 7,598 & 145,12 & 3,07 & 63,97 \\
\hline \multirow{6}{*}{3,5} & 1 & 1386,07 & 62,99 & 34,93 & 5,512 & 127,34 & 3,65 & 55,45 \\
\hline & 2 & 1202,74 & 64,02 & 39,23 & 6,678 & 133,86 & 3,41 & 61,28 \\
\hline & 3 & 1143,65 & 64,73 & 40,70 & 7,133 & 136,01 & 3,34 & 62,87 \\
\hline & 4 & 1006,65 & 66,50 & 43,74 & 8,232 & 138,11 & 3,16 & 65,78 \\
\hline & 5 & 1092,70 & 65,53 & 42,00 & 7,571 & 137,88 & 3,28 & 64,10 \\
\hline & 6 & 960,73 & 67,20 & 44,69 & 8,605 & 137,79 & 3,08 & 66,50 \\
\hline
\end{tabular}

As pressões baixas (0,5 bar; 0,75 bar e 1 bar) e as maiores (3 bar e 3,5 bar) não apresentam ponto de máxima potência na faixa de rotações estudada. As pressões médias (1,5 bar; 2 bar e 2,5 bar) possuem seus pontos de máxima potência em rotações que variam de $940 \mathrm{rpm}$ até $1200 \mathrm{rpm}$. As pressões baixas possuem sua maior potência em rotações mais elevadas, e as pressões maiores possuem sal maior potência em rotações menores. A maior potência dos ciclos da máquina a vapor é de 144,2 W, um valor significativamente baixo caso exista o interesse de utilizar essa máquina para mover algo ou gerar eletricidade.

O ganho de potência com o acréscimo de pressão é mais significativo para pressões intermediárias (entre 1,5 bar e 3 bar). Para as outras pressões, o acréscimo de pressão tem pouca influência da potência do ciclo. 
Em todos os pontos simulados, o consumo em massa tem uma variação linear com a rotação e com a pressão. Quando maior a pressão ou rotação, maior o consumo em massa da máquina a vapor. O consumo de massa é pequeno também em todos os casos, variando de $0,56 \mathrm{~g} / \mathrm{s}$ até $3,63 \mathrm{~g} / \mathrm{s}$, o que é igual a $33,6 \mathrm{~g} / \mathrm{min}$ e $217,8 \mathrm{~g} / \mathrm{min}$.

Os dados da tabela mostram que a menor eficiência isentrópica do ciclo é igual a 50,68\% ocorrendo para a pressão de 2 bar a 1471,66 rpm, e a maior é $74,44 \%$ ocorrendo para a pressão de 0,5 bar a 437,48 rpm. A maioria dos pontos estudados possuem eficiência isentrópica na faixa dos 60\%. Segundo Badr et al. (1991), é necessário que a máquina de expansão de um ORC possuam eficiência isentrópica entre $65 \%$ e $75 \%$, para que se obtenha uma eficiência total do sistema na casa dos $20 \%$. Considerando essa afirmação, pode-se dizer que se essa máquina fosse utilizada em um ORC, deveria trabalhar com pressões até 1 bar ou 1,5 bar em baixas rotações. Para maiores pressões, apenas as rotações mais baixas alcançam o limite inferior de eficiência citado por Badr et al. (1991).

5.4.2 Resultados para a simulação com válvulas que abrem e fecham instantaneamente.

Em relação às simulações realizadas para a máquina a vapor funcionando com válvulas carretel, os diagramas $\mathrm{PxV}$ não se assemelham com os diagramas $\mathrm{PxV}$ teóricos, com exceção dos diagramas para baixas rotações que se aproximam do ciclo de pior eficiência isentrópica quando não há sobre-expansão ou sobrecompressão. Ao realizar as simulações com válvulas ideais, que comutam entre "aberta" e "fechada" instantaneamente, verifica-se que em quase todos os casos, os diagramas PxV são muito próximos ao diagrama PxV da Figura 2.2, que possui eficiência isentrópica igual a 100\%. Isso significa que esses ciclos simulados possuem alta eficiência, devido ao acionamento instantâneo das válvulas. As imagens que estão no intervalo da Figura 5.21 até a Figura 5.26 mostram os diagramas PxV para as duas câmaras do cilindro para simulações com diferentes rotações e pressões.

Dessa forma, a válvula de admissão abre quando o pistão está no ponto morto de menor volume e a válvula de escape abre quando o volume da câmara é máximo. O instante de abertura da válvula de admissão está indicada como ponto (1) nos diagramas $\mathrm{PxV}$, e a o instante de abertura da válvula de escape está indicada pelo ponto (3). Após a válvula de admissão abrir, o pistão inicia seu curso de expansão, e a válvula permanece totalmente aberta 
até o ponto (2), no qual é fechada; No processo (2)-(3) ocorre uma expansão isentrópica do fluido no interior da câmara, de forma a fazer com que a pressão interna da câmara do cilindro esteja igual ou próxima à pressão de escape. A válvula de escape abre no ponto (3) e permanece aberta por quase todo o retorno do pistão para a outra extremidade do seu curso, chegando ao ponto 4. Nesse ponto, todas as válvulas estão fechadas, permitindo que o fluido sofra uma compressão isentrópica, até o ponto (1), reiniciando o ciclo.

$\mathrm{O}$ ponto $(\mathrm{P})$ indica o instante que a pressão dentro da câmara fica maior que a pressão de admissão, caracterizando uma sobrecompressão.

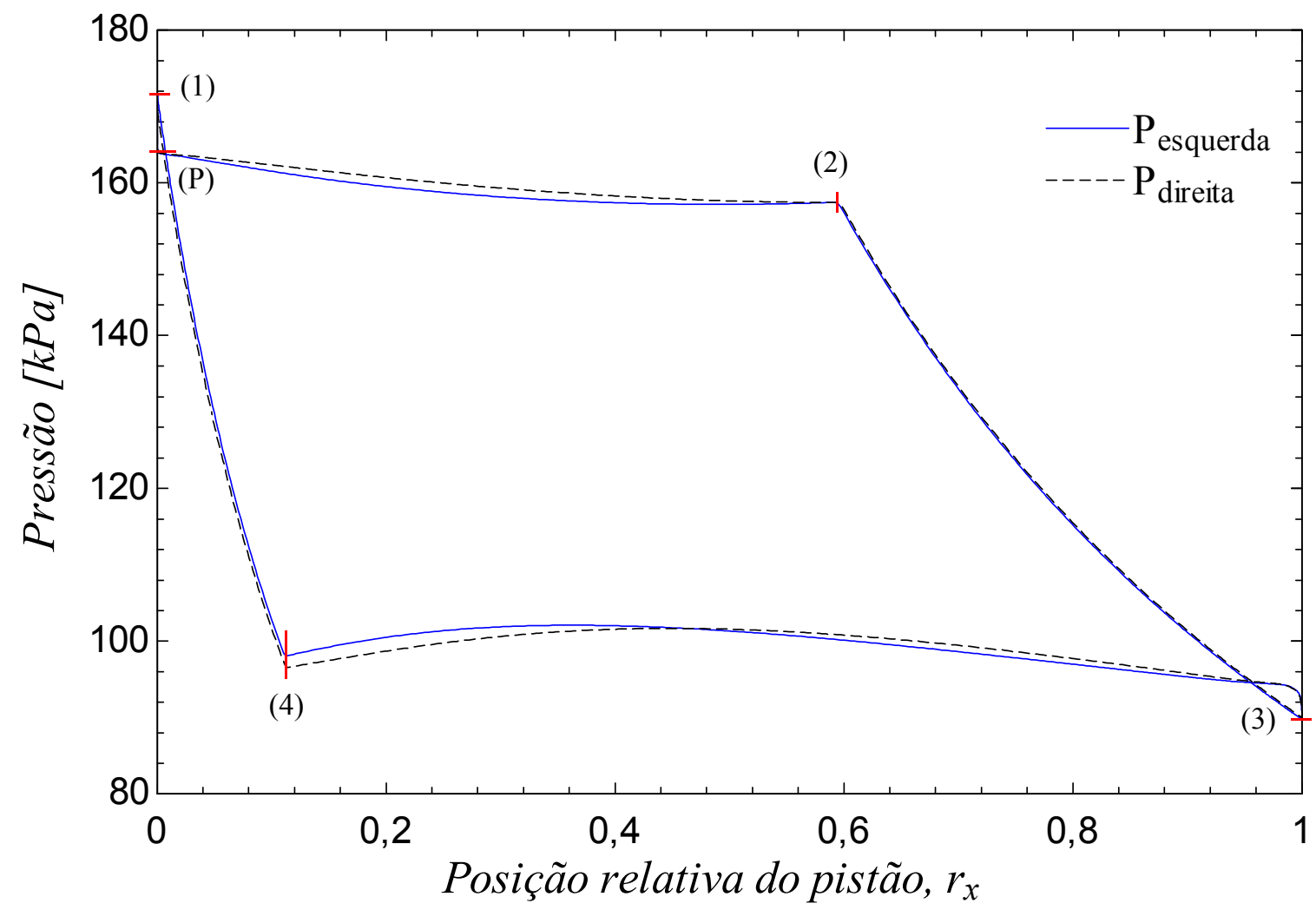

Figura 5.21 - Diagrama PxV para as câmaras da máquina a vapor que utiliza válvulas de comutação instantâneas para pressão nominal de 0,5 bar à 792,6 rpm 


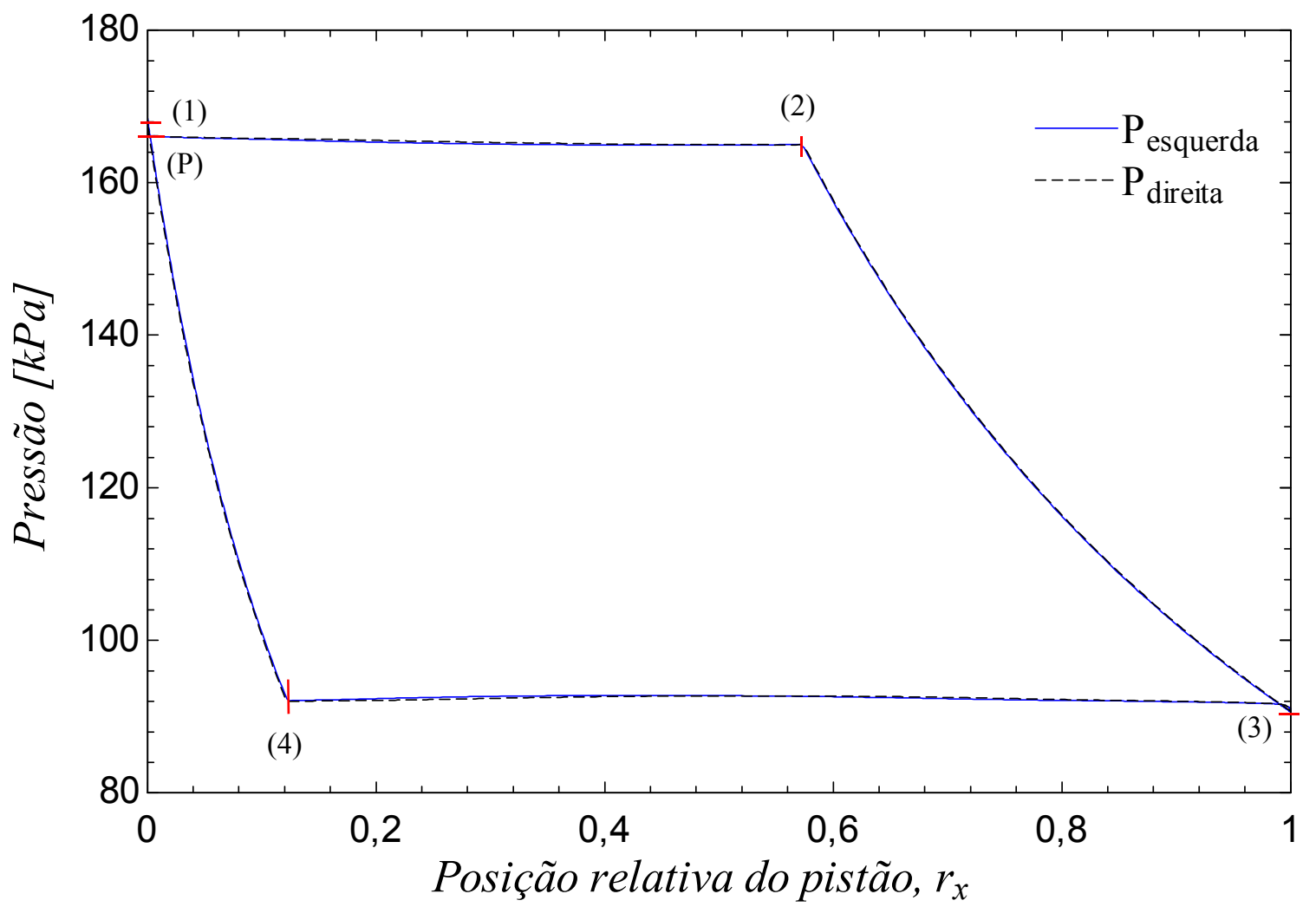

Figura 5.22 - Diagrama PxV para as câmaras da máquina a vapor que utiliza válvulas de comutação instantâneas para pressão nominal de 0,5 bar à 354,3 rpm

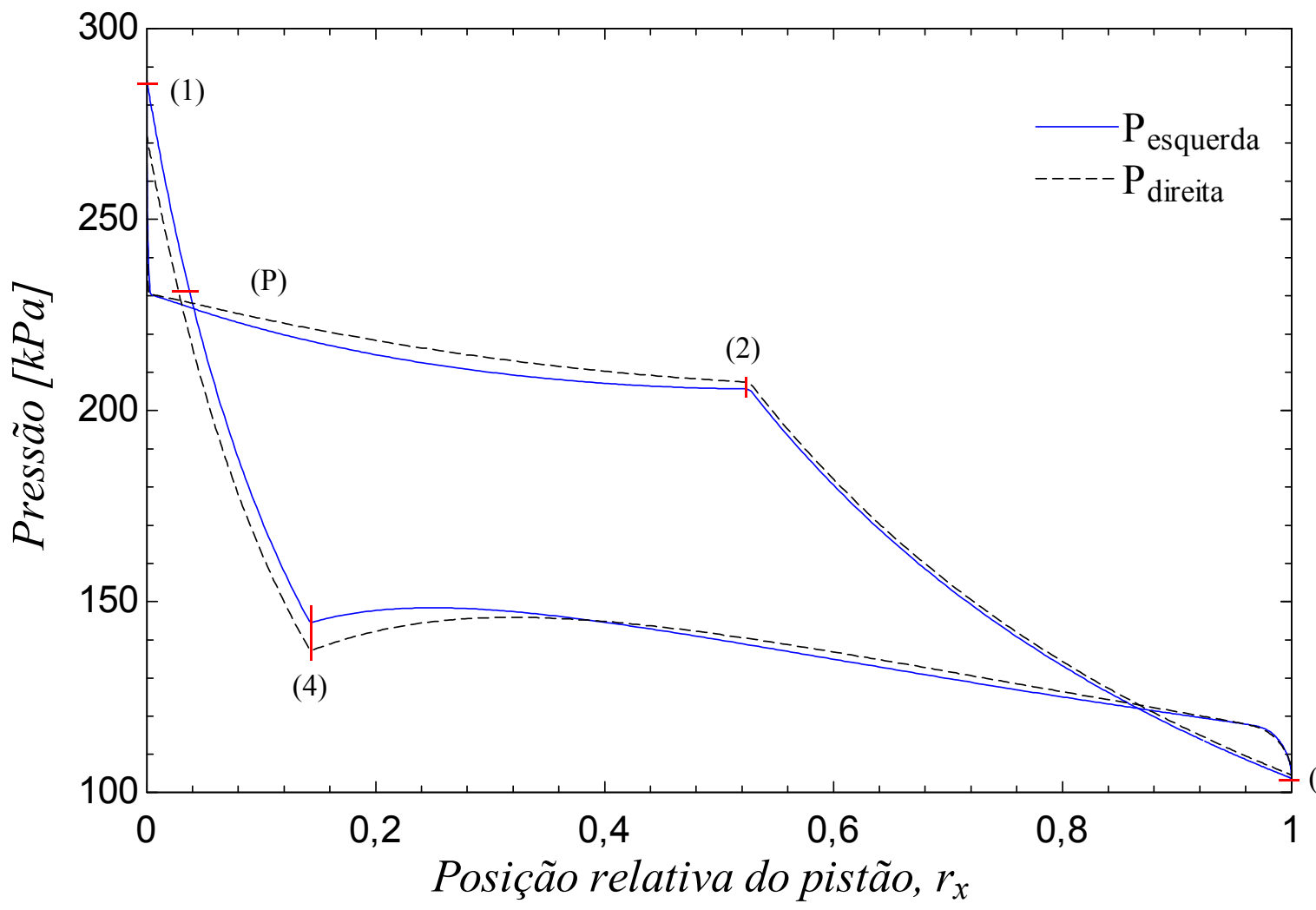

Figura 5.23 - Diagrama PxV para as câmaras da máquina a vapor que utiliza válvulas de comutação instantâneas para pressão nominal de 1,5 bar à 1358,6 rpm 


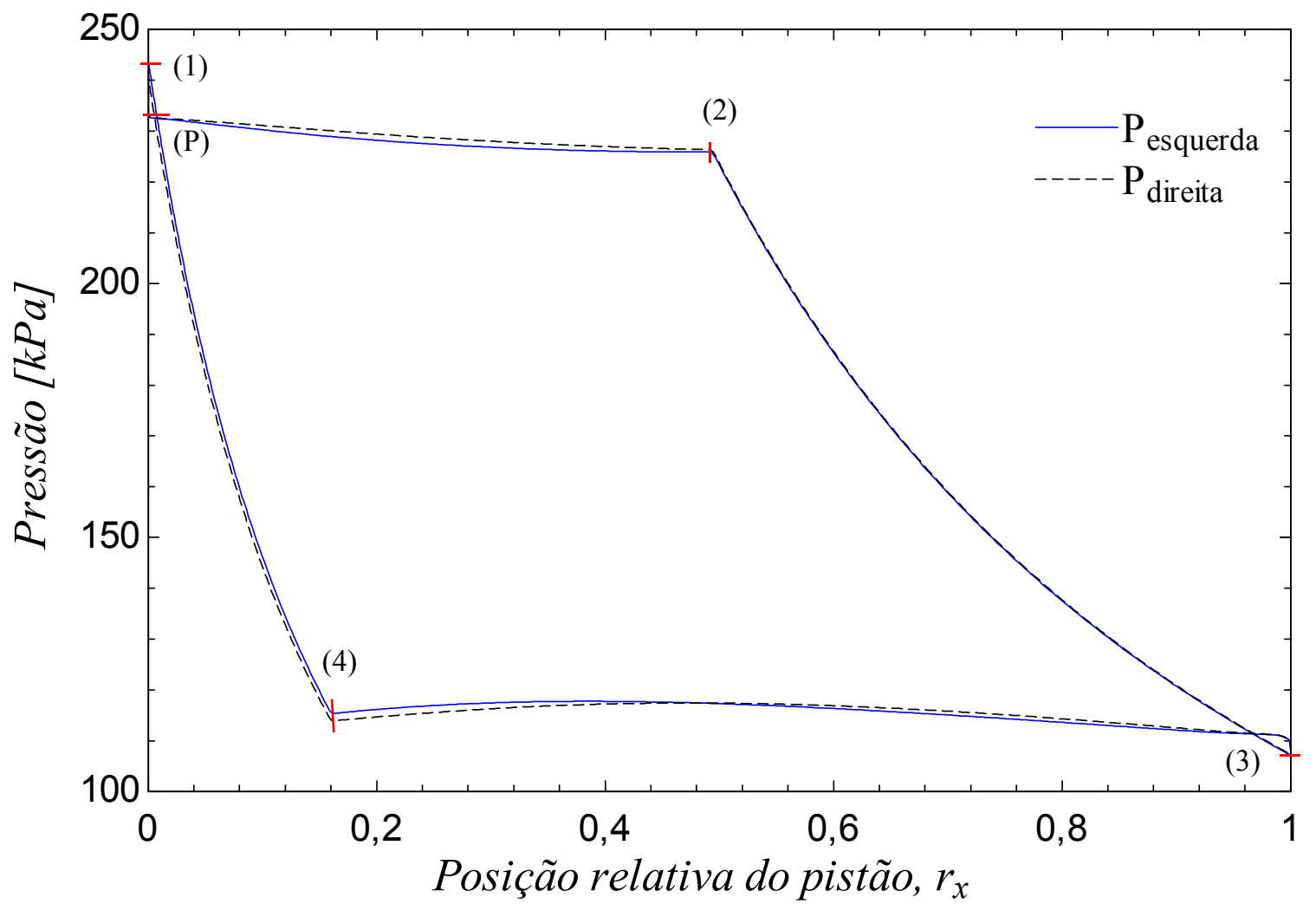

Figura 5.24 - Diagrama PxV para as câmaras da máquina a vapor que utiliza válvulas de comutação instantâneas para pressão nominal de 1,5 bar à 676,5 rpm

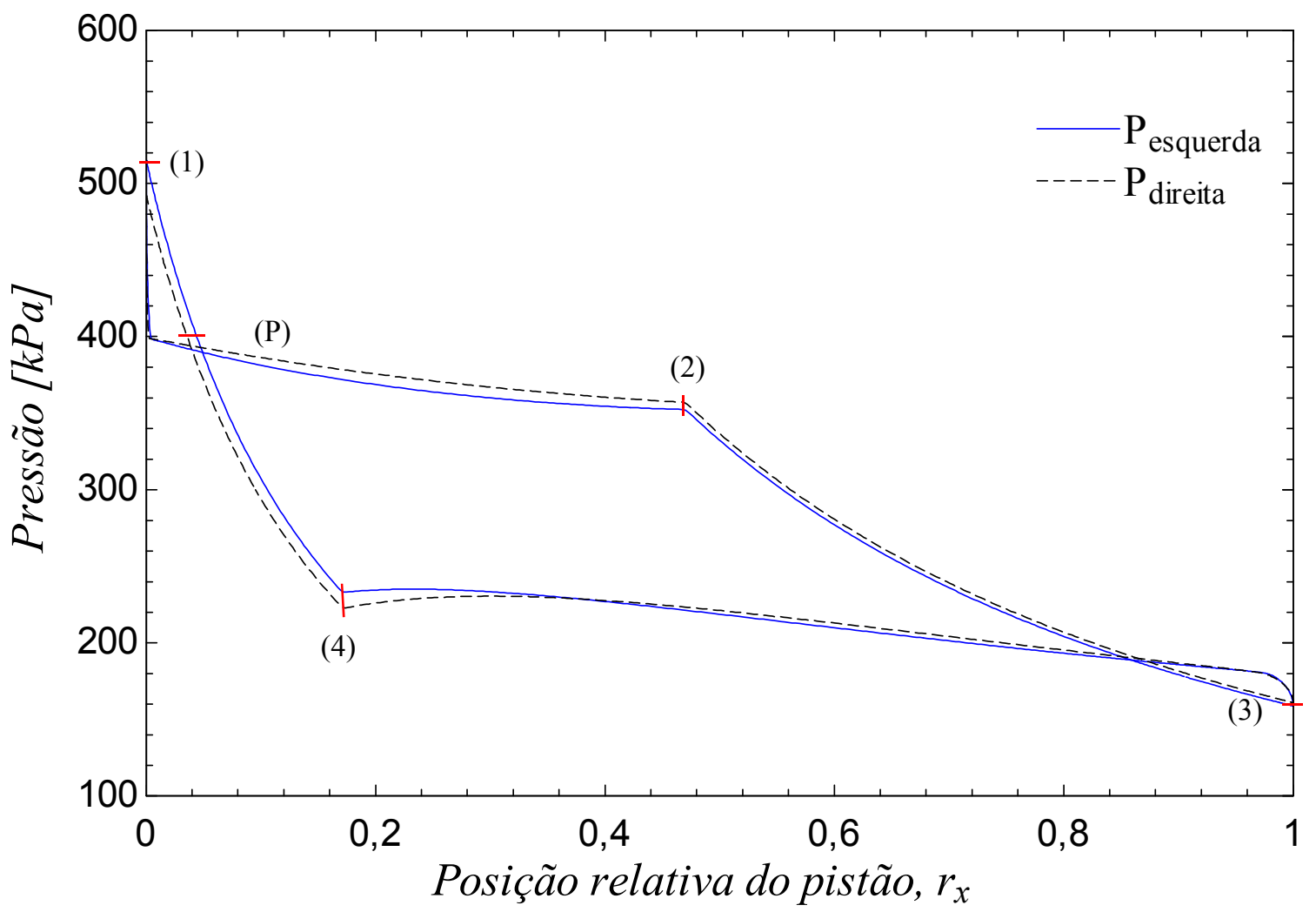

Figura5.25 - Diagrama PxV para as câmaras da máquina a vapor que utiliza válvulas de comutação instantâneas para pressão nominal de 3,5 bar à $1386 \mathrm{rpm}$ 


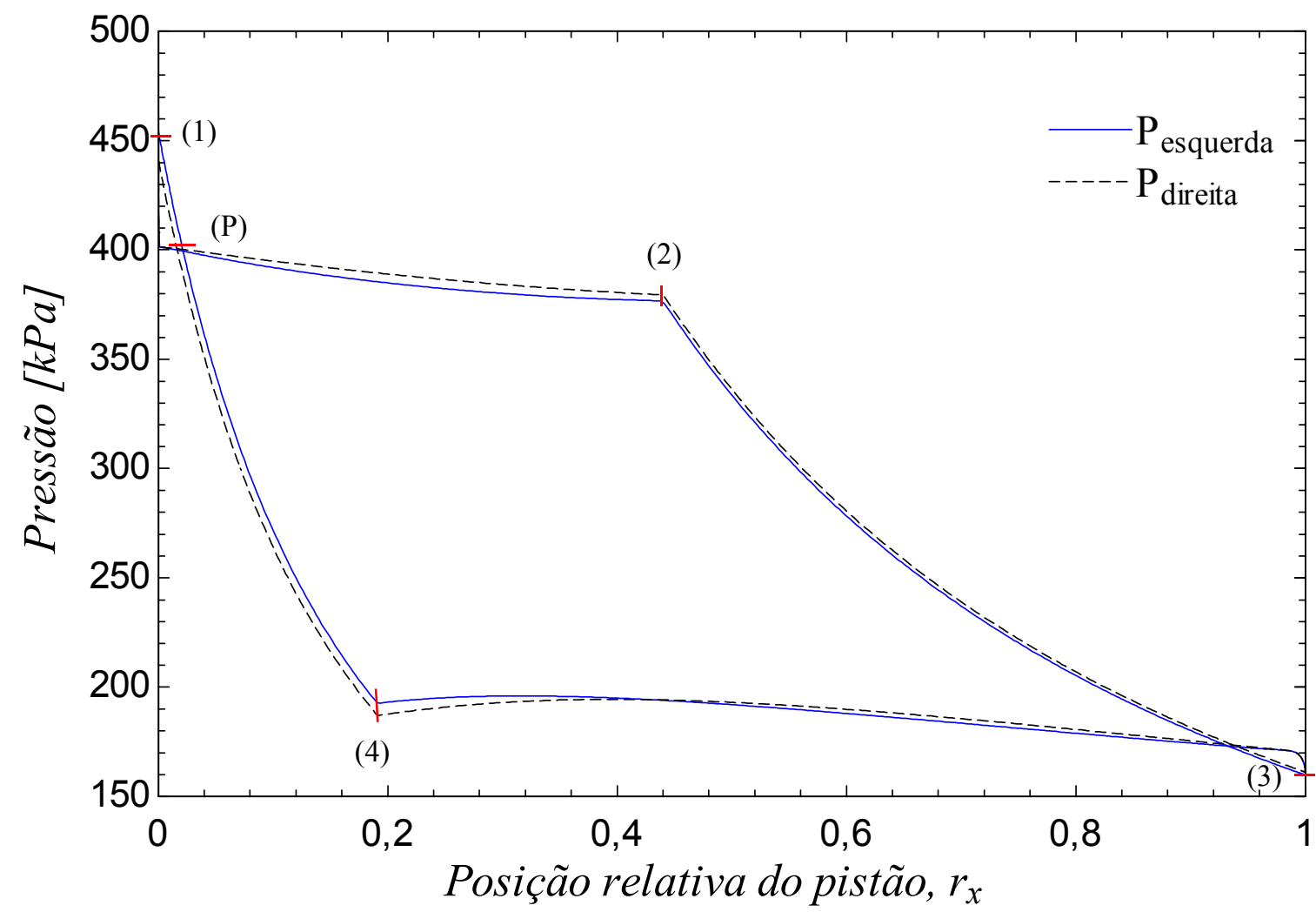

Figura 5.26 - Diagrama PxV para as câmaras da máquina a vapor que utiliza válvulas de comutação instantâneas para pressão nominal de 3,5 bar à $960,7 \mathrm{rpm}$

Ao se utilizar as válvulas carretel com a geometria da máquina simulada, ocorre uma assimetria entre as pressões das duas câmaras, devido ao diferentes instantes de abertura e fechamento. Com válvulas de acionamento instantâneo, essa diferença não existe, pois ambas as válvulas são ajustadas para abrir nos pontos ótimos, dados pelas eqs. (3.55) e (3.56). Essas equações fornecem o ponto teórico de abertura das válvulas de forma a não existir sobrecompressão ou sobre-expansão. Ao observar as imagens entre a Figura 5.21 e Figura 5.26, nota-se que existe sobre-expansão e sobrecompressão, o que não deveria ocorrer ao se utilizar os pontos fornecidos pelas equações citadas para a abertura das válvulas de admissão e escape.

Essa diferença entre os processos teóricos e simulados é provocada pela variação de pressão dentro da câmara nos processos de admissão e escape. Na teoria, esses processos ocorrem à pressão constante, porém nas simulações e na prática, a pressão é variável. As pressões nesses dois processos seguem as curvas tracejadas da Figura 2.7. Essa variação de pressão dentro das câmaras nos processos de admissão e escape é uma combinação da velocidade do pistão e da relação da área de abertura da válvula com o volume interna da câmara. 
O processo de expansão isentrópica (2-3) ocorre da mesma forma que no ciclo ideal, porém como a pressão no início desse processo (2) é menor que a pressão de admissão, existe uma sobre-expansão do fluido quando o pistão se aproxima do ponto morto de maior volume. $\mathrm{O}$ mesmo ocorre no processo de escape, onde a pressão no início do processo de compressão (4) é maior que a pressão de escape, provocando uma sobrecompressão do fluido.

Para melhor visualização da diferença entre o ciclo ideal teórico e essas simulações, na Figura 5.27 e a Figura 5.28, estão indicados os diagramas simulados sobrepostos ao ciclo ideal correspondente, que possui eficiência isentrópica igual a 1 . O ponto (1) indica a abertura da válvula admissão, o ponto (2) indica o fechamento da válvula de admissão, o ponto (3) marca a abertura da válvula de escape e o ponto (4) marca o fechamento da válvula de escape. Esses pontos são os mesmo para os ciclos simulados e o ciclo ideal. Nos pontos (2) e (4), é perceptível a diferença entre as pressões simuladas e as pressões teóricas, e essa diferença de pressões que provoca a sobre-expansão e a sobrecompressão. Para que não exista a sobreexpansão, os pontos de fechamento da válvula de admissão devem ocorrer nos pontos (2’) e (2”) para as câmaras esquerda e direita, respectivamente. E para evitar a sobrecompressão, o fechamento da válvula de escape deve ser realizado nos pontos (4') e (4”) para as câmaras esquerda e direita respectivamente. Esse pontos são obtidos pela extensão da curvas de admissão e escape até cruzarem com as curvas de expansão e compressão isentrópicas.

Nas simulações que consideram a movimentação das válvulas carretel por um sistema bielamanivela existe uma diferença considerável no comportamento da pressão nas duas câmaras, como citado anteriormente, isso é devido à assimetria do movimento das válvulas com a posição do pistão. Para as simulações que utilizam válvulas de acionamento instantâneo, essa assimetria não existe, porém o comportamento das duas câmaras ainda não são iguais, como pode ser observado nas imagens entre a Figura 5.21 e a Figura 5.28. A diferença do comportamento entre as duas câmaras advém da diferença de volume das duas câmaras. $O$ volume da câmara esquerda é $1,8 \%$ maior que o volume da câmara direita, pois na câmara direita está o eixo do pistão com diâmetro de $4 \mathrm{~mm}$, e o diâmetro do cilindro é de $30 \mathrm{~mm}$. 


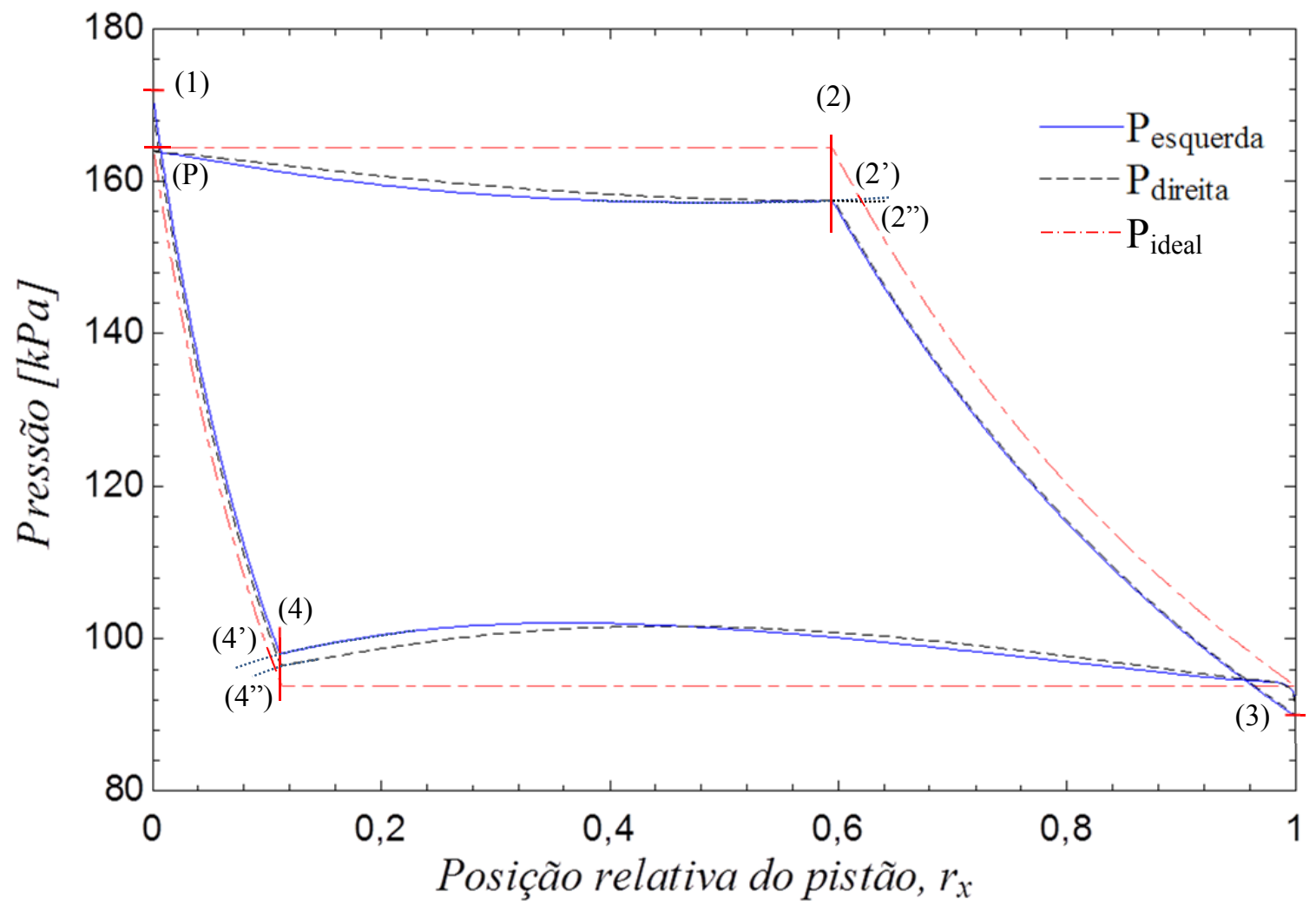

Figura 5.27 - Sobreposição dos diagramas PxV simulados e do ciclo ideal para pressão nominal de 0,5 bar à 792, 6 rpm.

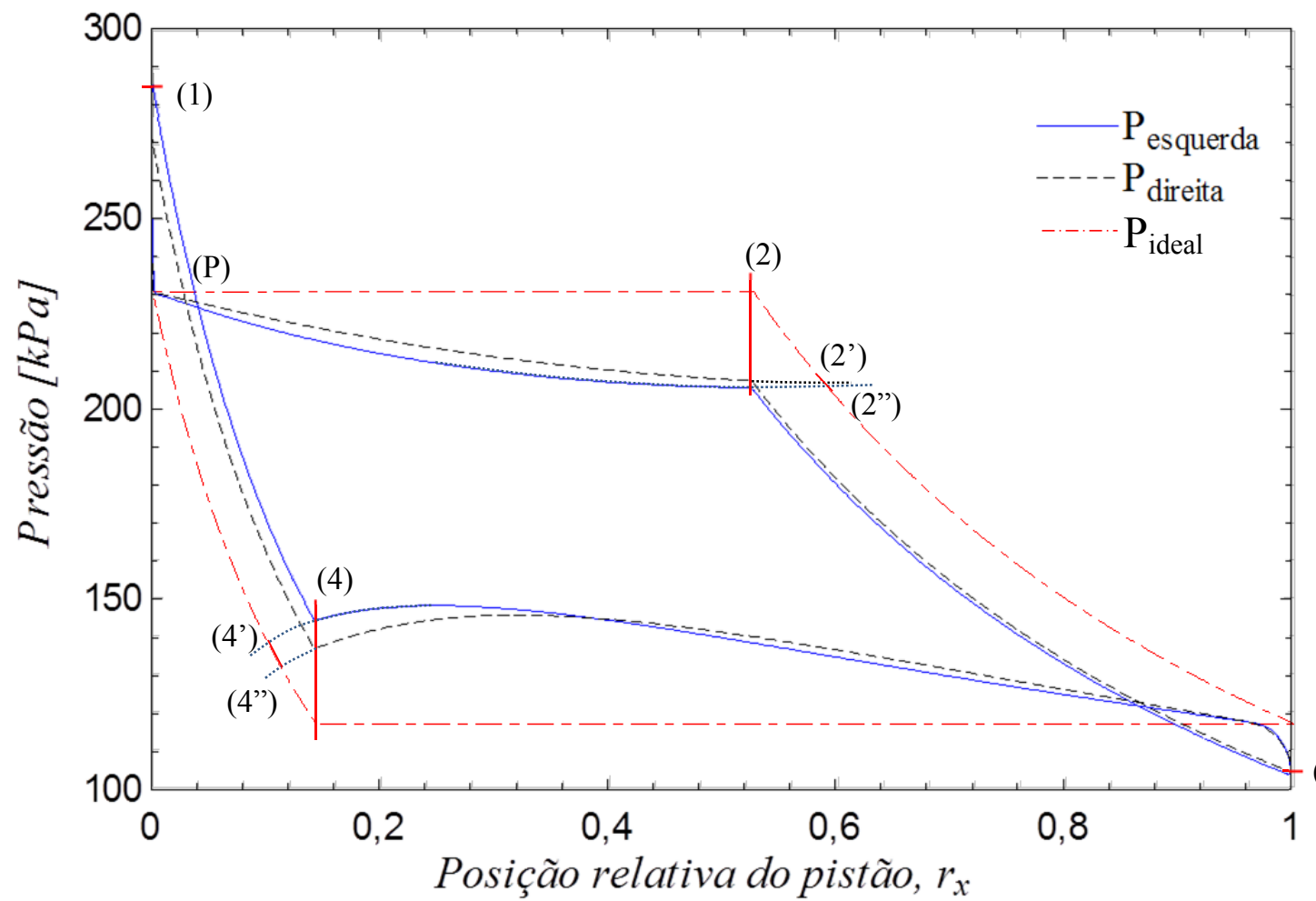

Figura 5.28 - Sobreposição dos diagramas PxV simulados e do ciclo ideal para pressão nominal de 1,5 bar à $1358,6 \mathrm{rpm}$. 
Como anteriormente citado, a variação de pressão no interior das câmaras nos processos de admissão e escape ocorre devido a uma combinação da velocidade do pistão com a razão entre a área de abertura da válvula com o volume da câmara. Quanto maior a velocidade do pistão ou menor a razão entre a área de abertura da válvula e o volume da câmara, maior a variação da pressão interna em relação às pressões de admissão e de escape. Como a câmara direita possui um volume ligeiramene menor que o da câmara esquerda, a razão entre a área de abertura da válvula de admissão e o volume da câmara é maior que a mesma relação para a câmara esquerda. Isso faz com que a variação da pressão da câmara direita nos processos de admissão e escape seja menor que a variação da câmara esquerda, gerando uma pequena diferença no comportamento das duas câmaras. A menor variação de pressão nos processos de admissão e escape indica um melhor fluxo mássico. Não significa que o fluxo mássico seja maior, mas sim que esse fluxo tem uma maior capacidade de preencher o volume da câmara em menos tempo, ou como é dito popularmente, um melhor "respiro do motor".

$\mathrm{Na}$ Tabela 5.3 estão escritos os resultados calculados nas simulações para a máquina funcionando com o acionamento instantâneo das válvulas, para que seja possível comparar com a máquina utilizando as válvulas carretel. Os valores mostrados na tabela são o trabalho realizado pelas duas câmaras em uma rotação (W/ciclo), a vazão em massa (m), o trabalho específico $(w)$, a potência média ( Pot $\left._{\text {media }}\right)$ e a eficiência isentrópica (n)

\begin{tabular}{|c|c|c|c|c|c|c|c|c|}
\hline $\begin{array}{c}\text { Pressão } \\
\text { [bar] }\end{array}$ & Medida & $\begin{array}{c}\text { Rotação } \\
{[\mathrm{rpm}]}\end{array}$ & $\begin{array}{c}\mathrm{W}_{\text {iso }} \\
{[\mathrm{kJ} / \mathrm{kg}]}\end{array}$ & $\begin{array}{c}\mathrm{w} \\
{[\mathrm{kJ} / \mathrm{kg}]}\end{array}$ & $\begin{array}{c}\text { W/ciclo } \\
{[\mathrm{J}]}\end{array}$ & $\begin{array}{c}\text { Pot }_{\text {media }} \\
{[\mathrm{W}]}\end{array}$ & $\begin{array}{c}\dot{\mathrm{m}} \\
{[\mathrm{g} / \mathrm{s}]}\end{array}$ & $\eta_{\text {iso }}[\%]$ \\
\hline \multirow{7}{*}{0,5} & 1 & 792,56 & 45,40 & 38,13 & 2,495 & 32,95 & 0,86 & 83,98 \\
\hline & 2 & 692,24 & 46,17 & 40,57 & 2,68 & 30,92 & 0,76 & 87,88 \\
\hline & 3 & 623,14 & 46,81 & 42,22 & 2,8 & 29,08 & 0,69 & 90,19 \\
\hline & 4 & 508,33 & 46,93 & 43,74 & 2,911 & 24,67 & 0,56 & 93,20 \\
\hline & 5 & 437,48 & 47,39 & 44,92 & 3,001 & 21,88 & 0,49 & 94,77 \\
\hline & 6 & 386,42 & 48,70 & 46,63 & 3,124 & 20,12 & 0,43 & 95,75 \\
\hline & 7 & 354,34 & 48,33 & 46,49 & 3,112 & 18,37 & 0,40 & 96,19 \\
\hline \multirow{5}{*}{0,75} & 1 & 729,85 & 47,16 & 40,94 & 2,705 & 32,91 & 0,80 & 86,82 \\
\hline & 2 & 658,06 & 47,79 & 42,68 & 2,842 & 31,17 & 0,73 & 89,31 \\
\hline & 3 & 604,20 & 48,35 & 43,99 & 2,945 & 29,66 & 0,67 & 90,99 \\
\hline & 4 & 552,52 & 48,46 & 44,76 & 3,002 & 27,65 & 0,62 & 92,35 \\
\hline & 5 & 494,74 & 49,02 & 45,96 & 3,098 & 25,55 & 0,56 & 93,76 \\
\hline
\end{tabular}


Tabela 5.3 - Continuação

\begin{tabular}{|c|c|c|c|c|c|c|c|c|}
\hline $\begin{array}{c}\text { Pressão } \\
\text { [bar] }\end{array}$ & Medida & $\begin{array}{c}\text { Rotação } \\
{[\mathrm{rpm}]}\end{array}$ & $\begin{array}{c}\mathrm{W}_{\text {iso }} \\
{[\mathrm{kJ} / \mathrm{kg}]}\end{array}$ & $\begin{array}{c}\mathrm{w} \\
{[\mathrm{kJ} / \mathrm{kg}]}\end{array}$ & $\begin{array}{c}\text { W/ciclo } \\
{[\mathrm{J}]}\end{array}$ & $\begin{array}{c}\text { Pot }_{\text {media }} \\
{[\mathrm{W}]}\end{array}$ & $\begin{array}{c}\dot{\mathrm{m}} \\
{[\mathrm{g} / \mathrm{s}]}\end{array}$ & $\eta_{\text {iso }}[\%]$ \\
\hline \multirow{6}{*}{1} & 1 & 897,04 & 52,50 & 43,15 & 2,876 & 43,00 & 1,00 & 82,18 \\
\hline & 2 & 807,73 & 52,44 & 44,82 & 3,01 & 40,53 & 0,90 & 85,47 \\
\hline & 3 & 658,89 & 53,64 & 48,48 & 3,324 & 36,50 & 0,75 & 90,38 \\
\hline & 4 & 576,13 & 54,49 & 50,44 & 3,481 & 33,42 & 0,66 & 92,57 \\
\hline & 5 & 455,85 & 54,86 & 52,12 & 3,6 & 27,35 & 0,52 & 95,01 \\
\hline & 6 & 591,43 & 54,24 & 49,99 & 3,601 & 35,50 & 0,71 & 92,17 \\
\hline \multirow{6}{*}{1,5} & 1 & 1358,57 & 57,12 & 35,45 & 2,37 & 53,66 & 1,51 & 62,07 \\
\hline & 2 & 1157,05 & 58,50 & 42,87 & 2,966 & 57,19 & 1,33 & 73,28 \\
\hline & 3 & 943,28 & 59,67 & 49,33 & 3,567 & 56,07 & 1,14 & 82,67 \\
\hline & 4 & 852,23 & 60,47 & 51,95 & 3,795 & 53,90 & 1,04 & 85,91 \\
\hline & 5 & 734,94 & 61,10 & 54,69 & 4,063 & 49,77 & 0,91 & 89,50 \\
\hline & 6 & 676,53 & 61,66 & 56,13 & 4,168 & 46,99 & 0,84 & 91,03 \\
\hline \multirow{8}{*}{2} & 1 & 1471,66 & 62,40 & 37,03 & 2,525 & 61,93 & 1,67 & 59,34 \\
\hline & 2 & 1335,29 & 63,43 & 42,59 & 3,01 & 66,97 & 1,57 & 67,14 \\
\hline & 3 & 1283,52 & 63,09 & 43,85 & 3,157 & 67,54 & 1,54 & 69,51 \\
\hline & 4 & 1229,21 & 63,76 & 46,13 & 3,353 & 68,70 & 1,49 & 72,34 \\
\hline & 5 & 1002,80 & 65,99 & 54,23 & 4,114 & 68,76 & 1,27 & 82,19 \\
\hline & 6 & 961,46 & 66,28 & 55,43 & 4,219 & 67,61 & 1,22 & 83,63 \\
\hline & 8 & 963,90 & 65,38 & 54,50 & 4,142 & 66,55 & 1,22 & 83,36 \\
\hline & 9 & 823,31 & 66,71 & 58,69 & 4,587 & 62,95 & 1,07 & 87,98 \\
\hline \multirow{9}{*}{2,5} & 1 & 1513,36 & 68,10 & 41,39 & 2,982 & 75,22 & 1,82 & 60,77 \\
\hline & 2 & 1524,24 & 67,90 & 40,75 & 2,909 & 73,89 & 1,81 & 60,02 \\
\hline & 3 & 1419,01 & 68,44 & 44,95 & 3,327 & 78,69 & 1,75 & 65,67 \\
\hline & 4 & 1262,77 & 69,44 & 50,86 & 3,955 & 83,24 & 1,64 & 73,24 \\
\hline & 5 & 1202,60 & 70,40 & 53,51 & 4,19 & 83,99 & 1,57 & 76,01 \\
\hline & 6 & 1167,29 & 69,62 & 53,59 & 4,258 & 82,85 & 1,55 & 76,98 \\
\hline & 7 & 1093,29 & 70,57 & 56,53 & 4,566 & 83,21 & 1,47 & 80,10 \\
\hline & 8 & 962,07 & 71,81 & 60,85 & 5,044 & 80,88 & 1,33 & 84,74 \\
\hline & 9 & 704,43 & 75,09 & 68,81 & 5,808 & 68,19 & 0,99 & 91,64 \\
\hline \multirow{4}{*}{3} & 1 & 1363,06 & 70,01 & 48,16 & 3,964 & 90,06 & 1,87 & 68,79 \\
\hline & 2 & 1322,61 & 70,35 & 49,78 & 4,135 & 91,16 & 1,83 & 70,77 \\
\hline & 3 & 1115,91 & 73,46 & 58,72 & 5,05 & 93,93 & 1,60 & 79,93 \\
\hline & 4 & 1145,98 & 73,80 & 58,34 & 4,941 & 94,37 & 1,62 & 79,04 \\
\hline
\end{tabular}


Tabela 5.3 - Continuação

\begin{tabular}{c|c|c|c|c|c|c|c|c}
$\begin{array}{c}\text { Pressão } \\
\text { [bar] }\end{array}$ & Medida & $\begin{array}{c}\text { Rotação } \\
{[\mathrm{rpm}]}\end{array}$ & $\begin{array}{c}\mathrm{W}_{\text {iso }} \\
{[\mathrm{kJ} / \mathrm{kg}]}\end{array}$ & $\begin{array}{c}\mathrm{w} \\
{[\mathrm{kJ} / \mathrm{kg}]}\end{array}$ & $\begin{array}{c}\mathrm{W} / \text { ciclo } \\
{[\mathrm{J}]}\end{array}$ & $\begin{array}{c}\text { Pot }_{\text {media }} \\
{[\mathrm{W}]}\end{array}$ & $\begin{array}{c}\dot{\mathrm{m}} \\
{[\mathrm{g} / \mathrm{s}]}\end{array}$ & $\eta_{\text {iso }}[\%]$ \\
\hline \multirow{5}{*}{3,5} & 1 & 1386,07 & 62,99 & 40,38 & 4,197 & 96,95 & 2,40 & 64,10 \\
\cline { 2 - 9 } & 2 & 1202,74 & 64,02 & 46,51 & 5,017 & 100,58 & 2,16 & 72,64 \\
\cline { 2 - 9 } & 3 & 1143,65 & 64,73 & 48,81 & 5,302 & 101,09 & 2,07 & 75,40 \\
\cline { 2 - 9 } & 4 & 1006,65 & 66,50 & 54,05 & 6,036 & 101,28 & 1,87 & 81,28 \\
\cline { 2 - 9 } & 5 & 1092,70 & 65,53 & 50,99 & 5,603 & 102,04 & 2,00 & 77,82 \\
\cline { 2 - 9 } & 6 & 960,73 & 67,20 & 55,75 & 6,22 & 99,59 & 1,79 & 82,95
\end{tabular}

Ao comparar os dados das duas simulações que estão na Tabela 5.2 e na Tabela 5.3, pode-se verificar que os valores são consideravelmente diferentes, e a única condição que difere entre as simulações é o acionamento das válvulas. Ao trabalhar com válvulas instantâneas, o trabalho realizado em cada ciclo e a potência são menores do que quando se utiliza a válvula carretel, chegando a ser aprox. 33\% menor que a configuração das válvulas carretel. O baixo consumo de fluido é a principal característica que aumenta a eficiência da máquina, sendo que o consumo é de $15 \%$ a $49 \%$ menor do que quando se utiliza as válvulas carretel. Devido aos pontos de abertura das válvulas não serem otimizados para cada combinação de pressão e rotação, ao utilizar as válvulas instantâneas, as menores eficiências se aproximam das eficiências com a válvula carretel, e as maiores se aproximam do ciclo ideal. A menor eficiência isentrópica indicada na Tabela 5.3 é de aprox. 59\% e a maior é de aprox. 96\%. 


\section{COMPARAÇÃO SIMULAÇÕES/EXPERIMENTOS}

\subsection{ACOPLAMENTO DOS DADOS SIMULADOS E OBTIDOS EXPERIMENTALMENTE}

Para poder comparar os dados os ciclos experimentais e os ciclos simulados, é necessário comparar os trechos correspondentes de cada ciclo. Como não foram obtidos dados referentes à posição do pistão nos experimentos, é necessário fazer um acoplamento dos ciclos simulados com os respectivos ciclos obtidos experimentalmente. E para isso se faz necessário encontrar pontos comuns que se repetem em todos os ciclos, e assim pode-se acoplar os dados a partir desses pontos comuns.

A principal característica que ocorre em todas as simulações é que quando o pistão se aproxima do ponto morto de menor volume $\left(r_{x}=0\right)$ ocorre uma sobrecompressão do ar no interior da câmara e quando ele atinge esse ponto morto, a pressão é igual ou muito próxima à pressão de admissão. Essa região característica é ilustrada para a simulação feita com pressão nominal de 2,5 bar a 1513,3 rpm, indicada na Figura 6.1. Como apenas se tem dados experimentais em relação ao tempo, é necessário localizar essa característica no diagrama $P_{\mathrm{x}} t$. Essa característica está indicada circulada no diagrama da Figura 6.2. 


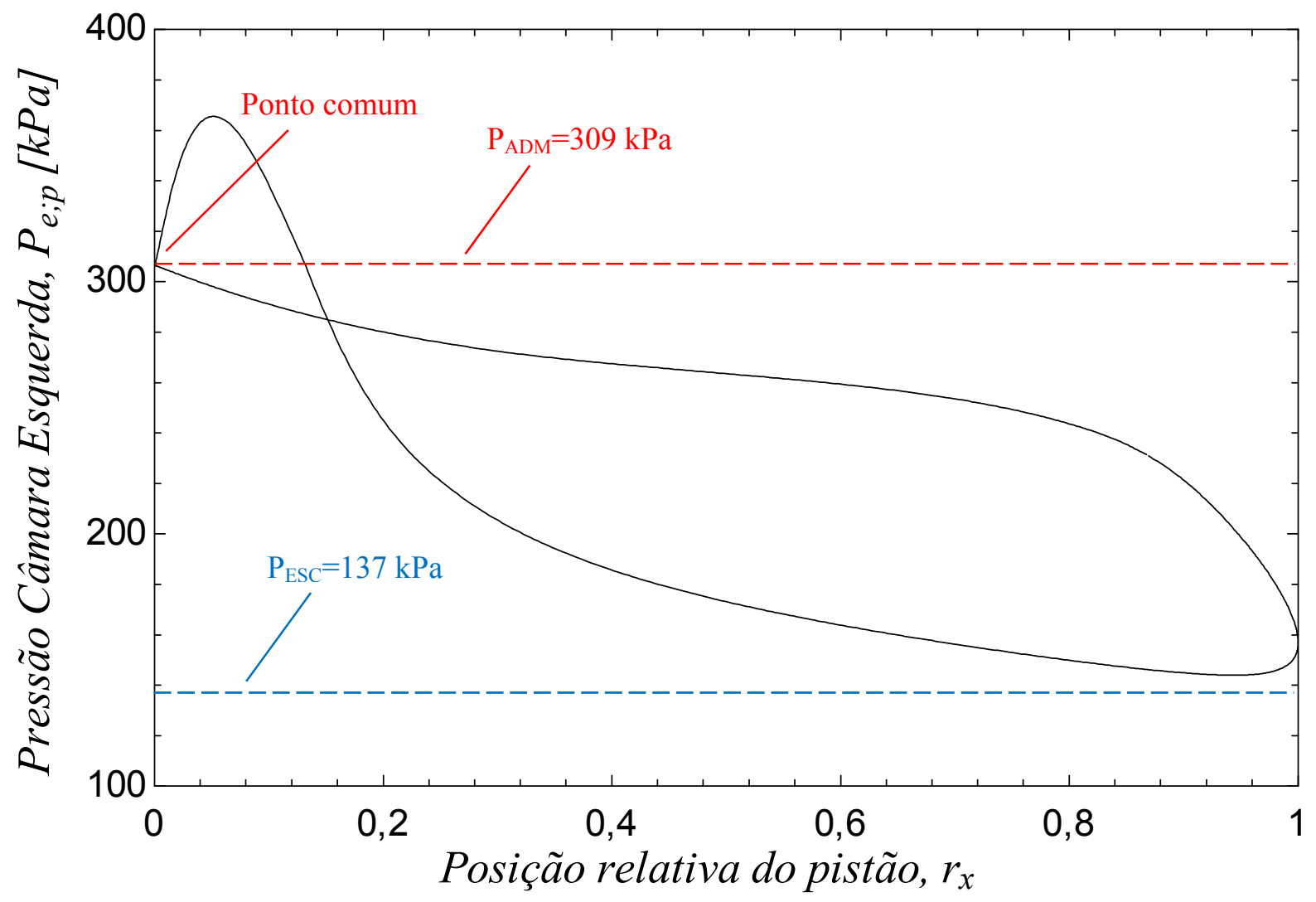

Figura 6.1 - Diagrama PxV simulado da câmara esquerdada máquina a vapor para pressão nominal de 2,5 bar à 1513,3 rpm, com indicação da principal característica que se repete em todas simulações.

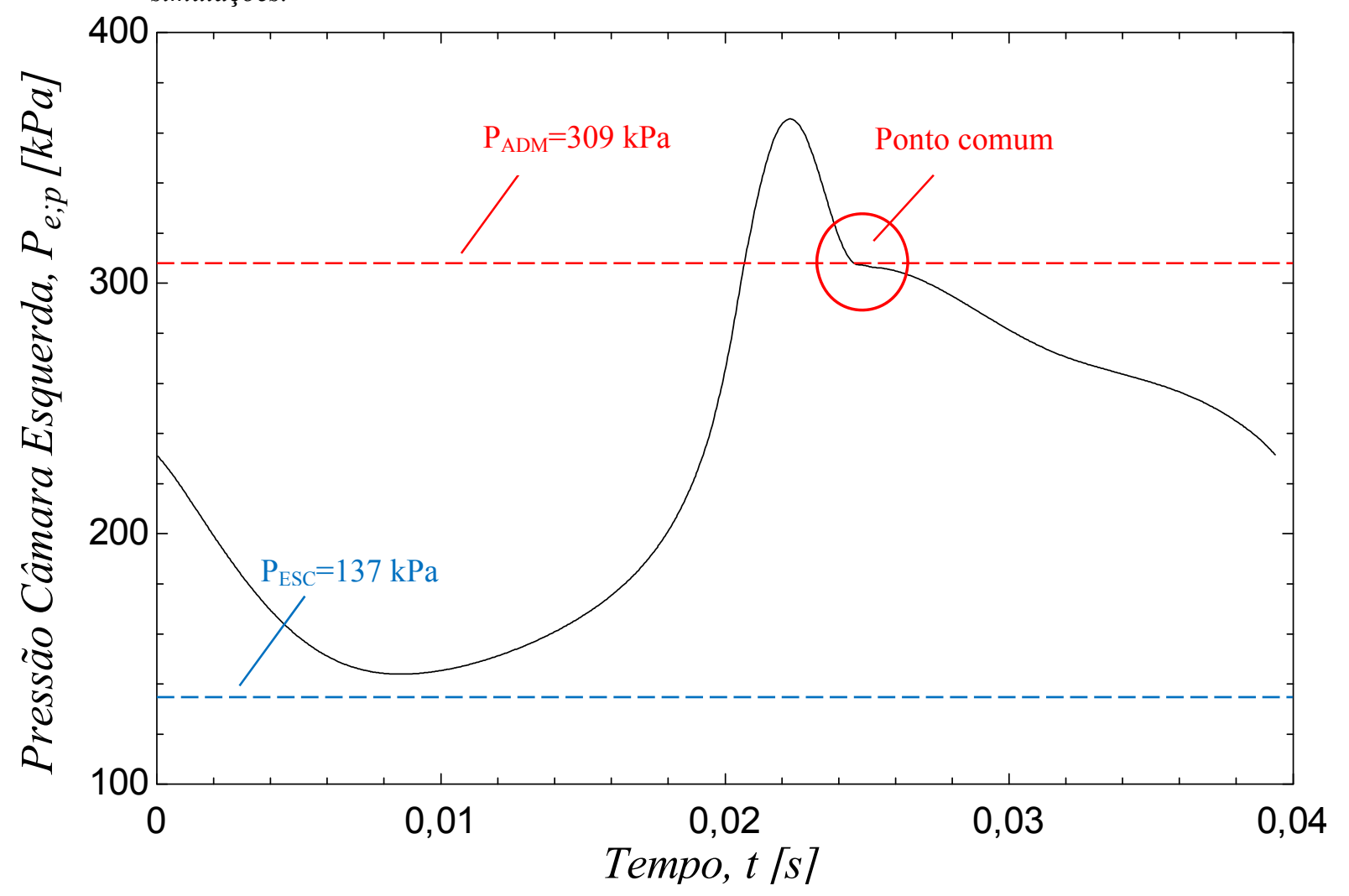

Figura 6.2 - Diagrama $P_{x}$ t simulado para a câmara esquerda da máquina a vapor para pressão nominal de 2,5 bar à 1513,3 rpm, com indicação da principal característica que se repete em todas simulações. 
Além se existir a sobrecompressão, é possível localizar o ponto morto, pois como nesse ponto a velocidade do pistão é nula e a pressão é igual ou próxima à pressão de admissão, formando um pequeno trecho horizontal no diagrama $\mathrm{P}_{\mathrm{x}} \mathrm{t}$.

O instante inicial dos ciclos medidos experimentalmente é ajustado de forma a fazer com que essa pequena reta após a sobrecompressão ocorra no mesmo instante em que ocorre nos ciclos simulados. Teoricamente, se esse ajuste for feito analisando apenas uma das câmaras, a outra está automaticamente ajustada, porém devido a não simetria de funcionamento dessa máquina a vapor, isso não ocorre. Então os ajustes foram feitos de forma que a posição do ponto comum das duas câmaras fique a mais próxima possível desse mesmo ponto comum na simulação. Na Figura 6.3 e na Figura 6.4 estão mostrados os diagramas ajustados para as duas câmaras e o melhor acoplamento conseguido.

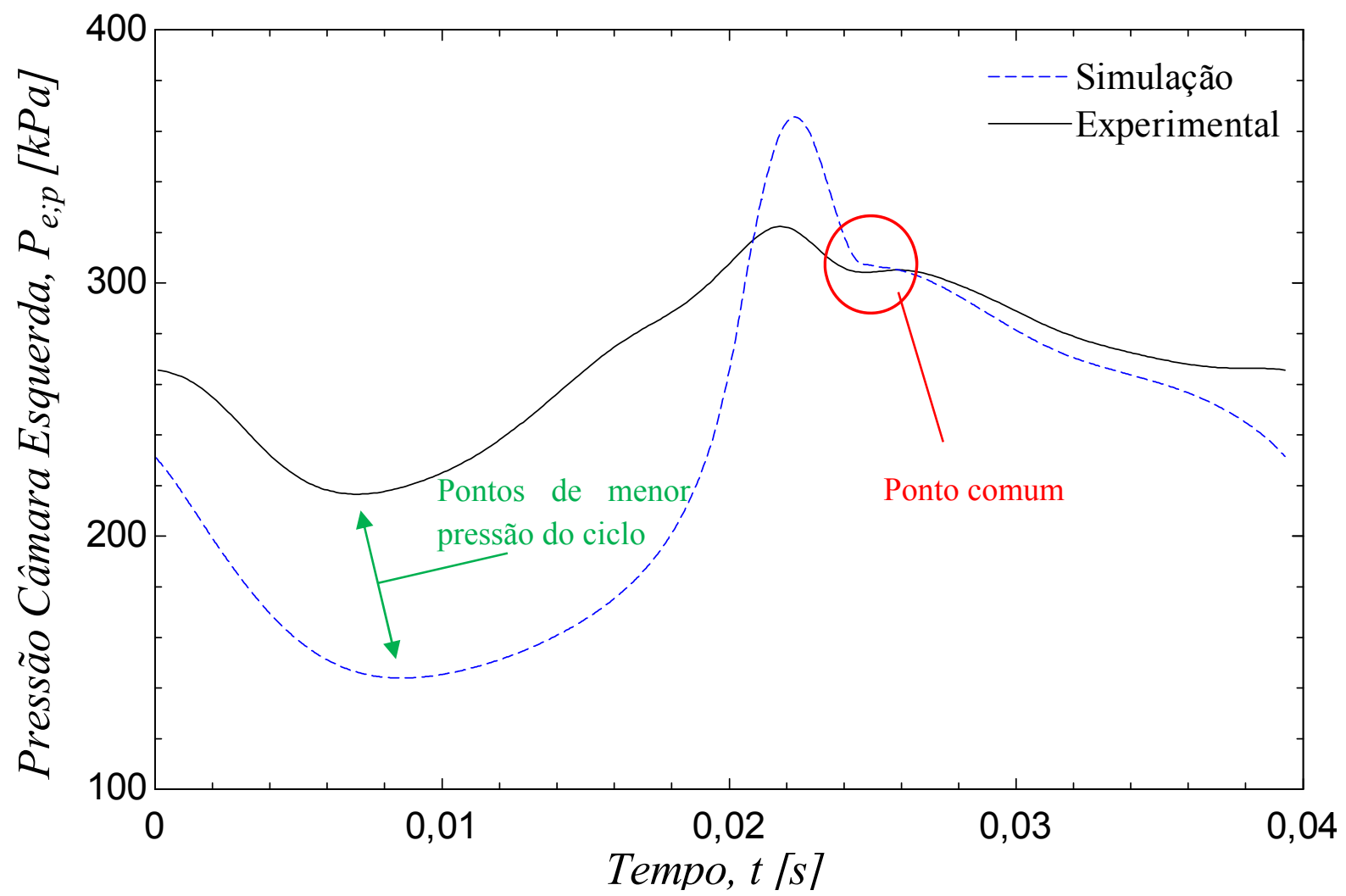

Figura 6.3 - Diagrama $P_{x} t$ para o acoplamento do ciclo simulado e o ciclo experimental para a pressão de 2,5 bar e 1531,3 rpm utilizando as pressões da câmara esquerda. 


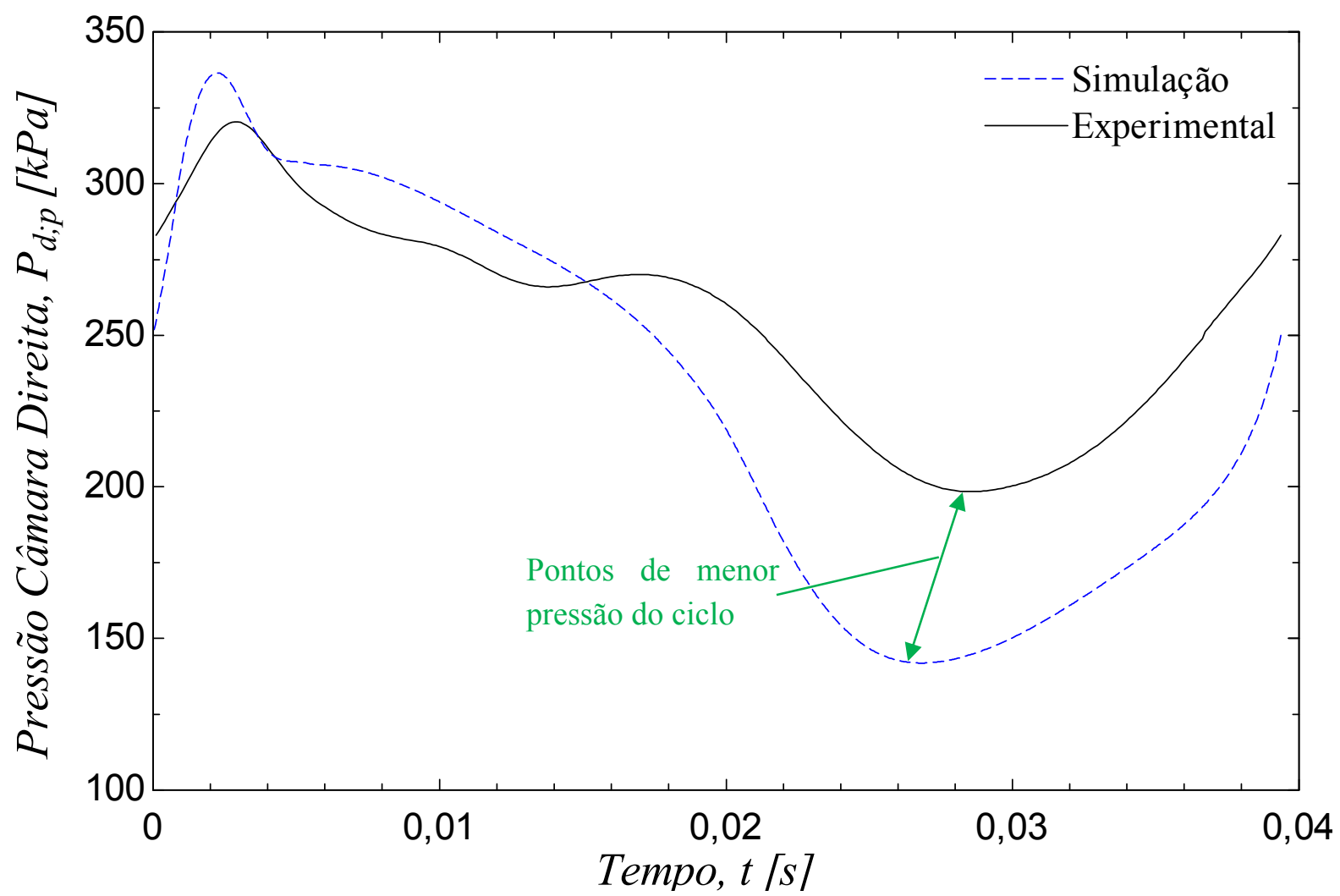

Figura 6.4 - Diagrama $P_{x}$ t para o acoplamento do ciclo simulado e o ciclo experimental para a pressão de 2,5 bar e 1531,3 rpm utilizando as pressões da câmara direita.

Nota-se pelo diagrama da Figura 6.3 que existe um pequeno trecho de pressão praticamente constante nas pressões adquiridas para a máquina a vapor, sendo possível acoplar os dois diagramas por esse trecho. Já na Figura 6.4 não existe esse trecho de pressão constante nos dados experimentais, o que dificulta ou impede o acoplamento utilizando esse diagrama. Para essa medição, o acoplamento foi feito utilizando unicamente o diagrama para a câmara esquerda do cilindro.

Outra característica que pode ser utilizada para verificar se o ajuste está coerente é verificar os pontos de menor pressão dos diagramas. Nas simulações, os pontos de menor pressão do ciclo ocorrem na mesma posição relativa do pistão, portanto se a máquina testada funcionar de forma parecida com o esperado, o mesmo deve ocorrer. Em alguns casos, ao alinhar os pontos comuns, pode-se verificar que os pontos de mínimo se alinham também, e em outros casos, os pontos de mínimo obtidos experimentalmente ficam um pouco deslocados dos pontos de mínimo simulados. Quando isso ocorre, geralmente um fica deslocado para a esquerda e outro para a direita em relação aos mínimos simulados, como mostrado no exemplo acima. 
Existem medições onde essas características são mais fáceis de serem observadas e o acoplamento é realizado sem dificuldades, mas em outras medições esse ponto não são muito claros, dificultando um pouco o acoplamento.

\subsection{DIAGRAMAS $\mathrm{P}_{\mathrm{X}} \mathrm{V}$ COMPARATIVOS ENTRE DADOS SIMULADOS E DADOS EXPERIMENTAIS}

Com o acoplamento é possível relacionar a posição do pistão com a pressão em cada instante do ciclo obtido experimentalmente. Dessa forma, pode-se construir os diagramas PxV dos ciclos experimentalmente e compará-los com os ciclos simulados. As figuras no intervalo entre a Figura 6.5 e a Figura 6.16 mostram diagramas $\mathrm{PxV}$ simulados e experimentais sobrepostos para as duas câmaras de ciclos, para que seja possível estudá-los de forma comparativa. ,

Observando os diagramas $\mathrm{PxV}$ simulados sobrepostos aos diagramas medidos, mostrados na Figura 6.6, na Figura 6.8, na Figura 6.10 e na Figura 6.16, verifica-se o comportamento similar dos processos de admissão da câmara esquerda para pressão de até 1bar e que envolvem rotações menores que $1000 \mathrm{rpm}$. Para a câmara direita nessas mesmas condições, os valores medidos são menores que os valores simulados no início do processo de admissão e maiores no fim do processo de admissão. Essa diferença se deve principalmente ao fato de existir um fluxo de massa contínuo saindo da câmara direita pelas folgas no eixo do pistão, reduzindo a pressão da câmara direita do pistão.

Como citado no capítulo 4, a capacidade de admitir e expulsar o fluxo de fluido é uma relação entre a rotação da máquina, as pressões envolvidas e a área de abertura das válvulas. Para os diagramas da Figura 6.15 e da Figura 6.16 existe uma grande similaridade entre os processos de admissão simulados e medidos para ambas as câmaras, mesmo a rotação sendo alta em relação às demais medições. O comportamento desses dois diagramas é devido à alta pressão que facilita o fluxo de massa para dentro do cilindro. 


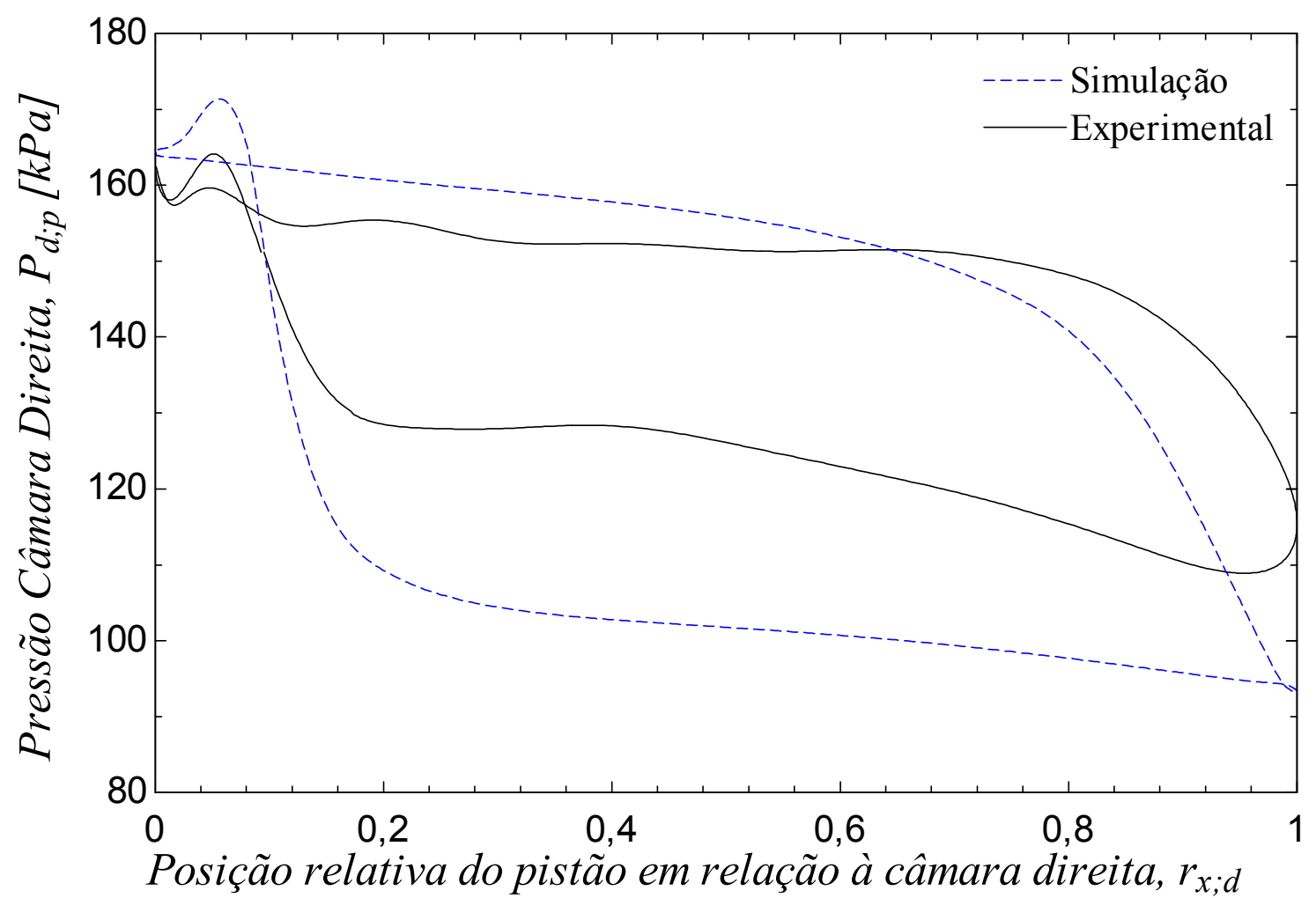

Figura 6.5 - Diagramas PxV simulado e medido da câmara direita do cilindro para uma pressão de 0,5bar e 792,6 rpm.

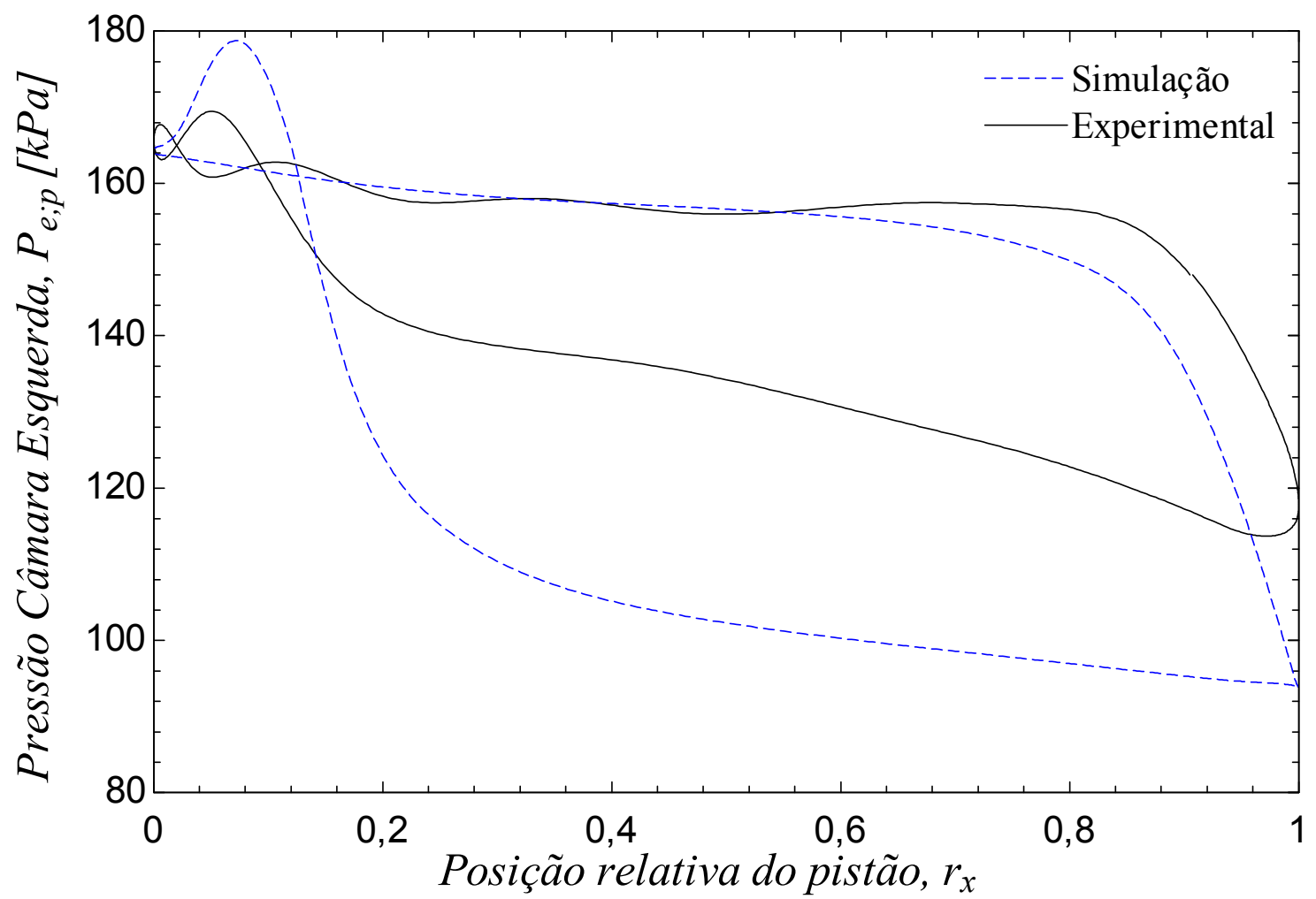

Figura 6.6 - Diagramas PxV simulado e medido da câmara esquerda do cilindro para uma pressão de 0,5bar e 792,6 rpm. 


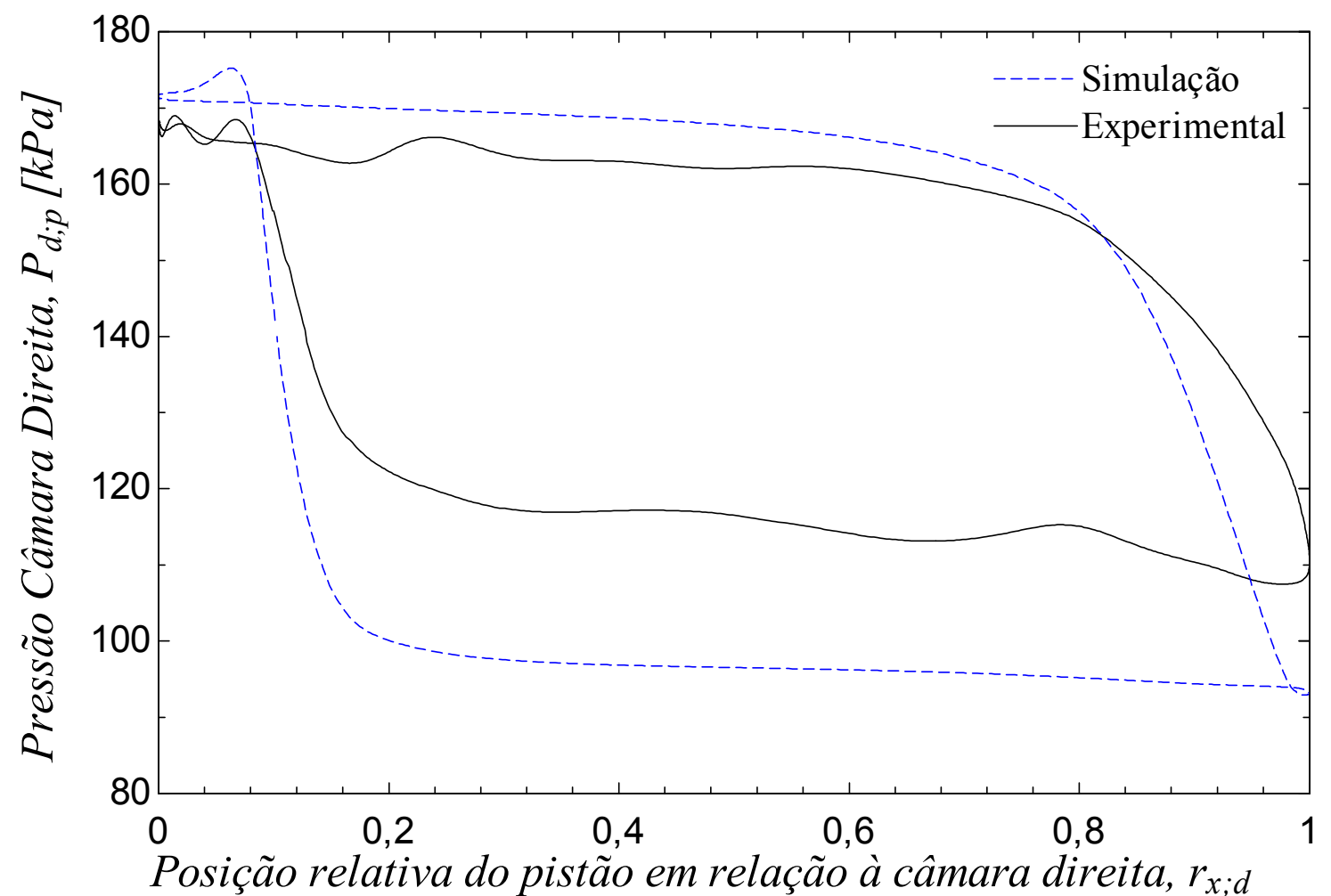

Figura 6.7 - Diagramas PxV simulado e medido da câmara direita do cilindro para uma pressão de 0,75bar e 494, $7 \mathrm{rpm}$.

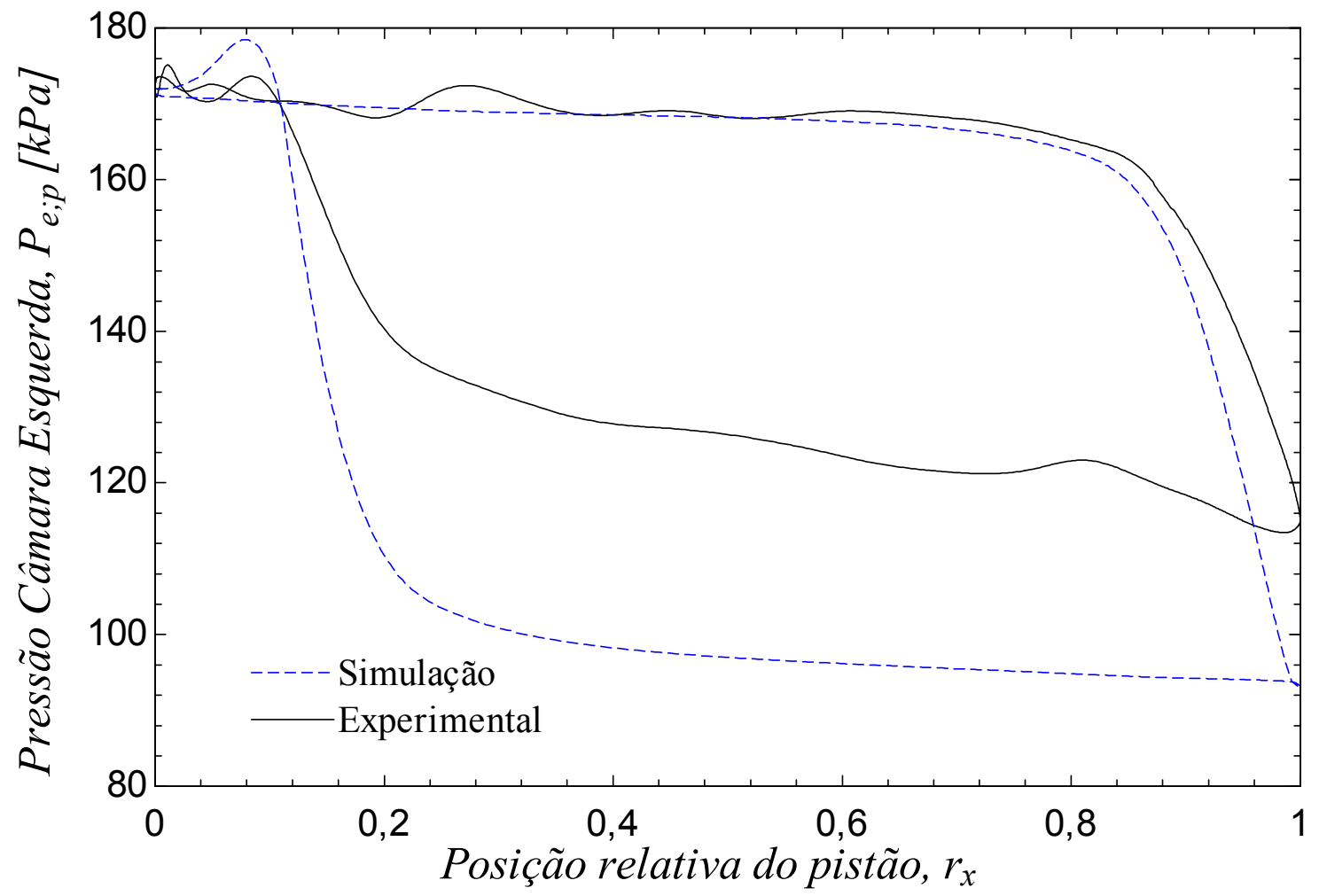

Figura 6.8 - Diagramas PxV simulado e medido da câmara esquerda do cilindro para uma pressão de 0,75bar e 494,7 rpm. 


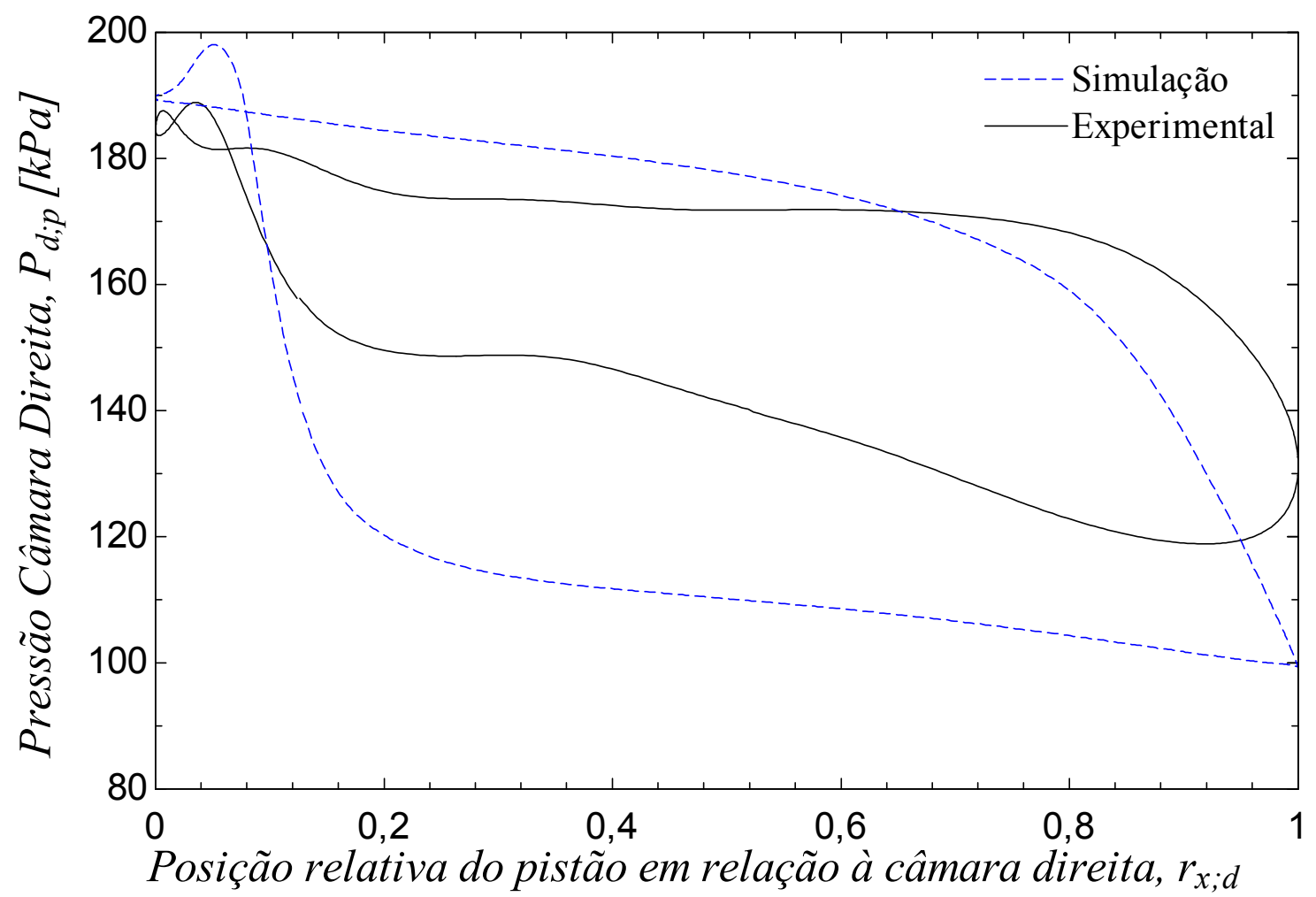

Figura 6.9 - Diagramas PxV simulado e medido da câmara direita do cilindro para uma pressão de lbar e 897 rpm.

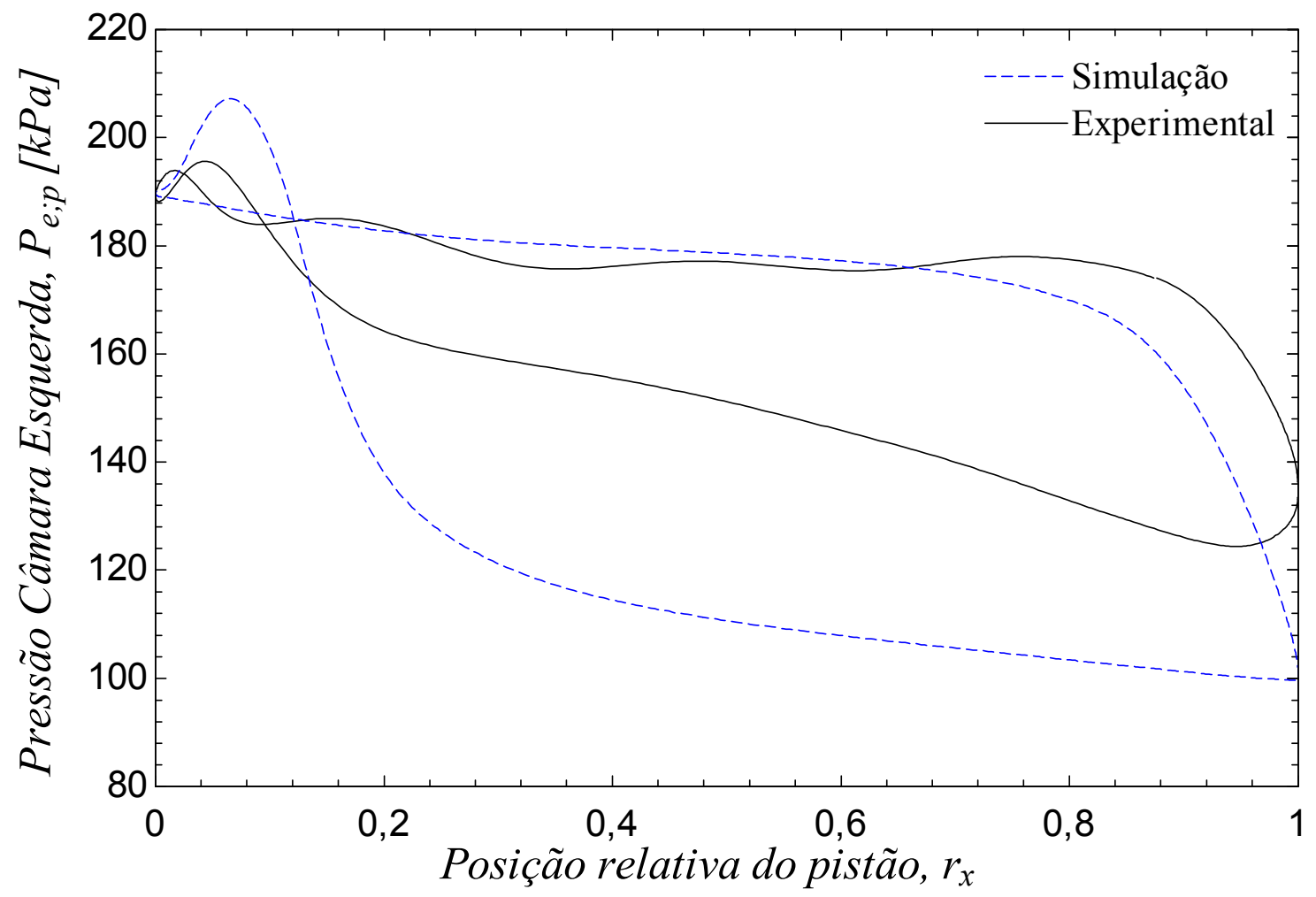

Figura 6.10 - Diagramas PxV simulado e medido da câmara esquerda do cilindro para uma pressão de lbar e 897 rpm. 


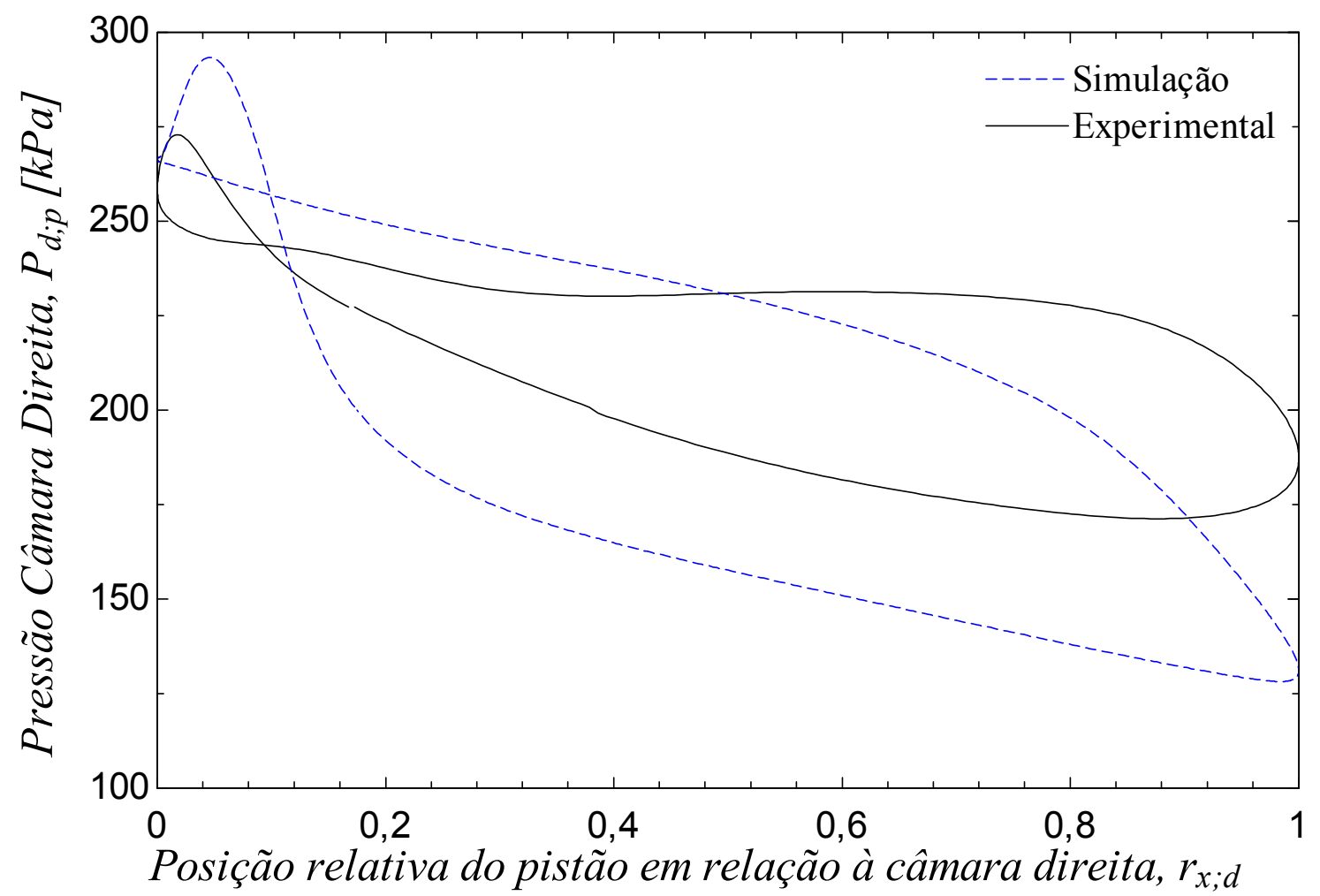

Figura 6.11 - Diagramas PxV simulado e medido da câmara direita do cilindro para uma pressão de 2 bar e 1471,7 rpm.

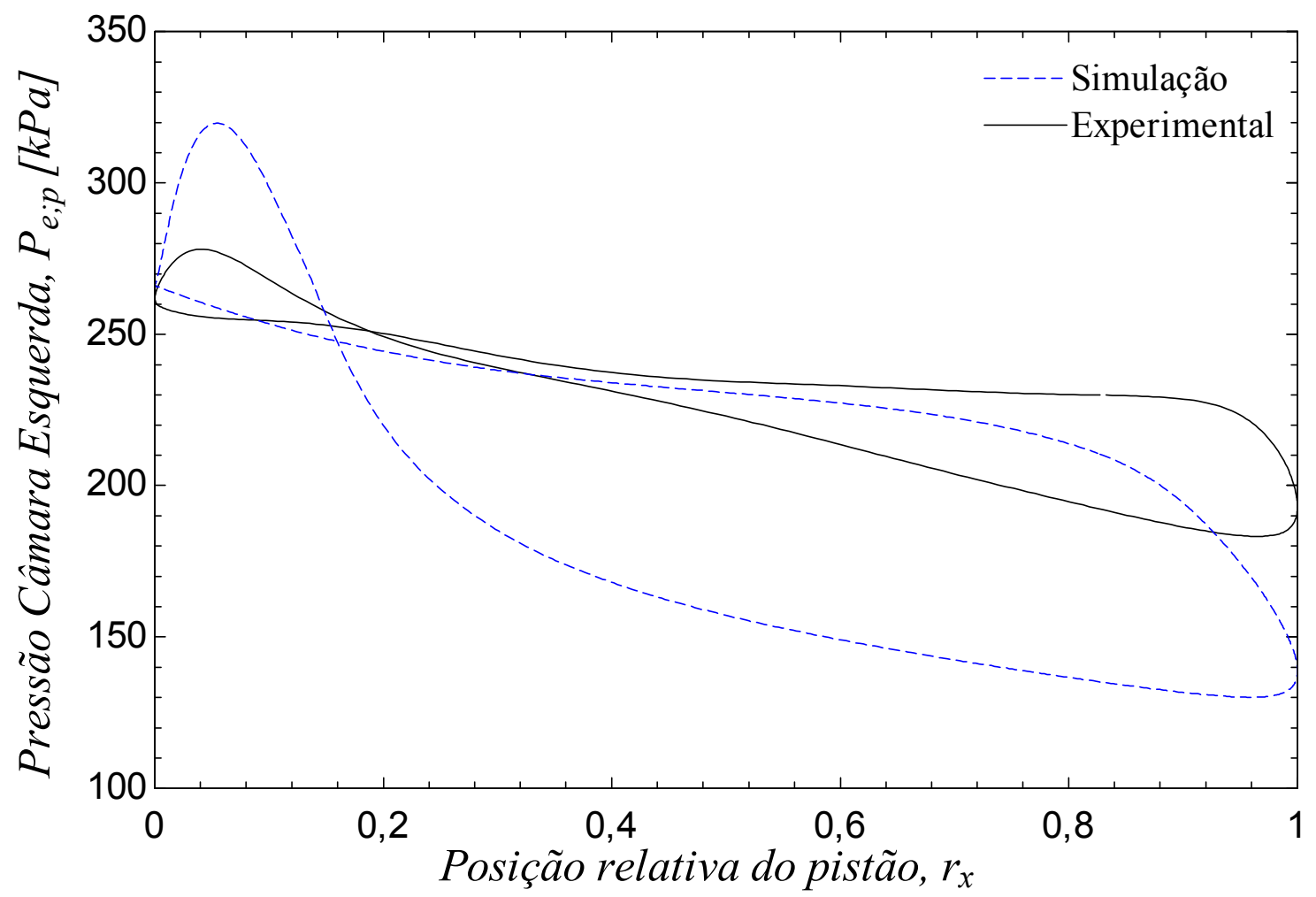

Figura 6.12 - Diagramas PxV simulado e medido da câmara esquerda do cilindro para uma pressão de 2 bar e 1471,7 rpm. 


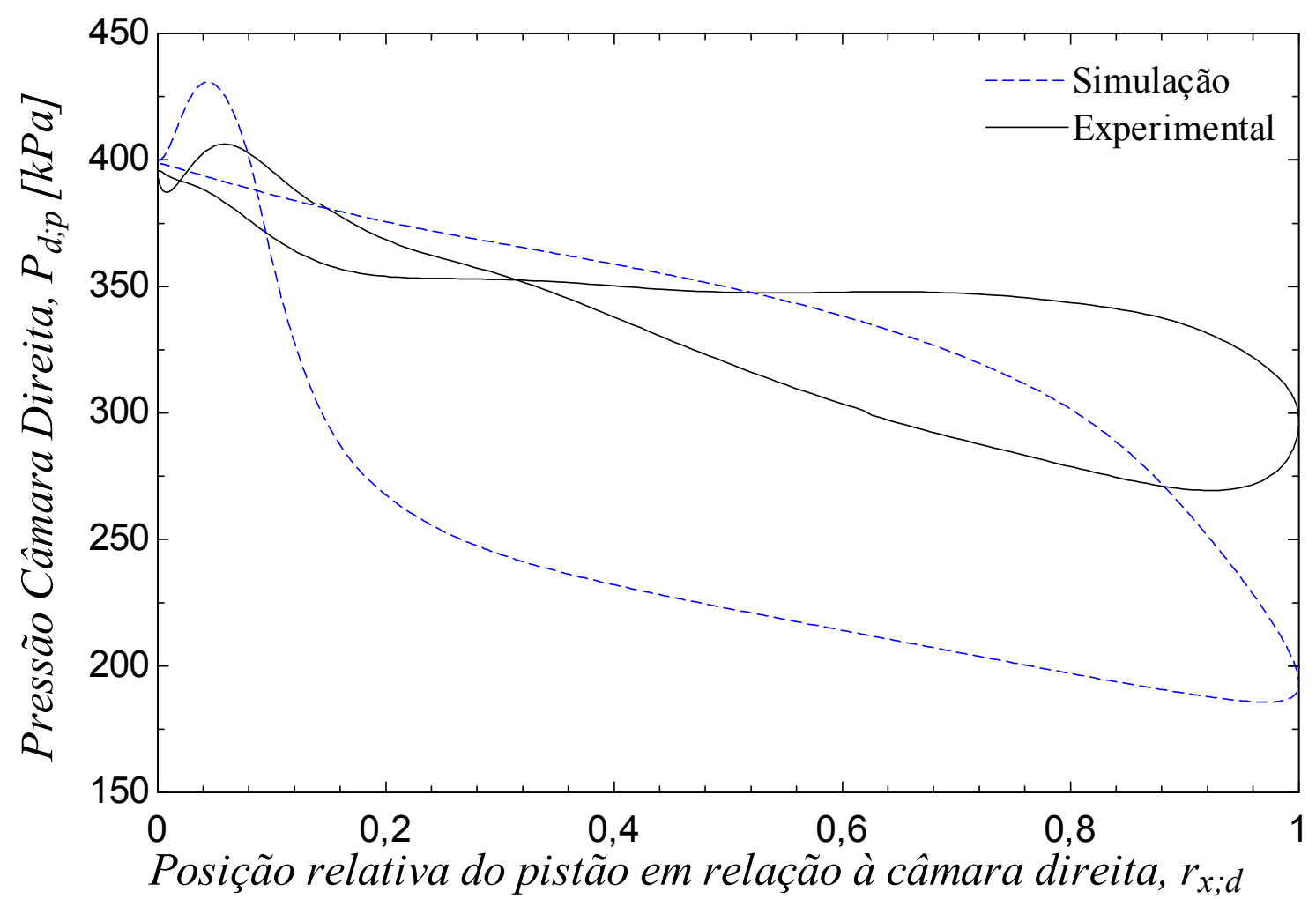

Figura 6.13 - Diagramas PxV simulado e medido da câmara direita do cilindro para uma pressão de 3.5 bar e $1386 \mathrm{rpm}$.

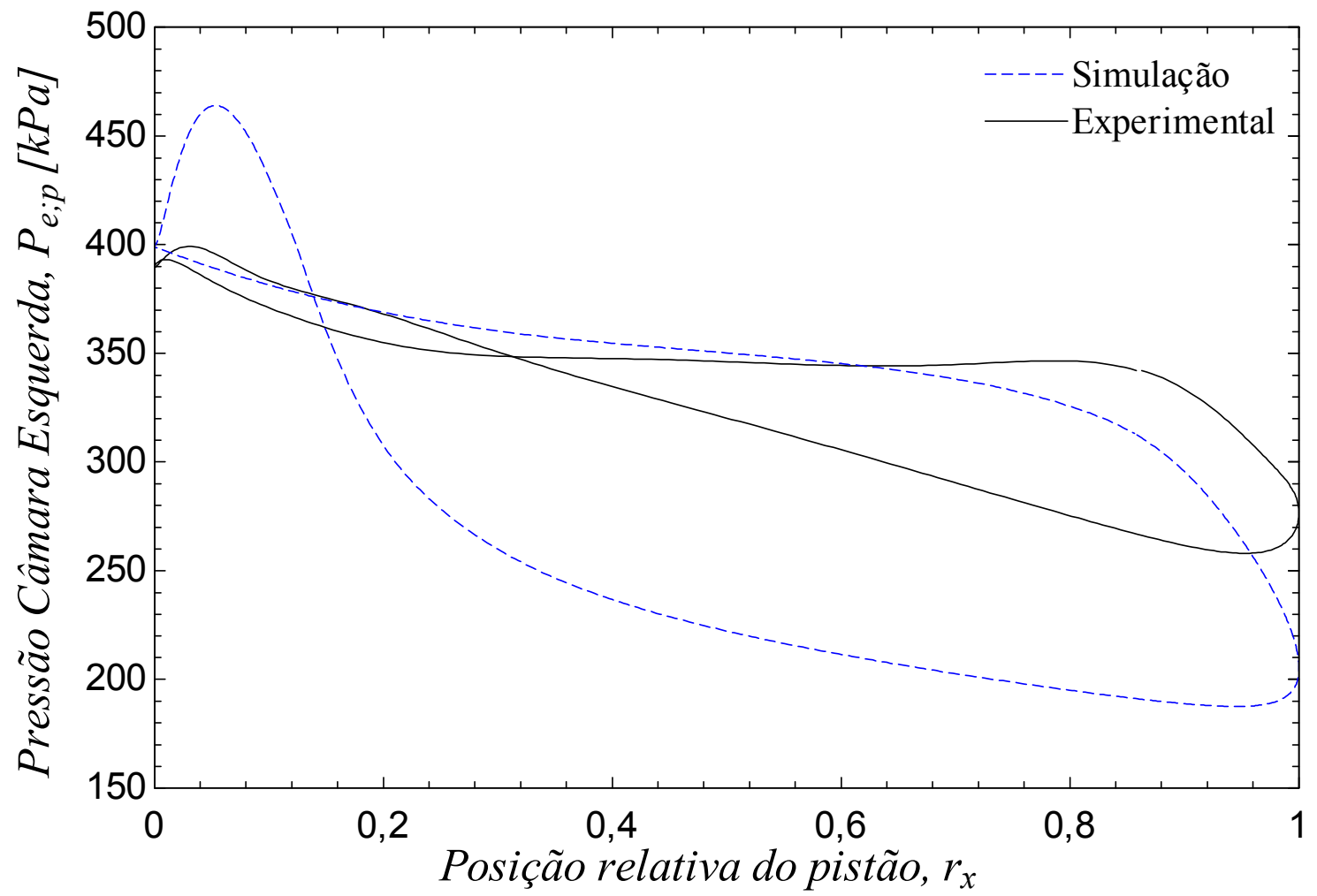

Figura 6.14 - Diagramas PxV simulado e medido da câmara esquerda do cilindro para uma pressão de 3.5 bar e 1386 rpm. 


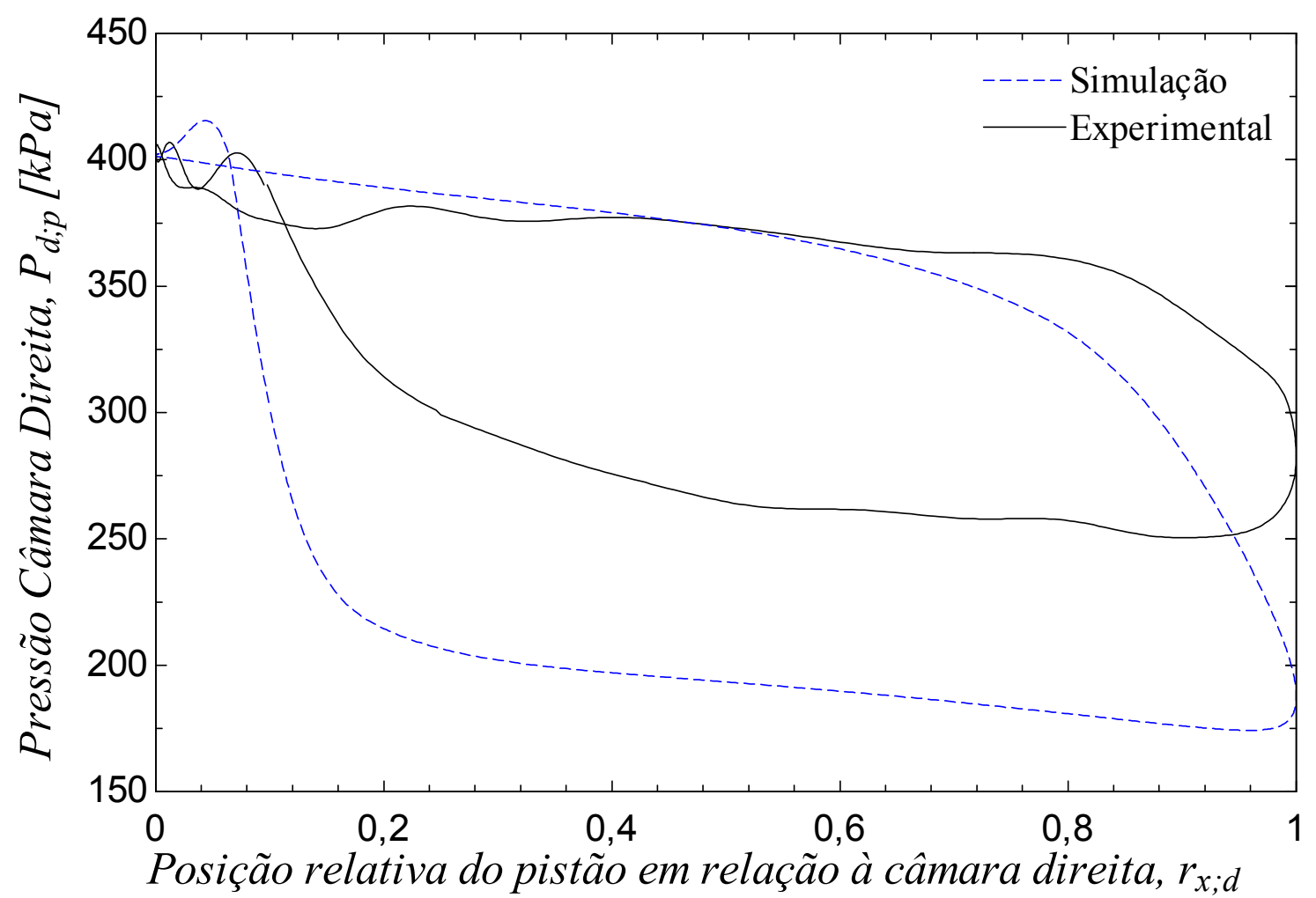

Figura 6.15 - Diagramas PxV simulado e medido da câmara direita do cilindro para uma pressão de 3.5 bar e $1146 \mathrm{rpm}$.

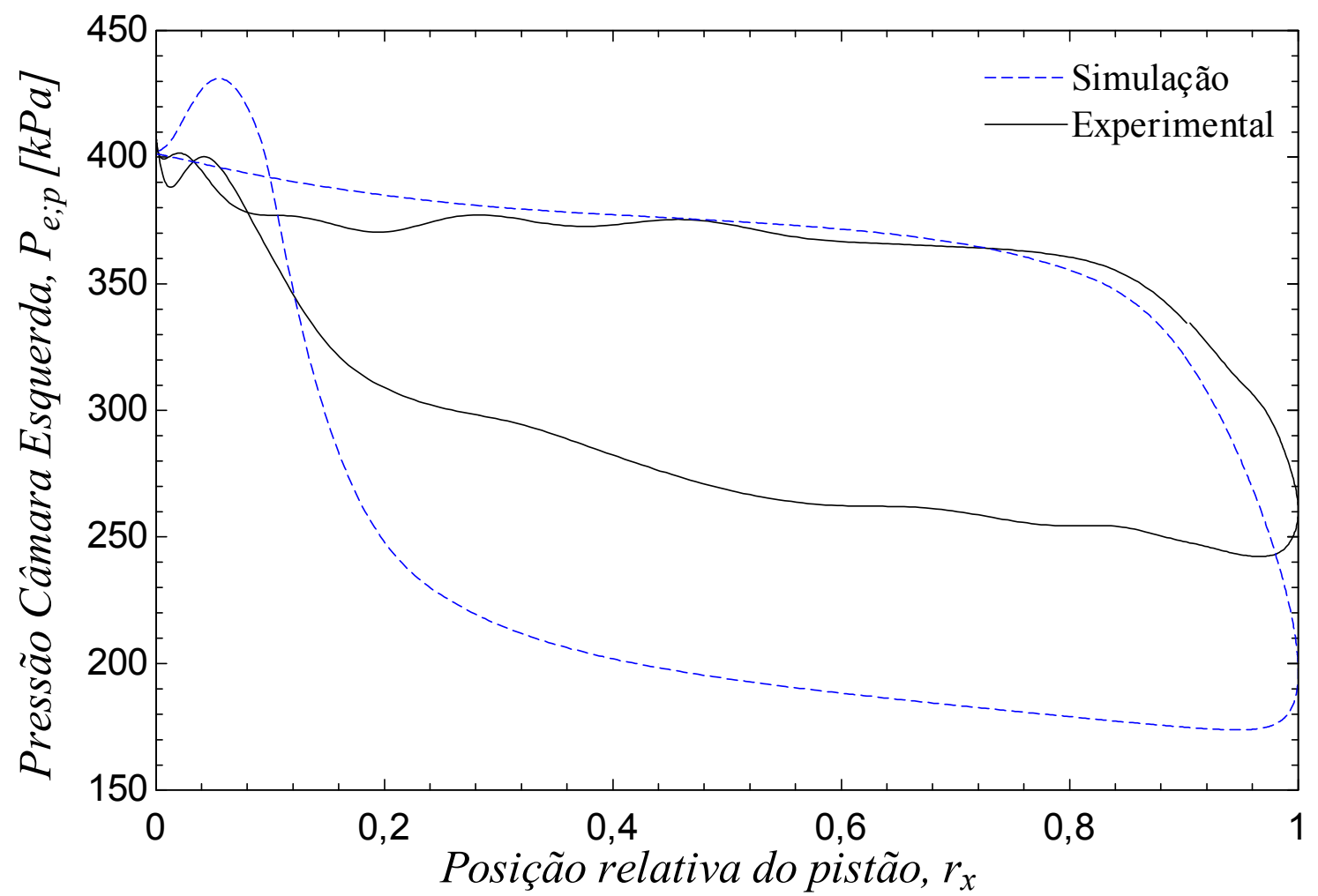

Figura 6.16 - Diagramas PxV simulado e medido da câmara esquerda do cilindro para uma pressão de 3.5 bar e 1146 rpm. 
Como citado no capítulo 4, os comportamentos medidos para as duas câmaras para a pressão de 3,5 bar são iguais, a diferença de pressão entre as duas câmaras é pequena e se deve ao fato da assimetria do funcionamento das válvulas.

Para pressões acima de 1 bar, a rotação se eleva e os diagramas simulados e medidos começam a divergir no processo de admissão os processos de admissão dos ciclos medidos se aproximam mais de uma reta horizontal do que os processos de escape, indicando um melhor fluxo de fluido nos processos de admissão, quando comparado com as simulações. Essa característica pode ser conferida nas Figura 6.5, Figura 6.9, Figura 6.11, Figura 6.13, e Figura 6.14. Para os ciclos simulados, a inclinação do processo de admissão e de escape são sempre iguais ou muito parecidas, mostrando que as resistências à admissão ou escape do fluido são iguais ou parecidas.

Outra característica que indica que o fluxo de admissão simulado tende a ser menor que o fluxo medido é a sobrecompressão que ocorre em todos os casos quando o pistão se aproxima do ponto morto de menor volume. Em todos os diagramas a pressão máxima do ciclo simulado, que ocorre na sobrecompressão do fluido, é maior do que a pressão máxima medida experimentalmente, onde também existe uma tendência a gerar uma sobrecompressão. Isso ocorre mesmo que as pressões de escape dos ciclos medidos sejam maiores que as pressões dos ciclos simulados, o que tenderia a causar uma sobrecompressão maior nos ciclos reais. Característica essa que indica que quando a válvula de admissão começa a abrir, a pressão real dentro do cilindro tende a se estabilizar mais rapidamente que a pressão simulada, impedindo que a pressão real aumente como ocorre nas simulações. A estabilização mais rápida da pressão de admissão mostra que o fluxo de massa real na admissão é maior que o fluxo simulado.

Em todas as imagens é perceptível que existe uma grande diferença entre os processos de escape simulados e medidos. A pressão dentro do cilindro para os diagramas simulados fica próxima ou atinge a pressão de escape quando o pistão atinge o ponto morto de maior volume, algo que não ocorre em nenhum diagrama $\mathrm{PxV}$ medido experimentalmente. Em todos os diagrama PxVs experimentais, a menor pressão dentro das câmaras durante o processo de escape está entre $20 \mathrm{kPa}$ (Figura 6.9) e $90 \mathrm{kPa}$ (Figura 6.13) acima da pressão de escape. Essa informação indica que existe uma restrição grande à saída do fluido de dentro do cilindro, fazendo com que as pressões de escape permaneçam muito altas durante todo o processo. 
Nas Figura 6.7, Figura 6.8, Figura 6.11, Figura 6.15, e Figura 6.16 a inclinação do trecho de curva que indica o processo de escape é igual ou próxima aos processos simulados, mostrando que os processos de escape simulados e medidos são similares, e na Figura 6.10, Figura 6.12, Figura 6.13, e na Figura 6.14 a inclinação do processo de escape é maior que a inclinação do mesmo processo simulado. Dessa forma conclui-se que as restrições reais à passagem do fluido para esses casos são maiores que as restrições simuladas.

Em relação aos fluxos mássicos de admissão e de escape, pode-se concluir que os fluxos simulados para a admissão são menores que os reais, e os fluxos simulados para o escape são maiores que os reais. Como o coeficiente de descarga utilizado para as simulações é o mesmo tanto para a admissão quanto para o escape, ambos os processos possuem um comportamento similar nas simulações. Para poder fazer uma simulação mais realista, deve-se utilizar coeficientes de descarga mais próximos da realidade, utilizando equações especificas para a admissão e para o escape. O coeficiente de descarga utilizado não é específico para válvulas carretel, e sim para orifícios. Não foi encontrado na literatura disponível equações para coeficientes de descarga para válvulas carretel com orifícios de tamanho similar aos simulados.

Duas diferenças notáveis entre alguns ciclos simulados e medidos estão indicados na Figura 6.17 E na Figura 6.5. A primeira delas é que nos ciclos medidos existem oscilações de pressão no processo de admissão, indicado nas figuras com o número (1). Como citado na seção 4.7, essas oscilações de pressão podem ser resultados de ondas de pressão que percorrem a tubulação de admissão. A outra diferença está indicada com o número (2) nas figuras e mostra uma variação na pressão de escape dos dados experimentais, e essa característica também foi comentada na seção 4.7. Essa variação na pressão de escape ocorre simultaneamente com uma variação na pressão de admissão da outra câmara do cilindro, indicando um fenômeno que interfere em ambas as câmaras. Isso pode ser justificado por uma variação na velocidade do pistão. 


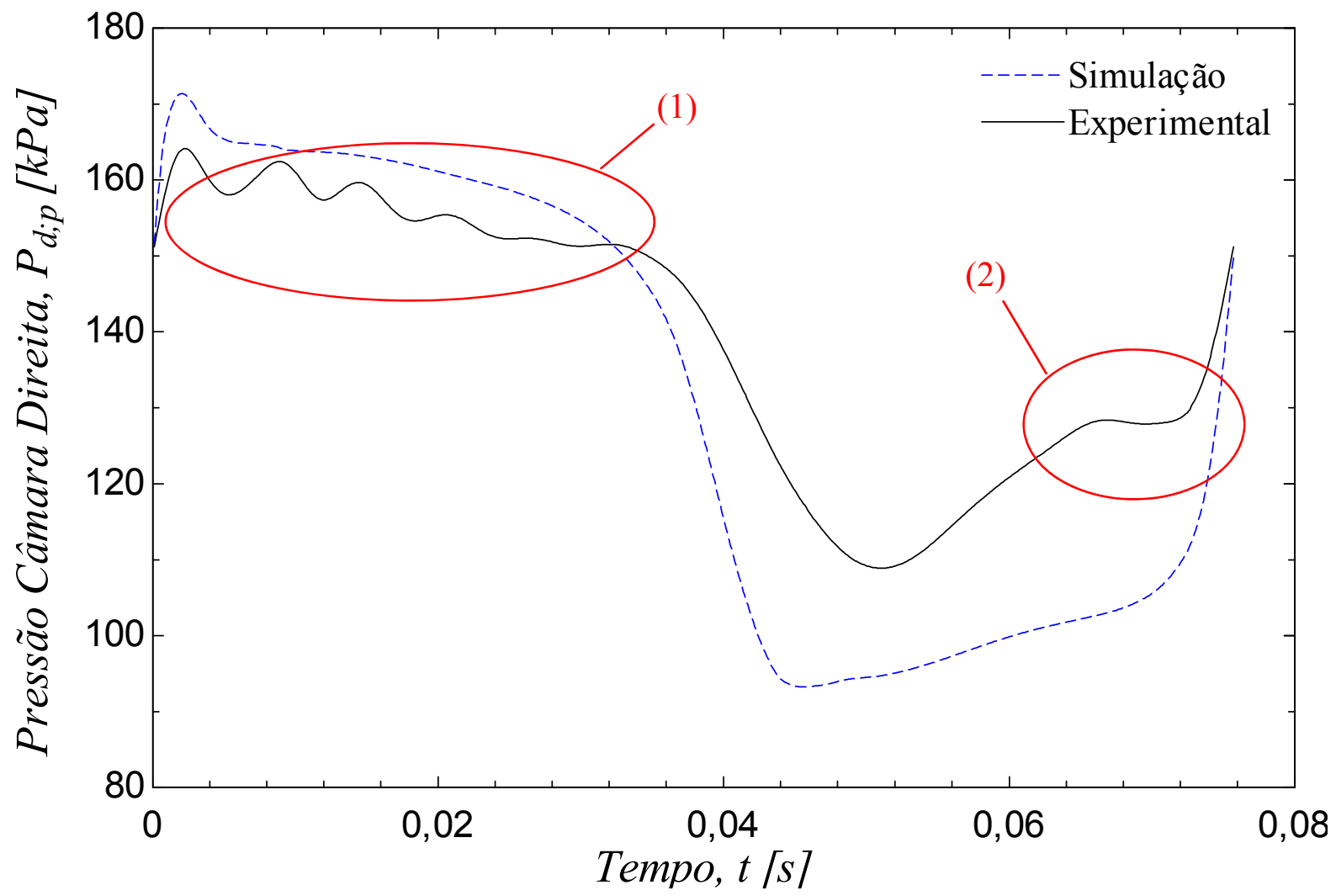

Figura 6.17 - Diagramas $P_{x} t$ indicados simulado e medido da câmara direita do cilindro para uma pressão de 0.5 bar e 792,6 rpm.

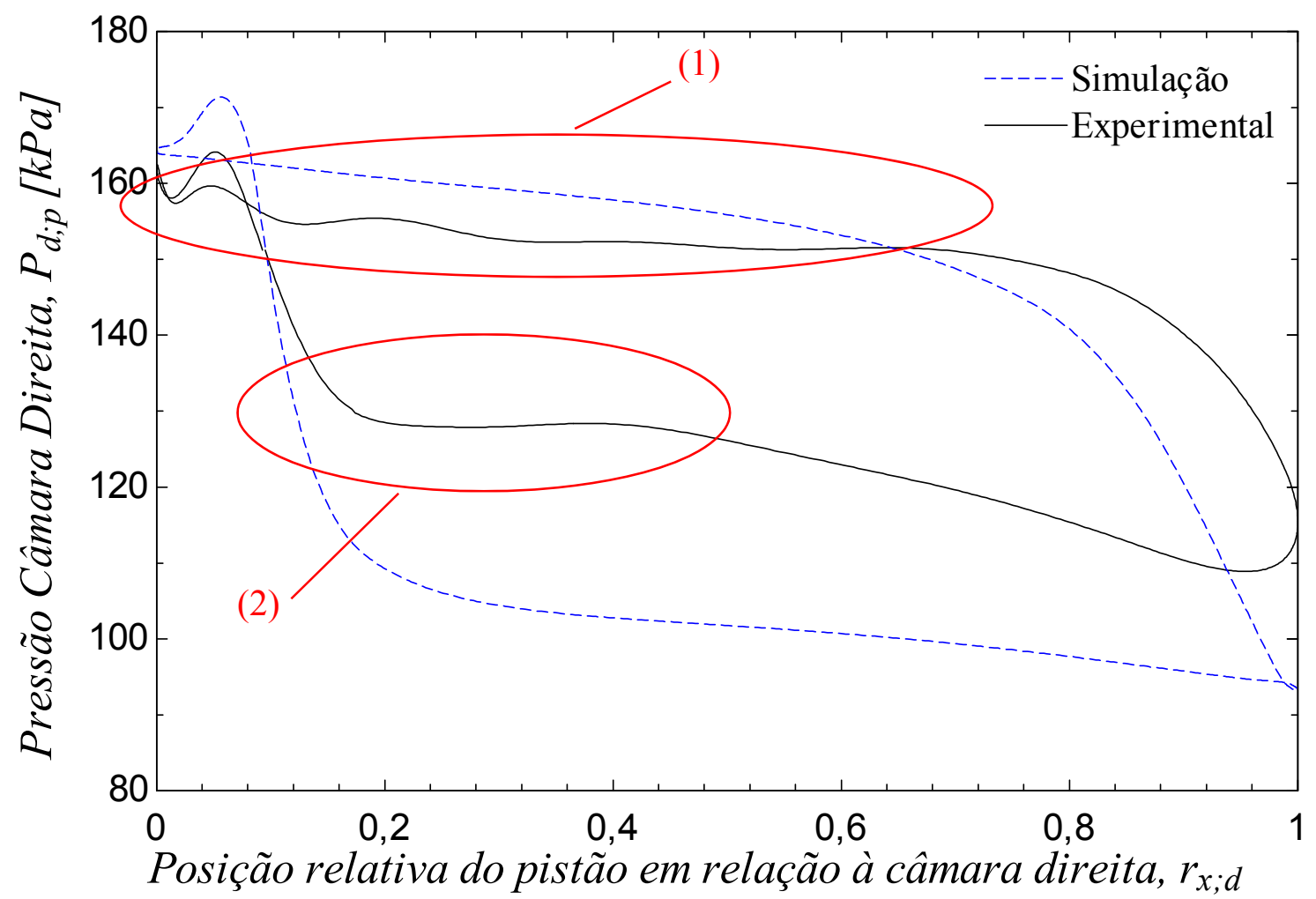

Figura 6.5 - Diagramas PxV simulado e medido da câmara direita do cilindro para uma pressão de 0,5bar e 792,6 rpm. 


\subsection{COMPARAÇÃO ENTRE O CICLO TEÓRICO, O SIMULADO E O EXPERIMENTAL}

A Figura 6.18 mostra a sobreposição entre o ciclo teórico generalizado, um ciclo obtido por simulação e um ciclo obtido experimentalmente.

A comparação entre o ciclo teórico e os ciclos simulados e experimentais se torna inviável devido à grande diferença entre eles. No ciclo simulado, conforme mostrado no Capítulo 5 existem 8 pontos notáveis que representam a abertura e o fechamento das válvulas de admissão e escape. Embora não esteja indicado no diagrama, o ciclo experimental também possui os mesmos 8 pontos notáveis, enquanto o ciclo teórico possui apenas 6 pontos, como mostrado no Capítulo 3. A dificuldade de comparação não se dá apenas pelo número de pontos, e sim pelo que eles representam.

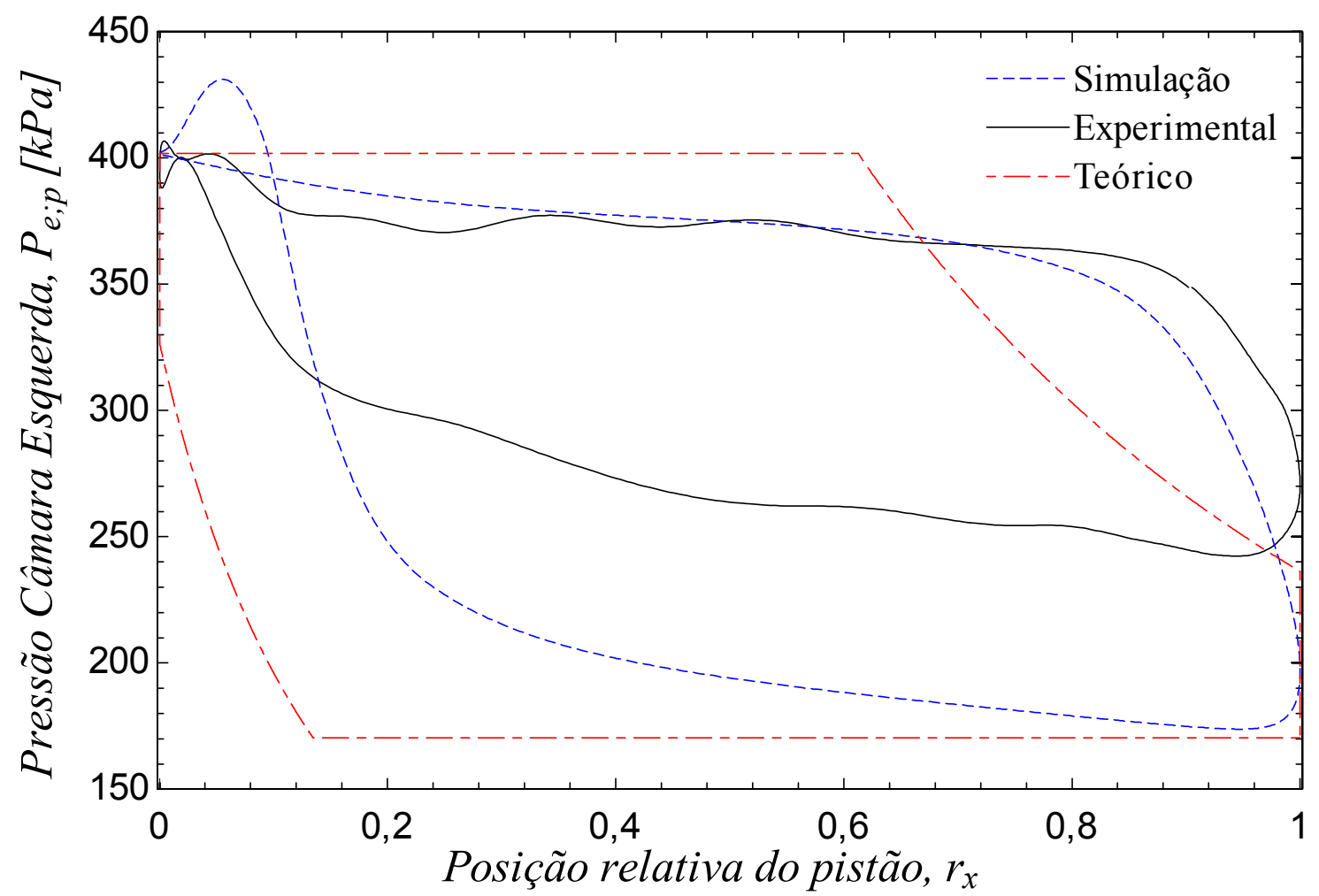

Figura 6.18 - Sobreposição dos diagramas PxV simulado, experimental e teórico (utilizando o ciclo generalizado) para pressão de 3,5 bar e rotação de 960,7 rpm. 
No ciclo teórico, 4 pontos representam abertura e fechamento de válvulas, pois nesse ciclo é considerado que as válvulas abrem e fecham instantaneamente. Nos ciclos simulado e experimental, a abertura e fechamento das válvulas é um processo e o pistão percorre uma distância durante a abertura e o fechamento das válvulas. Se essa distância representasse uma pequena porcentagem do percurso do pistão, não haveria problema, porém essa distância é muito grande e faz com que ocorra uma grande alteração no diagrama PxV.

Outra característica é o fato de que no ciclo simulado e no ciclo experimental não existe nenhum processo onde a válvula de admissão e a válvula de escape estejam fechadas simultaneamente. Isso faz com que não haja nenhum processo isentrópico nos ciclos simulados e experimentais, sendo que uma característica de todos os ciclos teóricos são expansões e compressões isentrópicas. 


\section{CONCLUSÕES}

Um estudo teórico sobre os ciclos padrões existentes para máquina a vapor ou máquinas de expansão foi realizado. Por meio desse estudo, foi possível determinar um ciclo generalizado que pode ser utilizado para substituir todos os outros ciclos anteriores. Esse ciclo generalizado pode assumir a forma de qualquer outro ciclo estudado por outros autores apenas manipulando a relação entre suas variáveis. Esse ciclo foi equacionado e foram estudadas diferentes combinações de seus parâmetros a fim de verificar as combinações que resultam e uma maior eficiência isentrópica.

Nesse estudo foi verificado que as razões de corte que mais beneficiam a eficiência isentrópica são baixas, ou seja, o instante em que a válvula de admissão deve fechar é quando o pistão está mais próximo do ponto morto de menor volume. Para baixas razões de pressão a razão de fechamento tem grande influência na eficiência isentrópica da máquina a vapor, fazendo com que as maiores eficiência estejam para razões de fechamento pequenas, ou seja, a válvula de escape deve fechar também quando o pistão está mais próximo do ponto morto de menor volume. Para altas razões de pressão, a razão de fechamento tem pouca influência na eficiência isentrópica. Para baixas razões de pressão, a razão de volume desempenha um papel importante na eficiência da máquina, gerando melhores resultados com baixas razões de volume. Para altas razões de pressão, a razão de compressão exerce pouca influência na eficiência isentrópica.

Contudo esse ciclo generalizado não é o mais eficiente, pois também foi verificado que existe um ciclo ideal que possui eficiência isentrópica teórica igual a 1. Esse ciclo também possui pontos de otimização, em que se pode maximizar o trabalho total realizado ou tentar diminuir a massa consumida.

Caso não exista sobrecompressão ou sobre-expansão, existe um ciclo que traz a pior eficiência isentrópica possível. Em casos que possuem sobre-expansão ou sobrecompressão, é possível ter uma eficiência menor que a desse ciclo.

Para compreender os fenômenos que ocorrem dentro da máquina a vapor, um estudo experimental foi conduzido em uma máquina já existente. Essa máquina a vapor foi 
instrumentada e testada com ar comprimido. Os dados obtidos nos experimentos são as pressões e temperatura de admissão e escape, pressões internas das câmaras da máquina a vapor, vazão em massa e torque. Com esses dados foi possível determinar o trabalho específico realizado pela máquina a vapor, sua potência e sua eficiência isentrópica para todos os pontos medidos.

As eficiências isentrópicas calculadas para a máquina são muito baixas (inferiores a 10\%), e existem diversos fatores que contribuem para que isso ocorra. Esses fatores podem ser listados como o tipo de válvula, folgas entre o pistão e o cilindro, dificuldade de lubrificação em alguns pontos, desgaste e atrito das peças, grande restrição ao fluxo do fluido nas válvulas de admissão e escape, perda de fluido para o ambiente devido ao desgaste. Todos esses fatores influenciam para o aumento no consumo de massa ou a diminuição do trabalho realizado, resultando em uma baixa eficiência isentrópica.

Com as pressões internas das câmaras do cilindro foi possível determinar um ciclo específico de funcionamento para cada combinação de pressão e rotação. Para estudar os diagramas PxV reais, foi necessário realizar um acoplamento das pressões medidas com as pressões simuladas. Após realizar o acoplamento, verificou-se que os ciclos reais diferem muito dos ciclos simulados. No caso específico dessa máquina a vapor, uma influência para isso é o fato de que ela não realiza expansão ou compressão isentrópicas, pois em nenhum momento a válvula de escape e de admissão estão fechadas simultaneamente. As válvulas do tipo carretel também contribuem para que o diagrama PxV se afaste dos ciclos teóricos, assim como um fluxo de escape deficiente. Para baixas rotações, a admissão e o escape ocorrem com pouca restrição, fazendo com que as maiores eficiências ocorram para essas rotações.

Simulações foram realizadas a fim de prever o comportamento real da máquina a vapor em diferentes condições. As simulações conseguiram prever que as válvulas carretel provocam uma sobrecompressão no vapor quando o pistão está próximo do ponto morto de menor volume. Também foi previsto que em altas rotações os fluxos de admissão e de escape são baixos, reduzindo o trabalho realizado pela máquina a vapor e a eficiência do ciclo. Assim como também foi prever que as pressões da câmara direita são ligeiramente menor que as da câmara esquerda, devido ao acionamento assimétrico das válvulas em relação às duas câmaras. 
Em baixas rotações a sobrecompressão provocada pelo posicionamento da válvula carretel é praticamente nula, e tanto nas simulações quanto nos experimentos, o ciclo da máquina a vapor se aproxima do ciclo teórico de menor eficiência possível sem sobre-expansão ou sobrecompressão.

As mesmas simulações foram realizadas, porém considerando que as válvulas de admissão e escape abrem e fecham instantaneamente, a fim de compreender a influência das válvulas no comportamento e na eficiência da máquina a vapor. Nessa simulação foi possível notar que as válvulas são responsáveis por uma grande diminuição na eficiência isentrópica da máquina a vapor. E que se fosse possível acionar as válvulas instantaneamente, a eficiência isentrópica do ciclo pode passar de $90 \%$, chegando a $96 \%$ nas simulações.

Os fluxos mássicos previstos nas simulações são diferentes dos fluxos reais. Os fluxos previstos para a admissão são menores que os reais, e aos fluxos mássicos de escape são maiores que os fluxos reais. Para que as simulações se adequem aos dados reais, devem ser utilizados coeficientes de descarga mais específicos para as válvulas carretel.

Existem características que ocorrem nos ciclos reais que a simulação não consegue prever. Uma dessas características são oscilações de pressão no processo de admissão, e uma possível explicação para essas oscilações é de que elas são frutos de ondas de pressão que percorrem a tubulação de admissão. Outra característica que a simulação não prevê é que em alguns momentos as pressões das duas câmaras possuem um comportamento simétrico. Por ser uma variação nas duas câmaras simultaneamente, essa oscilação deve ter origem em uma variação na velocidade do pistão em alguns instantes.

As diferenças entre as simulações e os resultados obtidos experimentalmente se dão em grande parte por equações e coeficiente que não representam com exatidão alguns fenômenos que ocorrem quando se utiliza esse tipo de válvula, além de existirem condições específicas para essa máquina particularmente. Outra influência é não prever ondas de pressão, e a influência do meio externo quando existem folga que permitem a comunicação com o meio interno da máquina, assim como desprezar folgas e vazamentos internos do equipamento. 


\subsection{TRABALHOS FUTUROS}

- Realizar um estudo similar em uma máquina a vapor com um sistema de acionamento de válvulas diferente, e que existam coeficientes de descarga apropriados.

- Realizar estudos variando o fluido de trabalho, para verificar a influência do fluido na eficiência isentrópica

- Realizar simulações que consideram o movimento e as forças atuantes de todas as peças da máquina a vapor para verificar os pontos críticos da máquina a vapor 


\section{REFERÊNCIAS BIBLIOGRÁFICAS}

ALANNE, K.; SAARI, K.; KUOSA, M.; JOKISALO, J.; MARTIN, A. R. Thermo-economic analysis of a micro-cogeneration system based on a rotary steam engine (RSE). Applied Thermal Engineering, V. 44, p. 11-20, 2012

ANTONELLI, M.; MARTORANO, L. A study on the Rotary steam engine for distributed generation in small size power plants. Applied Energy, V.27, p. 642-647, 2012.

ANTONELLI, M; BACCIOLI, A; FRANCESCONI, M.; DESIDERI, U.; MARTORANO, L. Operating maps of a Rotary engine used as an expander for micro-generation with various working fluids, Applied Energy, V. 113, p. 742-750, 2014.

ASSOCIAÇÃO BRASILEIRA DE NORMAS TÉCNICAS. NBR ISO 5167-1 (1994): Medição de vazão de fluidos por meio de instrumentos de pressão - Parte 1: Placas de orifício, bocais e tubos de Venturi em seção transversal circular de condutos forçados. Rio de Jnaiero, 1994

BADAMI, M; MURA, M.; CAMPANILE, P.; ANZIOSO, F. Design and performance evaluation of an innovative small scale combined cycle cogeneration system. Energy, v. 33, p. $1264-1276,2008$

BADAMI, M; MURA, M. Preliminary design and controlling strategies of a small-scale wood waste Rankine Cycle (RC) with a reciprocating steam engine (SE). Energy, v. 34, p. 1315-1324, 2009

BADR, O.; NAIK, S.; O'CALLAGHAN, P. W.; PROBERT, S. D. Expansion machine for a low power-output steam Rankine-cycle. Applied energy, v. 39, p. 93-116, 1991

BAEK, J. S.; GROLL, E. A.; LAWLESS, P.B. Piston-cylinder work producing expansion device in a transcritical carbon dioxide cycle. Part II: theoretical model. International Journal of Refrigeration, v. 28, p. 152-164, 2005

BAO, J.; ZHAO, Li A review of working fluid and expander selections for organic Rankine cycle. Renewable and Sustainable Energy Reviews, V. 24, p 325-342, 2013.

BASBOUS, T.; YOUNES, R. ILINCA, A.; PERRON, J. F. A new hybrid pneumatic combustion engine to improve fuel consumptions of wind-diesel power system for noninterconnected areas. Applied Energy, V. 96, p. 459-476, 2012 
BASSI, L. A. F.; MACHADO, R. A., Projeto e construção de um protótipo de máquina a vapor, trabalho apresentado no $19^{\circ}$ SIICUSP - Simpósio Internacional de Iniciação Científica, são Carlos, SP, 2011

BRUNETTI, F. Mecânica dos Fluidos, São Paulo: Pearson Prentice Hall, 2005, 410 p.

EES: Engineerings Equation Solver for Microsoft Windows Operating Systems Manual. FChart Software, Middleton, WI, 1998

F-CHART Software: Help. ES Disponível em

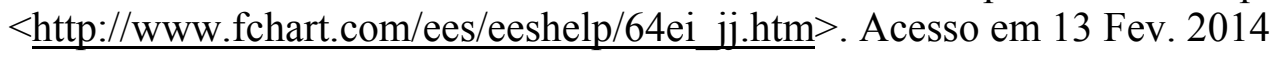

FAREY, J. A Treatise on the steam engine, historical, practical and descriptive, Londres, A. \& R. Spottiswoode, 1827, 790 p.

FERRARA, G.; MANFRIDA, G.; PESCIONI, A. Model os a small steam engine for renewable domestic CHP (combined heat and power) system, Energy, V. 58, p. 78-85, 2013

GARI, H.; KHALIFA, A. e RADHWAN, A. - Design and Simulation of a SolarPowered/Fuel-Assisted Rankine Engine for Power Generation, Applied Energy (1988), v. 30, No. 4, pp. 245-260

HOLMAN, J. P. Experimental methods for engineers. Sexta Edição, McGraw-Hill Hightstown, NJ,1994. 620 p. (264-269)

HUANG, F. F. Engineering Thermodynamics. New York: Macmillan Publishing Co., Inc., 1976. $535 \mathrm{p}$.

KALEKIN, V. S.; KALEKIN, D. V. Working process of a direct-flow piston gas engine with a fundamentally new gas distribution system. Chemical and Petroleum Engineering, v. 45, nos. 3-4, 2009

KEENAN, J. H. Thermodynamics. Edicion Revolucionaria, La Habana, Cuba, 1966. 499 p.

MARIÑO, R. Termodinâmica Tecnica. Segunda Edição. Dossat. Madrid. 1948. 698 p. 
PRASAD, S. B., Steam engine characteristics and theoretical performance. Energy Convers. Mgmt., v. 34, No 12, pp. 1323-1333, 1993

PRILUTSKII, A. I. Use of piston expander in plants utilizing energy of compressed natural gas. Chemical and Petroleum Engineering, v. 44, Nos 3-4, 2008

TARIQUE, A. Experimental Investigation of a Scroll Based Organic Rankine Systems. Dissertação de mestrado, The Faculty of Engineering and Applied Science, University of Ontario Institute of Technology, Ontario, Canada, 2011.

TRAJKOVIC, S. The Pneumatic Hybrid Vehicle: A New Concept for Fuel Consumption Reduction. Tese de Doutorado, Division of Combustion Engines, Department of Energy Sciences, Faculty of Engineering, Lund University, Lund, Sweden. 2010. 148 p.

VANYASHOV, A. D.; KOVALENKO, S. V. Determining the principal parameters of piston expansion engines by different computational methods, Chemical and Petroleum Engineering, v. 40, Nos. 9-10, 2004

VANYASHOV, A. D.; KALEKIN, V. S.; KOVALENKO, S. V. Piston expander-compressor unit having self-acting gas distribution systems, Chemical and Petroleum Engineering, v. 37, Nos. 9-10, 2001 


\section{APÊNDICE A - EQUAÇÕES PARA O CICLO GENERALIZADO EM FUNÇÃO DAS RAZÕES DE CORTE E DE FECHAMENTO NA FORMA DE PORCENTAGEM}

$$
\begin{aligned}
& W_{1-2}=P_{a d m} \times \forall_{1} \times r_{C X}\left(r_{V}-1\right) \\
& W_{2-3}=\frac{P_{a d m} \times \forall_{1} \times\left[r_{C X}\left(r_{V}-1\right)+1\right]}{k-1}\left\{1-\left[\frac{r_{C X}\left(r_{V}-1\right)+1}{r_{V}}\right]^{k-1}\right\} \\
& W_{4-5}=\frac{-P_{a d m} \times \forall_{1}\left(1-r_{F X}\right)\left(r_{V}-1\right)}{r_{P}} \\
& W_{5-6}=\frac{-P_{a d m} \times \forall_{1}\left\{\left[r_{F X}\left(r_{V}-1\right)+1\right]^{k}-r_{F x}\left(r_{V}-1\right)-1\right\}}{r_{P}(k-1)} \\
& W_{\text {ciclo }}=\frac{\forall_{1} \times P_{a d m}}{k-1}\left(k \times r_{C x}\left(r_{V}-1\right)+1-r_{V}\left[\frac{r_{C x\left(r_{V}-1\right)+1}}{r_{V}}\right]^{k}+\right. \\
& \left.\frac{1}{r_{P}}\left[r_{V}-k\left(r_{V}-1\right)\left(1-r_{F x}\right)-\left[r_{F x}\left(r_{V}-1\right)+1\right]^{k}\right]\right) \\
& m_{\text {ciclo }}=m_{2}-m_{6}=\frac{P_{a d m} \times \forall_{1}}{k \times R \times T_{a d m}}\left(k \times r_{C X}\left(r_{V}-1\right)+1-\frac{\left[r_{F x}\left(r_{V}-1\right)+1\right]^{k}}{r_{P}}\right) \\
& m_{4}=\frac{P_{\text {evap }} \times \forall_{1} \times r_{V}\left(r_{P} \times k \times r_{C X}\left(r_{V}-1\right)+r_{P}-\left[r_{F X}\left(r_{V}-1\right)+1\right]^{k}\right)}{k \times R \times T_{a d m} \times r_{P}\left[\left(r_{V}-1\right)\left(r_{P}{ }^{1 / k} \times r_{C X}-r_{F X}\right)+r_{P}{ }^{1 / k}-1\right]} \\
& m_{2}=m_{3}=\frac{m_{4} \times r_{P}^{1 / k} \times\left[r_{C X}\left(r_{V}-1\right)+1\right]}{r_{V}} \\
& m_{1}=m_{2}-\frac{P_{a d m} \times \forall_{1} \times r_{C X}\left(r_{V}-1\right)}{R \times T_{a d m}}
\end{aligned}
$$




$$
m_{5}=m_{6}=\frac{m_{4} \times\left[r_{F X}\left(r_{V}-1\right)+1\right]}{r_{V}}
$$

$$
\begin{gathered}
T_{1}=\frac{T_{a d m}}{\left(\frac{\left[r_{C X}\left(r_{V}-1\right)+1\right]\left(r_{P} \cdot k \cdot r_{C X}\left(r_{V}-1\right)+r_{P}-\left[r_{F X}\left(r_{V}-1\right)+1\right]^{k}\right)}{k \cdot r_{P}^{\frac{k-1}{k}}\left(\left(r_{V}-1\right)\left(r_{P} \frac{1}{k} \cdot r_{C X}-r_{F X}\right)+r_{P}^{\frac{1}{k}}-1\right)}-r_{C X}\left(r_{V}-1\right)\right)} \\
T_{2}=\frac{k \cdot T_{a d m} \cdot r_{P}^{\frac{k-1}{k}} \cdot\left(\left(r_{V}-1\right)\left(r_{P}{ }^{\frac{1}{k}} \cdot r_{C X}-r_{F X}\right)+r_{P}{ }^{\frac{1}{k}}-1\right)}{r_{P} \cdot k \cdot r_{C X}\left(r_{V}-1\right)+r_{P}-\left[r_{F X}\left(r_{V}-1\right)+1\right]^{k}} \\
T_{3}=T_{2}\left(\frac{r_{C X}\left(r_{V}-1\right)+1}{r_{V}}\right)^{k-1} \\
T_{6}=\frac{T_{2} \cdot\left[r_{F X}\left(r_{V}-1\right)+1\right]^{k-1}}{r_{P}^{\frac{k-1}{k}}}
\end{gathered}
$$

$$
w_{\text {ciclo }}=
$$

$$
\frac{\frac{k \cdot R \cdot T_{a d m}}{k-1}\left\{k \times r_{C x}\left(r_{V}-1\right)+1-r_{V}\left[\frac{r_{C x\left(r_{V}-1\right)+1}}{r_{V}}\right]^{k}+\frac{1}{r_{P}}\left[r_{V}-k\left(r_{V}-1\right)\left(1-r_{F x}\right)-\left[r_{F x}\left(r_{V}-1\right)+1\right]^{k}\right]\right\}}{\left(k \times r_{C X}\left(r_{V}-1\right)+1-\frac{\left[r_{F x}\left(r_{V}-1\right)+1\right]^{k}}{r_{P}}\right)}
$$

$$
\begin{gathered}
\eta_{i s o}= \\
\frac{k \times r_{C x}\left(r_{V}-1\right)+1-r_{V}\left[\frac{r_{C x\left(r_{V}-1\right)+1}}{r_{V}}\right]^{k}+\frac{1}{r_{P}}\left[r_{V}-k\left(r_{V}-1\right)\left(1-r_{F x}\right)-\left[r_{F x}\left(r_{V}-1\right)+1\right]^{k}\right]}{\left(k \times r_{C X}\left(r_{V}-1\right)+1-\frac{\left[r_{F x}\left(r_{V}-1\right)+1\right]^{k}}{r_{P}}\right) \cdot\left(1-\frac{1}{r_{P} \frac{k-1}{k}}\right)}
\end{gathered}
$$




\section{APÊNDICE B -DEMONSTRAÇÃO DA EFICIÊNCIA DE $100 \%$ NO CICLO IDEAL}

Partindo da expressão da eficiência isentrópica deduzida no Capítulo 3.

$$
\eta_{i s o}=\frac{k\left(r_{C}-1\right)+1-\frac{r_{C}{ }^{k}}{r_{V}{ }^{k-1}}+\frac{1}{r_{P}}\left[(k-1)\left(r_{F}-r_{V}\right)-r_{F}\left(r_{F}^{k-1}-1\right)\right]}{\left(k\left(r_{C}-1\right)+1-\frac{r_{F}^{k}}{r_{P}}\right) \cdot\left(1-\frac{1}{r_{P} \frac{k-1}{k}}\right)}
$$

Considerando a razão de corte $r_{C}$ igual a $r_{C M I N}$ e a razão de fechamento $r_{F}$ igual a $r_{F M A X}$ escritas abaixo e deduzidas no mesmo capítulo:

$$
\begin{gathered}
r_{C}=r_{C \min }=\frac{r_{V}}{r_{P}^{1 / k}} \\
r_{F}=r_{F \max }=r_{P}^{1 / k}
\end{gathered}
$$

Substituindo na expressão da eficiência isentrópica, tem-se:

$$
\eta_{\text {iso }}=\frac{k\left(\frac{r_{V}}{r_{P}{ }^{1 / k}}-1\right)+1-\frac{\left(\frac{r_{V}}{r_{P}{ }^{1 / k}}\right)^{k}}{r_{V}{ }^{k-1}}+\frac{1}{r_{P}}\left[(k-1)\left(r_{P}^{1 / k}-r_{V}\right)-r_{P}^{1 / k}\left(\left(r_{P}^{1 / k}\right)^{(k-1)}-1\right)\right]}{\left(k\left(\frac{r_{V}}{r_{P}^{1 / k}}-1\right)+1-\frac{\left(r_{P}^{1 / k}\right)^{k}}{r_{P}}\right) \cdot\left(1-\frac{1}{r_{P} \frac{k-1}{k}}\right)}
$$

Fazendo algumas distributivas e simplificações:

$$
\eta_{\text {iso }}=\frac{k\left(\frac{r_{V}}{r_{P}{ }^{1 / k}}-1\right)+1-\frac{r_{V}}{r_{P}}+\frac{k}{r_{P}}\left(r_{P}{ }^{1 / k}-r_{V}\right)-\frac{r_{P}{ }^{1 / k}}{r_{P}}+\frac{r_{V}}{r_{P}}-1+\frac{r_{P}{ }^{1 / k}}{r_{P}}}{k\left(\frac{r_{V}}{r_{P}^{1 / k}}-1\right) \cdot\left(1-\frac{r_{P}{ }^{1 / k}}{r_{P}}\right)}
$$


Realizando novas simplificações e distributivas:

$$
\eta_{\text {iso }}=\frac{k\left(\frac{r_{V}}{r_{P}{ }^{1 / k}}-1\right)+\frac{k}{r_{P}}\left(r_{P}^{1 / k}-r_{V}\right)}{k\left(\frac{r_{V}}{r_{P}^{1 / k}}-1\right)-\frac{k \cdot r_{V}}{r_{P}{ }^{1 / k}} \cdot \frac{r_{P}{ }^{1 / k}}{r_{P}}+\frac{k \cdot r_{P}{ }^{1 / k}}{r_{P}}}
$$

Simplificando e colocando $\mathrm{k} / \mathrm{r}_{\mathrm{P}}$ em evidência no denominador:

$$
\begin{aligned}
\eta_{\text {iso }}=\frac{k\left(\frac{r_{V}}{r_{P}^{1 / k}}-1\right)+\frac{k}{r_{P}}\left(r_{P}^{1 / k}-r_{V}\right)}{k\left(\frac{r_{V}}{r_{P}^{1 / k}}-1\right)+\frac{k}{r_{P}}\left(r_{P}^{1 / k}-r_{V}\right)} \\
\eta_{\text {iso }}=1
\end{aligned}
$$




\section{APÊNDICE C - ALGORITMO DA SIMULAÇÃO TERMODINÂMICA DA MÁQUINA A VAPOR}

Primeiramente deve-se ser definido a pressão de admissão (P_max), a pressão de escape (P_min), a temperatura de admissão (T_max), a temperatura de escape (T_min), o ângulo da manivela inicial (theta_i), o número de ciclos a serem simulados (n_ciclos), a quantidade de pontos a serem calculados para cada ciclo (n_pontos) e o fluido de trabalho (fluido\$)

"! Procedure para calcular a vazão em massa pela abertura da válvula

procedure fluxo(a_v;d_h;k;R_fluido;P_j;P_0;T_0:m_dot)

\$Common T_min;T_max; fluido\$

$"(\mathrm{p} 1 / \mathrm{p} 2)=(\mathrm{t} 1 / \mathrm{t} 2)^{\wedge}(\mathrm{k} /(\overline{\mathrm{k}}-1))=(\mathrm{rho} 1 / \mathrm{rho} 2)^{\wedge}(\mathrm{k}) "$

$r=R_{-}$fluido

rho_0 $=$ P_O $0 /\left(r^{*} T \_0\right)$

montante do fluxo"

$\operatorname{Machj}=\left(\operatorname{abs}\left(\left(\mathrm{P}_{-} \mathrm{O} / \mathrm{P} \_\mathrm{j}\right)^{\wedge}((\mathrm{k}-1) / \mathrm{k})-1\right)^{\star} 2 /(\mathrm{k}-1)\right)^{\wedge}(1 / 2)$

relação de pressões"

Mach $=\min (1 ; \text { Machj })^{*} \operatorname{step}($ Machj $)$

máximo Mach=1"

T_s_iso=T_0/(1+((k-1)/2)* $\left.\mathrm{Mach}^{\wedge} 2\right)$

válvula) para esc. Isentrópico"

v_s_iso= $\operatorname{Mach}^{*}\left(k^{*} r^{*} T \text { _s_iso }\right)^{\wedge}(1 / 2)$

da válvula) para esc. İsentrópico"

rho_s_iso=rho_0/((1+((k-1)/2) $\left.\left.{ }^{*} \operatorname{Mach}^{\wedge} 2\right)^{\wedge}(1 /(\mathrm{k}-1))\right)$

da válvula) para esc. Isentrópico"

mu:=Viscosity(fluido $\$ ; T=T \_0 ; P=P \_0$ )

$\operatorname{Re} D$ : $=$ rho_ $0^{*} v \_s$ iso*d_h/mu+0, $\overline{1}$

abertura da válvula"

beta: $=d \mathrm{~h} / 0,012$

beta $=d \bar{h} / D^{\prime \prime}$

C_d: $=0,5959+0,0132^{*}$ beta $^{\wedge} 2,1-0,184^{*}$ beta $^{\wedge} 8+0,0029^{*}$ beta $^{\wedge} 2,5^{*}(1 \mathrm{e} 6 / \operatorname{Re} \mathrm{D})^{\wedge}(3 / 4) \quad$ "Coeficiente de descarga"

m_dot_iso=v_s_iso*rho_s_iso*a_v

m_dot=m_dot_iso*C_d

descarga"

END

!! pelas aberturas das válvulas

Procedures para determinar as propriedades à montante e a jusante do escoamento

"!Procedure referente à admissão do lado direito"

procedure vazãoAD(h_max;h_d;P_max;P_d;T_max;T_d:m_dot_ad;h_ad;sinal_ad)

\$Common theta;r_x;Aad;alfa;r_xref;d_had;k_max;R_fluido_max;k_d; $\bar{R} \_$fluido_d

$\operatorname{tg}:=\tan ($ theta)

verificar a posição do pistão"

DP_ref $=500$

amortecimento numérico"

DP $\min =0$

amörtecimento numérico"
"Definição do R do fluido"

"Densidade de estagnação da câmara à

"Número de Mach na saída, definido pela

"Definição do Mach, considerando o valor

"Temp. de saída do bocal (área mínima da

"Velocidade na saída do bocal (área mínima

"Densidade na saída do bocal (área mínima

"Viscosidade dinâmica do fluido"

"Reynolds na área mínima da passagem pela

"Coeficiente beta para o cálculo do C_d,

"Vazão se o escoamento fosse isoentrópico"

"Vazão considerando o coeficiente de
"Tangente do ângulo da manivela, para

"Delta_P de referência máximo para o

"Delta_P de referência mínimo para o 
DP_ad=abs (P_max-P_d)

a pressão de admissão"

"Delta_P entre a pressão da câmara direita e

IF (r_x<=1-r_xref) THEN

"Verificação se o pistão está fora do extremo do curso menor que r_xref para amortecimento numérico devido à posição. Existe amortecimento numérico nas extremidades do curso do pistão"

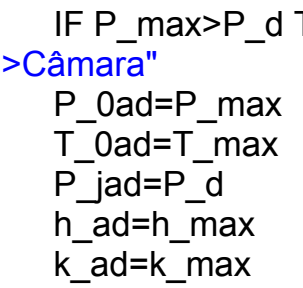

"Verifica se o fluxo vai no sentido Admissão--

do fluxo"
R_fluido_ad=R_fluido_max
ELSE

"Define a pressão de estagnação"

"Define a temperatura de estagnação"

"Define a pressão da jusante"

"Define a eltalpia do fluxo"

"Define a constante adiabática k para o fluido

a pressão da câmara, ou seja, o fluxo vai no sentido Câmara-->Admissão "
P_Oad=P_d
T_0ad=T_d
$P$ jad $=P$ - max
h_ad=h_d
k_ad=k_d

"Define a constante R do fluido do fluxo"

"Caso a pressão de admissão for menor que

do fluxo"

R_fluido_ad=R_fluido_d

ENDIF

IF (DP_ad<=DP_ref) THEN

"Define a pressão de estagnação"

"Define a temperatura de estagnação"

"Define a pressão da jusante"

"Define a eltalpia do fluxo"

"Define a constante adiabática k para o fluido

"Define a constante R do fluido do fluxo"

jusante é menor que o Delta_P de referência, caso positivo, haverá um amortecimento numérico devido ao Delta P"

sinal_ad $=\left(\left(-2 / D P \_r e f^{\wedge} 3\right)^{*} D P \_a d^{\wedge} 3+\left(3 / D P \_r e f^{\wedge} 2\right)^{*} D P \_a d^{\wedge} 2\right)^{*} \operatorname{sign}\left(P \_m a x-P \_d\right)$ "Informa o sinal do fluxo, com o fator multiplicativo do amortecimento numérico; fluxo entrando na câmara (+), fluxo saindo da câmara (-)"

\section{ELSE}

portanto não há amortecimento"

sinal_ad=sign(P_max-P_d)

"Delta_P maior que o Delta_P de referência,

amortecimento; fluxo entrando na câmara (+), fluxo saindo da câmara (-)"

ENDIF

ELSE

"Verificação se o pistão está no extremo do curso menor que r_xref para amortecimento numérico devido à posição"

IF $(\operatorname{tg}<=0)$ THE $\bar{N}$

"Tangente do ângulo da manivela $<0$ significa que o pistão está se aproximando do ponto morto, e há amortecimento numérico devido à posição"

P_Oad=P_d

T_0ad $=\left(T_{-} \text {d }-T \_m a x\right)^{*}\left(1-r \_x\right) / r \_x r e f+T \_m a x$

um amortecimento numérico ${ }^{-}$evido à posição"

$$
P \_ \text {jad }=\text { P_max }
$$

h_ad=(h_d-h_max $)^{*}\left(1-r \_x\right) / r \_x r e f+h \_m a x$

amortecimento numérico devido à posição"

k_ad=k_d

do fluxo"

R_fluido_ad=R_fluido_d

ELSE - "Se a tangente do ângulo da manivela $>0$, signifida que o pistão está se afastando do ponto morto, e não há amortecimento numérico devido à posição"

$$
\begin{aligned}
& \text { P_0ad=max }\left(P \_ \text {max; } P \_d\right) \\
& \text { T_0ad=T_max } \\
& \text { P_jad=min(P_d;P_max }) \\
& \text { h_ad=h_max } \\
& \text { k_ad=k_max } \\
& \text { fluxo" } \\
& \text { R_fluido_ad=R_fluido_max } \\
& \text { ENDIF }
\end{aligned}
$$

do fluxo"
"Define a pressão de estagnação"

"Define a temperatura de estagnação, com

"Define a pressão da jusante"

"Define a eltalpia do fluxo, com

"Define a constante adiabática k para o fluido

"Define a constante $\mathrm{R}$ do fluido do fluxo"

"Se a tangente do ângulo da manivela $>0$,

"Define a pressão de estagnação"

"Define a temperatura de estagnação"

"Define a pressão da jusante"

"Define a eltalpia do fluxo"

"Define a constante adiabática $\mathrm{k}$ para o fluido

"Define a constante R do fluido do fluxo" 
IF (DP_ad $<=$ DP_ref) THEN

"Verifica se o Delta_P entre a montante e a jusante é menor que o Delta_P de referência, caso positivo, haverá um amortecimento numérico devido ao Delta_P"

DP_ref_ad=(DP_ad-DP_ref) $)^{*}\left(1-r \_x\right) / r \_x r e f+D P \_r e f \quad$ "Delta_P variável para o amortecimento devido à posição do pistão"

sinal_ad $=\left(\left(-2 / D P \_r e f^{\wedge} 3\right)^{*} D P \_a d^{\wedge} 3+\left(3 / D P \_r e f^{\wedge} 2\right)^{*} D P \_a d^{\wedge} 2\right)^{*} \operatorname{sign}\left(P \_m a x-P \_d\right)$ "Informa o sinal do fluxo, com o fator multiplicativo do amortecimento numérico; fluxo entrando na câmara $(+)$, fluxo saindo da câmara (-)"

ELSE

sinal_ad=sign(P_max-P_d) "Determina o sinal do fluxo, se amortecimento; fluxo entrando na câmara (+), fluxo saindo da câmara (-)"

\section{ENDIF}

ENDIF

ENDIF

"Termina a determinação das propriedades à

call fluxo(Aad;d_had;k_ad;R_fluido_ad;P_jad;P_0ad;T_0ad:m_dot_ad_1) "Chama o procedure para calcualr o fluxo mássico entre a câmara direita e a correspondente câmara de admissão"

m_dot_ad=m_dot_ad_1*sinal_ad

sinal"

END

câmara direita e a câmara de admissão"

"Calcula o fluxo mássico com o respecivo

"Termina o procedure do escoamento entre a

"!Procedure referente à admissão do lado esquerdo"

procedure vazãoAE(h_max;h_e;P_max;P_e;T_max;T_e:m_dot_ae;h_ae;sinal_ae)

\$Common theta;r_x;Aae;alfa;r_xref;d_hae;k_max;R_fluido_max;k_e;R_fluido_e

$\operatorname{tg}:=\tan ($ theta)

verificar a posição do pistão"

DP_ref $=500$

amortecimento numérico"

DP_min $=0$

amortecimento numérico"

DP_ae=abs(P_max-P_e)

esquerda e a pressão de admissão"

"Tangente do ângulo da manivela, para

"Delta_P de referência máximo para o

"Delta_P de referência mínimo para o

"Delta_P entre a pressão da câmara

IF (r_x $>=r_{-}$xref) THEN

"Verificação se o pistão está fora do extremo do curso menor que r_xref para amortecimento numérico devido à posição. Existe amortecimento numérico nas extremidades do curso do pistão"

$$
\begin{gathered}
\text { >Câmara" } \\
\text { P_0ae=P_max } \\
\text { T_0ae=T_max } \\
\text { P_jae=P_e } \\
\text { h_ae=h_max } \\
\text { k_ae=k_max }
\end{gathered}
$$$$
\text { IF P_max }>\text { P_e THEN }
$$

do fluxo"

$$
\begin{aligned}
& R \text { fluido_ae=R_fluido_max } \\
& \text { ELSE }
\end{aligned}
$$

pressão

$$
\begin{aligned}
& \text { P_0ae=P_e } \\
& \text { T_0ae=T_e } \\
& \text { P_jae=P_max } \\
& \text { h_ae =h_e } \\
& \text { k_ae=k_e }
\end{aligned}
$$

do fluxo"

$$
\text { R_fluido_ae=R_fluido_e }
$$

EÑDIF

IF (DP_ae $<=$ DP_ref) THEN

"Verifica se o fluxo vai no sentido Admissão--
"Define a pressão de estagnação"
"Define a temperatura de estagnação"
"Define a pressão da jusante"
"Define a eltalpia do fluxo"
"Define a constante adiabática k para o fluido

"Define a constante R do fluido do fluxo"

"Caso a pressão de admissão for menor que o fluxo vai no sentido Câmara-->Admissão "

"Define a pressão de estagnação"

"Define a temperatura de estagnação"

"Define a pressão da jusante"

"Define a eltalpia do fluxo"

"Define a constante adiabática k para o fluido

"Define a constante R do fluido do fluxo"

"Verifica se o Delta_P entre a montante e a jusante é menor que o Delta_P de referência, caso positivo, haverá um amortecimento numérico devido ao Delta_P" 
sinal_ae $=\left(\left(-2 / D P \_r e f^{\wedge} 3\right)^{*} D P \_a e^{\wedge} 3+\left(3 / D P \_r e f^{\wedge} 2\right)^{*} D P \_a e^{\wedge} 2\right)^{*} \operatorname{sign}\left(P \_m a x-P \_e\right)$ "Informa o sinal do fluxo, com o fator multiplicativo do amortecimento numérico; fluxo entrando na câmara (+), fluxo saindo da câmara (-)"

ELSE

sinal_ae=sign(P_max-P_e) "Determina o sinal do fluxo, se

amortecimento; fluxo entrando na câmara (+), fluxo saindo da câmara (-)"

\section{ENDIF}

ELSE

"Verificação se o pistão está no extremo do curso menor que r_xref para amortecimento numérico devido à posição"

IF ( $\operatorname{tg}<=0)$ THEN

"Tangente do ângulo da manivela $<0$ significa que o pistão está se aproximando do ponto morto, e há amortecimento numérico devido à posição"

P_Oae=P_e

T_Oae $=\left(T_{-} \text {e-T_max }\right)^{*} r_{-} x / r_{-} x r e f+T \_m a x$

um amortecimento numéricodevido à posição"

$P$ jae $=$ P_max

h_ae $=\left(h \_e-h \_m a x\right)^{*}$ __x/r_xref+h_max

amortecimento numérico devido à posição"

$$
\text { k_ae=k_e }
$$

do fluxo"

$$
\text { R_fluido_ae=R_fluido_e }
$$

ELSE

"Define a constante R do fluido do fluxo"
"Se a tangente do ângulo da manivela $>0$, signifida que o pistão está se afastando do ponto morto, e não há amortecimento numérico devido à posição"

$$
\begin{aligned}
& \text { P_0ae=P_max } \\
& \text { T_0ae=T_max } \\
& \text { P_jae=P_e } \\
& \text { h_ae=h_max } \\
& \text { k_ae=k_max }
\end{aligned}
$$

do fluxo"

$$
\text { R_fluido_ae=R_fluido_max }
$$

EÑDIF

IF (DP ae<=DP ref) THEN

"Define a pressão de estagnação"

"Define a temperatura de estagnação, com

"Define a pressão da jusante"

"Define a eltalpia do fluxo, com

"Define a constante adiabática k para o fluido

"Define a constante $\mathrm{R}$ do fluido do fluxo"
"Se a tangente do ângulo da manivela $>0$ jusante é menor que o Delta_P de referência, caso positivo, haverá um amortecimento numérico devido ao Delta P"

DP_ref_ae $=\overline{(D P}$ _ae-DP_ref $)^{*}\left(r_{-} x\right) / r_{\text {r }} x r e f+D P \_r e f \quad$ "Delta_P variável para o amortecimento devido à posição do pistão"

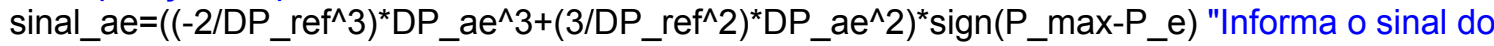
fluxo, com o fator multiplicativo do amortecimento numérico; fluxo entrando na câmara $(+)$, fluxo saindo da câmara (-)"

\section{ELSE}

sinal_ae=sign $\left(P \_m a x-P \_e\right)$

"Determina o sinal do fluxo, se

amortecimento; fluxo entrando na câmara (+), fluxo saindo da câmara (-)"

\section{ENDIF}

ENDIF

"Termina a determinação das propriedades à montante e à jusante do escoamento, assim como o sinal do fluxo."

call fluxo(Aae;d_hae;k_ae;R_fluido_ae;P_jae;P_Oae;T_0ae:m_dot_ae_1) "Chama o procedure para calcualr o fluxo mássico entre a câmara direita e a correspondente câmara de admissão" m_dot_ae=m_dot_ae_1*sinal_ae sinal"

END

câmara direita e a câmara de admissão"

"Calcula o fluxo mássico com o respecivo

"Termina o procedure do escoamento entre a

"!Procedure referente ao escape do lado esquerdo" procedure vazãoEE(h_min;h_e;P_min;P_e;T_min;T_e:m_dot_ee;h_ee;sinal_ee) \$Common theta;r_x;Aee;alfa;r_xref;d_hee;k_min;R_fluido_min;k_e;R_fluido_e

$\operatorname{tg}:=\tan ($ theta)

verificar a posição do pistão" 
DP_ref $=500$

amortecimento numérico"

DP_min $=0$

amortecimento numérico"

DP_ee=abs (P_min-P_e $)$

esquerda e a pressão de escape"
"Delta_P de referência máximo para o

"Delta_P de referência mínimo para o

"Delta_P entre a pressão da câmara

IF (r_x $<=1-r_{-}$xref) THEN

"Verificação se o pistão está fora do extremo do curso menor que r_xref para amortecimento numérico devido à posição. Existe amortecimento numérico nas extremidades do curso do pistão"

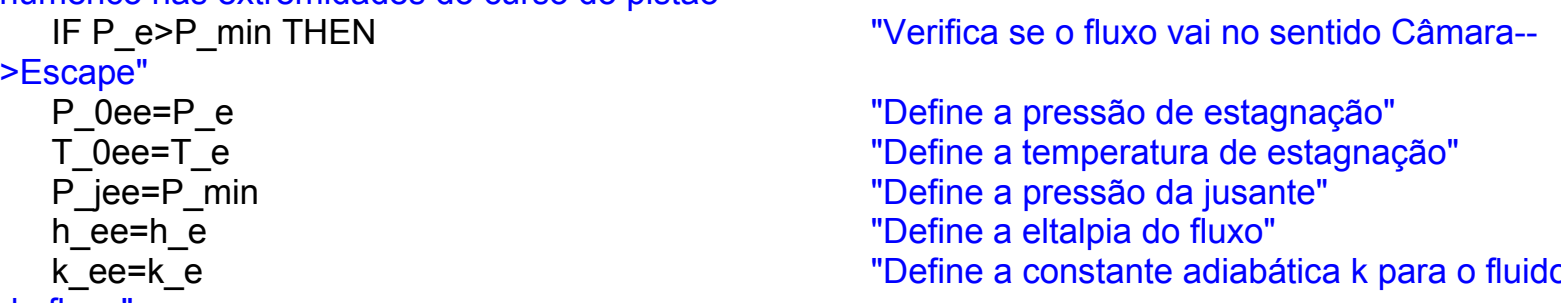

do fluxo"

R_fluido_ee=R_fluido_e "Define a constante $R$ do fluido do fluxo"

ELSE

"Caso a pressão de admissão for menor que a pressão da câmara, ou seja, o fluxo vai no sentido Escape-->Câmara "
$P$ 0ee $=P$ min
$\mathrm{T}^{-}$- $\mathrm{ee}=\mathrm{T}^{-}$min
$P$ jee $=P$ e
h_ee=h_min
k_ee $=k \_$min

"Define a pressão de estagnação"

"Define a temperatura de estagnação"

"Define a pressão da jusante"

"Define a eltalpia do fluxo"

"Define a constante adiabática k para o fluido

do fluxo"

R_fluido_ee=R_fluido_min

ENDIF

IF (DP_ee<=DP_ref) THEN

"Define a constante R do fluido do fluxo"

jusante é menor que o Delta $P$ de referência, caso positivo, haverá um amortecimento numérico devido ao Delta $P^{\prime \prime}$

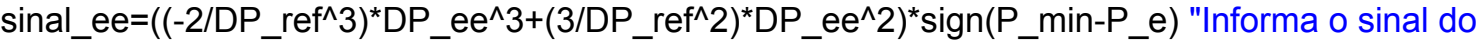
fluxo, com o fator multiplicativo do amortecimento numérico; fluxo entrando na câmara (+), fluxo saindo da câmara (-)"

ELSE

sinal_ee=sign $\left(P \_\right.$min- $\left.P \_e\right) \quad$ "Determina o sinal do fluxo, se

amortecimento; fluxo entrando na câmara (+), fluxo saindo da câmara (-)"

\section{ENDIF}

ELSE

"Verificação se o pistão está no extremo do curso menor que r_xref para amortecimento numérico devido à posição"

IF ( $\operatorname{tg}<=0)$ THEN

"Tangente do ângulo da manivela $<0$ significa que o pistão está se aproximando do ponto morto, e há amortecimento numérico devido à posição"

$>$ Escape"

$$
\text { IF P_e>P_min THEN }
$$

$$
\begin{aligned}
& P \_0 e e=P \_e \\
& T \_0 e e 1=\bar{T} \_e
\end{aligned}
$$

será modificada"

$$
\begin{aligned}
& \text { P_jee=P_min } \\
& \text { h_ee1=h_e } \\
& \text { modificada" } \\
& \text { k_ee=k_e } \\
& \text { do fluxo" } \\
& \text { R_fluido_ee=R_fluido_e } \\
& \text { ELSE }
\end{aligned}
$$

a pressão da câmara, ou seja, o fluxo vai no sentido Escap

$$
\begin{aligned}
& \text { P_0ee }=P \text { _min } \\
& \text { T_0ee1 }=\bar{T} \text { _min }
\end{aligned}
$$

será modificada"

$$
P \text { jee }=P_{-} \text {e }
$$

"Verifica se o fluxo vai no sentido Câmara--

"Define a pressão de estagnação"

"Define a temperatura de estagnação, que

"Define a pressão da jusante"

"Define a eltalpia do fluxo, que será

"Define a constante adiabática k para o fluido

"Define a constante $\mathrm{R}$ do fluido do fluxo"

"Caso a pressão de admissão for menor que cape-->Câmara "

"Define a pressão de estagnação"

"Define a temperatura de estagnação, que

"Define a pressão da jusante" 
do fluxo"

h_ee1=h_min

modificada"

k_ee=k_min

R_fluido_ee=R_fluido_min

EÑNIF

$T \_0 e e=\left(\left(-2 / r \_x r e f^{\wedge} 3\right)^{*}\left(1-r \_x\right)^{\wedge} 3+\left(3 / r \_x r e f^{\wedge} 2\right)^{*}\left(1-r \_x\right)^{\wedge} 2\right)^{*}\left(T \_0 e 1-T \_e\right)+T \_e$ "Define a temperatura de estagnação"

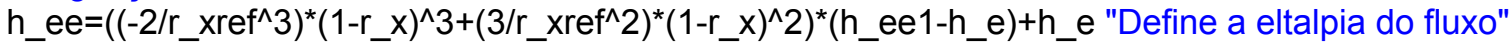

ELSE

"Se a tangente do ângulo da manivela $>0$, signifida que o pistão está se afastando do ponto morto, e não há amortecimento numérico devido à posição"

P_Oee=max $\left(P_{-}\right.$e $; P_{-}$min $)$

T_0ee=T_e

$P_{\text {jee }}=\min \left(P_{-} \min ; P_{-} e\right)$

h_ee=h_e

k_ee=k_e

do fluxo"

$R$ fluido_ee=R fluido e

ENDIF

IF (DP_ee<=DP_ref) THEN

"Define a pressão de estagnação"

"Define a temperatura de estagnação"

"Define a pressão da jusante"

"Define a eltalpia do fluxo"

"Define a constante adiabática k para o fluido

"Define a constante R do fluido do fluxo" jusante é menor que o Delta_P de referência, caso positivo, haverá um amortecimento numérico devido ao Delta $P^{\prime \prime}$

DP_ref_ee $=\overline{(D P}$ _ee-DP_ref $)^{*}\left(1-r \_x\right) / r \_x r e f+D P \_r e f \quad$ "Delta_P variável para o amortecimento devido à posição do pistão"

sinal_ee $=\left(\left(-2 / D P \_r e f^{\wedge} 3\right)^{*} D P \_e e^{\wedge} 3+\left(3 / D P \_r e f^{\wedge} 2\right)^{*} D P \_e e^{\wedge} 2\right)^{*} \operatorname{sign}\left(P_{-}\right.$min-P_e $) \quad$ "Informa o sinal do fluxo, com o fator multiplicativo do amortecimento numérico; fluxo entrando na câmara (+), fluxo saindo da câmara (-)"

ELSE

sinal_ee=sign(P_min-P_e ) "Determina o sinal do fluxo, se

amortecimento; fluxo entrañdo na câmara (+), fluxo saindo da câmara (-)"

ENDIF

ENDIF

"Termina a determinação das propriedades à montante e à jusante do escoamento, assim como o sinal do fluxo."

call fluxo(Aee;d_hee;k_ee;R_fluido_ee;P_jee;P_0ee;T_0ee:m_dot_ee_1) "Chama o procedure para calcualr o fluxo mássico entre a câmara direita e a correspondente câmara de admissão"

m_dot_ee=m_dot_ee_1sinal_ee

"Calcula o fluxo mássico com o respecivo

sinal"

END

câmara direita e a câmara de admissão"

"Termina o procedure do escoamento entre a

"!Procedure referente ao escape do lado direito"

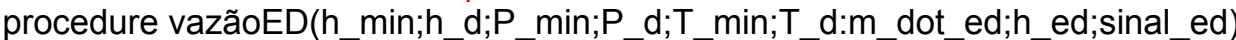

\$Common theta;r_x;Aed;alfa;r_xref;d_hed;k_min;R_fluido_min;k_d;R_fluido_d

$\operatorname{tg}:=\tan ($ theta)

verificar a posição do pistão"

DP_ref $=500$

amortecimento numérico"

DP $\min =0$

amortecimento numérico"

DP_ed=abs(P_min-P_d)

a pressão de escape"

IF ( $\left.r \_x>=r \_x r e f\right)$ THEN

"Tangente do ângulo da manivela, para

"Delta_P de referência máximo para o

"Delta P de referência mínimo para o

"Delta_P entre a pressão da câmara direita e do curso menor que r_xref para amortecimento numérico devido à posição. Existe amortecimento numérico nas extremidades do curso do pistão"

IF $P$ d $>P$ min THEN

$>$ Escape"
"Verifica se o fluxo vai no sentido Câmara-- 


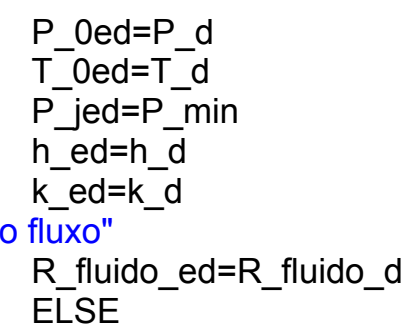

ELSE a pressão da câmara, ou seja, o fluxo vai no sentido Escap

"Define a pressão de estagnação"

"Define a temperatura de estagnação"

"Define a pressão da jusante"

"Define a eltalpia do fluxo"

"Define a constante adiabática k para o fluido

"Define a constante R do fluido do fluxo"

"Caso a pressão de admissão for menor que cape-->Câmara "

"Define a pressão de estagnação"

"Define a temperatura de estagnação"

"Define a pressão da jusante"

"Define a eltalpia do fluxo"

"Define a constante adiabática k para o fluido

do fluxo"

R_fluido_ed=R_fluido_min

ENDIF

IF (DP_ed $<=$ DP_ref) THEN

"Define a constante R do fluido do fluxo"

"Verifica se o Delta_P entre a montante e a jusante é menor que o Delta_P de referência, caso positivo, haverá um amortecimento numérico devido ao Delta P"

sinal_ed $=\left(\left(-2 / D P \_r e f^{\wedge} 3\right)^{*} D P \_e d^{\wedge} 3+\left(3 / D P \_r e f^{\wedge} 2\right)^{*} D P \_e d^{\wedge} 2\right)^{*} \operatorname{sign}\left(P \_m i n-P \_d\right) \quad$ "Informa o sinal do fluxo, com o fator multiplicativo do amortecimento numérico; fluxo entrando ná câmara (+), fluxo saindo da câmara (-)"

ELSE

sinal_ed=sign(P_min-P_d) "Determina o sinal do fluxo, se

amortecimento; fluxo entrando na câmara (+), fluxo saindo da câmara (-)"

\section{ENDIF}

\section{ELSE}

"Verificação se o pistão está no extremo do curso menor que r_xref para amortecimento numérico devido à posição"

$$
\text { IF }(\operatorname{tg}<=0) \text { THEN }
$$

"Tangente do ângulo da manivela $<0$ significa que o pistão está se aproximando do ponto morto, e há amortecimento numérico devido à posição"
IF P_d $>$ P_min THEN
"Verifica se o fluxo vai no sentido Câmara--

$$
\begin{aligned}
& \text { P_0ed=P_d } \\
& \text { T_0ed1 }=\bar{T}+d
\end{aligned}
$$

será módificada"

$$
P \text { _jed }=P \_ \text {min }
$$$$
\text { h_ed1=h_d }
$$

modificăda"

do fluxo"

$$
\text { k_ed=k_d }
$$

"Define a temperatura de estagnação"

"Define a temperatura de estagnação, que

"Define a pressão da jusante"

"Define a eltalpia do fluxo, que será

"Define a constante adiabática k para o fluido

$$
\text { R_fluido_ed=R_fluido_d }
$$

ELSE

"Define a constante R do fluido do fluxo"

"Caso a pressão de admissão for menor que a pressão da câmara, ou seja, o fluxo vai no sentido Escape-->Câmara "

$$
\begin{aligned}
& \text { P_0ed=P_min } \\
& \text { T_0ed1 }=\bar{T}_{-} \min \\
& \text { será módificada" } \\
& P \_ \text {jed }=P \_d \\
& \text { h_ed1=h_min } \\
& \text { modificada" } \\
& \text { do fluxo" } \\
& \text { k_ed=k_min } \\
& \text { "Define a temperatura de estagnação" } \\
& \text { "Define a temperatura de estagnação, que } \\
& \text { "Define a pressão da jusante" } \\
& \text { "Define a eltalpia do fluxo, que será }
\end{aligned}
$$




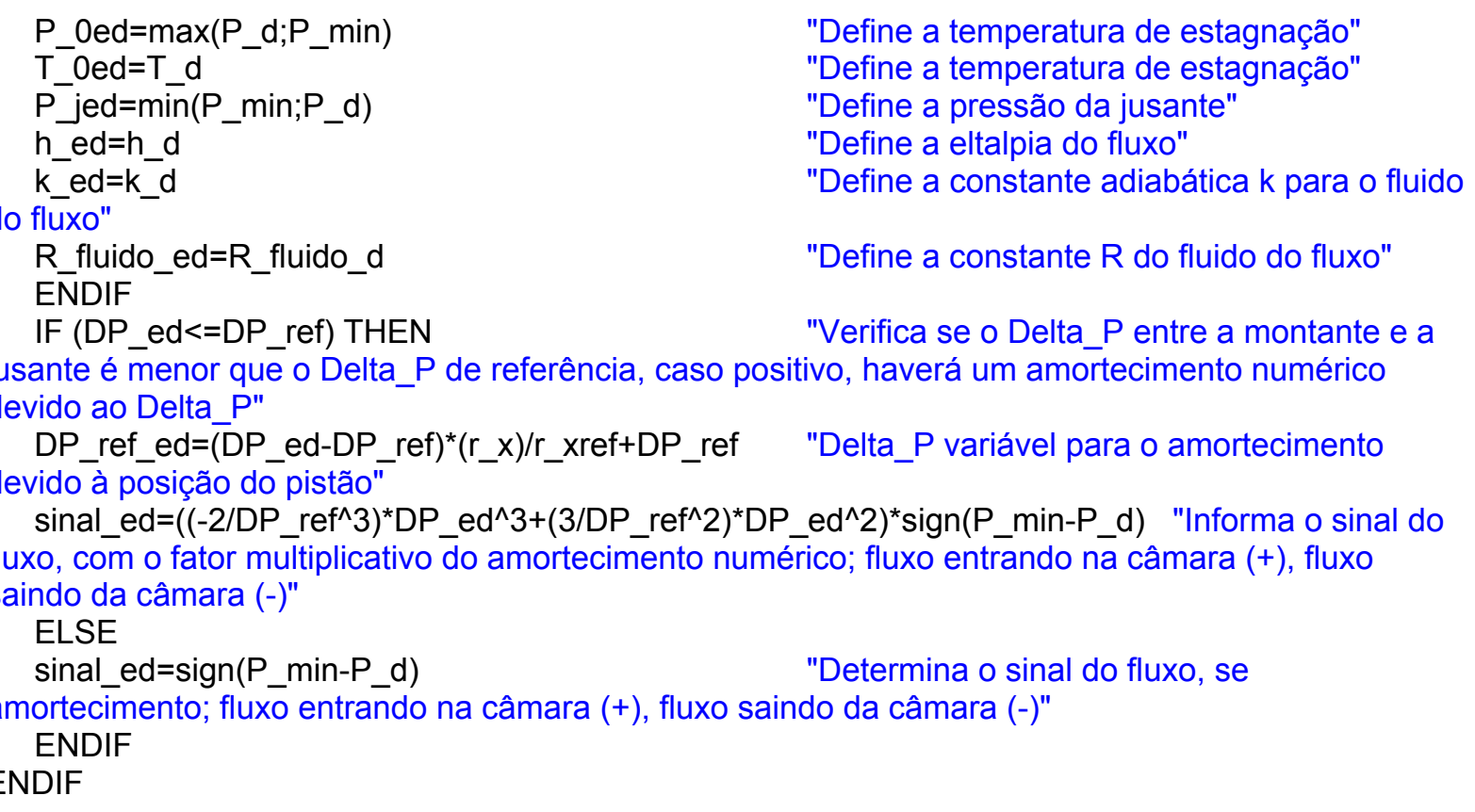

call fluxo(Aed;d_hed;k_ed;R_fluido_ed;P_jed;P_0ed;T_0ed:m_dot_ed_1) "Chama o procedure para calcualr o fluxo mássico entre a câmara direita e a correspondente câmara de admissão" m_dot_ed=m_dot_ed_1*sinal_ed "Calcula o fluxo mássico com o respecivo sinal"

END

câmara direita e a câmara de admissão"

"Termina o procedure do escoamento entre a

"!Procedure referente ao fluxo de admissão da câmara de admissão"
procedure vazãoACA(h_max;h_d;P_max;P_d;T_max;T_d:m_dot_ad;h_ad;sinal_ad)
\$Common theta;r_x;alfa;r_xref;A_admissao;k_max;R_fluido_max;k_ca;R_fluido_ca

$\operatorname{tg}:=\tan ($ theta)

verificar a posição do pistão"

DP_ref $=500$

amortecimento numérico"

DP_min $=0$

amortecimento numérico"

DP_ad=abs(P_max-P_d)

a pressão de escape"

IF P_max $>P \_d$ THEN

Pressão-->Câmara de Admissão"

$$
\begin{aligned}
& \text { P_0ad=P_max } \\
& \text { T_0ad=T_max } \\
& \text { P_jad=P_d } \\
& \text { h_ad=h_max } \\
& \text { k_ad=k_max }
\end{aligned}
$$

do fluxo"

R_fluido_ad=R_fluido_max

ELSE

Admissão-->Alta Pressão"

$P$ Oad $=P$ d

$T^{-}$Oad $=T^{-} d$

$P$ jad $=P$ max

h_ad=h_d

k_ad $=$ k_ca

do fluxo"

R_fluido_ad=R_fluido_ca
"Tangente do ângulo da manivela, para

"Delta_P de referência máximo para o

"Delta_P de referência mínimo para o

"Delta_P entre a pressão da câmara direita e

"Verifica se o fluxo vai no sentido Alta

"Define a temperatura de estagnação"

"Define a temperatura de estagnação"

"Define a pressão da jusante"

"Define a eltalpia do fluxo"

"Define a constante adiabática $\mathrm{k}$ para o fluido

"Define a constante $\mathrm{R}$ do fluido do fluxo"

"Verifica se o fluxo vai no sentido Câmara de

"Define a temperatura de estagnação"

"Define a temperatura de estagnação"

"Define a pressão da jusante"

"Define a eltalpia do fluxo"

"Define a constante adiabática $\mathrm{k}$ para o fluido

"Define a constante R do fluido do fluxo" 
ENDIF

IF (DP_ad<=DP_ref) THEN

"Verifica se o Delta_P entre a montante e a jusante é menor que o Delta_P de referência, caso positivo, haverá um amortecimento numérico devido ao Delta P"

sinal_ad $=\left(\left(-2 / D P \_r e f^{\wedge} 3\right)^{*} D P \_a d^{\wedge} 3+\left(3 / D P \_r e f^{\wedge} 2\right)^{*} D P \_a d^{\wedge} 2\right)^{*} \operatorname{sign}\left(P \_m a x-P \_d\right)$ "Informa o sinal do fluxo, com o fator multiplicativo do amortecimento numérico; fluxo entrando na câmara (+), fluxo saindo da câmara (-)"

ELSE

sinal_ad=sign(P_max-P_d)

"Determina o sinal do fluxo, se

amortecimento; fluxo entrando na câmara (+), fluxo saindo da câmara (-)"

ENDIF

call fluxo(A_admissao;0,008;k_ad;R_fluido_ad;P_jad;P_0ad;T_0ad:m_dot_ad_1) "Chama o procedure para calcualr o fluxo mássico entre a câmara direita e a correspondente câmara de admissão" m_dot_ad=m_dot_ad_1 ${ }^{*}$ sinal_ad

"Calcula o fluxo mássico com o respecivo sinal"

END

"Termina o procedure do escoamento entre a

câmara direita e a câmara de admissão"

"!Procedure referente ao fluxo de escape da câmara de escape"

procedure vazãoACED(h_min;h_d;P_min;P_d;T_min;T_d;k;R_fluido:m_dot_ed;h_ed;sinal_ed)

\$Common theta;r_x;alfa;r_xref;A_escape;k_min;R_fluido_min

$\operatorname{tg}:=\tan ($ theta)

verificar a posição do pistão"

DP_ref $=500$

amörtecimento numérico"

DP $\min =0$

amortecimento numérico"

DP_ed=abs(P_min-P_d)

a pressão de escape"

IF P_d>P_min THEN

Escape-->Baixa Pressão"

$P$ 0ed $=P$ d

T_0ed $=T_{-}^{-} d$

$P \_$jed $=P \_$min

h_ed=h_d

k ed $=k$

do fluxo"

$R \_$fluido_ed=R_fluido

ELSE

Pressão-->Câmara de Escape"

$P$ Oed $=P$ min

T_Oed=T_min

$\mathrm{h}$ ed $=\mathrm{h}$ min

k_ed $=k \_$min

do fluxo"

$\mathrm{R}$ fluido ed=R fluido $\mathrm{min}$

EN̄DIF
$P$ jed $=P_{-}{ }_{d}$

IF (DP_ed<=DP_ref) THEN

"Tangente do ângulo da manivela, para

"Delta_P de referência máximo para o

"Delta_P de referência mínimo para o

"Delta_P entre a pressão da câmara direita e

"Verifica se o fluxo vai no sentido Câmara de

"Define a temperatura de estagnação"

"Define a temperatura de estagnação"

"Define a pressão da jusante"

"Define a eltalpia do fluxo"

"Define a constante adiabática k para o fluido

"Define a constante R do fluido do fluxo"

"Verifica se o fluxo vai no sentido Baixa

"Define a temperatura de estagnação"

"Define a temperatura de estagnação"

"Define a pressão da jusante"

"Define a eltalpia do fluxo"

"Define a constante adiabática k para o fluido

"Define a constante R do fluido do fluxo"

"Verifica se o Delta_P entre a montante e a jusante é menor que o Delta_P de referência, caso positivo, haverá um amortecimento numérico devido ao Delta $P^{\prime \prime}$

sinal_ed $=\left(\left(-\overline{2} / D P \_ \text {ref }{ }^{\wedge} 3\right)^{*} D P \_ \text {ed }{ }^{\wedge} 3+\left(3 / D P \_ \text {ref }{ }^{\wedge} 2\right)^{*} D P \_ \text {ed }{ }^{\wedge} 2\right)^{*} \operatorname{sign}\left(P \_\right.$min- $P$ d $)$ "Informa o sinal do fluxo, com o fator multiplicativo do amortecimento numérico; fluxo entrando na câmara (+), fluxo saindo da câmara (-)"

ELSE

sinal ed $=\operatorname{sign}(P$ min- $P$ d $)$

"Determina o sinal do fluxo, se

amortecimento; fluxo entrando na câmara (+), fluxo saindo da câmara (-)" 


\section{ENDIF}

call fluxo(A_escape;0,006;k_ed;R_fluido_ed;P_jed;P_0ed;T_0ed:m_dot_ed_1) "Chama o procedure para calcualr o fluxo mássico entre a câmara direita e a correspondente câmara de admissão" m_dot_ed=m_dot_ed_1*sinal_ed sinal"

END

câmara direita e a câmara de admissão"

"Calcula o fluxo mássico com o respecivo

"Termina o procedure do escoamento entre a $" !$ Procedure para determinar a abertura e consequentemente a área de cada válvula

Procedure posicoes(x:x_v;xvae;xvee;xvad;xved;Aae;Aee;Aad;Aed;d_hae;d_had;d_hee;d_hed)

\$Common d_v;y_v; L_valv; R_valv; theta_valv

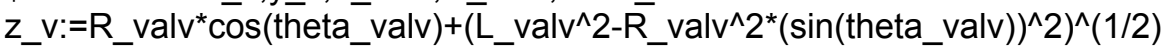

X_v:=L_valv+R_valv-z_v $\quad$ "x_v - Deslocamento da válvula desde o ponto morto superior (mais à esquerda) até a sua posição atual"

x_v_0:=R_valv+y_v/2-d_v/2 "x_v_0 - Distância entre a face esquerda do pistão da válvula até o início do furo de admissão/escape da câmara quando a válvula está no ponto morto superior (mais à esquerda possível)"

"LADO ESQUERDO"

"ADMISSÂO"

IF (x_v $\left.>=x \_v \_0+d \_v-y \_v\right)$ THEN

"Verifica se a válvula está totalmente

fechada"

xvae: $=0$

ENDIF

IF $\left(x \_v<x \_v \_0+d \_v-y \_v\right)$ AND (x_v>x_v_0-y_v) THEN "Verifica se a válvula está parcialmente aberta"

xvae:=x_v_0+d_v-(x_v+y_v)

ENDIF

IF $x \quad v<=x \vee 0-y \_$THEN

$\mathrm{xvae}:=\mathrm{d} v$

ENDIF

"ESCAPE"

IF $(x \vee v<=x \vee 0)$ THEN

fechada"

xvee: $=0$

ENDIF

IF (x_v>x_v_0) AND (x_v<x_v_0+d_v) THEN "Verifica se a válvula está parcialmente aberta"

xvee:=x_v-x_v_0

ENDIF

IF $\quad\left(x \_v>=x \_v \_0+d \_v\right)$ THEN

$\mathrm{xvee}:=\mathrm{d} \_\mathrm{v}$

ENDIF

"LADO DIREITO"

"ADMISSÃO"

IF (x_v<=x_v_0) THEN

fechada"

xvad: $=0$

ENDIF

IF (x_v>x_v_0) AND (x_v<x_v_0+d_v) THEN "Verifica se a válvula está parcialmente aberta"

xvad:=x_v-x_v_0

ENDIF

IF (x_v>=x_v_0+d_v) THEN

"Verifica se a válvula está totalmente aberta"

xvad:=d_v

ENDIF

"ESCAPE"

IF (x_v<=x_v_0-y_v) THEN

"Verifica se a válvula está totalmente

"Verifica se a válvula está totalmente aberta"

"Verifica se a válvula está totalmente

"Verifica se a válvula está totalmente aberta"

"Verifica se a válvula está totalmente aberta" 


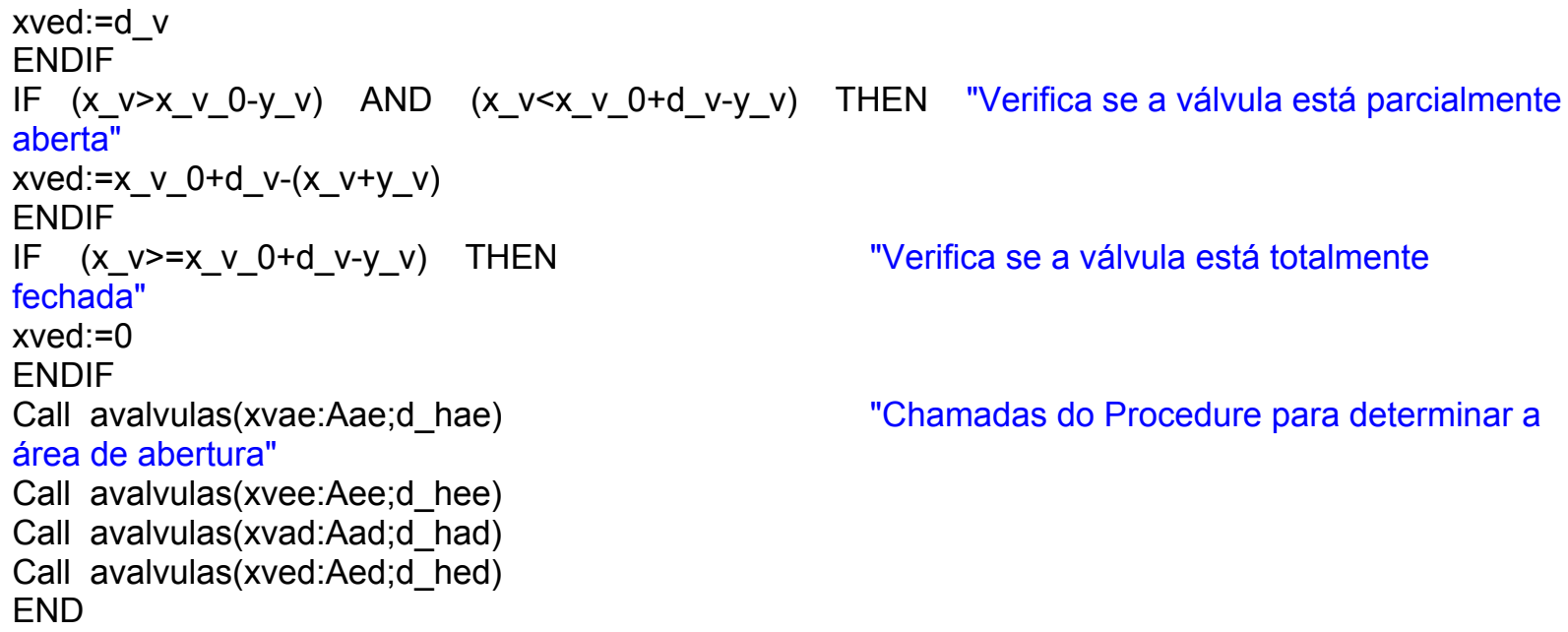

"d - diâmetro do pistão"

"a_e - Área do pistão do lado esquerdo"

"d_haste - diâmetro da haste do pistão"

"a_d - Área do pistão do lado direito"

"Espessura do pistão"

"Espaço morto"

"x_d -- Posição x da face direita do pistão, do

"V_Oe -- Volume morto da câmara esquerda"

"V-Od - Volume morto da câmara direita"

"S -- Curso do pistão"

"V_deslocado -- Volume deslocado pelo

"Comprimento da biela"

"Comprimento da manivela"

"r_v -- Razão de Volumes" 


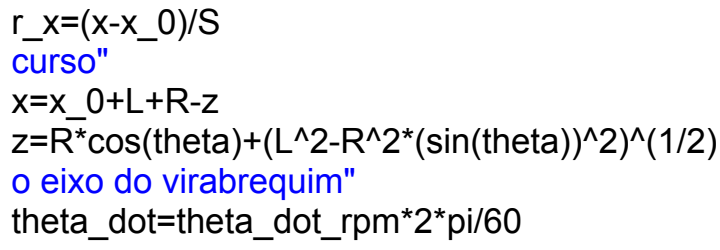

\section{"RELAÇÕES GEOMÉTRICAS VÁLVULAS"}

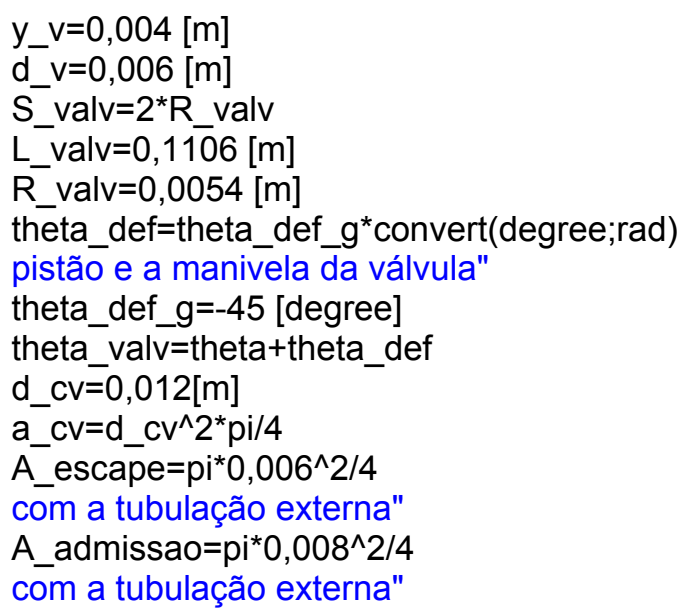

"Posição x inicial da face direita do pistão, do ponto de vista da câmara do lado direito" $x \_d \_i=2 * x \_0+S-x$ i

"theta_i $=0, \overline{2}$ "

(Infomação fornecida no diagrama de entrada)"

$P$ cd $i=P$ min +100

$\mathrm{T}^{-} \mathrm{Cd}^{-} \mathrm{i}=\mathrm{T}^{-} \min$

direita"

V_cd_i=a_cv* $\left(0,0174-x \_v\right)$

rho_cd_i=density(fluido $\overline{\$} ; \mathrm{P}=\mathrm{P} \_$cd_i $; \mathrm{T}=\mathrm{T}$ _cd_i) direita"

m_cd_i=V_cd_i*rho_cd_i

u_cd_i=intenergy(fluido $\overline{\$} ; P=P$ _cd_i $T=T$ _cd_i $)$

direita"

$P$ ce $i=P$ min +100

esquerda"

$T$ ce $\mathrm{i}=\mathrm{T}$ min

esquerda" "r_x -- Posição do pistão em relação ao seu

"x -- Posição da face esquerda do pistão"

"Distância entre a face esquerda do pistão e

"Velocidade ângular da manivela"

"Espessura da válvula"

"d v -- Diâmetro das válvulas"

"Curso da válvula"

"Comprimento da biela da válvula"

"Comprimento da manivela da válvula"

"Ângulo de defasagem entre a manivela do

"Ângulo da manivela da válvula"

"Diâmetro das Câmaras das válvulas"

"Área das câmaras das válvulas"

"Área da conexão das câmaras de escape

"Área da conexão das câmaras de escape
"Pressão inicial na câmara direita"

"Temperatura inicial na câmara direita"

"Volume inicial da câmara direita"

"Densidade inicial da câmara direita"

"Massa inicial da câmara direita"

"Energia Interna inicial da câmara direita"

"Pressão inicial na câmara esquerda"

"Temperatura inicial na câmara esquerda"

"Volume inicial da câmara esquerda"

"Densidade inicial da câmara esquerda"

"Massa inicial da câmara esquerda"

"Energia Interna inicial da câmara esquerda"

"Posição linear inicial" 


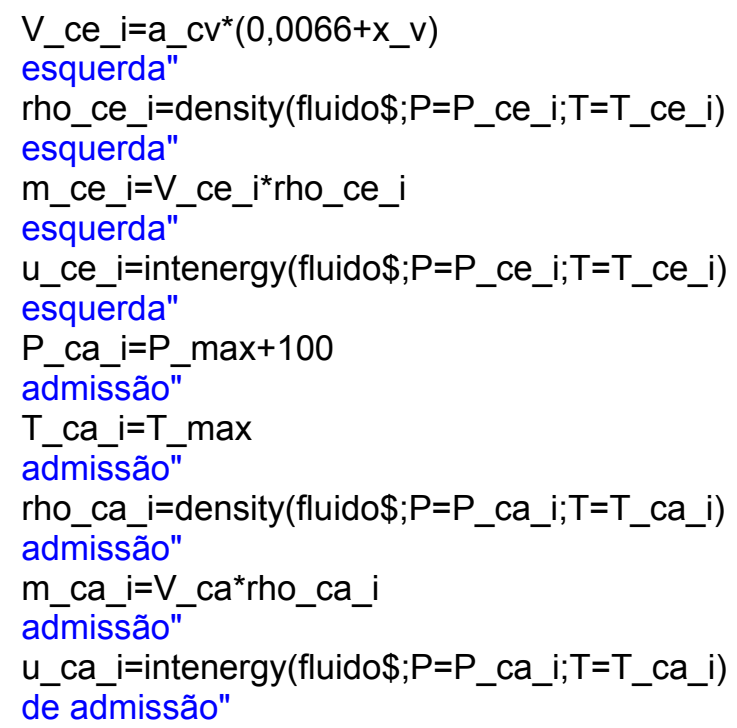

\author{
"Volume inicial da câmara da válvula \\ "Densidade inicial da câmara da válvula \\ "Massa inicial da câmara da válvula \\ "Energia Interna inicial da câmara da válvula \\ "Pressão inicial na câmara da válvula de \\ "Temperatura inicial na câmara da válvula de \\ "Densidade inicial da câmara da válvula de \\ "Massa inicial da câmara da válvula de \\ "Energia Interna inicial da câmara da válvula
}

"! CONDIÇÕES DE OPERAÇÃO

"fluido\$='Air_ha'"

diagrama)"

"theta_dot_rpm=900"

(Informação fornecida no diagrama)"

"n ciclos $=10$ "

(Informação fornecida no diagrama)"

Delta_t $=n$ _ciclos* $(60 /$ theta_dot_rpm $)$

'n_ciclos' ciclos da máquina)"

"n_pontos=1000"

máquina (Informação fornecida no diagrama)"

$\mathrm{dt}=(60 /$ theta_dot_rpm $) / \mathrm{n} \_$pontos

pontos por ciclo da máquina)"

$\mathrm{dt}$ int $=\mathrm{dt}$

'n_pontos' pontos por ciclo da máquina)"

P_atm $=93192,34[\mathrm{~Pa}]$

"P_max $=5 * 10^{\wedge} 5 "$

diagrama)"

"T_max=T_atm"

fornecida no diagrama)"

h_max=enthalpy(fluido $\$ ; P=P \_$max; $T=T \_$max)

"P_min=P_atm"

no diagrama)"

"T_min=T_atm"

fornecida no diagrama)"

h_min=enthalpy(fluido $\$ ; P=P \_$min;T=T_min)
"Fluido de trabalho (Informação fornecida no

"Velocidade angular da manivela do pistão

"Número de ciclos a serem simulados

"Tempo total de simulação (Feito para

"Pontos para simular em cada ciclo da

"Passo da simulação (Feito para 'n_pontos'

"Passo para a integral numérica (Feito para

"Pressão atmosférica"

"Pressão admissão (Informação fornecida no

"Temperatura de admissão (Informação

"Entalpia de admissão"

"Pressão de descarga (Informação fornecida

"Temperatura de descarga (Informação

"Entalpia de escape"

"! EQUAÇÕES DINÂMICA

$x$ _dot $=R^{*}\left(\sin (\text { theta })+\left(R^{*} \sin (\text { theta })^{*} \cos (\text { theta })\right) /\left(\left(L^{\wedge} 2-R^{\wedge} 2^{*}(\sin (\text { theta }))^{\wedge} 2\right)^{\wedge}(1 / 2)\right)\right)^{*}$ theta_dot "Velocidade instantânea do pistão"

x_dot_v=R_valv*(sin(theta_valv) $+\left(R \_v a l{ }^{*} \sin (\text { theta_valv })^{*} \cos (\right.$ theta_valv $\left.)\right) /\left(\left(L \_v a l v^{\wedge} 2-\right.\right.$

$\left.\left.\left.R^{-} \operatorname{valv}^{\wedge} 2^{\star}(\overline{\sin }(\text { theta valv }))^{\wedge} 2\right)^{\wedge}(1 / 2)\right)\right)^{\bar{*}}$ theta dot

"Velocidade instantânea da válvula"

theta=theta_i+integral(theta_dot;t;0;Delta_t;dt_int)

"Posição angular da manivela do pistão"

Call posicoes(x:x_v;xvae;xvee;xvad;xved;Aae;Aee;Aad;Aed;d_hae;d_had;d_hee;d_hed) "Cálcula a posição das válvulas e as respectivas áreas de abertura, diâmetros hidráulicos e áreas de passagem" 
"!EQUAÇÕES PARA A CÂMARA DO LADO DIREITO"

m_dot_ad*h_ad $+m_{-}$dot_ed*h_ed-P_d*dVddt=m_d*duddt+u_d*m_dot_d "1a $^{\text {a }}$ LEI PARA A CÂMARA DO LADO DIREITO"

h_d=enthalpy(fluido $\$ ; P=P \_d ; T=T$ d)

$u_{-} d=$ =intenergy (fluido $\$ ; P=\bar{P} \_d ; v=1 /$ rho_d)

u_d=u_d_i+integral(duddt; ; 0 ; Delta_t; $\overline{d t} \_$int)

"Entalpia da câmara do lado direito"

câmara do lado direito"

$V \_d=a \_d^{*} x \_d$

$d \bar{V} d d t=-a d^{*} x$ dot

do lado direito"

m_dot_d=m_dot_ad+m_dot_ed

m_d $=m$ m_d_i+integral(m_dot_d; t;0;Delta_t; dt_int $)$

rho $d=\bar{m} \bar{d} / V d$

$T$ detemperature(fluido $\$ ; P=P \_d ; v=1 /$ rho_d $)$

"Energia interna da câmara do lado direito"

"Variação instantânea da energia interna da

"Volume da câmara do lado direito"

"Variação instantânea do volume da câmara

"Vazão em massa da câmara do lado direito"

"Massa contida na câmara direita"

"Densidade da câmara do lado direito"

"Temperatura da câmara do lado direito"

call vazãoED(h_cd; $h$ d; $P$ _cd; $P$ _d;T_cd;T_d:m_dot_ed; $h$ ed;sinal_ed)

call vazãoAD(h_ca;h_d;P_ca;P_d;T_ca;T_d:m_dot_ad;h_ad;sinal_ad)

"!EQUAÇÕES PARA A CÂMARA DO LADO ESQUERDO"

$m \_d o t \_a e^{*} h \_a e+m \_d o t=e e^{*} h \_e-P \_e^{*} d V e d t=m \_e^{*} d u e d t+u+e^{*} m \_d o t=e$ " $1^{a}$ LEI PARA A CÂMARA DO LADO ESQQUER'DO"

h_e=enthalpy(fluido $\left.\$ ; P=P \_e ; T=T \_e\right)$

u_e=intenergy(fluido $\$ ; P=P_{-} e ; v=1 /$ rho_e $)$

esquerdo"

u_e=u_e_i+integral(duedt;t;0;Delta_t;dt_int)

cầmara do lado esquerdo"

$V \_e=a \_e^{*} x$

$\mathrm{d} \overline{\mathrm{V}} \mathrm{edt}=\mathrm{a} \_\mathrm{e}^{*} \mathrm{x}$ dot

do lado esquerdo"

m_dot_e=m_dot_ae+m_dot_ee

esquerdo"

m_e $=m$ _e_i+integral $\left(m \_d o t \_e ; t ; 0 ;\right.$ Delta_t; dt_int $)$

rho e $=\bar{m} \bar{e} / \mathrm{V}$ e

T_e=temperature(fluido $\$ ; P=P \_e ; v=1 /$ rho_e $)$

"Entalpia da câmara do lado esquerdo"

"Energia interna da câmara do lado

"Variação instantânea da energia interna da

"Volume da câmara do lado esquerdo"

"Variação instantânea do volume da câmara

"Vazão em massa da câmara do lado

"Massa contida na câmara esquerda"

"Densidade da câmara do lado esquerdo"

"Temperatura da câmara do lado esquerdo" "Determinação dos fluxos de massa que entram e saem da câmara esquerda"

call vazãoEE(h_ce;h_e;P_ce;P_e;T_ce;T_e:m_dot_ee;h_ee;sinal_ee)

call vazãoAE(h_ca;h_e;P_ca;P_e;T_ca;T_e:m_dot_ae;h_ae;sinal_ae)

"!EQUAÇÕES PARA A CÂMARA DE ESCAPE DO LADO ESQUERDO"

$m$ dot_ace*h_ace+m_dot_ece*h_ece-P_ce*dVcedt $=m \_c e^{*} d u c e d t+u \_c e^{*} m \_d o t \_c e$ "1a LEI PARA A CÂMARA DE ESCAPE DO LADO ESQŪERDO DAS VÁLVULAS "

m_dot_ece=-m_dot_ee

esquerda do cilindro"

$\mathrm{h}$ ece=h ee

esquerda do cilindro"

h_ce=enthalpy(fluido $\$ P=P \_c e ; T=T$ ce $)$

u_ce=intenergy (fluido $\$ ; P=P_{-}$ce $;=1 /$ rho_ce)

esquerdo"

u_ce=u_ce_i+integral(ducedt;t;0;Delta_t;dt_int)

câmara do lado esquerdo"

$\mathrm{V} \_\mathrm{ce}=\mathrm{a}$ _c $\mathrm{v}^{*}\left(0,0066+\mathrm{x} \_\mathrm{v}\right)$

$\mathrm{d} \overline{\mathrm{V}}$ cedt $=$ a_c $\mathrm{Cv}^{*} \mathrm{x}$ _dot_v

do lado esquerdo"

m_dot_ce=m_dot_ace+m_dot_ece

esquerdo"

m_ce $=m$ _ce_i+integral (m_dot_ce;t;0;Delta_t;dtint)

"Vazão em massa em relação à camara

"Entalpia do fluxo em relação à câmara

lado esquerdo"

"Entalpia da câmara do lado esquerdo"

"Energia interna da câmara do lado

"Variação instantânea da energia interna da

"Volume da câmara do lado esquerdo"

"Variação instantânea do volume da câmara

"Vazão em massa da câmara do lado

"Massa contida na câmara de escape do 
rho_ce=m_ce/V_ce

T_ce=temperature(fluido $\$ ; P=P \_c e ; v=1 /$ rho_ce) "Determinação do fluxo de massa que entra ou sai da câmara de escape esquerda na comunicação com a baixa pressão"

call vazãoACED(h_min;h_ce;P_min;P_ce;T_min;T_ce;k_ce;R_fluido_ce:m_dot_ace;h_ace;sinal_ace)

"!EQUAÇÕES PARA A CÂMARA DE ESCAPE DO LADO DIREITO"

m_dot_acd*h_acd+m_dot_ecd*h_ecd-P_cd*dVcddt=m_cd*ducddt+u_cd ${ }^{*} m$ _dot_cd "1a LEI PARA A CÂAMARA DE ESCAPE DO LADŌ DIREITO DAS VÁLVULAS "

m_dot_ecd=-m_dot_ed

direita do cilindro"

h_ecd=h ed

direita do cilindro"

h_cd=enthalpy(fluido $\left.\$ ; P=P \_c d ; T=T \_c d\right)$

u_cd=intenergy(fluido $\$ ; P=P_{-}$cd; $v=1 /$ rho_cd)

u_cd=u_cd_i+integral(ducd $\overline{d t} ; \mathrm{t} ; 0 ;$ Delta_t; $d \mathrm{dt}$ int)

câmara do lado direito"

$V \_c d=a \_c v^{*}\left(0,0174-x \_v\right)$

$\mathrm{dV}$ cddt=-a_cv*x_dot_v

do lado direito"

m_dot_cd=m_dot_acd $+m \_d o t \_e c d$

m_cd=m_cd_- ìtintegral(m_dot_cd;t;0;Delta_t;dt_int)

lā̄o direito"

rho $c d=m$ cd $/ V$ cd

T_cd=temperature(fluido $\$ ; P=P$ cd $; \mathrm{v}=1 /$ rho_cd)

"Vazão em massa em relação à camara

"Entalpia do fluxo em relação à câmara

"Entalpia da câmara do lado direito"

"Energia interna da câmara do lado direito"

"Variação instantânea da energia interna da

"Volume da câmara do lado direito"

"Variação instantânea do volume da câmara

"Vazão em massa da câmara do lado direito" "Massa contida na câmara de escape do

"Densidade da câmara do lado direito"

"Temperatura da câmara do lado direito"

"Determinação do fluxo de massa que entra ou sai da câmara de escape direita na comunicação com a baixa pressão"

call vazãoACED(h_min;h_cd;P_min;P_cd;T_min;T_cd;k_cd;R_fluido_cd:m_dot_acd; $\left.h \_a c d ; s i n a l \_a c d\right)$

"!EQUAÇÕES PARA A CÂMARA DE ADMISSÃO"

m_dot_aca*h_aca+m_dot_ecae*h_ecae+m_dot_ecad*h_ecad=m_ca*ducadt+u_ca*m_dot_ca "1a LEl PĀRA A CÂMARA DE ADMISSÃO DAS VÁL̄ VUL'AS "

m_dot_ecae=-m_dot_ae

esquerda do cilindro"

h_ecae=h_ae

esquerda do cilindro"

m_dot_ecad=-m_dot_ad

direita do cilindro"

h_ecad=h_ad

direita do cilindro"

h_ca=enthalpy(fluido $\$ ; P=P$ ca; $T=T$ ca)

u_ca=intenergy(fluido $\$ ; P=\bar{P}$ _ca; $v=1 /$ rho_ca)

u_ca=u_ca_i+integral(ducadt; $t ; 0 ;$ Delta_t; dt_int)

câmara do lado direito"

V_ca $=a \_c v^{*} 0,058$

m_dot_ca $=$ m_dot_aca $+\mathrm{m} \_$dot_ecae $+\mathrm{m}$ _dot_ecad

m_ca=m_ca_ìtintegral(m_dot_ca;t;0;Delta_t; dt_int)

lā̄o direito"

rho ca $=m$ ca/ $\mathrm{V}$ ca

T ca=temperature(fluido $\$ ; P=P$ ca; $v=1 /$ rho ca)

"Vazão em massa em relação à camara

"Entalpia do fluxo em relação à câmara

"Vazão em massa em relação à camara

"Entalpia do fluxo em relação à câmara

"Entalpia da câmara do lado direito"

"Energia interna da câmara do lado direito"

"Variação instantânea da energia interna da

"Volume da câmara do lado direito"

"Vazão em massa da câmara do lado direito"

"Massa contida na câmara de escape do

"Densidade da câmara do lado direito"

"Temperatura da câmara do lado direito" "Determinação do fluxo de massa que entra ou sai da câmara de admissão na comunicação com a alta pressão"

call vazãoACA(h_max;h_ca;P_max;P_ca;T_max;T_ca:m_dot_aca;h_aca;sinal_aca)

"! _ Medidas de desempenho da máquina de expansão

m_adm_ladoE=integral(m_dot_ae;t;0;Delta_t;dt_int) "Somatória de todo o fluxo que entra na câmara esquerda do cilindro" 
m_adm_ladoD=integral(m_dot_ad;t;0;Delta_t;dt_int) $\quad$ "Somatória de todo o fluxo que entra na câmara direita do cilindro"

m_dot_medio $=\left(m \_a d m \_l a d o E+m \_a d m \_l a d o D\right) /\left(t+10^{\wedge}(-10)\right)$ "Cálcula da vazão em massa média da máquina de expansão"

W_e=integral((P_e-P_atm)*a_e*_dot;t;0;Delta_t;dt_int) "Trabalho total realizado pela câmara esquerda"

W_d=integral((P_d-P_atm)*a_d*(-x_dot);t;0;Delta_t;dt_int)"Trabalho total realizado pela câmara direita"

Wt=integral((P_e*a_e-P_d*a_d $)^{*} x \_d o t ; t ; 0 ; D e l t a \_t ; d t$ int $)$ "Trabalho total realizado pelas duas câmaras"

W_dot medio $=\left(W \_e+W \_d\right) /\left(t+10^{\wedge}(-10)\right)$

"Potência média da máquina de expansão"

w_espec $=$ W_dot_medio/(m_dot_medio+10^(-10))

de expansão"

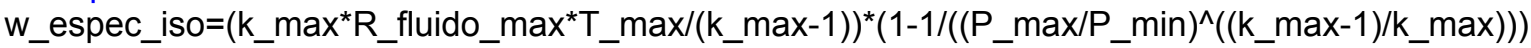

"Trabalho específico realizado em uma expansão isentrópica entre a alta e a baixa pressão"

eta_iso=w_espec/w_espec_iso

expansão"

"Eficiência isentrópica da máquina de

$" !$

Valores de referência para o amortecimento numérico devido à posição

X_ref $=x \_0+L+R-z \_r e f$

"Posição x do pistão para definir se é feito

amortecimento numérico"

z_ref $=R^{*} \cos ($ alfa $)+\left(L^{\wedge} 2-R^{\wedge} 2^{*}(\sin (\text { alfa }))^{\wedge} 2\right)^{\wedge}(1 / 2)$

r_xref $=\left(x \_r e f-x \_0\right) / S$

é deito amortecimento numérico"

r_xref $=0,001$

curso onde é feito o amortecimento numérico"

"Posição relativa $x \_r$ do pistão para definir se

"Porcentagem do curso do pistão nos fins de

"!__ Propriedades do fluido em cada câmara

"Propriedades do fluido na alta pressão"

$\mathrm{k} \max =\mathrm{cp} \max / \mathrm{cv} \max$

R_fluido_max $=c p \_$max-cv_max

$c p \_m a x=C p$ (fluido $\$ ; T=T \_$max; $P=P \_$max)

cv_max $=\mathrm{Cv}$ (fluido $\$ ; T=T$ max; $P=P \_$max)

"Propriedades do fluido na baixa pressão"

$\mathrm{k} \_\mathrm{min}=\mathrm{cp} \_\mathrm{min} / \mathrm{cv} \_\mathrm{min}$

R_fluido_min $=c p \_m i n-c v \_m i n$

$c p \_$min $=\bar{C} p$ (fluido $\$ ; T=T$ min; $P=P$ _min)

cv_min $=C v$ (fluido $\$ ; T=T$ min; $P=P$ - min)

"Propriedades do fluido na câmara esquerda"

k_e=cp_e/cv_e

$R \_$fluido_e $=c p \_e-c v \_e$

$c p \_e=C p$ (fluido $\left.\$ ; T=\bar{T} \_e ; P=P \_e\right)$

$c v e=C v\left(\right.$ fluido $\$ ; T^{-} T^{-}$e; $P=P^{-}$)

"Propriedades do fluido na câmara direita"

k_d $=c p \_d / c v \_d$

$R_{-}$fluido_d $d=c p \_d-c v \_d$

$c \bar{c} d=\overline{C p}$ (fluido $\$ ; T=\bar{T} d ; P=P \quad d)$

$c v \_d=C v$ (fluido $\$ ; T=T \_d ; P=P \_d$ )

"Propriedades do fluido na câmara de escape do lado direito"

$\mathrm{k} \_\mathrm{cd}=\mathrm{cp} \_\mathrm{cd} / \mathrm{cv} \_\mathrm{cd}$

R_fluido_cd=cp_cd-cv_cd

$c p \_c d=C p$ (fluido $\$ ; T=T$ _cd; $P=P$ _cd $)$

cv_cd $=\mathrm{Cv}$ (fluido $\$ ; T=T \_c d ; P=P \_c d$ )

"Propriedades do fluido na câmara de escape do lado esquerdo"

k_ce=cp_ce/cv_ce

R_fluido_ce $=c p$ ce-cv_ce

$\mathrm{cp}$ _ce $=\overline{\mathrm{Cp}}$ (fluido $\$ ; \mathrm{T}=\mathrm{T}$ _ce;P=P_ce)

Cv_ce $=C v$ (fluido $\$ ; T=T$ ce; $P=P \_c e$ )

"Propriedades do fluido na câmara de admissão" 
k_ca=cp_ca/cv_ca

R_fluido_ca $=c p \_c a-c v \_c a$

$c \bar{p} \_c a=\overline{C p}$ (fluido $\left.\overline{\$} ; T=T+c a ; P=P \_c a\right)$

cv_ca $=C v$ (fluido $\$ ; T=T$ ca; $P=P$-ca)

"Verificação da fase do fluido nas câras esquerda e direita"

phase_e $\$=$ phase $\$$ (fluido $\$ ; P=P \_e ; T=T \_e$ )

phase_d $\$=$ phase $\$$ (fluido $\$ ; P=P_{-}^{-} d ; T^{-}=T_{-}^{-} d$ )

\$IntegralTable t:dt r_x theta P_d T_d rho_d m_dot_d m_d V_d h_d u_d P_e T_e rho_e m_dot_e m_e V_e h_e u_e x x_d x_v x_dot x_dot_v r_x Aad Aed Aae Aee duedt duddt m_dot_ae sinal_ae m_dot_ee sinal_ee m_dot_ad sinal_ad m_dot_ed sinal_ed h_ae h_ee h_ad h_ed P_ce P_cd P_ca T_ce T_cd T_ca m_adm_ladoE m_adm_ladoD m_dot_medio W_e W_d Wt W_dot_medio w_espec w_espec_iso eta_iso 


\section{APÊNDICE D - ALGORITMO PARA A GERAÇÃo dO CICLO CARACTERÍSTICO DE CADA MEDIÇÃO}

Primeiramente deve-se determinar o ângulo inicial da manivela do pistão (theta_i) e a pressão de referência (P_ref), na qual os ciclos serão separados

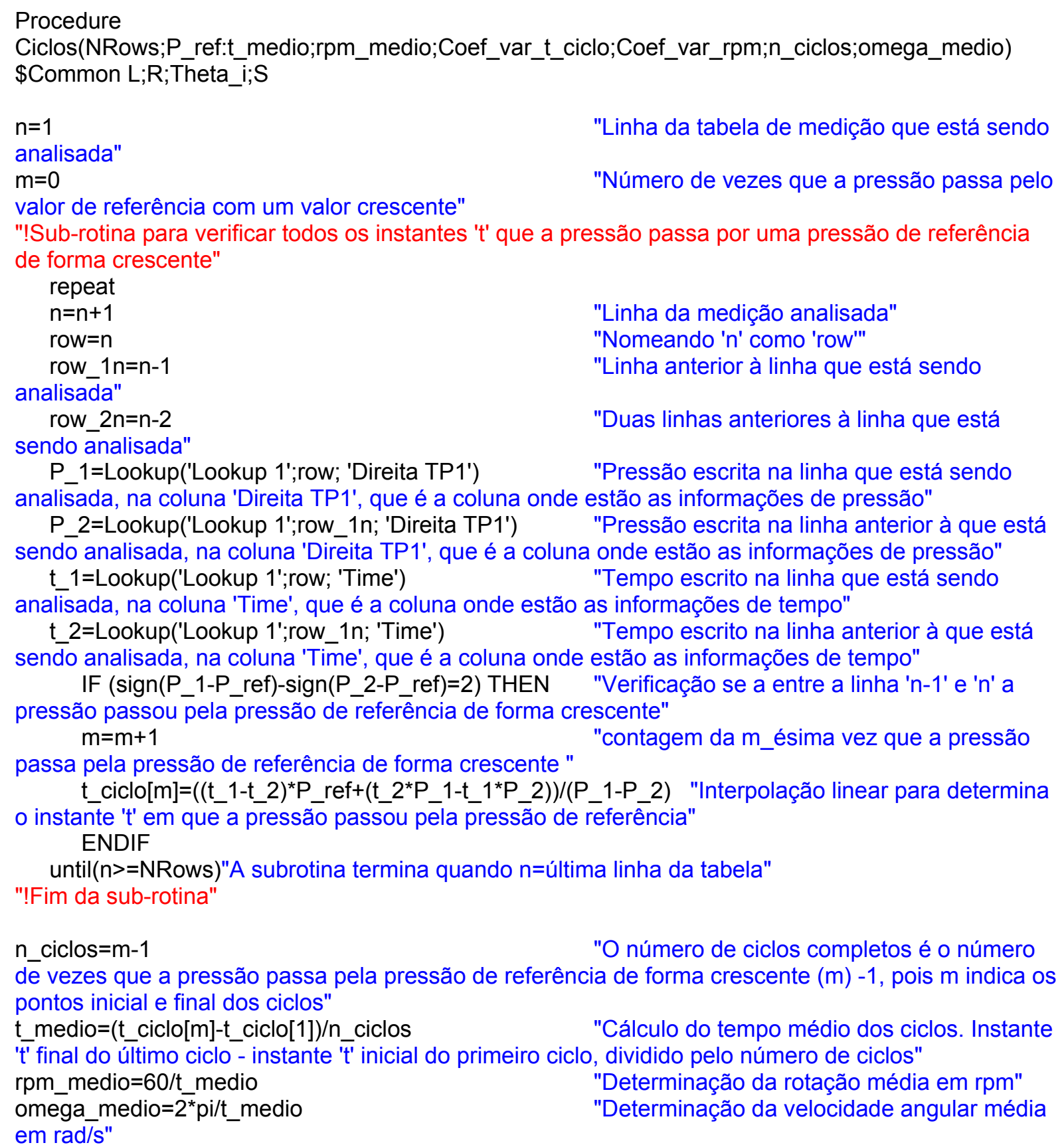

"!Sub-rotina para determinar o período de cada um dos ciclos" $\mathrm{i}=0$

"Inicia contador do ciclo em estudo" repeat 
$\mathrm{i}=\mathrm{i}+1$

$\mathrm{dt}[\mathrm{i}]=\left(\mathrm{t} \_\right.$ciclo[i+1]-t_ciclo[i])

"Determina o tempo do i-ésimo ciclo"

$\mathrm{rpm}[\mathrm{i}]=60 / \mathrm{dt}[\mathrm{i}]$

"Calcula a rotação média daquele ciclo"

until(i>=m-1) "Repete o processo até o último ciclo (também poderia ser utilizada a variável n_ciclos)"

"!Fim da sub-rotina"

"!Sub-rotina para calcular a soma de todos '(valor(i)-média)^2' necessária para o desvio padrão e o coeficiente de variação"

soma_1 $=0$

variável dt (tempo de cada ciclo)"

soma_2=0

variável rpm (rotação média de cada ciclo)"

$\mathrm{x}=0$ "Inicia contador para indicativo do ciclo que está sendo estudado"

repeat

$\mathrm{x}=\mathrm{x}+1$

soma_1=soma_1+(dt[x]-t_medio $)^{\wedge} 2$

"Adiciona o termo do ciclo estudado à soma

acumulada para a variável $\mathrm{dt} "$

soma_2=soma_2+(rpm[x]-rpm_medio $)^{\wedge} 2$

acumülada para a variável rpm"

until( $\mathrm{x}=\mathrm{n}$ _ciclos)

"IFim da sub-rotina"

"Inicia a soma da respectiva soma para a

"Inicia a soma da respectiva soma para a

Coef_var_t_ciclo $=100^{*}($ soma_1/(n_ciclos-1) $){ }^{\wedge}(1 / 2) / t$ medio "Determina o coeficiente de variação para a variável dt, ou t_ciclo"

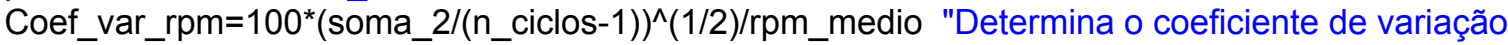
para a rotação média dos ciclos"

"!Sub-rotina para determina o instante final/inicial de todos os ciclos considerando que todos durem o tempo médio de um ciclo. Padronizando assim o intervalo de tempo de cada ciclo"

i=0 "Inicia o contador do instante t do fim/início do ciclo estudado"

repeat

$\mathrm{i}=\mathrm{i}+1$

t_padrao[i]=t_ciclo[1]+(i-1)*t_medio "Determina todos os instante 't' onde os ciclos deveriam começar/terminar caso a rotação fosse constante e igual à rotação média" until(i>=m) "Repete o processo para m pontos, correspondente ao número de ciclos que ocorreram" "!Fim da Sub-rotina"

SampleRate $=10000$

pontos_ciclo=trunc $\left(\min (\mathrm{dt}[1 . .(\mathrm{m}-1)])^{*}\right.$ SampleRate $)$ mesma quantidade de pontos"

"! (padronizado em relação à porcentagem correspondente do instante 't' dentro do ciclo) de cada ciclo, considerando que todos os ciclos tenham a mesma duração

$\mathrm{p}=0$ "Porcentagem que o ponto analisado representa no período do ciclo"

repeat

$p=p+1$

$c=0$

"O ciclo que está sendo analisado"

"!Sub-rotina para determinar a pressão em cada câmara, em uma mesma porcentagem de todos os ciclos"

repeat

$\mathrm{c}=\mathrm{c}+1$

$\mathrm{t}=\mathrm{t} \_$ciclo[c]+(t_ciclo[c+1]-t_ciclo[c] $)^{*} \mathrm{p} /$ pontos_ciclo $\quad$ "O instante 't' que representa uma

porcentagem 'p' decorrido no c-ésimo ciclo"

P_d[c]=INTERPOLATE('Lookup 1';'Direita TP1';'Time';Time=t) "A pressão da câmara direita no instante 't' citado acima"

P_e[c]=INTERPOLATE('Lookup 1';'Esquerda TP3';'Time';Time=t) "A pressão da câmara esquerda no instante 't' citado acima"

until(c=n_ciclos)
"O processo é realizado para todos os ciclos" 


\section{"!Fim dessa sub-rotina"}

"!Cálculos referentes à pressão na mesma porcentagem 'p' em todos os ciclos para a câmara direita" $P \_d \_p[p]=s u m\left(P \_d\left[1 . . n \_c i c l o s\right]\right) / n \_c i c l o s$ correspondente à porcentagem 'p' do ciclo"

\section{"Determinação da pressão média}

"!Sub-rotina para determina o coeficiente de variação para as pressões na porcentagem 'p' do ciclo" soma $=0$

"Inicia a soma'(pressão(ciclo=x;

porcentagem=p)-média(porcentagem=p) $)^{\wedge} 2^{2}$, necessária para o cálculo do desvio padrão e do coeficiente de variação "

$\mathrm{x}=0$

"Inicia a contagem do ciclo de estudo"

repeat

$\mathrm{x}=\mathrm{x}+1$

soma=soma $+\left(P_{-} d[x]-P \_d \_p[p]\right)^{\wedge} 2$

acumulada para a variável $\mathrm{dt} "$

until(x=n_ciclos)

Coef_Var_P_d[p]=100* $\left((\text { soma/(n_ciclos-1) })^{\wedge}(1 / 2)\right) / P \_d \_p[p] \quad$ "Calcula o coeficiente de variação para a pressão na porcentagem 'p' de todos os ciclos"

"!Fim dessa sub-rotina"

P_d_pmin[p]=min (P_d[1..n_ciclos])

porcentagem ' $p$ ' dentre todos os ciclos"

P_d_pmax[p]=max(P_d[1..n_ciclos])

porcentagem ' $p$ ' dentre todos os ciclos"
"Determina a mínima pressão na

"Determina a máxima pressão na

"!Cálculos referentes à pressão na mesma porcentagem 'p' em todos os ciclos para a câmara esquerda"

$P$ e_p[p] $=\operatorname{sum}\left(P \_e\left[1 . . n \_c i c l o s\right]\right) / n \_c i c l o s$

correspondente à porcentagem ' $p$ ' do ciclo"

"Determinação da pressão média

"!Sub-rotina para determina o coeficiente de variação para as pressões na porcentagem ' $p$ ' do ciclo" soma $=0$

"Inicia a soma'(pressão(ciclo=x;

porcentagem=p)-média(porcentagem=p)^^2', necessária para o cálculo do desvio padrão e do coeficiente de variação "

$\mathrm{x}=0$

"Inicia a contagem do ciclo de estudo"

repeat

$\mathrm{x}=\mathrm{x}+1$

soma $=$ soma $+\left(P \_ \text {_e }[x]-P \_e \_p[p]\right)^{\wedge} 2$

acumulada para a variável dt"

until( $\mathrm{x}=\mathrm{n}$ ciclos)

Coef_Var_P_e[p] $=100^{*}\left((\text { soma/ }(\text { n_ciclos-1) }))^{\wedge}(1 / 2)\right) / P \_e \_p[p] \quad$ "Calcula o coeficiente de variação para a pressão na porcentagem ' $p$ ' de todos os ciclos"

"!Fim dessa sub-rotina"

P_e_pmin[p]=min(P_e[1..n_ciclos])

porcentagem ' $p$ ' dentre todos os ciclos"

P_e_pmax[p]=max (P_e[1..n_ciclos])

porcentagem ' $p$ ' dentre todos os ciclos"

$\mathrm{t}[\mathrm{p}]=\mathrm{t} \_$medio*p/pontos_ciclo

correspondente à porcentagem ' $p$ ' do ciclo"

theta[p]=theta_i+omega_medio*t[p]

porcentagem ' $p$ ' do ciclo, considerando rotação constante"

$z=R^{*} \cos ($ theta $[p])+\left(L^{\wedge} 2-\left(R^{*} \sin (\text { theta }[p])\right)^{\wedge} 2\right)^{\wedge}(1 / 2)$

manivelas e a conexão da biela com o eixo do pistão"

$r_{-} x[p]=((L+R)-z) / S$

correspondente ao ângulo 'theta' para a câmara esquerda"

r_x_d[p] $=1-r_{-} x[p]$

correspondente ao ângulo 'theta' para a câmara direita" until( $p=$ pontos_ciclo)
"Determina a mínima pressão na

"Determina a máxima pressão na

"Calcula o instante de tempo ' $\mathrm{t}$ '

"Calcula o ângulo 'theta' correspondente à

"Calcula a distância entre o eixo de

"Determina a posição relativa no pistão

"Determina a posição relativa no pistão "! Fim da subrotina 
\$Arrays on

END

"!Fim do Procedure ciclos"

Call Ciclos(NRows;P_ref:t_medio;rpm_medio;Coef_var_t_ciclo;Coef_var_rpm;n_ciclos;omega medio)

NRows=NLOOKUPRÖWS('Lookup 1')

$\mathrm{R}=0,022[\mathrm{~m}]$

$\mathrm{L}=0,1[\mathrm{~m}]$

"Determina o número de linhas da tabela"

X $0=0,01[\mathrm{~m}]$

"Comprimento da manivela"

$S=2 * R$

"Posição 'x' do volume morto"

"Curso do pistão" 


\section{APÊNDICE E - ARTIGO ACEITO PARA O ENCIT 2012}

**** This is an electronically generated message. You need not reply to it. If you need assistance, please use the official event contact email.

Rio de Janeiro, RJ, Brazil, September, 19, 2012.

Dear author josé r. Simões moreira,

The scientific committee of the 14th brazilian congress of thermal sciences and engineering encit2012, is pleased to inform you that the paper identified below was accepted for publication and presentation in encit2012.

Code: encit2012-0161

title: A PROPOSED THEORETICAL STANDARD CYCLE FOR A RECIPROCATING

\section{STEAM ENGINE}

authors:

Rodrigo Bernardello / sisea/epusp (bernardello.r@gmail.com)

José r. Simões-moreira / sisea/epusp (jrsimoes@usp.br)

you may submit a final version of your work, if you wish.

The final version should be submitted through the swge system, before the deadlines listed at the event webpage.

Please note that the swge system is already open for registrations.

In order for your paper to be presented at the event and published in the proceedings, the corresponding author must complete the payment of registration publication fees.

More information regarding the scientific program of encit2012 will be soon available at the event website.

We thank you for your valuable collaboration, and look forward to meeting you at encit2012.

Sincerely,

swge support team / encit2012 


\title{
A PROPOSED THEORETICAL STANDARD CYCLE FOR A RECIPROCATING STEAM ENGINE
}

\author{
Rodrigo Bernardello Unzueta, bernardello.r@gmail.com \\ José Roberto Simões Moreira, jrsimoes@usp.br \\ Alternative Energy Systems Lab, Mechanical Eng. Dept., Escola Politécnica da Universidade de São Paulo, Av. Prof. Mello \\ Moraes, 2231, CEP 05508-970 - Cidade Universitária - São Paulo
}

Abstract. The reciprocating steam machine played an important role in the industrial revolution and it was widely used in many sectors of industry. But with the development of the internal combustion engines and steam turbines, this technology was virtually abandoned. Nowadays the interest in steam machine began to grow again, due to the growth of distributed generation of eletricity. This type of power generation usually uses the organic Rankine cycle (ORC) to generate low power, making the steam machine viable when compared to the steam turbines. In the literature, each author uses a different cycle to study or design his equipment, so it is interesting to study a single standard cycle for the reciprocating steam engines to serve as standard for comparing cycles already studied. The results show that there are maximum operational points, which depend in some conditions and constructive features.

Keywords: Steam engine, Organic Rankine Cycle (ORC), Standard cycle, Expansion machine

\section{INTRODUCTION}

To develop a cycle for the reciprocating machine, it is necessary to understand and study their mode of operation. The reciprocating steam machine played an important role in the industrial revolution and was widely used in many sectors of industry in the previous centuries. In the beginning of the $20^{\text {th }}$ century, this technology was replaced by engines which operate according to Otto and Diesel cycles and, at the same time, steam turbines were conceived. In any case, steam machines were relegated to a second plane due its low efficiency and to a very low power generation to volume density ratio. During the $20^{\text {th }}$ century, the steam machine technology remained stagnant e without any practical use.

Recently the steam machine became again an interesting technology. This fact comes from the increasing interest in Organic Rankine Cycles (ORC), used to generate energy through low power systems installations, generally using solar energy as a heat source. The ORC are most used in places away from the large centers, where the electricity is more difficult to be obtained. Because of its use and constructive form, the powers involved are small and according to Prasad (1993), for low output powers (a few hundred kilowatts), steam motors are still superior to turbines in most respects. Thereby, the steam machine becomes a viable alternative to replace the turbine as the ORC equipment expansion. Literature on steam machine lacks of precise information of a standard cycle in a similar fashion as the Otto and Diesel cycles. So it is interesting to establish and study a standard cycle that can be used by anyone, without neglecting the various cycles already studied.

\section{DEVELOPMENT}

To develop a standard cycle for reciprocating steam machines, it is necessary to understand and study their mode of operation. The cycle used in earlier studies on steam engines is shown in Fig. 1 (Mariño, 1948), and it is still used nowadays by some authors (Alanne et al., 2012). The cycle begins at the top dead center (1) with steam at high pressure and high temperature entering the cylinder and pushing the piston toward the bottom dead center. The intake valve closes at a point (2) along the movement of the piston, terminating the admission process and starting the expansion process. The steam expands until it reaches the condenser pressure at the bottom dead center (3). At this point, the exhaust valve opens instantaneously and the steam is expelled from the cylinder during the return stroke of the piston to top dead center (4). On reaching the top dead center, the intake valve opens instantaneously, increasing the internal pressure of the cylinder to the intake pressure and restarting the cycle. This cycle, as well as other cycles studied, is not exclusive of the steam engine, it can be used by any equipment operating cyclically by performing the expansion of a high pressure gas, such as compressed air motors.

\subsection{Indicated diagrams}

However in practical terms, it is not feasible to build a machine with a zero dead volume, because it would cause an impact between the piston and the cylinder head. This impact causes great stress on parts and a 
However in practical terms, it is not feasible to build a machine with a zero dead volume, because it would cause an impact between the piston and the cylinder head. This impact causes great stress on parts and a significant reduction in equipment life. For this reason it is necessary to have a non-zero dead volume, but for purpose of efficiency is interesting that this dead volume is minimized. Prasad (1993) and Baek et al. (2005) consider that the ideal cycle is the one shown in Fig. 1, but considering a non-zero dead volume.

Because of the dead volume, as the internal pressure of the cylinder is lower than the evaporator pressure at the point of the exhaust valve closing and opening the inlet valves (point 4), a portion of the high-pressure steam that enters in cylinder will fill the dead volume and increase the internal pressure until it reaches the pressure of the inlet steam. This portion of steam does not generate useful work, reducing the efficiency of the machine.

To solve this issue and make no part of steam be wasted in increasing the pressure of the dead volume, the pressure inside the cylinder must be equal to the inlet pressure when the intake valve opens. To make this possible, the exhaust valve must close before the piston reaches the TDC. Therefore, the range in which both valves are closed, the steam undergoes compression, increasing the pressure until it reaches the inlet pressure. Thus, when the intake valve opens, the internal pressure of the cylinder is the inlet pressure and no steam is used to fill the dead volume. This cycle is used by Trajkovic (2010) and the corresponding pressure-volume indicated diagram is shown in Fig. 2. If the expansion and compression of steam are isentropic, then there are two isobaric processes and two isentropic processes.

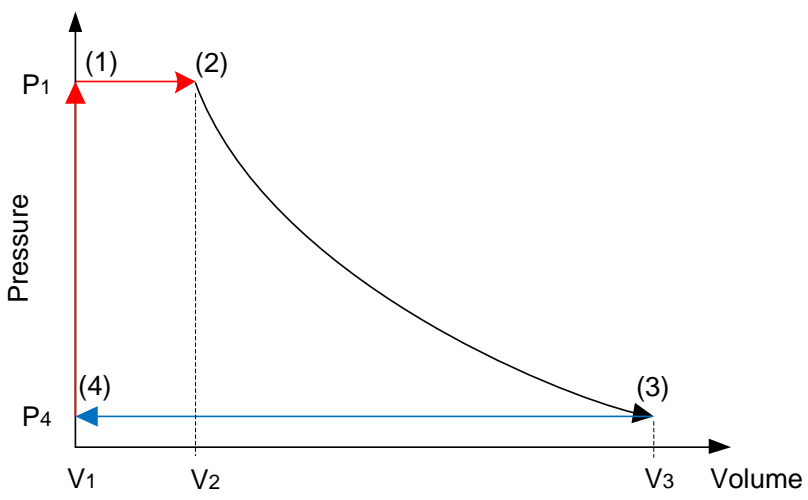

Figure 0.1. Pressure-volume indicated diagram for an ideal cycle for a reciprocating steam machine without dead volume (Mariño (1948) and Alanne et al. (2012)).

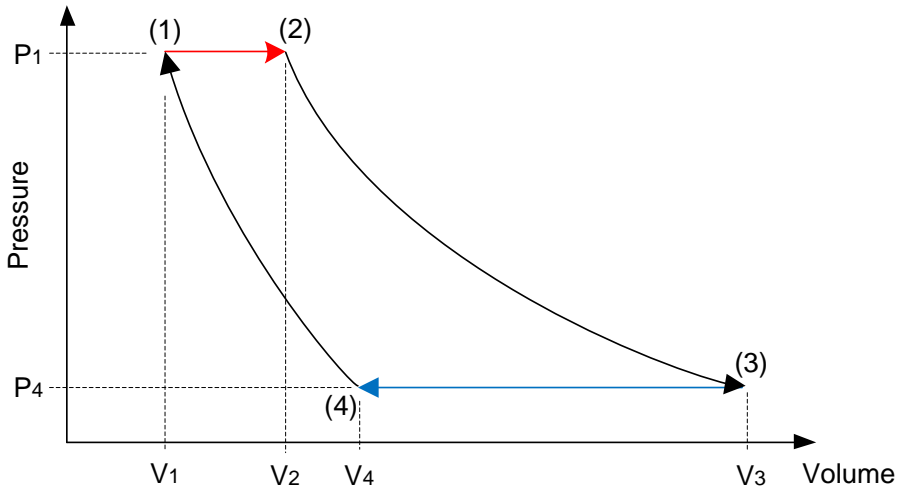

Figure 0.2. Pressure-volume indicated diagram for an ideal cycle with dead volume and vapor compression (Trajkovic (2010)).

Generally, due to technical limitations, it is not possible to achieve the complete expansion of steam (process 2-3 of Fig. 2) or the complete compression of steam until the inlet pressure (process 4-1 of Fig. 2). These limitations may be due to a variable inlet pressure, there may be a high inlet pressure, and the volume ratio is not enough to completely expand the steam, or in the end of expansion, the working gain is so small as to be smaller than the energy dissipated by the friction. These limitations lead to the incomplete expansion and/or compression of steam. Based on this, Prasad (1993) solve this issue in his simulations using the cycle shown in Fig. 3, where there is an incomplete expansion and an incomplete compression of the steam inside the cylinder. It makes the efficiency to become lower when compared with the efficiency of the cycle of Fig. 2.

Badami and Mura (2009) use a cycle with an incomplete expansion and compression, but they consider steam inlet along the piston stroke. This cycle is represented in Fig. 4 and has an isentropic efficiency lower than 1 , but it is closer to the actual operation of the steam engines than the previous cycles. 
Antonelli and Martorano (2012) e Basbous et al. (2012) use the indicated diagram of Fig. 5, which is the closest cycle to the actual operation of the steam engine. This cycle takes into account that the exhaust valve remains opened during a portion of the return stroke of the piston, and along this stroke it closes, causing the vapor to be compressed until the piston reaches the TDC. This cycle becomes the most generalized cycle, where all the other cycles become special cases of this one. By allowing a study of the points of opening and closing the valves and for being the nearest cycle of the real operating cycle of a steam engine, this cycle can become the starting point of any study on the working of steam engines.

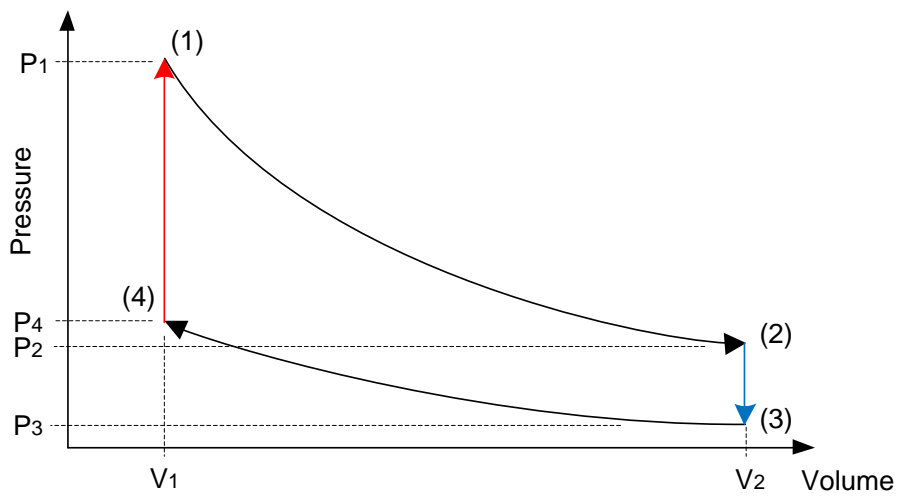

Figure 0.3. Pressure-volume indicated diagram with incomplete expansion and compression (Prasad, 1993).

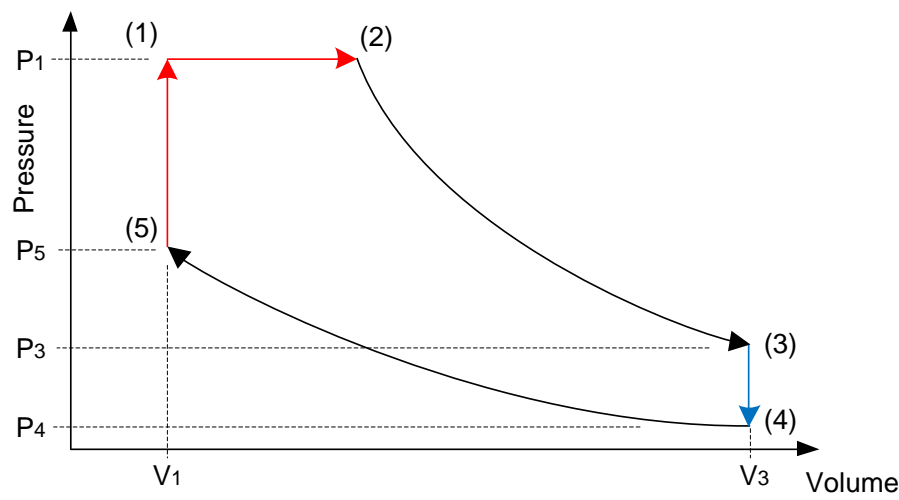

Figure 0.4. Pressure-volume indicated diagram with incomplete expansion and compression, considering inlet steam along the stroke of the piston (Badami and Mura, 2009).

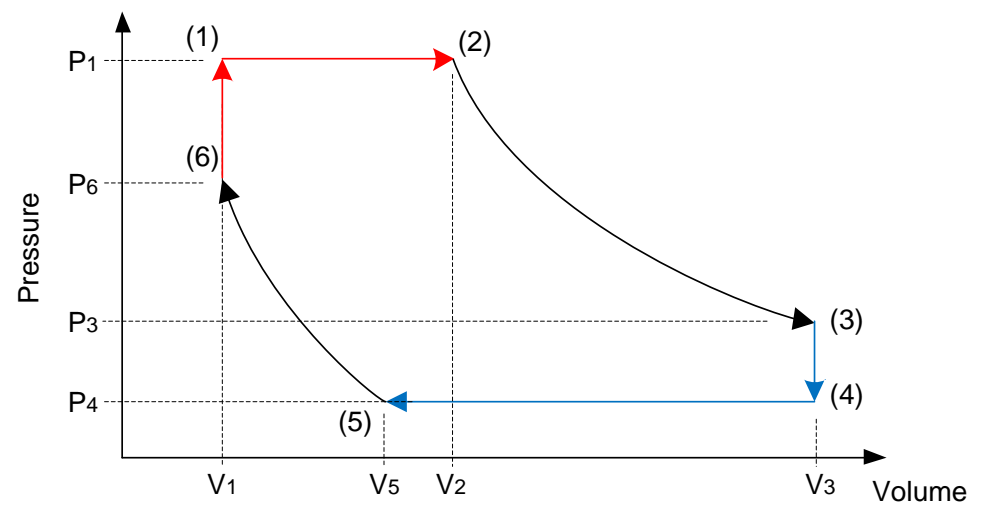

Figure 0.5. Generalized pressure-volume indicated diagram for an ideal cycle considering the incomplete expansion and compression (Antonelli and Martorano (2012) and Basbous et al. (2012)).

\subsection{Equations and analysis}

In order to analyze the proposed cycle of Fig. 5, it is necessary to define some relationship between the volumes of the cylinder, so it becomes easier to analyze and choose which volumes must be used to get better efficiency. Is defined as the cut-off ratio $\left(r_{C}\right)$ the ratio between the volumes $V_{2}$ and $V_{l}$. The closure ratio $\left(r_{F}\right)$ is 
defined as the ratio between $V_{5}$ and $V_{l}$. And the volume ratio $\left(r_{V}\right)$ is defined as the relation between the maximum and the minimum volume, $V_{3}$ and $V_{1}$ respectively.

$$
\begin{aligned}
& r_{C}=\frac{V_{2}}{V_{1}} \\
& r_{F}=\frac{V_{5}}{V_{1}} \\
& r_{V}=\frac{V_{3}}{V_{1}}
\end{aligned}
$$

Furthermore, it is appropriate to express the cut-off ratio and the closure ratio in percentage form, where zero (0) means the dead volume and one (1) means the maximum volume within the cylinder. Therefore, these ratios can be written as:

$$
\begin{gathered}
r_{C x}=\frac{r_{C}-1}{r_{V}-1} \\
r_{F x}=\frac{r_{F}-1}{r_{V}-1}
\end{gathered}
$$

It also becomes appropriate to define a pressure ratio, defined as the ratio between de working pressure of the evaporator and the condenser, given by Eq. (6):

$$
r_{P}=\frac{P_{\text {evap }}}{P_{\text {cond }}}
$$

The total work by cycle $\left(W_{\text {cycle }}\right)$ can be calculated by the internal area of the diagram of Fig. 5 . To define this equation, the steam was considered as a perfect gas with constant properties. The processes (1-2) and (4-5) are considered isobaric processes, the processes (2-3) and (5-6) are considered isentropic processes, and to calculate the work of the isentropic processes, this was considered a polytropic process, where the polytropic exponent is the adiabatic gas constant $(k)$. The adiabatic gas constant is given by Eq. (7), where $C_{P}$ and $C_{V}$ are the specific heats at constant pressure and constant volume, respectively. Finally, the processes (3-4) and (6-1) are considered isochoric. There are then two isobaric processes, two isochoric processes and two isentropic processes. Since the total work is the sum of the work of each process of the steam engine, it can be defines by Eq. (8).

$$
\begin{aligned}
& k=\frac{C_{P}}{C_{V}} \\
& W_{\text {cycle }}=\frac{V_{1} \times P_{\text {evap }}}{k-1}\left((k-1)\left(r_{C}-1\right)+r_{C}\left[1-\left(\frac{r_{C}}{r_{V}}\right)^{k-1}\right]+\frac{1}{r_{P}}\left[(k-1)\left(r_{F}-r_{V}\right)-r_{F}\left(r_{F}^{k-1}-1\right)\right]\right)
\end{aligned}
$$

One way of evaluating the efficiency of the cycle is through the specific work, but it is necessary to find the mass flow through the machine in a cycle. The mass spend in one cycle can be calculated as the difference between maximum and minimum mass inside the cylinder during one cycle. The mass contained in the cylinder at point (2) is the same at the point (3), which is the maximum mass in the cylinder $\left(m_{2}\right)$. The mass contained in the cylinder at point $(5)$ is the same at the point $(6)$, which is the minimum mass in the cylinder $\left(m_{5}\right)$. Thus the mass spent per cycle $\left(m_{\text {cycle }}\right)$ can be written as:

$$
m_{\text {cycle }}=m_{2}-m_{5}=\frac{V_{1} \times P_{\text {evap }}}{k \times R \times T_{\text {evap }}}\left[k\left(r_{c}-1\right)+1-\frac{r_{F}{ }^{k}}{r_{P}}\right]
$$


Where $T_{\text {evap }}$ is the working temperature of the evaporator and $R$ is the difference between the two specific heats, given

by Eq. (10):

$$
R=C_{P}-C_{V}
$$

This way the specific work of the cycle $\left(w_{\text {cycle }}\right)$ is:

$$
w_{\text {cycle }}=\frac{w_{\text {cycle }}}{m_{\text {cycle }}}
$$

The maximum possible work to be done by a machine is if it works isentropically, (i.e., causes an isentropic expansion on the steam). According to Sonntag et al. (2003), the isentropic specific work of an ideal gas is:

$$
w_{i s o}=-\frac{k R}{k-1}\left(T_{f}-T_{i}\right)
$$

The isentropic specific work can be written as a function of the temperature of the evaporator and the volume ratio.

$$
w_{i s o}=\frac{k R}{k-1} T_{\text {evap }}\left(1-\frac{1}{r_{P} \frac{k-1}{k}}\right)
$$

\subsection{Efficiency}

The isentropic efficiency $\left(\eta_{\text {iso }}\right.$ ) of the machine is given by the relation between the specific work by the engine and the isentropic specific work of an ideal gas.

$$
\eta_{\text {iso }}=\frac{w_{\text {cycle }}}{w_{\text {iso }}}
$$

For this study, it is considered that at point (1) of all cycles, the pressure and the temperature within the cylinder are equal to the pressure and the temperature of the evaporator.

The calculations made through the above equations show that the isentropic efficiency of the cycle of Fig. 1 tends to one (1) when the dead volume tends to zero (0), and the larger the dead volume, lower the efficiency. The cycle shown in Fig. 2 has always an isentropic efficiency equal to 1, independently of the dead volume, and tends to the diagram of Fig. 1 when the dead volume tends to zero. The cycle of Fig. 3 has always an isentropic efficiency smaller then 1, and tends to 1 when the difference between the maximum and the minimum pressures tends to zero. The cycle shown in Fig. 4 always has an isentropic efficiency smaller then 1 . The cycle of the Fig. 5 , as shown in the diagram, always has a isentropic efficiency smaller then 1, but changing the cut-off ratio and the closure-ratio in a way this cycles becomes the cycle in Fig. 2, it reaches an isentropic efficiency equal to 1.

Thus, it can be noted that the efficiency of all cycles tends to 1, when the cycles tends to the cycle of the Fig. 2. it makes this diagram the ideal when considering the best efficiency. As mentioned, in practice is very difficult to make a machine that operates according to the cycle of Fig. 2, for reasons mentioned above.

Noting that in these diagrams, one point does not correspond to a thermodynamic state, since the mass within the cylinder varies. And for this reason it is not interesting study the indicated diagram using the specific volume, since not always a change in specific volume means that the piston is producing work.

If the generalized cycle shown in Fig. 5 is used in a design of a steam engine, one must be careful with the point of opening and closing the valves. If de cut-off ratio and the closure ratio are chosen inappropriately, there may be an over-compression (when the steam is compressed to pressures above the inlet pressure) or an overexpansion (when the steam is expanded to pressures below the condenser pressure) or cause it to work as compressor. A cycle with over-expansion and over-compression is shown in Fig. 6. If the steam is compressed to pressures above the intake pressure or expanded to pressures below the condenser pressure, the cycle efficiency will decrease due to the decreased area of useful work (7-2-8-5), besides the formation of areas where the work is negative (area 7-6-1) and (8-4-3). Depending on the opening and closing position of valves, the steam engine can even work as a compressor.

To prevent this to happening, it is necessary that the inlet valve closes after a certain position (closer to the BDC) and the exhaust valve closes before a certain position (closer to the TDC). These positions are called $r_{C m i n}$ and $r_{\text {Fmax }}$, respectively, and may be written as: 


$$
\begin{aligned}
& r_{C \min }=\frac{r_{V}}{r_{P}{ }^{1 / k}} \\
& r_{\text {Fmax }}=r_{P}^{1 / k}
\end{aligned}
$$

Note that these values of $r_{C}$ and $r_{F}$ are such that, in the expansion process, the steam reaches the condenser pressure exactly at the BDC and in the compression process, the steam reaches the evaporator pressure exactly at the TDC. Therefore, if the valves open and close at these points during a cycle, it becomes the cycle of Fig. 2, and it has the highest possible isentropic efficiency.

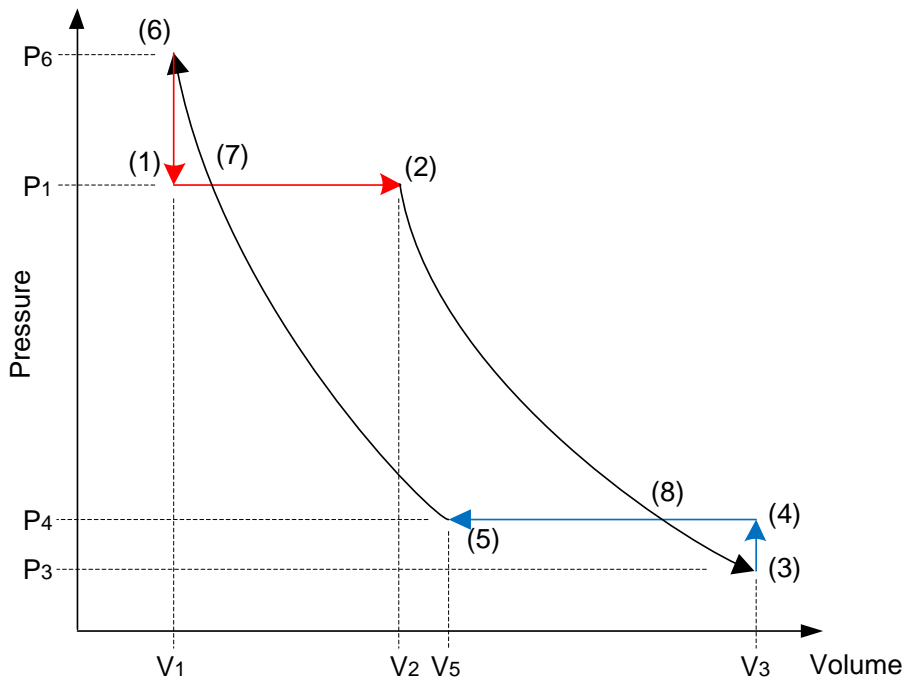

Figure 0.6. Pressure-volume indicated diagram with over-compression and over-expansion

Using the software EES, although having an isentropic efficiency equal to one (1), the ideal cycle of Fig. 2 was studied to verify if it is still possible to optimize it. The calculations were made for an engine with an $8 \mathrm{~cm}$ diameter piston, the minimum distance between the piston and the cylinder head (dead space) of $3 \mathrm{~cm}$, working with an absolute pressure in the condenser $\left(P_{\text {cond }}\right)$ of $100 \mathrm{kPa}$ and a working temperature of the evaporator $\left(T_{\text {evap }}\right)$ of $350^{\circ} \mathrm{C}$.

The results are shown in Fig. 7 and Fig. 8, noting that all point in these diagrams have the maximum possible isentropic efficiency. For both figures, it is noted that for a fixed volume ratio, there is a pressure that results in the maximum work done and the maximum mass consumption in one cycle. However, for a fixed pressure, the higher the volume ratio, higher the work done and the mass consumption in one cycle.

The operation pressure of the evaporator which results in the maximum work done is different from the operation pressure which results in the maximum mass consumption. The advantage of working at the pressure which results in maximum work per cycle is that the engine can operate at lower speeds or it is possible to achieve a higher output power at the same speed. 


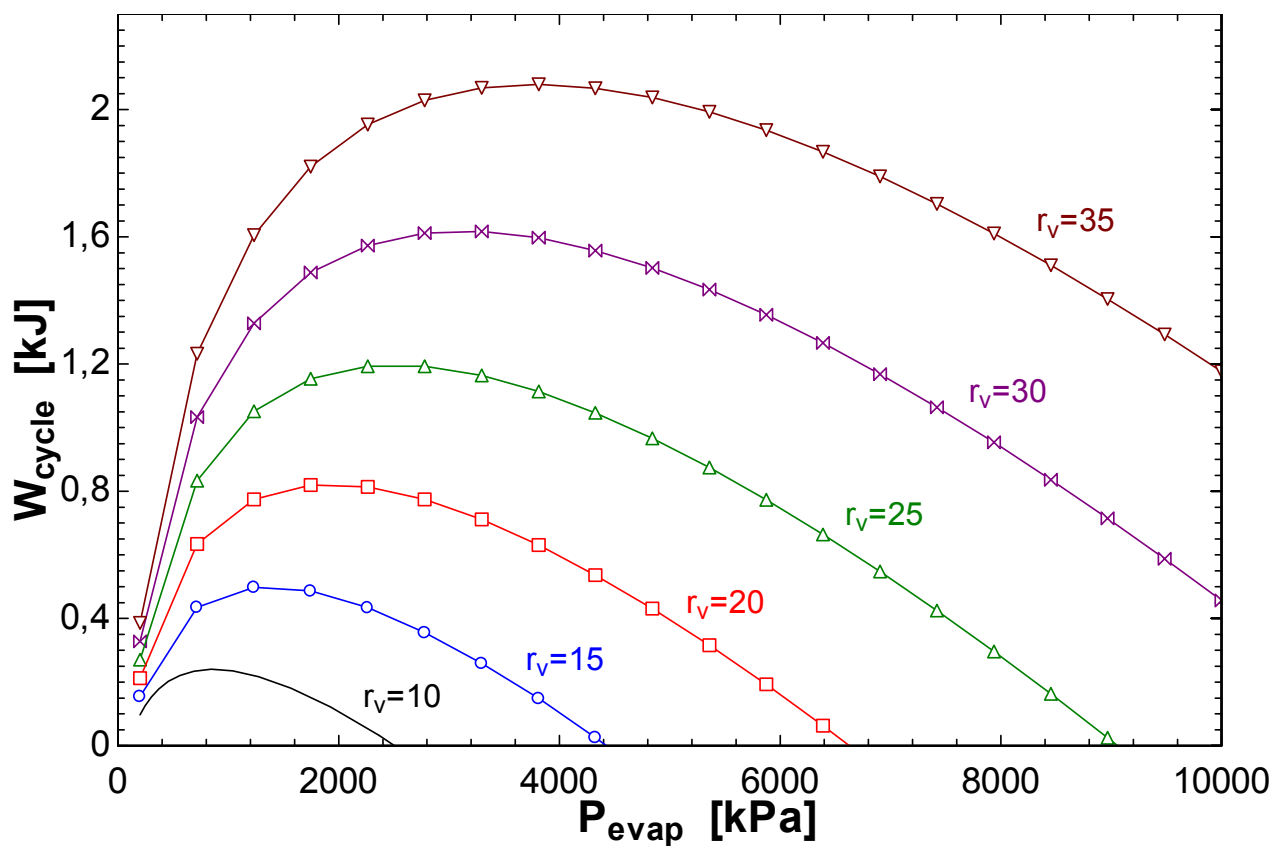

Figure 7. Work done in one cycle of operation for different volume ratios as a function of the pressure of the evaporator.

Considering that neither over-expansion nor over-compression occurs, the minimum isentropic efficiency occurs when the intake valve closes at the BDC and the exhaust valve closes at the TDC. In this case, the minimum isentropic efficiency can be written as:

$$
\eta_{\min }=\frac{(k-1)\left(r_{V}-1\right)\left(1-\frac{1}{r_{P}}\right)}{\left(k\left(r_{V}-1\right)+1-\frac{1}{r_{P}}\right)\left(1-\frac{1}{r_{P} \frac{k-1}{k}}\right)}
$$

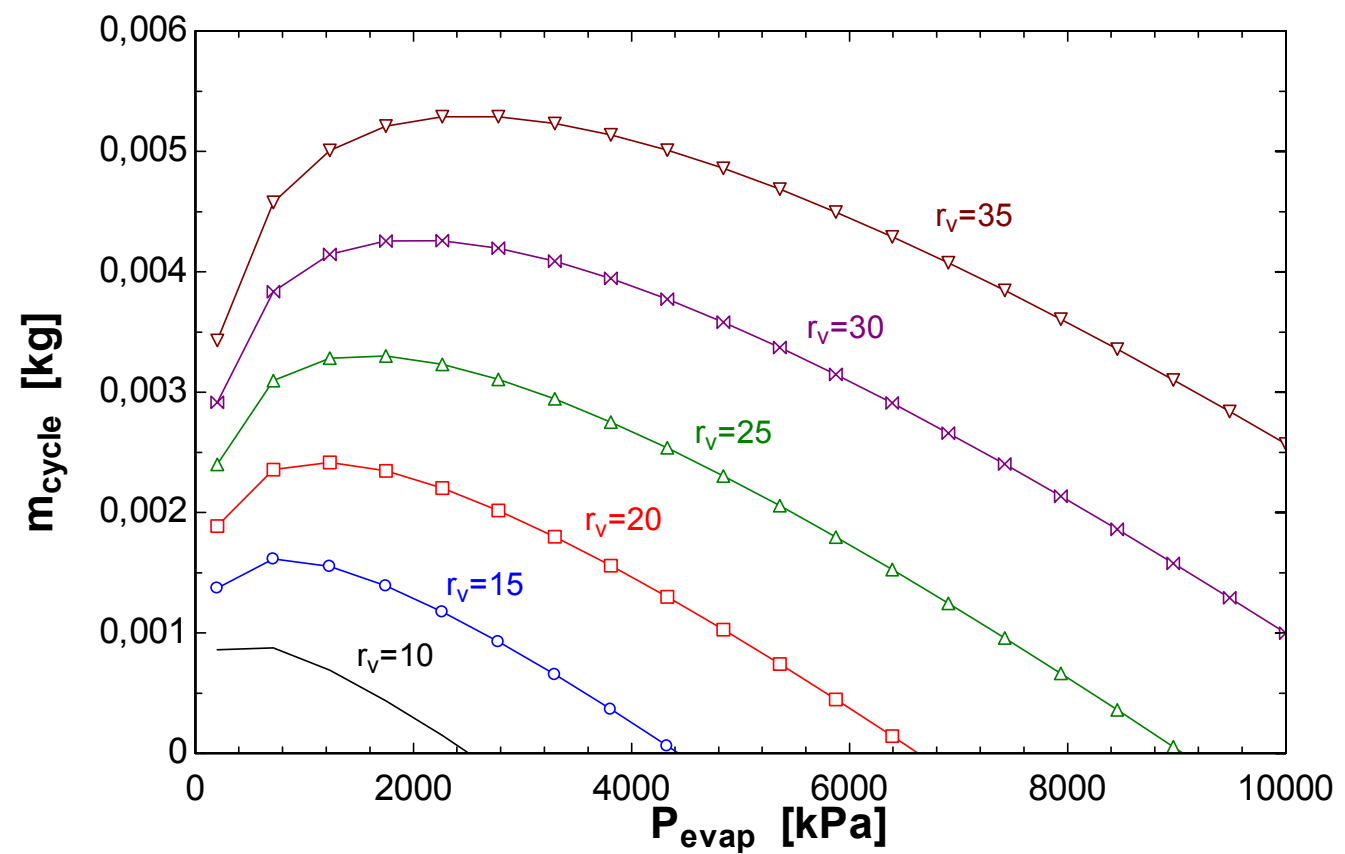

Figure 8. Mass consumption in one cycle of operation for different volume ratios as a function of the pressure of the evaporator. 


\subsection{Irreversibilities}

In all cycles studied, all processes are adiabatic and the cycle showed in Fig. 2 is also reversible, which also means that all processes in Fig. 2 are isentropic within the cylinder, and hence this cycle has always an isentropic efficiency equal to 1 . For the others cycles, which have a lower efficiency, will be studied the generalized cycle of Fig. 5.

The processes at constant volume are not isentropic, i. e. in those processes a quantity of energy that shall produce useful work is wasted. The process 6-1 is not isentropic because there is a mixture of gases at different pressures and temperatures within the cylinder. The process 3-4 is isentropic inside the cylinder, but when the gases exit the cylinder at a pressure greater than the condenser pressure, there is an increase in entropy due to the mixing of gases at different pressures and temperatures.

\section{CONCLUSION}

A generalized standard cycle for a reciprocating steam engine was defined (Fig. 5) and equated, since this cycle is the closest to the actual functioning of the engine and allows the study of the points of opening and closing the valves. However, the cycle with the maximum possible efficiency is the cycle of Fig. 2 , and it is desirable that the steam engines or other expansion engines work in accordance with it, although this is very difficult in practice.

In the operation of expansion engines, such as steam engines, should be avoided isochoric processes, since they always cause useful energy waste.

\section{ACKNOWLEDGEMENTS}

The first author thanks the Coordenação de Aperfeiçoamento de Pessoal de Nível Superior (CAPES) for the personal financial support.

\section{REFERENCES}

Alanne, K., Saari, K., Kuosa, M., Jokisalo, J. and Martin, A. R., 2012. "Thermo-economic analysis of a microcogeneration system based on a Rotary steam engine (RSE)", Applied Thermal Engineering, Vol. 44, pp. 1120.

Antonelli, M., Martorano, L., 2012. "A study on the rotary steam engine for distributed generation in small size power plants", Applied Energy.

Baek, J. S., Groll, E. A. and Lawless P. B., 2005. "Piston-cylinder work producing expansion device in a transcritical carbon dioxide cycle. Part II: theoretical model”, International journal of refrigeration, Vol. 28, pp. 152-164.

Badami, M., Mura, M., 2009. "Preliminary design and controlling strategies of a small-scale wood waste Rankine Cycle (RC) with a reciprocating steam engine (SE)", Energy, Vol. 34, pp. 1315-1324.

Basbous, T., Younes, R., Ilinca, A. and Perron, J., 2012. "A new-hybrid pneumatic combustion engine to improve fuel consumption of wind-Diesel power systems for non-interconnected areas", Applied Energy.

Marino, R., 1948. "Termodinamica tecnica”, Madrid: Dossat, 2 ed.

Prasad, S. B., 1993, "Steam engine characteristics and theoretical performance". Energy Conversion and Management, Vol. 34, No. 12, pp. 1323-1333.

Sonntag, R. E., Borgnakke, C., Van Wylen, G. J., 2003. “Fundamentos da termodinâmica”, São Paulo, Editora Edgard Blücher Ltda. 6 ed.

Trajkovic, S., 2010. The Pneumatic Hybrid Vehicle. Ph.D. thesis, Faculty of Engineering, Lund University, Lund, Sweden

\section{RESPONSIBILITY NOTICE}

The author(s) is (are) the only responsible for the printed material included in this paper. 